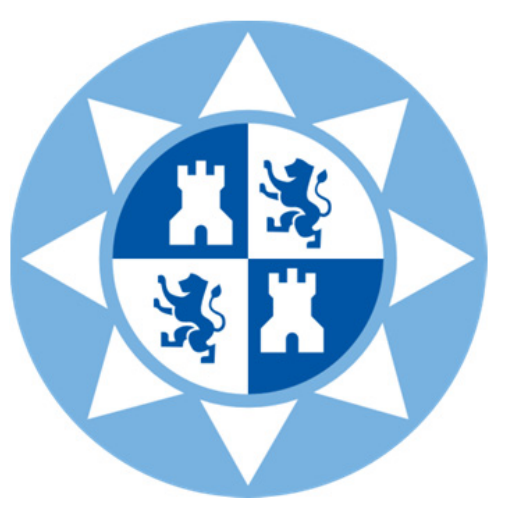

Universidad Politécnica de Cartagena

Departamento de Ingeniería Térmica y de Fluidos

\title{
Estudio de la influencia de la refrigeración con aire de forma natural e inducida en el comportamiento de instalaciones fotovoltaicas
}

Rocio Mazón Hernández 



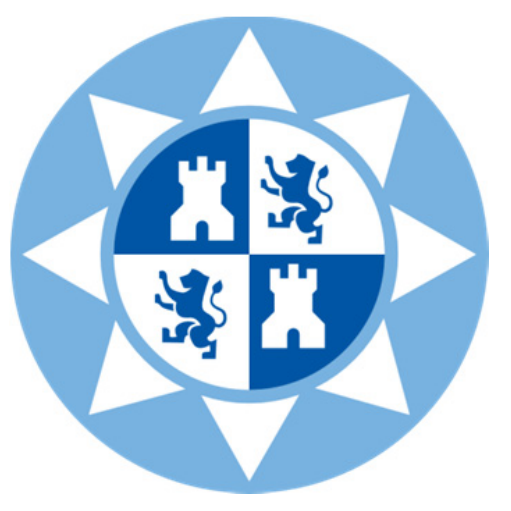

Universidad Politécnica de Cartagena

Departamento de Ingeniería Térmica y de Fluidos

\section{Estudio de la influencia de la refrigeración con aire de forma natural e inducida en el comportamiento de instalaciones fotovoltaicas}

Rocio Mazón Hernández Directores José Ramón Garcia Cascales

Francisco Vera García 2014 



\title{
TESIS DOCTORAL
}

Con Mención Europea

\section{ESTUDIO DE LA INFLUENCIA DE LA REFRIGERACIÓN CON AIRE DE FORMA NATURAL E INDUCIDA EN EL COMPORTAMIENTO DE INSTALACIONES FOTOVOLTAICAS}

\author{
Defendida el 28 Noviembre de 2014 por: \\ Rocio Mazón Hernández \\ Bajo la supervisión de: \\ Dr. José Ramón García Cascales \\ Dr. Francisco Vera García \\ MIEMBROS DEL TRIBUNAL:
}

PRESIDENTE: Dr. Mariano Alarcón García Universidad de Murcia

SECRETARIO: Dr. Antonio Sánchez Káiser Universidad Politécnica de Cartagena

VOCAL: Dr. Rafa García Valverde Danish Technical University

MIEMBROS SUPLENTES

Dr. José Gozálvez Macia

Universidad Politécnica de Valencia

Dr. Blas Zamora Parra

Universidad Politécnica de Cartagena

Dr. Gianfranco Claudio

Loughborough University

EVALUADORES PARA MENCIÓN EUROPEA

Dr. Enmmanuel Kymakis

Technological Education Institute of Crete

Dr. Nieves Espinosa Martínez

Technical University of Denmark 



\section{Dedicado a}

mis padres 



\section{Contenido}

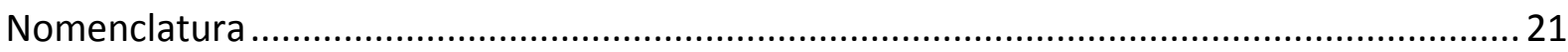

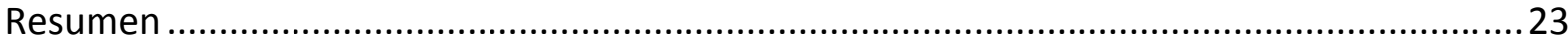

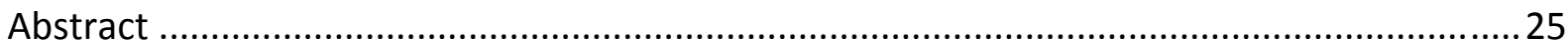

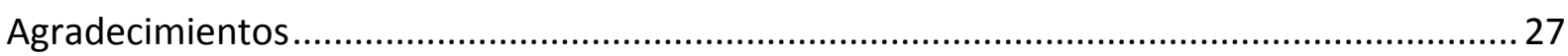

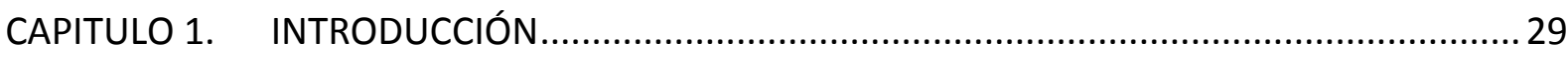

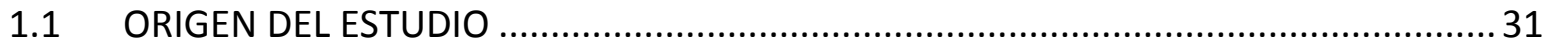

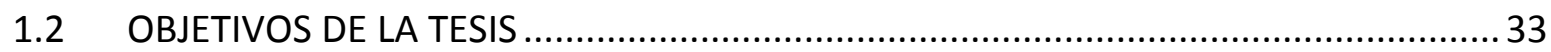

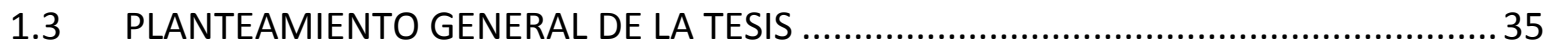

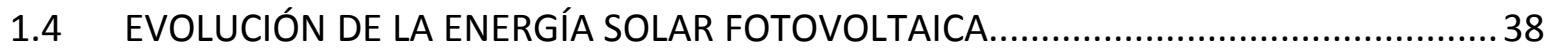

1.4.1 FUNCIONAMIENTO BÁSICO DE UNA CÉLULA FOTOVOLTAICA ...........................42

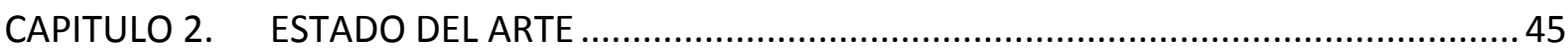

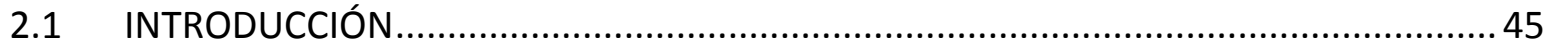

2.2 MÉTODOS DE REDUCCIÓN DE LA TEMPERATURA DE LOS PANELES FOTOVOLTAICOS 46

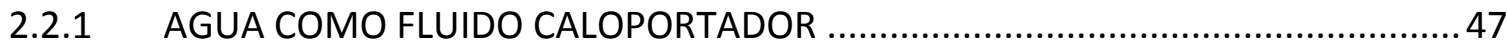

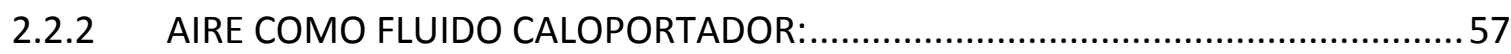

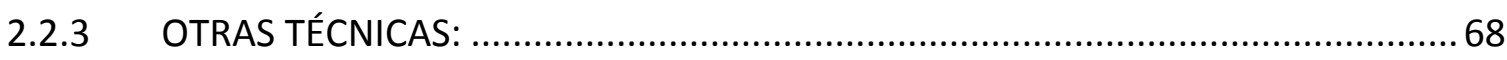

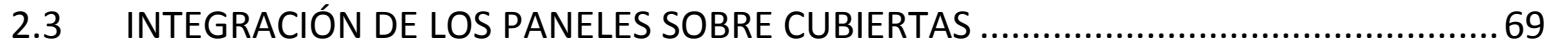

2.3.1 TECNOLOGÍAS FOTOVOLTAICAS SOBRE CUBIERTAS ........................................ 70

2.3.2 APROVECHAMIENTO FOTOVOLTAICO EN LA CUBIERTA DE INVERNADEROS....78 2.4 INFLUENCIA DE LA TEMPERATURA EN EL FUNCIONAMIENTO DE MÓDULOS

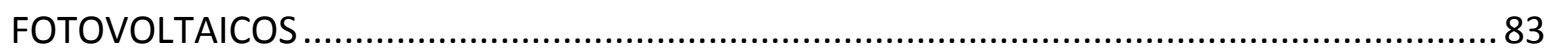

2.5 INFLUENCIA DE LA CAPACIDAD DE VENTILACIÓN EN LA TEMPERATURA DE FUNCIONAMIENTO

2.5.1 CORRELACIONES EXPLICITAS PARA LA TEMPERATURA DE FUNCIONAMIENTO 95

2.6 CONSIDERACIONES SOBRE EL ESTADO DEL ARTE

CAPITULO 3. DESCRIPCIÓN DE LAS INSTALACIONES FOTOVOLTAICAS PARA EL ANÁLISIS DE SU REFRIGERACIÓN CON AIRE 


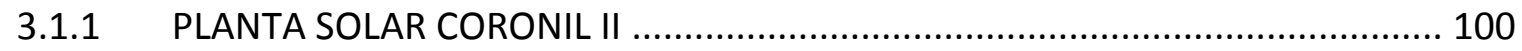

3.1.2 PLANTA SOLAR CORONIL IV EN INSTALACIÓN AGROENERGÉTICA.................... 105

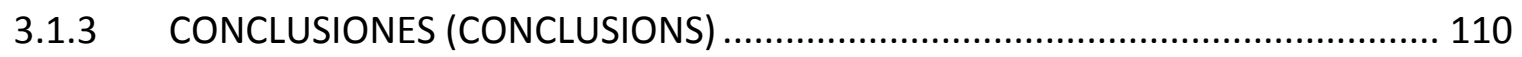

3.2 INSTALACIONES FOTOVOLTAICAS EXPERIMENTALES DESARROLLADAS ................ 112

3.2.1 INSTALACIÓN FOTOVOLTAICA EXPERIMENTAL SOBRE CUBIERTA METÁLICA. 112

3.2.2 INSTALACIÓN FOTOVOLTAICA EXPERIMENTAL SOBRE LA CUBIERTA DE

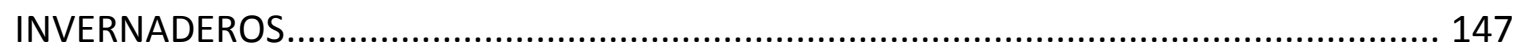

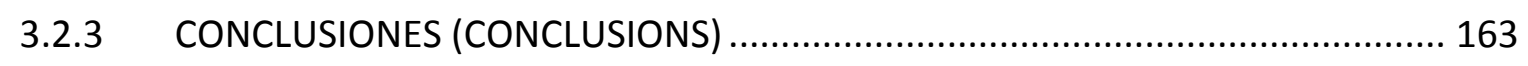

CAPITULO 4. DESCRIPCIÓN DE LA METODOLOGÍA LLEVADA A CABO EN EL REGISTRO DE

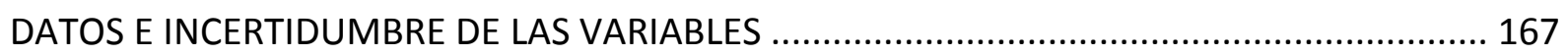

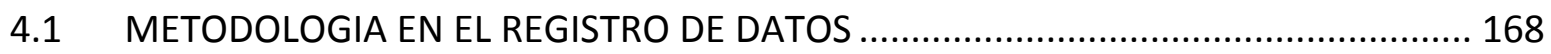

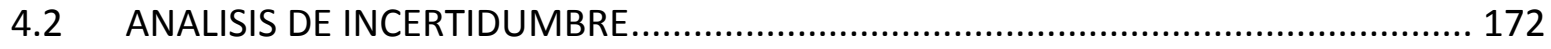

4.2.1 EVALUACIÓN DE LA INCERTIDUMBRE TÍPICA, COMBINADA Y EXPANDIDA .... 172

4.2.2 CÁLCULO DE LA INCERTIDUMBRE EN LAS VARIABLES DE ESTUDIO .................. 175

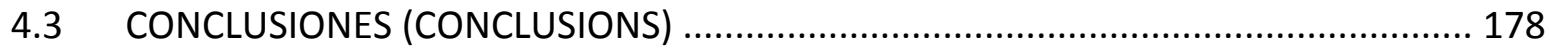

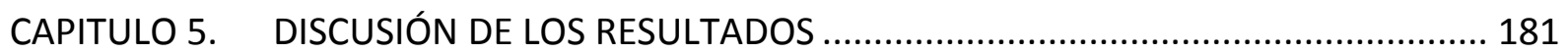

5.1 ESTUDIO COMPARATIVO EN EL COMPORTAMIENTO DE PANELES FOTOVOLTAICOS TRABAJANDO EN UNA PLANTA SOLAR FRENTE A LOS VALORES MEDIDOS EN LA

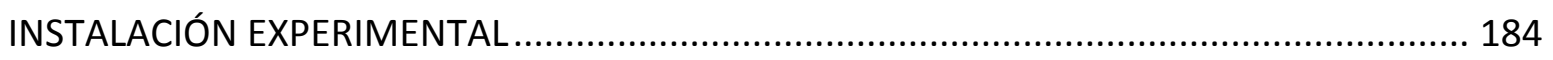

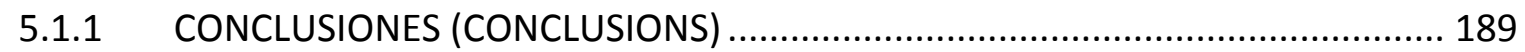

5.2 COMPORTAMIENTO DEL PANEL FOTOVOLTAICO COLOCADO SOBRE UNA CUBIERTA METÁLICA . 191

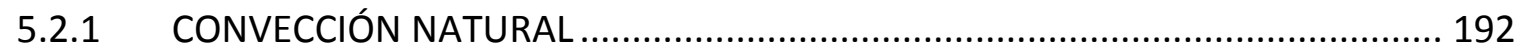

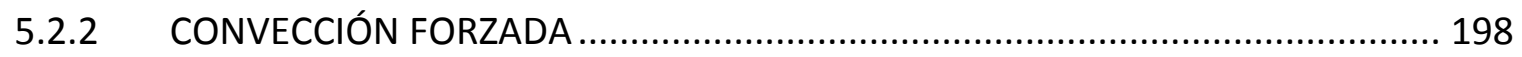

5.2.3 COMPARACIÓN ENTRE CONVECCIÓN NATURAL Y FORZADA .......................... 202

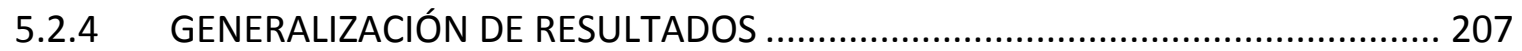

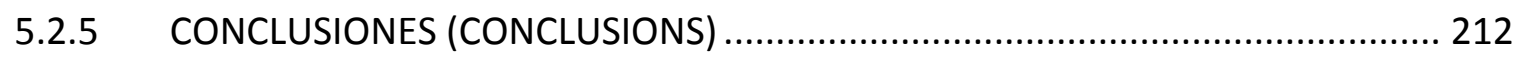

5.3 COMPORTAMIENTO DEL PANEL FOTOVOLTAICO COLOCADO SOBRE UNA CUBIERTA

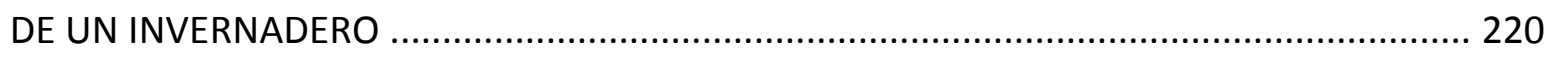

5.3.1 INFLUENCIA DE LA TEMPERATURA DEL PANEL EN LAS VARIABLES ELÉCTRICAS 221

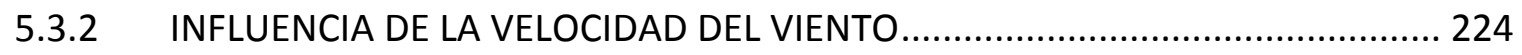

5.3.3 TRANSFERENCIA DE CALOR EN EL CANAL DE AIRE DE REFRIGERACIÓN .......... 227

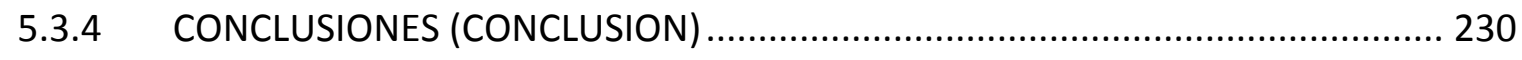


CAPITULO 6. CONCLUSIONES Y TRABAJOS FUTUROS (CONCLUSIONS) ...........................233

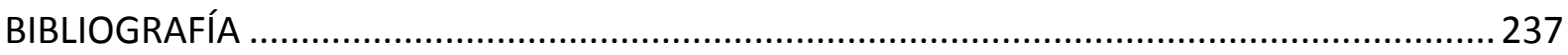

ANEXO A: PRINCIPIOS DE FUNCIONAMIENTO EN EL APROVECHAMIENTO SOLAR

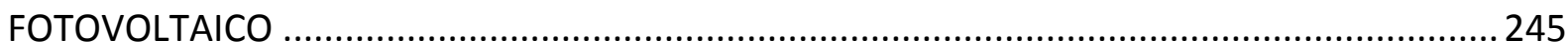

ANEXO B: CONFIGURACIÓN DEL CAMPO FOTOVOLTAICO DE LA INSTALACIÓN SOLAR

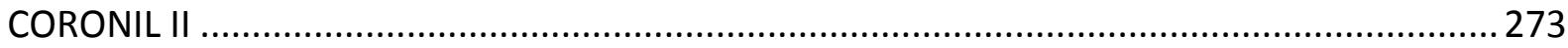

ANEXO C: CARGA ELECTRÓNICA PARA PANELES FOTOVOLTAICOS ....................................275 



\section{ÍNDICE DE FIGURAS}

Figura 1.1 Potencia generada y proyección de energía fotovoltaica por regiones [1] ...........30

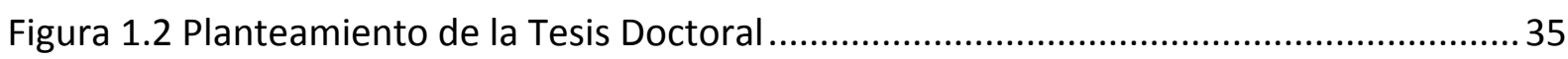

Figura 1.3 Anuncio que los Laboratorios Bell hicieron del primer panel fotovoltaico

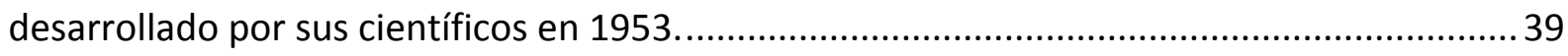

Figura 1.4 Primer satélite con placas solares, Vanguard I.................................................. 40

Figura 1.5 Hitos de instalaciónes fotovoltaicas en satélites espaciales................................. 40

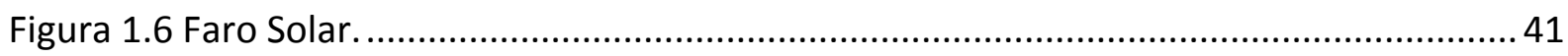

Figura 1.7 Componentes internas de la corriente en una célula fotovoltaica........................ 43

Figura 1.8 Curva característica de una célula fotovoltaica...................................................44

Figura 2.1 Células refrigeradas mediante el bombeo de agua [3]. ......................................47

Figura 2.2 Esquema del sistema de bombeo y pulverización de agua [3]. .............................48

Figura 2.3 Comparación de los resultados medidos, con y sin pulverizar agua a lo largo del día de: a) La tensión del panel, b) temperatura de funcionamiento [3]......................................49

Figura 2.4 Comparación de los resultados medidos en el panel fotovoltaico con y sin pulverizar agua: a) Eficiencia del módulo, b) Eficiencia del subsistema [3]............................50 Figura 2.5 Comparación de la eficiencia total del sistema con y sin pulverización de agua [3].

Figura 2.6 Creación de la capa de agua sobre el módulo PV a través de las boquillas [2] .....52

Figura 2.7 Evolución de las temperaturas del módulo PV en distintos casos [2]. ...................53

Figura 2.8 Eficiencia del módulo PV con y sin refrigeración con agua [2] ..............................53

Figura 2.9 Diagrama del sistema de refrigeración [12] .......................................................54

Figura 2.10 Perfil de temperaturas entre ambas superficies para una célula de $3 \mathrm{~mm}$ de ancho, para distintos tiempos tras la refrigeración con agua a $28^{\circ} \mathrm{C}[12]$.............................54

Figura 2.11 Influencia de la temperatura sobre la tensión de circuito abierto [12]...............55

Figura 2.12 Medida de la tensión y perfil de temperatura de un módulo PV refrigerado con

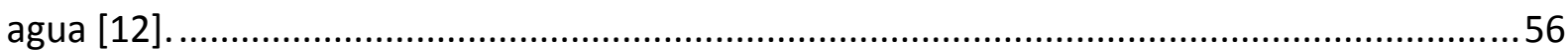

Figura 2.13 Convección natural en paneles fotovoltaicos [18] ............................................... 58

Figura 2.14 Relación entre la velocidad del aire y el espesor del canal de aire para diferentes

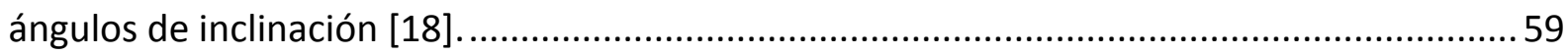

Figura 2.15 Variación de la temperatura para un espesor de 0,1m en función del número de

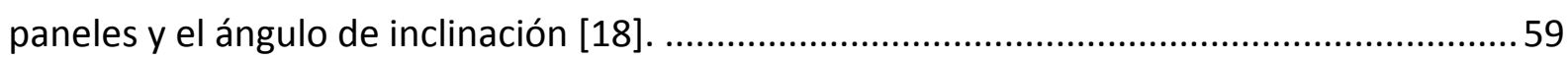

Figura 2.16 Variación de la temperatura para un espesor de $0.2 \mathrm{~m}$ en función del número de

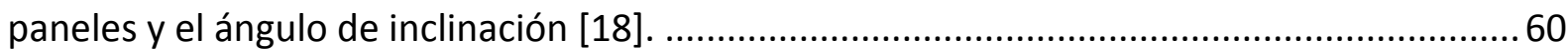

Figura 2.17 Módulos PV refrigerados por aire en su parte posterior [19]............................61

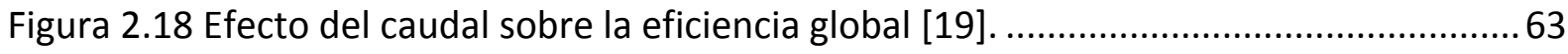

Figura 2.19 Efecto de la longitud del conducto eficiencia [19] ...........................................63

Figura 2.20 Efecto de profundidad en la sobre la eficiencia [19] .........................................63

Figura 2.21 Esquema de las diferentes configuraciones ensayadas, cristal-cristal y cristaltedlar [20]. 
Figura 2.22 Variación de la eficiencia eléctrica con y sin conducto para refrigerar [20]....... 64

Figura 2.23 Variación de la eficiencia y temperatura con conducto para refrigerar [20]...... 64

Figura 2.24 Modelo de la estructura estudiada por Nynne Friling et al. [21]. ........................ 65

Figura 2.25 Evolución de la temperatura del panel a lo largo del día a dos velocidades [21]. 65

Figura 2.26 Coeficiente de convección frente velocidad de viento [21] . ...............................66

Figura 2.27 Modelo del conducto de aire para refrigerar el módulo PV [22]. ....................... 67

Figura 2.28 Descripción de los sistemas fotovoltaicos sobre un tejado [35]......................... 71

Figura 2.29 Proceso de ingeniería de la integración fotovoltaica en la cara sur de un edificio

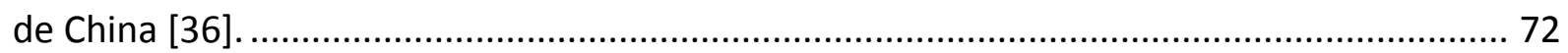

Figura 2.30 Vista global de la integración fotovoltaica sobre la cara este de la cubierta de un

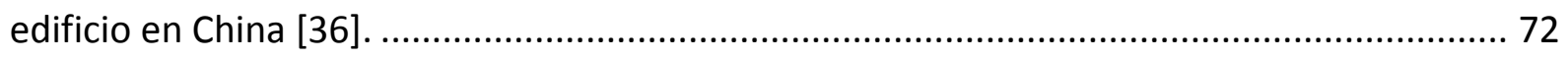

Figura 2.31 Integración de paneles laminados de película fina sobre una cubierta plana. .... 73

Figura 2.32 Sistema de fijación de paneles PV sobre cubierta plana. ................................... 74

Figura 2.33 Sistema fotovoltaico basado en módulos que sustituyen el tejado convencional

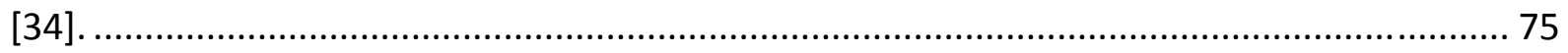

Figura 2.34 Tejado fotovoltaico originario de Japón, ubicado sobre la cubierta inclinada [34]. 76

Figura 2.35 Módulo fotovoltaico de $35 \mathrm{Wp}$, sustituyente a cuatro tejas convencionales [34].

Figura 2.36 Invernadero de Nueva Delhi con módulos fotovoltaicos integrados [37]........... 79

Figura 2.37 Temperatura experimental y teórica del panel PV a lo largo de un día [37]........ 79

Figura 2.38 Esquema de ubicación de los módulos sobre el invernadero [38]...................... 80

Figura 2.39 Energía fotovoltaica generada frente a los meses de estudio. Orden de

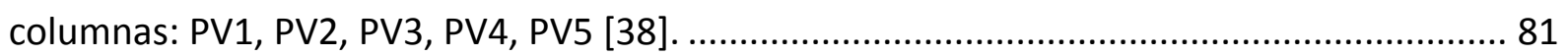

Figura 2.40 Proyectos de integración fotovoltaica en la cubierta de invernaderos en China. a) Vista del interior del invernadero solar en Heihe. b) Vista exterior del proyecto en Peony

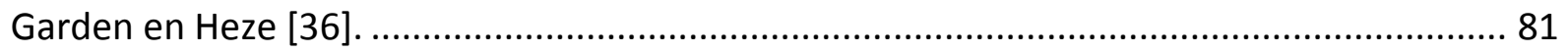

Figura 2.41 Boceto del diseño de una parte $(50 \mathrm{KW})$ del nuevo proyecto agrícola con integración fotovoltaica en la cubierta de $1 \mathrm{MWp}$ ubicado en la ciudad de Weifang, Shandong [36].

Figura 2.42 Esquema simple del proceso térmico de energía en un módulo fotovoltaico..... 83

Figura 2.43 Relación entre la tensión de circuito abierto con la temperatura [50]. 86

Figura 2.44 a) Representación de la curva característica del funcionamiento de una célula fotovoltaica. b) Modificación de la curva característica de funcionamiento con el aumento de la temperatura.

Figura 2.45 Influencia de un aumento de la temperatura en los parámetros que definen al Factor de llenado. a) Representación del concepto del factor de llenado en la curva característica. b) Variación de los parámetros del factor de llenado con la temperatura..... 88 Figura 2.46Dependencia de la temperatura en la tensión de circuito abierto para diferentes módulos fotovoltaicos [54].

Figura 2.47 Dependencia de la temperatura en la potencia máxima para diferentes módulos fotovoltaicos [54]. 
Figura 2.48 Efecto de la temperatura de funcionamiento de un panel fotovoltaico sobre su eficiencia, comparando los resultados medidos y el modelo teórico [58].....

Figura 2.49 Variación de la tensión de circuito abierto, intensidad de cortocircuito y eficiencia con la temperatura para una célula de silicio en el rango de temperatura de $295-$ $320 \mathrm{~K}[51]$

Figura 3.1 Planta fotovoltaica "El Coronil II". 101

Figura 3.2 Estructura soporte de los paneles con 3 y 4 metros de hipotenusa respectivamente. 103

Figura 3.3 Radiación solar medida en el plano de captación y temperatura ambiente registrada durante el mes de Marzo de 2009. 104

Figura 3.4 Variación del rendimiento teórico de de cada modelo de panel PV en función de la temperatura ambiente. 105

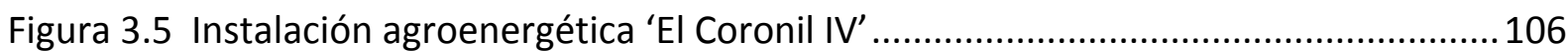

Figura 3.6 Distribución de los paneles en la cubierta de la instalación agroenergética........107

Figura 3.7 Alzado de la estructura de la instalación agropecuaria. .....................................108

Figura 3.8 Esquema unifilar de la instalación.................................................................... 109

Figura 3.9 Estructura soporte del panel. Medidas en $\mathrm{cm}$. ................................................ 114

Figura 3.10 Alzado y planta de la estructura base. Medidas en $\mathrm{cm}$......................................114

Figura 3.11 Fotografías de la estructura soporte y base de la instalación fotovoltaica

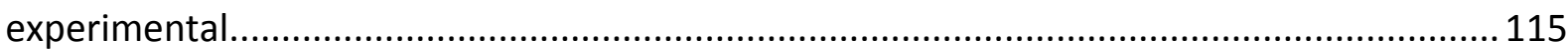

Figura 3.12 Características de los módulos fotovoltaicos utilizados en la instalación. ..........116

Figura 3.13 Instalación fotovoltaica experimental constituida por Panel A el izquierdo y Panel B el derecho en convección natural.

Figura 3.14 Instalación fotovoltaica experimental constituida por Panel A el izquierdo y Panel B el derecho en convección forzada.

Figura 3.15 Representación de la ubicación de los sensores de medida en los paneles y

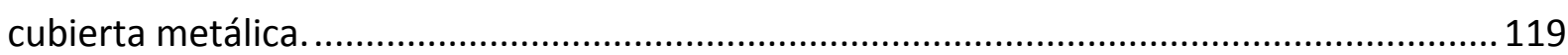

Figura 3.16 Fotografía del transmisor de humedad relativa y temperatura ambiente.........121

Figura 3.17 Curvas características de algunos metales...................................................... 122

Figura 3.18 Esquema de construcción del dieléctrico.......................................................... 123

Figura 3.19 Esquema de la relación entre las variables en un dieléctrico............................124

Figura 3.20 Dispositivo de protección a la radiación solar.................................................. 125

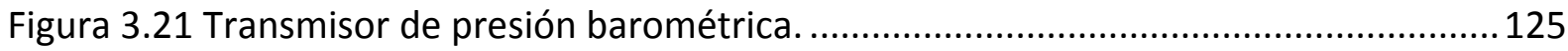

Figura 3.22 Esquema eléctrico del puente de Wheatstone................................................ 126

Figura 3.23 Esquema de un sensor piezoresistivo. ............................................................. 127

Figura 3.24 Anemómetro ultrasónico. ........................................................................... 129

Figura 3.25 Esquema gráfico del funcionamiento del anemómetro ultrasónico. .................129

Figura 3.26 Piranómetro empleado para la medida de la radiación global..........................131

Figura 3.27 Esquema de la constitución interna del piranómetro........................................132

Figura 3.28 Banda de sombra del piranómetro que registra la radiación difusa..................133

Figura 3.29 Célula fotovoltaica calibrada. ...................................................................... 134

Figura 3.30 Principio de funcionamiento de una célula fotovoltaica, efecto fotovoltaico....135 
Figura 3.31 Sonda flexible Pt100 utilizada para medir la temperatura de la cara posterior de los módulos fotovoltaicos. 136

Figura 3.32 Principio de funcionamiento del detector de temperatura por resistencia. a) Conexión a dos hilos. b) Conexión a cuatro hilos.

Figura 3.33 Sonda de temperatura Pt100 para medir la temperatura del aire en el canal. . 137 Figura 3.34 Anemómetro de placa caliente para medir la velocidad de aire en el interior del canal. 138

Figura 3.35 Carga electrónica para obtener la curva característica de los paneles fotovoltaicos. 140

Figura 3.36 Sistema de adquisición de datos, data logger 34980A................................... 141

Figura 3.37 Ventana principal de Benchlink Data Logger................................................ 142

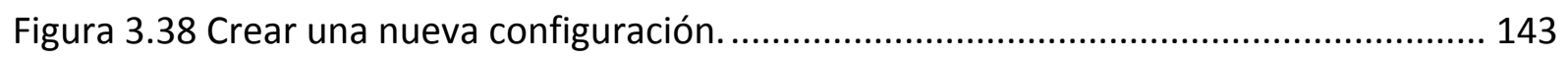

Figura 3.39 Ventana de configuración............................................................................. 143

Figura 3.40 Ventana que muestra los canales conectados y permite su configuración. ...... 144

Figura 3.41 Ventana de configuración las opciones para el registro de datos...................... 145

Figura 3.42 Ventana resumen con los datos recogidos y opciones de exportación. ............ 146

Figura 3.43 Representación gráfica de las variables medidas............................................. 146

Figura 3.44 Fotografía aérea de la instalación agroenergética Coronil IV........................... 148

Figura 3.45 Alzado del plano en el que se aprecia la configuración del invernadero y paneles.

Figura 3.46 Invernadero de referencia, Coronil IV e instalación experimental..................... 149

Figura 3.47 Esquema de la estructura con identificación de los perfiles (izquierda) y

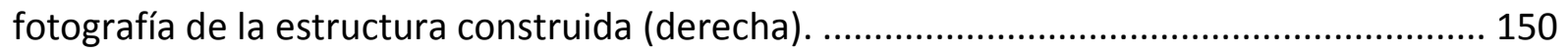

Figura 3.48 Descripción de los perfiles y elementos de unión utilizados en el montaje de la

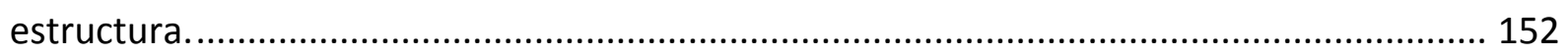

Figura 3.49 Alzado y perfil de la estructura metálica con las dimensiones en mm. ............. 152

Figura 3.50 Grupos de paneles fotovoltaicos y esquema de conexión. ............................... 154

Figura 3.51 Fotografías de dos configuraciones estudiadas. Izquierda: Primera configuración con menor sección de aire de paso y con cubierta de plástico. Derecha: cuarta configuración con canal de aire de mayor sección y con aislante sobre la cubierta.................................... 155

Figura 3.52 Ubicación de los sensores utilizados en la instalación experimental. a) Sensores emplazados en el canal de aire y adheridos a los paneles. b) Sensores adheridos a la cubierta de plástico. c) Sondas de temperatura en el interior del invernadero................................. 156

Figura 3.53 Transmisor de la temperatura ambiente y su ubicación en la instalación

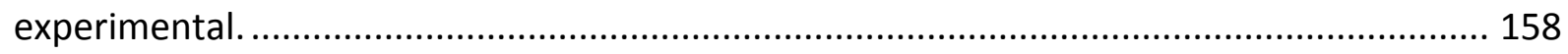

Figura 3.54 Anemómetro Windsonic y su ubicación en la instalación experimental............ 159

Figura 3.55 Transmisor de la temperatura del aire tanto en el canal como en el interior del

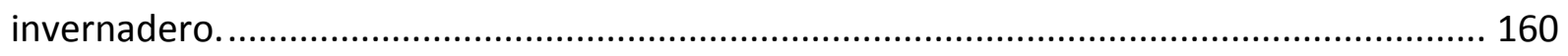

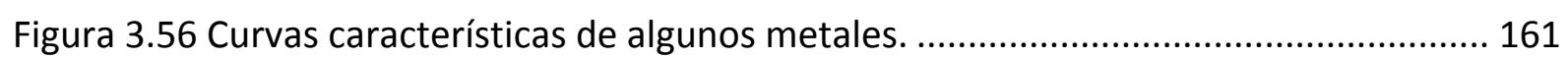

Figura 3.57 Aerotermo para calentar el interior del invernadero...................................... 162

Figura 3.58 Diagrama de conexión entre DIN-A-MITE y PID. .............................................. 163

Figura 4.1 Fotografía de la tarjeta utilizada para el disparo de la carga electrónica............. 168 
Figura 4.2 Ejemplo de curva característica I-V obtenida de los paneles 1 y 2 conectados en

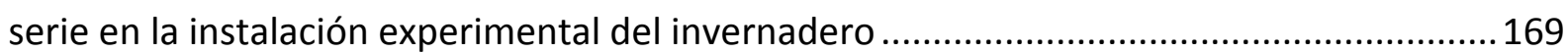

Figura 4.3 Panel frontal de aplicación desarrollada en Labview ${ }^{\circledR}$...........................................170

Figura 4.4 Diagrama de bloques de uno de los casos implementados en LabView ${ }^{\circledR}$.............171

Figura 5.1 Parámetros eléctricos característicos de los paneles fotovoltaicos ET270........... 184

Figura 5.2 Comparativa de los resultados experimentales medidos en la instalación, con los proporcionados por el fabricante, en función de la radiación solar. a) Intensidad de cortocircuito b) Potencia máxima.

Figura 5.3 Comparativa de los resultados experimentales medidos en la instalación, con los proporcionados por el fabricante, en función de la temperatura del panel. a) Tensión de circuito abierto b) Factor de llenado.

Figura 5.4 Comparativa en la eficiencia eléctrica de los resultados experimentales medidos en la instalación, con los proporcionados por el fabricante, en función de la temperatura del panel.

Figura 5.5 Radiación solar y potencia obtenida en la planta solar fotovoltaica Coronil II, a lo largo de cuatro días de agosto.

Figura 5.6 Correlación del rendimiento de los paneles en la planta fotovoltaica Coronil II con la temperatura alcanzada por el panel.

Figura 5.7 Configuración del panel B, representando el canal de aire entre el panel fotovoltaico y la superficie metálica.

Figura 5.8 Diferencia de temperatura de cada panel fotovoltaico y la ambiente respecto la radiación solar, en convección natural para diferentes relaciones de aspecto del canal de aire.

Figura 5.9 Rendimiento eléctrico del Panel A y Panel B respecto la radiación solar, en convección natural, para diferentes relaciones de aspecto del canal de aire.

Figura 5.10 Comparación del comportamiento entre ambos paneles, panel A y panel B con $b / L=0.0825$. a) Diferencia de temperatura de panel y la ambiente b) Rendimiento eléctrico a lo largo del día. 195

Figura 5.11 Influencia de la relación de aspecto en convección natural sobre la temperatura del panel. 196

Figura 5.12 Influencia de la relación de aspecto en convección natural sobre el rendimiento eléctrico del panel.

Figura 5.13 Influencia de la relación de aspecto sobre las variables eléctricas a diferentes condiciones ambientales. a) Alta radiación solar, con $G_{\text {pira }}=970 \mathrm{~W} / \mathrm{m}^{2}$ y Táamb $=29^{\circ} \mathrm{C}$. b) Media-baja radiación solar, con $\mathrm{G}_{\text {pira }}=225 \mathrm{~W} / \mathrm{m}^{2}$ y $\mathrm{T}$ a $a \mathrm{mb}=23^{\circ} \mathrm{C}$. 198 Figura 5.14 Influencia de la relación de aspecto en la temperatura y rendimiento del panel en función de la radiación solar para $\mathrm{V}_{\mathrm{v}}=2 \mathrm{~m} / \mathrm{s}$. a) Diferencia de temperatura del panel con el ambiente. b) Rendimiento del panel, para las diferentes relaciones de aspecto...... 200 Figura 5.15 Influencia de la relación de aspecto en la temperatura y rendimiento del panel en función de la radiación solar para $\mathrm{V}_{\mathrm{v}}=4 \mathrm{~m} / \mathrm{s}$. a) Diferencia de temperatura del panel con el ambiente. b) Rendimiento del panel, para las diferentes relaciones de aspectos. 
Figura 5.16. Diferencia entre temperatura de panel y ambiente en función de la radiación solar para diferentes niveles de velocidad inducida. a) $b / L=0.0675$. b) $b / L=0.0825$. 203 Figura 5.17 Comparación entre convección natural y forzada para las diferentes relaciones de aspecto, para una radiación de $950 \mathrm{~W} / \mathrm{m} 2$ y Táambiente de $28^{\circ} \mathrm{C}$. a) Potencia pico. b) Diferencia de temperatura del panel y ambiente. 205 Figura 5.18 Relación entre el rendimiento del panel con la temperatura. a) Para la menor relación de aspecto medida (0.0525). b) Pala la mayor relación de aspecto medida (0.0825).

Figura 5.19 Resultados experimentales y correlaciones propuestas del coeficiente de Ross (k) medido para diferentes relaciones de aspecto y velocidades inducidas en el canal. Correlaciones experimentales propuestas por Skoplaki et al. [72] para sistemas PV no integrados en cubierta $(w=1)$.. 208

Figura 5.20 Comparación de los valores experimentales medidos y los predichos por el modelo experimental para la temperatura del panel fotovoltaico integrado sobre cubierta, a lo largo de un día y para diferentes valores de velocidad inducida en el canal (b/L=0.0825).

Figura 5.21 Comparación entre los datos experimentales de la eficiencia eléctrica con la correlación propuesta para diferentes valores de velocidad inducida, $b / L=0.0675$ y $T_{a m b}=25^{\circ} \mathrm{C}$.

Figura 5.22 Influencia de la velocidad inducida del aire en el canal sobre la potencia pico del panel fotovoltaico en función de la radiación solar, a partir de la correlación propuesta para $b / L=0.0825$ y $T_{a m b}=25^{\circ} \mathrm{C}$.

Figura 5.23 Dependencia con la temperatura de: a) la tensión de circuito abierto (Voc), b) la intensidad de cortocircuito (Isc) y c) el rendimiento.

Figura 5.24 Influencia de la velocidad del viento en el salto de temperatura del panel respecto la ambiente en función de la radiación solar, para las diferentes configuraciones de estudio.

Figura 5.25 Influencia de la velocidad del viento en el rendimiento del panel en función de la radiación solar, para las diferentes configuraciones de estudio. 226 Figura 5.26 Diferencia de temperatura del panel respecto a la de la superficie de la cubierta del invernadero para las cuatro configuraciones estudiadas. 227 Figura 5.27 Potencia calorífica absorbida por el canal de aire circulante por el canal entre los módulos fotovoltaicos y la cubierta del invernadero, para las configuraciones propuestas.229 


\section{ANEXOS}

Figura A.1 Estructura del átomo y sus niveles de energía...................................................246

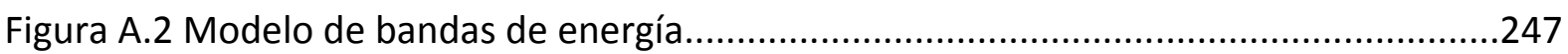

Figura A.3 Modelo de bandas de energía para conductores, semiconductores y aislantes..248

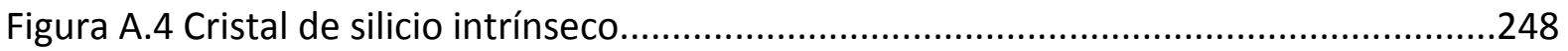

Figura A.5 Creación de un electrón-hueco en un cristal de silicio......................................249

Figura A.6 Movimiento de los electrones y los huecos en semiconductores........................249

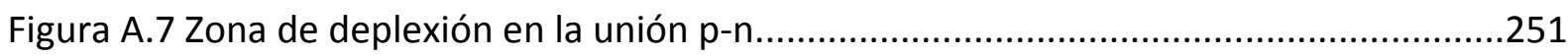

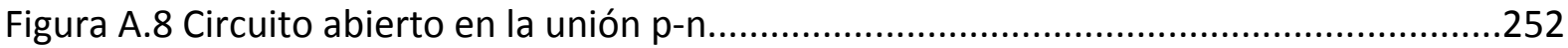

Figura A.9 Separación de los portadores por el campo de la unión $p-n$.................................254

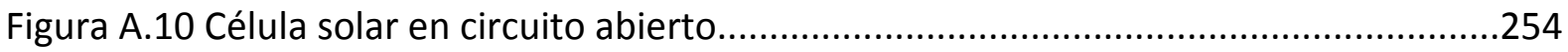

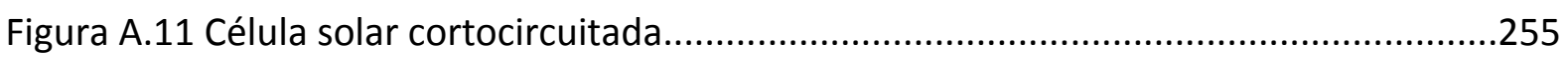

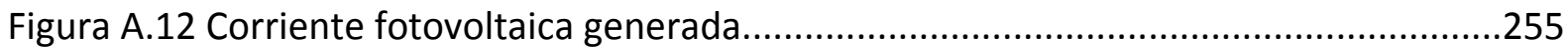

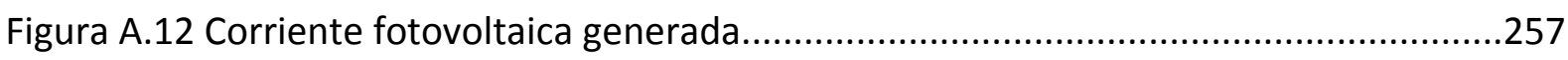

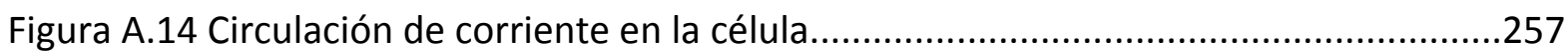

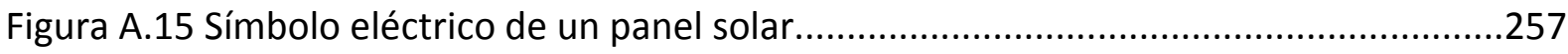

Figura A.16 Curva I-V de una célula fotovoltaica...............................................................258

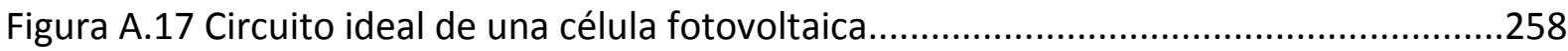

Figura A.18 Curva característica de una célula fotovoltaica..............................................259

Figura A.19 Representación del PMP en la curva característica.........................................260

Figura A.20 Circuito equivalente de una célula fotovoltaica............................................262

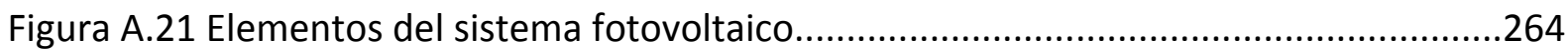

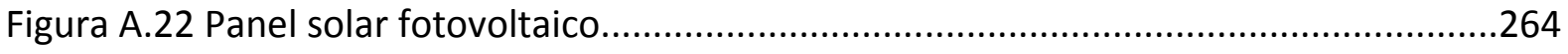

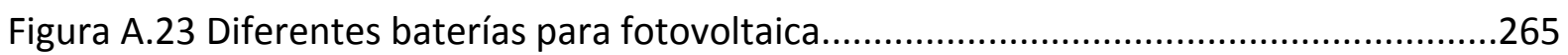

Figura A.24 Controlador de carga solar de 30A para un campo de paneles de corriente

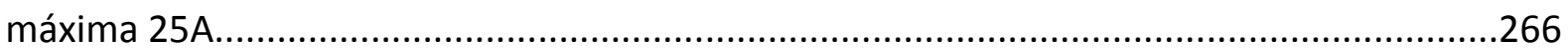

Figura A.25 Inversores DC/AC de baja potencia para un módulo fotovoltaico y grupos de inversores para grandes centrales fotovoltaicas................................................................267

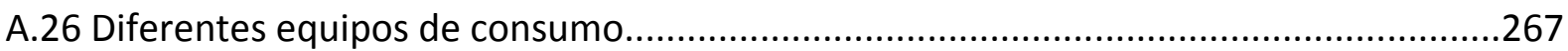

Figura A.27 Esquema de una instalación aislada de la red................................................269

Figura A.28 Esquema de una instalación conectada a la red...........................................270

Figura A.29 Comparación de la radiación captada por instalaciones fijas e instalaciones con seguimiento a dos ejes a lo largo de un día.....

Figura B.1 Distribución de los diferentes paneles fotovoltaicos y potencia pico por inversor en el campo fotovoltaico Coronil II................................................................................273

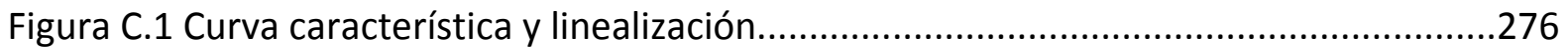

Figura C.2 Circuito simplificado. Fuente de corriente........................................................276

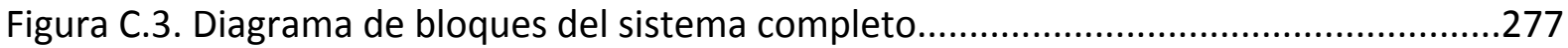

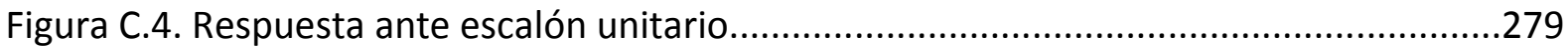

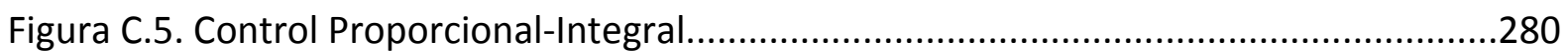

Figura C.6. Respuesta a escalón unitario con control I......................................................281 


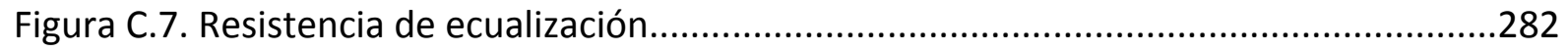

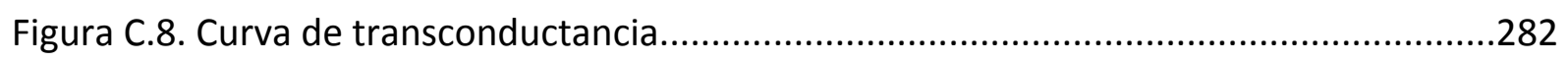

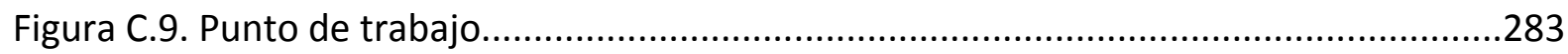

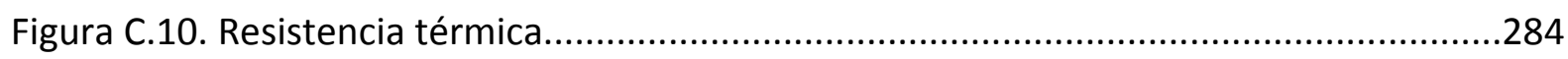

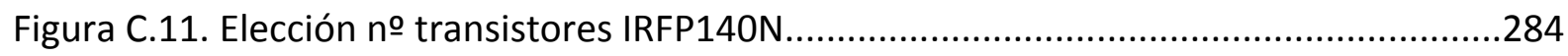

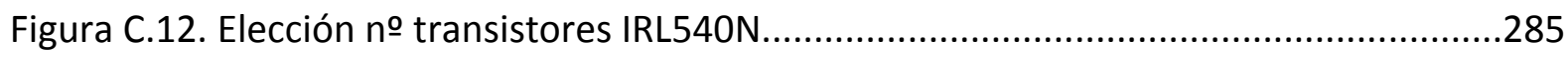

Figura C.13. Fuente de tensión para obtener tensiones negativas.......................................286

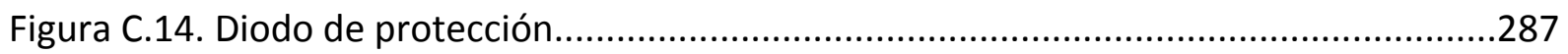

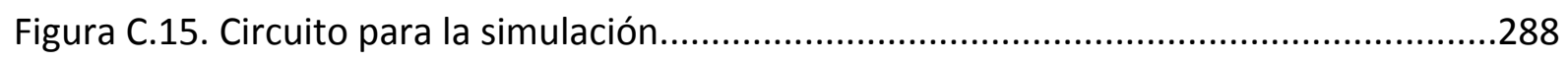

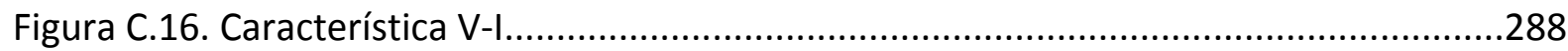

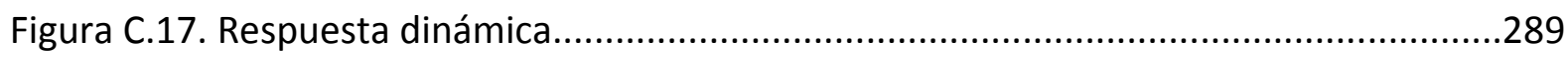

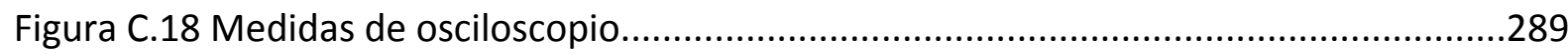

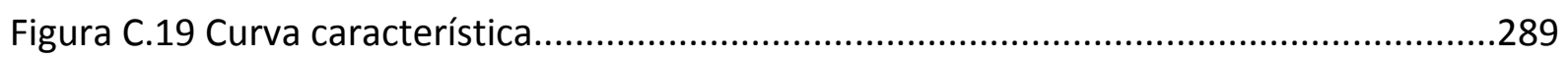




\section{INDICE DE TABLAS}

Tabla 2.1 Datos medidos de las variables influyentes para las diferentes configuraciones [2].

Tabla 2.2 Espesor del canal de aire necesario para reducir la temperatura del panel [18]. ...60 Tabla 2.3 Resultados experimentales para convección natural [19].

Tabla 2.4 Resultados experimentales para convección forzada, utilizando un ventilador [19].

Tabla 2.5 Resultados experimentales para convección forzada, utilizando dos ventiladores [19].

Tabla 2.6 Valores experimentales de las variables eléctricas de dos células de Silicio para el rango de temperaturas de 295 a $320 \mathrm{~K}$ [51].

Tabla 2.7Coeficientes de proporcionalidad de Isc, Voc y Pm con la temperatura para los módulos evaluados [54]

Tabla 2.8 Valores experimentale del coeficiente de Ross para diferentes configuraciones [72].

Tabla 3.1 Características eléctricas de los diferentes modelos de paneles instalados en la planta fotovoltaica "El Coronil II" ....................................................................................... 102

Tabla 3.2 Número total de paneles y potencia instalada de cada modelo de paneles .........102

Tabla 3.3 Características del sensor de humedad relativa y temperatura ambiente.............124

Tabla 3.4 Características del transmisor de presión barométrica...........................................127

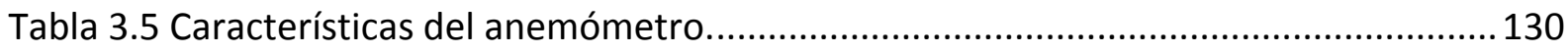

Tabla 3.6 Características técnicas de los piranómetros y amplificadores.............................133

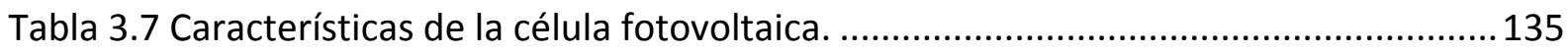

Tabla 3.8 Especificaciones de la sonda de temperatura de contacto. ...................................137

Tabla 3.9 Especificaciones de la sonda de temperatura de aire en el conducto....................138

Tabla 3.10 Especificaciones técnicas de los transductores de la velocidad del aire en el canal.

Tabla 3.11 Características de la carga electrónica.

140

Tabla 3.12 Especificaciones de la tarjeta multiplexora 34921A........................................... 141

Tabla 3.13 Propiedades del plástico empleado en la instalación experimental. ...................153

Tabla 3.14 Características del sensor de temperatura del aire en el canal y en el interior del invernadero.

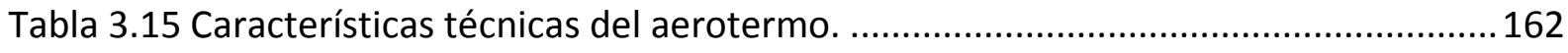

Tabla 3.16 Características técnicas del PID y Din-a-mite. ................................................... 163

Tabla 4.1 Precisión y errores de lectura y rango de los sensore de medida de las variables de

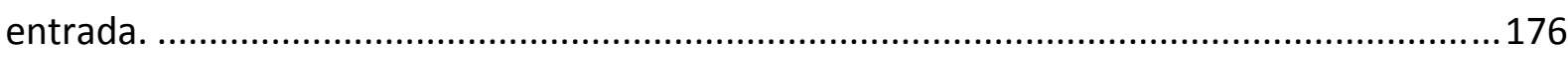

Tabla 4.2 Resultado de la evaluación de la Incertidumbre de las variables. ${ }^{*}$ Resultados calculados mediante la ley de propagación de incertidumbre. ........................................... 177

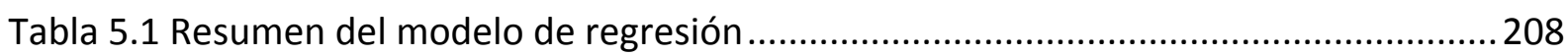

Tabla 5.2 Coeficientes del modelo de regresión. ................................................................ 209 



\section{Nomenclatura}

A

$A_{c}$

$b$

$b / L$

$C$

$C_{p}$

$d$

$E_{c}$

$E_{f}$

$E_{G O}$

FF

$g$

$G_{\text {pira }}$

$G_{T}$

$h$

$I_{D}$

$I_{L}$

$I_{m p}$

Is

$I_{s c}$

$I_{s c, o}$

$K$

$k$

$k_{c}$

$L$

$m$

$m_{e}$

$\dot{m}_{a}$

$n$

$n_{e}$

$P_{a t m}$

$P_{m}$

$P_{m, o}$

$P_{\text {th }}$

$q$

$Q$

$\dot{Q}_{i n v}$

$\dot{Q}_{\text {panel }}$

$R$

$R_{o}$

$R^{2}$

$S$

Sanal

$T$ área o superficie del panel fotovoltaicos

área del condensador

espesor del canal de aire

relación de aspecto

capacidad del condensador

calor específico del aire

distancia entre las placas del condensador

energía en la banda de conducción

energía en ele nivel de Fermi

energía del ancho de banda prohibida a $0 \mathrm{~K}$

factor de forma

aceleración de la gravedad

radiación solar por unidad de superficie

potencia luminosa recibida por la radiación solar

altura o salto de bombeo de agua

intensidad e corriente de diodo

intensidad de corriente fotogenerada en una célula fotovoltaica

intensidad de corriente en el punto de máxima corriente

intensidad de corriente de saturación de oscuridad

intensidad de corriente de cortocircuito

intensidad de cortocircuito a $25^{\circ} \mathrm{C}$

constante de Boltzman

coeficiente de Ross Ec. 2.18

factor de cobertura en la incertidumbre expandida Ec. 4.7

longitud del canal de aire

factor de idealidad en Ec. 1.1

masa del electrón

flujo másico de aire

Índice de refracción

número de electrones en Ec. 2.5

presión atmosférica

potencia pico o potencia máxima (Punto de máxima potencia) de una

célula fotovoltaica

potencia máxima de una célula fotovoltaica a $25^{\circ} \mathrm{C}$

potencia máxima teórica de una célula fotovoltaica

carga del electrón

caudal de agua

calor trasferido del interior del invernadero al canal de aire

calor trasferido del panel al canal de aire

resistencia eléctrica

resistencia electrica a $0^{\circ} \mathrm{C}$

coeficiente de regresión

área de captación de radiación solar en el panel fotovoltaico

área de la sección transversal del canal de aire

temperatura 


\begin{tabular}{|c|c|}
\hline$T_{a m b}$ & temperatura ambiente \\
\hline$T_{\text {panel }}$ & temperatura del panel fotovoltaico \\
\hline$T_{\text {panel, } 1} T_{\text {panel, }, 2}$ & medida de varios sensores de la temperatura del panel fotovoltaico \\
\hline$T_{\text {panel,3 }} T_{\text {panel, } 4}$ & medida de varios sensores de temneratura del aire en la entrada al \\
\hline$T_{\text {air }, i, 1} T_{\text {air }, i, 2}$ & canal \\
\hline$T_{\text {air,o,1 }} T_{\text {air, o }}$ & medida de varios sensores de temperatura del aire en la salida al canal \\
\hline$u$ & incertidumbre típica de una medida \\
\hline$U$ & incertidumbre expandida \\
\hline$u_{c}$ & incertidumbre típica combinada \\
\hline$v_{f}$ & velocidad del viento en Ec. 2.19 \\
\hline$v_{w}$ & velocidad del aire que circula bajo el panel \\
\hline$V_{\text {air }, 1} V_{\text {air }, 2}$ & medida de varios sensores de la velocidad del aire en el canal \\
\hline$V$ & tensión o voltaje eléctrico \\
\hline$V_{m p}$ & tensión en el punto de máxima corriente de un célula fotovoltaica \\
\hline$V_{o c}$ & tensión de circuito abierto de un célula fotovoltaica \\
\hline$V_{o c, o}$ & tensión de circuito abierto de un célula fotovoltaica a $25^{\circ} \mathrm{C}$ \\
\hline$V_{T}$ & potencial térmico en Ec.1.1 \\
\hline$w$ & coeficiente de montaje en Ec.2.21 \\
\hline$\Delta H_{\text {aire }}$ & salto de entalpia en el canal de aire \\
\hline$\Delta T$ & diferencia de temperatura entre el panel y ambiente \\
\hline
\end{tabular}

\section{Símbolos griegos}

$\beta \quad$ constante en Ec. 2.7

$\gamma \quad$ constante en Ec. 2.7

$\eta \quad$ eficiencia o rendimiento

$\rho \quad$ densidad

$\rho_{a} \quad$ densidad del aire

$\varepsilon \quad$ constante dielectrica del medio 


\section{Resumen}

La investigación realizada tiene su origen en la necesidad e interés despierto por la empresa Apia XXI en colaborar con el Departamento de Ingeniería Térmica y de Fluidos de la Escuela Técnica Superior de Ingeniería Industrial de la Universidad Politécnica de Cartagena, sobre el desarrollo e investigación del comportamiento eléctrico de los paneles fotovoltaicos al alcanzar altas temperaturas, cuando se encuentran ubicados sobre diferentes cubiertas. Este trabajo de tesis se centra en caracterizar y analizar la influencia negativa de la temperatura en la producción eléctrica de paneles fotovoltaicos, y por ende, en su rendimiento, al estar emplazados sobre una cubierta de acero, como puede ser una nave industrial o sobre la de un invernadero, y además, ensayar diferentes posibles configuraciones que permitan refrigerar los paneles, reduciendo su temperatura y mejorar su rendimiento.

Para abordar este problema, se han construido dos instalaciones experimentales a ensayar sobre la cubierta del Aulario General del Campus Alfonso XIII de la Universidad Politécnica de Cartagena, donde el Departamento de Ingeniería Térmica y Fluidos tiene algunas instalaciones docentes y de investigación relacionadas con energía solar.

La primera instalación engloba dos paneles fotovoltaicos montados sobre una estructura fija al suelo, que permite variar la inclinación de éstos. Uno de los paneles, que se ha denominado panel $A$, se encuentra aislado, sin ninguna cubierta en su parte inferior, el cual utilizaremos como panel de referencia, ya que trabaja en condiciones normales al estar expuesto a condiciones ambientales y su única influencia térmica es la temperatura ambiente. El otro panel, denominado panel $B$, está emplazado en dicha estructura sobre una superficie paralela y metálica, la cual influenciará a la temperatura alcanzada por dicho panel. Entre ambas superficies se ha dejado un espacio que posibilita un flujo de aire que permite refrigerar en mayor o menor medida el panel por convección natural, gracias al efecto chimenea. Se ha estudiado el comportamiento del panel para diferentes separaciones del canal de aire, comparándolo con el panel de referencia (panel A). Tras la toma de datos y el análisis de los resultados, a dicha instalación se le incorporó un ventilador acoplado al panel $B$, mediante el uso de diferentes toberas, que impulsa el aire desde el exterior al interior del canal entre el panel B y la cubierta metálica, con el fin de analizar para cada separación del canal de aire y diferentes velocidades del aire impulsado, el comportamiento del panel en convección forzada y así compararlo con el panel A de referencia y con los resultados obtenidos previamente mediante convección natural. Por último, se pretende generalizar todos los resultados (diferentes secciones de aire, velocidades inducidas en canal, condiciones ambientales), mediante un modelo experimental que establezca correlaciones que nos permita determinar la temperatura del funcionamiento, potencia $y$ eficiencia del módulo en función de las variables influyentes. 
Adicionalmente, se ha analizado el comportamiento eléctrico de paneles similares (mismo modelo y características), instalados en una planta fotovoltaica en funcionamiento, Coronil II ubicada en Sevilla. Se han analizado los datos reales de esta planta, correspondientes a los cuatro meses más calurosos del año: mayo, junio, julio y agosto, para los cuales se alcanzan las mayores temperaturas. Con dichos datos se han obtenido correlaciones entre la temperatura del panel y las variables eléctricas tales como potencia, rendimiento y, además, se ha comparado el comportamiento eléctrico de los paneles de la planta con el de nuestra instalación, para las diferentes configuraciones experimentadas.

La segunda instalación experimental, es una réplica de la planta fotovoltaica montada sobre la cubierta de la instalación agroenergética Coronil IV, Ilevada a cabo por la empresa Apia XXI en Sevilla. La instalación experimental reproduce una parte de la instalación, formada por cuatro paneles fotovoltaicos colocados sobre el plástico del invernadero, existiendo un canal divergente entre ambas superficies. Con esta instalación, se pretende estudiar y analizar la influencia de las altas temperaturas en el interior del invernadero sobre la producción eléctrica de los paneles, dado la existencia de una transferencia de calor del interior del invernadero a través de la cubierta. Por consiguiente, se ha ensayado dicha instalación, para dos separaciones diferentes y, posteriormente, se colocó un aislante sobre el plástico, para cada separación, con el fin de evitar la transferencia del calor del interior a los paneles y analizar las mejoras eléctricas en el comportamiento de los paneles. En la instalación experimental se ha colocado, en el interior del invernadero, un calefactor que nos permita testear dichas configuraciones a diferentes temperaturas.

El estudio realizado sobre ambas instalaciones ha proporcionado un conocimiento profundo del funcionamiento de cada una de ellas, así como información válida para una mejora de futuros diseños de instalaciones fotovoltaicas sobre cubiertas. 


\section{Abstract}

This research has been carried out due to necessity and interest from the company Apia XXI in collaboration with the Department of Thermal and Fluids Engineering of the Universidad Politécnica de Cartagena, for the development of facilities and research into the electrical behaviour of photovoltaic panels at high operating temperature when they are placed on different roofs.

The aim of this study is to characterise and analyse the negative influence of high panel temperatures on electrical production and consequently performance, when they are placed on steel roofs of industrial buildings and also on greenhouse roofs. Different configurations have been tested in order to allow cooling of photovoltaic panels to decrease panel temperature and improve electrical performance.

To investigate this problem two experimental facilities have been built to test panels on the roof of the 'Aulario General' of the Campus Alfonso XIII, Universidad Politécnica de Cartagena. Experimental and research facilities related to solar energy, belonging to the Thermal and Fluids Engineering Department, are located in this building.

The first experimental facility includes two photovoltaic panels fixed on a structure which allows changes in the photovoltaic panels slope. One panel, designated as Panel A, is fixed to the structure without a plate underneath it. This panel works at normal operation conditions and is used as a referent. It is exposed to ambient conditions and hence, the ambient temperature and wind are the important operational variables.

The other panel, Panel B, is placed on the same structure and on a parallel steel plate which does not allow sufficient cooling and thus increases the panel temperature. Between the surface of the photovoltaic panel and steel plate, there is an open air channel in which an air flow is created by the chimney effect thus cooling the panel by natural convection.

The slopes of both panels are the same for the different trials; $30^{\circ}$ horizontally and facing south. The electrical behaviour of Panel B has been studied for three different spaces of the air channel and has also been compared with the behaviour of the reference panel $A$.

Once data for all three channel air spaces were collected, the facility was modified by adding a fan connected to Panel B by means of nozzle. This fan induces a flow inside the channel air space and allows us to study the effect of forced convection. Three fan induced velocities have been used for each of the three channel air spaces and results have been compared with concurrent data from reference Panel A. The final aim is to generalize all results (different sections of air, induced velocities in channel and ambient conditions), by an experimental model to establish correlations which allow to determine the temperature, power and efficiency of the module depending on the influential variables. 
The same model of these photovoltaic panels, with the same operating characteristic, is installed in a working photovoltaic solar plant 'Coronil II', located in Sevilla, south of Spain. The real data of this plant have been studied throughout the warmest months (May, June, July and August) and the electrical behaviour has been analysed. This research also analyses these results and the correlations between the photovoltaic panel temperature and the electrical variables such as electrical power and performance. A comparison with the photovoltaic panel's behaviour in the experimental facility and the solar plant is also presented.

The second experimental facility is a replica of a photovoltaic plant mounted on the roof of a greenhouse installation 'Coronil IV', also built by Apia XXI in Sevilla. Only a part of the photovoltaic greenhouse has been replicated in the experimental facility and consists of four photovoltaic panels placed on the plastic roof of the greenhouse. There is an open and divergent channel between both surfaces thus creating an air flow by the chimney effect.

This research aims to study the effect of high temperatures within the greenhouse which will be transferred by the plastic roof and will thus affect the electrical production of photovoltaic panels placed there. In order to simulate different temperatures inside the greenhouse, the experimental facility includes a PID controlled electric heater.

In addition to this, two channel air gap spacings were used and the effect of adding insulating material to the plastic roof was investigated. This material reduces the heat transfer from inside the greenhouse to the photovoltaic panel whilst maintaining the open air channel. The electrical variables of the panels are analysed for both air gaps with and without insulating material to compare and select the best configuration.

The presented research about both facilities provides a deep knowledge of how they work as well as information and results for an improvement in future designs of building integrated photovoltaics. 


\section{Agradecimientos}

A mis directores de tesis Dr. José Ramón García Cascales y Dr. Francisco Vera García por su continua cooperación, ayuda, apoyo y comprensión tanto a nivel técnico y profesional como personal.

A Dr. Antonio Sánchez Kaiser, Dr. Blas Zamora y Dr. José Antonio Villarejo Mañas que junto a mis directores de tesis han querido formar parte de este proyecto, tanto por su constante consejo, colaboración y tiempo empleado, además de haber representado para mí grandes modelos a seguir.

A la empresa Apia XXI, especialmente a Marcos Pantaleón Prieto, Cesar Fernández González y José Luis Sobradillo Agüeros, en primer lugar por haberme propuesto esta línea de investigación, seguido por su cooperación en el diseño de las instalaciones y por último, por haber participado junto al departamento de Ingeniería Térmica y de Fluidos en los contratos que enmarcan este proyecto.

A mis compañeros y amigos Ramón y Alejandro, por vuestra continua predisposición y dedicación, por estar siempre ahí de forma desinteresada y por los buenos momentos de trabajo compartidos.

A los ex-alumnos Laura Granados y Antonio Fuentes Cano por su colaboración y haber dedicado conmigo intensos periodos de trabajo juntos.

A todo el personal del departamento de Ingeniería Térmica y de Fluidos con los que he compartido docencia y trámites administrativos, entre ellos a Loli, por haberme orientado y enseñado muchas cosas y porque sin vuestra ayuda no hubiese sido tan asequible el día a día.

A mis amigos, por haberme apoyado siempre, sacándome una sonrisa cuando más lo necesitaba y hacerme sentir la fé y confianza que siempre habeis tenido en mí.

A mis padres, mi hermano Dani, mis tíos, primos y abuelos, porque siempre habéis estado a mi lado, por vuestro incondicional y constante apoyo en todo momento, especialmente en aquellos, no tan buenos, en los que me habéis comprendido, animado y hecho sentir que el esfuerzo realizado por aquello que quieres merece la pena.

A mi marido Diego, tanto por completar la otra parte de mi vida que no es trabajo, por hacer suyos mis propios problemas con mucha paciencia y comprensión, como por hacerme ver la vida con optimismo, porque sin ti parte de este trabajo no hubiese sido posible. 


\section{CAPITULO 1. INTRODUCCIÓN}

El crecimiento y la evolución de la población mundial junto a su actividad traen consigo que la demanda energética aumente día a día pero las fuentes clásicas ya no pueden satisfacernos en la cuantía necesaria. El consumo del petróleo se incrementa constantemente, cosa que no puede continuar por mucho tiempo, fundamentalmente porque las reservas económicamente explotables se están agotando. El carbón es el combustible fósil más importante de la Tierra y sus reservas son grandes, pero el problema que conlleva su aprovechamiento energético es que contamina con $\mathrm{CO}_{2}$ la atmosfera, por lo que su uso es limitado.

Por ello, se recurre a las fuentes renovables de energía, entre ellas la energía solar fotovoltaica que como energía limpia no contamina y contribuye a luchar contra el efecto invernadero. La energía es una necesidad, y por ello se debe de ser consciente de la situación energética, y la necesidad de desarrollar instalaciones fotovoltaicas para poder seguir manteniendo nuestro estilo de vida sin comprometer la economía, la autonomía energética y la sostenibilidad medioambiental del planeta.

En la actualidad, aunque representan todavía no muy altos porcentajes respecto al total de de energía primaria a nivel mundial, algunas fuentes renovables, como la eólica o solar en sus distintas formas, están creciendo a un ritmo acelerado en algunas partes del planeta. La energía solar fotovoltaica ha ido creciendo a una velocidad mayor a la esperada, a pesar de la crisis económica durante el año 2011. Europa ha liderado el mercado fotovoltaico, con un $75 \%$ de la nueva capacidad conectada en 2011 (durante 2011 se conectaron a la red $29,7 \mathrm{GW}$, de los cuales $21,9 \mathrm{GW}$ se instalaron en Europa) y alrededor del $75 \%$ de la capacidad global instalada. Pero los mercados no europeos empiezan a mostrar signos de que esta tendencia va a cambiar ya que en ellos está el mayor potencial de crecimiento: fuera de Europa el sector fotovoltaico se expande rápidamente, con más de un $100 \%$ de crecimiento. En lo que se refiere a la energía solar fotovoltaica, tanto la potencia instalada como generada ha sufrido un crecimiento espectacular en los últimos años, concentrándose en su mayoría en Europa, China, Japón y USA. 


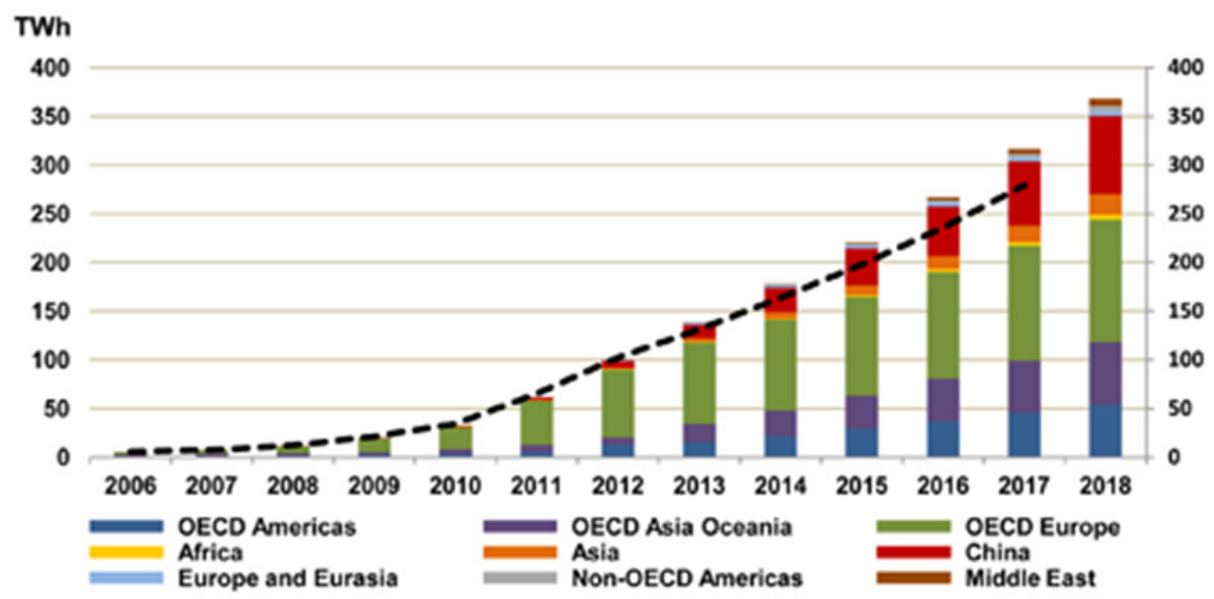

Figura 1.1 Potencia generada y proyección de energía fotovoltaica por regiones [1].

Ese crecimiento ha llevado consigo un desarrollo tecnológico que está consiguiendo progresivamente aumentar las aplicaciones, reducir los costes de producción y mejorar la eficiencia de las células. Partiendo de esta situación y a la vista de los resultados presentados por diversos estudios, parece seguro que la energía solar fotovoltaica seguirá en los próximos años ampliando progresivamente su cuota de participación en la producción de energía. Con esta investigación se pretende colaborar en el desarrollo de aquellas instalaciones que sigan adelante con el aprovechamiento de la energía solar fotovoltaica y que sean planteadas como inversión en salud, sostenibilidad y responsabilidad. 


\subsection{ORIGEN DEL ESTUDIO}

Este proyecto está enmarcado en dos contratos firmados entre los grupos de investigación "Modelado de Sistemas Térmicos y Energéticos" y "Mecánica de Fluidos e Ingeniería Térmica" de la Universidad Politécnica de Cartagena y la empresa Apia XXI para el análisis de la influencia de la temperatura en el comportamiento eléctrico de paneles fotovoltaicos colocados sobre cubiertas y el ensayo de diferentes configuraciones que permita su refrigeración.

Como se ha mencionado anteriormente, el punto de partida de este trabajo es estudiar y analizar el comportamiento eléctrico de un panel fotovoltaico cuando alcanza altas temperaturas, al estar colocado sobre una cubierta y caracterizar la influencia negativa de su temperatura. Con ello se pretende estudiar diferentes configuraciones analizando los parámetros eléctricos e identificando aquella que consiga una reducción de la temperatura de funcionamiento de los paneles fotovoltaicos colocados sobre cubierta, lo que conlleva una mejora de la eficiencia.

El problema que presentan los paneles fotovoltaicos al alcanzar altas temperaturas se lleva estudiando tiempo pero es cierto que la mayoría de los paneles que funcionan en plantas fotovoltaicas de nuestro país, lo presentan y en mayor medida aquellos ubicados en el sur de España. La empresa Apia XXI nos propuso profundizar en esta línea de investigación al ser consciente de la reducción en producción eléctrica que sufrían los paneles en la planta fotovoltaica que tienen en Coronil, Sevilla, especialmente durante los meses de verano, debido a la reducción del rendimiento a causa de las altas temperaturas. Los paneles utilizados en esta investigación son los proporcionados y utilizado por dicha empresa, policristalinos modelo ET $270 \mathrm{~W}$. Además, este problema se le agravaría en los nuevos proyectos de Apia XXI, en los que los paneles se colocan sobre diferentes cubiertas.

La primera instalación experimental de estudio consiste en estudiar y analizar el comportamiento eléctrico de un panel colocado sobre una cubierta de acero, comparándolo con el de un panel aislado, trabajando en las mismas condiciones ambientales. Se han estudiado diferentes técnicas hasta ahora utilizadas para refrigerar los paneles, con el fin de reducir su temperatura y mejorar su producción eléctrica. Una vez conocidas, la que se presenta en este estudio es la refrigeración de los paneles fotovoltaicos con aire como fluido caloportador, que consiste en el aprovechamiento de "un efecto chimenea" por convección natural y convección forzada a través de una conducción de aire por su superficie posterior es decir, entre el panel fotovoltaico y la cubierta sobre la que se encuentra colocado. En ambos casos, convección natural y forzada, se ha modificado el espesor del canal de aire con el fin de conocer la existencia o no, de una influencia entre la separación del panel y la cubierta con la temperatura de funcionamiento del panel. Además, los ensayos de convección forzada se han llevado a cabo para diferentes velocidades forzadas por el 
ventilador, para cada sección de paso de aire. Con los resultados obtenidos para las diferentes configuraciones podremos concluir cual es la más idónea. Además, se establece una comparativa en el comportamiento del panel en función de las variables que realmente influyen en la temperatura para poder obtener correlaciones que determinen la temperatura de funcionamiento, potencia y eficiencia del módulo bajo diferentes condiciones ambientales y constructivas.

La otra instalación experimental es una réplica de una instalación real y se centra en el estudio y análisis del mismo problema, diferenciándose en que los paneles en este caso se encuentran ubicados sobre la cubierta de un invernadero, institucionalmente denominado como instalación agroenergética cuya cubierta es a dos aguas y los paneles se encuentran a una. En su interior se cultivan diferentes plantas ornamentales y variedades de setas en una zona aislada y refrigerada, todos ellos son cultivos que no necesitan mucha luz. Con el prototipo experimental construido se pretende estudiar la influencia de las altas temperaturas en el interior del invernadero sobre los paneles colocados a una pequeña separación de la cubierta de plástico, existiendo un canal divergente por el que circula el aire exterior. Por consiguiente, en el interior de la instalación experimental se ha dispuesto de un calefactor industrial conectado a un PID que nos permite establecer y mantener la temperatura que se desee con el fin de caracterizar el comportamiento de los paneles a altas temperaturas en el interior.

Esta instalación tiene su origen en la necesidad de Apia XXI por conocer la existencia de una mayor o menor influencia de las altas temperaturas en el interior de los invernaderos sobre los paneles y en tal caso, poder proponer modificaciones a la configuración actual tales como variar el diseño de la estructura soporte de los paneles, aumentando la sección de paso de aire, poniendo un aislante sobre el plástico, etc. de cara a la construcción de próximas instalaciones agroenergéticas previstas. 


\subsection{OBJETIVOS DE LA TESIS}

El objetivo principal de este trabajo de tesis doctoral es estudiar la influencia de la temperatura en el comportamiento eléctrico de módulos fotovoltaicos colocados sobre la cubierta de diferentes instalaciones, así como la posible mejora en la producción eléctrica, mediante la refrigeración por convección natural e inducida, a través de un canal de aire entre su cara posterior y la cubierta sobre la que están ubicados.

Del objetivo primordial se derivan una serie de sub-objetivos específicos (detallados a continuación) que pasan por el diseño, construcción de varias instalaciones experimentales para el registro de medidas y análisis experimental, además de estudiar las medidas de instalaciones en explotación con la intención y fin último de poder asistir en el diseño de instalaciones fotovoltaicas montadas sobre cubiertas.

En primer lugar, conocer las instalaciones comerciales en explotación que nos han servido de prototipo tanto para entender el funcionamiento de los paneles, como para el diseño de las instalaciones fotovoltaicas experimentales. De ellas, elegir los módulos que mejor se comportan respecto a su temperatura de funcionamiento, para ser utilizados en los diferentes ensayos experimentales. Con los datos proporcionados por la empresa, de una de las instalaciones comerciales, medidos durante el periodo Mayo- Agosto de 2010, se quiere estudiar los parámetros característicos de los módulos, comparando los datos experimentales medidos y los proporcionados por el fabricante bajo las mismas condiciones ambientales. Con este estudio, se pretende obtener las relaciones de dependencia con la temperatura de los paneles de la planta fotovoltaica y comparar los resultados con los obtenidos en la instalación experimental construida.

Se debe diseñar y construir cada una de las instalaciones experimentales, siendo fiel a la instalación comercial de referencia y elegir toda la instrumentación necesaria para medir y registrar las variables influyentes en el estudio. Ambas instalaciones pretenden estudiar diferentes configuraciones constructivas, cuando los paneles se emplazan sobre una cubierta bien metálica (como sucede en las naves industriales) como de plástico (en los invernaderos), existiendo un espacio entre panel y cubierta que permite la refrigeración del panel con aire por convección natural.

La instalación experimental fotovoltaica sobre cubierta metálica engloba dos casos de estudio, uno mediante refrigeración por convección natural y otro por convección forzada. En cada caso resultan diferentes configuraciones de ensayo. En convección natural se plantea tres diferentes configuraciones, diferenciándose en la separación existente entre el panel fotovoltaico y la cubierta metálica. En refrigeración inducida además de ensayar las tres secciones del canal de aire planteadas en convección natural, para cada sección se han fijado diferentes valores de la velocidad inducida por un ventilador. Con todas ellas, el propósito es estudiar el comportamiento eléctrico del panel al estar integrado en una 
cubierta, analizar sus parámetros eléctricos característicos, conocer la influencia de las diferentes variables en el diseño y no sólo concluir la configuración más idónea sino también poder globalizar los datos experimentales, estableciendo una correlación que nos permita conocer la temperatura de funcionamiento del módulo, su rendimiento y potencia en función de las variables influyentes en la refrigeración y diferentes condiciones ambientales.

La segunda instalación experimental de estudio, fiel al diseño de una instalación comercial agroenergética, se centra en estudiar la respuesta eléctrica de los paneles fotovoltaicos colocados sobre la cubierta de un invernadero, permitiendo su refrigeración por su cara posterior mediante convección natural. En esta instalación también se ha variado la separación entre los módulos y la cubierta de plástico, estudiando dos secciones de entrada de aire diferentes. Además, del diseño inicial, se ha incorporado un material aislante sobre el plástico para cada sección de paso de aire. En las diferentes configuraciones, se pretende estudiar y comparar el comportamiento de los módulos en esta aplicación fotovoltaica, analizando sus variables eléctricas, dependencia con la temperatura de funcionamiento y la posible influencia del calor en el interior del invernadero, transferido al canal de aire. Con este estudio se persigue analizar las variables influyentes en cada caso y conocer la configuración que permita una mayor producción eléctrica del panel. 


\subsection{PLANTEAMIENTO GENERAL DE LA TESIS}

Los objetivos planteados en este estudio se han llevado a cabo siguiendo el esquema de la figura 1.2. Aunque el bloque central de trabajo lo constituirá el estudio y análisis del comportamiento eléctrico de los paneles en diferentes aplicaciones fotovoltaicas, el resto de bloques del esquema también formarán parte de la presente investigación por entender que los segundos dan sentido al primero y viceversa.

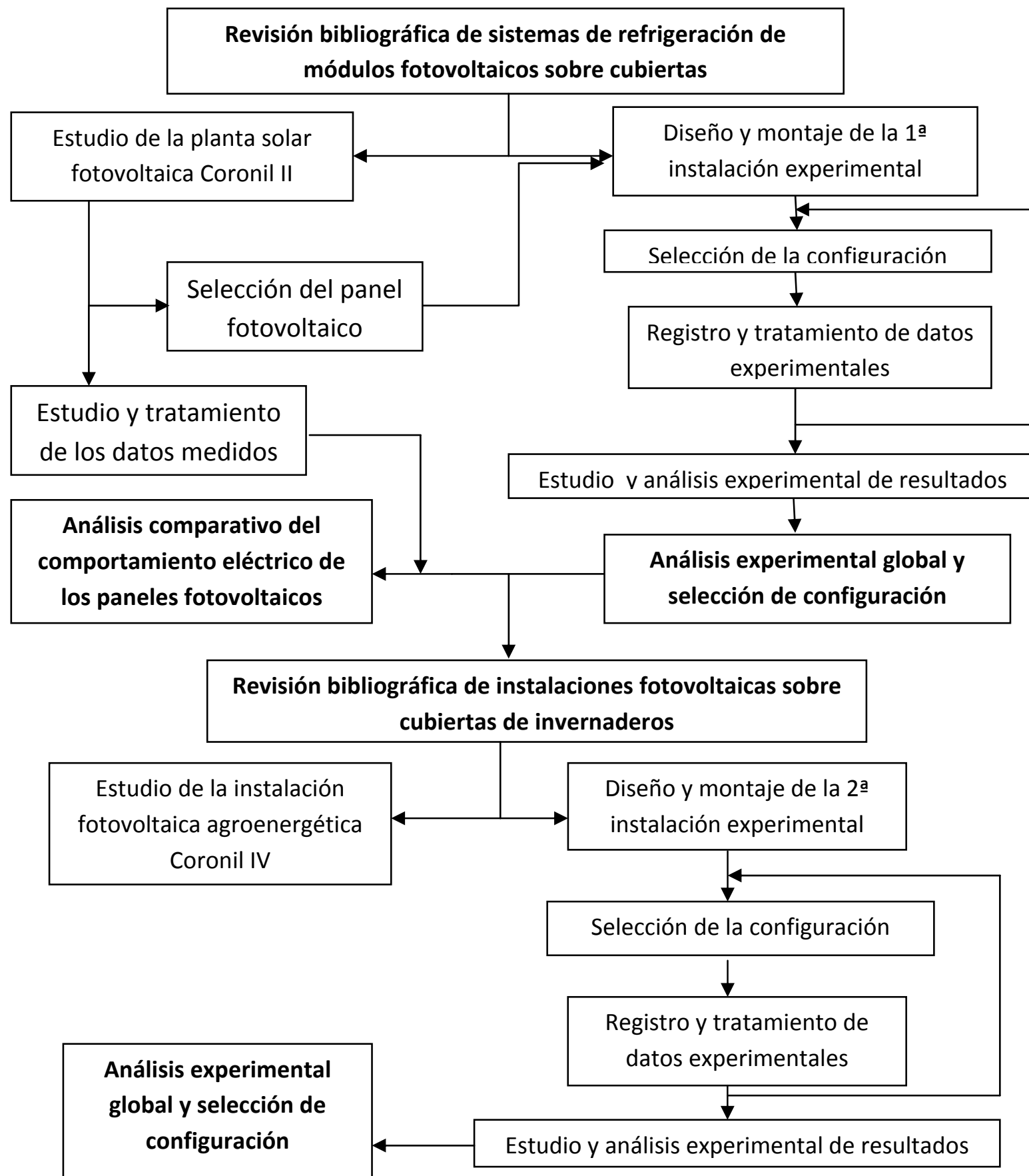

Figura 1.2 Planteamiento de la Tesis Doctoral. 
Este planteamiento general se desarrolla en los capítulos que se describen brevemente a continuación.

Cómo apartado final de este capítulo se incluye de forma resumida los antecedentes de la energía fotovoltaica y los principios básicos de funcionamiento, con el fin de introducir conceptos y variables de estudio que presentan en capítulos posteriores.

En el capítulo 2 se presenta la revisión bibliográfica del estado de la investigación referida al campo objeto de estudio. En primer lugar se exponen los diferentes métodos que se han utilizado para reducir la temperatura de los módulos, con el fin de determinar que método sería viable de estudiar en nuestras aplicaciones, por el interés que en este campo presentan. En segundo lugar se clasifican los estudios bibliográficos desarrollados sobre la integración de los paneles sobre diferentes cubiertas, para conocer el estado del arte tanto en la tecnología como diseño estructural utilizados en diferentes aplicaciones similares a las que se estudian. En tercer lugar se incluyen las ecuaciones que determinan la influencia de la temperatura en las variables eléctricas del panel, establecidas por diversos estudios. En último lugar, se presenta la revisión bibliográfica de estudios llevados a cabo en los que se determinan correlaciones de la temperatura del módulo, considerando las variables influyentes en su capacidad de ventilación.

En el capítulo 3 se expone la descripción de las instalaciones fotovoltaicas estudiadas. El primer apartado presenta las instalaciones comerciales en explotación que nos han servido de prototipo para el diseño y montaje de las experimentales, una planta fotovoltaica con paneles sobre estructura fija y una instalación agroenergética con módulos sobre la cubierta del invernadero que la constituye. En el segundo apartado se describe las dos instalaciones experimentales diseñadas y construidas en la Universidad Politécnica de Cartagena para el estudio y análisis del comportamiento eléctrico de los paneles fotovoltaicos y una posible mejora en el comportamiento eléctrico de los módulos fotovoltaicos mediante la refrigeración con aire en su cara posterior. En cada una de ellas se detalla su diseño constructivo, las configuraciones y variables de estudio, colocación de los sensores de medida y descripción de la instrumentación utilizada en el registro y tratamiento de datos.

El capítulo 4 incluye la descripción del proceso llevado a cabo en la medida y registro de datos de ambas instalaciones experimentales y su automatización. Además se presenta el estudio de las incertidumbres cometidas en la medida con estos equipos para poder establecer el grado de validez de las mismas.

En el capítulo 5 se aborda los estudios y análisis de los resultados medidos y obtenidos de las diferentes instalaciones descritas en el capítulo 3. En primer lugar se expone el estudio comparativo del funcionamiento de módulos fotovoltaicos en la planta solar Coronil II frente a los valores medidos en la instalación experimental. El estudio demuestra que el comportamiento eléctrico del panel en una planta fotovoltaica se puede predecir a partir de 
un prototipo experimental, para diferentes condiciones o configuraciones. En un segundo apartado, se incluyen los resultados obtenidos para las diferentes configuraciones de ensayo de la primera instalación experimental, con el propósito de estudiar el funcionamiento de un panel fotovoltaico al estar sobre una cubierta metálica, existiendo un espacio entre ambas superficies que permite la circulación de aire por convección natural e inducida. Primeramente se compara el comportamiento eléctrico del módulo para diferentes secciones del canal de aire en convección natural respecto a un panel de referencia, sin ningún canal ni superficie en su cara posterior, trabajando ambos en las mismas condiciones. Posteriormente, se estudia el funcionamiento del módulo para las mismas secciones de entrada en convección forzada, impulsando aire en el canal mediante un ventilador. Para cada sección de estudian diferentes valores de velocidades inducidas para analizar su influencia. Por último, se comparan los resultados obtenidos en convección natural y forzada analizando las variables influyentes en la capacidad de refrigeración, tales como la sección de aire de canal y la velocidad del aire a su través. Con ello, finalmente se pretende no sólo seleccionar la configuración más idónea sino también establecer una correlación de la temperatura del módulo para las diferentes configuraciones que permita generalizar los resultados para las diferentes configuraciones de estudio. El tercer apartado contiene los resultados obtenidos de la segunda instalación experimental, en la que los paneles fotovoltaicos están colocados en la cubierta de un invernadero, existiendo también un canal de aire. En esta instalación se pretende estudiar el comportamiento de los paneles para diferentes configuraciones, diferenciándose tanto en la sección de entrada de aire en el canal como en el material constituyente de la cubierta. Se analiza el efecto de la temperatura en las variables características para cada configuración así como la influencia de diferentes variables, tales como la velocidad del viento y la transferencia de calor en el canal de aire de refrigeración. El estudio compara las configuraciones ensayadas bajo las mismas condiciones lo que permite conocer la configuración en la que el panel alcanza menor temperatura de funcionamiento y una mayor producción eléctrica.

El capítulo 6 es una recopilación de las conclusiones más importantes obtenidas en los capítulos anteriores, y en el que se apuntan las diferentes líneas de continuación de la presente tesis. 


\subsection{EVOLUCIÓN DE LA ENERGÍA SOLAR FOTOVOLTAICA}

La conversión de la energía solar en energía eléctrica es un fenómeno físisco conocido como efecto fotovoltaico, descubierto en 1838 por Alexandre Edmond Bequerel, mientras experimentaba con una pila electrolítica. El siguiente paso se dio en 1873 cuando el ingeniero eléctrico inglés Willoughby Smith descubre el efecto fotovoltaico en sólidos, en este caso sobre el Selenio. Pocos años más tarde, en 1877, El profesor inglés William Grylls Adams, junto con su alumno Richard Evans Day, crearon la primera célula fotovoltaica de selenio, con rendimientos del $1 \%$. Durante 1880 , las primeras células fotovoltaicas eran fabricadas con Selenio y solamente conseguían entre el 1-2\% de eficiencia de conversión.

En 1904 Albert Einstein publica su trabajo acerca del efecto fotovoltaico, recibiendo el premio Noblel en el año 1923, por sus teorías sobre el efecto fotovoltaico. Este hecho supuso un avance importantísimo para el desarrollo de ésta tecnología. El método Czochralski de 1918 supuso uno de los mayores avances, que posibilitó en la década 19401950 la obtención de monocristales de Silicio con la suficiente pureza para el desarrollo de células solares (junto con transistores y diodos).

Más tarde, a principios de los años 50, se implantó a la práctica el proceso Czochralski que permitía la obtención de silicio cristalino puro. Esto a la vez permitió la aparición de los semiconductores y fue en el año 1953 cuando Gerald Pearson de Bell Laboratories, mientras experimentaba con las aplicaciones en la electrónica del silicio, fabricó casi accidentalmente una célula fotovoltaica basada en este material, que resultaba mucho más eficiente que cualquiera hecha de selenio, con un rendimiento del $4 \%$, tecnología que rápidamente mejoraron hasta un $11 \%$.

A partir de este descubrimiento, otros dos científicos también de Bell, Daryl Chaplin y Calvin Fuller perfeccionaron este invento y produjeron células solares de silicio capaces de proporcionar suficiente energía eléctrica como para que pudiesen obtener aplicaciones prácticas de ellas. De esta manera empezaba la carrera de las placas fotovoltaicas como proveedoras de energía. 


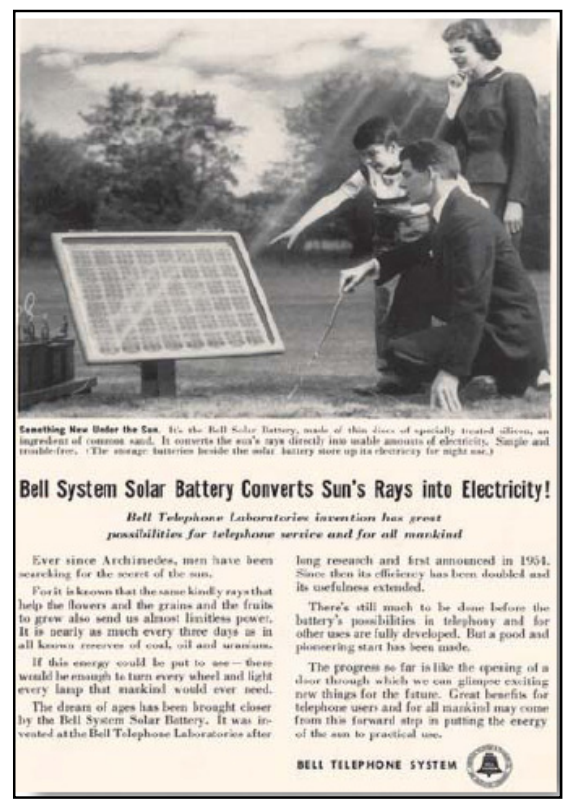

Figura 1.3 Anuncio que los Laboratorios Bell hicieron del primer panel fotovoltaico desarrollado por sus científicos en 1953.

La demanda de paneles solares solo venía de la industria juguetera, que los empleaba para suministrar potencia a pequeños artefactos como maquetas de aviones y coches, o de la industria electrónica, para aplicarlos en pequeños aparatos eléctricos sencillos como radios para la playa. Esta situación limitaba mucho el desarrollo de esta tecnología ya que eran muy reducidos los ingresos que se generaban haciéndose muy difícil destinar cantidades de dinero importantes a su desarrollo. Por fortuna, se encontró una aplicación ideal para el estado del desarrollo de los paneles solares fotovoltaicos en aquel momento; la alimentación del equipo de los satélites espaciales en la incipiente carrera espacial. El costo no fue un factor limitante ya que los recursos dedicados en la carrera del espacio eran enormes. Primaba la capacidad de proveer energía eléctrica de manera fiable en áreas de muy difícil acceso. En eso la energía solar fotovoltaica resultaba muy competitiva.

Así, en 1955, se le asigna a la industria de EEUU la producción de paneles fotovoltaicos para aplicaciones espaciales, lo que significó sin duda un importantísimo impulso que permitió un crucial desarrollo tecnológico del sector. El 17 de Marzo de 1958, finalmente, se lanza el Vanguard I, el primer satélite alimentado con paneles solares fotovoltaicos. El satélite llevaba $0,1 \mathrm{~W}$ en una superficie aproximada de $100 \mathrm{~cm}^{2}$ para alimentar un transmisor de 5 $\mathrm{mW}$. 

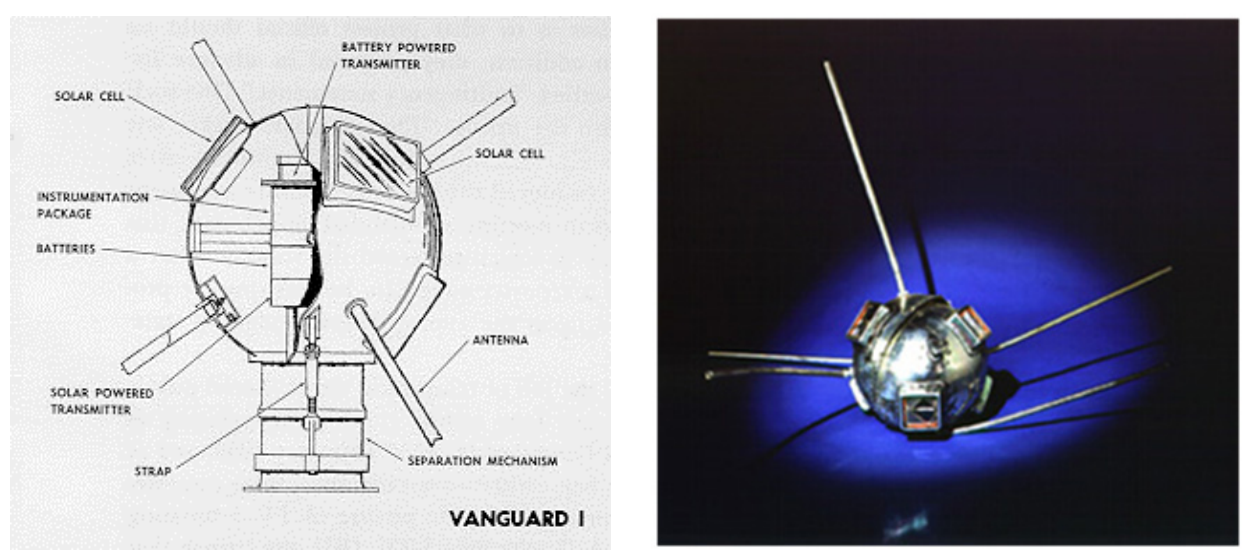

Figura 1.4 Primer satélite con placas solares, Vanguard I.

Si bien en este satélite los paneles solares eran solo la fuente de energía de respaldo, acabaron por convertirse en la fuente principal cuando las baterías consideradas como fuente de alimento principal se agotaron en tan solo 20 días. El equipo estuvo operativo con esa configuración durante 5 años.

La fiabilidad que habían demostrado los paneles solares fotovoltaicos propició su empleo sistemático en gran número de misiones espaciales y supuso un enorme impulso para la industria fotovoltaica (no sólo Estados Unidos utilizó esta tecnología, La Unión Soviética también empleó sistemáticamente los paneles solares fotovoltaicos para alimentar sus satélites). Sin lugar a dudas, la carrera espacial tal como la conocemos no hubiera sido posible sin la existencia de los paneles solares fotovoltaicos. De igual manera se puede afirmar que el actual desarrollo de los paneles solares fotovoltaicos y su importante proyección de futuro hubieran sido muy difíciles sin el impulso que le dio la carrera espacial.

\section{HITOS DE INSTALACIONES FOTOVOLTAICAS EN SATÉLITES ESPACIALES}

\begin{tabular}{|c|c|c|}
\hline AÑO & PROYECTO ESPACIAL & $\begin{array}{l}\text { POTENCIA DE SU } \\
\text { INSTALACIÓN } \\
\text { FOTOVOLTAICA }\end{array}$ \\
\hline 1958 & Vanguard I & $0,1 \mathrm{~W}$ \\
\hline 1962 & Telstar & $14 \mathrm{~W}$ \\
\hline 1964 & Nimbus & $470 \mathrm{~W}$ \\
\hline 1966 & $\begin{array}{l}\text { Observatorio } \\
\text { Astronómco Espacial }\end{array}$ & $1 \mathrm{~kW}$ \\
\hline 1973 & Skylab & $20 \mathrm{KW}$ \\
\hline
\end{tabular}

Figura 1.5 Hitos de instalaciónes fotovoltaicas en satélites espaciales.

En la década de los 60 se empezó a considerar la opción de la energía solar como una alternativa a los problemas que surgieron a consecuencia del abastecimiento y aumento del precio del petróleo. Así se empezaron a implantar colectores solares planos (para calentar agua) y a aumentar la producción de paneles fotovoltaicos. Otro hecho importante fue la 
creación del 'Federal Photovoltaic Utilitzation Program' en Estados Unidos en consecuencia a la crisis del petróleo de 1973-1974. Mediante este programa se instalaron aproximadamente unos 3100 sistemas fotovoltaicos la mayoría de los cuales siguen funcionando actualmente.

Las aplicaciones prácticas de la energía solar fotovoltaica empezaron entonces a multiplicarse: electricidad para la protección contra la corrosión de oleoductos y gaseoductos, iluminación de boyas marinas y faros, repetidores de sistemas de telecomunicaciones, sistemas de iluminación en líneas férreas. Para todas estas finalidades, la instalación de paneles solares resultaba mucho más rentable económicamente y más eficiente en su labor.

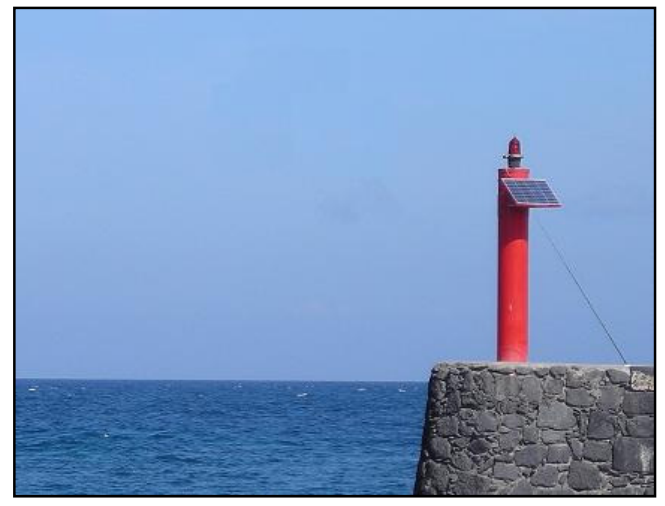

Figura 1.6 Faro Solar.

Tal fue el impulso de esta tecnología, que supuso el hecho de que en el año 1975 las aplicaciones terrestres habían ya superado a las espaciales. Tambíen en los años 70 del Siglo $\mathrm{XX}$, surgió la idea de potenciar las bombas de extracción de agua con paneles solares. Poco a poco, en las siguientes décadas, se fueron encontrando nuevas aplicaciones para la energía solar fotovoltaica, lo que conllevó a continuar con el desarrollo del uso de esta tecnología.

Desde los años 80, las instalaciones fotovoltaicas están y han estado continuamente mejorando sus prestaciones y procesos de fabricación, ofreciendo así al consumidor mejores productos y consolidándose como una alternativa viable. En la década de los 90 y en los primeros años del Siglo XXI las células fotovoltaicas han experimentado un continuo descenso en su coste junto con una ligera mejora de su eficiencia. Estos factores unidos al apoyo por parte de algunos gobiernos hacia esta tecnología, han provocado un espectacular impulso de la electricidad solar en los últimos años.

Siempre en la vanguardia tecnológica, la historia de la energía solar fotovoltaica está marcada por un desarrollo lento pero constante. Descubierto el efecto fotovoltaico como fenómeno de difícil aplicación práctica, poco a poco los avances técnicos fueron permitiendo aprovecharlo más eficientemente hasta lograr que se convirtiera en una fuente de energía práctica y fiable. A inicios del Siglo XXI la energía solar fotovoltaica se presenta como una de las opciones con más futuro para liderar la revolución energética que se aproxima. 


\subsubsection{FUNCIONAMIENTO BÁSICO DE UNA CÉLULA FOTOVOLTAICA}

Las células fotovoltaicas consisten de un semiconductor de silicio, que al incidir fotones de la luz del Sol permiten transmitir su energía a los electrones de valencia del semiconductor para romper el enlace que les mantiene ligados a los átomos respectivos. Por cada enlace roto queda un electrón libre circulando dentro del sólido. La ausencia de electrón en el enlace roto, denominado hueco, también puede desplazarse libremente por el interior del sólido, transfiriéndose de un átomo a otro debido al desplazamiento del resto de electrones de los enlaces. El movimiento de los electrones y huecos en direcciones opuestas genera una corriente eléctrica en el semiconductor.

La célula fotovoltaica consiste en dos capas muy delgadas de semiconductores. La capa superior es un semiconductor del tipo $\mathrm{n}$ y la capa inferior es un semiconductor del tipo $\mathrm{p}$. Un semiconductor del tipo $\mathrm{n}$ (tipo negativo) es un semiconductor con un exceso de electrones libres, lo que se logra impurificando el cristal de silicio con átomos que tienen electrones libres. Un semiconductor del tipo $p$ (tipo positivo) está impurificado con átomos que tienen una escasez de átomos libres, que también pueden catalogarse con átomos con huecos.

Cuando dos capas delgadas de materiales tipo $\mathrm{p}$ y tipo $\mathrm{n}$ se unen, los electrones libres de la capa tipo $n$ fluirán hacia los huecos de la capa tipo $p$ y llenarán estos huecos. Al hacer esto causan una carga positiva en la capa del tipo $n$ porque los electrones negativos dejaron esta capa, al mismo tiempo en la capa del tipo $p$ se da una carga negativa debido a la recepción de electrones de la capa tipo $n$. La diferencia de cargas crea un voltaje interno que impide a más electrones fluir de la capa del tipo $n$ a la capa del tipo $p$.

Cuando la luz solar cae sobre las capas se crearán más electrones libres en la capa $\mathrm{p}$ y huecos en la capa $n$, alterando por tanto el equilibrio. Para reponer el equilibrio, fluirá una corriente eléctrica, creando un voltaje en los contactos externos de las dos capas. Si no se hace ninguna conexión externa entre las dos capas, este voltaje externo permanecerá tal como está porque no hay electrones que puedan fluir de la capa $\mathrm{n}$ a la capa $\mathrm{p}$.

Si se ilumina una célula fotovoltaica conectada a una carga externa se producirá una diferencia de potencial en dicha carga y una circulación de corriente, teniendo lugar los siguientes fenómenos:

- Los fotones incidentes con energía igual o mayor que el ancho de banda prohibida (energía necesaria para que un electrón pase de una capa a otra) se absorben en el semiconductor y generan pares electrón-hueco, actuando como portadores de corriente. 


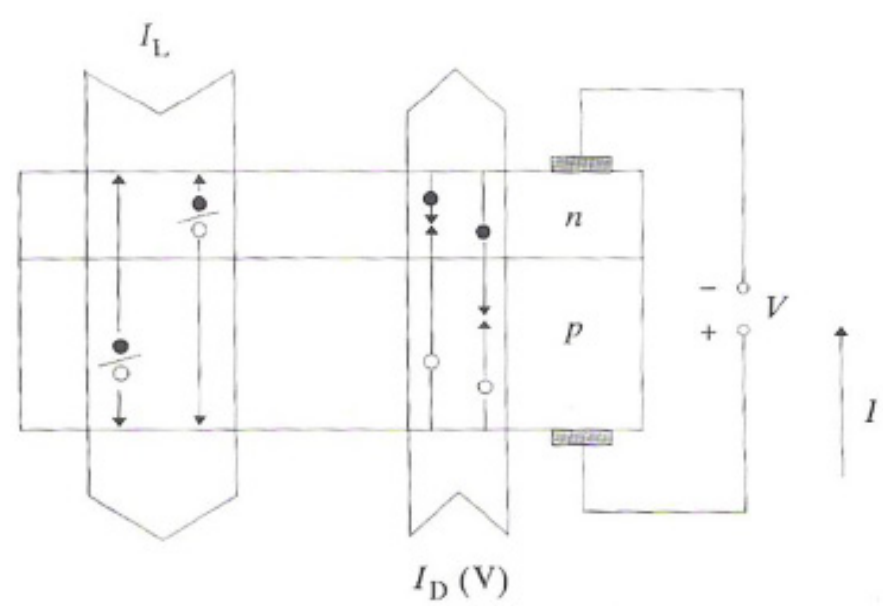

Figura 1.7 Componentes internas de la corriente en una célula fotovoltaica.

- El campo eléctrico o diferencia de potencial producida por la unión p-n es la causa de la separación de los portadores antes de que puedan recombinarse de nuevo y por consiguiente, la causa de circulación de la corriente por la diferencia de potencial externa en la carga.

- La diferencia de potencial en la unión p-n produce fenómenos de inyección y recombinación de pares electrón-hueco, que en la célula actúan como pérdidas de recombinación.

La corriente que circula por la carga es el resultado neto de dos componentes internas de corriente que se oponen: la corriente fotogenerada $\left(I_{L}\right)$, debida a la generación de portadores y la corriente de diodo $\left(I_{D}\right)$ debida a la recombinación de portadores que produce el voltaje externo necesario para entregar energía a la carga y es definida por la ley del diodo ideal. Por lo tanto, $I=I_{D}-I_{L}$.

En el Anexo A, se explican con más detalle los principios físicos, eléctricos y descriptivos que definen los sistemas fotovoltaicos. A continuación se definen las variables que caracterizan el comportamiento eléctrico de una célula fotovoltaica (objeto de estudio), a partir de la curva característica I-V definida por:

$$
I=I_{S}\left[e^{\frac{V}{m V_{T}}}-1\right]-I_{L}
$$

Donde:

$I_{s}$ : corriente de saturación de oscuridad.

$V$ : tensión aplicada.

$m$ : factor de idealidad (varía entre 1 y 2 )

$\frac{k T}{q}=V_{T}$ : potencial térmico (para el silicio a $25^{\circ} \mathrm{C}$ es igual a $25,7 \mathrm{mV}$ ) 


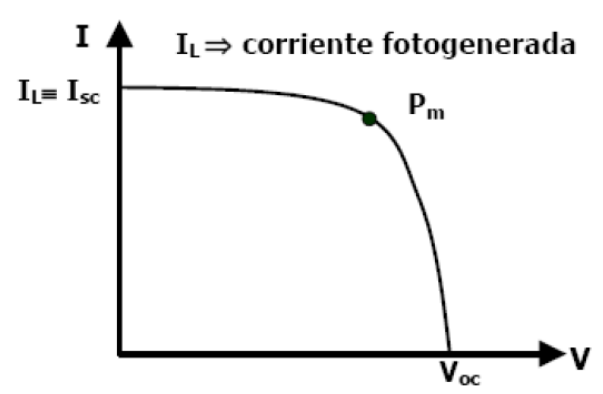

Figura 1.8 Curva característica de una célula fotovoltaica.

- Corriente de Cortocircuito $\left(I_{s c}\right)$ : Es la corriente resultante de cortocircuitar la célula fotovoltaica $(V=0)$, de la ecuación se deduce que $I_{S C}=I_{L}$.

- Tensión de circuito abierto $\left(V_{o c}\right)$ : Es la diferencia de potencial existente al abrir la célula, por lo que no circula corriente $(\mathrm{I}=0)$. Sustituyendo en la ecuación se tiene:

$$
V_{o c}=m \cdot V_{T} \ln \left(1+\frac{I_{L}}{I_{S}}\right)
$$

- Potencia: La potencia entregada por la célula se define como el producto d la tensión y la intensidad, por lo tanto:

$$
P=V \cdot I=V \cdot I_{L}-V \cdot I_{S}\left[e^{\frac{V}{m V_{T}}}-1\right]
$$

El punto en el que se hacen trabajar los sistemas fotovoltaicos se denomina Punto de Máxima Potencia (PMP) o potencia pico, correspondiente a un valor de corriente $\left(I_{\mathrm{mp}}\right) \mathrm{y}$ de tensión $\left(\mathrm{V}_{\mathrm{mp}}\right)$ al hacer $\frac{d P}{d V}=0$.

- Eficiencia: Se define el rendimiento o eficiencia ( $\eta$ ) de una célula solar fotovoltaica como el cociente entre la potencia máxima que puede dar a la carga y la potencia luminosa recibida por la célula $\left(\mathrm{G}_{T}\right)$.

$$
\eta=\frac{V_{m p} \cdot I_{m p}}{\mathrm{G}_{\mathrm{T}}}
$$

- Factor de forma (FF): ). Este factor se define como el cociente entre la potencia máxima que la célula solar fotovoltaica puede dar a la carga y la potencia teórica máxima definida por el punto de cortocircuito y circuito abierto $\left(I_{s c}, V_{o c}\right)$.

$$
F F=\frac{V_{m p} \cdot I_{m p}}{V_{o c} \cdot I_{S C}}
$$

Es una medida de la calidad de la unión y de la resistencia serie de la célula. Cuanto mayor es este factor, cuanto más próximo a 1 , la curva característica $I-V$ con iluminación se aproxima más al rectángulo de máxima potencia teórica y, por tanto, la célula es de mayor calidad. 


\section{CAPITULO 2. ESTADO DEL ARTE}

Un aspecto que se hace indispensable antes de comenzar a desarrollar un conocimiento es comprobar si ese conocimiento no ha sido ya obtenido. Por este motivo se presenta a continuación una revisión bibliográfica del estado de la investigación en el campo objeto de estudio.

Los estudios bibliográficos desarrollados sobre el tema se clasifican en varios bloques por separado, aunque estén fuertemente relacionados. Por un lado necesitamos conocer el estado de la investigación actual en los métodos de refrigeración de los módulos utilizados y su funcionamiento respecto la temperatura. Esto nos permitirá determinar qué métodos son susceptibles de ser estudiados por el interés que en este campo presentan, para configuraciones similares a la propia. Además, nos proporciona lo que se conoce sobre el efecto de la temperatura sobre diferentes tipos de módulos, según su configuración y sistema de refrigeración, con lo que se establecerá lo que es preciso estudiar con mayor profundidad en los sistemas objeto de estudio.

Por otro lado, y dado que las instalaciones de estudio corresponden a integración fotovoltaica sobre cubierta, será preciso conocer cuál es el estado de la investigación en este campo. Se clasifican los estudios bibliográficos desarrollados en la integración de los paneles sobre diferentes cubiertas, para conocer el estado del arte tanto en la tecnología como en el diseño estructural utilizado para diferentes aplicaciones similares a las que se estudian.

Con el fin de establecer un sistema de refrigeración en módulos fotovoltaicos para reducir su temperatura y así mejorar su eficiencia eléctrica, se debe estudiar y comprender la influencia de la temperatura en el comportamiento eléctrico del módulo, mediante el conocimiento de los diversos estudios bibliográficos que lo caracterizan.

Por último, se incluye el estado de la investigación de las variables influyentes en la capacidad de refrigeración con aire en sistemas de integración fotovoltaica y en consecuencia en la temperatura del módulo, con el propósito de conocer las correlaciones estudiadas que nos permitan comparar nuestras medidas experimentales además de establecer un modelo experimental que determine no sólo la temperatura, sino también su rendimiento en función de dichas variables.

\subsection{INTRODUCCIÓN}

Las células fotovoltaicas permiten la transformación directa de energía solar en energía eléctrica con una eficiencia máxima en torno al 9-12\% (policristalino), dependiendo del tipo de células solares. Más del $80 \%$ de la radiación solar que llega a la célula fotovoltaica (PV) no se convierte en electricidad, bien se refleja o se transforma en energía térmica. 
El reflejo de la radiación solar, reduce el rendimiento eléctrico de los módulos en torno al 8$15 \%$. Son numerosas las ideas propuestas para reducir la reflexión, pero la mayoría tienen inconvenientes; los recubrimientos antireflectantes no son duraderos y la superficie estructural es cara, se acumula el polvo y son difícil les de limpiar [2].

El calor generado, conduce a un aumento de la temperatura de las células y en consecuencia, un descenso de la eficiencia en la conversión de la electricidad. Esto se debe a que mientras la corriente de cortocircuito $\left(I_{s c}\right)$ aumenta ligeramente con el aumento de la temperatura, la tensión de circuito abierto $\left(V_{o c}\right)$ disminuye significativamente con el aumento de la temperatura, resultando una reducción de la potencia eléctrica y por tanto del rendimiento en torno al $0,4-0,5 \% /{ }^{\circ} \mathrm{C}$ para células de silicio mono y policristalino.

La producción de electricidad en los paneles fotovoltaicos es la principal prioridad y dado que dicha transformación depende de su temperatura de funcionamiento, es necesario reducir dicha temperatura, manteniendo al sistema a no elevada temperatura. Para la refrigeración de los paneles fotovoltaicos se han estudiado diversas técnicas utilizando como fluido trasportador de la energía térmica, el aire o el agua.

Con el fin de aumentar la competitividad de la energía fotovoltaica y para lograr una mayor cuota de mercado, el aumento de la eficiencia y la reducción de costes son los principales objetivos en el desarrollo de la tecnología fotovoltaica. Para alcanzar estas estrategias de mejora se puede llevar a cabo:

1. Aumentar la eficiencia de células y módulos.

2. Usar módulos de concentración.

3. Utilizar uno o dos ejes de seguimiento conjunto.

4. Minimizar las pérdidas, tales como el desequilibrio y cableado del módulo.

5. Reducir la temperatura mediante la refrigeración.

En este trabajo nos centraremos en la técnica de refrigeración de los paneles fotovoltaicos, para conseguir mantener una baja temperatura de funcionamiento y así subsanar los efectos inversos producidos por la elevada temperatura sobre la eficiencia.

\subsection{MÉTOdOS DE REDUCCIÓN DE LA TEMPERATURA DE LOS PANELES FOTOVOLTAICOS}

Debido a que los paneles solares sufren una disminución de la eficiencia y del rendimiento eléctrico por un aumento de su temperatura de funcionamiento, se han estudiado diferentes métodos para poder evitarlo y mantener el sistema a baja temperatura. Hay dos métodos a seguir para conseguirlo, la refrigeración pasiva y la refrigeración activa. La refrigeración pasiva se basa en utilizar sólidos de alta conductividad térmica o añadiendo aletas para disipar calor incluso en los casos más complejos que se plantean cambios de fase. 
En la aplicación de esta investigación engloba un gran número de paneles fotovoltaicos, de modo que la solución más atractiva y conveniente es la refrigeración activa, que consiste en utilizar agua o aire como fluido calorportador.

A continuación se describen diferentes técnicas desarrolladas, centrándonos en la refrigeración de los paneles pulverizando agua y la refrigeración con aire, prestando atención a algunos trabajos ligados con estas metodologías.

\subsubsection{AGUA COMO FLUIDO CALOPORTADOR}

En la refrigeración de los paneles fotovoltaicos mediante líquidos, el más utilizado es el agua. Una de las razones del uso del agua como fluido térmico, se debe a que tiene un bajo índice de refracción $(n=1,3)$, valor intermedio entre el vidrio $(n=1,5)$ y aire $(n=1)$, siendo también el fluido más abundante en la Tierra y por lo tanto el menos costoso. Además de ayudar a mantener limpia la superficie, el agua reduce la reflexión entre el 2-3,6\%, disminuyendo la temperatura de la célula y el rendimiento a su vez aumenta.

M. Addolzadeh et al. [3], estudiaron el efecto de la pulverización de agua sobre los paneles fotovoltaicos lo que producía una disminución en la temperatura de la célula y de la reflexión [4,5]. El propósito de este estudio es investigar la posibilidad de mejorar el rendimiento de un sistema fotovoltaico de bombeo, esto se realiza por aspersión de agua sobre las células fotovoltaicas y así investigar el efecto de la pulverización de agua encima de las células fotovoltaicas y de la disminución en la temperatura de la célula y la reflexión. Además, se ha investigado que el rendimiento de sistemas de bombeo fotovoltaicos se mejora con la disminución de la temperatura de la célula y la reflexión de la célula $[3,6]$.

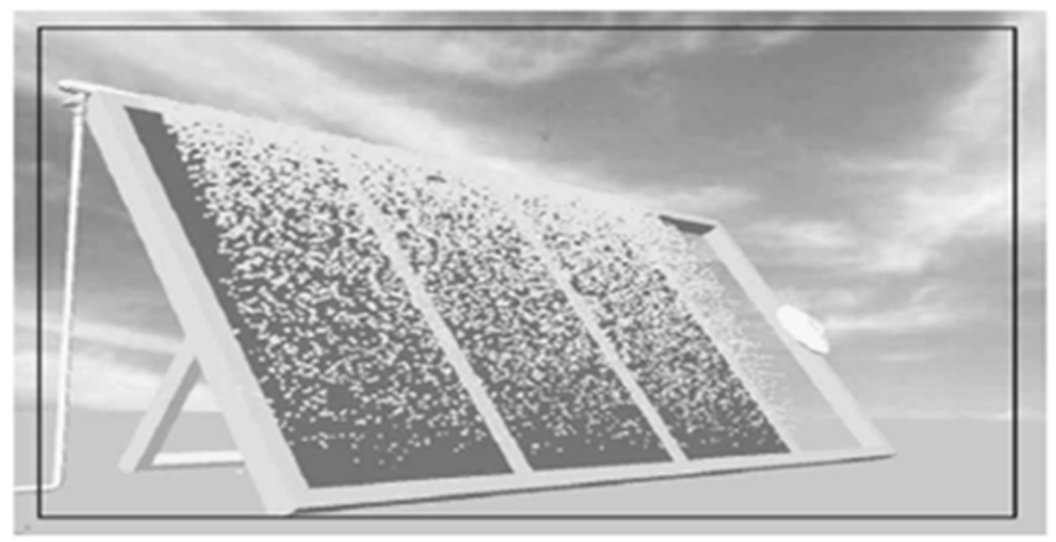

Figura 2.1 Células refrigeradas mediante el bombeo de agua [3].

El agua necesaria para pulverizar las células se bombea desde un depósito y posteriormente se transmite a las células por un tubo en la parte superior de las células, a través de pequeños agujeros. Se observó que el agua produjo un aumento del rendimiento en torno al 3\% tanto para la transmitancia óptica como la generación 
eléctrica, para ello emplearon un modelo de tres capas, basado en el frente de vidrio, EVA y revestimiento de células de silicio anti-reflectante, lo cual ya había sido estudiado previamente $[7,8]$. El esquema de la instalación se muestra en la Figura 2.2.

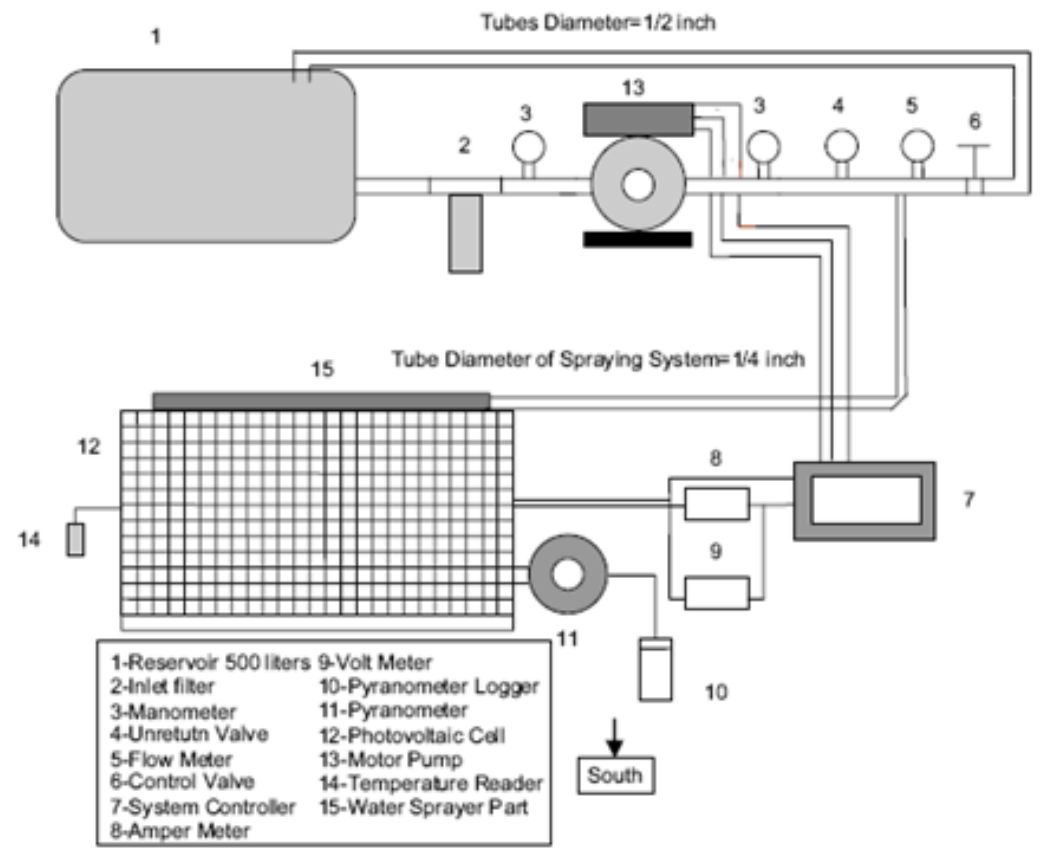

Figura 2.2 Esquema del sistema de bombeo y pulverización de agua [3].

Las mediciones se registraron durante los días claros de julio de 2006, en Kerman Irán, recogiéndolos cada 15 minutos.

Los principales parámetros del sistema de bombeo de agua que se verán afectados por la pulverización de agua sobre las células son la energía extraída de la célula y el caudal de bombeo.

En cuanto a los resultados obtenidos, la eficiencia de la célula fotovoltaica disminuye al aumentar la temperatura. Las células se expondrán a una degradación a largo plazo, si la temperatura supera un cierto límite. Gracias al 'spraying' de agua y la adicional refrigeración por evaporación, el voltaje aumenta y las temperaturas de funcionamiento de las células se reducen significativamente en comparación con un módulo sin tener un atomizador de agua, como se puede observar en la Figura 2.3. 

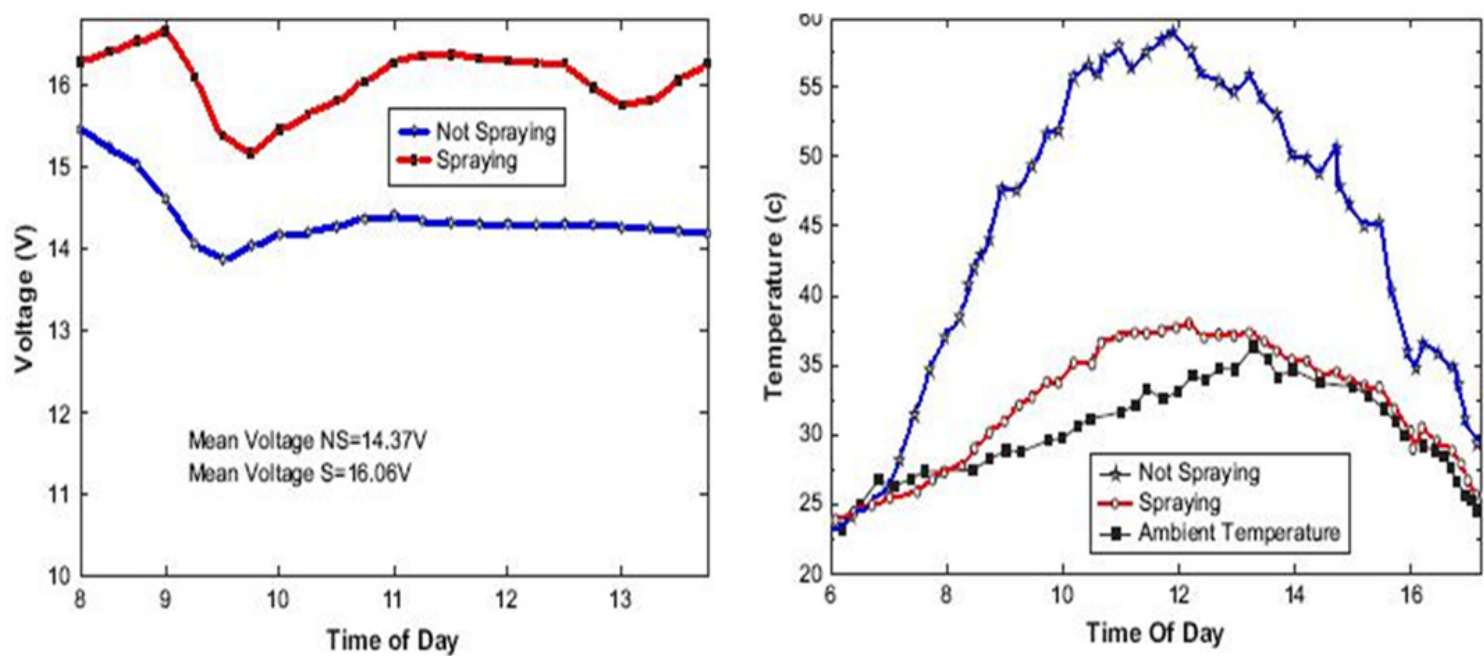

Figura 2.3 Comparación de los resultados medidos, con y sin pulverizar agua a lo largo del día de: a) La tensión del panel, b) temperatura de funcionamiento [3].

El cálculo de la eficiencia total del sistema fotovoltaico de bombeo, se llevó a cabo mediante las siguientes fórmulas:

$$
\begin{gathered}
P_{\text {max }}=I_{m p} \cdot V_{m p} \\
\eta_{p v}=\frac{P_{\text {max }}}{G_{\text {pira }} \cdot S} \\
\eta_{S U B}=\frac{P_{H y d}}{P_{\text {max }}} \\
\eta_{T}=\eta_{S U B} \cdot \eta_{p v}=\frac{\rho g h Q}{G_{p i r a} \cdot S}
\end{gathered}
$$

Para mostrar el efecto de la pulverización de agua sobre las células frente al rendimiento del sistema, se probaron varias configuraciones de montaje, para el transporte del agua encima de las células, durante más de dos meses. Esto se hizo con el fin de consumir menos agua para rociar las células y reducir los costes de instalación. Este diseño obtuvo una reducción efectiva de la temperatura de la célula y de las reflexiones. El agua prácticamente absorbe el calor generado por el módulo y reduce la reflexión durante el día. Con el fin de investigar el efecto de la pulverización sobre la instalación fotovoltaica de bombeo de agua se ensayó el sistema a dos alturas de bombeo, $10 \mathrm{~m}$ y $16 \mathrm{~m}$. El aumento de energía eléctrica producida durante todo el día fue alrededor del $17 \%$ a $16 \mathrm{~m}$. 
En las siguientes gráficas se recogen los resultados experimentados para la altura de bombeo de $16 \mathrm{~m}$, como ya hemos comentado la eficiencia no sólo del panel sino del sistema global sufre un aumento considerable.
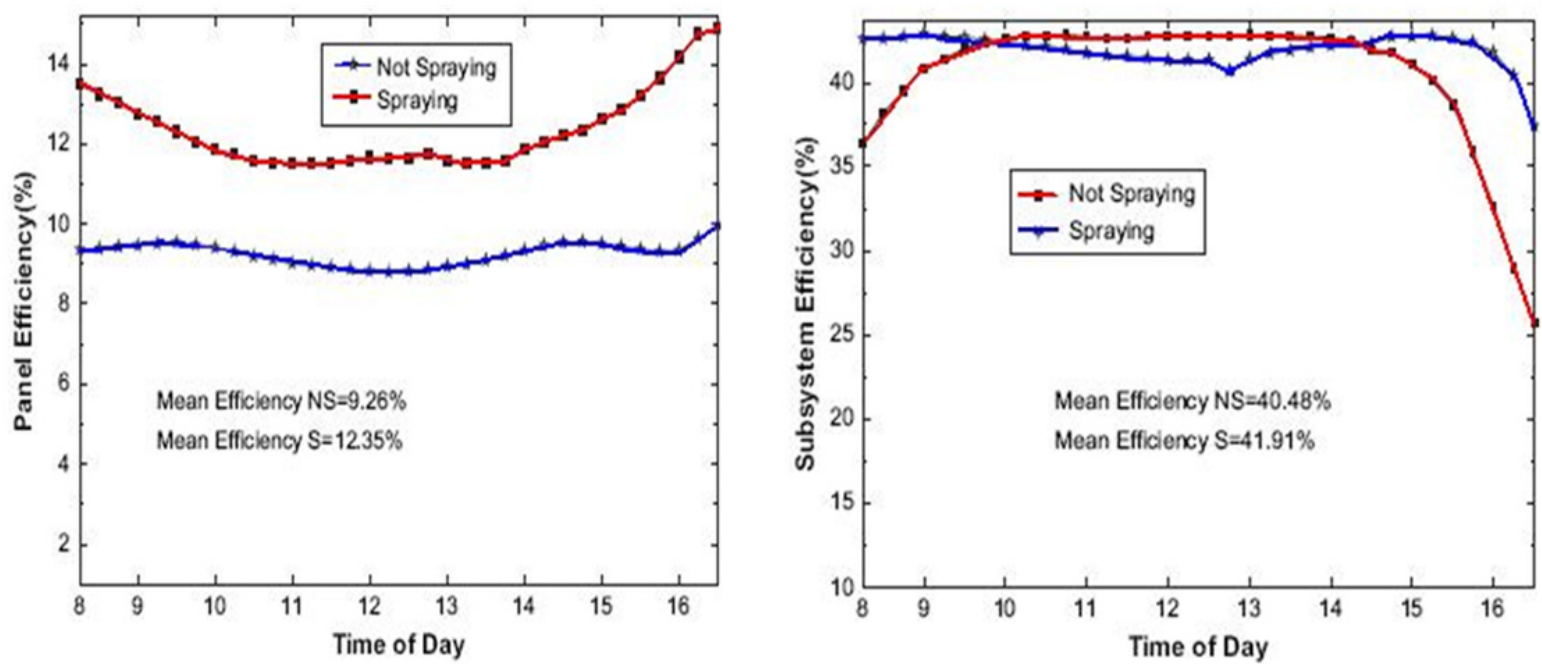

Figura 2.4 Comparación de los resultados medidos en el panel fotovoltaico con y sin pulverizar agua: a) Eficiencia del módulo, b) Eficiencia del subsistema [3].

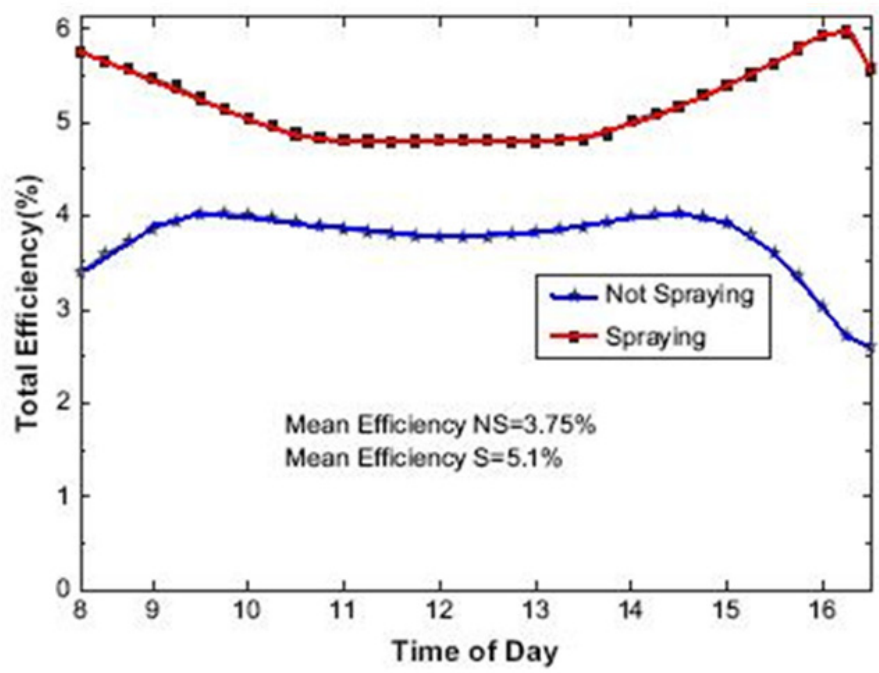

Figura 2.5 Comparación de la eficiencia total del sistema con y sin pulverización de agua [3].

Como se observa en la siguiente tabla, el caudal de la bomba aumenta al pulverizar agua sobre las células. El caudal de agua pulverizada sobre las células es de alrededor de $50 \mathrm{~L} / \mathrm{h}$ a $16 \mathrm{~m}$ mientras que el total acumulado para rociar las células durante el día, fue aproximadamente $165 \mathrm{~L} / \mathrm{h}$. 


\begin{tabular}{|c|c|c|c|c|}
\hline \multirow[t]{2}{*}{ Mean influenced parameter } & \multicolumn{2}{|c|}{ Not spraying } & \multicolumn{2}{|l|}{ Spraying } \\
\hline & $h=10 \mathrm{~m}$ & $h=16 \mathrm{~m}$ & $h=10 \mathrm{~m}$ & $h=16 \mathrm{~m}$ \\
\hline$\overline{P_{M}(W)}$ & 52.3 & 55.4 & 61.4 & 66.9 \\
\hline$Q_{n}(L / h)$ & 663 & 479 & 768 & 644 \\
\hline$\eta_{M P V}(\%)$ & 7.09 & 9.26 & 8.4 & 12.35 \\
\hline $\mathrm{G}_{\mathrm{M}}\left(\mathrm{W} / \mathrm{m}^{2}\right)$ & 745 & 740 & 745 & 740 \\
\hline$\eta_{\text {MSub }}(\%)$ & 34.11 & 40.84 & 34.61 & 41.4 \\
\hline$\eta_{\mathrm{Mr}}(\%)$ & 2.24 & 3.7 & 2.839 & 5.1 \\
\hline Water spray (L/h) & - & - & 15 & 50 \\
\hline
\end{tabular}

Tabla 2.1 Datos medidos de las variables influyentes para las diferentes configuraciones [3].

Como se puede apreciar, el aumento de caudal es más significativo a mayores alturas. Esta variación se debe principalmente al criterio de diseño en el que el rendimiento del sistema está cerca de aumentar cuando se alcanza la máxima velocidad de la bomba. Esta velocidad corresponde a cierto valor de la entrada. La eficiencia de las células PV se ve disminuida porque no se utiliza la bomba para su mayor potencia. Sin embargo, mayores alturas, consumen más agua para pulverizar las células. No obstante, el aumento de la eficiencia del sistema y subsistema sigue siendo elevado y pueden compensar la pérdida de agua para la pulverización de las células.

La característica importante de este sistema de pulverización de agua dulce sobre las células a una temperatura cercana a la temperatura ambiente, así como el agua purificada que pasa sobre las células, ofrece un sistema de limpieza de la celda. La pulverización de agua sobre las células fotovoltaicas puede ser útil en la mayoría de las aplicaciones fotovoltaicas de bombeo de agua que alcanzan altas temperaturas de las células, encontrándose en climas cálidos. Estos sistemas pueden proporcionar el agua necesaria para rociar las células a través de la bomba. Además, los resultados experimentales tomados en clima cálido, muestran el número de células necesarias para el suministro de los clientes, se reducirán por lo que consecuentemente, los costes de instalación se verán disminuidos.

El aumento de la masa térmica de los módulos fotovoltaicos, vinculados a pequeños tanques de agua es un método muy utilizado por Ronnelid et al.[9] y Krauter et al.[2] consiguiendo la refrigeración a través de un flujo de agua en la parte delantera de los paneles fotovoltaicos. Sin embargo se encontró que esta técnica aumenta el peso del módulo en el orden de $200 \mathrm{~kg} /$ módulo. Krauter et al. [2] montó el módulo PV con un tanque lleno de agua y debido a la alta capacidad térmica del agua, la temperatura de operación se podía mantener en niveles bajos durante la mayor parte del día. Así el agua absorbe prácticamente el calor generado por el módulo y además la evaporación de agua debe disminuir aún más las temperaturas, por lo tanto, aumentará el rendimiento eléctrico. Este diseño se mejoró de diferentes prototipos de años anteriores $[10,11]$ y se ha traducido en un aumento del rendimiento de la energía eléctrica, 12\%. El inconveniente es el enorme peso de $200 \mathrm{~kg} /$ módulo que hace que el montaje en techos convencionales sea 
difícil. Obsérvese que un panel convencional pesa menos de $25 \mathrm{~kg}$, para una potencia entre 240 y $280 \mathrm{Wp}$.

El enfriamiento mediante la utilización de una película de agua fluyendo sobre la cara frontal del módulo debería permitir teóricamente operar a temperaturas más bajas que el dispositivo descrito anteriormente. Debido a la rápida circulación del agua sólo puede haber un aumento mínimo en la temperatura del agua. Además, la evaporación de agua debe disminuir aún más las temperaturas, por lo tanto, aumentará los rendimientos eléctricos.

Las mediciones fueron registradas durante un día en Río de Janeiro el 21 de marzo de 1999, y los sensores de temperatura ( $p t$ 100) se instalaron en la parte posterior de los módulos donde la temperatura es alrededor de $1,5^{\circ} \mathrm{C}$ por debajo que en la parte frontal del módulo.

El agua se bombea desde un depósito de agua situado debajo del módulo y cuya capacidad es de 53 litros, a razón de $2 \mathrm{l} / \mathrm{min}$ y a través de doce boquillas situadas en la parte superior que generan un flujo de agua que rocía la superficie de los paneles, en un espesor de 1 $\mathrm{mm}$. El consumo de agua registrado fue de $4,4 \mathrm{I} / \mathrm{min}^{2}$.

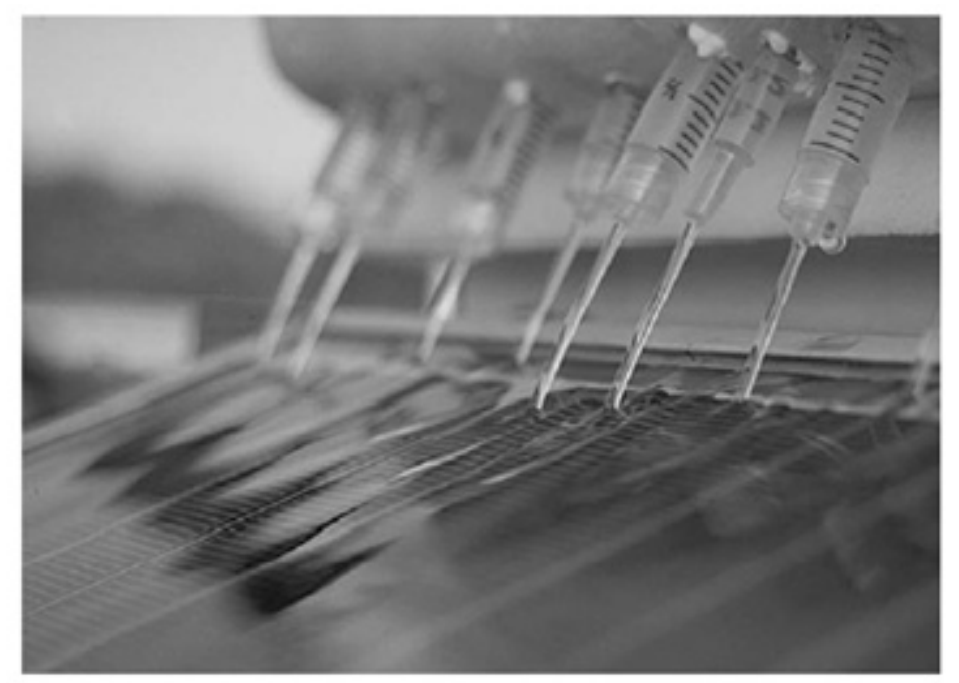

Figura 2.6 Creación de la capa de agua sobre el módulo PV a través de las boquillas [2].

Las temperaturas de funcionamiento de las células se llegaron a reducir hasta $22^{\circ} \mathrm{C}$, debido al flujo de agua y la refrigeración por evaporación adicional, una reducción significativa en comparación con las de una convencional que se medían al mismo tiempo como se puede apreciar en las gráficas siguientes. 


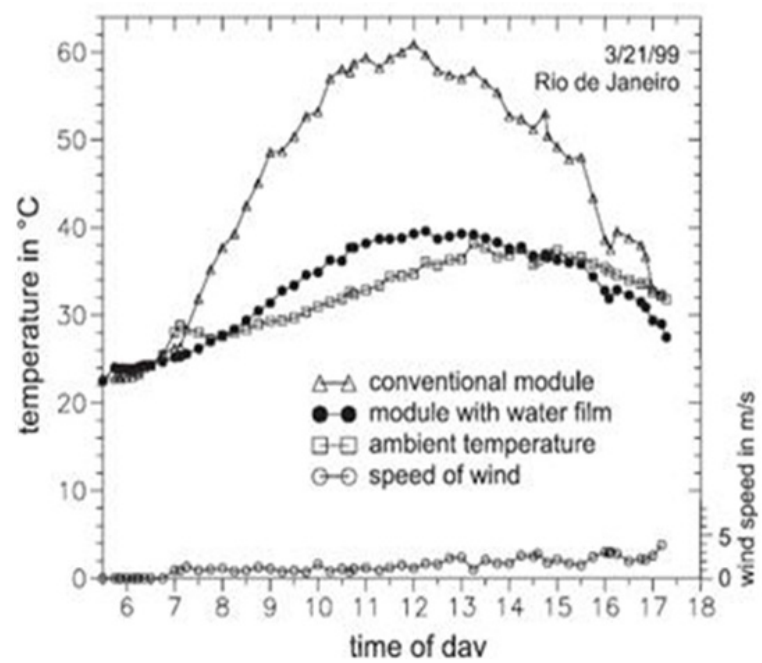

Figura 2.7 Evolución de las temperaturas del módulo $\mathrm{PV}$ en distintos casos [2].

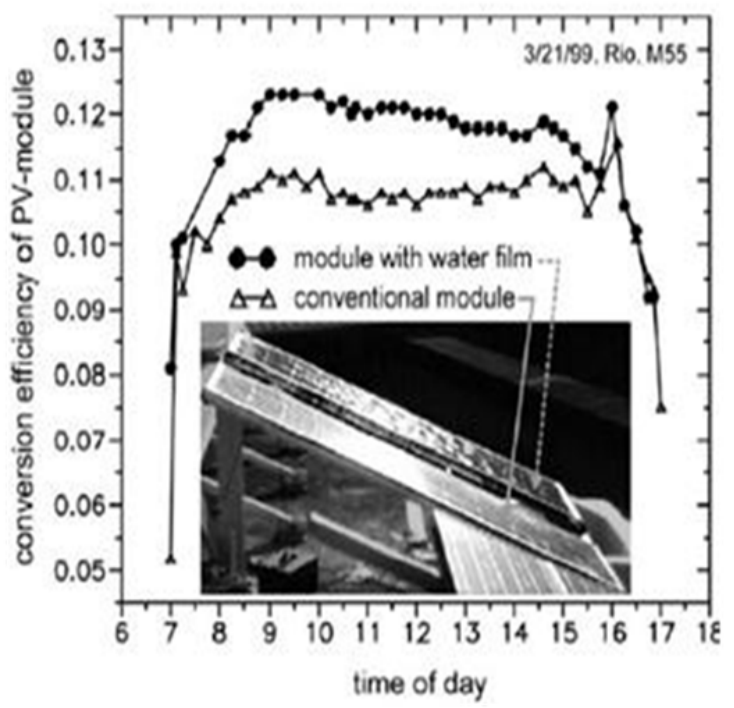

Figura 2.8 Eficiencia del módulo PV con y sin refrigeración con agua [2].

Las mediciones de la corriente de cortocircuito del módulo, que es casi independiente de la temperatura, indicaron que el flujo de agua mejora rendimiento óptico en un 1,5\%, una mejora inferior al 3\% de ganancia que teóricamente se esperaba. Una explicación de esa discrepancia puede ser dada por el espesor no homogéneo de los flujos de agua y/o la luz absorbida por las propiedades del agua. Hay que señalar, que en este caso el uso de la bomba no justifica el uso de la película de agua en términos de ganancias de energía dentro de un balance energético.

Otro método de refrigeración de los módulos empleando agua, es haciéndola pasar por su parte posterior, como estudió Earle Wilson et al. [12], que además lo llevó a cabo sin el uso de una bomba, sino aprovechando un salto hidráulico. Es decir, el agua se desvía de una fuente aguas arriba, como un río, o de cualquier posición elevada, incluyendo captación de agua de lluvia, se canaliza a través de la parte de atrás de un módulo PV, el módulo se enfría y el agua se devuelve al río. La potencia necesaria para conducir el agua a través del sistema viene de la carga hidráulica de la corriente de flujo por gravedad, debido a la diferencia de altitud, de modo que no se requiere de una bomba.

Los objetivos de esta investigación son dobles. En primer lugar, se propone para analizar el rendimiento operativo de los módulos "mojados" en el término del impacto del sistema de refrigeración en la tensión de circuito abierto $\left(V_{o c}\right) y$, por correlación, la eficiencia de conversión. El segundo objetivo es determinar el rango de caudales para el agua de enfriamiento que satisface las hipótesis matemáticas. 
a

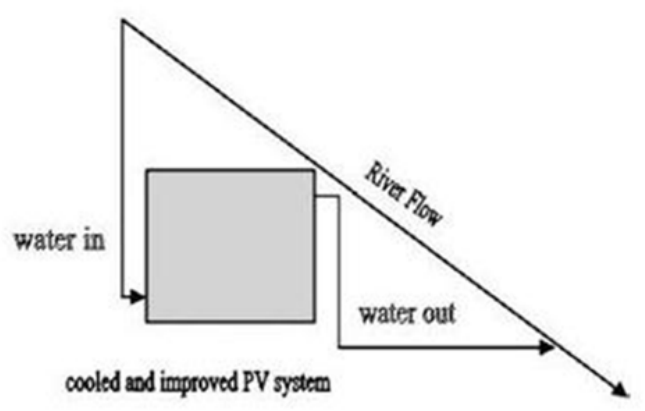

b

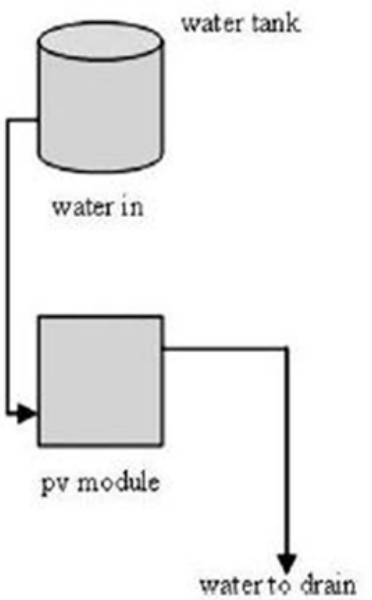

Figura 2.9 Diagrama del sistema de refrigeración [12].

Así mismo en su estudio se logra obtener un modelo matemático que se ajusta a los resultados experimentales, obteniendo una reducción de la temperatura desde los $60{ }^{\circ} \mathrm{C}$ a $28^{\circ} \mathrm{C}$, lo que supone un aumento del $12,8 \%$ de la eficiencia sin reducción de la tensión en circuito abierto, $V_{o c}$. Además la reducción de $32^{\circ} \mathrm{C}$ en la temperatura de funcionamiento de la célula se compara con los $22^{\circ} \mathrm{C}$ obtenidos por Krauter et al. [2], que hacía circular el agua por la parte frontal del módulo. En la gráfica se muestran los resultados del modelo matemático con una irradiancia solar de $1000 \mathrm{~W} / \mathrm{m} 2$ incidente en la cara frontal y la parte de atrás mantiene el agua de refrigeración la temperatura de $28^{\circ} \mathrm{C}$.

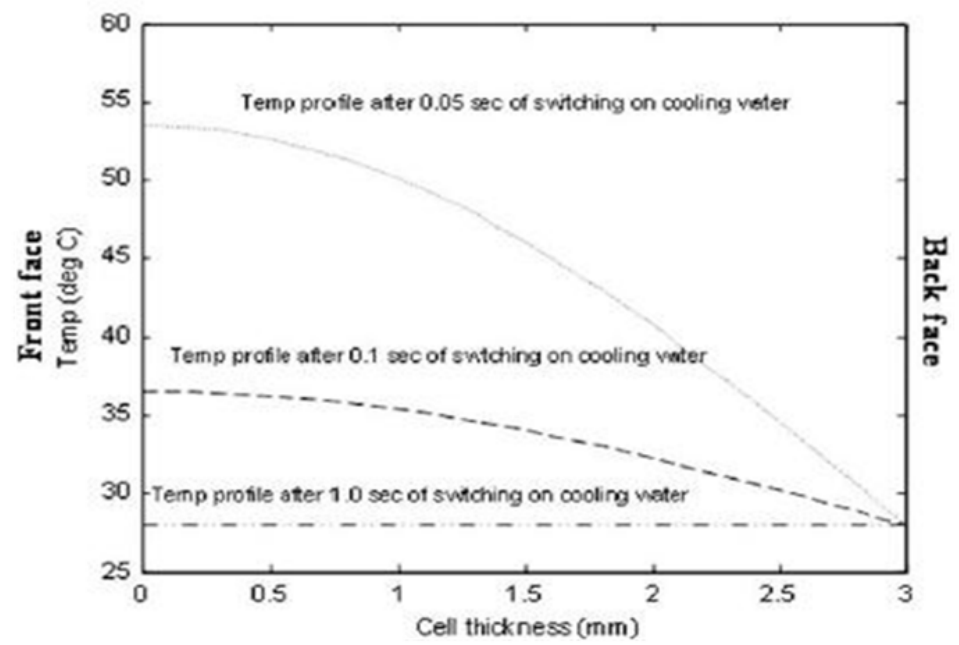

Figura 2.10 Perfil de temperaturas entre ambas superficies para una célula, para distintos tiempos tras la refrigeración con agua a $28^{\circ} \mathrm{C}[12]$.

La siguiente gráfica muestra los resultados experimentales de un módulo de ocho células PV con $V_{o c}$ de 4,5 V que están expuestas a una irradiancia solar constante (promedio) de $989 \mathrm{~W} / \mathrm{m}^{2}$ (rango: 924 a $1053 \mathrm{~W} / \mathrm{m}^{2}$ ) incidente sobre la cara frontal. La tensión en circuito abierto y por tanto la eficiencia de un módulo fotovoltaico es una función lineal de la 
temperatura de la célula con una irradiancia constante. La figura muestra un $11 \%$ de caída de tensión para un aumento de temperatura $28^{\circ} \mathrm{C}$.

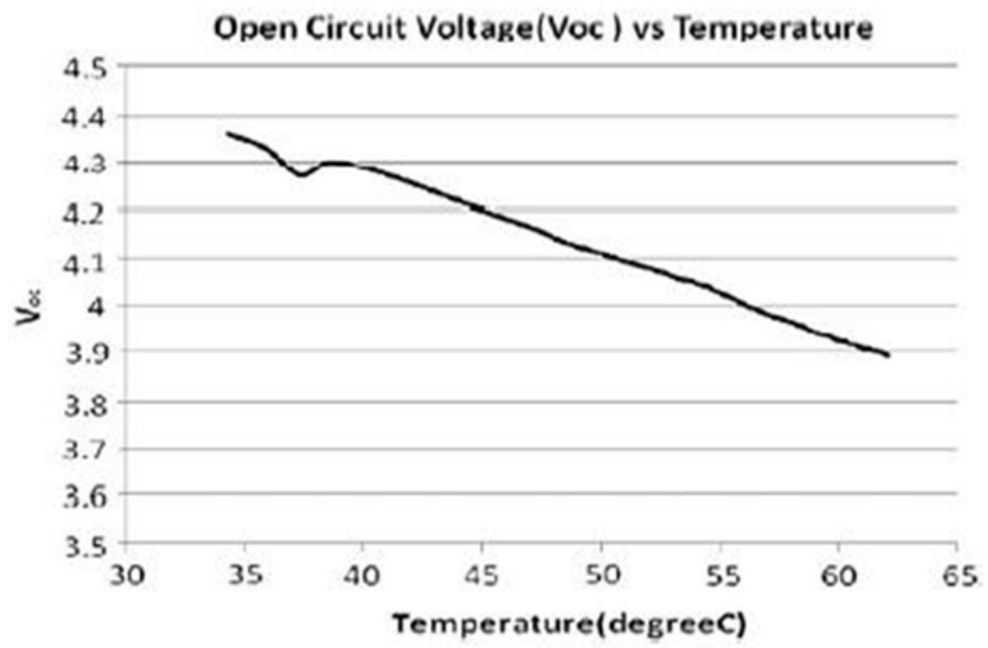

Figura 2.11 Influencia de la temperatura sobre la tensión de circuito abierto [12].

Posteriormente se muestran los resultados de las mismas ocho células del módulo PV con $V_{o c}$ nominal de $4,5 \mathrm{~V}$ y que están expuestas a la misma radiación solar incidente de 989 $\mathrm{W} / \mathrm{m}^{2}$ en la cara frontal, y en la posterior se mantiene la temperatura de $28^{\circ} \mathrm{C}$ con el agua de refrigeración, que se inicia cuando la temperatura del módulo llegó a $34{ }^{\circ} \mathrm{C}$ y tensión de $4,36 \mathrm{~V}$.

La temperatura del módulo alcanzó los $62{ }^{\circ} \mathrm{C}$ antes de comenzar a refrigerar, a los 25,5 minutos, a partir de ese momento, se observa en la Figura 2.12 el rápido enfriamiento del módulo después de la aplicación de agua de refrigeración. En un período muy corto de tiempo el módulo alcanza el estado estacionario, descendiendo la temperatura desde $62{ }^{\circ} \mathrm{C}$ a $30{ }^{\circ} \mathrm{C}$ (difiriendo dos grados de la temperatura del agua de refrigeración). También podemos apreciar la relación inversa entre la tensión y la temperatura. La tensión cae de $4,4 \mathrm{~V}$ a $3,9 \mathrm{~V}$ cuando la temperatura pasa de $34^{\circ} \mathrm{C}$ a $62^{\circ} \mathrm{C}$. Sin embargo, dentro de un corto período de tiempo, al comenzar a refrigerar con agua (25,5 minutos), el módulo de tensión va a la tensión nominal de 4,5 V y permanece allí. Este resultado apoya los resultados del modelo matemático que un módulo fotovoltaico puede mantener su tensión nominal a una determinada radiación solar y lo cual influirá en su eficiencia. 


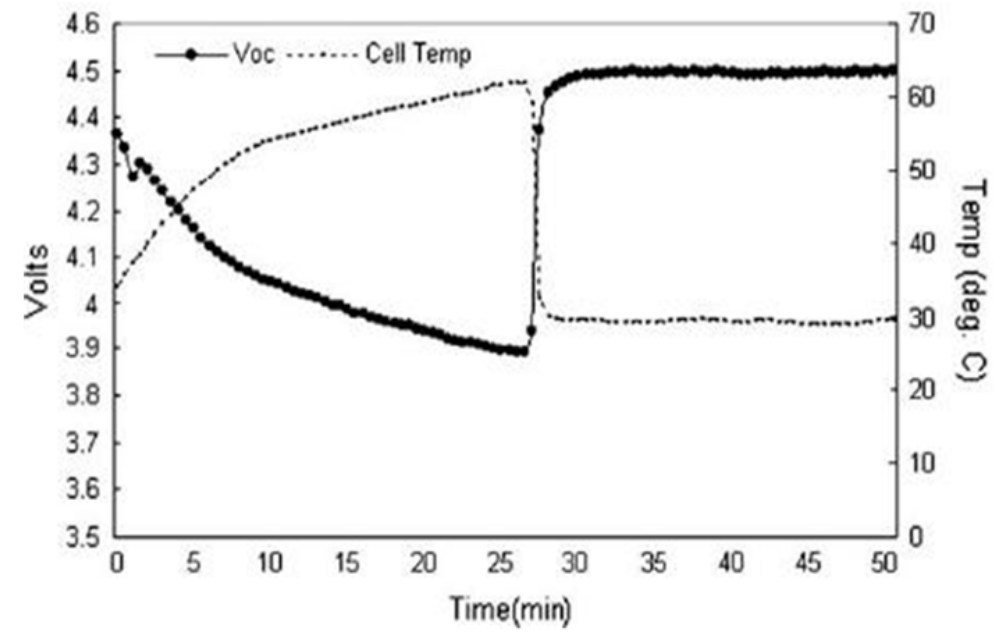

Figura 2.12 Medida de la tensión y perfil de temperatura de un módulo PV refrigerado con agua [12].

Cabe señalar que esta técnica de refrigeración del sistema está limitada a las regiones que tengan suministro de agua natural, a pesar de comprobarse que los resultados experimentales se acercan al modelo matemático para caudales de 1,0 l/min y ambos demuestran que el sistema mantiene la temperatura de funcionamiento del módulo por encima de 5 grados de la del diseño, $25^{\circ} \mathrm{C}$. Este método de refrigeración supone una reducción de $32{ }^{\circ} \mathrm{C}$ en la temperatura de funcionamiento, ya que un día determinado, la temperatura del módulo alcanza los $62{ }^{\circ} \mathrm{C}$ si no hay refrigeración. Por lo tanto, dado un coeficiente de eficiencia de $0,4 \% / K$, una reducción de temperatura de $32{ }^{\circ} \mathrm{C}$ se traduce en un aumento de 12,8\% para la eficiencia de conversión del módulo.

También podemos encontrar otros estudios y análisis del comportamiento térmico de los colectores solares $[13,14]$, así como variadas técnicas de enfriamiento y transferencia de calor con agua. Chow et al. [15] analiza el colector de agua PV/T con acristalamiento simple en condiciones transitorias, usando conductos en la parte posterior del colector, consiguiendo así un aumento de la eficiencia termo-eléctrica del $2 \%$. En el trabajo de Huang et al. [16], se ha estudiado experimentalmente un sistema solar fotovoltaico y térmico (IPVTS) para calentamiento de agua bajo un modo de operación natural, observando que conseguían una eficiencia la cual era mayor que la de un sistema solar convencional calentador de agua o un sistema fotovoltaico puro.

De entre todas las técnicas para enfriar las células, según Brogren et al. [17], la circulación de agua mediante conductos por la cara posterior de la célula es la más eficaz. Sin embargo, como hemos visto Krauter et al. [2] y M. Addolzadeh et al. [3], distribuyen agua en la parte frontal del panel PV consiguiendo muy buenos resultados, pero este método corre el riesgo de que se creen depósitos de cal sobre la cara de las células y, por tanto, reducir su eficacia. Además la técnica de circulación de agua mediante conductos tiene de importante señalar que necesita el funcionamiento de bombas, en la mayoría de los casos 
y corre el riesgo de aparecer legionela al ser un circuito cerrado de agua sin renovar y a altas temperaturas.

\subsubsection{AIRE COMO FLUIDO CALOPORTADOR:}

Debido al gasto económico extra que supone la refrigeración de los módulos fotovoltaicos con agua junto a los inconvenientes que conlleva, a continuación nos centraremos en métodos más aconsejables como es la refrigeración mediante aire, haciéndolo pasar por su cara posterior mediante convección natural o forzada.

Gracias al viento que se produce en el ambiente, los módulos que no están colocados sobre ningún tejado, cubierta o fachada, no alcanzan temperaturas tan extremas como los que sí lo están, obteniendo más o menos la eficiencia esperada en condiciones normales de funcionamiento. Por otro lado, los módulos fotovoltaicos instalados sobre estructuras sólidas como tejados, cubiertas de naves industriales, etc. sufren un aumento en su temperatura de funcionamiento, con la consecuencia de que no responden con la eficiencia esperada, sino que la producción eléctrica es menor, siendo bastante significativo a altas temperaturas ambientales.

\subsubsection{Convección natural}

La refrigeración por convección natural consiste en la transferencia de calor desde el panel fotovoltaico al aire que circula por su cara posterior, creando un canal de paso de aire entre el panel fotovoltaico y una superficie inferior (cubierta), para ello habrá que dejar un espacio entre ambas superficies. El aire que se encuentra a la temperatura ambiente, al circular por el canal se le transfiere calor del panel fotovoltaico (el cual suele estar a mayor temperatura) incrementándose la temperatura del aire, al calentarse aumenta su volumen por lo que disminuye su propia densidad y asciende, generando un flujo de aire por la parte posterior del módulo fotovoltaico que ejerce como fluido caloportador, pudiendo aprovechar dicho efecto para la reducción de la temperatura del panel fotovoltaico.

No siempre se va a conseguir la misma refrigeración del panel PV mediante convección natural ya que son muchos los factores influyentes en este proceso de transmisión de calor tales como las condiciones ambientales, inclinación del panel, características y propiedades de la cubierta o superficie inferior del canal de paso de aire, así como la separación entre ambas superficies. Su influencia en la capacidad de refrigeración para determinar la temperatura del módulo se aborda en el apartado 2.5 de este capítulo.

Mediante su estudio, Guohui Gan et al. [18], determinó el espacio necesario que debe haber entre el panel PV y el sólido sobre el que se encuentre y así conseguir el descenso de la temperatura. Para este trabajo se utilizaron placas fotovoltaicas de dimensiones $1209 \times 537 \times 50 \mathrm{~mm}$. 


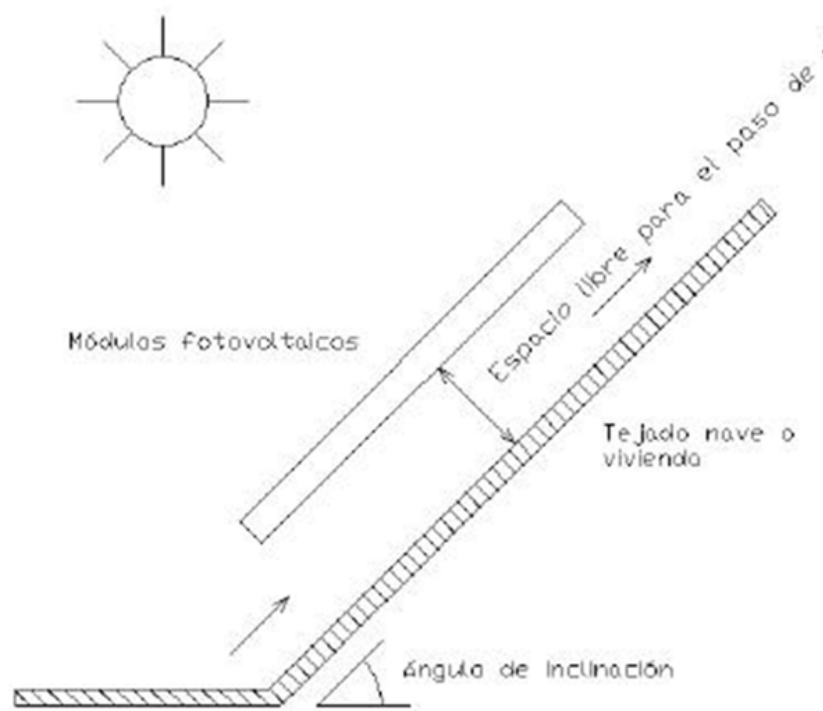

Figura 2.13 Convección natural en paneles fotovoltaicos [18].

Para convección natural se encontró que la velocidad del aire que pasa por el espacio libre en la cara posterior del panel, incrementa con el grosor del hueco al encontrar una menor resistencia a su paso. Además hay que tener en cuenta que el espacio $(h)$ mínimo que tiene que haber entre el módulo y el tejado tomara distintos valores según sean las condiciones del ángulo de inclinación o el número de módulos.

Estos casos los vemos reflejados en las Figura 2.14, 2.15 y 2.16. En la primera de ellas se representa la velocidad media del aire a través del canal en función de su espesor, el cual se ha variado entre $0.06 \mathrm{~m}$ a $0.2 \mathrm{~m}$. En ella apreciamos que la velocidad del flujo de aire aumenta con forme es mayor el espesor del canal de paso de éste, siguiendo una misma tendencia para todos los ángulos de inclinación ensayados (roof picth). Las mayores velocidades de aire alcanzadas han sido para un ángulo de $60^{\circ}$ para todos los espesores, seguidas de las correspondientes a ángulos de $45^{\circ}$ y $75^{\circ}$. Como se podría esperar, las menores velocidades del flujo de aire son para pequeñas inclinaciones como consecuencia de haber un menor efecto chimenea. 


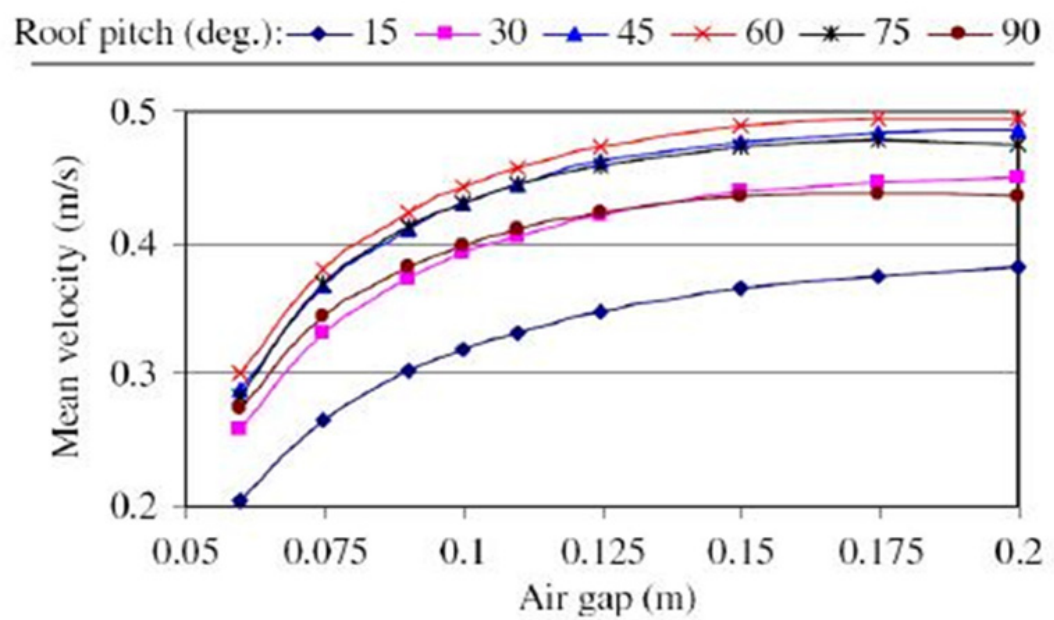

Figura 2.14 Relación entre la velocidad del aire y el espesor del canal de aire para diferentes ángulos de inclinación [18].
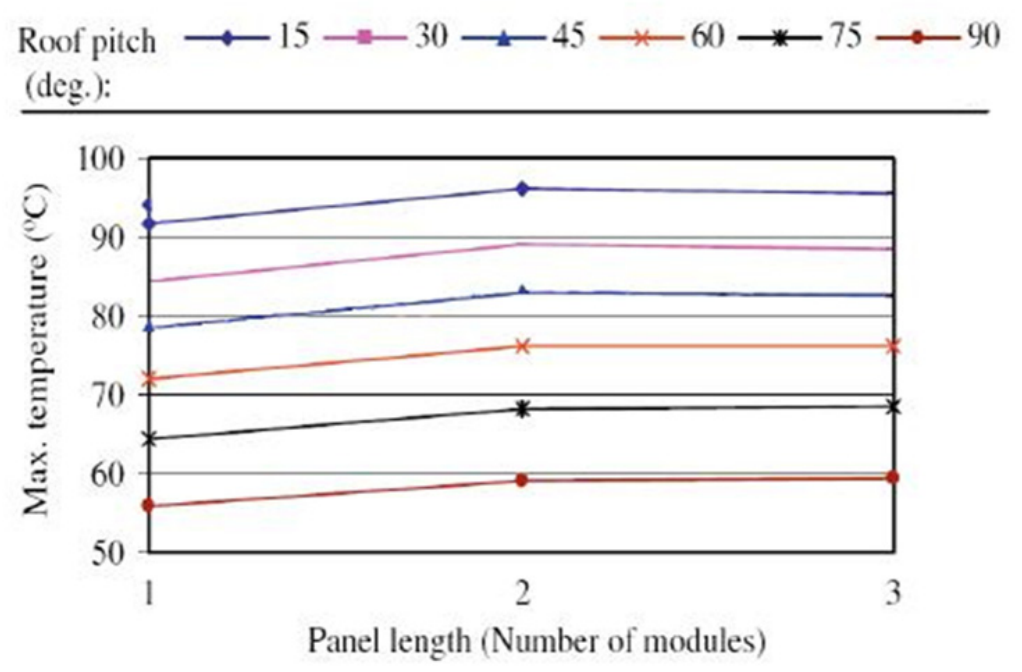

Figura 2.15 Variación de la temperatura para un espesor de 0,1m en función del número de paneles y el ángulo de inclinación [18].

En los gráficos de las Figura 2.15 y 2.16 se representa la temperatura máxima que alcanza el panel fotovoltaico en función del número de paneles fotovoltaicos instalados de forma continua, siendo la primera de ellas la correspondiente a un espesor del canal de aire de $0,1 \mathrm{~m}$ y la segunda de 0,2 m. Podemos apreciar en ellas como un aumento mínimo del espesor del canal de paso de aire, como son $10 \mathrm{~cm}$, puede hacer disminuir la temperatura $5{ }^{\circ} \mathrm{C}$ (inclinación de $15^{\circ}$ ). Por otro lado, el aumento del espesor de canal de paso de aire no impide que la temperatura aumente, o en los mejores casos, se mantenga, si nuestra instalación tiene más de un módulo instalado de forma continua, lo que aumenta la longitud del canal de aire. 

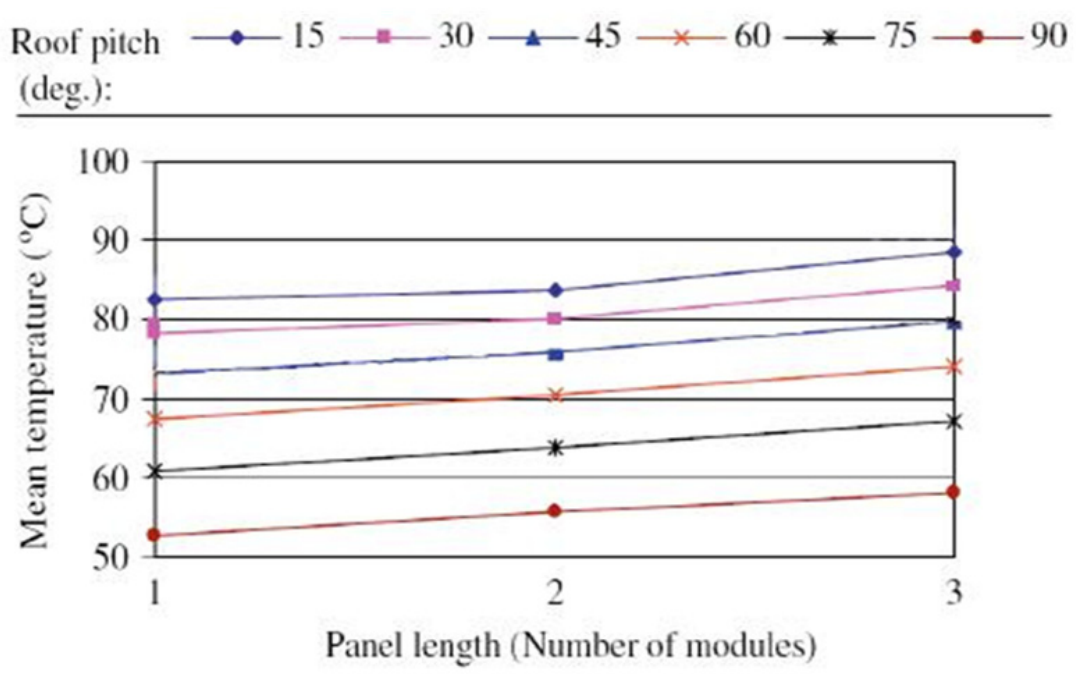

Figura 2.16 Variación de la temperatura para un espesor de $0.2 \mathrm{~m}$ en función del número de paneles y el ángulo de inclinación [18].

Las conclusiones de este estudio nos muestran que el espacio mínimo entre el panel y la cubierta, por el que circula el aire, debe ser el mostrado en la Tabla 2.2 en función del número de paneles instalados y la inclinación de estos.

\begin{tabular}{|c|c|c|c|}
\hline \multicolumn{5}{|c|}{$\begin{array}{c}\text { Espacio necesario en base para disminuir la temperatura } \\
\text { máxima alcanzada }\end{array}$} \\
\hline $\begin{array}{c}\text { Ángulo de } \\
\text { inclinación }\end{array}$ & $\begin{array}{c}1 \\
\text { módulo }\end{array}$ & $\begin{array}{c}2 \\
\text { módulos }\end{array}$ & módulos \\
\hline 15 & 0,2 & 0,2 & 0,2 \\
\hline 30 & 0,2 & 0,2 & 0,15 \\
\hline 45 & 0,2 & 0,175 & 0,125 \\
\hline 60 & 0,2 & 0,15 & 0,125 \\
\hline 75 & 0,2 & 0,15 & 0,125 \\
\hline 90 & 0,2 & 0,15 & 0,125 \\
\hline
\end{tabular}

Tabla 2.2 Espesor del canal de aire necesario para reducir la temperatura del panel [18].

Podemos observar que conforme se aumenta el número de módulos instalados, el espacio necesario para su refrigeración es algo menor y que para ángulos de inclinación entre $60^{\circ}$ y $90^{\circ}$ el espesor es el mismo independiente del número de módulos dado que no se han encontrado cambios significativos en temperatura y velocidad del aire.

\subsubsection{Convección forzada}

La refrigeración por convección forzada consiste en obligar al aire recorrer un espacio definiéndole un sentido y una dirección mediante medios externos, como puede ser un ventilador o una bomba.

Tiwari et al. [19] llevaron a cabo la evaluación del rendimiento de los módulos fotovoltaicos, integrándoles un conducto de aire por su cara posterior, con lo que se 
obtenía una mayor eficiencia en la generación de energía eléctrica. Su estudio consistía en el uso de aire haciéndole que fluyera por debajo del panel a través de un conducto tanto por convección natural como forzada mediante el funcionamiento de uno o dos ventiladores. Como cabía de esperar, la temperatura de la superficie trasera del módulo es menor respecto a las superficie superior en todos los casos, al igual que se apreciaba una caída de la temperatura de la superficie posterior al módulo cuando se hacía fluir aire con un ventilador, siendo esta caída mayor, en comparación con la convección natural, debido a la evacuación de calor de la superficie posterior del módulo.

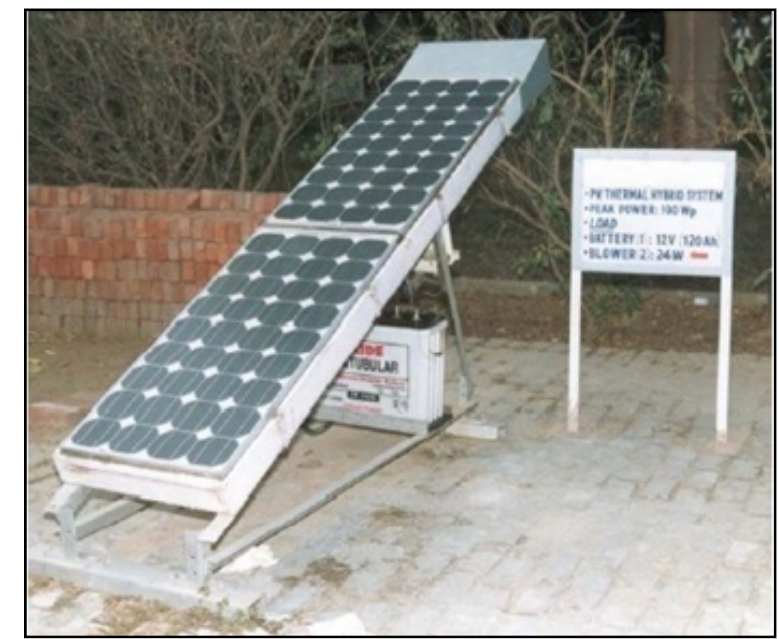

Figura 2.17 Módulos PV refrigerados por aire en su parte posterior [19].

Además se apreciaba una temperatura inferior en el aire de salida usando dos ventiladores, lo que da una mayor velocidad de flujo a lo esperado.

Los resultados obtenidos con las valores de las temperaturas de los paneles fotovoltaicos a los largo de un día, se presentan en las siguientes tablas tanto en condiciones de convección natural como forzada mediante el uso de uno o dos ventiladores.

\begin{tabular}{|c|c|c|c|c|c|c|}
\hline \multirow[t]{2}{*}{ Time (h) } & \multirow{2}{*}{$\begin{array}{l}\text { Intensity } \\
\left(\mathrm{W} / \mathrm{m}^{2}\right)\end{array}$} & \multirow{2}{*}{$\begin{array}{l}\text { Inlet air } \\
\text { temperature } \\
\left({ }^{\circ} \mathrm{C}\right)\end{array}$} & \multirow{2}{*}{$\begin{array}{l}\text { Ambient } \\
\text { temperature } \\
\left({ }^{\circ} \mathrm{C}\right)\end{array}$} & \multicolumn{2}{|c|}{ Panel temperature $\left({ }^{\circ} \mathrm{C}\right)$} & \multirow{2}{*}{$\begin{array}{l}\text { Outlet air } \\
\text { temperature } \\
\left({ }^{\circ} \mathrm{C}\right)\end{array}$} \\
\hline & & & & Back surface & Top surface & \\
\hline 8 & 77 & 9.4 & 9 & 11.5 & 10.6 & 9.1 \\
\hline 9 & 211 & 15.3 & 12 & 22.4 & 21.7 & 14.4 \\
\hline 10 & 434 & 24 & 15 & 38.1 & 35 & 19.4 \\
\hline 11 & 569 & 30.5 & 18 & 46 & 41.3 & 22.9 \\
\hline 12 & 565 & 31.7 & 19 & 47.8 & 43.5 & 24.7 \\
\hline 1 & 542 & 32.1 & 21 & 49.4 & 42.7 & 24.4 \\
\hline 2 & 501 & 34.5 & 22 & 47.9 & 42.4 & 25.4 \\
\hline 3 & 325 & 29.1 & 21 & 41.4 & 36.5 & 23.8 \\
\hline 4 & 185 & 26.1 & 21 & 33.1 & 30.5 & 22.6 \\
\hline
\end{tabular}

Tabla 2.3 Resultados experimentales para convección natural [19]. 


\begin{tabular}{|c|c|c|c|c|c|c|c|c|}
\hline \multicolumn{9}{|c|}{ Observation obtained for forced mode of operation with air flow (single fan) } \\
\hline \multirow[t]{2}{*}{$\begin{array}{l}\text { Time } \\
\text { (h) }\end{array}$} & \multirow[t]{2}{*}{$\begin{array}{l}\text { Intensity } \\
\left(\mathrm{W} / \mathrm{m}^{2}\right)\end{array}$} & \multirow{2}{*}{$\begin{array}{l}\text { Inlet air } \\
\text { temperature } \\
\left({ }^{\circ} \mathrm{C}\right)\end{array}$} & \multirow{2}{*}{$\begin{array}{l}\text { Ambient } \\
\text { temperature } \\
\left({ }^{\circ} \mathrm{C}\right)\end{array}$} & \multicolumn{2}{|c|}{$\begin{array}{l}\text { Panel temperature } \\
\left({ }^{\circ} \mathrm{C}\right)\end{array}$} & \multirow{2}{*}{$\begin{array}{l}\text { Outlet air } \\
\text { temperature } \\
\left({ }^{\circ} \mathrm{C}\right)\end{array}$} & \multicolumn{2}{|c|}{ Air velocity $(\mathrm{m} / \mathrm{s})$} \\
\hline & & & & $\begin{array}{l}\text { Back } \\
\text { surface }\end{array}$ & $\begin{array}{l}\text { Top } \\
\text { surface }\end{array}$ & & In duct & $\begin{array}{l}\text { Above } \\
\text { panel }\end{array}$ \\
\hline 8 & 43 & 10.1 & 9 & 11.9 & 11.2 & 10 & 1.6 & 0 \\
\hline 9 & 222 & 14.2 & 12 & 20.1 & 20.7 & 15.5 & 1.7 & 0 \\
\hline 10 & 433 & 19.1 & 15 & 32.4 & 31 & 22.6 & 1.8 & 0 \\
\hline 11 & 558 & 21.5 & 18 & 37.9 & 36.4 & 26 & 1.9 & 0 \\
\hline 12 & 677 & 23.1 & 20 & 41.8 & 40.1 & 28.8 & 2 & 0 \\
\hline 1 & 602 & 24 & 22 & 43.1 & 41.1 & 29.8 & 2.4 & 0 \\
\hline 2 & 283 & 23.4 & 22 & 33.8 & 33.5 & 26.4 & 1.9 & 0.3 \\
\hline 3 & 261 & 23.4 & 22 & 32.2 & 31.8 & 25.9 & 1.9 & 0.08 \\
\hline 4 & 104 & 22.5 & 21 & 27.6 & 26.9 & 23.7 & 1.9 & 0.08 \\
\hline
\end{tabular}

Tabla 2.4 Resultados experimentales para convección forzada, utilizando un ventilador [19].

\begin{tabular}{|c|c|c|c|c|c|c|c|c|}
\hline \multicolumn{9}{|c|}{ Observation obtained for forced mode of operation with air flow (two fan) } \\
\hline \multirow[t]{2}{*}{$\begin{array}{l}\text { Time } \\
\text { (h) }\end{array}$} & \multirow[t]{2}{*}{$\begin{array}{l}\text { Intensity } \\
\left(\mathrm{W} / \mathrm{m}^{2}\right)\end{array}$} & \multirow{2}{*}{$\begin{array}{l}\text { Inlet air } \\
\text { temperature } \\
\left({ }^{\circ} \mathrm{C}\right)\end{array}$} & \multirow{2}{*}{$\begin{array}{l}\text { Ambient } \\
\text { temperature } \\
\left({ }^{\circ} \mathrm{C}\right)\end{array}$} & \multicolumn{2}{|c|}{$\begin{array}{l}\text { Panel temperature } \\
\left({ }^{\circ} \mathrm{C}\right)\end{array}$} & \multirow{2}{*}{$\begin{array}{l}\text { Outlet air } \\
\text { temperature } \\
\left({ }^{\circ} \mathrm{C}\right)\end{array}$} & \multicolumn{2}{|c|}{ Air velocity $(\mathrm{m} / \mathrm{s})$} \\
\hline & & & & $\begin{array}{l}\text { Back } \\
\text { surface }\end{array}$ & $\begin{array}{l}\text { Top } \\
\text { surface }\end{array}$ & & In duct & $\begin{array}{l}\text { Above } \\
\text { panel }\end{array}$ \\
\hline 8 & 23 & 10.8 & 10 & 13.2 & 13.2 & 11.1 & 2.6 & 0 \\
\hline 9 & 118 & 12 & 10.5 & 16 & 16.5 & 12.8 & 2.9 & 0 \\
\hline 10 & 404 & 14.8 & 13 & 25.1 & 27.5 & 17.3 & 3 & 0 \\
\hline 11 & 546 & 17.8 & 16 & 31.2 & 33.1 & 21.2 & 3.17 & 0.27 \\
\hline 12 & 546 & 21.2 & 19 & 34.8 & 37 & 24.7 & 3.3 & 0.13 \\
\hline 1 & 534 & 21.5 & 20 & 34.4 & 36.4 & 24.9 & 3.33 & 0.03 \\
\hline 2 & 509 & 22.4 & 20 & 34.9 & 37.1 & 25.6 & 3.2 & 0.53 \\
\hline$\overline{3}$ & 334 & 22.6 & 20 & 30.6 & 31 & 24.3 & 2.97 & 1.27 \\
\hline 4 & 134 & 21.3 & 20 & 25.8 & 26.4 & 22 & 2.9 & 0.67 \\
\hline
\end{tabular}

Tabla 2.5 Resultados experimentales para convección forzada, utilizando dos ventiladores [19].

Con los resultados mostrados en las Tablas 2.3-2.5, se observa que la temperatura de la superficie trasera del módulo está entre $1-8{ }^{\circ} \mathrm{C}$ por debajo de la superficie superior en todos los casos. Es de señalar la apreciada caída de $5{ }^{\circ} \mathrm{C}$ en la temperatura de la superficie trasera del módulo PV, cuando está refrigerado con un ventilador en comparación a la temperatura que alcanza en convección natural, debido a la transferencia de calor de la superficie posterior del módulo, al igual que se aprecia una menor temperatura del aire a la salida, hasta de $3{ }^{\circ} \mathrm{C}$ utilizando dos ventiladores, lo que da mayor velocidad de flujo a lo esperado.

Los resultados del comportamiento de la eficiencia con la velocidad del flujo, se muestra en la Figura 2.18, en la que se muestra el aumento inicial de la eficiencia desde $1 \mathrm{~m} / \mathrm{s}$ hasta un caudal de $2 \mathrm{~m} / \mathrm{s}$, a partir del cual disminuía con forme aumenta la velocidad del flujo, por ello este caudal es el considerado como óptimo para dar los parámetros de diseño en este estudio. 


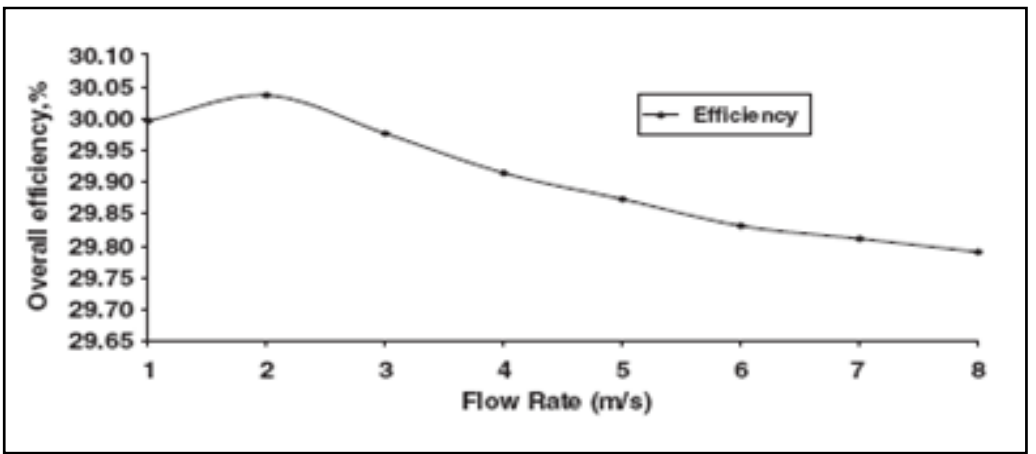

Figura 2.18 Efecto del caudal sobre la eficiencia global [19].

En cuanto a la longitud del conducto, se obtuvo que a partir de 3 metros, la eficiencia apenas sufre variación alguna, sin embargo, como cabía esperar, la eficiencia aumentaba considerablemente con el espacio de separación de aire en el conducto, como se muestra en las siguientes gráficas, Figura 2.19 y 2.20 .

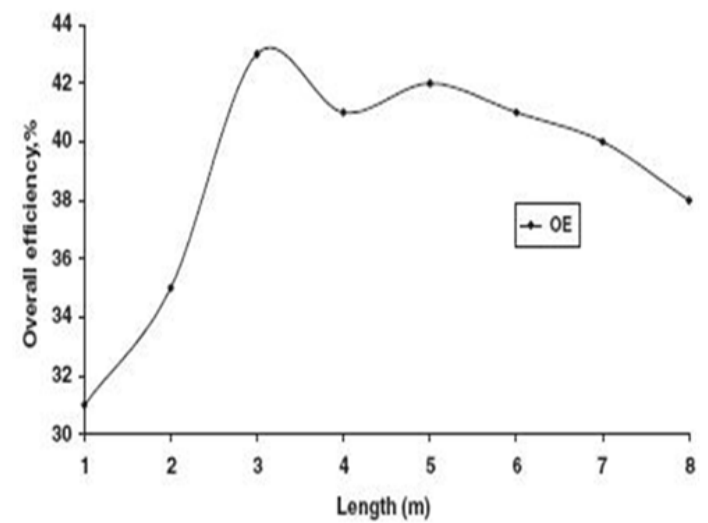

Figura 2.19 Efecto de la longitud del conducto eficiencia [19].

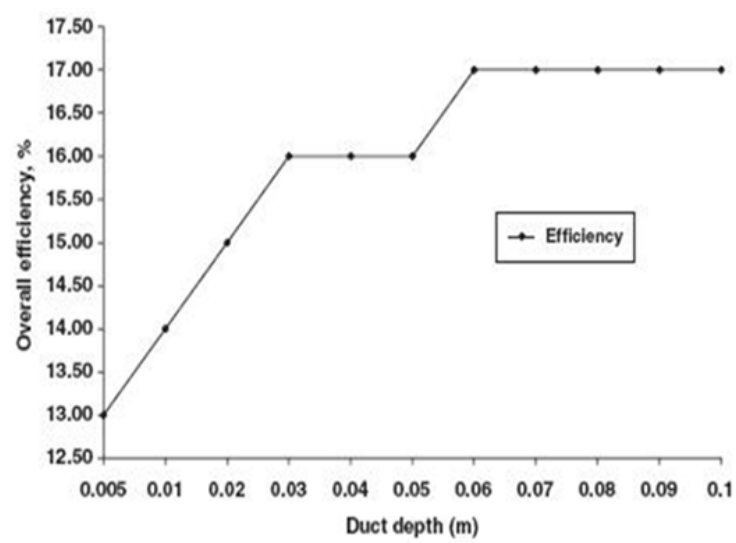

Figura 2.20 Efecto de profundidad en la sobre la eficiencia [19]

Swapnil et al. [20] investigaron el comportamiento de la eficiencia eléctrica de colectores híbridos, PV/T refrigerados con aire, estableciendo una expresión analítica de la eficiencia. Probaron con dos configuraciones diferentes de los módulos, cristal-cristal y cristal-Tedlar, Figura 2.21, considerando cada tipo con y sin conducto de aire. El conducto para la circulación de aire se inserta debajo de los módulos fotovoltaicos, fluyendo el aire de modo forzado con la ayuda de un ventilador. 

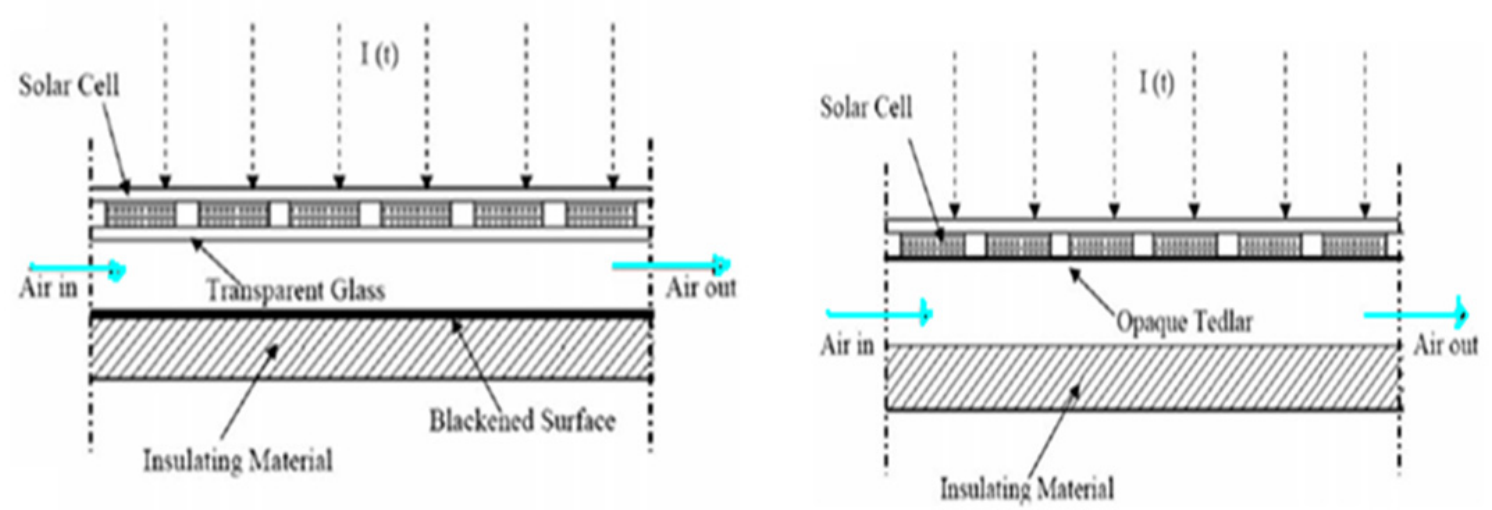

Figura 2.21 Esquema de las diferentes configuraciones ensayadas, cristal-cristal y cristal-tedlar [20].

Los resultados experimentales y teóricos coincidieron en que la eficiencia aumentaba cerca del $0,66 \%$ en los paneles refrigerados con aire, así como que la configuración cristalcristal es la más apropiada dado que presentaba mejor rendimiento frente a la de cristaltedlar. Esto se debe a que la radiación que llega a la zona envasada de cristal-cristal, es también transmitida a través de la tapa de cristal (vidrio), mientras que en el otro caso toda la radiación es absorbida por la tapa de tedlar y el calor se transmite a la conducción, la temperatura del módulo es mayor en este caso y en consecuencia la eficiencia es menor.

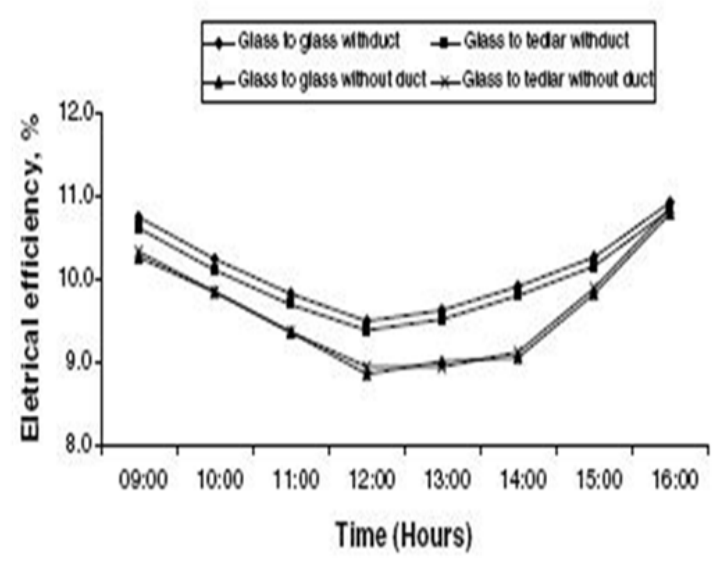

Figura 2.22 Variación de la eficiencia eléctrica con y sin conducto para refrigerar [20].

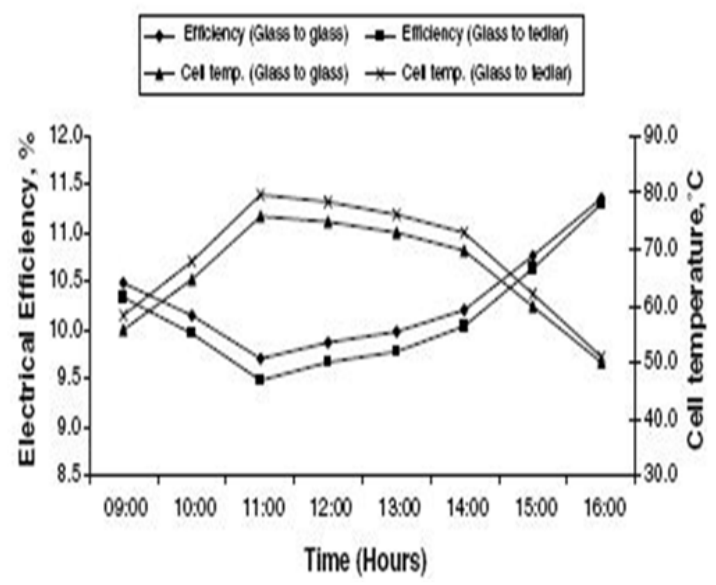

Figura 2.23 Variación de la eficiencia y temperatura con conducto para refrigerar [20].

Nynne Friling et al.[21] Ilevaron a cabo un modelo matemático de la transferencia de calor de módulos fotovoltaicos integrados en edificios y refrigerados por medio de ventilación. En este estudio se halló la influencia de las aletas incorporadas en el canal de paso de aire, bajo el panel fotovoltaico y del cambio de la velocidad del ventilador. En la Figura 2.24 se muestra la configuración de la estructura que consta de un orificio abierto por dos extremos por donde entra el aire por convección forzada. Los ensayos se han 
realizado para los valores de velocidad de aire forzado de $2,49 \mathrm{~m} / \mathrm{s}$ (level 10) y 3,43 m/s (level 13), manteniéndolas fijas durante las 24 horas para llevar a cabo los ensayos a lo largo del día.
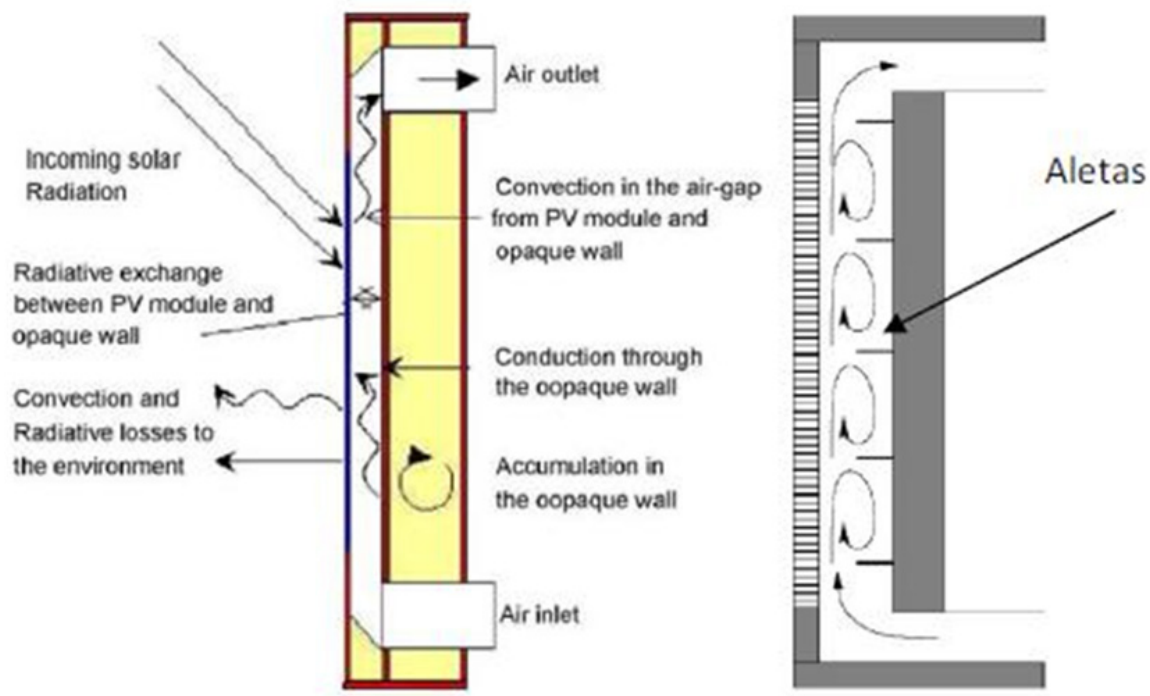

Figura 2.24 Modelo de la estructura estudiada por Nynne Friling et al. [21].

En la Figura 2.25 se representa la evolución de los valores experimentales registrados de la temperatura del panel fotovoltaico refrigerado, para ambas velocidades anteriormente mencionada. En ambos casos podemos comparar las temperaturas del panel refrigerado por su cara posterior utilizando o no aletas en el canal de paso de aire.
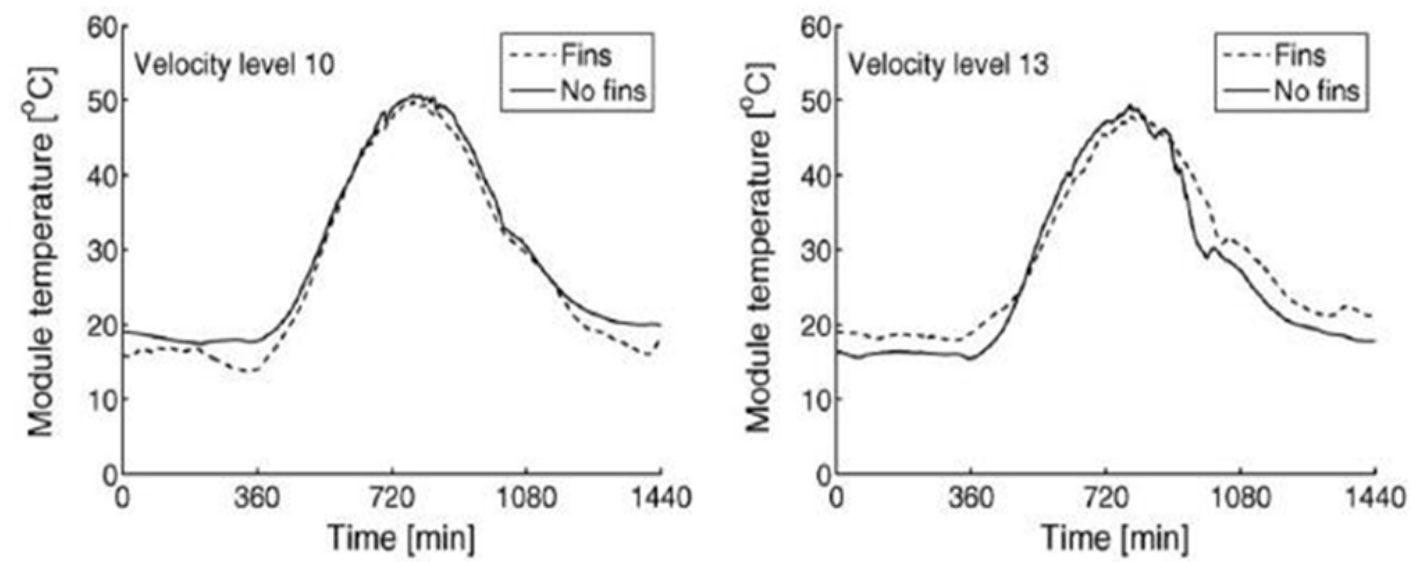

Figura 2.25 Evolución de la temperatura del panel a lo largo del día a dos velocidades [21].

Podemos observar que el hecho de poner aletas en el canal de aire no influye en la temperatura del panel fotovoltaico, una vez que se crea un flujo de aire por su cara posterior mediante convección forzada, las temperaturas alcanzadas para ambas configuraciones son muy similares. Además, para una mayor velocidad de aire forzado, la 
temperatura del panel refrigerado a través de una canal sin aletas es inferior a cuando se usan aletas.

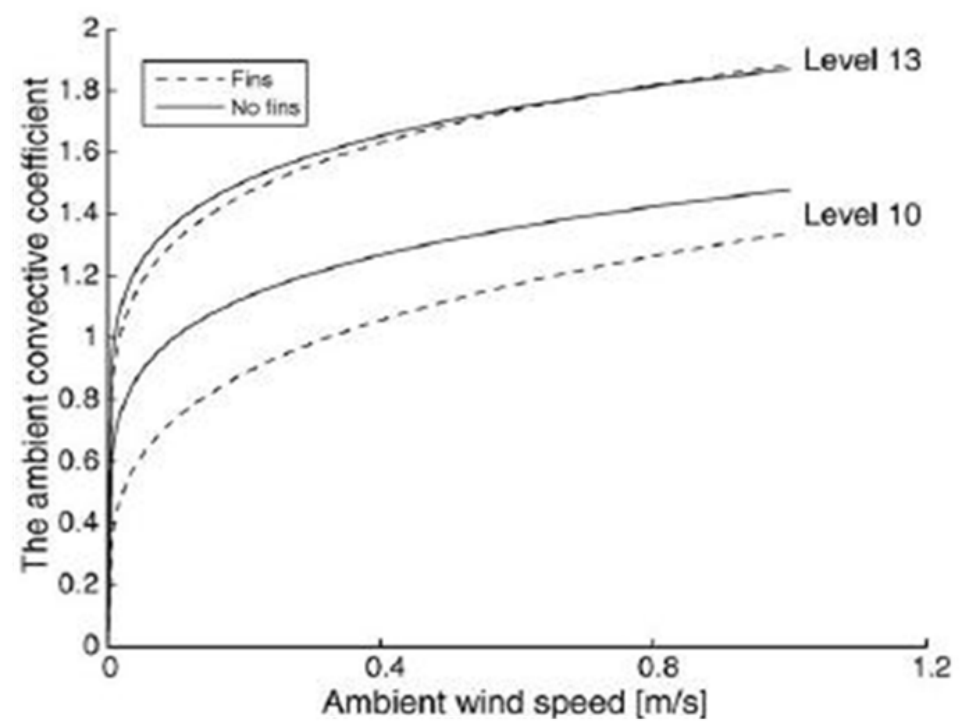

Figura 2.26 Coeficiente de convección frente velocidad de viento [21].

En este trabajo se concluyó que la velocidad del aire ambiente influye en la transferencia de calor. En la Figura 2.26 se muestra claramente que el aumento de la velocidad de aire forzado en el canal de aire afecta positivamente y en gran magnitud al aumento del coeficiente de convección. Sin embargo se ha observado que la presencia de aletas en el canal de paso desfavorece el objetivo de alcanzar menores temperaturas de panel, dado que trabajan como aislantes para la velocidad de $2,49 \mathrm{~m} / \mathrm{s}$ (level 10) y apenas influyen a una velocidad de $3,43 \mathrm{~m} / \mathrm{s}$ (level 13). En conclusión, la transferencia de calor se incrementa cuando la velocidad de ventilación forzada aumenta, sin necesidad del uso de atletas.

Esta técnica de refrigeración de los paneles fotovoltaicos con aire también fue llevada a cabo por Sweelem et al. [22], quien propuso impulsar aire en la parte trasera del módulo a través de un conducto de aire variable en espesor y además estudiar el efecto de ahorro de energía utilizando el aire caliente a la salida para calefacción de viviendas, sistemas de agua, aire acondicionado, etc.

Esta propuesta permite que el caudal de aire de refrigeración este controlado, ajustando la anchura del conducto de aire mediante una placa metálica paralela y móvil al panel dispuesta en su parte posterior. Por consiguiente, esta placa se podía fijar en una de las tres posiciones que se habían hecho mediante pares de ranuras laterales en los niveles de $51 \mathrm{~mm}, 89 \mathrm{~mm}$ y $127 \mathrm{~mm}$. La corriente de aire se conducía por medio de un ventilador 
eléctrico DC (24V) a través del conducto de refrigeración, entre la placa metálica fijada y el módulo PV.

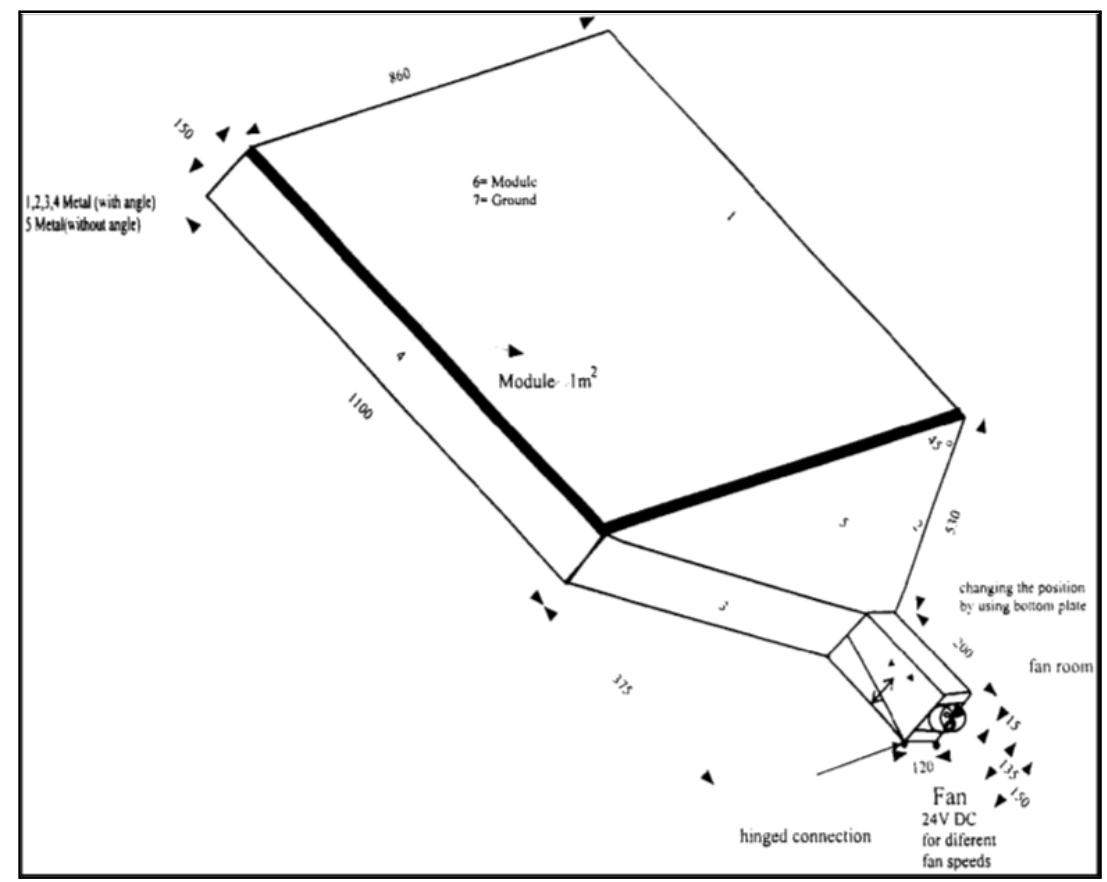

Figura 2.27 Modelo del conducto de aire para refrigerar el módulo PV [22].

De los resultados experimentales obtenidos en este trabajo, se aprecia que el efecto de las altas temperaturas de funcionamiento del módulo, es una reducción de la tensión de circuito abierto, tensión final de la curva I-V, y un muy ligero aumento de la corriente a bajos y nulos voltajes. Además, se hace notar un aumento de la potencia con el aumento de la tensión del módulo PV después de refrigerarlo. Sweelem et al.[22] concluyen que esta técnica tiene un efecto poco claro para los pequeños sistemas fotovoltaicos y sí tiene una gran respuesta para un gran sistema PV. Este modo de refrigeración se hace más efectivo si la velocidad del ventilador está controlada así como su funcionamiento y alimentación. Alternativamente, señala que la refrigeración por aire forzado, es muy eficaz en sistemas de energía solar convencional e incluso para uso doméstico, consiguiendo no sólo aumentar la potencia de salida y la eficiencia del módulo, sino que además permite utilizar la salida de aire caliente para el aire acondicionado de la casa o alimentar otras cargas térmicas.

También podemos encontrar como Kern et al. [23] presentaron el diseño y el rendimiento de sistemas PV/T enfriados por agua y aire, mientras que Hendiré et al.[24] y Florschuetz et al.[25] incluyen los sistemas PV/T de modelos en sus obras. Kalogirou et al.[26] ha llevado a cabo los sistemas híbridos, mediante convección forzada consiguiendo aumentos de la eficiencia del $2,8 \%$ hasta $7,7 \%$, con un rendimiento térmico del $49 \%$. Análogamente Lee et al.[27] y Chow et al.[28] dan interesantes resultados de la modelización de los módulos fotovoltaicos refrigerados por aire. 


\subsubsection{OTRAS TÉCNICAS:}

Con el fin de enfriar a los módulos fotovoltaicos, evitando que alcancen altas temperaturas, lo que significa una disminución de la eficiencia, se han estudiado diferentes técnicas a las mencionadas anteriormente.

Brogen et al. [17] utilizaron una cadena de módulos con celdas laminadas con aletas de cobre y con un tubo de agua soldado en la parte posterior, como método de evacuación de calor. El empleo de un difusor de calor, de aluminio y $3 \mathrm{~mm}$ de espesor, adjunto al módulo fue propuesto por Araki et al. [29].

Por otra parte encontramos que Farahat et al. [30] utiliza el método de refrigeración por evaporación basado en la teoría de los tubos de calor, de modo que diseñó el módulo PV con un control de gas de tuberías de calor, con diferentes variaciones en la forma del evaporador.

Para otra aplicación totalmente diferente, Infield et al. [31] obtiene un coeficiente de pérdida de calor y un factor de ganancia de energía térmica para la ventilación vertical del módulo PV con doble acristalamiento en los módulos PV de fachadas. Con esta ventilación se asegura que la eficiencia eléctrica del módulo es mejor debido a la baja temperatura, por debajo de $45^{\circ} \mathrm{C}$.

Otros estudios se centran en la mejora de la eficiencia de los módulos PV haciendo uso del efecto Stabler-Wronski (1977), basándose en que las células de silicio amorfo hidrogenadas poseen una mayor eficiencia que el resto aunque también se ven algo afectadas negativamente por las altas temperaturas. En un último estudio de la Universidad de Siria [32], se demostró que las células de silicio polimorfo hidrogenado tienen una mejor eficiencia y un mejor factor de llenado para un mayor rango de temperaturas en comparación a las células de silicio amorfo hidrogenado. Estos avances nos plantean nuevas alternativas que solventen el problema que suponen las elevadas temperaturas en los paneles fotovoltaicos. 


\subsection{INTEGRACIÓN DE LOS PANELES SOBRE CUBIERTAS}

Desde que se construyó la primera instalación con integración fotovoltaica en 1991, la integración fotovoltaica en edificios (BIPV) se ha convertido en uno de los segmentos de mercado con mayor crecimiento en la industria fotovoltaica [33].

En la última década, el desarrollo de elementos para cubiertas fotovoltaicas ha sido excepcional. Estos esfuerzos no se limitan a la mera mejora de los métodos de integración de los módulos fotovoltaicos estándar, sino que se dirige también hacia la producción de los elementos fotovoltaicos apropiados que podrían sustituir las tejas. Se ha demostrado que las estrategias actuales para la verdadera integración de elementos fotovoltaicos como tejas o cubiertas utilizando la estructura del edificio con pendiente son limitados. Sin embargo, existen importantes actividades en curso en lo que se refiere a la investigación y el desarrollo de diferentes sistemas de integración de cubiertas fotovoltaicas.

Si la demanda de energía eléctrica de muchos países se complementará con la utilización de la energía fotovoltaica, sería necesario integrar sistemas fotovoltaicos en la cubierta del edificio. Esto es esencial en países como Gran Bretaña y Alemania, donde hay una enorme presión sobre el uso del suelo y las superficies de edificios que cuentan con áreas relativamente libres.

La integración de la energía fotovoltaica tanto en los techos doméstico como comerciales, ofrece el mayor mercado potencial para la energía fotovoltaica. En los últimos cinco años la producción de células solares ha aumentado rápidamente en todo el mundo seguido de diferentes programas nacionales y la aplicación de la construcción de sistemas fotovoltaicos integrados. El desarrollo de las tecnologías en techos fotovoltaicos ha recibido mucha atención y la introducción de un subsidio para el costo del sistema y producción de energía, especialmente en Japón y Alemania se ha favorecido la demanda de azoteas con sistemas fotovoltaicos.

Sin embargo, en muchos de estos programas los módulos fotovoltaicos estándar se utiliza como elemento de cubierta en contra de la noción tradicional de la utilización de tejas para tejados. Los techos tradicionales no son estructuras estáticas y uniformes por ello no son idóneos para estos módulos que requieren unas estructuras precisas para su montaje e instalación. Hasta la fecha, son varios los intentos en la fabricación de tejas fotovoltaicas. La teja fotovoltaica ideal sería una que podría adaptarse a los actuales tejados, incluyendo su facilidad en la instalación e integración y proporcionara el efecto estético del escalonado igual que o ofrecen las tejas normales.

A continuación se presenta una revisión de algunas de las tecnologías existentes para cubiertas fotovoltaicas con especial énfasis en los que se encuentran en el Reino Unido [34]. 


\subsubsection{TECNOLOGÍAS FOTOVOLTAICAS SOBRE CUBIERTAS}

En cuanto a la exigencia de un usuario final, el sistema fotovoltaico ideal para cubiertas será aquel que tenga el mismo desgaste y propiedades estéticas que las tejas tradicionales, de modo que deberá cumplir las siguientes características:

- Ser fácilmente incorporados en cualquier diseño de la vivienda, formando la cubierta requerida y siendo tan duraderos como tejas tradicionales.

- La instalación del sistema fotovoltaico en cubierta deberá cumplir con la actual reglamentación y normas de construcción y debe llevar el mismo tiempo para su instalación que una cubierta normal.

- El conexionado eléctrico debe cumplir con el reglamento correspondiente, sin complicaciones añadidas en cuanto al tipo de conectores, cables y seguridad.

- El sistema fotovoltaico debe ser proporcionado de tal forma que ofrezca un fácil mantenimiento, seguimiento y las reparaciones necesarias.

En ausencia de un sistema tan idealizado, hoy en día, las instalaciones fotovoltaicas para tejados que se encuentran disponibles en el mercado, están comprometidas en una o más de las características anteriores. Los nuevos sistemas desarrollados abarcan módulos PV adaptados y tejas fotovoltaicas que en muchos casos requieren la reconfiguración o reingeniería de la estructura del tejado. Basándonos en el estudio llevado a cabo por AbuBakr et al. [34] algunas de las soluciones de éxito son las siguientes.

\subsubsection{Cubiertas fotovoltaicas instaladas en tejados inclinados}

Para cubiertas inclinadas, existen distintos sistemas de anclaje desarrollados que permiten o no dar el efecto estratificado de los paneles en la cubierta, para mantener los módulos fijados a la estructura del techo.

El sistema de anclaje puede estar formado por perfiles de aluminio fijados directamente a la estructura del tejado, recogiendo en ella los módulos que reemplazarán las tejas o la utilización de un sistema de anclaje fijo por debajo de tejas existentes. La mayoría de estos sistemas utilizan tornillos para fijar la estructura la cual se puede ajustar a diferentes pendientes, entre $20-50^{\circ}$ con la horizontal, y algunas también tienen ajustes de altura, aumentando la separación de los paneles con la cubierta inferior.

Un sistema de readaptación comercializado por BP Solar representa la mayoría de los sistemas instalados en el Reino Unido [35], este diseño se muestra en la siguiente figura. 

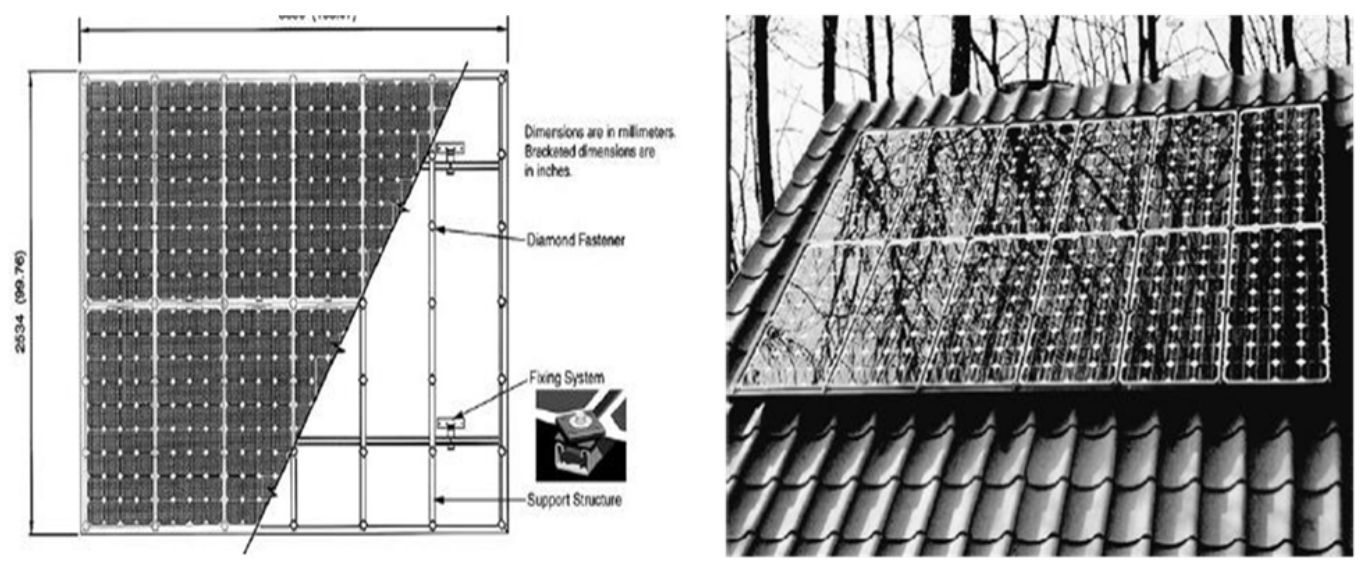

Figura 2.28 Descripción de los sistemas fotovoltaicos sobre un tejado [35].

En esta instalación, el sistema de anclaje se fija a las vigas del techo, sin penetrar en el tejado. Los perfiles de aluminio se fijan a dicho sistema y los módulos están sostenidos por las sujeciones que los fijan a la estructura. El uso de este diseño resulta ser una instalación con un rápido montaje sin el uso de una grúa.

Múltiples proyectos de integración fotovoltaica sobre diferentes tipos de cubiertas han sido desarrollados y aplicados en varias ciudades de China (Shandong, Shanxi y Heilongjiang). Para tejados inclinados de viviendas, Guoguang et al. [36] presentan una tecnología como alternativa que reemplaza la construcción de tejados tradicionales y habiéndose demostrado ser una tecnología sencilla, no muy costosa y efectiva.

En el diseño de este sistema se debe reformar la estructura que presenta el marco de los paneles fotovoltaicos con el fin de evitar cualquier fuga de agua entre ellos al igual que se deben añadir diversos elementos de fijación y canales para evacuar el agua de lluvia. En la siguiente figura se puede apreciar el proceso de ingeniería que se llevó a cabo para formar el sistema completo de integración fotovoltaica en la cara sur del tejado de un edificio. En ella se incluye la instalación de la estructura base en la cubierta (Figura 2.29a), instalación de travesaños (Figura 2.29b), fijación de canales de evacuación del agua (Figura 2.29c) y la colocación de los paneles fotovoltaicos (Figura 2.29d). 


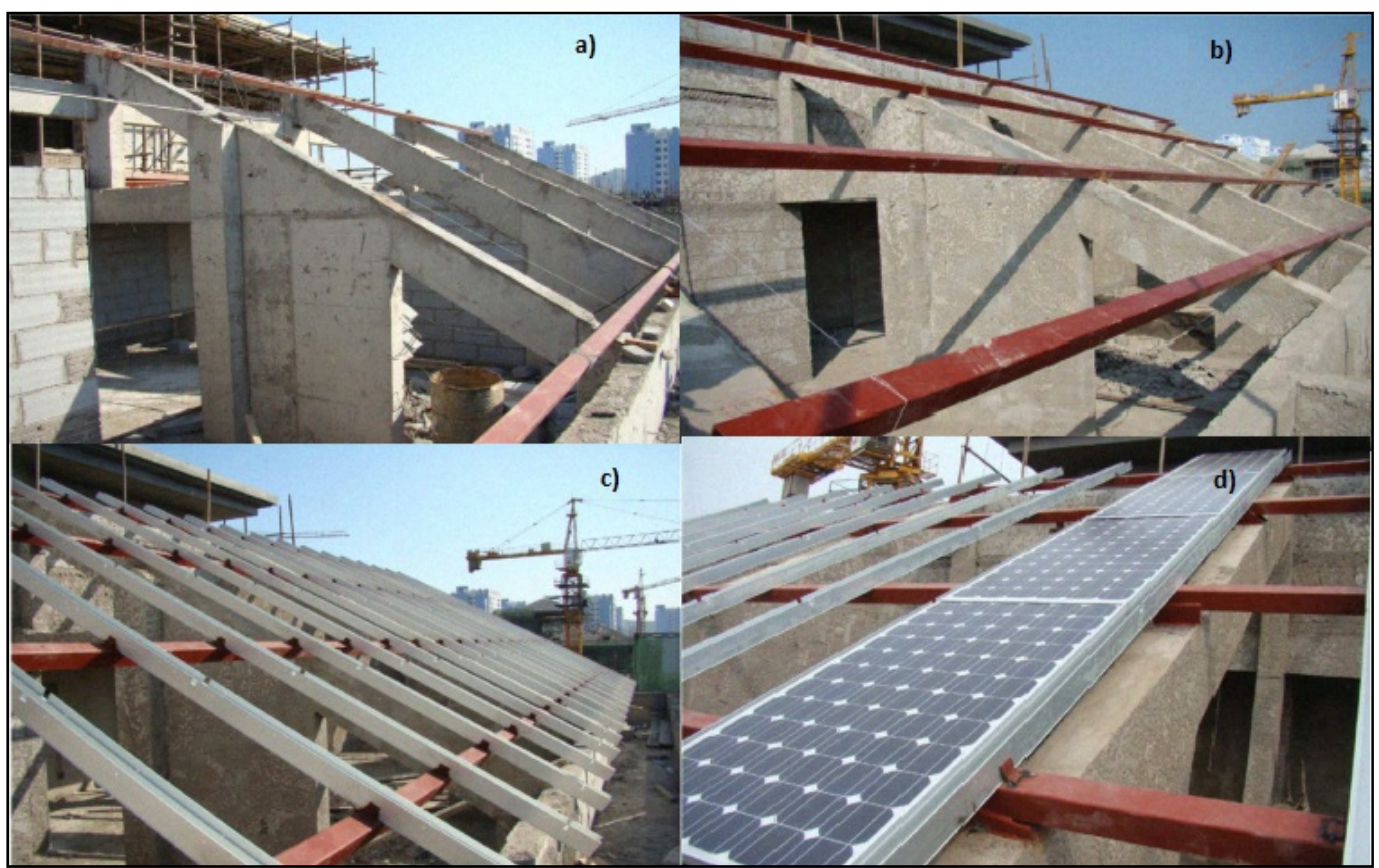

Figura 2.29 Proceso de ingeniería de la integración fotovoltaica en la cara sur de un edificio de China [36].

Esta nueva tecnología instalada en China es un sistema de integración sencillo, con un coste no muy elevado y presentando una buena estética arquitectónica. Este proyecto fue promovido por un plan subvencionado por Ministerios de Finanzas, de Ciencia y Tecnología junto a la Oficina Nacional de Energía de China, para acelerar el desarrollo de las empresas de generación de electricidad fotovoltaica y la comercialización de esta tecnología. El aspecto final que presenta la integración de esta tecnología sobre el tejado se muestra en la figura 2.30 .

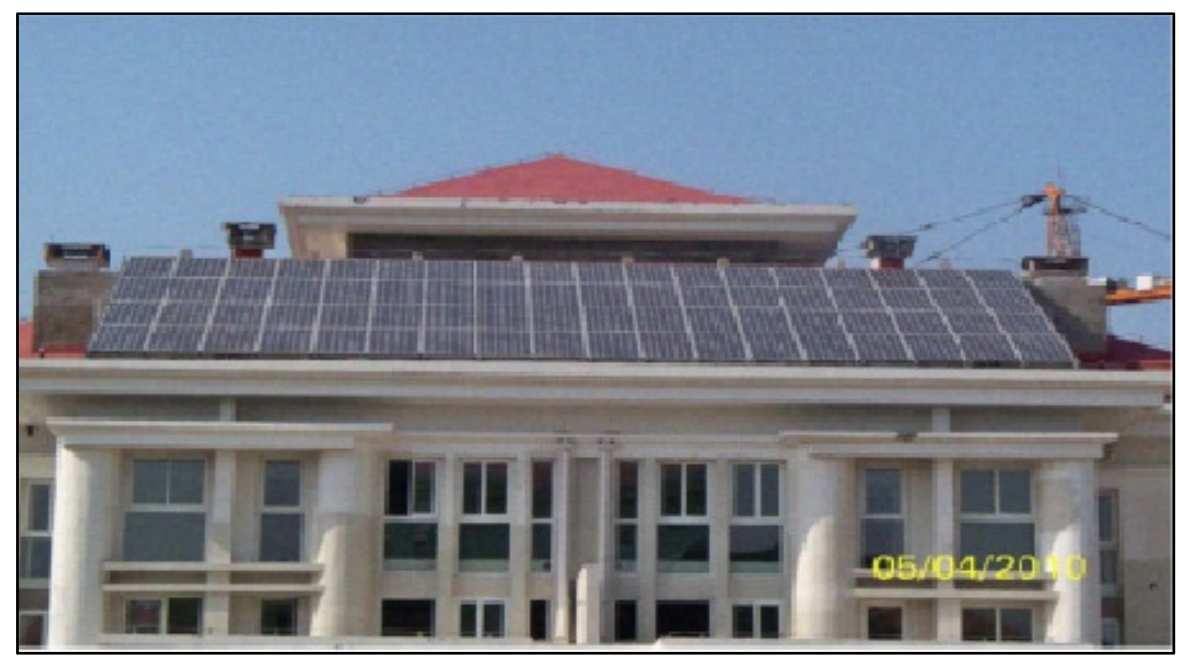

Figura 2.30 Vista global de la integración fotovoltaica sobre la cara este de la cubierta de un edificio en China [36]. 


\subsubsection{Cubiertas fotovoltaicas instaladas en tejados planos}

Hay muchos ejemplos de la energía fotovoltaica y sistemas de montaje para tejados planos. Pero podemos destacar los sistemas que integran los paneles fotovoltaicos en toda la cubierta, totalmente adheridos a una membrana de cubierta y los que requieren una estructura soporte para su montaje.

Para una total integración de cubiertas planas, sin estructuras soporte, los paneles fotovoltaicos de capa fina laminada son los más utilizados por ser flexibles, ligeros y de pequeño espesor ( $3 / 16$ pulgadas) además de adherirse perfectamente a cualquier material metálico o malla sobre la cubierta, un ejemplo son los IB Solar Wise. Este sistema de integración también es utilizado en las cubiertas inclinadas. Esta opción de integración fotovoltaica sobre tejados elimina dos puntos débiles; al estar totalmente adheridos a una malla o membrana de PVC en la cubierta evita las posibles goteras y además posibles problemas por levantamiento del viento. Además, hay que resaltar que los materiales utilizados para dicha integración son de mejores calidades que los de los tejados convencionales, ofreciendo un buen mantenimiento y una larga vida (40 - 50 años). Los costes globales de estos sistemas sobre cubiertas no son muy elevados, son considerablemente menores que si se instalara un tejado y una planta solar por separado. A pesar de ello, si presenta alguna limitación dado que este sistema de integración no permite variar la inclinación del panel, de modo que es más adecuado para cubiertas planas ubicadas en zonas cercanas al cinturón solar para provechar mejor las horas de sol y evitar la presencia de nieve en invierno que conllevaría la reducción de la producción eléctrica así como posibles daños.

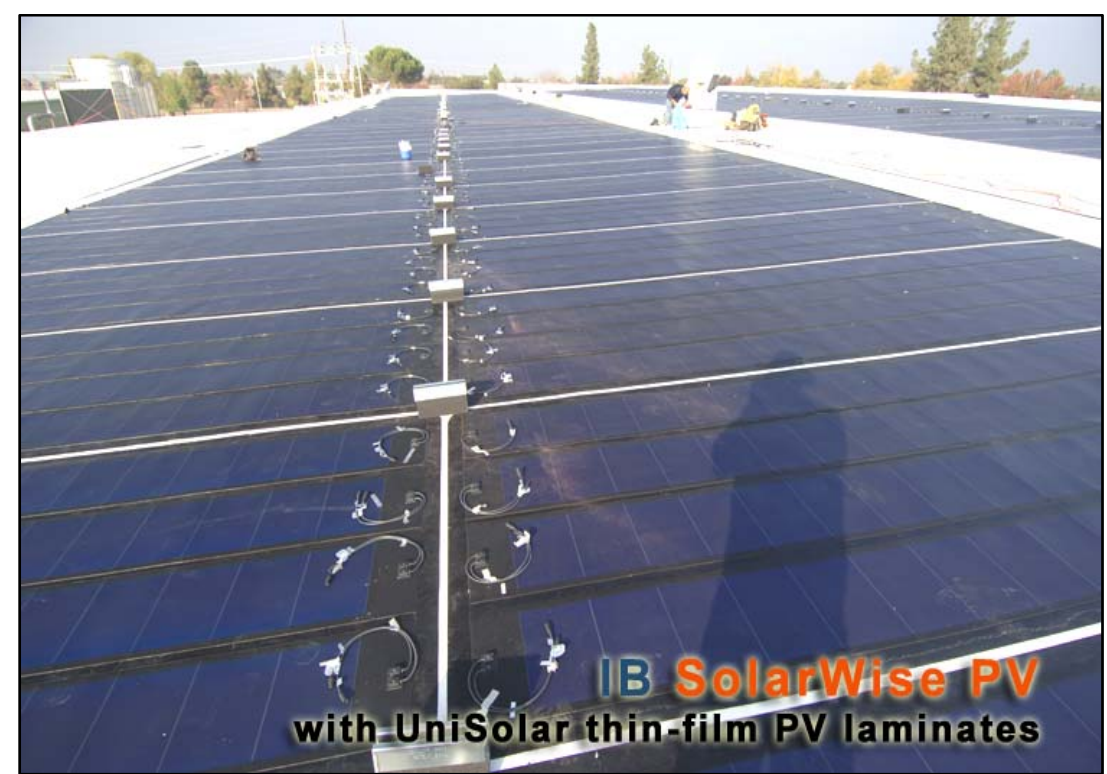

Figura 2.31 Integración de paneles laminados de película fina sobre una cubierta plana. 
Otra opción también muy utilizada consiste en fijar los módulos fotovoltaicos a una estructura que a su vez, ésta tiene que estar anclada a la cubierta plana del tejado. Este sistema de incorporación fotovoltaica sobre tejados planos es más propensa a las goteras, ya que existen espacios entre la cubierta y la estructura de anclaje del panel en los que el agua o bien va fluyendo poco a poco por el desagüe o se queda sobre la cubierta hasta su evaporación. Existen diferentes sistemas de fijación de paneles fotovoltaicos sobre cubiertas planas a base de estructuras metálicas, bloques de hormigón e incluso sistemas que permiten ajustar su ángulo para maximizar la producción según la temporada. Un aspecto importante hay que tener en cuenta, el peso, que puede presentar ciertos problemas si no nos aseguramos de que el techo es capaz de soportar este peso adicional.

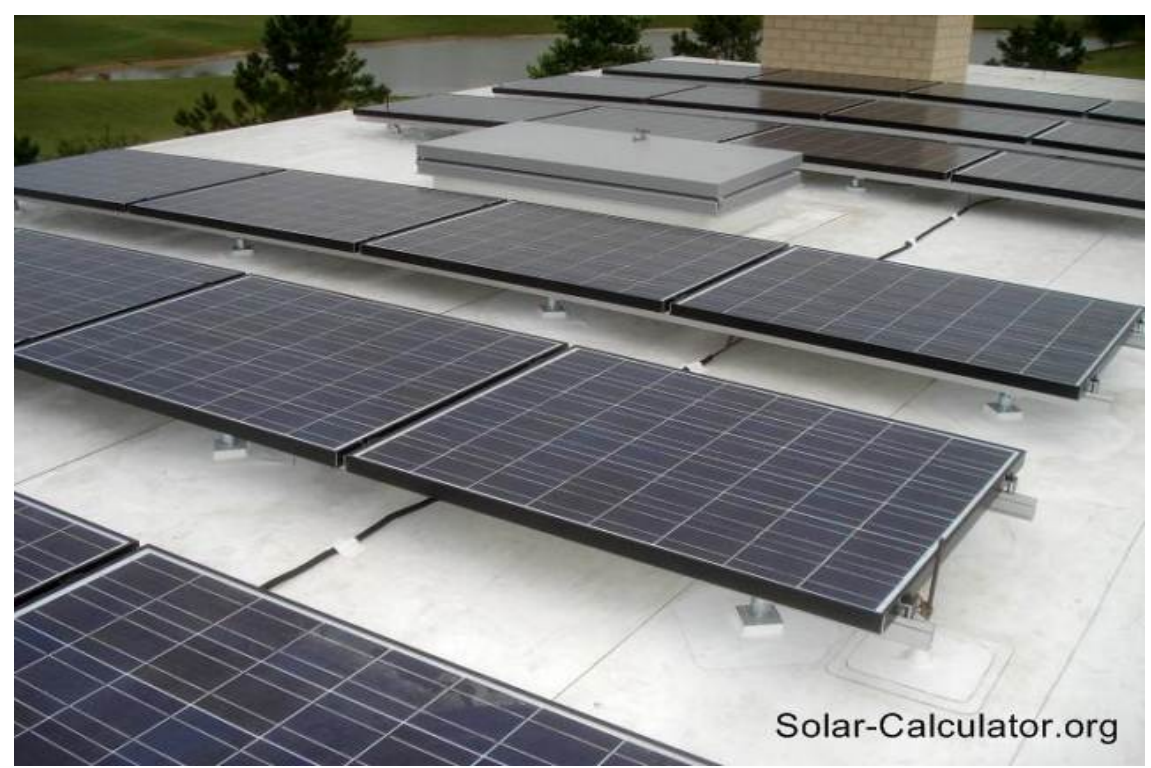

Figura 2.32 Sistema de fijación de paneles PV sobre cubierta plana.

Un ejemplo innovador de un sistema desarrollado para tejados planos de montaje se basa en un bloque macizo de hormigón para lograr la resistencia a la carga de viento. Estos sistemas están limitados en el uso, pero puede proporcionar una solución en la utilización de energía fotovoltaica en tejados planos de las unidades industriales, fábricas, hospitales y tal vez las escuelas siendo ecológico, generando energía limpia y renovable. La ventaja de este sistema se debe a los bajos costos de la estructura de montaje y facilidad de instalación.

\subsubsection{Tejas fotovoltaicas para tejados}

Las primeras tejas fotovoltaicas Europea para la cubierta se desarrolló en Suiza, denominada como Newtec [34]. Cada una contiene 24 células monocristalinas con una potencia nominal de $36 \mathrm{Wp}$. Las tejas se instalan directamente sobre los travesaños de madera del tejado inclinado convencional. Cada teja fotovoltaica Newtec reemplaza 
cuatro tejas convencionales planas como se muestra en la Figura 2.33 y están ventiladas por la corriente de aire natural que circula por detrás de la cubierta de tejas.

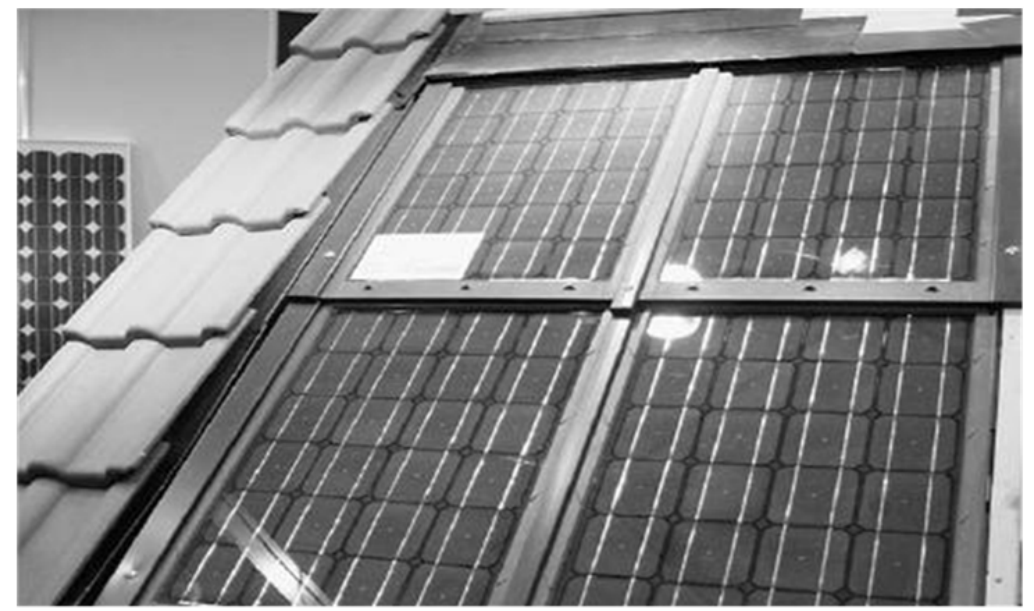

Figura 2.33 Sistema fotovoltaico basado en módulos que sustituyen el tejado convencional [34].

Estos sistemas de cubierta fotovoltaica se encuentran ventilados por convección natural, gracias al aire que circula por detrás del tejado de tejas. Un conjunto de piezas metálicas adicionales son necesarias para integrar las tejas fotovoltaicas y unirlas entre ellas. Tales sistemas fotovoltaicos no dan el efecto escalonado que normalmente ofrecen los tejados tradicionales.

Un sistema que fue desarrollado a través de un programa japonés, que tuvo un informe regular de impacto visual de módulos fotovoltaicos ha ganado mucha popularidad en el país. Sin embargo, el sistema requiere los perfiles de aluminio para la fijación de los módulos estándar, la perforación de agujeros para la ventilación y elementos de estanqueidad para evitar que penetre el agua entre los módulos.

El tamaño de cada módulo fotovoltaico especial es la mitad de una unidad de medida "tatamiarchitectural" en Japón. El sistema estructural se ha diseñado con una superposición para formar una superficie impermeable con unos $10 \mathrm{~cm}$ de espacio de ventilación entre el marco del módulo y la estructura del tejado. Aunque el sistema no se integra sobre las tejas normales, este techo fotovoltaico logra un aspecto agradable a pesar del complicado proceso de instalación (Figura 2.34). 


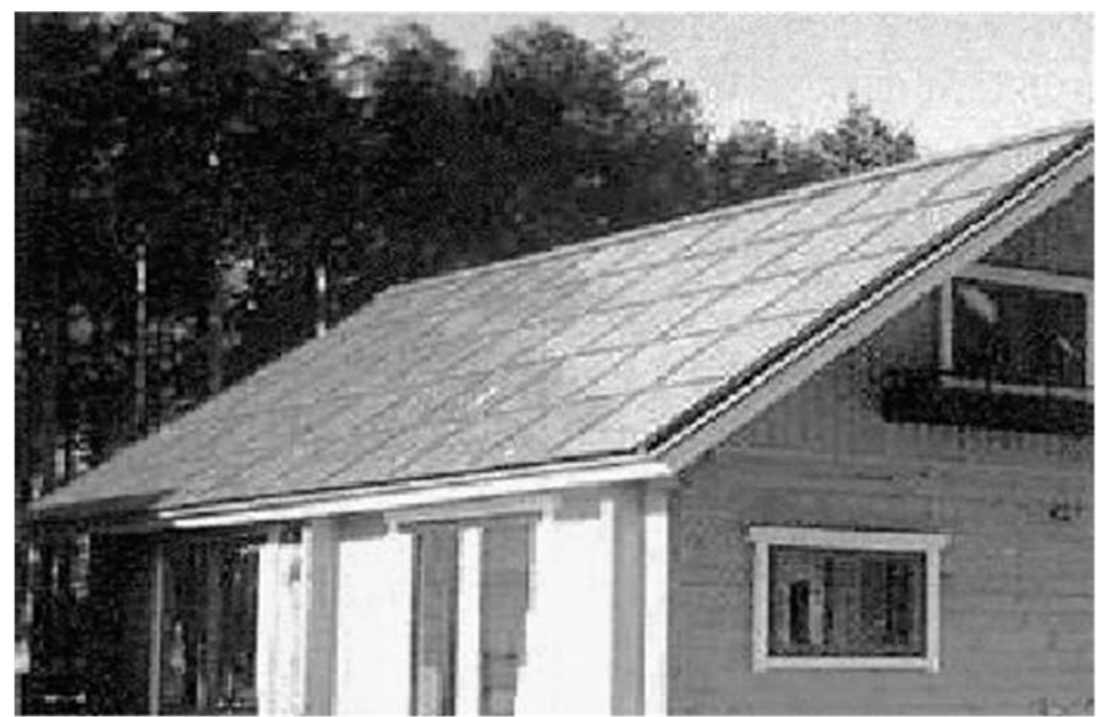

Figura 2.34 Tejado fotovoltaico originario de Japón, ubicado sobre la cubierta inclinada [34].

Los diferentes sistemas desarrollados y promovidos en Japón consisten en reemplazar los materiales de los tejados por tejas fotovoltaicas, las cuales se instalan directamente sobre la estructura del tejado, añadiendo algunos accesorios de fijación. Sin embargo, estas tejas fotovoltaicas requieren ciertas superficies (45 Wp por teja) lo que suponen reemplazar múltiplos de 4 tejas planas por cada una fotovoltaica.

Las tejas fotovoltaicas de cerámica ofrecen un nuevo enfoque a la integración de células solares en los tejados inclinados. Tales tejas fueron diseñadas para funcionar como un tejado de pizarra. Hay dos tipos, el primero se basa en material cerámico gris en la que las células solares monocristalinas están laminadas directamente lo que permite una zona libre para la superposición de tejas en forma de escamas de pescado. Las tejas fotovoltaicas se fijan directamente con tornillos en los travesaños de madera de la estructura del techo. El segundo es un producto para tejados elaborado sobre la enorme base de un tejado de fibra de cemento, común en Suiza.

Un desarrollo reciente en Europa se basa en la utilización de módulos de gran tamaño para reemplazar múltiples tejas. En dicho sistema de integración un elemento fotovoltaico se compone de una lámina de vidrio-vidrio colocado en una bandeja de plástico como apoyo, sujeto al techo por las fijaciones de acero inoxidable. Este último incluye las barras de refuerzo con los soportes de gancho en la base inferior de las bandejas. El módulo con $35 \mathrm{Wp}$ de potencia nominal sustituye a cuatro tejas, se fija en las bandejas y está integrado de forma homogénea en la estructura tradicional del techo, como se muestra en la Figura 2.35. 


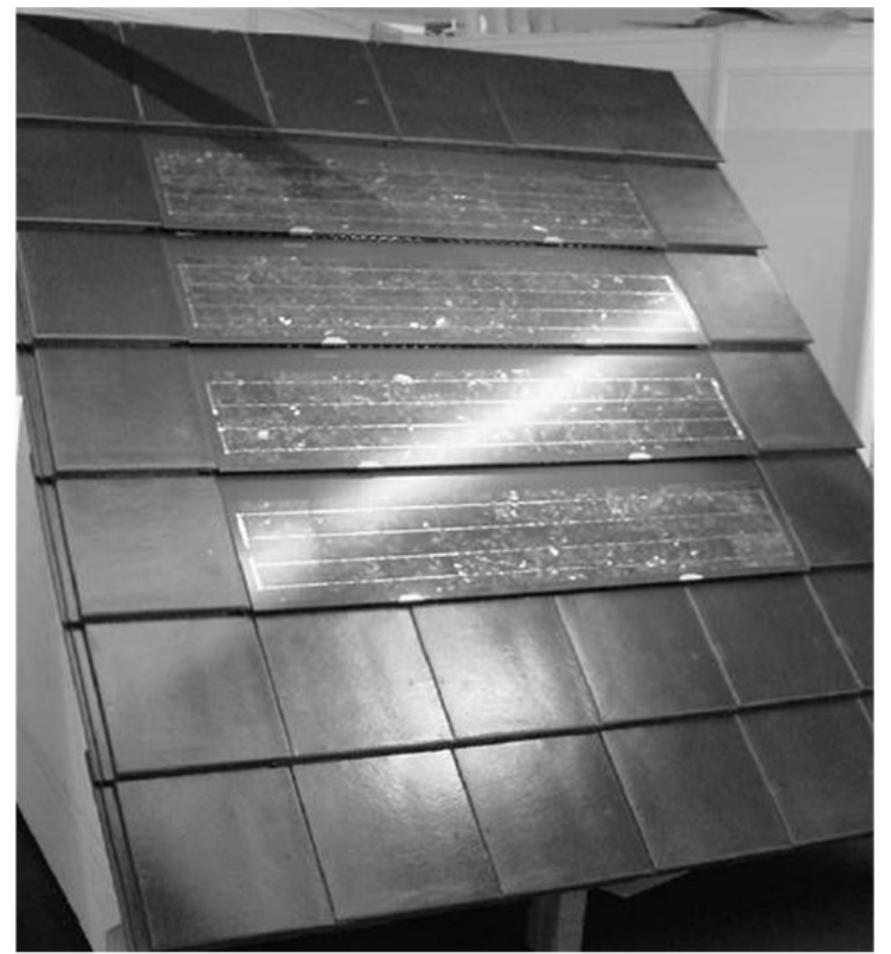

Figura 2.35 Módulo fotovoltaico de $35 \mathrm{Wp}$, sustituyente a cuatro tejas convencionales [34].

Otro sistema fotovoltaico que ha sido ampliamente difundido en el Reino Unido, consiste en una película delgada que puede ser enrollada en el techo como una alfombra. El componente fotovoltaico desarrollado en los EE.UU. consiste en una célula de silicio amorfo de triple unión. El silicio de película delgada se deposita mediante un proceso de enrollado sobre un sustrato de metal y se incorpora en un material plástico de protección (Tefzell), teniendo una eficiencia de $7.8 \%$. Dado que el producto es flexible, permite su fácil adaptación a muchos materiales de tejados. El sistema resultante como cubierta es multifuncional, produciendo electricidad y sirviendo como aislamiento de cubiertas. Este producto ofrece un agradable aspecto manteniendo el efecto de tejados tradicionales, mediante la colocación de 12 células solares amorfas en una sola pieza de plástico con un área de superposición de células libres en la parte superior.

El resumen presentado con las diferentes tecnologías de tejados fotovoltaicos muestra el desarrollo de elementos de cubierta fotovoltaica en la última década. Los esfuerzos no se han limitado a la mera mejora de los métodos de integración de los módulos estándares, sino que se dirige también hacia la producción de los elementos apropiados que podrían sustituir las tejas. Muchos de estos productos provienen de los programas nacionales que promueven el uso de la tecnología fotovoltaica.

En resumen, se han presentado los desarrollos y estudios actuales para la verdadera integración de elementos fotovoltaicos sobre la cubierta de edificios. Sin embargo, existen importantes actividades en curso de la investigación y el desarrollo de sistemas de y materiales que sustituyan las tejas tradicionales. 


\subsubsection{APROVECHAMIENTO FOTOVOLTAICO EN LA CUBIERTA DE INVERNADEROS}

Uno de los aprovechamientos estructurales fotovoltaicos que nos interesa y en el que se centra esta investigación es el de los invernaderos. Los invernaderos se construyen, generalmente, en lugares soleados, sin sombra debido a su necesidad de luz solar para la fotosíntesis de las plantas. Esto nos sugiere que una proporción de esa luz podría ser utilizada como fuente de energía eléctrica mediante la energía fotovoltaica y alimentar así los equipos necesarios para el mantenimiento de invernaderos.

En esa forma de aprovechamiento fotovoltaico, los módulos se instalan sobre las cubiertas utilizando así el terreno para cultivar y para producir la electricidad que sustituya a la procedente de combustible fósiles. El problema que se nos plantea es el siguiente: el invernadero está recubierto por plástico para que dentro del mismo se alcancen temperaturas altas necesarias para el cultivo, estas elevadas temperaturas en el interior afectarán a nuestros módulos fotovoltaicos ubicados en la cubierta, aumentando su temperatura de funcionamiento y reduciendo la producción eléctrica.

Por esta razón, nos centramos en estudiar y caracterizar la influencia de las altas temperaturas internas en el funcionamiento de los paneles, basándonos en una estructura real construida en la que existe un espacio libre de paso de aire entre el plástico de la cubierta y los paneles. Con estos resultados se pretende mejorar la configuración estructural cara a la construcción de próximos invernaderos con aprovechamiento fotovoltaico.

Uno de los estudios llevado a cabo basado en los invernaderos y la energía fotovoltaica es el realizado por el Instituto de Tecnología de la India en el que combina módulos fotovoltaicos y de energía solar térmica [37]. En este estudio se utiliza un invernadero real situado en Nueva Delhi (Figura 2.36) en cuyo interior se alcanzan temperaturas de $55^{\circ} \mathrm{C}$ en verano y de $40^{\circ} \mathrm{C}$ en invierno, a pesar de tener en el exterior unas temperaturas de 2 a 10 ${ }^{\circ} \mathrm{C}$ se llegan a conseguir unas cálidas temperaturas internas debido al efecto invernadero. Además, se utiliza un ventilador en el interior del invernadero para uniformizar la temperatura interna. 


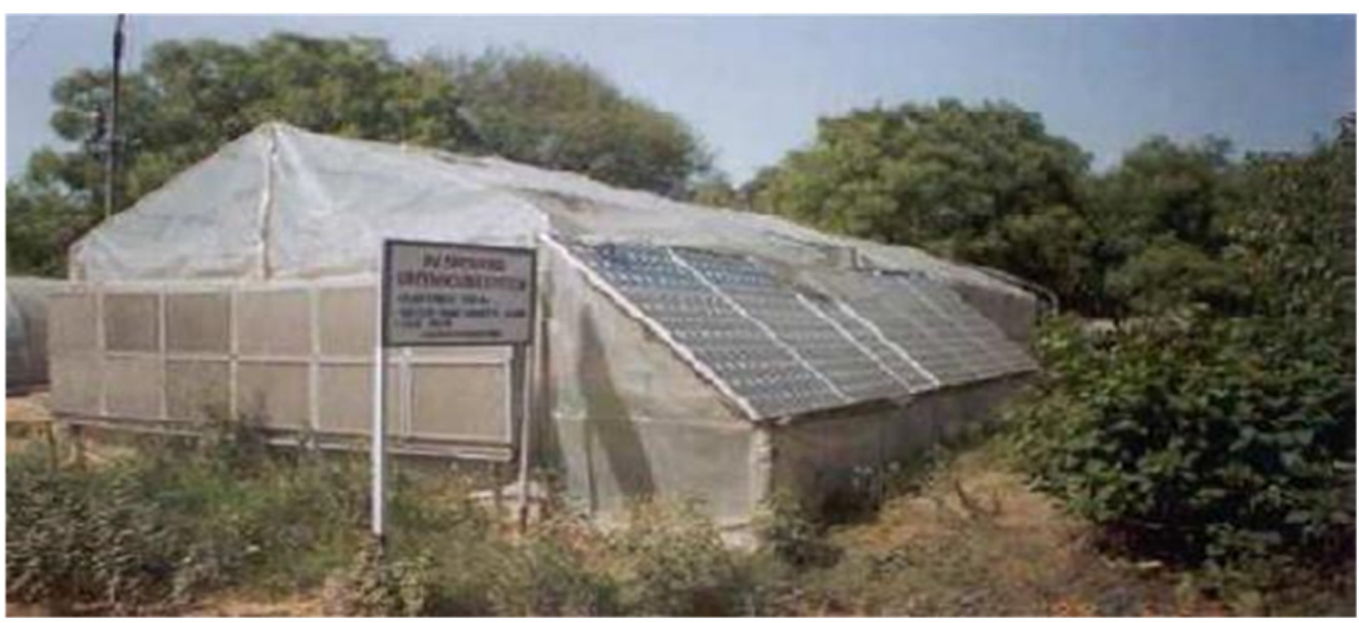

Figura 2.36 Invernadero de Nueva Delhi con módulos fotovoltaicos integrados [37].

Existe una concordancia entre los resultados experimentales y los teóricos referentes a la temperatura de los módulos que vienen representados en la Figura 2.37, en la que se muestra la evolución de la temperatura del panel a lo largo del día de ensayo. Apreciamos que ambas temperaturas del módulo, teórica y experimental, siguen una misma tendencia a lo largo del día, pero sus valores no coinciden. Así por ejemplo desde primera hora de la mañana la temperatura tiende a ascender hasta alcanzar su máximo a las 11 de la mañana, con un valor teórico de $81{ }^{\circ} \mathrm{C}$ mientras que el valor experimental medido es de $65{ }^{\circ} \mathrm{C}$ a la misma hora, por lo que los datos esperados son algo superiores a los experimentalmente medidos.

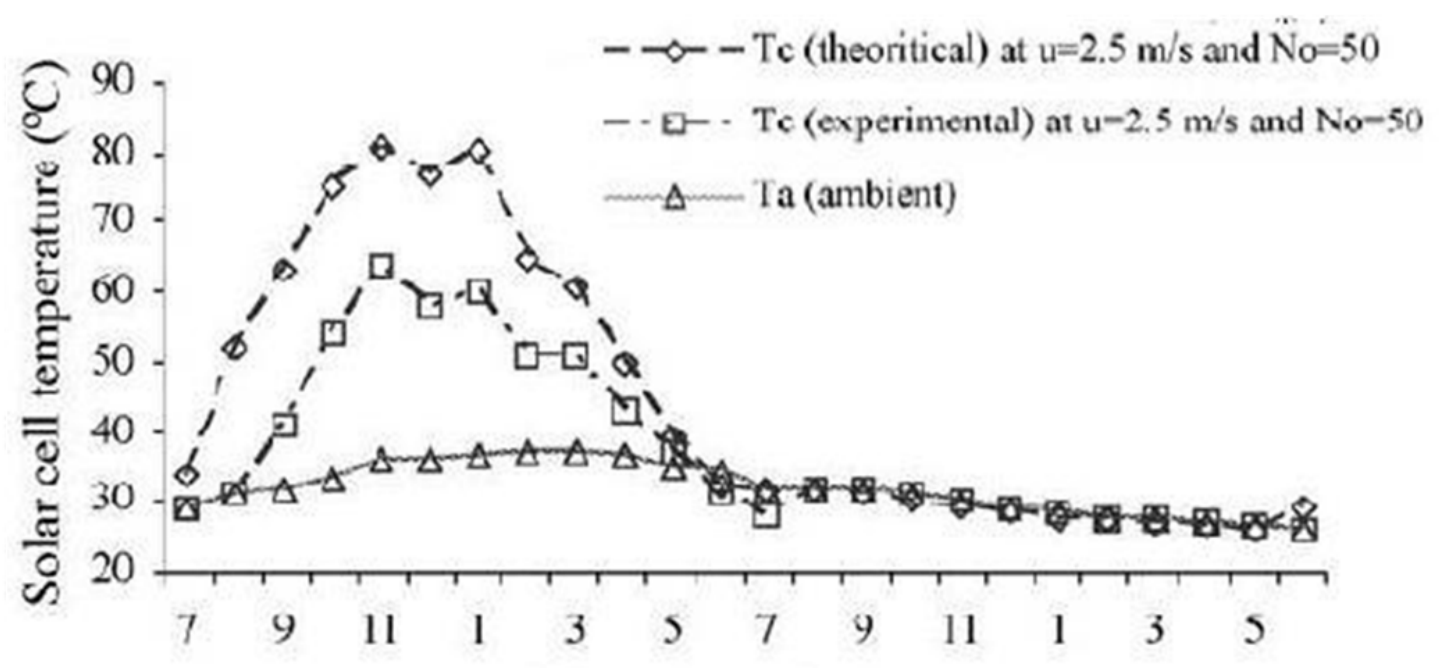

Figura 2.37 Temperatura experimental y teórica del panel PV a lo largo de un día [37].

A partir de los resultados experimentales medidos a lo largo de un día, se puede apreciar la evolución de la temperatura del panel fotovoltaico, en su cara posterior, respecto la temperatura del aire del interior del invernadero. De ellos se concluye que la temperatura real del módulo es $3-4{ }^{\circ} \mathrm{C}$ mayor que la de su cara posterior y alrededor de $15-16{ }^{\circ} \mathrm{C}$ mayor que la temperatura del aire del invernadero, en las horas de sol. En cuanto a la exergía 


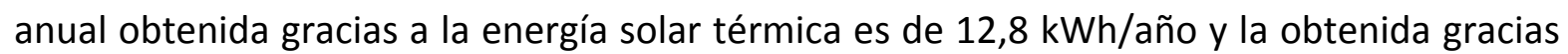
a la fotovoltaica es de 716 kWh/año. En el lugar donde se llevó a cabo el experimento, la exergía aportada por el Sol al invernadero es de $21291 \mathrm{kWh}$ por lo que obtenemos como resultado un rendimiento exergético de $4 \%$.

Otro estudio interesante basado en la integración fotovoltaica en invernaderos, se llevó a cabo en Japón [38], en el que se compara las ventajas e inconvenientes de colocar un módulo fotovoltaico en el exterior y en el interior de la cubierta de un invernadero al mismo tiempo que su mejor orientación e inclinación.

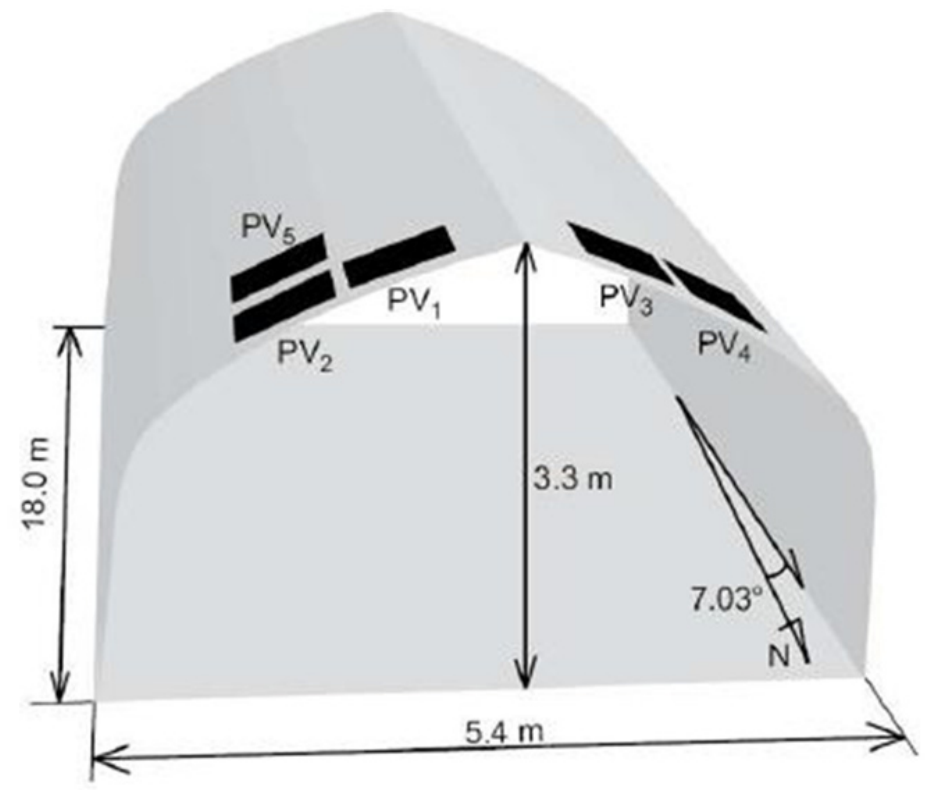

Figura 2.38 Esquema de ubicación de los módulos sobre el invernadero [38].

El invernadero de este estudio, cuyo esquema está representado en la Figura 2.38 , se encuentra ubicado de forma que la parte delantera esté orientada al norte, y por lo tanto, la parte trasera al sur. Como vemos en la figura anterior, los módulos PV1 hasta PV4 están instalados en el interior de la cubierta y PV5 en el exterior. PV1, PV2 y PV5 se encuentran en la cara este del invernadero, teniendo el primero una inclinación de $20^{\circ}$ y los dos últimos de $28^{\circ}$. En la cara oeste se ubican los módulos PV3 y PV4, con inclinaciones de $20^{\circ}$ y $28^{\circ}$ respectivamente.

Los resultados experimentales obtenidos de cada uno de los paneles a lo largo de siete meses, vienen representados en la siguiente figura. En ella, se representa mediante puntos la radicación solar de cada mes y mediante un diagrama de barras se representa la energía fotovoltaica obtenida para cada mes del año en el que se ha ensayado, correspondiéndose cada barra de izquierda a derecha en cada mes como la primera al módulo PV1, la segunda el PV2, la tercera PV3, la cuarta al PV4 y la última se corresponde con el módulo PV5. 


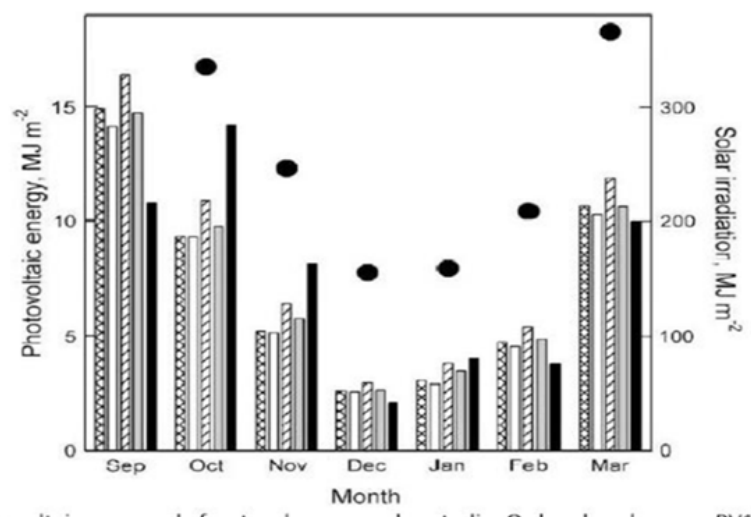

Figura 2.39 Energía fotovoltaica generada frente a los meses de estudio. Orden de columnas: PV1, PV2, PV3, PV4, PV5 [38].

Como se puede apreciar, los módulos de menor inclinación (PV1, PV3) generan mayor energía que los que se encuentran a $28^{\circ}$. Además, los módulos instalados con orientación oeste (PV3, PV4) deberían generar más energía que los de orientación este, cosa que no reflejan los resultados experimentales obtenidos y representados en la Figura 2.39, esto se debe a que la orientación del invernadero posee una desviación de $7,03^{\circ}$ respecto al eje norte sur. Entre los módulos fotovoltaicos instalados en el interior del invernadero, el módulo PV3 es el que más electricidad generó aunque se ve superado por el módulo PV5, que aún teniendo la desventaja de estar con una inclinación de $20^{\circ}$ y orientación este, se queda lejos del resto de resultados, mejorándolos considerablemente. No obstante, este módulo montado sobre la cubierta, presenta la desventaja de ser más vulnerable que el resto al estar expuesto a todo tipo de condiciones meteorológicas.

Guoguang et al. [36] presentan diferentes proyectos de integración fotovoltaica en diferentes instalaciones como una nueva alternativa a las cubiertas tradicionales. Dos invernaderos solares de $20 \mathrm{kV}$ se han construido en las ciudades chinas de Heihe en Heilongjiang y en Heze en Shandong.

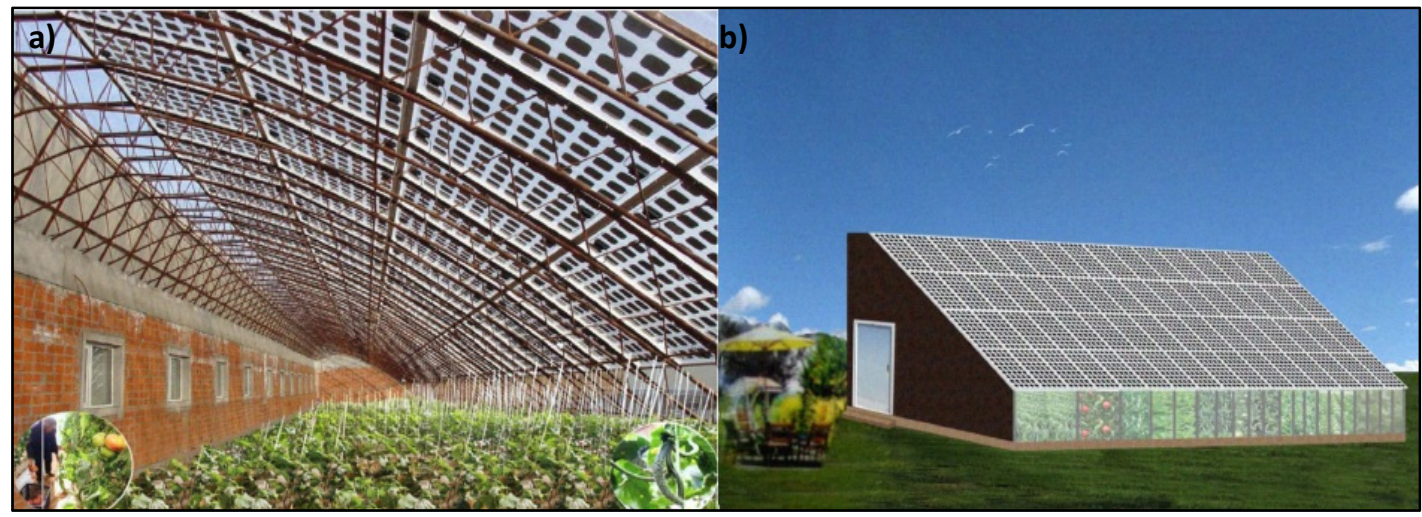

Figura 2.40 Proyectos de integración fotovoltaica en la cubierta de invernaderos en China. a) Vista del interior del invernadero solar en Heihe. b) Vista exterior del proyecto en Peony Garden en Heze [36]. 
En ambas instalaciones, parte de la luz natural se transmite al interior gracias al especial diseño de la cubierta en la que se dejan espacios entre cada célula, como se aprecia en la Figura 2.40a.

En el mismo trabajo presenta el mayor proyecto de integración fotovoltaica sobre cubierta en China, con $1 \mathrm{MWp}$ instalados. Este novedoso proyecto se encuentra en la ciudad de Weifang, Shandong y consiste en un moderno proyecto agrícola-energético, Figura 2.41. El hecho de llevarla a cabo se debe a que en la citada ciudad la radiación anual es de 5000$5800 \mathrm{MJ} / \mathrm{m}^{2}$, cantidad muy útil para generación fotovoltaica. Con esta instalación se pretende generar 1185,6 kWp (DC) con una eficiencia de 13,27\%, convirtiéndola posteriormente en corriente alterna y así vertiéndola a la red, obteniendo una suma anual de 1743000 kWh de electricidad generada.

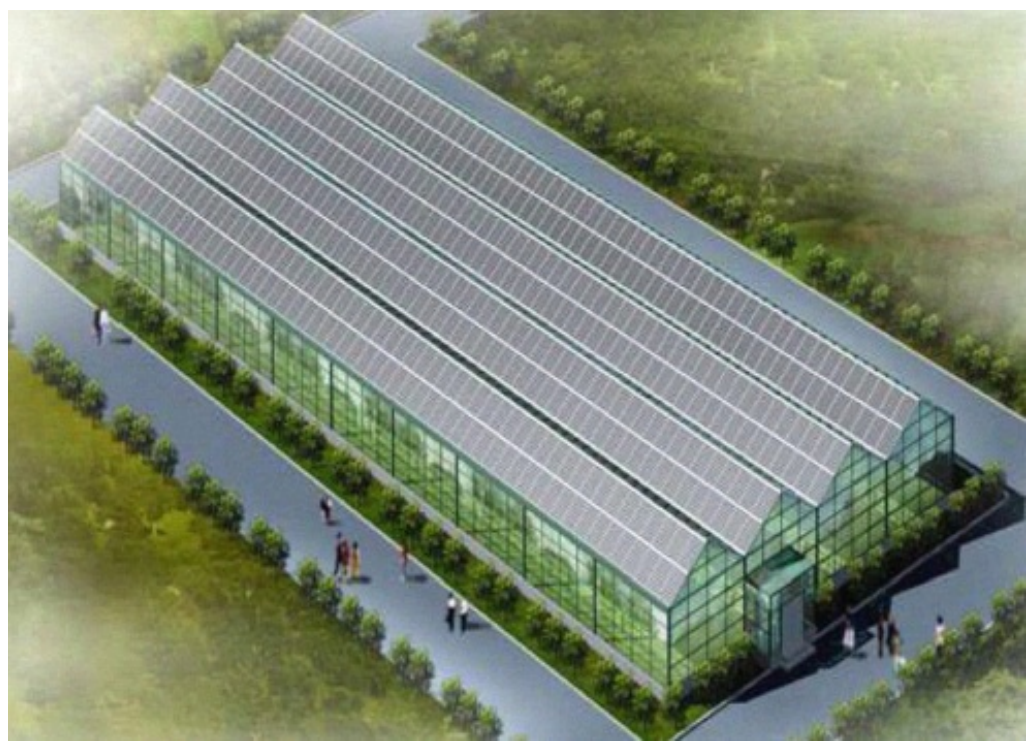

Figura 2.41 Boceto del diseño de una parte $(50 \mathrm{KW})$ del nuevo proyecto agrícola con integración fotovoltaica en la cubierta de 1MWp ubicado en la ciudad de Weifang, Shandong [36].

En la figura anterior se muestra una de las partes del nuevo proyecto de integración fotovoltaica en la cubierta de la instalación agrícola-energética, esta parte engloba $50 \mathrm{~kW}$ de los $1 \mathrm{MWp}$ instalados. Con su puesta en marcha se espera, no sólo generar energía eléctrica, sino una mejora en la contribución medioambiental, reduciendo 1737,8 toneladas de emisión de $\mathrm{CO}_{2}, 52,3$ toneladas de $\mathrm{SO}_{2}$ y 26,2 toneladas de $\mathrm{NO}_{x}$. 


\subsection{INFLUENCIA DE LA TEMPERATURA EN EL FUNCIONAMIENTO DE MÓDULOS FOTOVOLTAICOS}

Actualmente una célula fotovoltaica comercial no convierte más del $15-20 \%$ de la energía solar incidente en energía eléctrica, valores que dependen del tipo de célula. El resto de energía es tanto reflectada como absorbida en forma de calor, por consiguiente, si no se dispone de ningún medio eficaz de disipación de la energía absorbida, la acumulación de calor ocasiona un aumento substancial de la temperatura de funcionamiento de la célula. En la siguiente figura se muestra un esquema del intercambio de calor existente entre el módulo fotovoltaico y el ambiente [39].

Hoy en día, las células fotovoltaicas se utilizan en muy variadas aplicaciones, terrestres y constructivas, es por ello que generalmente se encuentran expuestas a valores de temperaturas de $10-70^{\circ} \mathrm{C}$, según la región en la que estén instaladas. En climas no muy fríos con buena radiación, los paneles suelen trabajar a altas temperaturas.

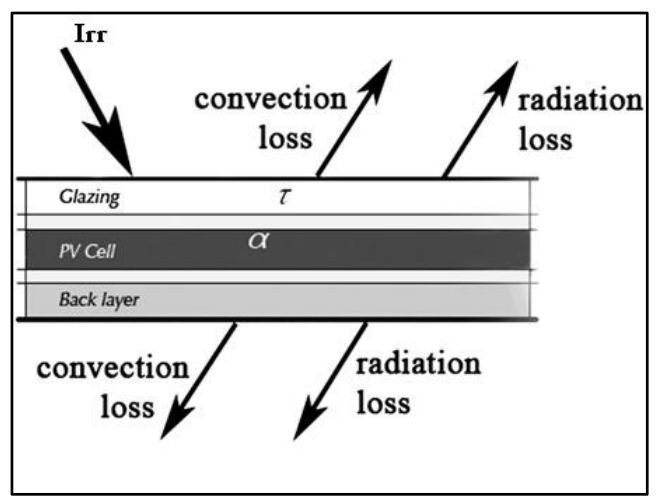

Figura 2.42 Esquema simple del proceso térmico de energía en un módulo fotovoltaico.

Altos valores de temperatura en los paneles fotovoltaicos, se traducen en un efecto negativo en sus parámetros eléctricos, tales como tensión de circuito abierto $\left(V_{o c}\right)$, intensidad de cortocircuito $\left(I_{s c}\right)$, factor de forma $(F F)$ y consecuentemente el rendimiento $(\eta)$, por lo tanto la temperatura juega un papel importante en el proceso de conversión de la radiación solar en energía eléctrica. Tanto el rendimiento como la potencia generada dependen de la temperatura de funcionamiento del panel, disminuyendo ambas con el aumento de ésta. La eficiencia en la conversión de energía desciende $0,4-0,5 \%$ por cada grado que asciende la temperatura [40]. Esta es la razón por la que muchos autores han estudiado diferentes técnicas que permitan la refrigeración de los paneles [41,42].

Las condiciones ambientales, como son la temperatura, radiación solar y el viento, también influyen en el comportamiento de los módulos fotovoltaicos instalados. Dentro de un amplio margen de funcionamiento, la fotocorriente generada por cada célula solar es directamente proporcional a la intensidad de la radiación incidente. Pero aparte de esta influencia, la radiación solar, el viento o la propia temperatura ambiente, afectan al panel fotovoltaico 
modificando su temperatura y ésta a su vez provoca como veremos una alteración de las variables de los módulos.

La temperatura de funcionamiento de las células solares es función de la temperatura ambiente, conductividad del material, características eléctricas del módulo $\left(I_{o}, I_{S C}, V_{o c}, F F\right.$, $\left.P_{m}\right)$, la intensidad de la radiación solar incidente en el módulo, y de otras variables que se verán en el siguiente apartado.

Se ha estudiado que la eficiencia en la conversión de las células fotovoltaicas, se traduce en un descenso de la potencia generada cuando la temperatura de la célula es elevada. Este fenómeno, según Maycock y Stirewalt [43] es más pronunciado en células de silicio que otras células, como el arseniuro de galio. Además, la física cuántica demuestra que el aumento en la conductividad de un semiconductor es directamente proporcional a la temperatura. En la banda de conducción de un semiconductor, la conductividad, $n$, (entendida como el número de electrones que circulan por la célula) depende de manera decisiva de la temperatura, como lo demuestra la fórmula.

$$
n_{e}=2 \cdot\left[\frac{2 \cdot \pi \cdot m_{e} \cdot k \cdot T}{h^{2}}\right]^{3 / 2} \cdot \exp \left(\frac{E_{f}-E_{c}}{k \cdot T}\right)
$$

Donde:

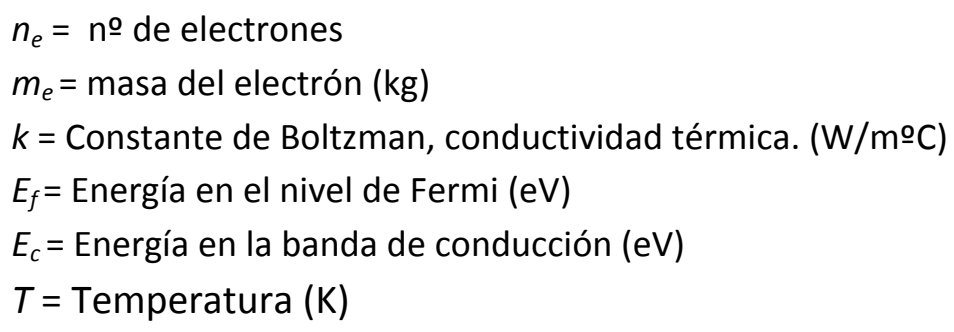

Este hecho parece sugerir que la conductividad de células PV como función de la temperatura sería limitada solamente por la alta temperatura que puede sostener, y por implicación también lo es la potencia de salida. Pero Maycock y Stirewalt [43] muestran que la potencia (eficiencia) de las células FV no sólo depende de la conductividad eléctrica, y que en ciertas condiciones de insolación, es inversamente proporcional a la temperatura. Esta relación inversa de la potencia de salida (eficiencia de conversión) con la temperatura se debe principalmente a la dependencia de la tensión de circuito abierto, $V_{o c}$, con la temperatura, de acuerdo con Angrist et al. [44-46].

La dependencia de la temperatura del panel con su comportamiento eléctrico difiere según el material constituyente de la célula. Aún así, podemos encontrar un gran número de correlaciones que expresan la dependencia de la eficiencia eléctrica de los módulos fotovoltaicos, en las que en la mayoría se asume la dependencia linear entre ambas variables 
y difiriendo tan sólo en los valores numéricos de los parámetros correspondientes al tipo de material o sistema de estudio $[47,48]$.

La principal dependencia de la temperatura de los módulos es con tres de las variables características que definen su comportamiento eléctrico [49]. Estas son; la intensidad de cortocircuito $\left(I_{S C}\right)$, que tiene la misma dependencia que la corriente fotogenerada $\left(I_{L}\right)$, la tensión de circuito abierto $\left(V_{o c}\right)$ que se define según el valor de la corriente de saturación $\left(I_{o}\right)$ y el factor de idealidad del diodo $(m)$ y el factor de llenado $(F F)$ que a su vez es función de la tensión de vacío, intensidad de cortocircuito y potencia máxima.

A continuación se muestra la relación de la temperatura con diferentes características o parámetros eléctricos del módulo fotovoltaico, para lo que debemos recordar la ecuación característica de la célula fotovoltaica(Ec. 1.1).

\section{A. FOTOCORRIENTE $I_{L}$}

La corriente fotogenerada $\left(I_{L}\right)$ aumenta ligeramente con la temperatura debido al aumento de las longitudes de difusión de los minoritarios y en parte al estrechamiento de la banda prohibida, que desplaza el umbral de absorción hacia fotones de menor energía. La mejora de la fotocorriente con la temperatura es más acusada en las células de GaAs que en las de Silicio pero, en todos los casos, la variación es muy pequeña.

\section{B. CORRIENTE INVERSA DE SATURACIÓN /s}

La corriente de saturación inversa es, como se mencionó en apartados anteriores, la corriente de fuga que se produce en la polarización inversa de la unión p-n y cuya dependencia con la temperatura viene dada por la siguiente ecuación:

$$
I_{S}=\beta \cdot T^{\gamma} \cdot e^{\left(\frac{-E_{G O}}{k \cdot T}\right)}
$$

Siendo $\beta, \gamma$ constantes y $E_{G O}$ el valor de la energía del ancho de banda prohibida a $0 \mathrm{~K}$.

\section{TENSIÓN DE CIRCUITO ABIERTO $V_{O C}$}

La ecuación correspondiente al voltaje en circuito abierto se obtiene a partir de la ecuación característica de la célula fotovoltaica, dado que en estas condiciones, circuito abierto, la intensidad es nula $(l=0)$.

$$
V_{o c}=\frac{m k T}{q} \ln \left(1+\frac{I_{L}}{I_{S}}\right)
$$


Desarrollando los términos dependientes de la temperatura, se obtiene la siguiente ecuación que muestra la considerable reducción de la tensión de circuito abierto con un aumento de la temperatura.

$$
V_{o c}(T)=\frac{E_{G O}}{q}-\frac{m k T}{q} \ln \left(\frac{k^{\prime} T^{3}}{I_{L}}\right)
$$

La relación inversa entre ambas variables se puede establecer calculando el coeficiente de variación, calculando su derivada:

$$
\frac{d V_{O C}}{d T}=\frac{1}{T}\left[\frac{E_{G O}}{q}-V_{O C}(T)\right]
$$

Esta expresión indica la disminución del voltaje en circuito abierto conforme aumenta la temperatura. En la siguiente figura se muestra claramente la dependencia linear decreciente, cuya pendiente toma un valor medio de $-2,48 \mathrm{mV} /{ }^{\circ} \mathrm{C}$ para células de silicio, según A. Usami et al. [50].

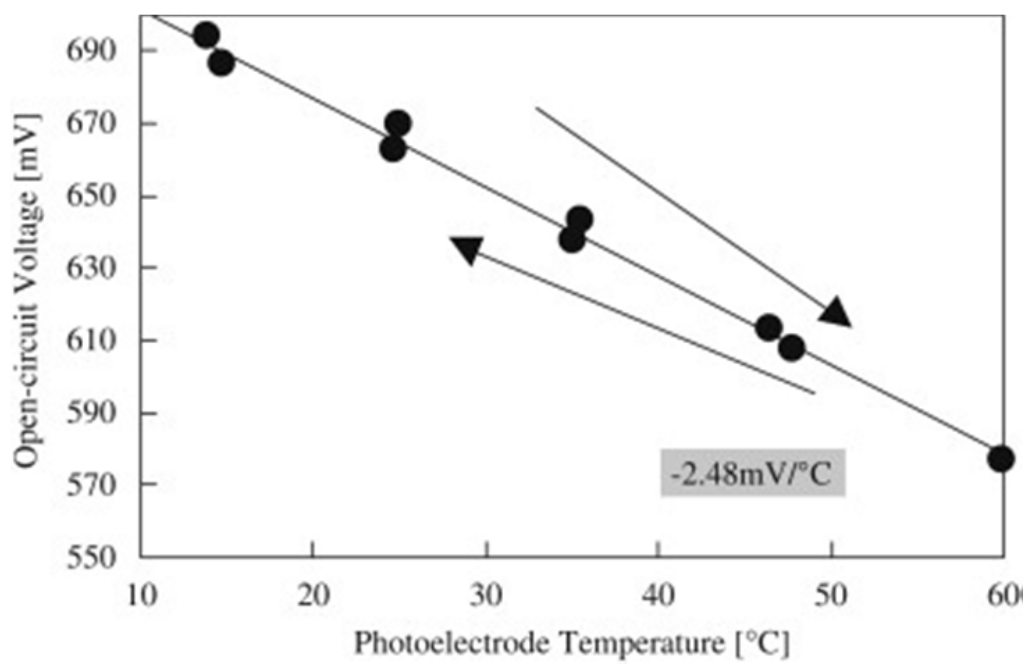

Figura 2.43 Relación entre la tensión de circuito abierto con la temperatura [50].

\section{CORRIENTE DE CORTOCIRCUITO ISC}

La corriente de cortocircuito es la correspondiente cuando la tensión es nula, por lo que sustituyendo en la ecuación característica,

$$
\begin{gathered}
I_{S C}=I_{L}-I_{S}\left[e^{0}-1\right] \\
I_{S C}=I_{L}
\end{gathered}
$$


Como se mencionó, la corriente fotogenerada aumenta ligeramente con la temperatura, que suele ser atribuido por el aumento de la absorción de la luz ocasionado por el estrechamiento de la banda prohibida. Por consiguiente, concluimos afirmando que la corriente de cortocircuito aumenta ligeramente con la temperatura. Según varios estudios $[50,51]$ concluyen que la tasa de crecimiento es del orden de $0,0006 \mathrm{~mA} /{ }^{\circ} \mathrm{C}$. En la siguiente tabla se muestras los valores experimentales recogidos para dos células de silicio, bajo las mismas condiciones de operación para un rango de temperatura de funcionamiento entre 295 a $320 \mathrm{~K}$.

\begin{tabular}{|c|c|c|c|c|c|c|c|}
\hline$T(\mathrm{~K}$ & $V_{o c}(\mathrm{~V}$ & $I_{s c}(\mathrm{~A})$ & $R_{\mathrm{sh}}(\Omega)$ & $T(\mathrm{~K})$ & $V_{o c}(\mathrm{~V})$ & $I_{s c}(\mathrm{~A})$ & $R_{\text {sh }}(\Omega$ \\
\hline & Cell 1 & & & & Cel & & \\
\hline 295 & 0.593 & 0.555 & 425 & 295 & 0.567 & 0.494 & 110 \\
\hline 300 & 0.582 & 0.557 & 407 & 300 & 0.552 & 0.496 & 104 \\
\hline 305 & 0.571 & 0.558 & 393 & 305 & 0.541 & 0.498 & 90 \\
\hline 310 & 0.561 & 0.560 & 378 & 310 & 0.528 & 0.501 & 75 \\
\hline 315 & 0.549 & 0.562 & 364 & 315 & 0.517 & 0.502 & 61 \\
\hline 320 & 0.538 & 0.563 & 350 & 320 & 0.508 & 0.504 & 49 \\
\hline
\end{tabular}

Tabla 2.6 Valores experimentales de las variables eléctricas de dos células de Silicio para el rango de temperaturas de 295 a $320 \mathrm{~K}$ [51].

Por lo tanto, un aumento en la temperatura de funcionamiento de la célula fotovoltaica, conlleva una disminución de $-0,5 \% /{ }^{\circ} \mathrm{C}$ en la tensión de circuito abierto y un ligero aumento del $+0,05 \% /{ }^{\circ} \mathrm{C}$ en la intensidad de cortocircuito, lo cual modifica la forma de la curva característica, tal y como se muestra a continuación.

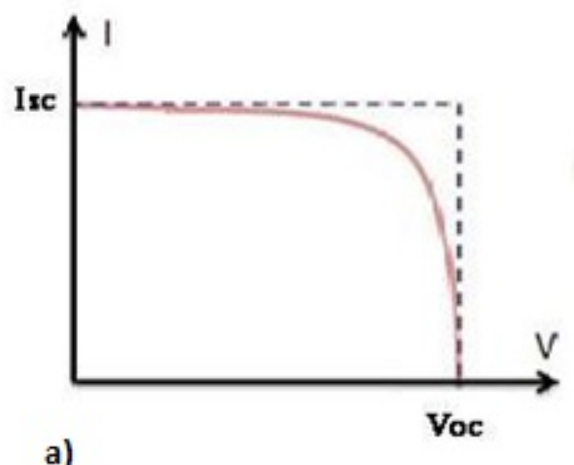

a)

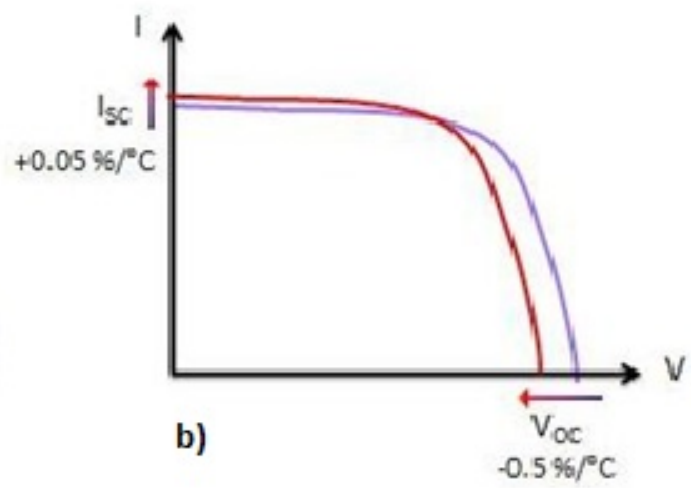

Figura 2.44 a) Representación de la curva característica del funcionamiento de una célula fotovoltaica. b) Modificación de la curva característica de funcionamiento con el aumento de la temperatura.

\section{E. FACTOR DE LLENADO O FACTOR DE FORMA FF}

El factor de forma, definido en el capítulo anterior, es una medida de la calidad de la unión y de las resistencias de la célula. A partir de su definición, relación entre la potencia máxima entregada y la máxima teórica a entregar, explicaremos su dependencia con la temperatura. 


$$
F F=\frac{P_{m}}{P_{t h}}=\frac{V_{m p} \cdot I_{m p}}{V_{o c} \cdot I_{S C}}
$$

En la Figura 2.45 a) podemos observar como este factor de llenado relaciona el área rectangular delimitada por ambos puntos, potencia máxima de funcionamiento y la máxima teórica. Esta variable depende de los parámetros de las células, los niveles de operación de la corriente e intensidad, factores de idealidad y resistencias características de la célula en cuestión. Por ellos es difícil deducir la sensibilidad de este parámetro con la temperatura.

La dependencia del factor de llenado con la temperatura viene en parte determinada por la forma adoptada por la curva característica, en la que se muestran los valores de potencia. Un aumento en la temperatura de funcionamiento conlleva una modificación de los parámetros que lo definen, disminuyendo considerablemente las tensiones y produciéndose un ligero aumento de la intensidad como se aprecia en la Figura 2.45 b). El factor de llenado sufre una ligera disminución con la temperatura, aunque no es muy acusada para temperaturas inferiores a $200^{\circ} \mathrm{C}$.

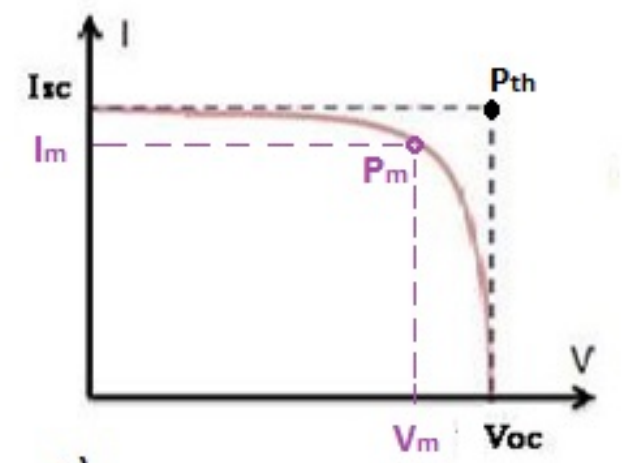

a)

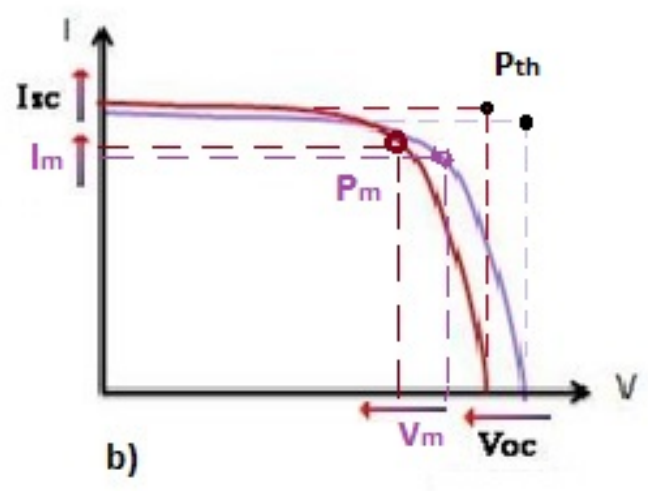

b)

Figura 2.45 Influencia de un aumento de la temperatura en los parámetros que definen al Factor de llenado. a) Representación del concepto del factor de llenado en la curva característica. b) Variación de los parámetros del factor de llenado con la temperatura.

El factor de llenado también se puede expresar mediante una ecuación empírica en función de la tensión de vacío, variable principalmente influyente considerando que no existen pérdidas de la resistencia parasitaria de la célula. Esta expresión es aplicable para casos ideales, presentando una precisión de 1 dígito en el cuarto decimal.

$$
F F=\frac{V_{o c}-\ln \left(V_{o c}+0,7\right)}{V_{o c}+1}
$$

Esta ecuación rige la siguiente relación con la temperatura, obteniéndose una disminución de su valor con el aumento de la temperatura. 


$$
\frac{1}{F F} \cdot \frac{d F F}{d T} \approx \frac{\left[\frac{1}{V_{o c}} \cdot \frac{d V_{o c}}{d T}-\frac{1}{T}\right]}{6} \approx-0,0015^{\circ} \mathrm{C}^{-1}
$$

En general, para buenas células fotovoltaicas (con valores del FF próximos a 1 en condiciones estándar), a elevados valores de temperatura el factor de llenado disminuye ligeramente mientras que a temperaturas más bajas no presenta gran dependencia [52].

\section{F. POTENCIA MÁXIMA $\boldsymbol{P}_{m}$}

La potencia máxima viene determinada por los valores de tensión e intensidad en el punto de máxima potencia de la curva característica, además se puede definir como el producto de tres de las variables características previamente descritas; intensidad de cortocircuito, tensión de circuito abierto y factor de llenado, tal y como se muestra en la siguiente ecuación [47].

$$
P_{m}=I_{m p} \cdot V_{m p}=I_{s c} \cdot V_{o c} \cdot F F
$$

A partir de esta ecuación y con lo descrito anteriormente, se deduce la proporcionalidad inversa existente entre la potencia y la temperatura de funcionamiento del panel fotovoltaico. Dado que un aumento de la temperatura conlleva una disminución de la tensión de circuito abierto $\left(2,48 \mathrm{mV} /{ }^{\circ} \mathrm{C}\right)$ y del factor de llenado $\left(0,0015{ }^{\circ} \mathrm{C}^{-1}\right)$ junto a un ligero aumento de la intensidad de cortocircuito $\left(0,0006 \mathrm{~mA} /{ }^{\circ} \mathrm{C}\right)$, la potencia máxima como producto de ellas, disminuye con la temperatura.

Diferentes estudios han demostrado la importancia del efecto de la temperatura de funcionamiento de los paneles fotovoltaicos, dando a lugar una pérdida del $7 \%$ en la potencia cuando alcanzan temperaturas del orden de los $40^{\circ} \mathrm{C}$ [53]. Esta pérdida de potencia se debe principalmente a la disminución de la tensión de circuito abierto con el aumento de la temperatura, a pesar de que exista un pequeño aumento de la intensidad de cortocircuito el cual resulta insignificante comparado a la reducción de la tensión.

Gxasheka et al. [54] demostraron dicha afirmación estudiando el efecto de la temperatura en cinco módulos fotovoltaicos, dos de ellos de Silicio cristalino (c-Si), dos de Silicio multicristalino (mc-Si) y otro "edge-defined film-fed growth silicon" (EFG-Si). Para los diferentes módulos estudiaron el efecto negativo de la temperatura sobre la potencia de salida de cada uno, el cual queda justificado por la proporcionalidad inversa entre la temperatura y la tensión de circuito abierto. De acuerdo con Mazer et al. [55], la disminución de la tensión con la temperatura es causada por el aumento de la corriente de saturación, la cual aumenta con la concentración de portadores intrínsecos que a su vez depende exponencialmente de la temperatura. 
Para los diferentes módulos utilizados, la intensidad de cortocircuito aumenta $0,7-3,1$ $\mathrm{mA} /{ }^{\circ} \mathrm{C}$, mientras que la tensión de circuito abierto disminuye en el rango de 51,9-78 $\mathrm{mV} /{ }^{\circ} \mathrm{C}$ obteniéndose una pérdida de potencia de $196-355,1 \mathrm{~mW} /{ }^{\circ} \mathrm{C}$. Los valores de los coeficientes de dependencia de cada variable con la temperatura se presentan en la Tabla 2.7 , siendo ' $\alpha$ ' el coeficiente de $I_{s c}$, ' $\beta$ ' el de la $V_{o c} Y$ ' $\gamma$ ' de la $P_{m}$.

\begin{tabular}{|cccc|}
\hline Module & $\alpha\left(\mathrm{mA} /{ }^{\circ} \mathrm{C}\right)$ & $\beta\left(\mathrm{mV} /{ }^{\circ} \mathrm{C}\right)$ & $\gamma\left(\mathrm{mW} /{ }^{\circ} \mathrm{C}\right)$ \\
\hline $\mathrm{c}-\mathrm{Si}-1$ & 0,7 & $-78,0$ & $-221,0$ \\
$\mathrm{c}-\mathrm{Si}-2$ & 2,1 & $-51,9$ & $-355,1$ \\
$\mathrm{mc}-\mathrm{Si}-1$ & 2,7 & $-72,6$ & $-344,72$ \\
$\mathrm{mc}-\mathrm{Si}-2$ & 3,0 & $-75,4$ & $-339,6$ \\
EFG-Si & 3,1 & $-76,9$ & $-196,0$ \\
\hline
\end{tabular}

Tabla 2.7Coeficientes de proporcionalidad de Isc, Voc y Pm con la temperatura para los módulos evaluados [54]

En las siguientes figuras se muestran el efecto de la temperatura sobre ambas variables, tensión de circuito abierto $\left(V_{o c}\right)$ y potencia máxima $\left(P_{m}\right)$. Se observa como ambas disminuyen considerablemente para elevadas temperaturas y que el efecto de la temperatura sobre la corriente de cortocircuito $\left(I_{s c}\right)$ es pequeño comparado con el de la tensión.

Es evidente que el coeficiente de la temperatura para la tensión de circuito abierto de c-Si2 es significativamente diferente del resto de los módulos, siendo un valor menor, tal y como se aprecia en la Figura 2.46. Esto se debe a la baja calidad de dicho módulo, lo cual es indicativo de que las células de baja calidad tienen en promedio valores de tensión $40 \mathrm{mV}$ inferiores a los de mejores módulos.

En otro estudio [56] se demostró que la tensión de circuito abierto de células de baja calidad es menos sensible a la temperatura que la de los módulos de mejor calidad. Esto explica el hecho de que este módulo tenga un coeficiente de dependencia inferior. 


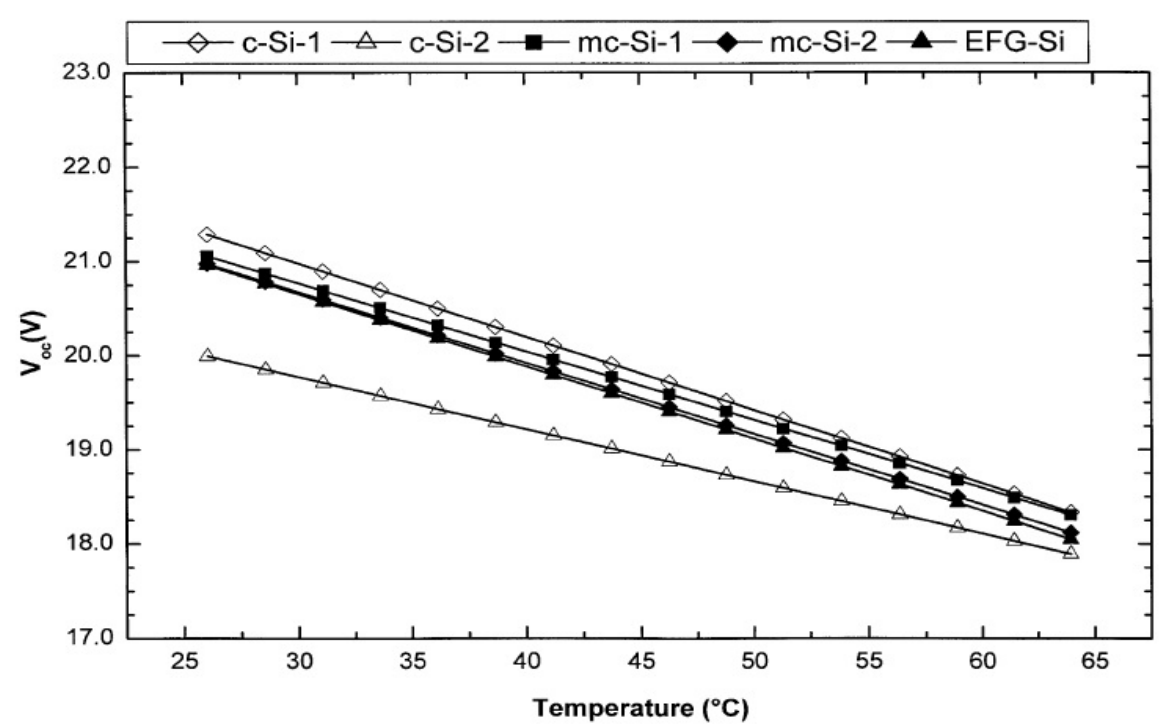

Figura 2.46Dependencia de la temperatura en la tensión de circuito abierto para diferentes módulos fotovoltaicos [54].

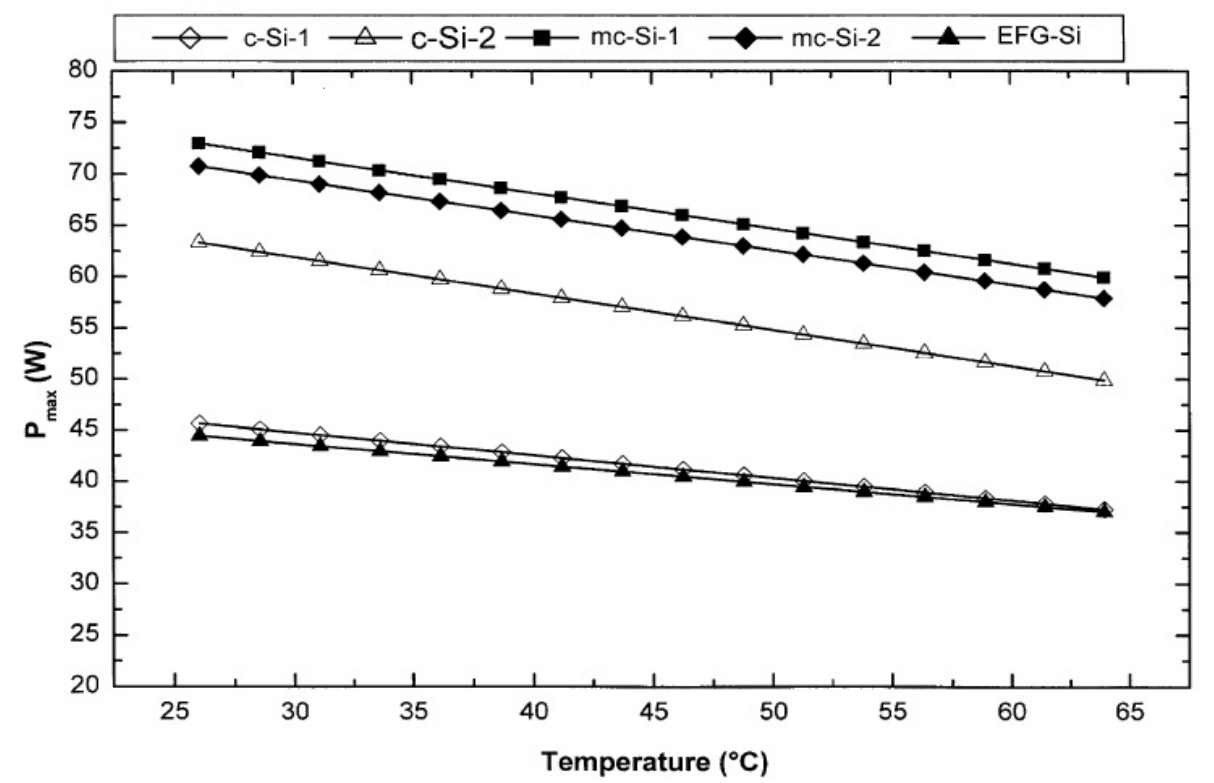

Figura 2.47 Dependencia de la temperatura en la potencia máxima para diferentes módulos fotovoltaicos [54].

Sin embargo, tanto en la Tabla 2.7 como en la Figura 2.47 observamos que el coeficiente de dependencia de la potencia máxima con la temperatura para este módulo es mayor que los del resto. Esto parece ser contradictorio con lo anterior, pero se puede explicar por la variación que sufre el factor de llenado con el aumento de temperatura, el cual presenta una gran dependencia con la temperatura $\left(-0,15 \% /{ }^{\circ} \mathrm{C}\right)$. Este factor como se ha mencionado previamente está directamente relacionado con la calidad de la unión p-n del dispositivo fotovoltaico. Otra observación interesante es la baja dependencia de la potencia con la temperatura para los módulos c-Si-1 y EFG-Si. Esto de atribuye a la propia estructura de ambos módulos, teniendo el c-Si-1 un cristal en la parte posterior y el EFG-Si de aluminio. 
Obviamente la estructura y el material utilizado para la encapsulación del módulo tiene una influencia sobre cómo la temperatura se distribuye entre las diferentes capas del módulo, ayudando así en la reducción del coeficiente de proporcionalidad de la potencia máxima con la temperatura. Podemos encontrar valores de coeficientes muy similares a los mostrados en la Tabla 2.7 en King et al. [57].

\section{G. RENDIMIENTO O EFICIENCIA ELÉCTRICA $\eta$}

Recordando la definición de la eficiencia de una célula fotovoltaica, como el cociente entre la potencia máxima entregada y la potencia luminosa (radiación solar,) captada por la célula, representada por la siguiente ecuación:

$$
\boldsymbol{\eta}=\frac{P_{m}}{G_{T}}
$$

Resulta evidente el efecto de la temperatura en la eficiencia eléctrica dado que las células fotovoltaicas alcanzan altas temperaturas cuando la irradiación o potencia luminosa recibida es también elevada y además esto produce un descenso de la potencia máxima. Tanto ambas situaciones (elevada radiación, disminución de potencia) o cada una por separado, conducen a reducir la eficiencia eléctrica de la célula. El coeficiente de proporcionalidad para la eficiencia es del orden de $-0,04--0,06 \% /{ }^{\circ} \mathrm{C}$ para las células de Silicio, siendo algo inferior, $-0,02--0,03 \% /{ }^{\circ} \mathrm{C}$, para las de Arseniuro de Galio (GaAs).

La dependencia de la temperatura en el rendimiento de módulos fotovoltaicos es un problema muy estudiado y analizado. Tomasz et al. [58] establecen diferentes ecuaciones teóricas que permiten determinar la temperatura, eficiencia y energía producida por el panel a partir de variables características de la célula y las variables ambientales, además de contratar las correlaciones teóricas con valores experimentales medidos. El rendimiento teórico considerado es una función lineal con la temperatura a partir de dos puntos, $\eta_{1}=10 \%$ para $T_{1}=20^{\circ} \mathrm{C}$ y $\eta_{2}=6 \%$ para $T_{2}=80^{\circ} \mathrm{C}$. Se puede observar como los valores medidos del rendimiento del panel, son inferiores a los teóricos, presentando una caída brusca para temperaturas superiores a los $44^{\circ} \mathrm{C}$, aún así podemos considerar una dependencia más o menos lineal. 


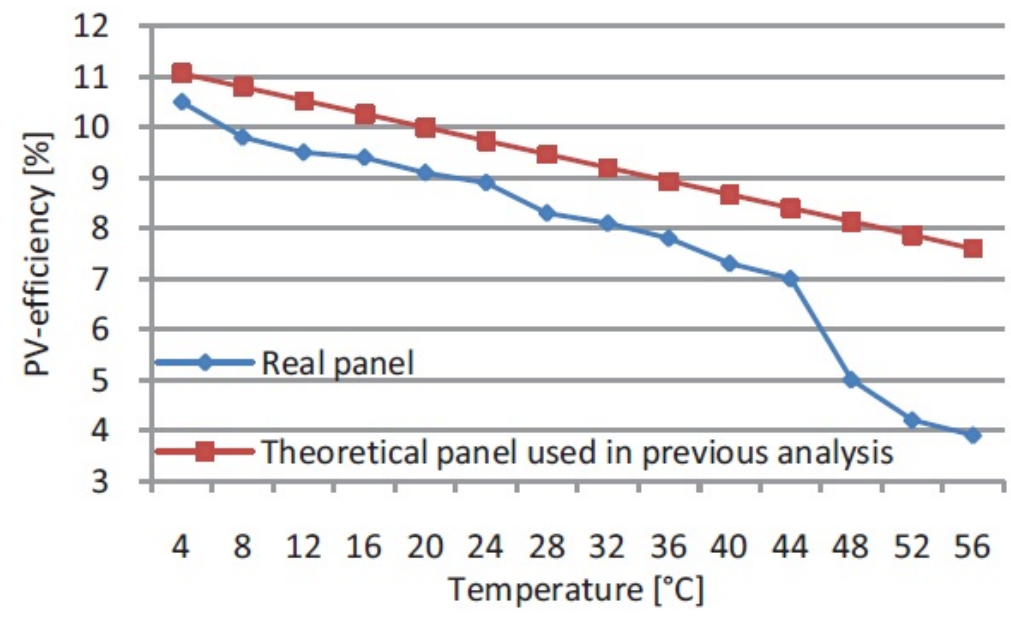

Figura 2.48 Efecto de la temperatura de funcionamiento de un panel fotovoltaico sobre su eficiencia, comparando los resultados medidos y el modelo teórico [58].

Resumiendo, la temperatura de funcionamiento de las células fotovoltaicas afecta negativamente en la producción eléctrica debido a su dependencia con las variables características de funcionamiento de los módulos fotovoltaicos. En la siguiente figura se muestra conjuntamente lo anteriormente descrito para una célula de silicio, un pequeño aumento de la intensidad de cortocircuito al aumentar la temperatura, un brusco descenso del rendimiento ocasionado principalmente por la pérdida de la potencia a elevadas temperaturas que es debido a la considerable disminución de la tensión de vacío con el aumento de la temperatura tal y como presentan Priyanka Singh et al. [51].

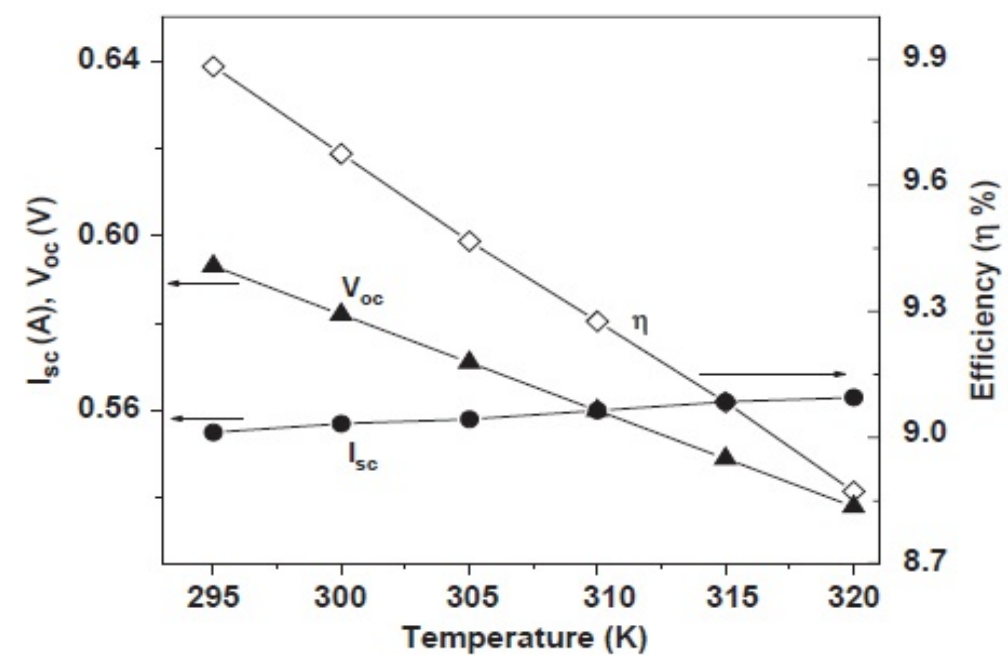

Figura 2.49 Variación de la tensión de circuito abierto, intensidad de cortocircuito y eficiencia con la temperatura para una célula de silicio en el rango de temperatura de 295 - 320K [51].

Tal y como se pretendía, en este apartado se muestra como la temperatura es un parámetro importante en el funcionamiento de la célula fotovoltaica, pues influye en sus variables características y es un factor importante a tener en cuenta. 
Este es el motivo de la realización de este estudio e investigación, cuyo fin es estudiar y analizar el efecto de la temperatura en el funcionamiento de la célula, para así poder diseñar una configuración que permita refrigerar los módulos que se encuentran emplazados sobre diferentes cubiertas, reduciendo su temperatura y por consiguiente mejorando su eficiencia.

\subsection{INFLUENCIA DE LA CAPACIDAD DE VENTILACIÓN EN LA TEMPERATURA DE FUNCIONAMIENTO}

En secciones anteriores se han presentado algunas de las muchas integraciones fotovoltaicas en edificios $u$ otras instalaciones que se están llevando a cabo por motivo del panorama energético y necesidad de aumentar la eficiencia energética en edificios. Como se ha estudiado, el rendimiento de sistemas fotovoltaicos depende estrechamente de la temperatura de la célula, pero además está influenciado por otros factores tales como su aislamiento, degradación, condiciones ambientales.

Los sistemas fotovoltaicos integrados en alguna construcción pueden sufrir un sobrecalentamiento, llegando a alcanzar mayores temperaturas de funcionamiento debido a la ausencia de refrigeración por efecto del viento exterior comparado con sistemas fijos aislados. Un eficaz método, aunque algo costoso, para regular la temperatura de los paneles fotovoltaicos integrados en cubiertas consiste en proporcionar un canal de aire abierto debajo del panel. En estos sistemas, la temperatura del módulo está muy influenciada por la capacidad de ventilación, la cuál puede ser modificada por diferentes factores. Estudios como Paylos et el.[59] muestran que la influencia del viento en la refrigeración de los paneles fotovoltaicos integrados en cubiertas forma un papel significativo en el balance energético de estos sistemas. Sin embargo, aún siendo un factor relevante en la refrigeración de los módulos, no es posible de controlar con el fin de reducir la temperatura de funcionamiento y mejorar la eficiencia del módulo fotovoltaico.

Otro factor influyente es la separación entre el módulo y la cubierta del edificio. Algunos autores centraron su investigación sobre esta cuestión. Kedari et al. [60,61] estudió un módulo fotovoltaico con una separación entre la cubierta y la parte posterior de éste de 0.14 $\mathrm{m}$. Mediante medidas experimentales, estudiaron los efectos del tamaño del espacio de aire y de las aberturas del canal en el flujo de aire inducido, comprobando que para separaciones amplias en el canal de aire se obtenía un mayor flujo de aire. Hirunlabth et al [62] sugirieron que un razonable espaciado en los colectores solares estaría comprendido entre 0.1 y 0.14 m. Sandberg y Moshfegh [63] obtuvieron expresiones para el flujo de masa, velocidad e incremento de la temperatura en el espacio de aire detrás de las células solares, considerando el efecto de la geometría (relación de aspecto del canal) y la ubicación de estas 
células solares. El estudio del efecto de la geometría del canal de aire sobre las características del flujo de aire inducido han sido investigadas por diversos autores, [64, 65], obteniendo mayor ventilación según la sección del canal e incluso el ángulo de inclinación. Otros autores han presentando procedimientos para determinar la temperatura de equilibrio del módulo, considerando la transferencia de calor y el flujo convectivo a través de un conducto de refrigeración en panel fotovoltaico. Por ejemplo, Brinkworth et al. [66] desarrolló un modelo analítico para predecir la refrigeración por aire de un sistema fotovoltaico integrado para flujo laminar libre y mixto debido al viento.

Diversos estudios se han realizado para caracterizar la refrigeración en el módulo fotovoltaico debido tanto a los efectos del viento y separación en el canal de aire. No obstante, otra posibilidad que permite variar la temperatura del módulo fotovoltaico integrado en edificios consiste en inducir un flujo de aire forzado que pueda ser dirigido. Este flujo de aire podría ser el utilizado para la ventilación del edificio, sin un consumo de energía elevado, haciéndolo pasar a través del canal de aire integrado bajo el módulo fotovoltaico, contribuyendo a una reducción de su temperatura, el aumento de su eficiencia y además la reducción del consumo de energía en el edificio, al precalentar el aire entrante. Este enfoque ha sido abordado por diversos estudios $[67,68,69]$, en los que se centran principalmente en el calentamiento del aire entrante.

\subsubsection{CORRELACIONES EXPLICITAS PARA LA TEMPERATURA DE FUNCIONAMIENTO}

En esta tesis se estudia la influencia de variables influyentes en la ventilación del canal de aire, tales como la separación en el canal y la velocidad inducida en éste, en la temperatura de funcionamiento de un módulo fotovoltaico integrado sobre una cubierta metálica. Con ello, el fin último es obtener correlaciones que determinen tanto la temperatura, como rendimiento de los sistemas fotovoltaicos para diferentes configuraciones y condiciones ambientales. Por ello es necesario hacer una revisión bibliográfica de las correlaciones que se conocen.

Varios autores han estudiado diversas formas para determinar la temperatura de funcionamiento en un módulo fotovoltaico. Existen dos formas que permiten describir el comportamiento del módulo; implícita o explícita. La temperatura de funcionamiento se puede correlacionar con variables que ellas mismas dependen de esta temperatura, donde es necesario llevar a cabo un procedimiento de iteración para el cálculo pertinente (la forma implícita), o mediante una correlación que puede resolverse directamente (de forma explícita). Una de las expresiones explícitas más empleada [70] relaciona la temperatura de funcionamiento $\left(T_{\text {panel }}\right)$ con la temperatura ambiente $\left(T_{a m b}\right)$ y radiación solar incidente $o$ irradiancia, $G_{\text {pira }}$ :

$$
T_{\text {panel }}=T_{a m b}+k \cdot G_{\text {pira }}
$$


En esta expresión, la constante $k$ (conocida como el coeficiente de Ross) se define como el cociente entre la diferencia de temperatura entre el panel y el ambiente y la radiación solar incidente, $\left(T_{\text {panel }}-T_{a m b}\right) / G_{\text {pira }}$. El principal problema de este modelo se encuentra en la estimación del coeficiente de Ross, el cual puede ser medido en un módulo pero no fácilmente predicho de antemano. Esta expresión fue propuesta inicialmente para unas condiciones de ausencia de viento y sistemas fotovoltaicos no integrados en cubiertas. Sin embargo, teniendo en cuenta que los efectos del viento son importantes y que la integración de sistemas fotovoltaicos en edificios ha aumentado, algunos autores [71] ampliaron los valores de $k$, diferenciando los resultados cualitativamente según el nivel de integración y la separación del canal de aire bajo la cara posterior de los módulos.

Las correlaciones semi-empíricas para el coeficiente de Ross propuestas por Skoplaki et al. [72] se muestran a continuación, las cuales se aplican a módulos fotovoltaicos emplazados en estructuras fijas, sin integración en edificio y para velocidades de viento nulo.

$$
\begin{aligned}
& k=\frac{0.32}{8.91+2.0 V_{f}} \\
& k=\frac{0.25}{5.7+3.8 V_{w}}
\end{aligned}
$$

En la ecuación 2.18, $V_{f}$ es la velocidad de la corriente libre del viento, en la parte alta del sistema y lo suficientemente alejado de éste, mientras que en la ecuación $2.19 V_{w}$ denota la velocidad local del aire que circula por la cara posterior al panel, que puede ser estimada por: $V_{w}=0.67 V_{f}$. Estas expresiones presentan un uso limitado a sistemas fotovoltaicos sin integración sobre edificios.

Skoplaki et al. [72] ampliaron el uso de esta correlación (Ec. 2.17), incluyendo un coeficiente de montaje $w$, definido como una proporción del coeficiente de Ross para la configuración de montaje del sistema fotovoltaico. Por lo tanto la correlación de temperatura del módulo propuesta por Skoplaki er al. es

$$
T_{\text {panel }}=T_{a m b}+w\left(\frac{0.32}{8.91+2.0 V_{f}}\right) \cdot G_{\text {pira }}
$$

válida para cualquier configuración de montaje y velocidades de viento $\left(V_{f}\right)$ mayores a cero. 


\begin{tabular}{|l|l|}
\hline \multicolumn{1}{|c|}{ PV array mounting type } & $\boldsymbol{k}\left(\mathrm{K} \mathrm{m}^{2} / \mathrm{W}\right)$ \\
\hline Free standing & 0.021 \\
\hline Flat roof & 0.026 \\
\hline Sloped roof, well cooled & 0.020 \\
\hline Sloped roof, nor so well cooled & 0.034 \\
\hline Sloped roof, highly integrated, poorly ventilated & 0.056 \\
\hline Fazade integrated, transparent PVs & 0.046 \\
\hline Fazade integrated, opaque PVs-narrow gap & 0.054 \\
\hline
\end{tabular}

Tabla 2.8 Valores experimentale del coeficiente de Ross para diferentes configuraciones [72].

Comparando las correlaciones, Ec. 2.17 y 2.20 se obtiene que $k=0.32 w /\left[8.91+2.0 V_{f}\right]$, expresión que se puede utilizar para determinar la temperatura de funcionamiento del panel fotovoltaico para diferentes configuraciones y un amplio rango de velocidad de la corriente libre de viento. Ahora bien, esta expresión no proporciona información sobre la influencia de la relación de aspecto y la ventilación forzada en esta temperatura de funcionamiento, con lo que se pretende obtener a partir de los valores experimentales medidos.

\subsection{CONSIDERACIONES SOBRE EL ESTADO DEL ARTE}

Diversos estudios sobre técnicas de refrigeración de paneles fotovoltaicos con el propósito de reducir su temperatura y mejorar la producción eléctrica se han presentado. Las técnicas de refrigeración en las que se emplean agua presentan buenos resultados en las instalaciones experimentales, no obstante se han descartado en este estudio por los inconvenientes que presentan en aplicaciones de integración sobre cubiertas: necesidad de suministro de agua, sistema de bombeo, aumento del peso de la estructura soporte, gasto económico etc. Sin embargo, los estudios que incluyen la refrigeración con aire, haciéndolo pasar por la cara posterior del módulo, resulta ser más ventajosa y viable en aplicaciones industriales.

A la vista de los resultados, los estudios sobre el uso de aire como técnica de refrigeración de los módulos están ampliamente documentados, aunque los relativos a sistemas de integración sobre cubierta como una nave industrial o invernadero se reducen a un restringido rango de parámetros significativos en el comportamiento de los módulos.

La información encontrada no incluye la contrastación de valores experimentales con valores medidos en una planta solar en explotación. Además, a nivel experimental resulta insuficiente para poder caracterizar tanto la producción eléctrica como eficiencia en función de su temperatura, en paneles integrados sobre diferentes cubiertas en aplicaciones existentes en la realidad y bajo diferentes condiciones de diseño y ambientales.

En aplicaciones con integración fotovoltaica sobre cubiertas, concretamente metálicas y en invernaderos, no se conoce con exactitud cómo afectan en la producción eléctrica aquellas 


\section{CAPITULO 2. ESTADO DEL ARTE}

variables que permiten variar la temperatura de funcionamiento, modificando la capacidad de refrigeración del panel con la circulación de aire por su cara posterior.

Estos motivos abogan a favor de la realización de la presente tesis, tras la necesidad de la

empresa colaboradora por estudiar sus instalaciones existentes y poder mejorar otras futuras. 


\section{CAPITULO 3. DESCRIPCIÓN DE LAS INSTALACIONES FOTOVOLTAICAS PARA EL ANÁLISIS DE SU REFRIGERACIÓN CON}

\section{AIRE}

Como se ha mencionado en capítulos anteriores, en este trabajo se han estudiado diversas instalaciones fotovoltaicas fruto de la colaboración establecida con la empresa Apia XXI en el marco de la cual se ha planteado. El objeto de este capítulo es describir las instalaciones fotovoltaicas estudiadas y analizadas, dos de ellas son instalaciones comerciales en explotación construidas por la propia empresa, y las otras dos se han diseñado y construido en la Universidad Politécnica de Cartagena.

El capítulo está estructurado en dos apartados. En el primero se describen las instalaciones comerciales que nos han servido de prototipo para el diseño y montaje de las experimentales. En primer lugar la planta solar Coronil II de $10 \mathrm{MW}$, constituida por 51412 paneles montados sobre estructura fija, describiendo el campo fotovoltaico, distribución y características de los módulos fotovoltaicos, la estructura soporte y elementos eléctricos de la instalación. Además, esta instalación ha sido utilizada para analizar datos recogidos durante varios meses, con el fin de comparar el funcionamiento (referido a los parámetros proporcionados por el fabricante) del módulo fotovoltaico en la planta fotovoltaica con la instalación experimental, como se presenta en el apartado 5.1. En segundo lugar se presenta la planta solar Coronil IV de $1 \mathrm{MW}$, engloba 4464 paneles fotovoltaicos montados sobre la cubierta de una instalación agroenergética. Del mismo modo, se ha descrito la distribución del campo fotovoltaico, características de los módulos, estructura de la instalación y principales elementos eléctricos constituyentes.

En el segundo apartado se describen las instalaciones experimentales estudiadas, las cuales han sido diseñadas y construido en la Universidad Politécnica de Cartagena para el estudio y análisis del comportamiento eléctrico de los paneles fotovoltaicos, no sólo para la configuración prototipo presentada por la instalación comercial de referencia, sino para otras configuraciones, con el propósito de estudiar una posible mejora en el comportamiento eléctrico de los módulos fotovoltaicos mediante la refrigeración con aire en su cara posterior, aprovechando el efecto chimenea creado por convección natural (Apartados 5.2 y 5.3). La primera instalación experimental está constituida por módulos sobre una cubierta metálica de estructura fija y la segunda sobre la cubierta de invernaderos. En ambas se detalla el diseño constructivo, con el objeto de describir su estructura soporte, parámetros eléctricos de los paneles, la instrumentación utilizada en cada una de ellas y las diferentes configuraciones estudiadas. 


\subsection{INSTALACIONES FOTOVOLTAICAS EN EXPLOTACIÓN}

Este apartado está enfocado en la descripción de las instalaciones fotovoltaicas construidas y en funcionamiento, por parte de la empresa Apia XXI. Estas instalaciones dan origen al estudio y análisis del presente trabajo de investigación y por consiguiente, nos sirven de referencia a la hora del diseño y montaje de las instalaciones experimentales de ensayo.

La primera instalación fotovoltaica descrita consiste en un huerto solar de $10 \mathrm{MW}$, constituida por 51412 paneles fotovoltaicos ubicados sobre estructura fija. Todos los módulos no presentan las mismas características eléctricas, ni presentan la misma respuesta eléctrica dado que se han utilizado seis marcas de modelos, con un total de ocho potencias diferentes. Con los resultados obtenidos de esta planta solar, elegiremos el tipo de panel que ofrezca una mejor respuesta eléctrica, sirviéndonos de ensayo en nuestra instalación experimental. Además, se pretende hacer un estudio comparativo con los resultados experimentales y los obtenidos en la planta para este modelo de panel.

La segunda instalación fotovoltaica consta de 4464 paneles fotovoltaicos montados sobre la cubierta de una instalación agroenergética (invernadero), alcanzando $1 \mathrm{MW}$ de potencia nominal. Esta nueva aplicación fotovoltaica conlleva que el panel fotovoltaico se encuentre cercano a la cubierta del invernadero, permitiendo la transferencia del calor interno hacia el módulo y viceversa. Los módulos utilizados, son los que mejor respondían eléctricamente a altas temperaturas, en la instalación anterior, pero aún así se verán afectados en esta configuración. Un prototipo que englobe una unidad estructural de toda la instalación y con idénticas magnitudes y materiales, ha sido construido para estudiar la influencia térmica en su producción eléctrica así como otras posibles configuraciones que la mejoren.

\subsubsection{PLANTA SOLAR CORONIL II}

La planta fotovoltaica 'Coronil II', alojada sobre estructura fija, alcanza los $10 \mathrm{MW}$ de potencia nominal, estando formada por 51412 paneles fotovoltaicos con potencias comprendidas entre los $175 \mathrm{Wp}$ y los $280 \mathrm{Wp}$. El parque solar fotovoltaico está formado por 6 agrupaciones de $1600 \mathrm{~kW}$. Cada una de estas agrupaciones cuenta con 4 inversores de $400 \mathrm{~kW}$ de potencia nominal y un centro de transformación 15/0.4 kV compuesto por dos transformadores de 1000 kVA. Además existe una séptima agrupación con un inversor de 400 kW y un centro de transformación 15/0.4 kV con una potencia de 630 kVA.

Así pues, la planta cuenta con 7 centros de transformación y 13 transformadores. La unión de los centros de transformación es en forma de doble anillo, conectados mediante una línea soterrada de media tensión a $15 \mathrm{kV}$. El anillo se cierra en celdas de línea de la nueva subestación "El Coronil" para conectarse con la red de Sevillana Endesa. 


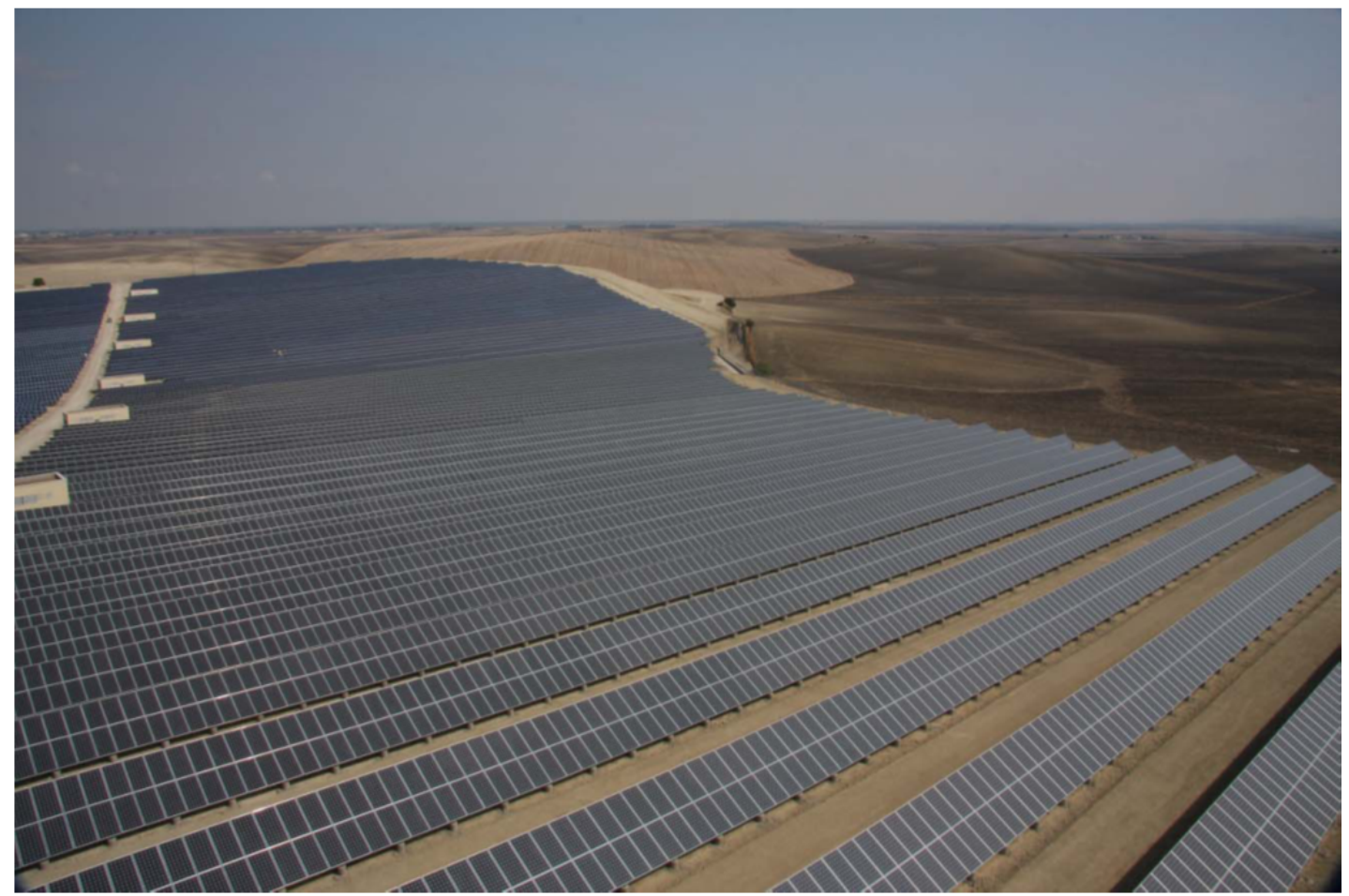

Figura 3.1 Planta fotovoltaica "El Coronil II".

\subsubsection{CAMPO FOTOVOLTAICO}

La energía eléctrica producida por los paneles fotovoltaicos en corriente continua es transformada en corriente alterna por los inversores. La red de baja tensión se une en el centro de transformación donde se realiza la conversión a 15 kV.

Los módulos fotovoltaicos están orientados al Sur, con una inclinación respecto a la horizontal de $30^{\circ}$ para conseguir captar el máximo de radiación solar a lo largo de todo el año. Todos los paneles están montados sobre unos soportes que tienen una altura total entre $1.7 \mathrm{~m}$ y $2.1 \mathrm{~m}$, quedando la parte inferior a $30 \mathrm{~cm}$ del suelo.

Debido a que el terreno donde se van a implantar las estructuras es de pendiente variable, las filas de paneles se sitúan a una distancia entre sí diferente en función de dicha pendiente. Esta separación queda justificada de manera que se garantiza un mínimo de 4 horas de sol en torno al mediodía del solsticio de invierno.

Se han instalado cinco marcas distintas de módulos fotovoltaicos, Sharp, Suntech, Yingli, ET, SolarWord. En total se dispone de seis modelos distinto de paneles, con ocho potencias. La suma de paneles de la planta fotovoltaica alcanza las 51412 unidades, estando cada uno de ellos localizado y con su correspondiente flash report. A continuación se muestra las principales características eléctricas de cada uno de los modelos de paneles instalados: 


\begin{tabular}{|c|c|c|c|c|c|c|}
\hline MARCA & MODELO & Potencia (Wp) & Voc (V) & Isc (A) & Vmp (V) & Imp (A) \\
\hline \multirow{2}{*}{ Sharp } & NT-175E1 & 175 & 44.4 & 5.40 & 35.4 & 4.95 \\
\cline { 2 - 7 } & UN-180 & 180 & 30 & 8.37 & 23.7 & 7.6 \\
\hline SolarWorld & SW 210 & 210 & 36.4 & 7.8 & 29 & 7.2 \\
\hline \multirow{3}{*}{ Suntech } & STP 260 & 260 & 44 & 8.09 & 34.8 & 7.47 \\
\cline { 2 - 7 } & STP 270 & 270 & 44.5 & 8.2 & 35 & 7.71 \\
\cline { 2 - 7 } & STP 280 & 280 & 44.8 & 8.33 & 35.2 & 7.95 \\
\hline ET & ET-P672270 & 270 & 43.63 & 8.10 & 36.4 & 7.42 \\
\hline Yingli & YL 220 & 220 & 36.6 & 8.10 & 30 & 7.4 \\
\hline
\end{tabular}

Tabla 3.1 Características eléctricas de los diferentes modelos de paneles instalados en la planta fotovoltaica "El Coronil II"

Finalmente indicar acerca del campo fotovoltaico, que la distribución del número total de paneles (51410) y la potencia instalada (11420 kWp) según cada modelo de panel es la siguiente:

\begin{tabular}{|c|c|c|c|}
\hline MARCA & MODELO & $\begin{array}{c}\text { Número } \\
\text { paneles }\end{array}$ & $\begin{array}{c}\text { Potencia instalada } \\
\mathbf{( k W p )}\end{array}$ \\
\hline \multirow{2}{*}{ Sharp } & NT-175E1 & 9000 & 1557 \\
\cline { 2 - 4 } & UN-180 & 7944 & 1431 \\
\hline SolarWorld & SW 210 & 4708 & 987.9 \\
\hline \multirow{3}{*}{ Suntech } & STP 260 & 3132 & 814 \\
\cline { 2 - 4 } & STP 270 & 5794 & 1566.6 \\
\cline { 2 - 4 } & STP 280 & 1872 & 524.5 \\
\hline \multirow{2}{*}{ ET } & ET-P672270 & 7344 & 1985 \\
\hline Yingli & YL 220 & 11616 & 2557 \\
\hline
\end{tabular}

Tabla 3.2 Número total de paneles y potencia instalada de cada modelo de paneles

La configuración del campo fotovoltaico con los diferentes modelos de paneles y su potencia pico con cada inversor y centro de transformación se incluye en el Anexo B.

\subsubsection{ESTRUCTURA SOPORTE}

Las estructuras soporte son instalaciones modulares de perfiles atornillados de acero galvanizado, instaladas en el suelo sobre una cimentación. La estructura está conectada eléctricamente a la toma de tierra general de la planta.

Según el tipo de panel utilizado, las estructuras presentan 4 o 3 metros de hipotenusa. La cimentación se ha llevado a cabo con pilotes de $30 \mathrm{~cm}$ de diámetro para la pata posterior de las estructuras de 4 metros de hipotenusa. En la Figura 3.2 se muestran las secciones de las estructuras utilizadas. 


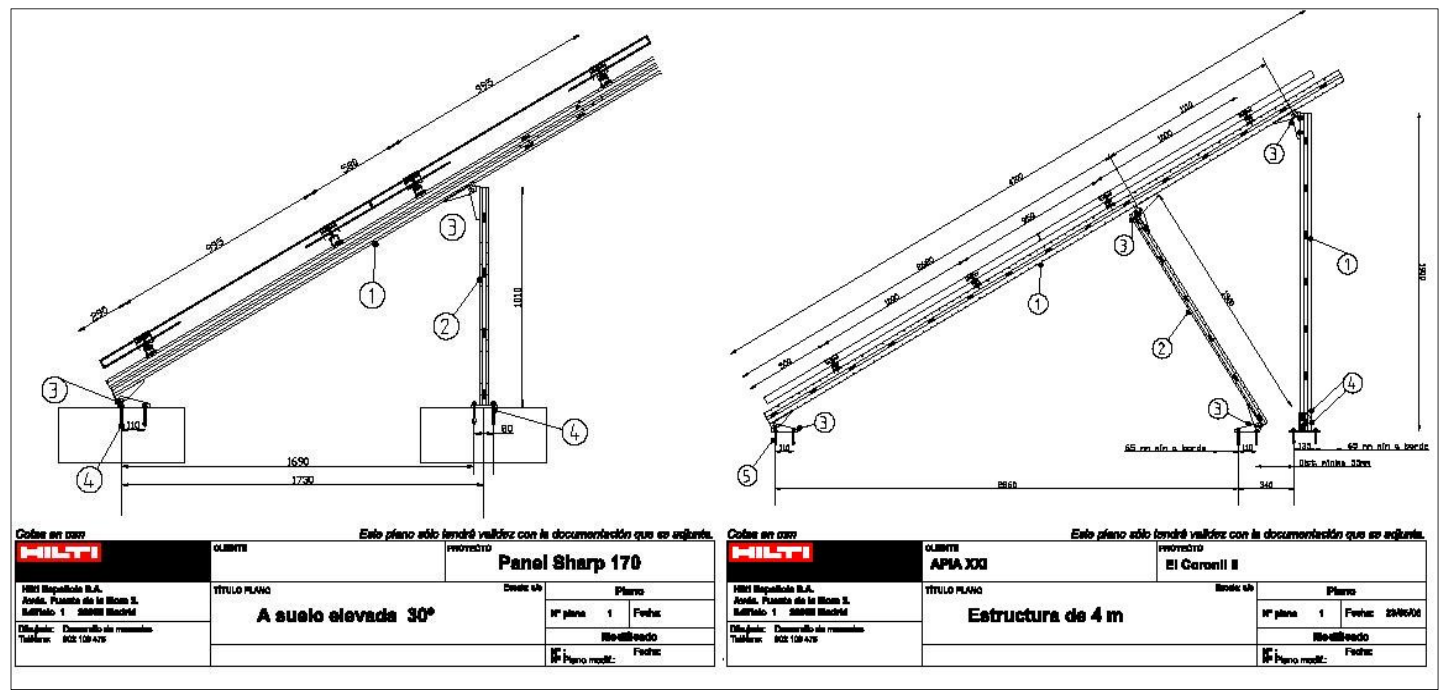

Figura 3.2 Estructura soporte de los paneles con 3 y 4 metros de hipotenusa respectivamente

\subsubsection{INVERSORES}

Los inversores instalados son trifásicos de $400 \mathrm{~kW}$, modelo Siemens Sinvert solar 420M, que disponen de un sistema de control que le permite un funcionamiento completamente automatizado. Durante los periodos nocturnos el inversor permanece parado, vigilando los valores de tensión de la red que alimenta al edificio y del generador fotovoltaico. Al amanecer, la tensión del generador fotovoltaico aumenta y pone en funcionamiento el inversor que comienza a inyectar energía a la red.

La ventilación de los edificios de inversores es un aspecto relevante en su rendimiento, por eso lleva incorporado un sistema de refrigeración por convección natural y forzada con termostatos electrónicos proporcional que controla la velocidad de los ventiladores.

La conexión entre inversores es del modo maestro/esclavo, de forma que si uno de los inversores trabaja a un rendimiento inferior al $40 \%$, toda la energía recibida es cedida a uno de ellos.

\subsubsection{PROTECCIONES}

La instalación está protegida contra contactos directos, de manera que los elementos activos son inaccesibles. Con el fin de proteger la instalación de corriente continua frente a sobreintensidades, se han utilizado en cada sector de la instalación elementos de corte y protección.

En la parte de alterna, se han instalado interruptores generales magnetotérmicos por cada inversor y cuadro de protección. También se ha dotado al sistema de protección diferencial para la protección frente a contactos indirectos. 


\subsubsection{RED DE MEDIA TENSIÓN}

La línea interna subterránea de media tensión a 15 kV tiene por objeto la interconexión en anillo de los siete centros de transformación. La sección de toda la línea subterránea es de $240 \mathrm{~mm}^{2}$ y con 2,640 $\mathrm{m}$ de longitud, siendo el cable del tipo HEPRZ1 y trabajando a una tensión de $15 \mathrm{kV}$ y frecuencia de $50 \mathrm{~Hz}$.

El punto de conexión con la Sevillana Endesa para el acceso de 10,000 kW, se establece en las celdas de entrada del lado de 15 kV de la nueva subestación eléctrica 66/15 kV El Coronil. La línea tiene su origen en una celda de línea de dicha subestación y se cierra en otra celda de línea de iguales características, ubicada en el mismo lugar.

\subsubsection{REGISTRO DE LOS DATOS EN LA PLANTA FOTOVOLTAICA}

La toma de datos de irradiancia se realiza a través de una célula calibrada en el plano horizontal y tres células en plano inclinado situadas en diferentes posiciones en la planta. La temperatura ambiente es medida por una sonda de temperatura de aplicación meteorológica y la temperatura del módulo se mide a través de seis termopares instalados en la parte posterior de cada uno de los diferentes tipos de paneles.

En la siguiente figura se muestra la radiación solar medida en el plano de captación y la temperatura ambiente recogida en el mes de Marzo de 2009.
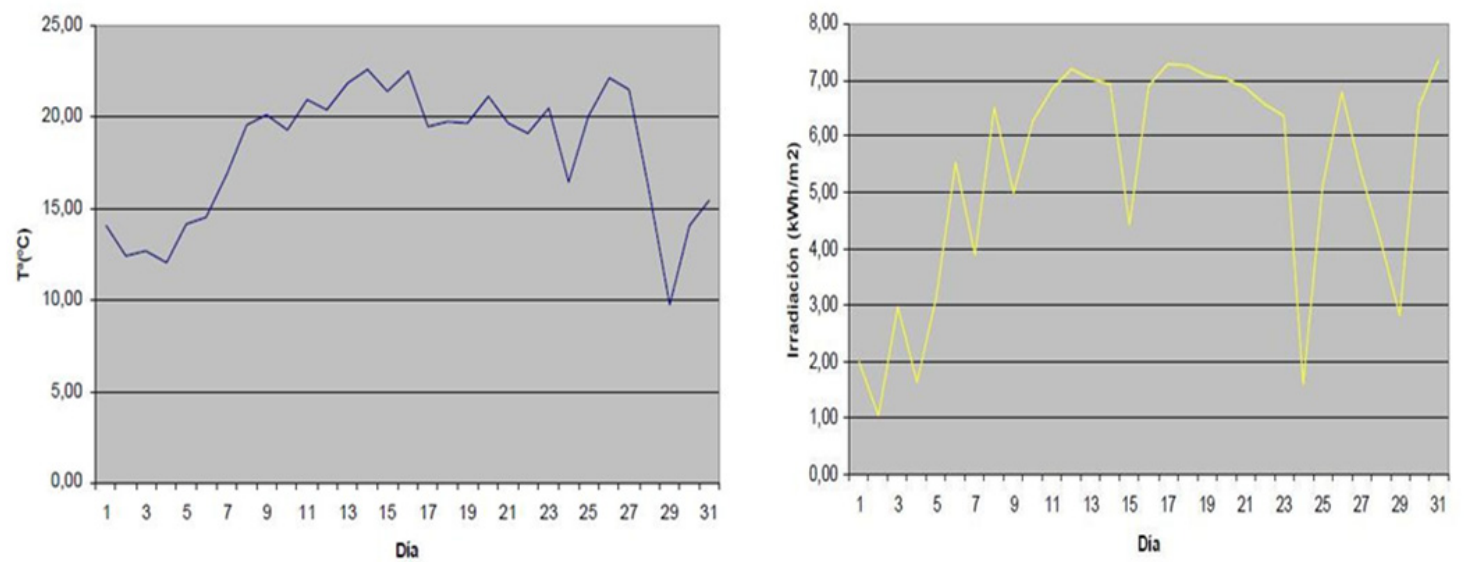

Figura 3.3 Radiación solar medida en el plano de captación y temperatura ambiente registrada durante el mes de Marzo de 2009.

Como se describió previamente, la instalación solar fotovoltaica está constituida por diferentes modelos de paneles fotovoltaicos, con diferentes características eléctricas, por consiguiente la producción eléctrica y rendimiento de cada uno difiere, bajo las mismas condiciones ambientales la Figura 3.4 representa la variación del rendimiento teórico de cada tipo de panel instalado en la planta en función de la temperatura ambiente. 


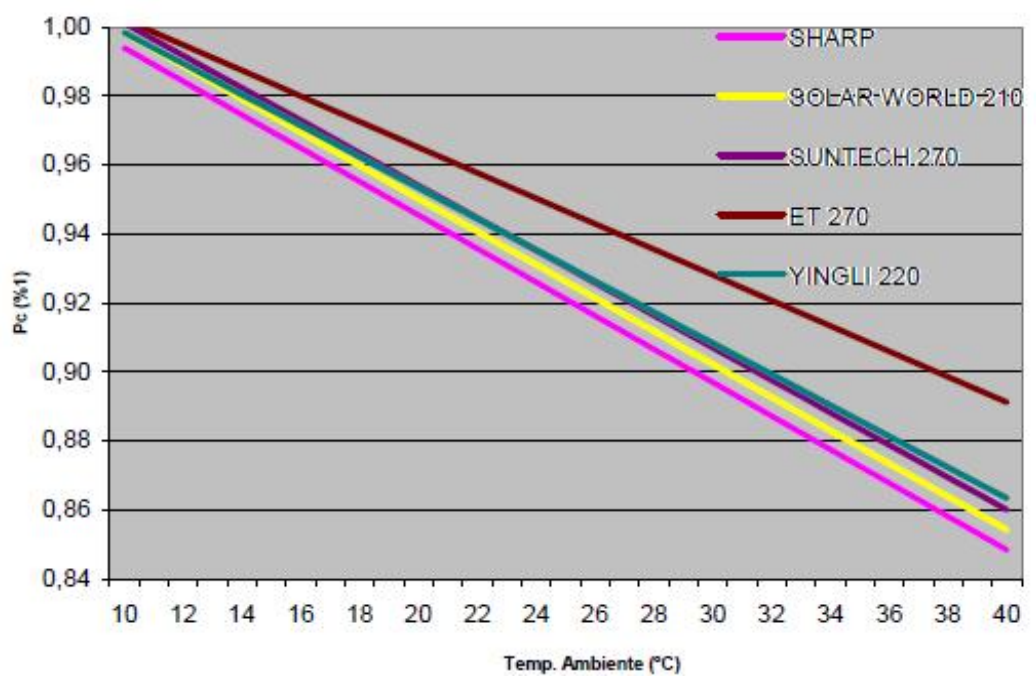

Figura 3.4 Variación del rendimiento teórico de de cada modelo de panel PV en función de la temperatura ambiente.

Se puede apreciar que el rendimiento de los diferentes tipos de módulos fotovoltaicos disminuye con la temperatura, tal y como se estudió en el capítulo anterior, pero la tasa de disminución no es la misma para cada uno, dado que presentan características eléctricas diferentes. Los paneles fotovoltaicos ET 270 son los que responden con un mejor rendimiento teórico para altas temperaturas, seguidos de los Yingli 220, Suntech 270, Solar World 210 y por último los Sharp.

Por esta razón, en la ampliación de la planta así como futuras instalaciones, el modelo de paneles instalados son los ET 270, con mejor respuesta eléctrica a altas temperaturas ambiente. Por el mismo razonamiento, son los paneles que se han utilizados y analizados en las instalaciones experimentales montadas, tal y como se describirán posteriormente. Además, el posterior análisis de los datos de la planta y de las instalaciones experimentales, se centra en el comportamiento eléctrico de este modelo de módulos fotovoltaicos.

\subsubsection{PLANTA SOLAR CORONIL IV EN INSTALACIÓN AGROENERGÉTICA}

La planta fotovoltaica 'Coronil IV', montada sobre la cubierta de la instalación agroenergética de mismo nombre, alcanza $1 \mathrm{MW}$ de potencia nominal, y está formada por 4464 paneles fotovoltaicos ET de $270 \mathrm{Wp}$. El parque solar fotovoltaico está formado por dos agrupaciones de $602.64 \mathrm{kWp}$ conectadas cada una de ellas a una máquina de inversor de $500 \mathrm{~kW}$ de potencia nominal. La instalación cuenta con un Centro de Transformación 0.4/15 kV compuesto por dos transformadores de $630 \mathrm{kVA}$.

La red de evacuación que se diseña tiene por objeto la conexión del Centro de Transformación de la planta con una línea soterrada de $15 \mathrm{kV}$ situada en la localidad de El Coronil, mediante una línea eléctrica en doble circuito tipo subterráneo entubado, con una 
tensión de $15 \mathrm{kV}$, nivel de aislamiento según lista 2 (MIE-RAT 12), y una frecuencia de 50 Hz. La sección de toda la línea es de $240 \mathrm{~mm}^{2}$, con cable del tipo RHZ1 Al 18/30 kV.

La canalización está formada por seis tubos de PVC de $200 \mathrm{~mm}^{2}$, de manera que dos tubos pertenecen a la futura línea de evacuación de la planta 'Coronil V', mientras que otros dos tubos restantes se utilizan para el doble circuito de esta instalación, dejando dos tubos adicionales de reserva.

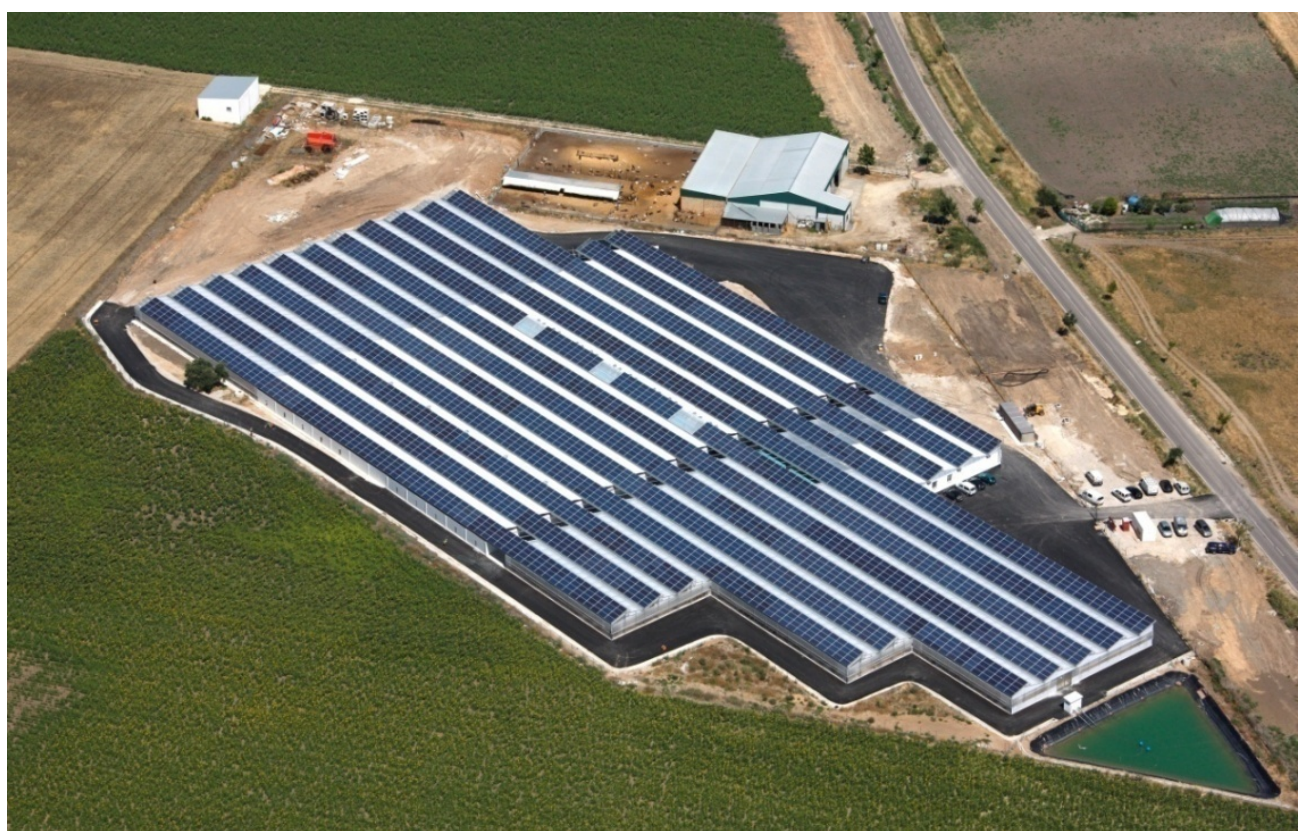

Figura 3.5 Instalación agroenergética 'El Coronil IV'

\subsubsection{CAMPO FOTOVOLTAICO}

La energía eléctrica producida por los paneles fotovoltaicos en corriente continua es transformada en corriente alterna por los inversores. La red de baja tensión se une en el centro de transformación donde se realiza la conversión a 15 kV.

La estructura que forman las instalaciones agropecuarias está compuesta por múltiples pórticos con cubierta a dos aguas y un pilar interior, transversalmente están unidos por vigas, sobre las que se apoyan los dinteles. Sobre uno de los faldones se instala un sistema de correas, y se considera fijo. El otro faldón no fijo, se puede abrir por lo que no cuenta con sistema de correas. La separación entre pórticos apoyados sobre pilares es de $6 \mathrm{~m}$, entre dinteles de $2 \mathrm{~m}$. 


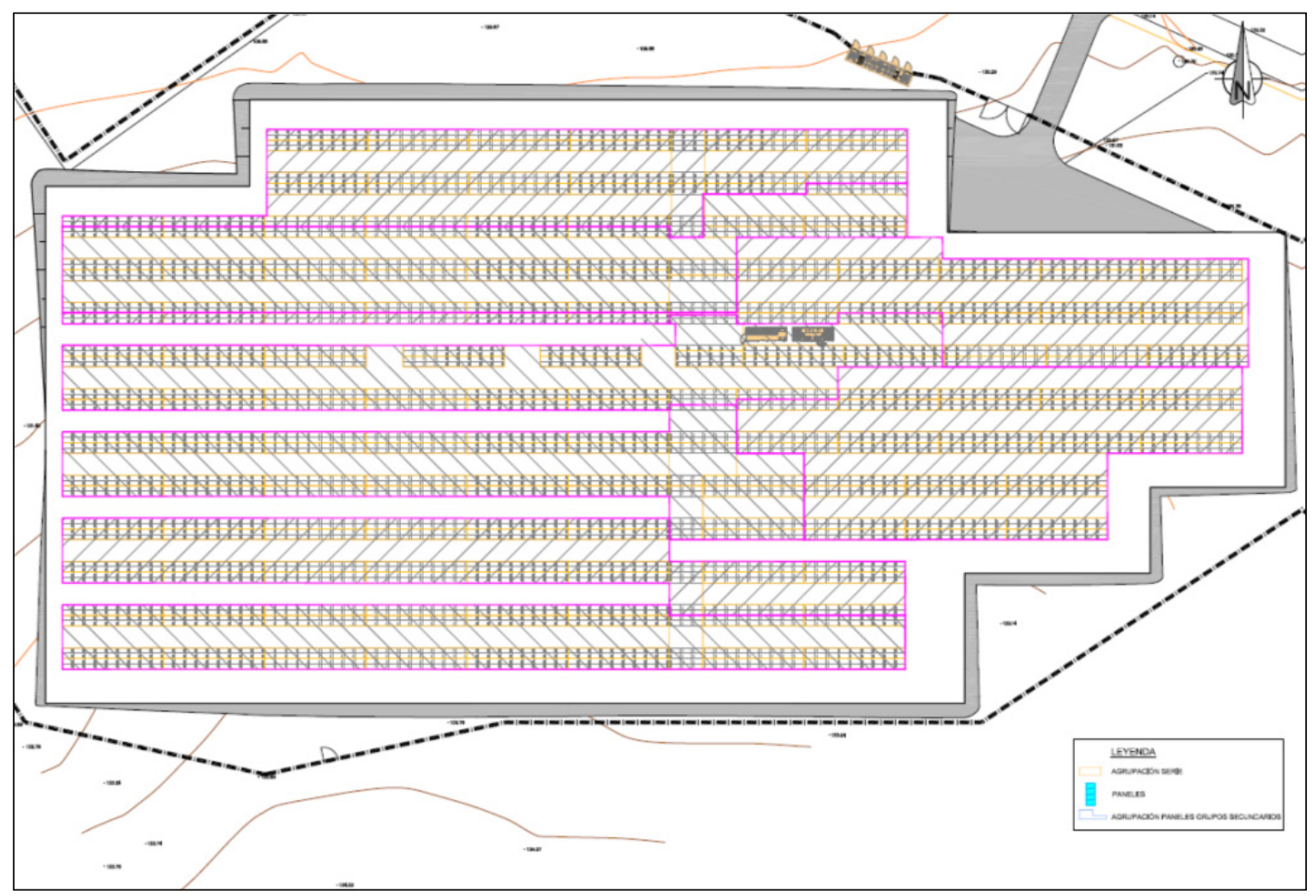

Figura 3.6 Distribución de los paneles en la cubierta de la instalación agroenergética.

Las uniones se realizan a modo de articulación. El dintel sobre el que se apoyan los faldones salva una luz de $3.000 \mathrm{~m}$ con un ángulo de $18.43^{\circ}$ y se prolonga $1.03 \mathrm{~m}$ de voladizo, de forma que su longitud total es de $4.200 \mathrm{~m}$.

El dintel del lado opuesto salva una luz de $4.600 \mathrm{~m}$ y tiene una longitud de $4.707 \mathrm{~m}$. La unión a los dos pilares se realiza mediante articulaciones.

Los pilares tienen una longitud de 3 y $4 \mathrm{~m}$. Los más cortos se encuentran empotrados en la base y articulados en la unión con ambos dinteles. Los pilares largos están empotrados en su unión con la cimentación y articulados en la unión con ambos dinteles.

El sistema de correas consta de 8 correas en el faldón fijo, disponiendo de juntas de dilatación cada 30 metros con el fin de asegurar la discontinuidad de las correas.

La estructura tiene un sistema de arriostramiento lateral a lo largo de sus caras laterales, y además un arriostramiento interior en los casos en que el número de pórticos consecutivos sea superior a cinco. 

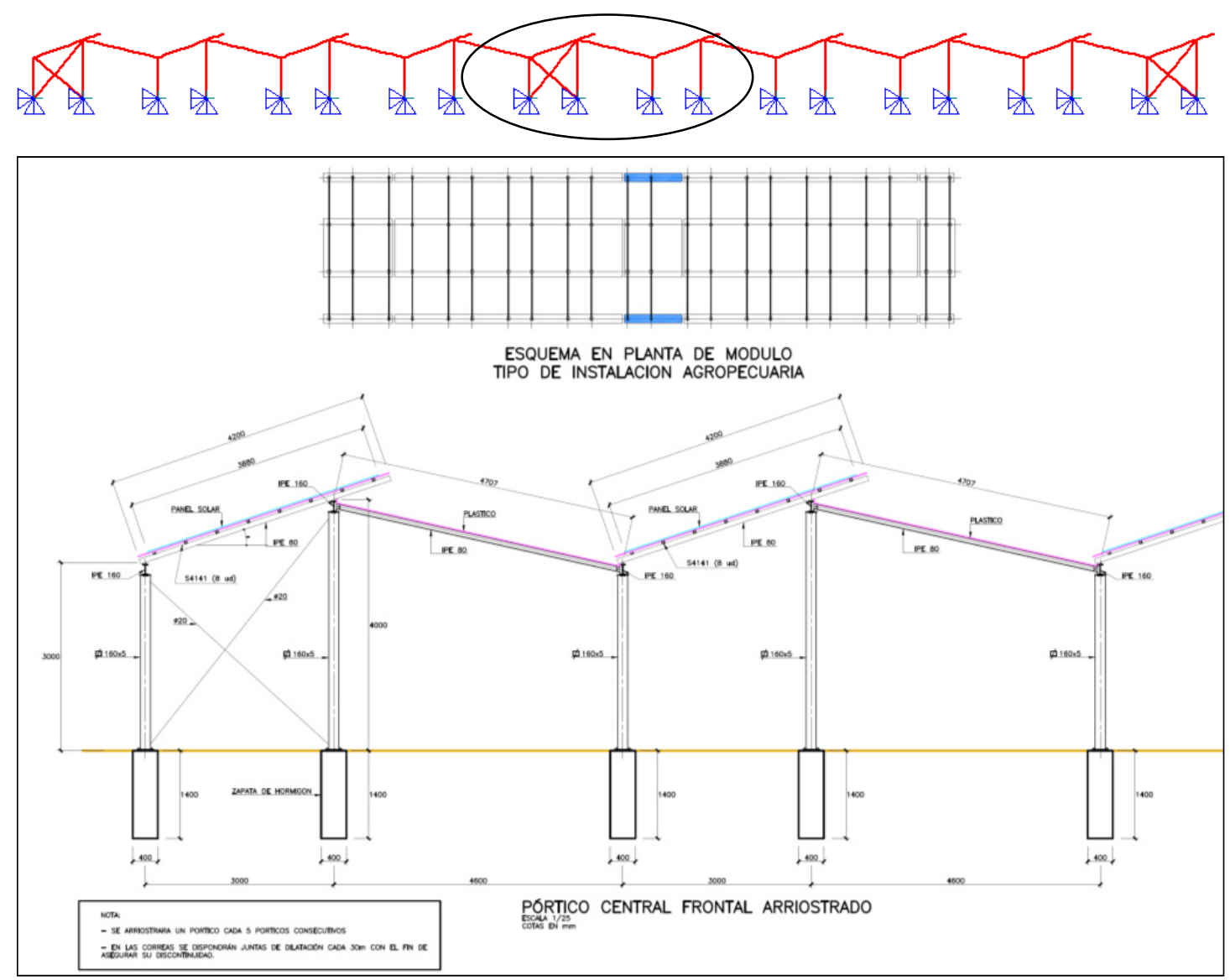

Figura 3.7 Alzado de la estructura de la instalación agropecuaria.

Los paneles fotovoltaicos instalados en la cubierta de la instalación se corresponden al modelo ET-270 Wp, cuyas características se han descrito en el apartado anterior.

\subsubsection{INVERSORES}

La instalación presenta un único inversor trifásico, compuesto por dos máquinas idénticas de 500 kW cada una. El modelo del inversor es Siemens Sinvert 1000MS TL.

Esta disposición, supone la división de la Planta en dos agrupaciones, una por cada máquina de $500 \mathrm{~kW}$ del inversor, quedando agrupados en un edificio. Junto al edificio se ubica un centro de transformación dotado de dos transformadores de 630 kVA.

La conexión entre inversores es del modo maestro-esclavo, de forma que si uno de los inversores trabaja a un rendimiento inferior al $40 \%$, toda la energía recibida es cedida a solo uno de ellos.

\subsubsection{PROTECCIONES}

La instalación está protegida contra contactos directos, de manera que los elementos activos son inaccesibles. Con el fin de proteger la instalación de corriente continua frente 
a sobreintensidades, se han utilizado elementos de corte y protección en cada sector de la instalación.

En la parte de alterna, se encuentran instalados interruptores generales magnetotérmicos por cada inversor y cuadro de protección. También se ha dotado al sistema de protección diferencial para la protección frente a contactos indirectos.

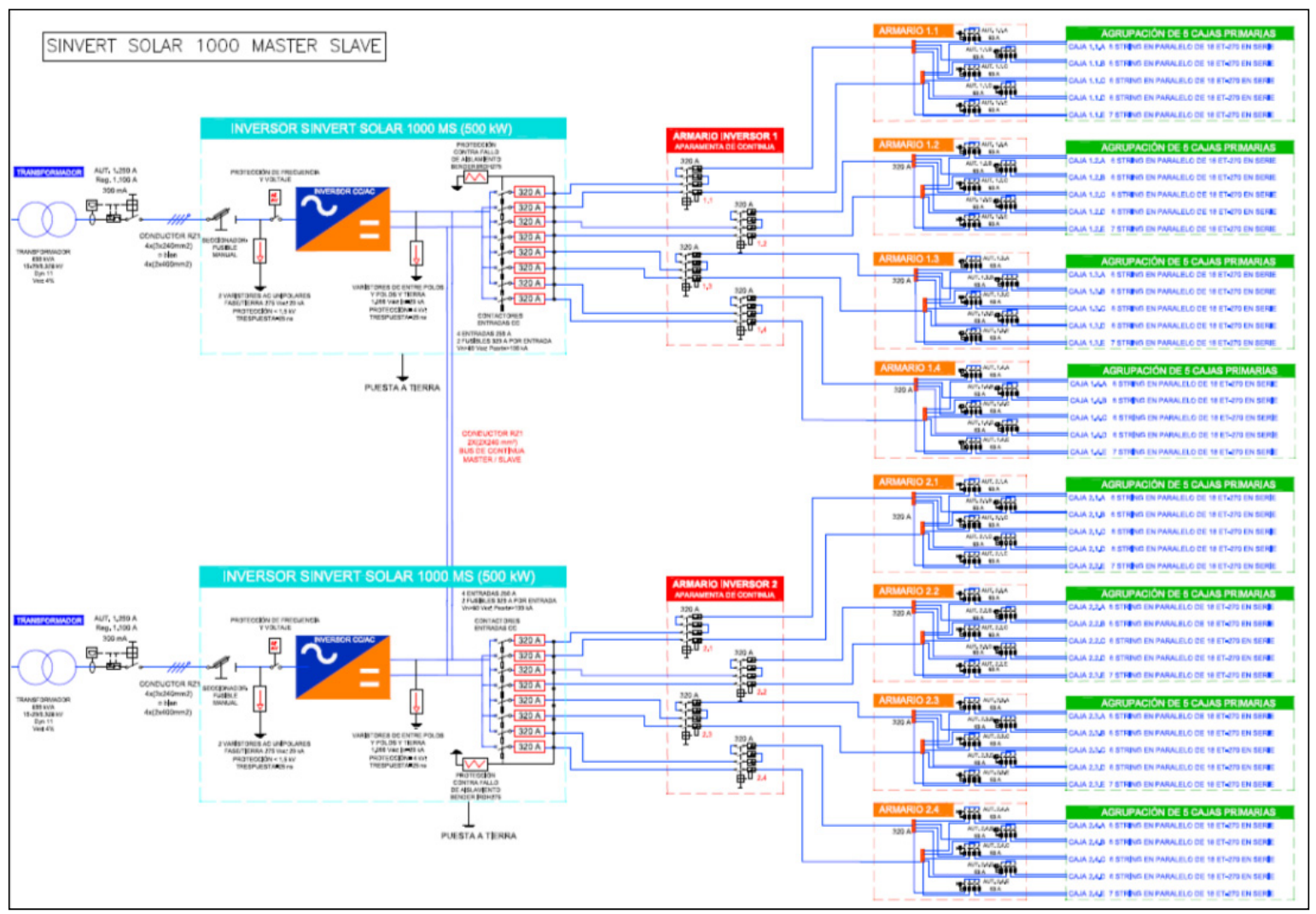

Figura 3.8 Esquema unifilar de la instalación.

\subsubsection{RED DE MEDIA TENSIÓN}

La red diseñada tiene por objeto la conexión del centro de transformación de la planta fotovoltaica EI Coronil IV con una línea soterrada de $15 \mathrm{kV}$ situada en la localidad de EI Coronil, mediante una línea eléctrica en doble circuito tipo subterráneo entubado, con una tensión de $15 \mathrm{kV}$, nivel de aislamiento según lista 2 (MIE-RAT 12), y una frecuencia de $50 \mathrm{~Hz}$. La sección de toda la línea será de $240 \mathrm{~mm}^{2}$, con cable tipo RHZ1 Al 18/30 kV.

La canalización estará formada por seis tubos de PVC de $200 \mathrm{~mm}$, de manera que dos tubos pertenezcan a la futura línea de evacuación de la planta "El Coronil V" mientras que otros dos tubos se utilizarán para el doble circuito de la línea del presente proyecto, dejando los dos tubos restantes de reserva. 


\subsubsection{CONCLUSIONES (CONCLUSIONS)}

Se han descrito las instalaciones fotovoltaicas comerciales que nos han servido de prototipo para el diseño y montaje de las experimentales, construidas en la Universidad Politécnica de Cartagena.

La primera instalación solar fotovoltaica, denominada Coronil II, es una planta de $10 \mathrm{MW}$ constituida por un total de 51412 módulos fotovoltaicos montados sobre estructura fija. Se ha descrito el campo fotovoltaico, distribución y características de los paneles que lo forman, la estructura soporte y elementos eléctricos de la instalación. En esta planta se han utilizado módulos de seis marcas diferentes, con un total de ocho potencias distintas. Con los datos proporcionados de la instalación, se ha elegido el modelo de panel que ofrece un mejor comportamiento eléctrico, siendo éste el que se ha utilizado en nuestra instalación experimental. Los datos recogidos en la planta fotovoltaica, durante los meses de Mayo, Junio, Julio y Agosto de 2010, se han filtrado para estudiar y analizar las variables eléctricas de los módulos fotovoltaicos del mismo modelo y características a los utilizados en las instalaciones experimentales, bajo unas condiciones ambientales similares de funcionamiento, con el fin de comparar el funcionamiento de los módulos en ambas instalaciones.

La segunda instalación fotovoltaica descrita (Coronil IV), corresponde a una planta agroenergética de $1 \mathrm{MW}$ de potencia nominal, con un total de 4464 paneles fotovoltaicos montados sobre la cubierta del invernadero o instalación agroenergética. Los módulos fotovoltaicos se corresponden al mismo modelo elegido en la instalación anterior. Del mismo modo se ha descrito la distribución del campo fotovoltaico, características de los módulos, estructura de la instalación y sus principales elementos eléctricos. Esta aplicación fotovoltaica implica que el módulo se encuentre cercano a la cubierta del invernadero, lo que cuestiona si las altas temperaturas del interior del invernadero afectan al modulo, debido a la transferencia de calor. Por este motivo, un prototipo que engloba una unidad estructural de toda la instalación, con las mismas características y materiales, ha sido diseñado y construido con el fin de estudio. Además se ha modificado la configuración original, modificando la separación en el canal bajo los módulos y el material de la cubierta para comparar el comportamiento de los paneles fotovoltaicos.

\section{CONCLUSIONS}

The commercial photovoltaic systems which have been used as prototype for the design and build of the experimental facility were studied and are described in this section.

The first solar photovoltaic system, referred to as Coronil II, is a solar plant which reaches $10 \mathrm{MW}$ of nominal power and is made up of 51412 photovoltaic panels ground-mounted on a fixed structure. The study includes the description of the photovoltaic plant, characteristics and distribution of the photovoltaic modules, and the base structure and 
the electric elements which take part in the plant. This plant has six different makes of modules, with a total of eight different levels of power. Using data from the solar plant from the different panel models, one of them was selected due to it providing better electrical behavior at high temperature. This is the one that was used in our experimental facilities. The collected measured data in the photovoltaic plant, in the months of May, June, July and August 2010, were screened to study and analyze the electrical variables of PV modules. These had the same model and features to those used in experimental facilities, under similar environmental conditions of operation. This process was done in order to compare the performance of the modules at both facilities.

The other commercial photovoltaic system (Coronil IV) is an agroenergetic or photovolatic greenhouse with $1 \mathrm{MW}$ of nominal power and is made up of 4464 photovoltaic modules which are placed on the roof of the greenhouse. The modules are the same model as what was chosen from the other plant. Similarly, the description and distribution of the photovoltaic system, the design of the structure which supports the panels, and the electrical elements were added. This photovoltaic application implies the modules were near the plastic roof of the greenhouse, so the high temperatures reached inside it could affect the panel behavior due to the heat transfer between inside and the air channel. For this reason, an experimental facility had been designed and built in order to study this influence. Moreover, the space of the air channel and the plastic of the roof were modified, resulting in a different configuration for comparison, and finally, the choosing of the one which provided the best electrical functionality of the panels. 


\subsection{INSTALACIONES FOTOVOLTAICAS EXPERIMENTALES DESARROLLADAS}

Este apartado está dedicado a la descripción de las instalaciones fotovoltaicas experimentales, diseñadas para el estudio y análisis del comportamiento eléctrico de los paneles fotovoltaicos. Se presentan las diferentes configuraciones ensayadas para cada instalación, planteadas con el fin de estudiar la posible mejora en el comportamiento eléctrico de los módulos fotovoltaicos mediante la refrigeración con aire en su cara posterior, aprovechando el efecto chimenea por convección natural y forzada.

La ubicación de ambas instalaciones fotovoltaicas de ensayo es la cubierta de los aularios del Campus Alfonso XIII de la Universidad Politécnica de Cartagena, donde además se encuentra la estación meteorológica utilizada en el registro de los datos que nos informan de las condiciones ambientales.

La instalación fotovoltaica sobre cubierta metálica engloba dos configuraciones, una mediante refrigeración por convección natural y otra por convección forzada. Cada una de ellas engloba diferentes casos, diferenciándose en la separación existente entre el panel fotovoltaico y la cubierta metálica. Con todas ellas, se pretende estudiar el comportamiento eléctrico del panel en cada caso, comparando las configuraciones para determinar la más idónea y desarrollar un modelo experimental que nos determine la temperatura de funcionamiento y su rendimiento en función de las variables influyentes.

Sin embargo, la instalación sobre la cubierta de invernadero ha sido diseñada para la refrigeración por convección natural. Esta configuración se ha estudiado también para diferentes secciones de paso de aire, variando la separación existente entre los módulos y el plástico. Además, se ha incorporado un material aislante sobre el plástico, para cada sección de paso para poder analizar la configuración más adecuada.

Toda la instrumentación utilizada para la toma y registro de los datos requeridos para el análisis de cada instalación, se ha descrito en este apartado.

\subsubsection{INSTALACIÓN FOTOVOLTAICA EXPERIMENTAL SOBRE CUBIERTA METÁLICA}

Con el fin de estudiar el comportamiento eléctrico de los paneles fotovoltaicos sobre una cubierta metálica para diferentes condiciones de refrigeración con aire por su cara posterior, se ha diseñado una instalación experimental que consta de dos módulos de iguales características. Ambos se fijarán a una misma estructura soporte, con la misma inclinación y bajo las mismas condiciones ambientales, sin embargo sólo uno de ellos se colocará sobre una superficie metálica, creando un canal de aire entre ambas superficies. Con ello, tendremos un panel fijo de referencia, para comparar el comportamiento de ambos para las diferentes configuraciones ensayadas. 
La técnica de refrigeración estudiada consiste en la utilización de aire como fluido caloportador, circulando por el conducto creado entre la cara posterior del panel y la cubierta metálica aprovechando el "efecto chimenea" creado por convección natural y en convección forzada por un ventilador.

El estudio de esta instalación en convección natural se centrará en analizar el comportamiento de las variables eléctricas entre ambos módulos fotovoltaicos, el de referencia y el panel sobre la cubierta metálica y la mayor o menor influencia de la temperatura de funcionamiento del panel en cada caso. Además, se analizarán las variables eléctricas y temperaturas para diferentes secciones de paso de aire, con el fin de conocer la configuración que permita una mayor refrigeración y por ende una mejora en el rendimiento.

Una vez estudiada en convección natural, la repercusión de la temperatura del panel en la producción eléctrica al estar emplazado sobre una cubierta dependiendo de la sección de paso, se estudiará y compararán los mismos casos en convección forzada. Un ventilador se encargará de impulsar el aire por el canal desde la parte inferior mediante el acoplamiento de una tobera metálica, para cada una de las secciones ensayadas en convección natural. Con esta configuración se pretende comparar la evolución de las temperaturas y las variables eléctricas entre el panel de referencia (aislado y bajo las condiciones ambientales) y el panel sobre la cubierta metálica refrigerado por convección forzada para diferentes secciones de paso de aire. Cada sección se ha ensayado a tres regímenes de funcionamiento del ventilador, fijando tres velocidades forzadas del aire en el canal para poder estudiar su influencia en la respuesta eléctrica del panel fotovoltaico.

Por último, se llevará a cabo un estudio comparativo de todos los resultados obtenidos para ambas configuraciones, convección natural y forzada, analizando la influencia de variables tales como el espesor del canal de aire y la velocidad forzada sobre la temperatura y eficiencia eléctrica del panel, comparándolo con el panel de referencia para así poder elegir la configuración más idónea y poder caracterizar su comportamiento obteniendo correlaciones explicitas.

\subsubsection{DISEÑO CONSTRUCTIVO DE LA INSTALACIÓN}

La instalación experimental diseñada consiste en una estructura base y otra soporte para fijar los paneles fotovoltaicos que se pretenden ensayar, para una geometría dada. Los dos paneles se soportan en una estructura tal y como se presenta en la Figura 3.9. La estructura soporte consta de unos perfiles L35 de acero galvanizado y dos pletinas simétricas de 50. En su parte inferior se ubican dos bisagras que permitirán fijar los soportes a una estructura base que se describirá posteriormente. Estos soportes fijos en su parte inferior, permiten variar de inclinación a través de unas barras tirantes fijadas en 
su lateral, atornillándolas en distintas posiciones a la estructura base, consiguiendo adoptar la inclinación deseada.

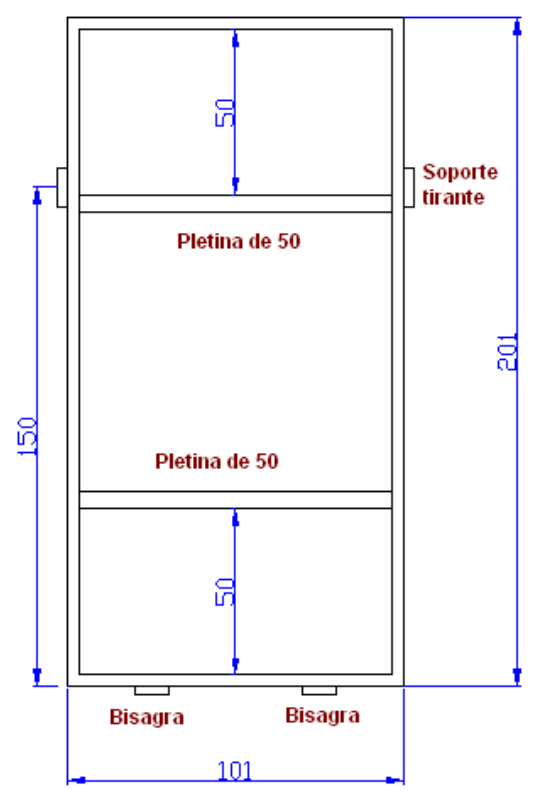

Figura 3.9 Estructura soporte del panel. Medidas en $\mathrm{cm}$.

Los paneles fotovoltaicos fijados mediante tornillos a sus soportes, se colocan sobre una estructura base que los elevará unos $750 \mathrm{~mm}$ del suelo, como se aprecia en el siguiente croquis (Figura 3.10). La base está construida con perfiles de $30 \times 30 \mathrm{~mm}$ de acero galvanizado y en ella se fijarán los dos módulos fotovoltaicos. En el alzado se aprecian las bisagras que fijan la estructura soporte de los paneles a ella y en la planta, la ubicación de los tirantes que atornillados darán la inclinación a los paneles.

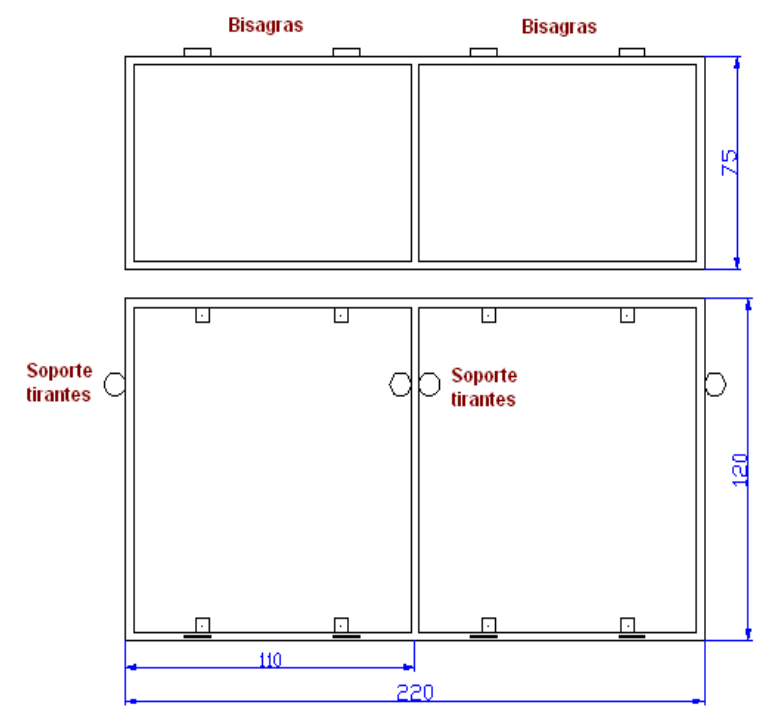

Figura 3.10 Alzado y planta de la estructura base. Medidas en cm. 
La estructura definida, ha sido diseñada con el fin de fijar y soportar los paneles fotovoltaicos, permitiéndoles adoptar diferente inclinación respecto la horizontal y adicionalmente conseguir elevarlos del suelo, para evitar cualquier influencia térmica de la superficie inferior, consiguiendo así que ambos se encuentren igualmente ventilados (por el viento exterior) y bajo las mismas condiciones ambientales (Figura 3.11).

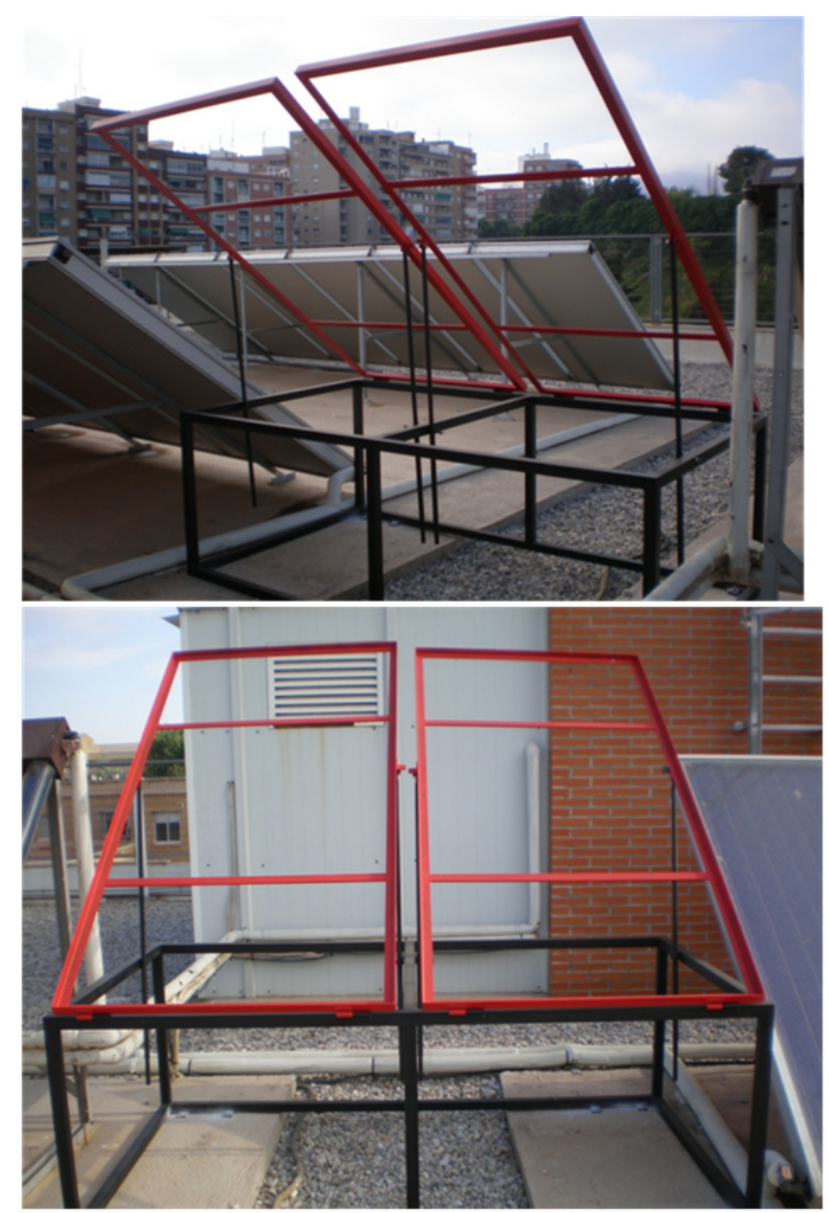

Figura 3.11 Fotografías de la estructura soporte y base de la instalación fotovoltaica experimental.

Como se ha mencionado, la instalación fotovoltaica de ensayo consta de dos módulos, uno de ellos lo designaremos como Panel A y otro como Panel B. Ambos paneles de silicio policristalino, se corresponden al modelo ET P672270, el mismo modelo utilizado en las instalaciones fotovoltaicas en explotación, descritas en el apartado anterior. Cada módulo tiene unas dimensiones de $2000 \times 1000 \times 50 \mathrm{~mm}$, y sus características eléctricas se incluyen en la siguiente figura. 


\begin{tabular}{|c|c|c|c|c|c|}
\hline Model type & ET-P672280 & ET-P672270 & ET-P672260 & ET-P672250 & ET-P672240 \\
\hline Peak power (Pmax) & $280 \mathrm{~W}$ & $270 \mathrm{~W}$ & $260 \mathrm{~W}$ & $250 \mathrm{~W}$ & $240 \mathrm{~W}$ \\
\hline Cell type & \multicolumn{5}{|c|}{ Potyerystalline Silicon, $156 \mathrm{~mm} \times 156 \mathrm{~mm}$} \\
\hline Number of cells & \multicolumn{5}{|c|}{72 cells in series } \\
\hline Weight & \multicolumn{5}{|c|}{$23.0 \mathrm{~kg}(50.7 \mathrm{lbs})$} \\
\hline Dimensions & \multicolumn{5}{|c|}{$1956 \times 992 \times 50 \mathrm{~mm}(77 \times 39.1 \times 2$ inch $)$} \\
\hline Maximum power voltage (Vmp) & $36.72 \mathrm{~V}$ & $36.40 \mathrm{~V}$ & $36.00 \mathrm{~V}$ & $35.20 \mathrm{~V}$ & $34.95 \mathrm{~V}$ \\
\hline Maximum power current (Imp) & $7.63 \mathrm{~A}$ & $7.42 \mathrm{~A}$ & $7.23 \mathrm{~A}$ & $7.12 \mathrm{~A}$ & $6.88 \mathrm{~A}$ \\
\hline Open circuit voltage (Voc) & $43.78 \mathrm{~V}$ & $43.63 \mathrm{~V}$ & $43.49 \mathrm{~V}$ & $43.20 \mathrm{~V}$ & $43.20 \mathrm{~V}$ \\
\hline Short circuit current (Isc) & $8.30 \mathrm{~A}$ & $8.10 \mathrm{~A}$ & $7.79 \mathrm{~A}$ & $7.70 \mathrm{~A}$ & $7.60 \mathrm{~A}$ \\
\hline Maximum system voltage & \multicolumn{5}{|c|}{ DC $1000 \mathrm{~V}$} \\
\hline Temp. Coeff. of Isc (TK Isc) & \multicolumn{5}{|c|}{$0.09 \% /{ }^{\prime C}$} \\
\hline Temp. Coeff, of Voc (TK Voc) & \multicolumn{5}{|c|}{$-0.34 \% / \mathrm{C}$} \\
\hline Temp. Coeff. of Pmax (TK Pmax) & \multicolumn{5}{|c|}{$-0.37 \% /{ }^{\prime} \mathrm{C}$} \\
\hline Normal Operating Cell Temperature & \multicolumn{5}{|c|}{$44.4 \pm 2^{\circ} \mathrm{C}$} \\
\hline
\end{tabular}

Figura 3.12 Características de los módulos fotovoltaicos utilizados en la instalación.

El Panel A se encuentra sobre la estructura que lo sostiene, quedando totalmente libre por su cara posterior de cualquier superficie. El comportamiento eléctrico de este panel así como la temperatura que alcance se toma de referencia, como la temperatura normal de funcionamiento de un panel fotovoltaico libre sobre estructura fija, dado que no está instalado sobre ninguna cubierta y no le puede afectar la temperatura de ningún sólido cercano, únicamente se verá afectado por las condiciones ambientales.

En cambio, el módulo fotovoltaico designado como Panel B, ubicado también sobre la estructura soporte presenta una plancheta metálica en la parte posterior del módulo, de pequeño espesor que simula la cubierta de cualquier vivienda o nave industrial. Esta plancheta se calentará conforme aumente la temperatura ambiente y la del módulo fotovoltaico, por lo que existirá un intercambio de calor entre ésta y el módulo, lo cual originará un aumento de la temperatura de funcionamiento del panel fotovoltaico. Estudiaremos el efecto de esta temperatura en el módulo, en su rendimiento eléctrico y potencia generada, y también analizaremos su comportamiento eléctrico utilizando diferentes métodos de refrigeración mediante convección natural y convección forzada, creando un canal de aire entre el panel y la plancheta metálica. Para ambas configuraciones, convección natural y forzada, cuatro secciones de paso de aire se han estudiado, aumentando la separación entre ambas superficies. La sección 1 es para una separación de $7.5 \mathrm{~cm}$ entre módulo y plancha metálica, la sección 2 de $10.5 \mathrm{~cm}$, la sección 3 de $13.5 \mathrm{~cm}$ y por último la sección 4 de $16.5 \mathrm{~cm}$. 


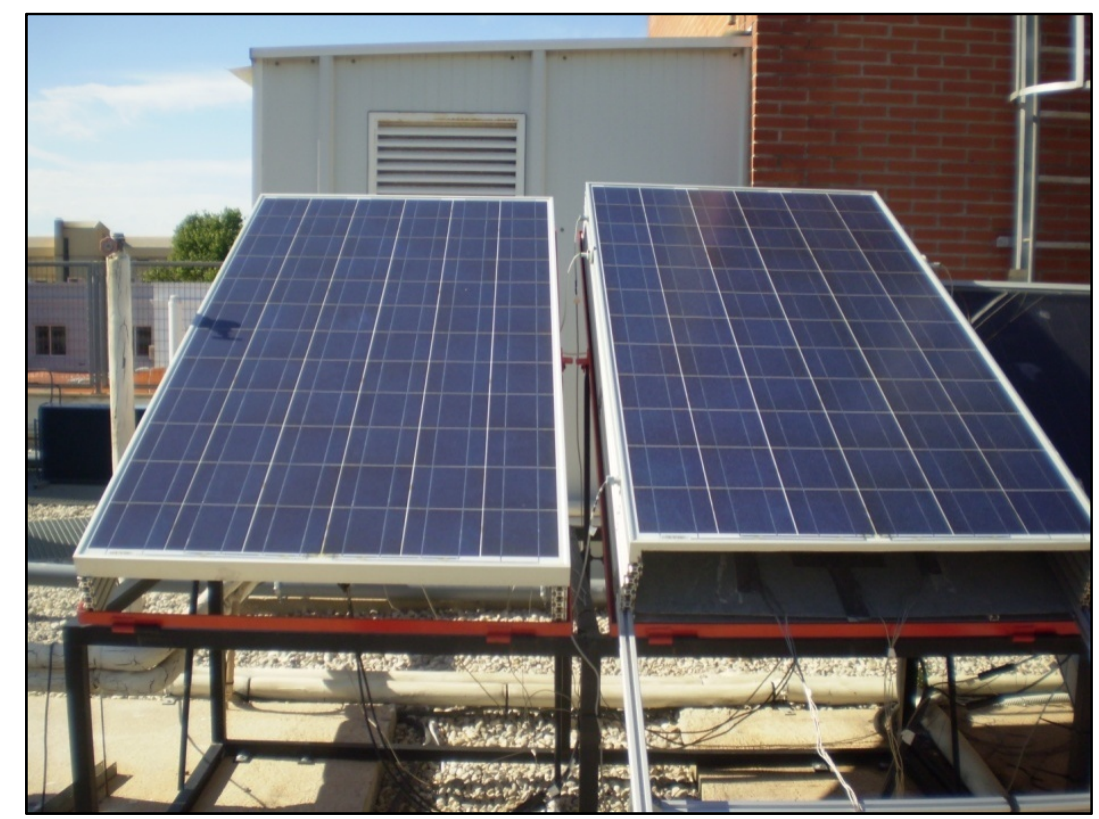

Figura 3.13 Instalación fotovoltaica experimental constituida por Panel A el izquierdo y Panel B el derecho en convección natural.

En la primera configuración ensayada, convección natural, estudiaremos el comportamiento eléctrico de ambos paneles, variando la sección de paso de aire bajo el panel B. Con los resultados obtenidos, se estudiarán las variables eléctricas de ambos paneles y así poder estudiar la influencia térmica, al estar colocado sobre una cubierta metálica (panel B), comparándolo con el panel A y además, elegir la sección del canal de aire que permita una mayor refrigeración del panel y con ello, mejor rendimiento.

Para ensayar la segunda configuración, convección forzada, utilizaremos los mismos sensores de medida que en convección natural, pero además se precisa de un ventilador de aspiración (TD 4000 de Soler \& Palau) para forzar el movimiento del aire en el canal, entre el módulo y la plancheta metálica. El ventilador se sitúa en la parte inferior del panel B que mediante una tobera metálica haremos el acoplamiento, intentando que el flujo sea lo más uniformemente posible (Figura 3.14). Por ello se han diseñado tres toberas diferentes, para el perfecto ajuste a las tres secciones de paso ensayadas, que corresponden a la sección 2 (10.5 cm de separación), la sección $3(13.5 \mathrm{~cm})$ y sección $4(16.5 \mathrm{~cm})$ estudiadas en convección natural. El panel A, no se refrigera por convección forzada, quedando siempre fijo a la estructura sin ninguna superficie inferior, considerándolo como de referencia. 


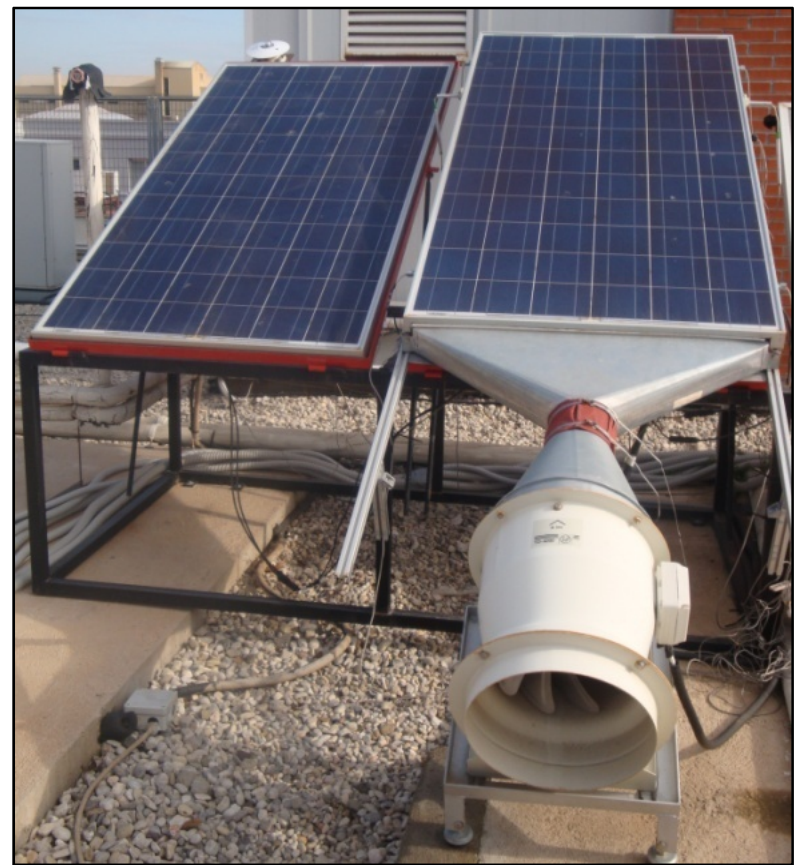

Figura 3.14 Instalación fotovoltaica experimental constituida por Panel A el izquierdo y Panel B el derecho en convección forzada.

Para cada una de las tres secciones de refrigeración de aire, se han realizado tres ensayos correspondientes a tres velocidades diferentes del ventilador. Un regulador de velocidad, conectado en serie ente el ventilador y su toma de corriente, nos ha permitido fijar tres regímenes de funcionamiento del ventilador proporcionando diferentes velocidades del aire en el canal. Las velocidades fijadas, que se han ensayado son de $3 \mathrm{~m} / \mathrm{s}, 4.5 \mathrm{~m} / \mathrm{s}$ y 6 $\mathrm{m} / \mathrm{s}$.

La instalación experimental ha sido instrumentada con diferentes sensores y aparatos de adquisición y registro de los datos necesarios para el análisis, cuyas especificaciones técnicas se detallarán más adelante. A continuación, se describirán los sensores utilizados así como su ubicación en la instalación y su finalidad.

La temperatura de ambos paneles es medida mediante cinco sondas de temperatura PT100 adhesivas y de cuatro hilos, colocadas simétricamente y en contacto con la cara posterior de cada módulo. Las correspondiente al panel $A$ se denominan como $A 1, A 2, A 3, A 4$ y $A 5$ y las del panel B como B1, B2, B3, B4 y B5. Con las cinco sondas adheridas a cada panel, se pretende conocer la distribución de la temperatura del panel, para así conocer la mayor o menor uniformidad térmica y además, poder obtener el valor medio que consideraremos en el análisis como el valor experimental de la temperatura de funcionamiento de cada panel.

En el canal de aire entre el panel $B$ y la plancha metálica se ubican cuatro sondas de temperatura, dos en la entrada (S3 y S4) y otras dos en la salida (S1 y S2), colocadas simétricamente. Estas sondas nos informaran de la temperatura del aire en el canal, tanto 
en la entrada como en la salida. El caudal de aire se puede calcular mediante los dos anemómetros (AN1 y AN2) que miden la velocidad del aire a través del conducto de sección contante, tanto en convección natural como en forzada. Estos anemómetros se han colocado dentro del canal, en una sección que se encuentra a $1.50 \mathrm{~m}$ desde la entrada del aire y lo suficientemente introducidos en el canal (a $0.35 \mathrm{~m}$ del borde del panel) para evitar los efectos de la pared en la distribución de velocidades.

Por último nos queda citar los sensores que nos informan de la temperatura de la plancheta metálica. Ocho sondas de temperatura adhesivas similares a las utilizadas en los paneles, se han fijado simétricamente en su cara superior, denominadas PC1, PC2, PC3,..., PC8.

En la siguiente figura se muestra la ubicación de todos los sensores mencionados, encargados de medir las variables termodinámicas correspondientes a los paneles y el canal de aire creado bajo el panel B.

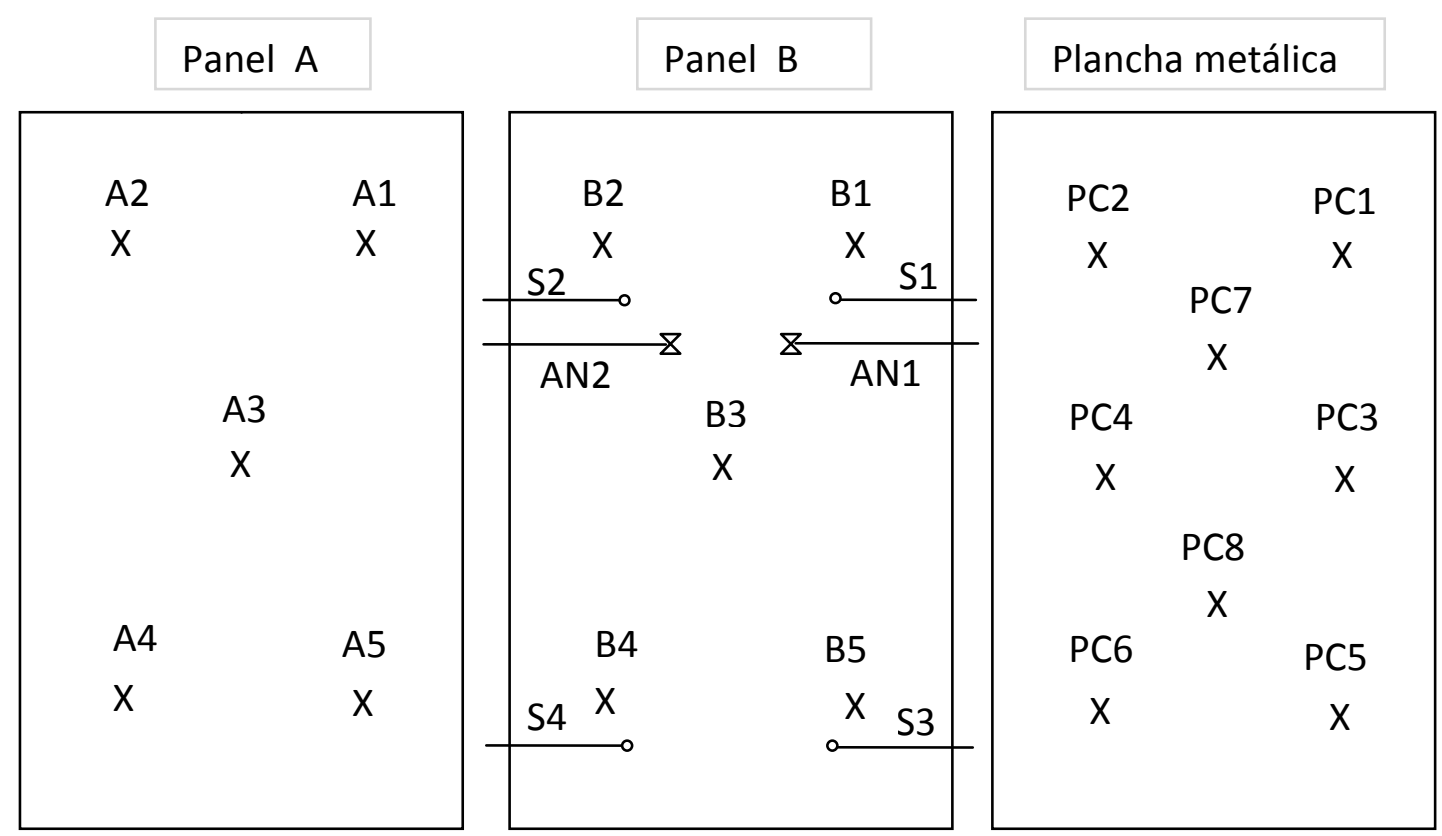

Figura 3.15 Representación de la ubicación de los sensores de medida en los paneles y cubierta metálica.

La radiación solar se mide con un piranómetro colocado sobre la estructura soporte de los paneles, parte superior al panel A, con el fin de que se encuentre con la misma inclinación que los módulos (Figura 3.14). Junto a la instalación experimental, se dispone de una estación meteorológica que nos proporciona los valores de la velocidad y dirección del viento, temperatura y humedad ambiental, radiación difusa y global. Estas variables serán igualmente registradas para el posterior análisis.

Uno se los objetivos de este trabajo, es estudiar el comportamiento eléctrico de los paneles fotovoltaicos para diferentes configuraciones. Para ello, necesitamos medir las variables eléctricas características tales como, tensión de circuito abierto $\left(V_{o c}\right)$, intensidad de 
cortocircuito $\left(I_{s c}\right)$, punto de máxima potencia $\left(P_{m}\right)$ y sus correspondientes valores de tensión e intensidad $\left(V_{m p}, I_{m p}\right)$. Personal docente e investigador del Departamento de Tecnología Electrónica diseñó y fabricó una carga o regulador electrónico diseñado para tal fin. Esta carga recibe la energía generada por el panel en cada instante. La carga permite variar la resistencia interna, para obtener los pares de valores de tensión e intensidad que definen la curva característica de cada panel. Pulsando unos segundo el botón disparo, se crea el cortocircuito para obtener la $I_{s c}$, la resistencia va aumentando considerablemente hasta que se llega al circuito abierto $V_{o c}$. Con una frecuencia alta de muestreo, se obtienen los pares de puntos que definen la curva característica, de entre los cuales podremos identificar el punto de máxima potencia $P_{m}$.

Todas las variables medidas, son registradas por el sistema de adquisición de datos o Data Logger conectado al ordenador. Se utilizará el software proporcionado por el sistema para el registro de todas las variables, creando dos configuraciones para el registro de los datos. Una de ellas que recoja las variables termodinámicas y otra las eléctricas de los paneles, ya que la frecuencia de muestreo es diferente.

\subsubsection{DESCRIPCIÓN DE LA INSTRUMENTACIÓN UTILIZADA}

A continuación se va a detallar la instrumentación empleada en la instalación experimental, para ello se va a hacer una diferenciación entre:

A) Condiciones ambientales: aquellos instrumentos que nos permiten obtener los valores de radiación solar y otras variables meteorológicas representativas.

B) Variables de operación: medición de los parámetros propios específicos que posibilitan la caracterización de la instalación experimental de estudio.

El emplazamiento de la instalación experimental así como de los dispositivos para la medición de las condiciones ambientales es el mismo, en la azotea del Aulario General del Campus universitario Alfonso XIII de la Universidad Politécnica de Cartagena.

\subsection{INSTRUMENTACIÓN PARA LA MEDIDA DE LAS CONDICIONES AMBIENTALES}

La estación meteorológica utilizada consta de una serie de aparatos de medida de las siguientes condiciones ambientales, necesarias para el análisis:

- Humedad relativa

- Temperatura ambiente

- Presión barométrica

- Velocidad del viento

- Dirección del viento

- Radiación global 
- Radiación difusa

En esta sección describiremos cada uno de ellos, incluyendo sus principales características.

\section{TRANSMISOR DE HUMEDAD RELATIVA Y TEMPERATURA AMBIENTE}

Este transmisor (Figura 3.16) nos proporciona conjuntamente las medidas de temperatura ambiente y humedad relativa. La medida de la temperatura se realiza mediante un sensor de temperatura Pt1000, que se basa en la variación de la resistencia del platino con la temperatura. La humedad relativa se mide mediante un dispositivo capacitivo $\mathrm{HC1000}$ de estado sólido, que cambia sus características eléctrica respondiendo a variaciones de humedad, de tal manera que al absorber la humedad disminuye la capacidad. Estos cambios son detectados, linealizados y amplificados por un circuito electrónico situado en la sonda que, además, compensa la humedad relativa con la temperatura.

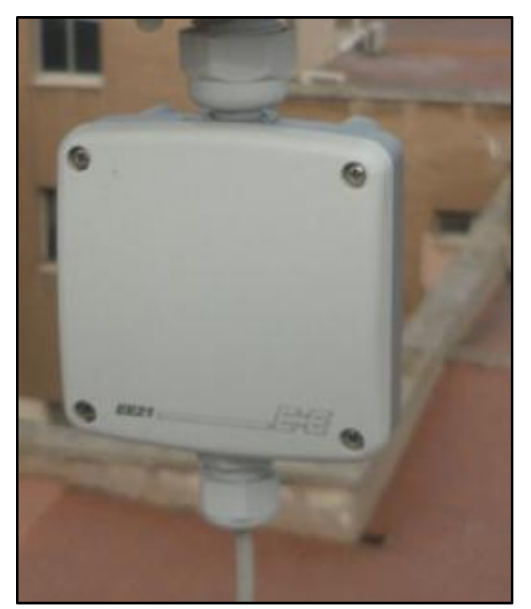

Figura 3.16 Fotografía del transmisor de humedad relativa y temperatura ambiente.

En resumen, la temperatura hace variar la resistencia de una sonda de platino, mientras que la humedad relativa varía las propiedades dieléctricas del material.

\section{- Principio de Operación}

Este aparato de medida, como se ha mencionado previamente, comprende dos sensores, temperatura ambiente y humedad relativa, por consiguiente los principios de funcionamiento de cada uno son diferentes.

\section{MEDIDA DE LA TEMPERATURA}

Para obtener el dato de la temperatura los transmisores llevan incorporados un detector de temperatura por resistencia (RTD) de platino (PRTD), la Pt 1000 clase A, DDIN-EN 60571. 
EI RTD es un sensor de temperatura basado en el cambio de resistividad que sufren las estructuras cristalinas de los metales con la temperatura, su comportamiento es aproximadamente lineal para ciertos metales.

Un RTD se fabrica para tener un valor nominal ' $R_{0}$ ' a una temperatura dada (por ejemplo $1000 \mathrm{ohms}$ a $0^{\circ} \mathrm{C}$ ). Al medir su resistencia a una temperatura desconocida y al compararla con $R_{0}$ (valor que se debe ajustar el resistor de referencia), puede conocerse la variación ' $d R$ '. Como la característica $R=f(T)$ también es conocida, la variación de resistencia ' $d T$ ' desde el punto inicial será conocida.

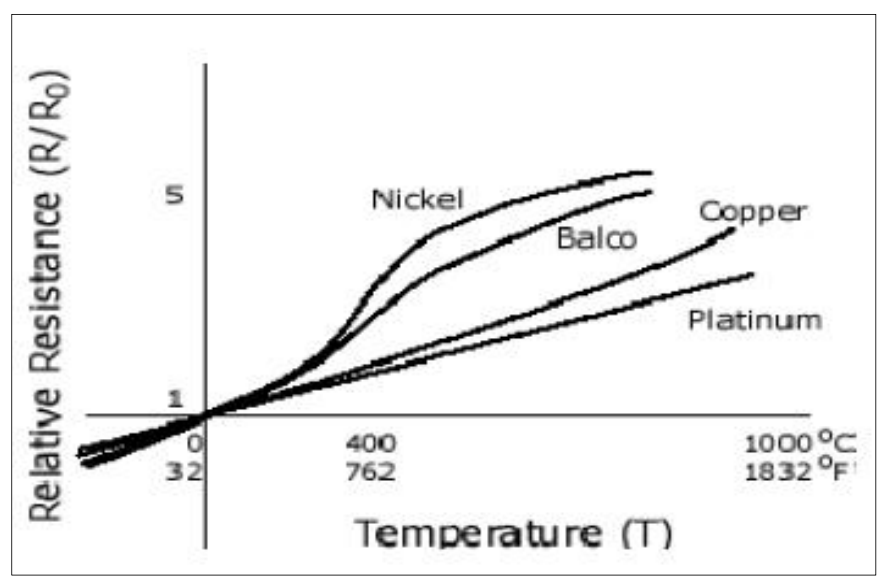

Figura 3.17 Curvas características de algunos metales.

El platino es el más popular de éstos, debido a su característica muy cercana a la linealidad en un rango amplio de temperaturas, estable a largo plazo. El coste de las PRTD's se vieron reducidos al implementarse en película delgada.

Las principales características encontradas en el platino son:

- Estabilidad química; resistencia a la oxidación y corrosión.

- Facilidad de manofactura.

- Disponibilidad de alambre de alta pureza.

- Buena reproducibilidad de características eléctricas (permite el poder reemplazar el elemento sensor sin tener que recalibrar el instrumento).

- Valores típicos: 100, 500, 1000 ohms.

- Identificación: Se identifican por el metal del que se componen (según la tabla periódica) y la resistencia que presentan a $0^{\circ} \mathrm{C}$. Ejemplo; Pt100, Ni120, Cu200, etc.

- Precision de los RTD (dada alrededor de los $0^{\circ} \mathrm{C}$, donde es mayor): Clase $\mathrm{A}$ es $\pm 0.15^{\circ} \mathrm{C}$ y Clase B es $\pm 0.30^{\circ} \mathrm{C}$. 


\section{MEDIDA DE LA HUMEDAD RELATIVA}

Para la medida de la humedad relativa se utiliza un sensor capacitivo. Los sensores capacitivos son quizás los más difundidos en la industria y meteorología, pues son de fácil producción, bajo coste y alta fidelidad. El principio en el cual se basa este tipo de sensor, es en el cambio que sufre la capacidad de un condensador al variar la constante dieléctrica del mismo. Si se utiliza la mezcla gaseosa como dieléctrico entre las placas del condensador, el valor de este estará determinado por:

$$
C=\varepsilon \frac{A_{c}}{d}
$$

Por lo que el valor de $C$ del condensador va a variar dependiendo de la cantidad de moléculas de agua que estén presentes entre las placas. En consecuencia basta medir, o convertir el cambio de capacitancia, a otro tipo de variable eléctrica más fácil de manejar, lo anterior se puede lograr con un puente de Wheatstone de condensadores, o un circuito resonante, o también utilizar el condensador como componente de un oscilador estable que varía su frecuencia de acuerdo al cambio de $C$.

La implementación de este sensor puede ser de variadas formas, ya sea con placas cilíndricas concéntricas o placas rectangulares paralelas. También se puede emplear un material higroscópico, para aumentar la concentración de agua ente las placas. En la Figura 3.18 Esquema de construcción del dieléctricose aprecia un posible esquema de construcción.

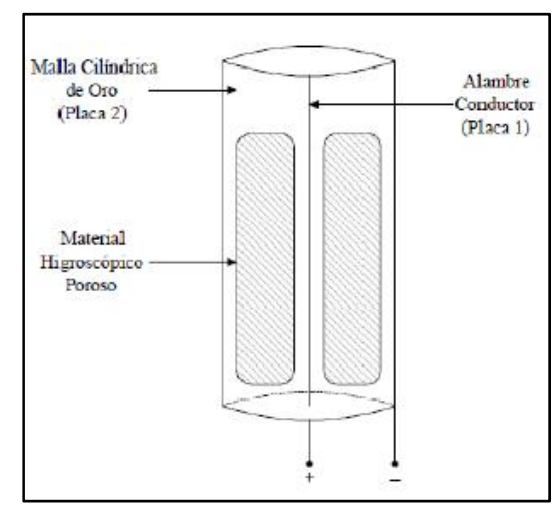

Figura 3.18 Esquema de construcción del dieléctrico

Se utiliza una de las placas como un alambre conductor, mientras que la otra es una malla fina de oro que permite el paso del gas, pero retiene impurezas. Como dieléctrico se utiliza un material higroscópico poroso (cerámico) que rodea el alambre, el cual absorbe el agua de la muestra, aumentando aun más la constante dieléctrica del condensador, en proporción a la humedad relativa existente. Las relaciones entre las variables físicas que son consideradas en este sensor se aprecian en la siguiente figura. 


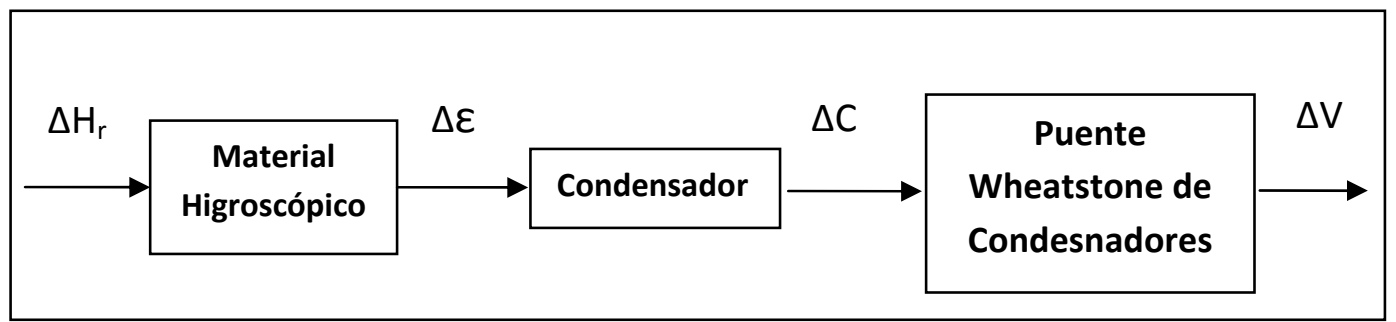

Figura 3.19 Esquema de la relación entre las variables en un dieléctrico.

Las principales características del sensor de medida de humedad relativa y temperatura ambiente, vienen recogidas en la Tabla 3.3

\begin{tabular}{|c|c|c|}
\hline & $\begin{array}{c}\text { Temperatura } \\
\text { Ambiente } \\
\end{array}$ & $\begin{array}{c}\text { Humedad } \\
\text { Relativa }\end{array}$ \\
\hline Modelo & \multicolumn{2}{|c|}{ EE21-FT1A56/T24 } \\
\hline Fabricante & \multicolumn{2}{|c|}{ E+E Elektronik } \\
\hline Rango & & $0-90 \%$ \\
\hline Tipo de sensor & Pt 1000 Clase A & HC 1000 \\
\hline Exactitud & $\begin{array}{c} \pm 0,2^{\circ} \text { a } 20^{\circ} \mathrm{C} \\
\pm 0,4^{\circ} \text { a } 0^{\circ} \mathrm{y} \\
45^{\circ} \mathrm{C} \\
\end{array}$ & $\begin{array}{c} \pm 2 \% \text { hasta } 90 \% \\
\pm 3 \% \text { hasta } \\
100 \%\end{array}$ \\
\hline Histéresis & & $<2 \% \mathrm{HR}$ \\
\hline Temperatura de operación & & $-40 \mathrm{a}+60^{\circ} \mathrm{C}$ \\
\hline Dependencia de la temperatura & & $0,06 \% \mathrm{HR} /{ }^{\circ} \mathrm{C}$ \\
\hline Salida & $0-1 \mathrm{Vcc}$ & $0-1$ Vcc \\
\hline Alimentación & $10-35 \mathrm{Vcc}$ & \\
\hline Temperatura de operación & $-35 \mathrm{a}+70^{\circ} \mathrm{C}$ & $5 \%$ a $100 \%$ \\
\hline
\end{tabular}

Tabla 3.3 Características del sensor de humedad relativa y temperatura ambiente.

La normativa recoge que hay que realizar tres medidas de temperatura, la de entrada y salida del colector y la de la temperatura ambiente, para la cual el sensor debe estar sombreado de la radiación solar directa. Dado que en nuestro caso nos concierne, esto se conseguirá por medio de un protector o pantalla de radiación solar.

El transmisor lleva como accesorio una pantalla o protector de radiación solar, cuyo fin es el de evitar que en la toma de medidas de la humedad relativa y de la temperatura afecte la radiación solar. Actualmente existen dos tipos de apantallamiento, los que funcionan con ventilación forzada o los de ventilación natural, siendo éste último tipo el que se dispone en la instalación.

Este dispositivo de apantallamiento múltiple protege al sensor de temperatura de la radiación directa y difusa, ya que, si ésta incidiese directamente sobre él, se registrarían medidas muy superiores a la real. Su efecto sobre el sensor de humedad Relativa es el de evitar la condensación o la lluvia, eliminando el efecto de histéresis que se produciría. 


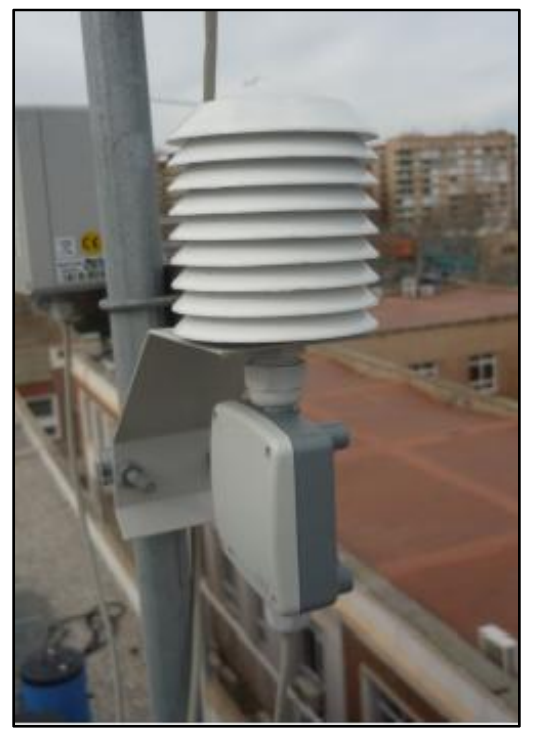

Figura 3.20 Dispositivo de protección a la radiación solar.

El protector utilizado es del modelo EE21, recomendado para la utilización al aire libre pues permite su uso en ambientes muy contaminados, puesto que posee una capa especial de protección para el elemento de detección. Su diseño es tal que permite la ventilación natural y facilita el acceso al sensor par su montaje y desmontaje.

\section{TRANSMISOR DE PRESIÓN BAROMÉTRICA}

Este transmisor (Figura 3.21) consiste en un barómetro electrónico que utiliza un sensor piezoresistivo compuesto por una membrana cuya deflexión nos proporciona el valor de la medida de la presión atmosférica.

La señal de salida de este sensor está condicionada para proveer un voltaje o corriente de salida linealmente proporcional a la presión atmosférica.

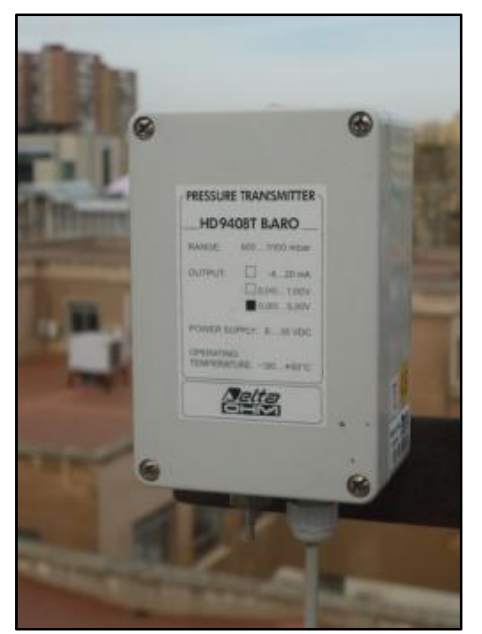

Figura 3.21 Transmisor de presión barométrica. 


\section{- Principio de Operación}

Su funcionamiento se basa en un sensor piezoresistivo, generalmente está compuesto por un chip de silicio grabado sobre una membrana (lamina de constante elástica conocida).

En nuestro caso se trata de una membrana de material cerámico especial, sobre la cual existen cuatro resistencias de medición dispuestas en un puente de Wheatstone. Esta membrana es sometida por un lado a una presión desconocida y por otro está abierta a la atmósfera, tomándose por tanto la presión atmosférica como referencia. Esta presión desconocida provoca la flexión de la membrana y por tanto una variación de las resistencias proporcional y lineal a la presión aplicada.

La Figura 3.22 refleja la disposición eléctrica de un puente de Wheatstone, siendo $R_{x}$ un valor desconocido que queremos encontrar, mientras que $R_{1}, R_{2}, R_{3}$ son valores conocidos ( $R_{2}$ es un valor variable). Con este circuito se busca el equilibrio, es decir, que el valor de las resistencia $R_{1}$ y $R_{2}$ sean igual a $R_{x}$ y $R_{3}$ respectivamente. Con esto se conseguirá un estado de equilibrio (no circula corriente entre los puntos $\mathrm{A}$ y $\mathrm{B}$ ).

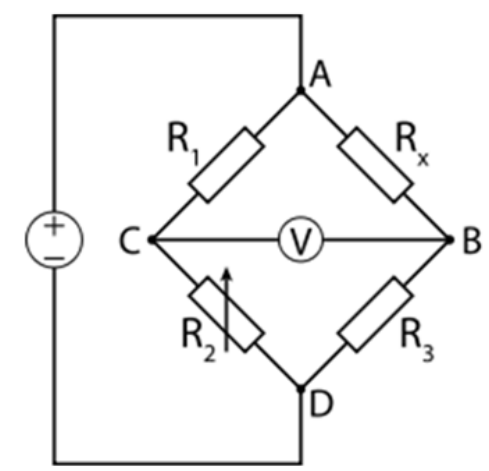

Figura 3.22 Esquema eléctrico del puente de Wheatstone.

En el estado de equilibrio se cumple la ecuación:

$$
R_{x}=\frac{R_{1} \cdot R_{3}}{R_{2}}
$$

A la menor variación de $R_{x}$ se modifica el estado de equilibrio y además se obtiene una salida proporcional a la variación existente. Esta salida normalmente suele ser amplificada.

La Figura 3.23 muestra un ejemplo de un sensor piezoresistivo. Los materiales de los que está compuesto pueden variar en función del fabricante. 


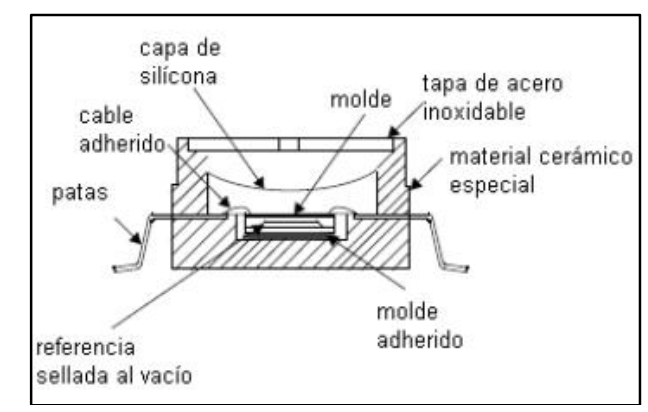

Figura 3.23 Esquema de un sensor piezoresistivo.

Las principales ventajas que presenta el sensor piezoresistivo son:

- Linealidad: valor de la desviación máxima de la curva característica de la línea ideal entre el punto cero y el punto final.

- Elevada exactitud

- Excelente comportamiento histéresis: en términos técnicos, histéresis significa la diferencia de la señal de salida de presión de camino hacia el rango final de medición y retorno

En la medición de presión, debido a la histéresis, el manómetro puede visualizar un valor diferente en el mismo punto del camino de subida (hacia el valor final del rango de medición) que en el retorno (hacia el punto cero).

Como desventaja, podemos destacar su pequeño tamaño que lo convierte en bastante susceptible a las fluctuaciones de temperatura (el sensor debe tener compensada la temperatura).

Las especificaciones dadas por el fabricante que lo caracterizan se recogen en la siguiente tabla.

\begin{tabular}{|l|c|}
\cline { 2 - 2 } \multicolumn{1}{c|}{} & Presión barométrica \\
\hline Modelo & HD 9408T BARO \\
\hline Tipo de sensor & Piezoresistivo \\
\hline Fabricante & Delta OHM \\
\hline Rango & $800-1100 \mathrm{mbar}$ \\
\hline Exactitud & $\pm 0,4$ mbar a $20^{\circ}$ \\
\hline Resolución & Infinita \\
\hline Salida & $0-5 \mathrm{Vcc}$ \\
\hline Alimentación & $9-30 \mathrm{Vcc}$ \\
\hline Temperatura de operación & $-40 \mathrm{a}+60^{\circ} \mathrm{C}$ \\
\hline
\end{tabular}

Tabla 3.4 Características del transmisor de presión barométrica. 


\section{ANEMÓMETRO}

Para obtener las medidas de velocidad y dirección del viento se ha utilizado un anemómetro ultrasónico (Figura 3.24), cuya principal ventaja es que emplea un sensor único sin partes móviles para la obtención de estas medidas.

Normalmente la velocidad y dirección del viento se mide por sensores separados. La dirección del viento se ha determinado por veletas durante muchos siglos, actualmente se utilizan como sensores meteorológicos pequeñas veletas para impulsar el contacto deslizante de un potenciómetro circular que proporciona una resistencia variable, o señal eléctrica proporcional a la dirección del viento en grados a partir del norte, conocida como la banda muerta del sensor.

En los últimos años, se han desarrollado anemómetros ultrasónicos. Las ventajas del sensor eólico ultrasónico son:

- Es un sensor único para medir la velocidad y dirección del viento.

- Abarca los 360 grados.

- No tiene partes móviles.

- Su puesta en funcionamiento es posible a velocidades de arranque muy bajas, es decir, condiciones de poco viento.

- La calibración puede realizarse en el lugar (una simple verificación de 'viento cero').

- Es de poco peso y compacto con un montaje estándar. El procesamiento integrado con salidas digitales o analógicas permite la interfaz directa con los sistemas actuales de medición de viento. 


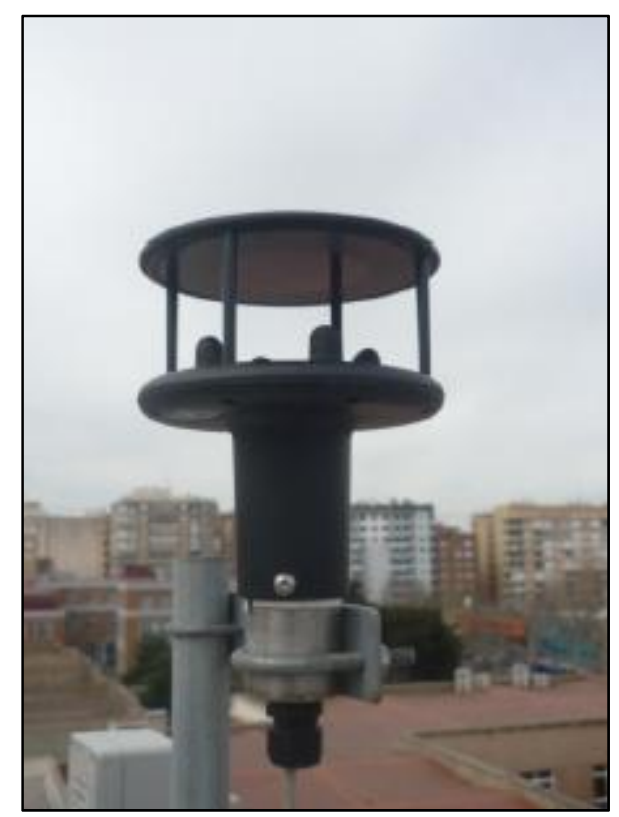

Figura 3.24 Anemómetro ultrasónico.

\section{- Principio de Operación}

Este anemómetro mide el tiempo utilizado por un pulso de sonido ultrasónico para viajar desde el transductor Norte hasta el transductor Sur, y lo compara con el tiempo utilizado por un pulso para viajar desde el transductor Sur al Norte. De la misma forma son comparados los tiempos entre el Oeste y el Este, y del transductor Este al Oeste.

Por ejemplo, si un viento del norte sopla, el tiempo utilizado por el pulso para viajar desde el Norte al Sur será más rápido que desde Sur a Norte, mientras que los tiempos de Oeste a Este y de Este a Oeste serán iguales. Entonces la velocidad y la dirección del viento se pueden calcular mediante las diferencias en los tiempos de vuelo en cada eje. Este cálculo es independiente de factores tales como la temperatura.

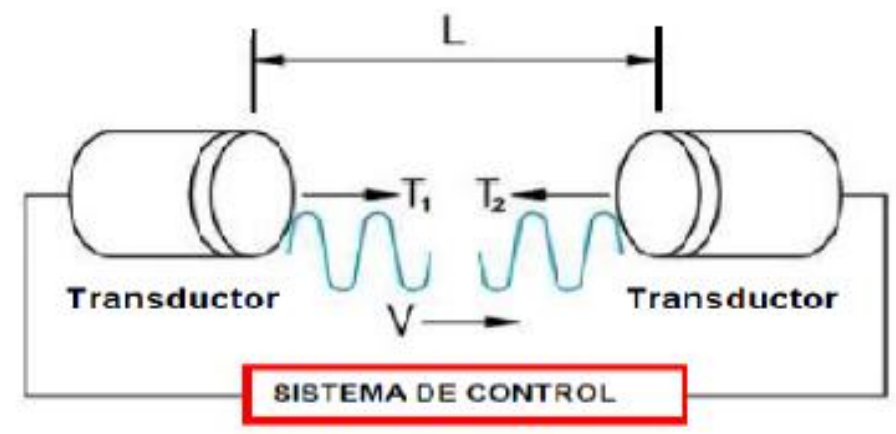

Figura 3.25 Esquema gráfico del funcionamiento del anemómetro ultrasónico.

Por consiguiente, obtendremos la dirección y velocidad del viento a partir del cálculo del tiempo empleado en recibir un determinado impulso de ultrasonidos en diversas direcciones. 
Las características técnicas del anemómetro ultrasónico se muestran a continuación.

\begin{tabular}{|l|c|c|}
\cline { 2 - 3 } \multicolumn{1}{c|}{} & \multicolumn{2}{c|}{ Anemómetro } \\
\cline { 2 - 3 } \multicolumn{1}{c|}{} & Velocidad & Dirección \\
\hline Modelo & \multicolumn{2}{c|}{ Windsonic } \\
\hline Fabricante & \multicolumn{2}{c|}{ Gill Instruments Ltd. } \\
\hline Rango & $0-60 \mathrm{~m} / \mathrm{s}$ & $0-359^{\circ}$ \\
\hline Exactitud & $\pm 2 \%$ & $\pm 3^{\circ}$ \\
\hline Resolución & $0.01 \mathrm{~m} / \mathrm{s}$ & $1^{\circ}$ \\
\hline Salida & $0-5 \mathrm{Vcc}$ & $0-5 \mathrm{Vcc}$ \\
\hline Alimentación & \multicolumn{2}{c|}{$9-30 \mathrm{Vcc}$} \\
\hline Protección & \multicolumn{2}{c|}{$\mathrm{IP} 65$} \\
\hline Temperatura de operación & $-35 \mathrm{a}+70^{\circ} \mathrm{C}$ & $5 \%$ a $100 \%$ \\
\hline
\end{tabular}

Tabla 3.5 Características del anemómetro.

\section{PIRANÓMETROS}

En la estación meteorológica se dispone de dos piranómetros; uno para la obtención de la radiación global y otro para la radiación difusa.

Estos piranómetros reciben la radiación solar de toda la bóveda celeste de forma que con ellos se puede medir tanto la radiación global como la difusa, si bien, para medir esta última es necesario instalar una banda de sombra, que bloquee la radiación directa recibida del Sol, evitando con ello la visión del disco solar en su recorrido diario.

Están basados en el efecto termoeléctrico, que consiste en la conversión directa de la diferencia de temperatura a voltaje eléctrico.

Será necesaria la utilización de amplificadores. En nuestra instalación hemos colocado dos con los que conseguimos amplificar el voltaje de salida de los sensores de radiación al nivel adecuado para la adquisición y transmisión de datos. 


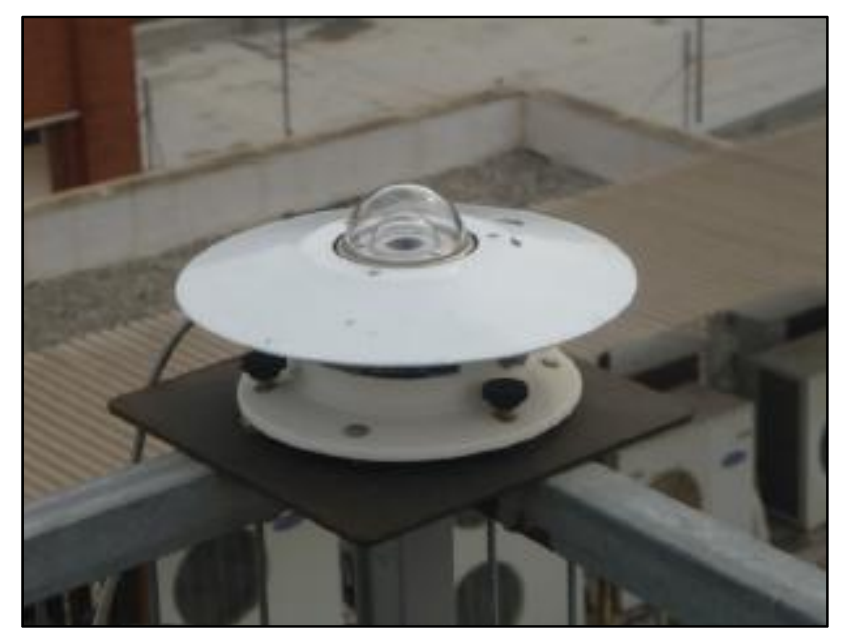

Figura 3.26 Piranómetro empleado para la medida de la radiación global.

\section{- Principio de Operación}

Estos piranómetros se basan en el efecto termoeléctrico, por el cual se genera electricidad a partir de la diferencia de temperatura entre diversas zonas del aparato, gracias a termopilas que tienen la capacidad de resistir el choque y las vibraciones mecánicas.

Cuando el sol ilumina al piranómetro, la radiación absorbida produce una disipación de calor hacia los bordes del disco cerámico. La temperatura en el centro del disco es mayor debido a la resistencia térmica del disco. Esta diferencia de temperaturas genera una señal eléctrica proporcional en origen a la propia irradiación absorbida y de este modo se puede calcular el valor de la radiación.

Los piranómetros utilizados constan de dos cúpulas, cuya función principal es filtrar la radiación infrarroja procedente de la atmósfera y la radiación de onda corta procedente del sol, evitando que alcance el receptor (Figura 3.27). Está constituido por una termopila, cuya unión caliente está recubierta de una pintura de alta absortividad. El cuerpo del instrumento, constituido por una pieza cilíndrica de bronce protegida por un disco de guarda pintado para reducir la absorción de irradiación solar, aloja los circuitos electrónicos y sirve de sumidero de calor para la unión fría de la termopila. El instrumento está dotado de un desecante para evitar la condensación en el interior del instrumento y de un nivel de burbuja para facilitar la nivelación. Mientras que su respuesta espectral es prácticamente plana en todo intervalo de interés, la mayor fuente de incertidumbre es su respuesta direccional. 


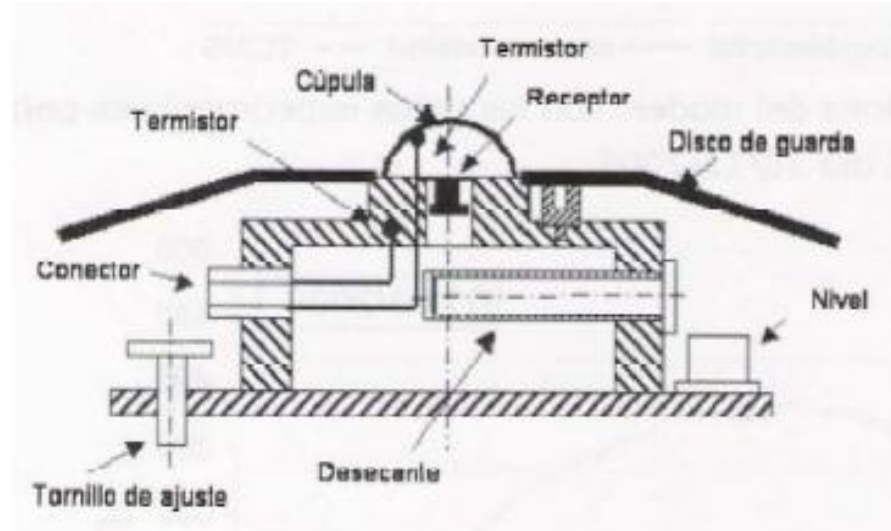

Figura 3.27 Esquema de la constitución interna del piranómetro.

Como se mencionó previamente, la medida de la radiación difusa, o radiación solar procedente de la dispersión de los rayos solares por los constituyentes atmosféricos, se realiza con piranómetros, a los que se acopla un elemento denominado banda de sombra, cuya función es evitar que la radiación directa alcance el receptor.

La banda de sombra debe de ser colocada en un lugar donde se asegure la incidencia del sol durante todo el periodo del año y durante todo el momento del día, esto quiere decir que no se podrá instalar la banda de sombra entre árboles o edificios, también es importante no instalarla cerca de tendidos eléctricos y es aconsejable vallar la instalación.

La inclinación es necesaria reajustarla, dependiendo de la época del año será necesario reajustarlo cada 5 o 20 días. Debido a la geometría de este aparato de medida (Figura 3.28), la banda de sombra evita que incida sobre el sensor una parte de la radiación difusa proveniente del cielo, por lo que es necesario aplicar un factor de corrección a las medidas. Debido al carácter anisótropo de la radiación difusa, el máximo se registra próximo al sol, hace que la determinación de este factor de corrección sea compleja, y se realiza mediante combinación de consideraciones teóricas y aproximaciones empíricas. En España este factor de corrección se ajustará a 1.15 y se dejará fijo para toda época del año. 


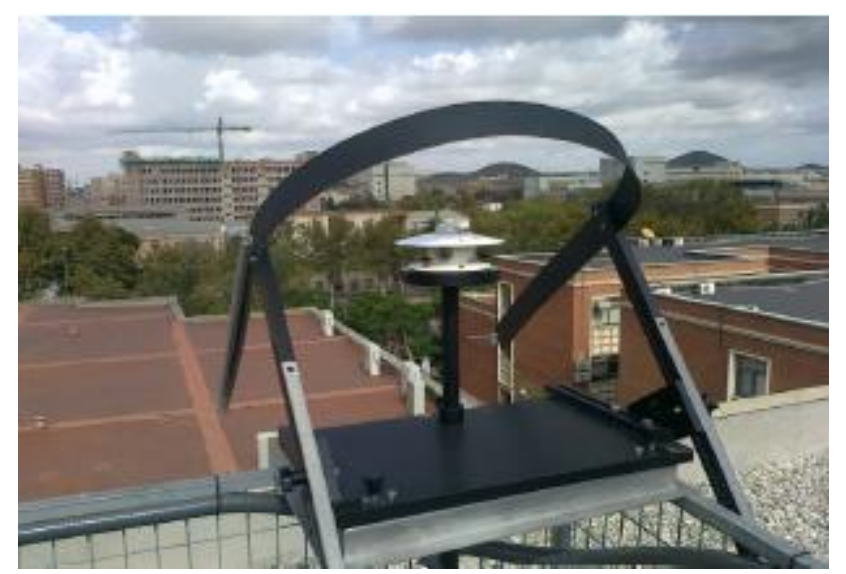

Figura 3.28 Banda de sombra del piranómetro que registra la radiación difusa.

Las especificaciones técnicas de ambos piranómetros así como sus amplificaciones utilizados se recogen en la Tabla 3.6.

\begin{tabular}{|c|c|c|}
\hline & \multirow{2}{*}{\multicolumn{2}{|c|}{ Piranómetros }} \\
\hline & & \\
\hline & Radiación global & Radiación difusa \\
\hline № de serie & $35672 \mathrm{~F} 3$ & $35681 \mathrm{~F} 3$ \\
\hline Fabricante & \multicolumn{2}{|c|}{$\begin{array}{c}\text { EPPLET Lab. Inc. } \\
\text { Piranómetro termoeléctrico PSP }\end{array}$} \\
\hline Clase & \multicolumn{2}{|c|}{ Secondary Standard } \\
\hline $\begin{array}{l}\text { Rango Comportamiento } \\
\text { Temperatura }\end{array}$ & \multicolumn{2}{|c|}{$-20^{\circ} \mathrm{C}-+40^{\circ} \mathrm{C}$} \\
\hline Resistencia & $697 \Omega 23^{\circ} \mathrm{C}$ & $714 \Omega 23^{\circ} \mathrm{C}$ \\
\hline \multirow[t]{2}{*}{ Sensibilidad } & $8.97 \cdot 10^{-6} \mathrm{~V} / \mathrm{Wm}^{2}$ & $8.80 \cdot 10^{-6} \mathrm{~V} / \mathrm{Wm}^{2}$ \\
\hline & \multicolumn{2}{|c|}{ Amplificador AC-420 } \\
\hline Rango de temperatura & \multicolumn{2}{|c|}{$-20^{\circ}-+50^{\circ} \mathrm{C}$} \\
\hline Deriva de cero & \multicolumn{2}{|c|}{$<0.25 \mu \mathrm{A} /{ }^{\circ} \mathrm{C}$} \\
\hline Deriva de rango & \multicolumn{2}{|c|}{$<0.01 \% /{ }^{\circ} \mathrm{C}$} \\
\hline Tensión de lazo & \multicolumn{2}{|c|}{$8-28 V_{D C}$} \\
\hline Exactitud & \multicolumn{2}{|c|}{$0.1 \%$} \\
\hline № de serie & 09042902 & 09042901 \\
\hline \multirow[b]{2}{*}{ Calibración } & $0 \mathrm{mV} \rightarrow 4 \mathrm{~mA}$ & $0 \mathrm{mV} \rightarrow 4 \mathrm{~mA}$ \\
\hline & $\begin{array}{l}8.971 \mathrm{mV} \rightarrow \\
13.999 \mathrm{~mA}\end{array}$ & $8.8 \mathrm{mV} \rightarrow 14 \mathrm{~mA}$ \\
\hline
\end{tabular}

Tabla 3.6 Características técnicas de los piranómetros y amplificadores. 


\section{CÉLULA FOTOVOLTAICA}

Para la obtención de la medida de la radiación global, se precisa además de una célula fotovoltaica monocristalina (Figura 3.29), a nivel comparativo con los piranómetros espectrales definidos.

Un sensor fotovoltaico se compone de una célula solar que produce una corriente eléctrica proporcional a la irradiación incidente, mediante el efecto fotovoltaico. Debido a que la respuesta espectral de las células fotovoltaicas no coincide totalmente con el espectro solar, la medida de una célula fotovoltaica es menos fiable que la de un piranómetro termoeléctrico. El objetivo que se pretende con el uso de la célula fotovoltaica es el conseguir sistemas a coste bajo para poder competir con los sistemas tradicionales.

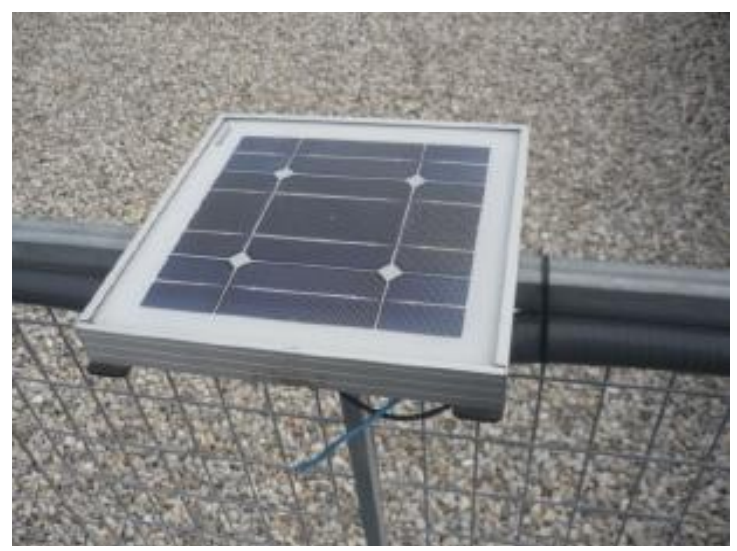

Figura 3.29 Célula fotovoltaica calibrada.

\section{- Principio de Operación}

Como se explicó en el capítulo 3, la célula fotovoltaica es un dispositivo electrónico, que permite convertir la radiación solar que incide sobre ella directamente en energía eléctrica gracias al efecto fotovoltaico. Cuando la luz, que es un flujo de fotones con determinada energía, incide en el material semiconductor con el que se fabrica la célula, cada fotón puede ceder su energía a los electrones del material de forma que pueden moverse libremente, generándose una corriente eléctrica. Para poder extraer la corriente del material de forma que sea útil, es necesario generar una pequeña diferencia de potencial (alrededor de 1 Voltio) entre los electrodos de la célula. Esto se consigue dopando el material de forma selectiva, tipo $\mathrm{p} /$ tipo $\mathrm{n}$, tal y como se presenta en la siguiente figura. 


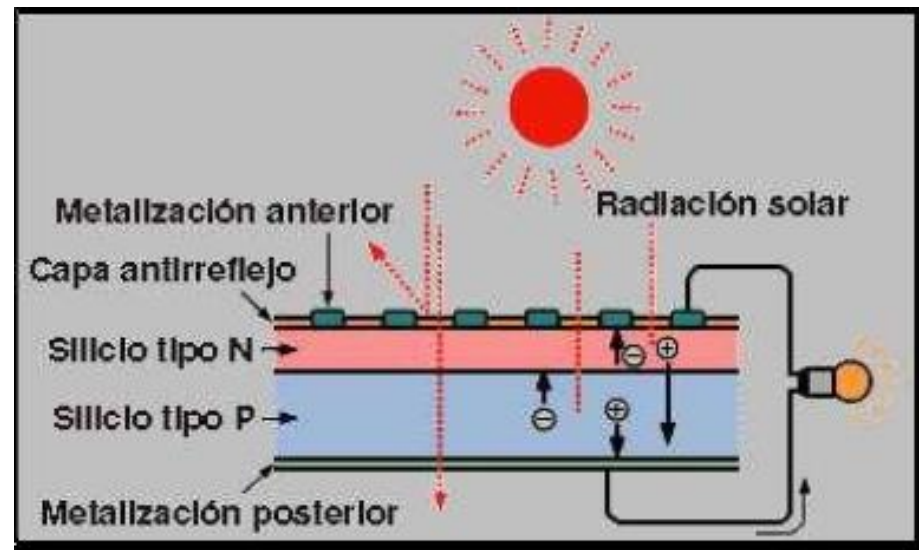

Figura 3.30 Principio de funcionamiento de una célula fotovoltaica, efecto fotovoltaico.

Las características de la célula fotovoltaica utilizada en la estación meteorológica se muestran a continuación.

\begin{tabular}{|c|c|}
\hline & Célula fotovoltaica \\
\hline Fabricante & Isofotón \\
\hline Tipo de sensor & Fotovoltiaico \\
\hline$I_{c c}\left(1000 \mathrm{~W} / \mathrm{m}^{2}, 25^{\circ} \mathrm{C}\right)$ & $3.26 \mathrm{~A}$ \\
\hline $\mathrm{K}\left(\mathrm{I}_{\mathrm{CC}}=\mathrm{K} \cdot \mathrm{G}_{\mathrm{TOTAL}}\right)$ & $3.26 \cdot 10^{-3} \mathrm{~A} /\left(\mathrm{W} / \mathrm{m}^{2}\right)$ \\
\hline Intensidad de operación & $2.5 \mathrm{~A}$ \\
\hline Potencia de operación & $100 \mathrm{~mW}$ \\
\hline Salida & $0-150 \mathrm{~mW}$ \\
\hline
\end{tabular}

Tabla 3.7 Características de la célula fotovoltaica.

\subsection{INSTRUMENTACIÓN DE LAS VARIABLES DE OPERACIÓN DE LA INSTALACIÓN}

Al inicio del apartado 3.2.1 además de describir la instalación experimental, se presenta la instrumentación necesaria para medir y registrar las variables de operación. En esta sección se pretende detallar su principio de funcionamiento, así como sus características técnicas. Los aparatos de medida y registro son:

- Transmisor de temperatura de contacto (paneles fotovoltaicos y cubierta metálica)

- Transmisor de temperatura del aire en el canal

- Anemómetros

- Carga electrónica

- Adquisición de datos

\section{TRANSMISOR DE TEMPERATURA DE CONTACTO}

La medida de la temperatura de la cara posterior del panel fotovoltaico y de la placa metálica se realiza mediante una sonda de temperatura flexible adhesiva Pt100, que se 
basa en la variación de la resistencia del platino con la temperatura. Se ha escogido este tipo de sonda por estar compuesta por una lámina robusta de goma de silicona adhesiva, y en cuyo interior, se encuentra el elemento sensor. Consta de 2 metros de cable aislado con teflón en malla de acero inoxidable.

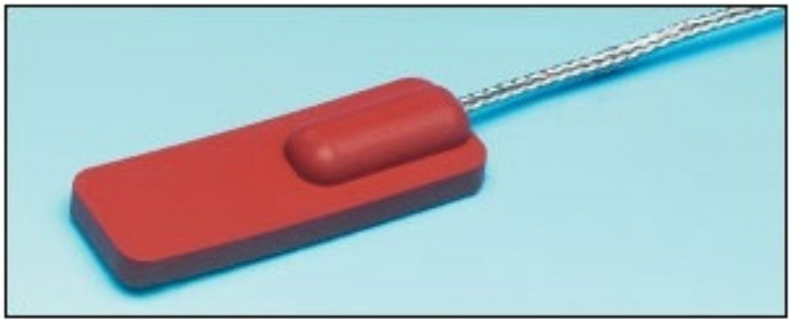

Figura 3.31 Sonda flexible Pt100 utilizada para medir la temperatura de la cara posterior de los módulos fotovoltaicos

\section{- Principio de Operación}

El detector de temperatura de resistencia (RTD) se basa en el principio según el cual la resistencia de todos los metales depende de la temperatura. La elección del platino en los RTD de la máxima calidad permite realizar medidas más exactas y estables hasta una temperatura de aproximadamente $500^{\circ} \mathrm{C}$.

Una posible desventaja, que afecta al uso de este dispositivo para medir la temperatura, es la resistencia de los RTD. Al ser tan baja, la resistencia de los hilos conductores que conectan el sensor puede provocar errores importantes. En la denominada técnica de dos hilos (Figura 3.32a), la resistencia se mide en los terminales del sistema de adquisición de datos, por lo que la resistencia de los hilos forma parte de la cantidad desconocida que se pretende medir. Por el contrario, la medición a cuatro hilos (Figura 3.32b) mide la resistencia en los terminales del sensor, con lo cual la resistencia de los hilos queda eliminada de la medida. La contrapartida es que se necesita el doble de cables y el doble de canales de adquisición de datos. También es posible medir usando tres hilos, eliminando un cable, opción que ofrece una solución intermedia pero no es tan precisa. 


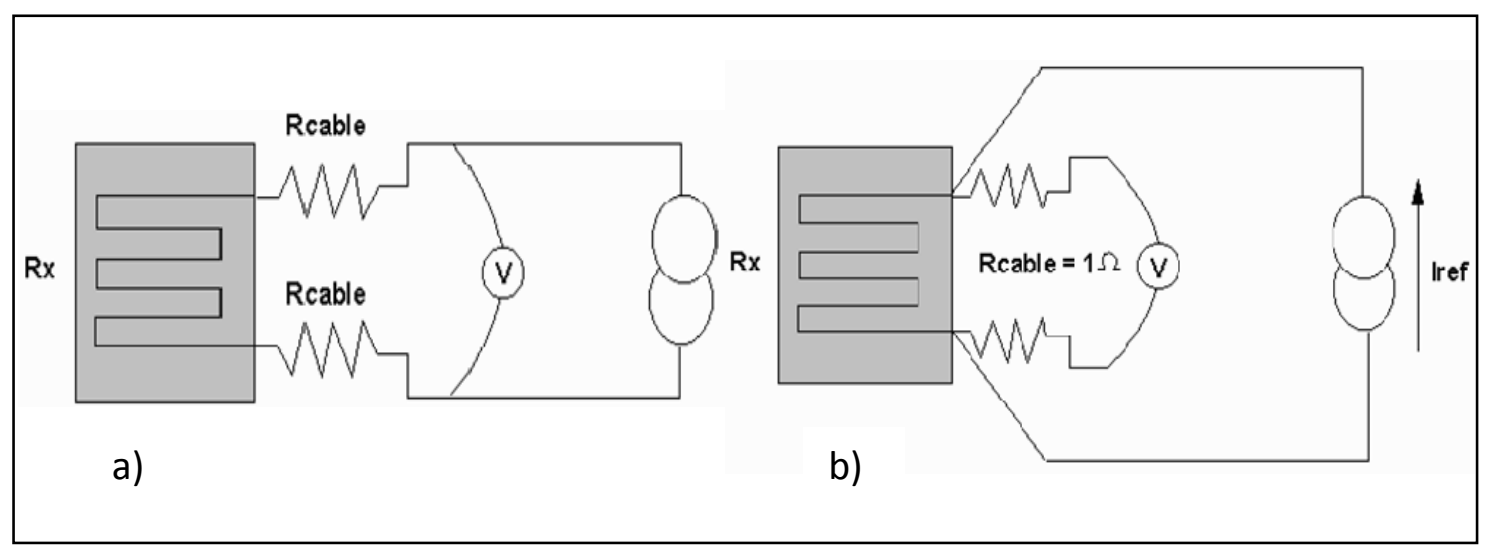

Figura 3.32 Principio de funcionamiento del detector de temperatura por resistencia. a) Conexión a dos hilos. b) Conexión a cuatro hilos.

Las características de las sondas de temperatura de contacto descritas se muestran en la siguiente tabla.

\begin{tabular}{|l|c|}
\cline { 2 - 2 } \multicolumn{1}{c|}{} & Temperatura de contacto \\
\hline Modelo & Pt 100 Flexible Adhesiva Robusta \\
\hline Fabricante & TC Direct \\
\hline Tipo sensor & Pt 100 Clase B (IEC 60751) \\
\hline Configuración & 4 hilos \\
\hline Encapsulado Sensor & $\begin{array}{c}\text { Flexible de silicona con una cara } \\
\text { adhesiva }\end{array}$ \\
\hline Cable conexión & $\begin{array}{c}2 \text { metros aislado con teflón en } \\
\text { malla metálica de acero inoxidable }\end{array}$ \\
\hline Rango de funcionamiento & -50 a $+150^{\circ} \mathrm{C}$ \\
\hline
\end{tabular}

Tabla 3.8 Especificaciones de la sonda de temperatura de contacto.

\section{TRANSMISOR DE TEMPERATURA DEL AIRE EN EL CANAL}

La medida de la temperatura del aire que circula por el conducto creado entre el panel fotovoltaico y la placa metálica se realiza mediante detectores de temperatura por resistencia Pt100, de gran precisión, basándose en el mismo principio de operación que las anteriores descritas, en la variación de la resistencia del platino con la temperatura. El sensor se encuentra en los primeros $20 \mathrm{~mm}$ de la vaina de acero inoxidable de $250 \mathrm{~mm}$ de longitud y diámetro de $3 \mathrm{~mm}$.

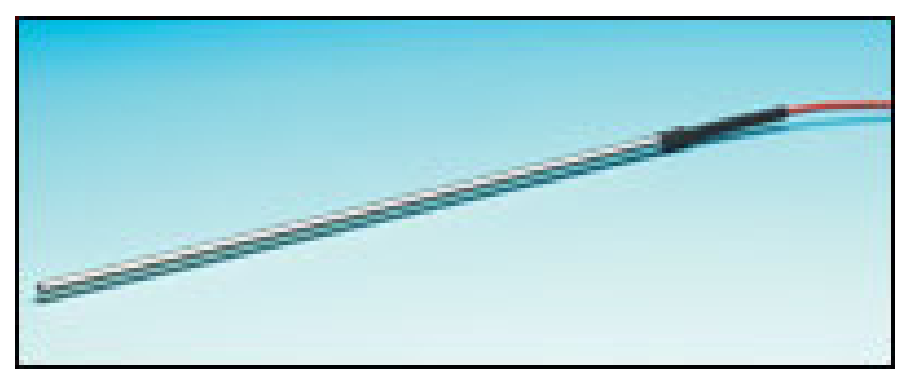

Figura 3.33 Sonda de temperatura Pt100 para medir la temperatura del aire en el canal.

Las características técnicas de las sondas utilizadas son: 


\begin{tabular}{|l|c|}
\cline { 2 - 2 } \multicolumn{1}{c|}{} & Temperatura de contacto \\
\hline Modelo & Pt 100 Precisión \\
\hline Fabricante & TC Direct \\
\hline Tipo sensor & Pt 100 Clase A (IEC 60751) \\
\hline Configuración & $\begin{array}{c}\text { Vaina en acero inoxidable AISI 316, } \\
\text { diámetro } 3 \text { mm con } 250 \text { mm longitud }\end{array}$ \\
\hline Encapsulado sensor & 2 metros aislado con PFA \\
\hline Cable conexión & $\pm 0.06^{\circ} \mathrm{C}$ \\
\hline Precisión & -50 a $+250^{\circ} \mathrm{C}$ \\
\hline Rango de funcionamiento &
\end{tabular}

Tabla 3.9 Especificaciones de la sonda de temperatura de aire en el conducto.

\section{ANEMOMETROS}

La velocidad en el interior del canal se mide mediante transmisores de velocidad térmicos, de película caliente. Este sensor mide la disipación de calor desde un conductor metálico de diámetro muy pequeño, cuando es expuesto al viento. El conductor se integra en un circuito eléctrico por el cual circula corriente. Si se mantiene constante la temperatura del conductor, la corriente eléctrica es una función conocida de la velocidad del viento. Los anemómetros de hilo caliente se utilizan cuando se requiere una alta tasa de muestreo de la velocidad del viento.

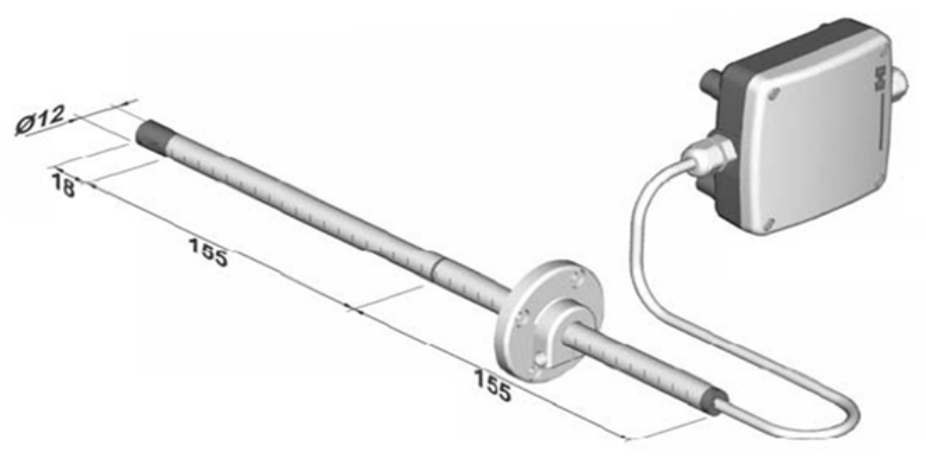

Figura 3.34 Anemómetro de placa caliente para medir la velocidad de aire en el interior del canal.

Con el fin de de ser lo más precisos en la medición, se han utilizado dos tipos de anemómetros de película caliente, difiriendo en el rango de medida. En convección natural, las velocidades del flujo de aire no son muy elevadas, el rango del anemómetro utilizado es de 0-2 m/s, mientras que en convección forzada se variar el régimen de funcionamiento del ventilador, obteniendo mayores velocidades. En esta configuración los anemómetros utilizados presentan un rango mayor, 0-20 m/s. Sus especificaciones se recogen en la Tabla 3.10. 


\section{- Principio de Operación}

El fenómeno en que se basan los anemómetros de hilo caliente es el efecto refrigerante que produce sobre un alambre que tiene una temperatura superior a la del fluido circundante. Cuando circula una corriente de aire, se produce un intercambio de calor entre el fluido y la sonda, dependiendo la cantidad de calor intercambiando con la velocidad del fluido. Como la conductividad de los metales depende de su temperatura, puede calibrarse el dispositivo para que en función de la temperatura de equilibrio alcanzada y por la variación de intensidad circulando por el hilo pueda medirse la velocidad de dicha corriente incidente. La corriente de aire produciría una disminución en la temperatura de la sonda, sin embargo se hace una retroalimentación de manera que la temperatura no baje, lo que se logra con un incremento en la potencia con que se alimenta a la sonda. Las sondas de hilo caliente se fabrican de platino o tungsteno, o de aleaciones entre ellas, ya que estos materiales tienen la característica de que su resistencia es proporcional a la temperatura. Existe una variante, las sondas de película o lámina caliente, que consisten en películas delgadas que se depositan en un sustrato cilíndrico [73].

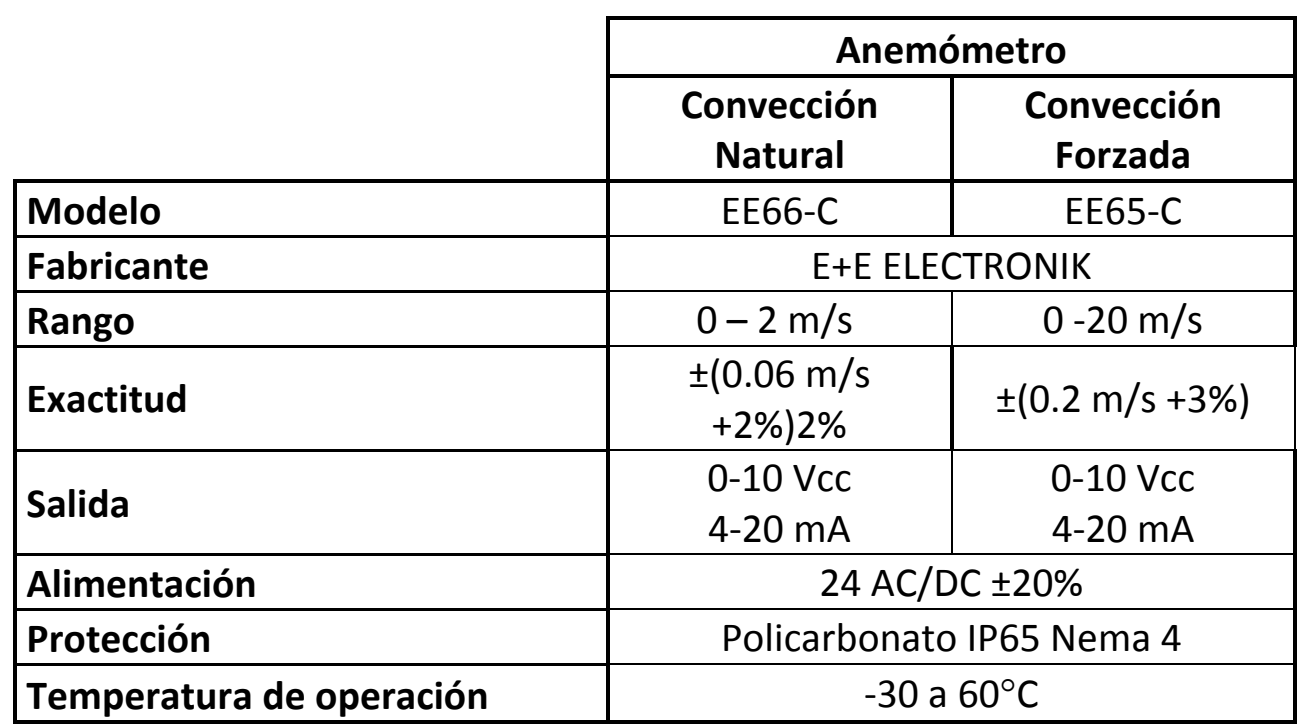

Tabla 3.10 Especificaciones técnicas de los transductores de la velocidad del aire en el canal.

\section{CARGA ELECTRÓNICA PARA PANELES SOLARES}

Para obtener la curva característica I-V de un panel solar, este deberá estar conectado a una carga variable que permita absorber la energía que genere en sus diferentes puntos de funcionamiento. Con tal fin, el Departamento de Tecnología Electrónica de la Universidad Politécnica de Cartagena ha diseñado una carga electrónica que podrá ser controlada desde un ordenador personal, permitiendo trabajar en dos modos de funcionamiento, a corriente constante y a tensión constante. 


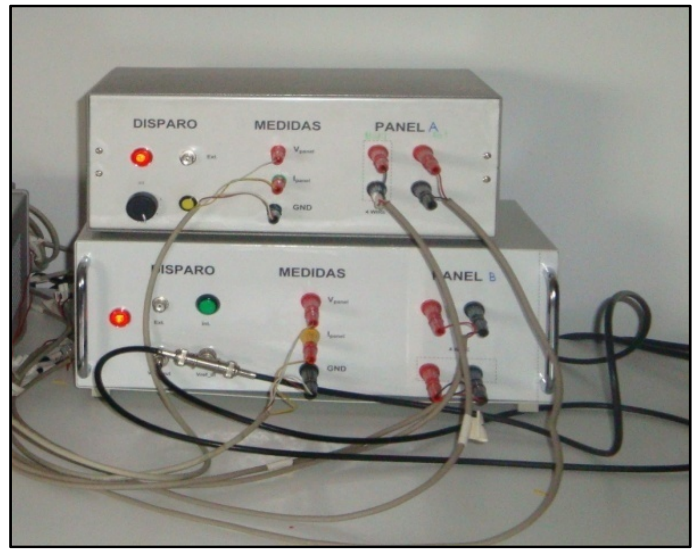

Figura 3.35 Carga electrónica para obtener la curva característica de los paneles fotovoltaicos.

Para obtener finalmente la curva característica completa de un módulo fotovoltaico deberá funcionar no solo como carga sino también como generador, ya que para obtener con seguridad el valor nulo de tensión (corriente de cortocircuito) se hará funcionar al panel como carga, es decir, con tensión negativa en sus extremos.

Las características de esta carga son:

\begin{tabular}{|l|c|}
\cline { 2 - 2 } \multicolumn{1}{c|}{} & Carga electrónica: Curva I-V \\
\hline Fabricante & UPCT \\
\hline Tensión de funcionamiento & $0-100 \mathrm{~V}$ \\
\hline Corriente de pico & $25 \mathrm{~A}$ \\
\hline Potencia máxima & $300 \mathrm{~W}$ \\
\hline Salida & $0-1 \mathrm{~V}$ \\
& $0-25 \mathrm{~A}$ \\
\hline Precisión & $\pm 0.0050 \mathrm{~V}$ \\
& $\pm 0.0054 \mathrm{~A}$ \\
\hline Rango de funcionamiento & $-20 \mathrm{a}+150^{\circ} \mathrm{C}$ \\
\hline
\end{tabular}

Tabla 3.11 Características de la carga electrónica.

El principio de operación de la carga para las diferentes respuestas del panel fotovoltaico, así como los elementos incorporados para tal fin se incluye en el Anexo C.

\section{SISTEMA DE ADQUISICIÓN DE DATOS}

El sistema de adquisición de datos utilizado es Data logger 34980A, y la tarjeta multiplexora 34921A de Agilent, ambos nos proporcionan un software muy útil y sencillo para la toma y recogida de datos, crear una base de datos y representación de ellos. El programa al que nos referimos es el Agilent BenchLink Data Logger, que de forma resumida se va a explicar su manejo.

El data logger 34980A es una unidad de medida compacta, económico y una solución para recoger una alta densidad de medidas en aplicaciones de verificación de diseño, de pruebas automatizadas y de adquisición de datos. Una computadora central puede 
acomodar hasta 560 mediciones de 2 hilos o 1024 canales multiplexor. El 34980A también incluye USB, Ethernet y GPIB como interfaces estándar para la PC, es fácilmente ampliable y reconfigurable y ofrece una amplia funcionalidad que se ajuste a su presupuesto sin sacrificar la precisión.

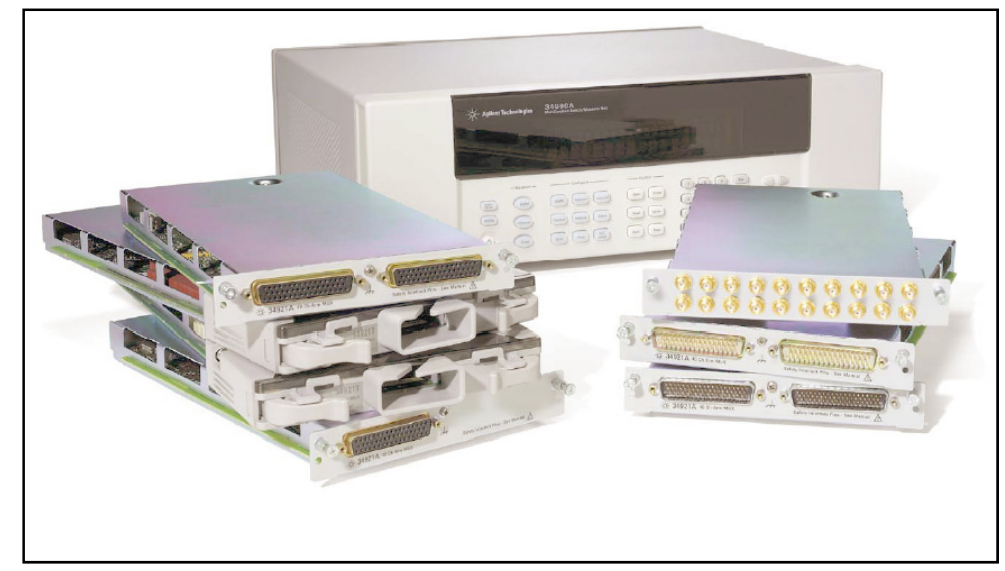

Figura 3.36 Sistema de adquisición de datos, data logger 34980A.

El Data logger 34980A tiene capacidad para 8 módulos para darle la flexibilidad que necesita. Se puede elegir entre 21 módulos diferentes para definir la configuración que se desee según las necesidades permitiendo así medir la temperatura, intensidad y voltaje AC o DC, resistencia, frecuencia....

El módulo multiplexor elegido para incorporar al sistema de adquisición es el 34921A, al ser el único que nos ofrece la posibilidad de de recoger todo tipo de medidas, voltaje y corriente AC/DC, frecuencia/periodo, Resistencias a 2 y 4 hilos, termopares, termistores y RTD a 2 y 4 hilos. Cuenta con 40 canales a configurar a 2 o 4 hilos y 4 canales de corriente.

Cuyas características principales vienen recogidas en la siguiente tabla:

\begin{tabular}{|l|c|}
\hline & Tarjeta multiplexora 34921 A \\
\hline Canales/configuración & $\begin{array}{c}40 \text { 2-hilos } \\
\text { 4- hilos } \\
\text { 4-corriente }\end{array}$ \\
\hline Características entrada (por canal) & $\pm 300 \mathrm{~V}$ \\
\hline Máximo voltage & $1 \mathrm{~A}$ \\
\hline Máxima corriente (DC, AC RMS) & $60 \mathrm{~W}$ \\
\hline Potencia & $10^{8}$ \\
\hline Volt-Hertz limite & 100 canales $/ \mathrm{sec}$ \\
\hline Especificaciones generales & $4 \mathrm{~ms} / 4 \mathrm{~ms}$ \\
\hline Velocidad testeo & \\
\hline Tiempo Abrir /cerrarl & \\
\hline
\end{tabular}

Tabla 3.12 Especificaciones de la tarjeta multiplexora 34921A. 


\section{- Descripción del Software para la adquisición de datos}

El software Agilent BenchLink Data Logger proporciona un forma conveniente para el control de instrumentos, recolectar y analizar datos. El control, recogida de datos y la toma de decisiones que siempre ha requerido conocimientos de programación, ahora puede hacerse de forma fácil, con el uso de hojas de cálculo. El software utiliza un entorno de hojas de cálculo familiar, la racionalización de las necesidades de prueba y medición. Simplemente hay que identificar las medidas que desee adquirir, iniciar el proceso, y ver los datos mostrados en la pantalla del ordenador. Se pueden utilizar muchas opciones para analizar y mostrar los datos, histogramas con análisis estadísticos, gráficos de barras y de dispersión, resultados de los canales individuales o en conjunto y mucho más.

Además de estas características de gran alcance, Data Logger software, presenta una gran funcionalidad, con características adicionales que se describen en las siguientes páginas.

Una vez que se tienen la tarjeta multiplexora conectada a la instrumentación, el data logger encendido y conectado al PC, se procederá a la configuración de cada instrumento en su canal correspondiente, a la recogida de datos, representación gráfica mediante el uso del software mencionado. La ventana principal que nos aparece, presenta este aspecto:

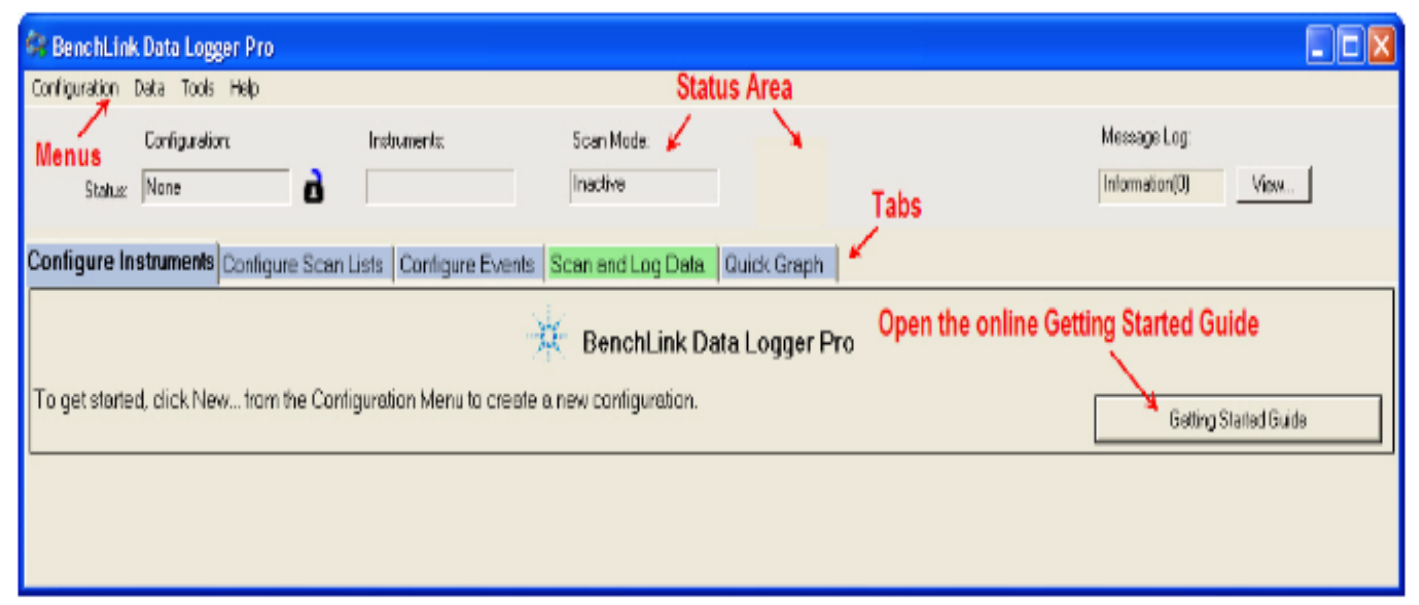

Figura 3.37 Ventana principal de Benchlink Data Logger.

Lo primero de todo, se debe crear una configuración, la cual recogerá todo lo que se programe en los diversos canales permitiendo en veces posteriores acceder a ella y hacer los cambios que se vean oportunos. Para ello, se hará click en Configuration, que se encuentra en la barra de menú, seleccionando New Configuration a la que le daremos el nombre que se desee. 


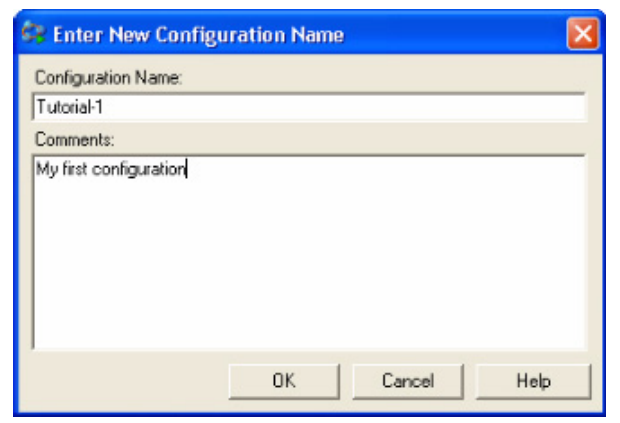

Figura 3.38 Crear una nueva configuración.

Una vez creada la configuración, hay que identificar cada uno de los instrumentos y añadirlos en su canal correspondiente. Dentro de la pestaña Configure Instrument, se selecciona la opción Connected Instrument y se pincha en Add Instrument. Nos aparecerá una nueva pantalla, tal y como se muestra en la Figura 3.39. Para poder buscar nuestra tarjeta, se le dará a Find, en la tabla se mostrará la tarjeta que haya encontrado en el sistema de adquisición, seleccionamos y pinchamos en Connect.

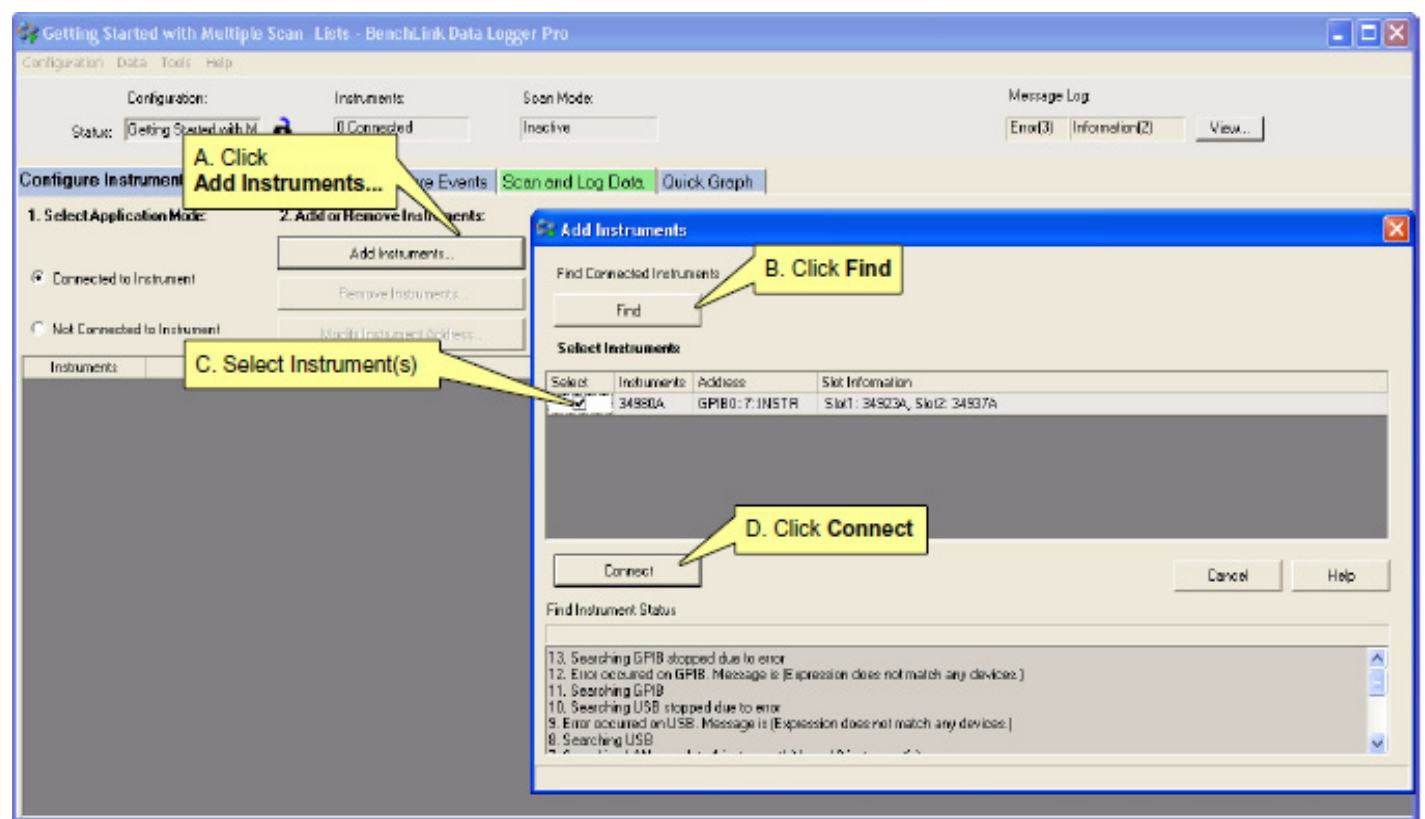

Figura 3.39 Ventana de configuración.

Una vez conectado se mostraran todos los canales de las tarjetas que se hayan introducido en el data logger. El siguiente paso es ir configurando la instrumentación con cada canal, seleccionando aquellos que se quieran registrar, asignándole un nombre, la medida de cada instrumento, los límites de medida... 


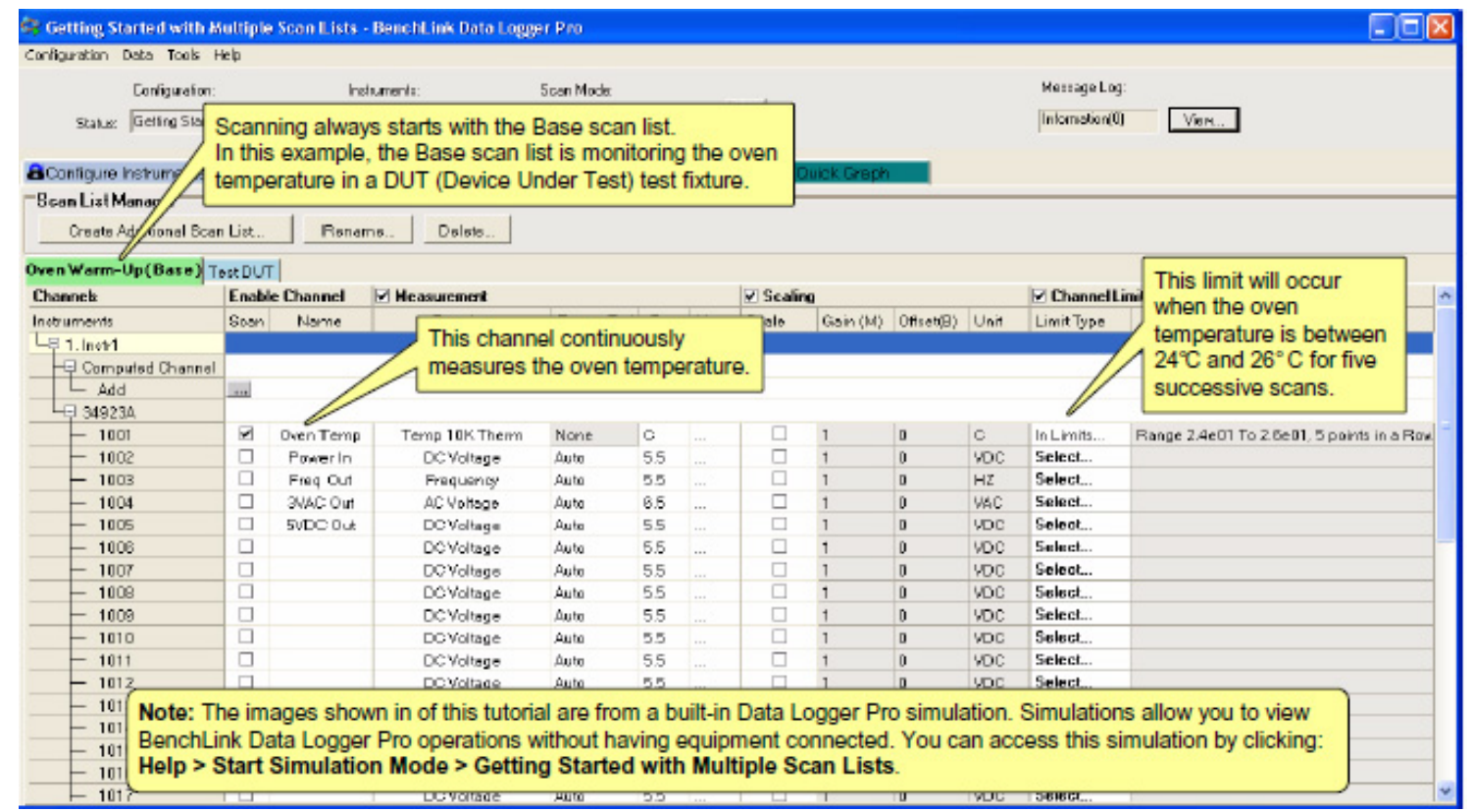

Figura 3.40 Ventana que muestra los canales conectados y permite su configuración.

Dentro de la pestaña de Scan List, se deben seleccionar los canales a configurar, en su correspondiente cuadradito de la columna Scan. En la siguiente columna, Name, nos permite introducir el nombre del canal que corresponderá con la instrumentación conectada. La medida se seleccionará en la columna anexa, eligiendo de entre las opciones que aparecen.

En las columnas restantes, measurement y scaling se puede modificar el rango de medida, así como poder hacer un cambio de unidades o de medida en función de los datos se quieran recoger, ya que la señal que llega al sistema pueden ser Amperios y lo que se quiera recoger son $\mathrm{W} / \mathrm{m}^{2}$. Para ello se deberá hacer el ajuste mediante la ecuación lineal adecuada para cada instrumentación.

A continuación, se debe pinchar la pestaña Scan and Log Data, (Figura 3.41) en la cual nos permitirá elegir los canales y datos a registrar, donde exportarlos, el tiempo que se desea estar testeando, intervalos de tiempo en la toma de medidas. 


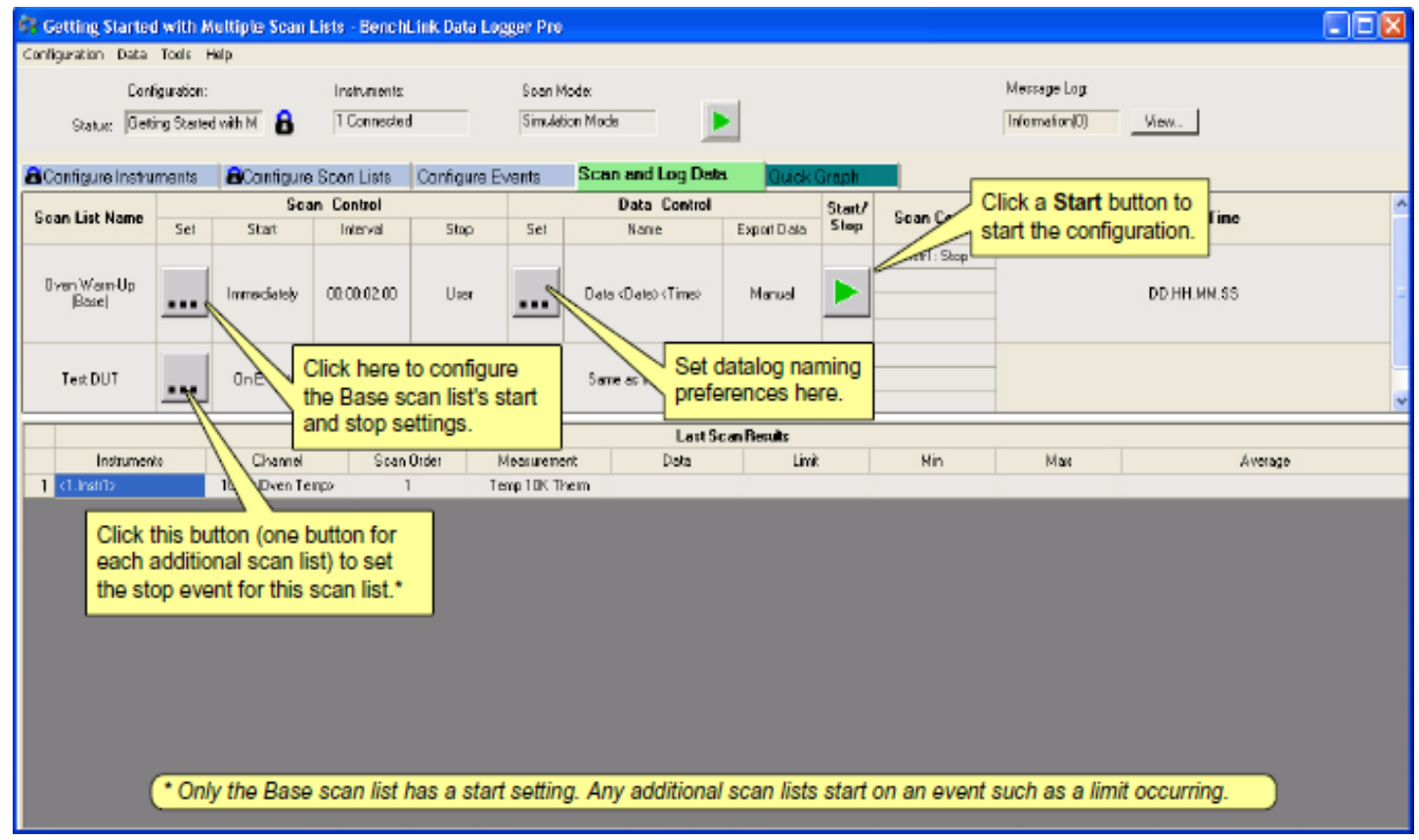

Figura 3.41 Ventana de configuración las opciones para el registro de datos.

En el cuadro de dialogo Scan Control, tenemos varios botones que nos permiten decidir el tiempo de escaneo, el número de de datos que se quieren recoger, los canales que se desean testear. Tan solo hay que escogiendo lo que se desee antes de empezar el registro.

Seleccionada todas las variables, por último hay que pinchar en el botón Start y se comienza el escaneo de los canales que se han configurado. En función de los valores que se hayas escogido en el Data Control, el análisis parará en el tiempo asignado o continuara indefinidamente hasta que se presione el botón Stop.

Una vez finalizado el escaneo, automáticamente aparece una ventana, Scan and Log Summary,(Figura 3.42). Desde ella se puede modificar el nombre del registro de datos, propietario, comentarios y además se tienen todas las opciones para la exportación de datos. Una vez seleccionado la carpeta y el nombre del registro, se le da a cerrar. Automáticamente se guarda una hoja Excell con todo el registro de datos. 


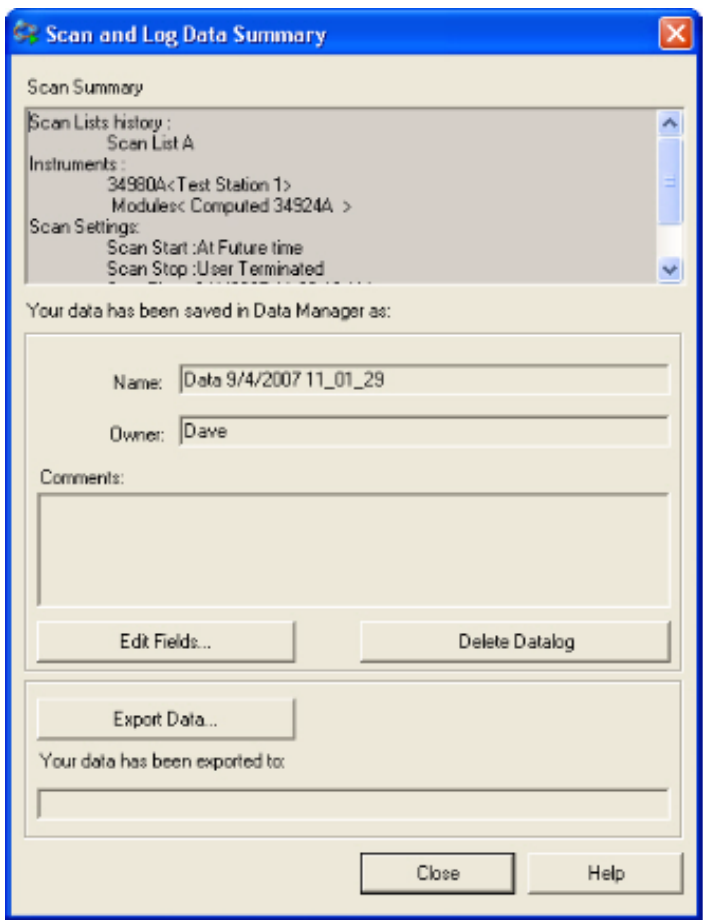

Figura 3.42 Ventana resumen con los datos recogidos y opciones de exportación.

Por último, se pueden visualiza los datos mediante gráficas pinchando el botón Quick Graph. Esta ventana te muestra los datos testeados a lo largo del tiempo de muestro y presenta diversas funciones para cambiar el color, la escala a cada canal, datos de la leyenda.

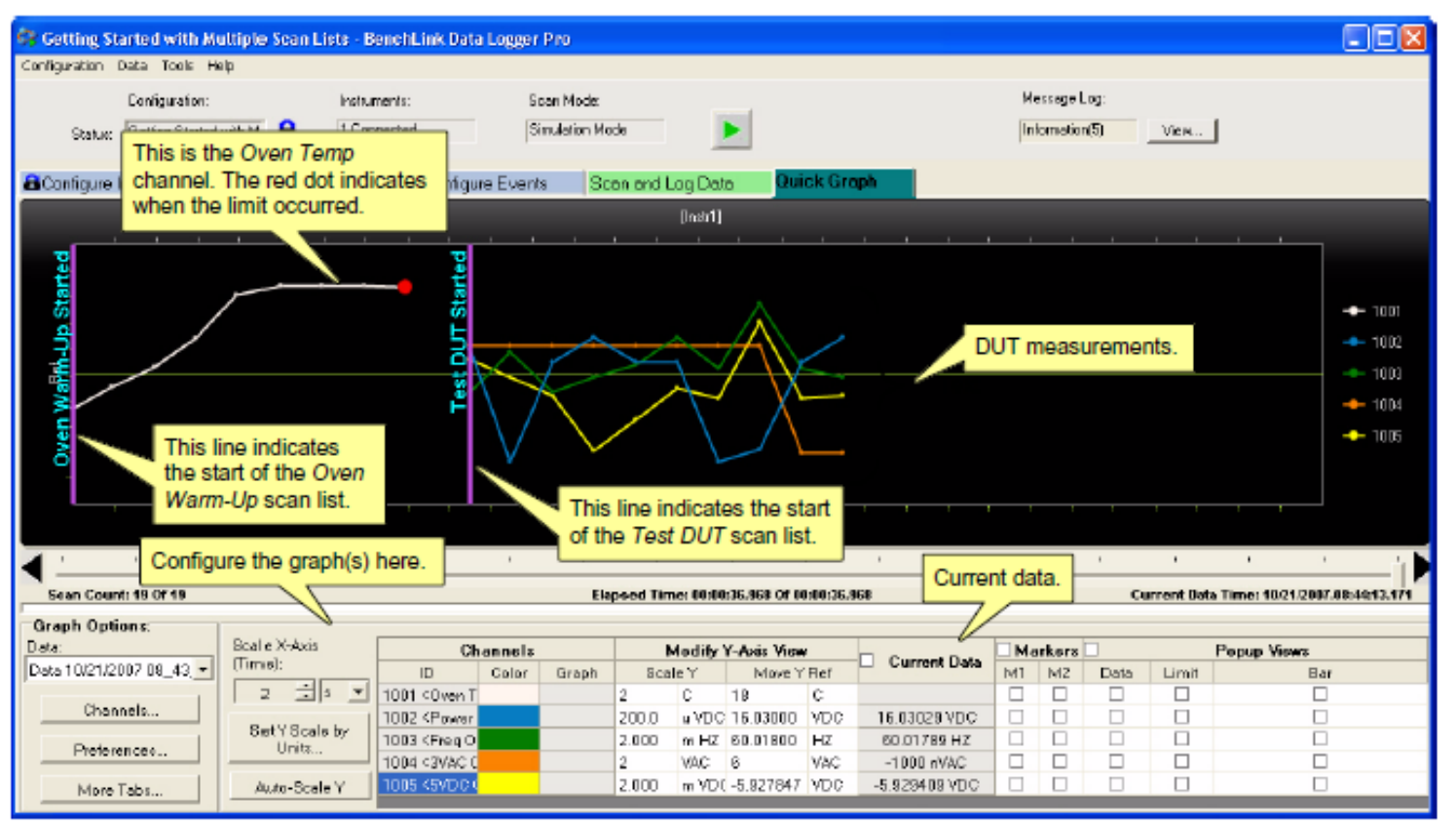

Figura 3.43 Representación gráfica de las variables medidas. 


\subsubsection{INSTALACIÓN FOTOVOLTAICA EXPERIMENTAL SOBRE LA CUBIERTA DE INVERNADEROS}

El diseño de esta instalación experimental está inspirado en la instalación agroenergética Coronil IV descrita en una sección anterior. La instalación de ensayo consiste en una réplica de una unidad estructural de la instalación comercial, constituida por una estructura metálica destinada a soportar cuatro módulos fotovoltaicos sobre la cubierta del invernadero. La instalación experimental constituida por paneles del mismo fabricante, idénticas característica, colocados a idéntica inclinación, y la estructura soporte se procuró que fuera lo más fiel posible a la original.

Esta instalación experimental, al igual que la instalación original de referencia, dispone de un espacio libre entre la cubierta del invernadero y los paneles fotovoltaicos, permitiendo el paso de aire a través de un canal divergente a través del cual, se creará un 'efecto chimenea' mediante convección natural. Se ha incorporado en su interior un calefactor, controlado con un PID, para simular diferentes condiciones de temperaturas internas del invernadero.

El objetivo planteado es estudiar el comportamiento eléctrico de los módulos sobre la cubierta de un invernadero, existiendo un canal de aire entre ambas superficies. Esta instalación difiere de la anteriormente descrita (en convección natural), no sólo a nivel estructural, sino que la cubierta sobre la que están emplazados los paneles es de plástico. Además, el interior del invernadero presenta unas condiciones de elevadas temperaturas, mayores en su parte superior, cubierta. El estudio de esta instalación se centra, análogamente a la otra instalación experimental, en analizar las variables eléctricas y su dependencia con la temperatura. También se pretende estudiar la posible influencia del calor dentro del invernadero en el comportamiento eléctrico de los módulos, para dicha configuración.

Una vez obtenidos los resultados para estas condiciones, se plantearan diferentes configuraciones estructurales que persigan una mejora en la producción eléctrica. Considerando la dependencia de la eficiencia eléctrica del panel con su temperatura de funcionamiento, las configuraciones adoptadas pretenden reducir la temperatura de los módulos que a priori parece estar afectada en mayor o menor medida, por el reducido espacio entre la cubierta de plástico y los paneles, y por la transferencia de calor del interior del invernadero. Por ello, se han adoptado dos secciones de paso de aire entre los módulos y el plástico, la que marcaba el diseño de la instalación original y otra mayor, y además, para cada una, se ha incorporado un material aislante sobre el plástico evitando la transferencia de calor a su través. Esta combinación, resulta un total de cuatro configuraciones diferentes, para dos secciones de paso de aire, cada una con o sin aislante. 
Finalmente, se estudiarán los resultados obtenidos de las cuatro configuraciones, analizando el comportamiento eléctrico de los paneles para cada una de ellas, las variables influyentes en él y llevar a cabo un estudio comparativo de todas ellas, para así concluir la configuración más idónea.

\subsubsection{DISEÑO CONSTRUCTIVO DE LA INSTALACIÓN}

La instalación experimental consiste en una estructura metálica que a su vez soporta a los cuatro paneles fotovoltaicos que se sitúan en la cubierta de dicho invernadero. Como se mencionó, el diseño se inspiró en el utilizado en la instalación agroenergética Coronil IV, con el fin de montar una réplica de una unidad estructural de la instalación original. La instalación experimental constituida por paneles del mismo fabricante, idénticas características, colocados a idéntica inclinación, y la estructura soporte se procuró que fuera lo más fiel posible a la original.

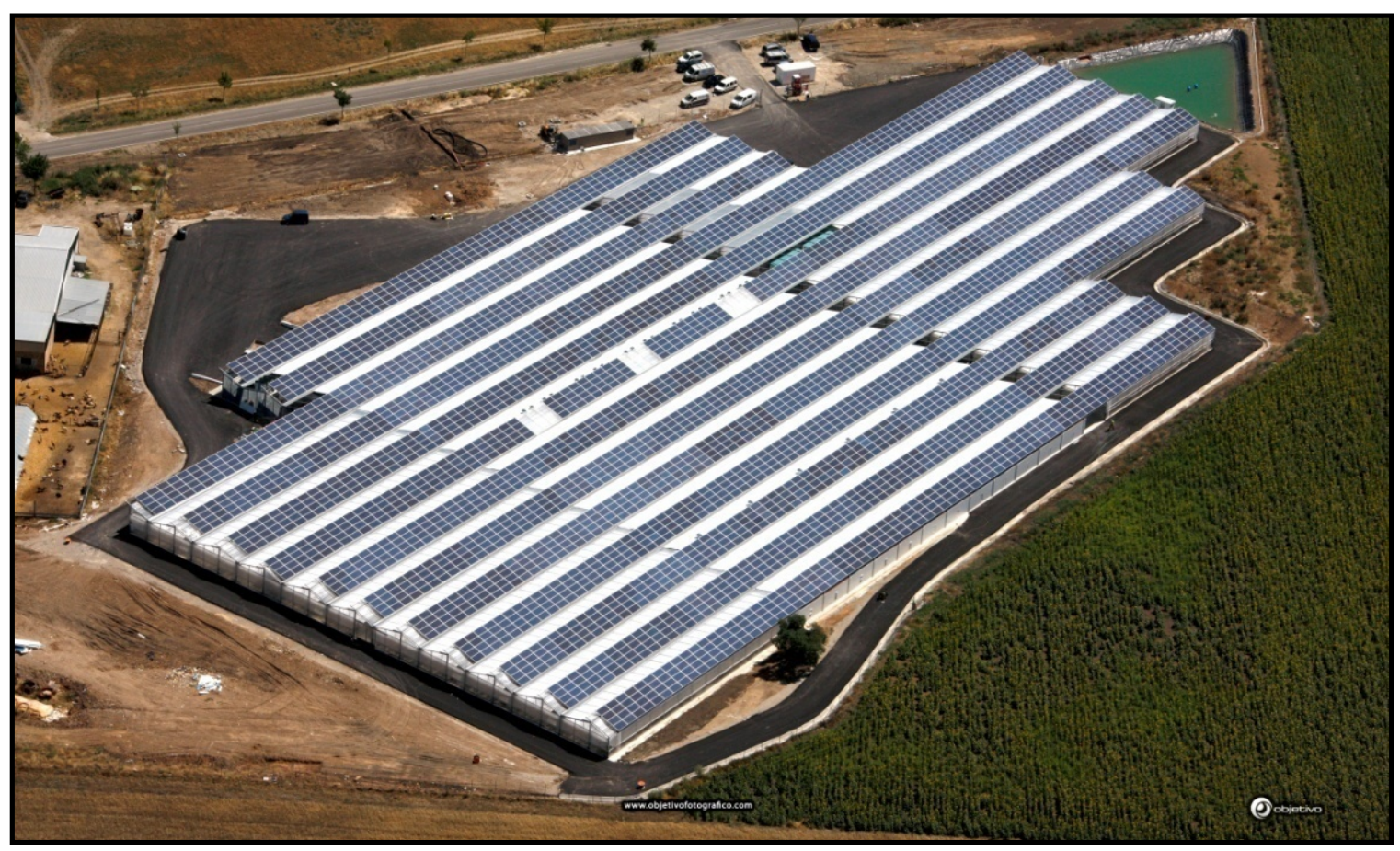

Figura 3.44 Fotografía aérea de la instalación agroenergética Coronil IV. 


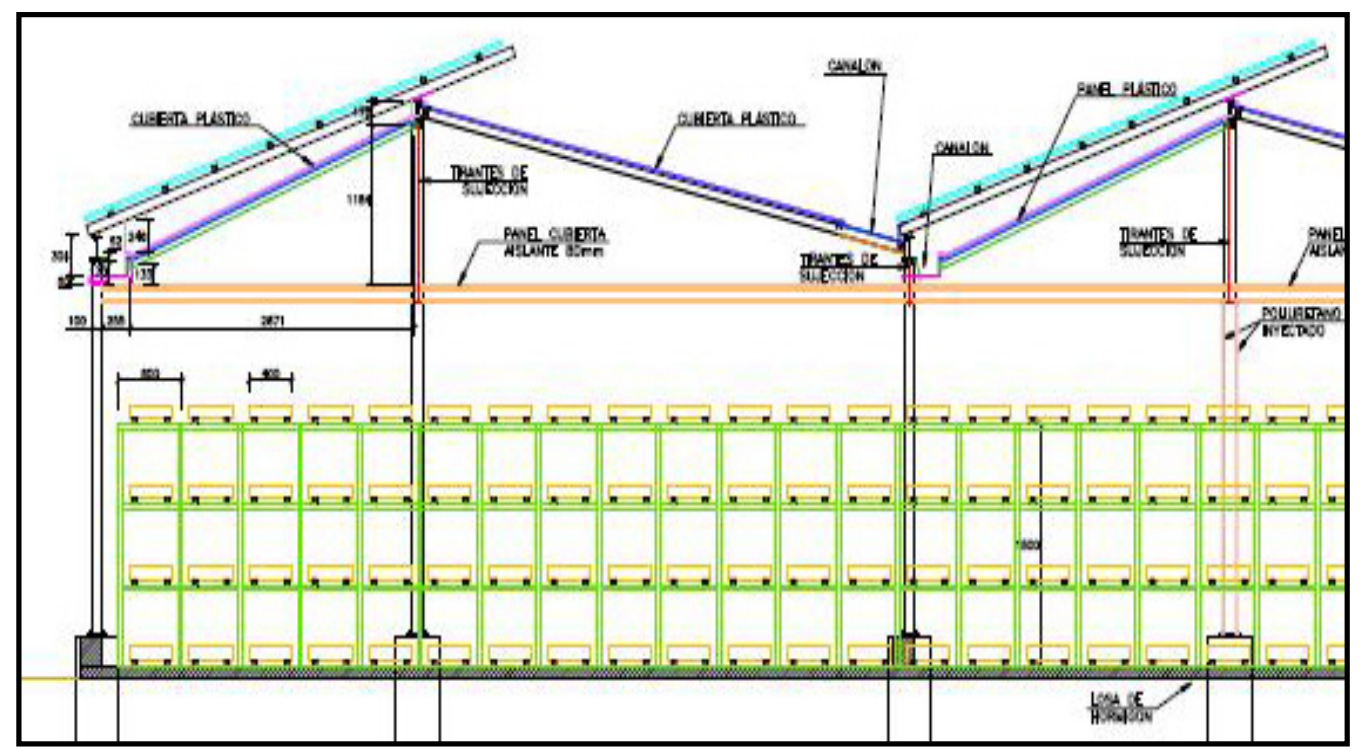

Figura 3.45 Alzado del plano en el que se aprecia la configuración del invernadero y paneles.

Sin embargo, la instalación experimental representa solamente la unidad constructiva en El Coronil IV, la cual se repite en ambas direcciones para dar forma la instalación fotovoltaica. Otros condicionantes, como la elevación de los paneles sobre el terreno, las condiciones exactas de cerramiento o el hecho del uso o no como un invernadero real, difieren de una a otra instalación. Siempre, se ha procurado que la combinación de todas las variables reflejen unas condiciones de trabajo tales, que los resultados que se obtengan sean los más cercanos posibles a la realidad para que sean de aplicación las conclusiones obtenidas de ellos.
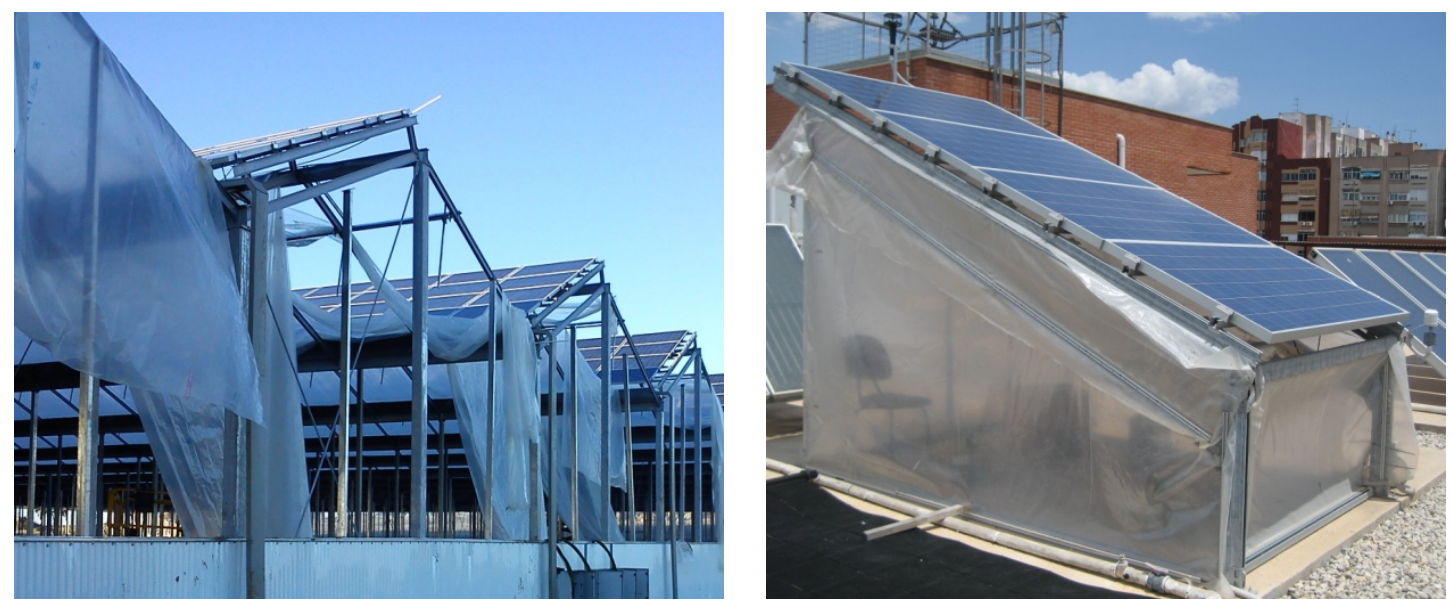

Figura 3.46 Invernadero de referencia, Coronil IV e instalación experimental.

Ambas instalaciones presentan un espacio libre entre el invernadero y los paneles fotovoltaicos, creado con el fin de permitir la circulación de aire a su través reduciendo en alguna medida la transferencia de calor de interno del invernadero a los módulos (Figura 3.46). Este espacio libre da a lugar a un canal divergente, con el inconveniente que la sección de entrada, parte inferior, es bastante menor que a la de salida, lo cual limitará las posibilidades de refrigeración por convección natural de los paneles fotovoltaicos. 
Los resultados que se obtengan de la configuración inicial planteada como réplica de la instalación original, nos servirán para proponer diferentes configuraciones que persigan la mejor solución de compromiso entre la obtención de un mayor rendimiento eléctrico y el coste de su adopción.

La estructura metálica consta de dos tipos diferentes de perfiles, los que constituyen la estructura base, pintados en color verde en la Figura 3.47 y los que sostienen a los paneles, representados de color rojo en la misma. Ambos perfiles, al igual que el resto se elementos de fijación, unión y elevación utilizados en el montaje, han sido proporcionados por la empresa Hilti, quien hizo las correspondientes comprobaciones de resistencia a flexión y pandeo, para la estructura diseñada.
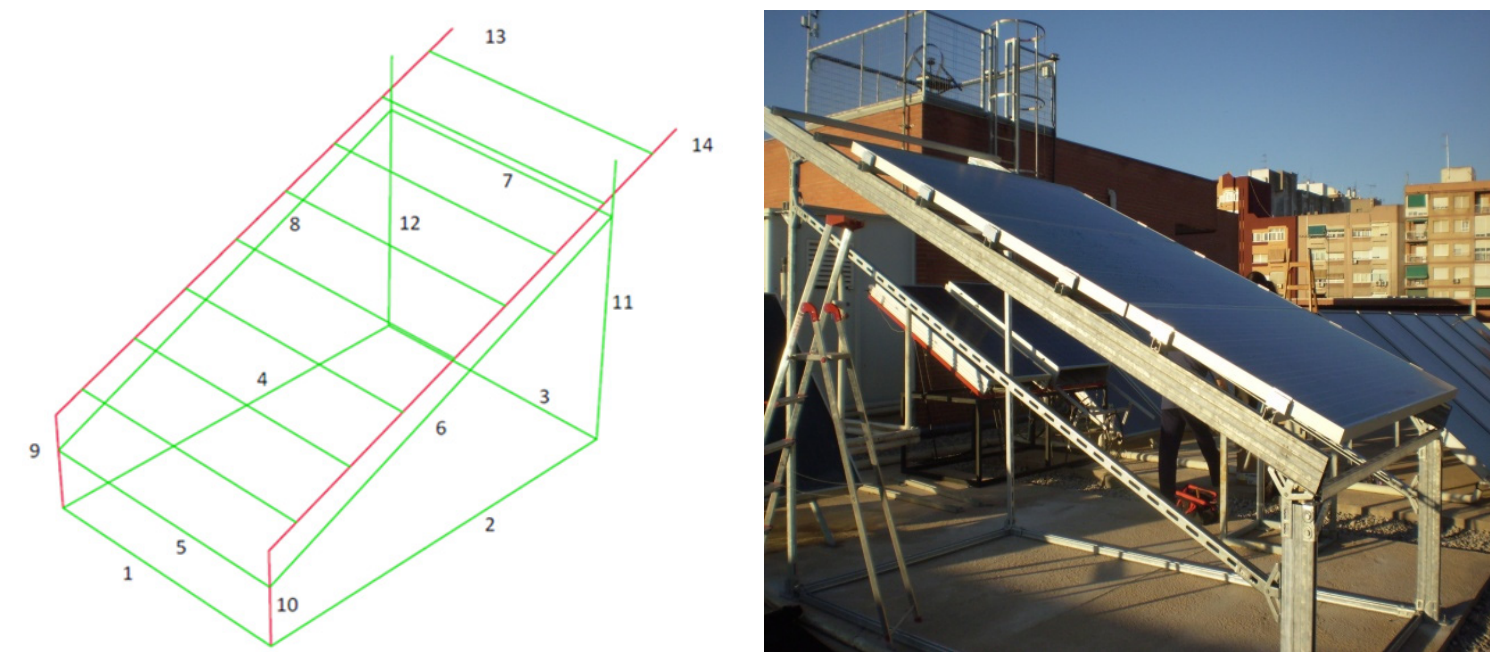

Figura 3.47 Esquema de la estructura con identificación de los perfiles (izquierda) y fotografía de la estructura construida (derecha).

En el esquema de la estructura (Figura 3.47) se ha incluido una numeración correspondiente a cada una de las barras que la forman, con el fin de poder describir con mayor rigor los elementos de unión utilizados en cada caso. A continuación, se describe de forma resumida los elementos constructivos utilizados.

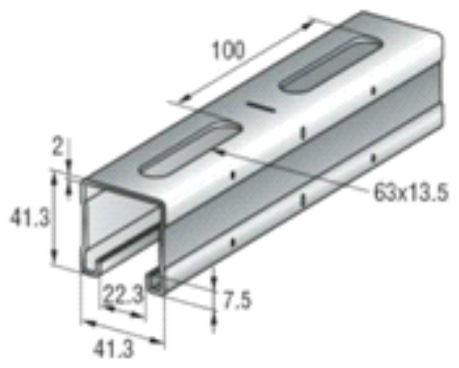

\section{MQ-41-F}

Carril simple, utilizado como perfil para la estructura base, coloreado en color verde en el esquema.

Altura: $41.3 \mathrm{~mm}$

Espesor: $2 \mathrm{~mm}$

Peso: $2.13 \mathrm{~kg} / \mathrm{m}$ 


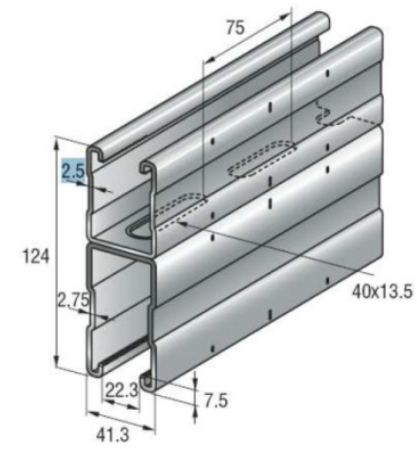

\section{MQ-52-72 D-F}

Carril doble utilizado como perfil soporte de los paneles, sobre la estructura base (representado en color rojo).

Altura: $124 \mathrm{~mm}$

Espesor: $2.5 / 2.75 \mathrm{~mm}$

Peso: 7.08 kg/m

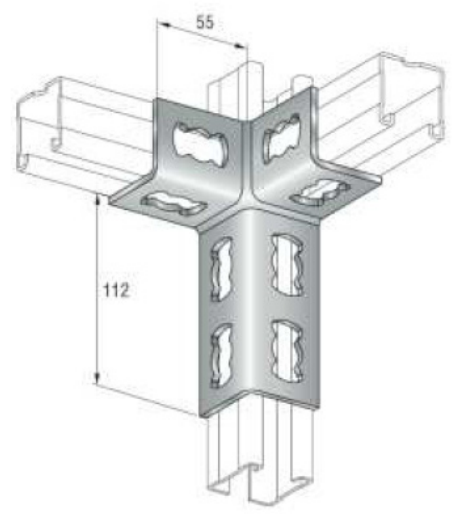

\section{ANGULAR DE TRES SALIDAS MQV-3-3D-F}

Este elemento permite la triple unión de los perfiles 1 y 4 con 9,1 y 2 con 10,2 y 3 con 11 y las barras 3,4 con 12.

La unión entre los carriles y estas piezas se estableció empleando la tornillería adecuada, M10x25F, mostrada en la figura. Este tipo de tornillería incluye sus respectivas tuercas o tuercas carril (MQN-HDG).

\section{ESCUADRA DE $90^{\circ} \mathrm{MQW}-\mathrm{S} / 1-\mathrm{F}$}

Estas escuadras permiten la unión de los perfiles 5 y 10; 5 y $9 ; 7$ y $11 ; 7$ y 12 mediante la misma tornillería descrita anteriormente.

Altura:198 mm

\section{BASE GIRATORIA MQP-G-F}

Consta de dos piezas unidas con bisagras que le permiten un giro de casi $180^{\circ}$. Se han utilizado para unir los perfiles inclinados 6 y 8 con los sus verticales colindantes en ambos extremos; 10,11 con 6 y 9,12 con 8.

Peso:1055 g 


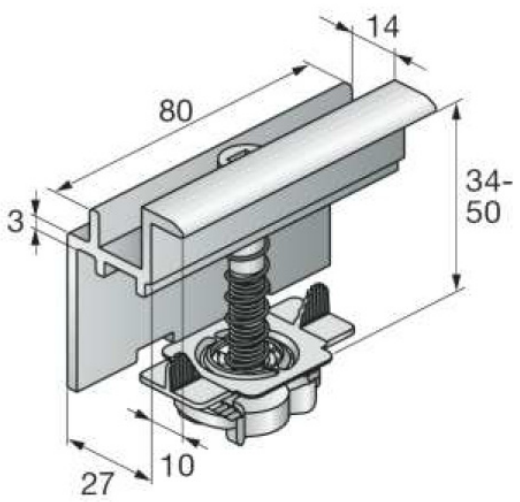

\section{PINZA TERMINAL MSP-MQ-EC50}

Estas pinzas están diseñadas para la sujeción de los módulos fotovoltaicos a las correas MQ-41-F, de la estructura soporte.

Grosor máximo: $50 \mathrm{~mm}$

Figura 3.48 Descripción de los perfiles y elementos de unión utilizados en el montaje de la estructura.

Las dimensiones de la estructura que constituye la instalación experimental vienen reflejadas en la siguiente figura.
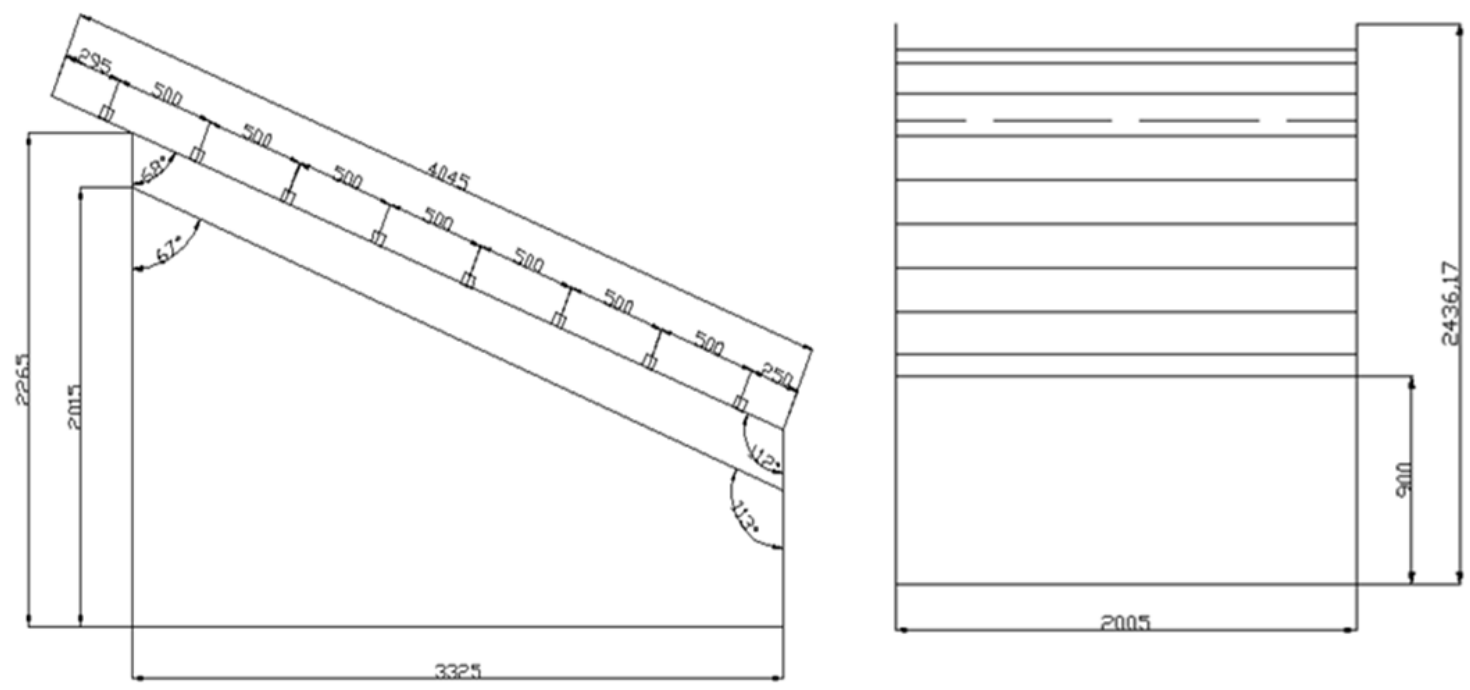

Figura 3.49 Alzado y perfil de la estructura metálica con las dimensiones en $\mathrm{mm}$.

El plástico empleado en el invernadero de la instalación experimental es el mismo al utilizado en la instalación agroenergética Coronil IV, Polietileno de baja densidad (PEBD).

La razón de su uso se debe a la característica más destaca del Polietileno, el alargamiento en el punto de rotura es bastante elevado, además de que su transmisividad a la radiación solar es buena, aunque disminuye con el tiempo al ensuciarse y envejecer. La vida del Polietileno se puede alargar mediante el uso de aditivos que limiten la acción de la radiación ultravioleta, resultando el polietileno de mayor duración. El Polietileno posee una baja opacidad al infrarrojo, pero igualmente mediante el uso de aditivos se consigue que el material absorba la radiación en esa franja y así favorecer el efecto invernadero, es el llamado Polietileno térmico. 
El nombre comercial del plástico colocado es INDASOL PLUS, fabricado por ASPLA, Plásticos Españoles S.A., con un espesor de $0.2 \mathrm{~mm}$ y una densidad de $960 \mathrm{~kg} / \mathrm{m}^{3}$. En la siguiente tabla se recogen sus principales características.

INDASOL PLUS

\begin{tabular}{|c|c|c|c|}
\hline MAGNITUD & VALOR & UNIDADES & NORMA \\
\hline Espesor & 200 & $\mu$ & ISO 4953 \\
\hline \multicolumn{4}{|l|}{ PROPIEDADES MECANICAS } \\
\hline \multicolumn{4}{|l|}{ Carga en rotura } \\
\hline D.M. & 25 & $\mathrm{MPa}$ & EN ISO 527 \\
\hline D.T. & 24 & $\mathrm{MPa}$ & EN ISO 527 \\
\hline \multicolumn{4}{|l|}{ Alargamiento en rotura } \\
\hline D.M. & 700 & $\%$ & EN ISO 527 \\
\hline D.T. & 850 & $\%$ & EN ISO 527 \\
\hline \multicolumn{4}{|l|}{ Traccion en pto. Fluencia } \\
\hline D.M. & 12 & $\mathrm{MPa}$ & EN 13206 \\
\hline D.T. & 11 & $\mathrm{MPa}$ & EN 13206 \\
\hline \multicolumn{4}{|l|}{ Resistencia al rasgado } \\
\hline D.M. & 5200 & $\mathrm{gr} / \mathrm{mm}$ & UNE 53.320 \\
\hline D.T. & 9750 & $\mathrm{gr} / \mathrm{mm}$ & UNE 53.320 \\
\hline \multicolumn{4}{|l|}{ Resistencia al impacto F50 } \\
\hline CARA & 1600 & gr & 1507765 \\
\hline PLIEGUE & 800 & gr & 1507765 \\
\hline \multicolumn{4}{|l|}{ PROPIEDADES ÓPTICAS } \\
\hline Transmisión global de luz visible & 90 & $\%$ & EN 2155 \\
\hline Transmitancia a la luz I.R.(TERMICIDAD) & 14 & $\%$ & EN 13206 \\
\hline Dispersión de luz visible & 60 & $\%$ & EN 2155 \\
\hline Reflectancia visible & & $\%$ & \\
\hline MAGNITUD & VALOR & UNIDADES & NORMA \\
\hline \multicolumn{4}{|l|}{ PROPIEDADES DE DURACIÓN } \\
\hline Envejecimiento Acelerado & $>2500$ & Horas & UNE 53.104 \\
\hline Campañas Agricolas & 3 ANESS & Campañas Almeria & \\
\hline Aditivos & \multicolumn{3}{|c|}{$\begin{array}{l}\text { - Carga Mineral } \\
\text { - Acetato de Vinilo } \\
\text { - Estabilizantes UV de última generación, especialmente resistentes } \\
\text { a los ataques químicos }\end{array}$} \\
\hline
\end{tabular}

Tabla 3.13 Propiedades del plástico empleado en la instalación experimental.

Como se mencionó previamente, la estructura descrita soporta cuatro módulos fotovoltaicos, orientados al Sur con una inclinación de $22^{\circ}$ (Figura 3.49) y para identificarlos han sido numerados del 1 al 4 desde la parte inferior a la superior. Estos módulos son del mismo fabricante y modelo que los utilizados en la instalación agroenergética Coronil IV, mismos que los también empleados en la anterior instalación experimental, cuyas especificaciones se mostraron en la Figura 3.12.

Los paneles han sido conectados en serie dos a dos, es decir el panel 1 con el 2 (grupo A) y el panel 3 con el 4 (grupo B), tal y como se muestra en la Figura 3.50. La razón de establecer esta conexión se debe a seguir la misma que en la instalación de Coronil IV. Por tanto, se tienen dos salidas (dos cables positivos y dos negativos) que se conectan a dos 
cargas electrónicas que nos proporcionarán las curvas características de cada par de paneles conectados en serie.

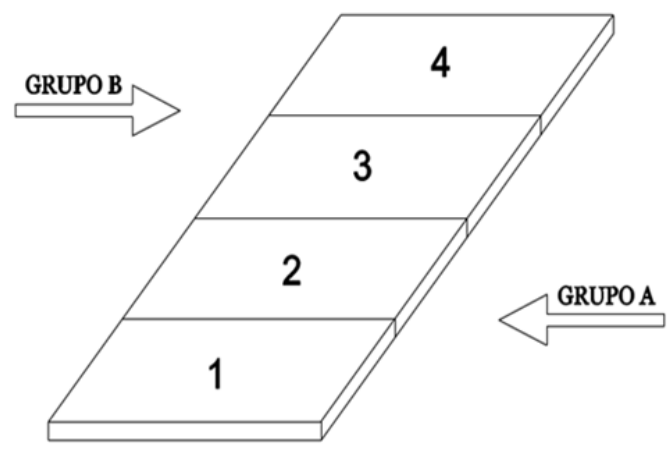

EN CADA GRUPO:

Figura 3.50 Grupos de paneles fotovoltaicos y esquema de conexión.

El diseño de esta instalación experimental se realizó para estudiar el comportamiento eléctrico de los paneles sobre su cubierta para la configuración descrita, además de analizar si la separación existente entre el plástico de la cubierta y los paneles es suficiente para evitar la influencia del calor interno del invernadero en la respuesta eléctrica de los módulos. Con tal fin, se plantearon diferentes configuraciones que nos permitirán comparar y seleccionar la configuración más idónea para futuras instalaciones.

La primera configuración (denominada Configuración 1) se corresponde con la descrita hasta ahora, siendo fiel al diseño de la instalación de Coronil IV y considerada de referencia, con una separación entre paneles y plástico de $15 \mathrm{~cm}$ en la entrada y de $29 \mathrm{~cm}$ a la salida. La segunda configuración estudiada (Configuración 2), se diferencia de la anterior en que se ha colocado un material aislante de poliuretano inyectado o panel sándwich, de $10 \mathrm{~cm}$ de grosor, estableciendo una barrera al paso del calor del interior del invernadero. La separación entre los módulos y el material aislante será similar.

Las dos configuraciones restantes presentan un canal de paso de aire de mayor sección a las anteriores, diferenciándose entre ellas en que el canal de aire de la configuración 3 está comprendido entre los paneles fotovoltaicos y la cubierta de plástico y en la configuración 4 entre los módulos y el material aislante. El espesor del canal de aire en ambas configuraciones no es exactamente de las mismas dimensiones, debido a que se ha respetado el diseño de la estructura inicial, y éste no nos ha permitido establecer la misma separación a la entrada al colocar el aislante. Las dimensiones de ambas separaciones son de $50 \mathrm{~cm}$ para la configuración 3 (cubierta de plástico) y de $40 \mathrm{~cm}$ en la configuración 4 (cubierta de aislante). En la Figura 3.51 se muestran la primera y cuarta configuración.

Además, se ha colocado un calefactor en el hueco interior de la estructura (invernadero). Este calefactor conectado a un PID (Watlow) y regulador de intensidad eléctrica (Watlow 


\subsection{INSTALACIONES FOTOVOLTAICAS EXPERIMENTALES DESARROLLADAS}

DIN-A-MITE) nos permite simular diferentes condiciones de temperatura interior, pudiendo aumentar la temperatura y posteriormente analizar si influye en la producción eléctrica de los paneles.

En resumen, se ha estudiado la influencia de la transferencia de calor del interior del invernadero sobre el comportamiento eléctrico de los paneles, recogiendo datos en funcionamiento normal, considerando dos separaciones en el canal de aire, cada una de ellas constituidas con una cubierta de plástico y colocando un aislante sobre esta.
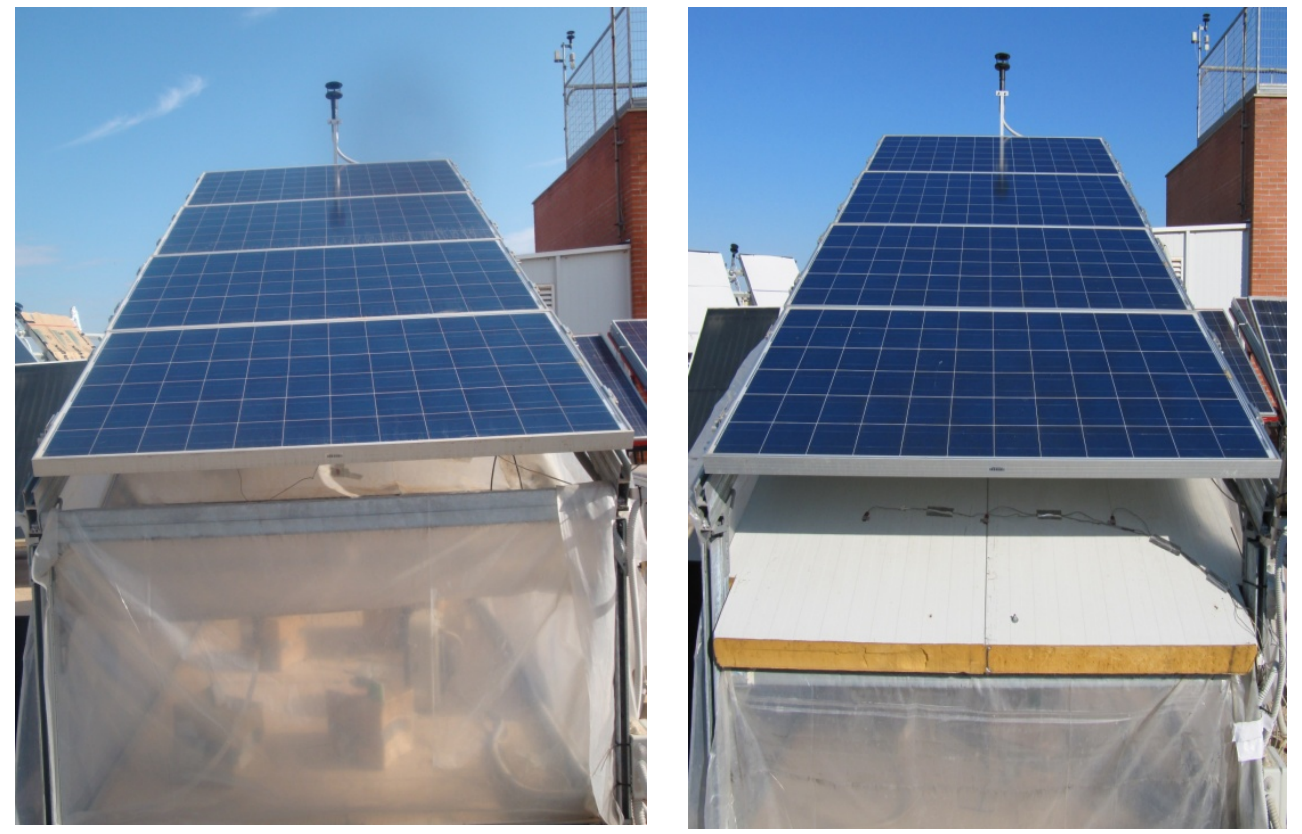

Figura 3.51 Fotografías de dos configuraciones estudiadas. Izquierda: Primera configuración con menor sección de aire de paso y con cubierta de plástico. Derecha: cuarta configuración con canal de aire de mayor sección y con aislante sobre la cubierta.

Para el estudio y análisis de las configuraciones descritas, se han instalado diferentes sensores y aparatos de registro de medida. En la presente sección se pretende nombrar la instrumentación utilizada así como su ubicación y finalidad.

La temperatura de cada panel fotovoltaico es medida mediante tres sondas de temperatura Pt100, adheridas simétricamente a la cara posterior del panel. Las correspondientes al panel 1 se han denominado; P1.1, P1.2 y P1.3, las del panel 2 como; P2.1, P2.2, P2.3 y así con cada módulo Figura 3.52a. En total se disponen de doce sondas de temperatura, que nos permitirá conocer la distribución de temperaturas en los paneles, a lo largo de la cubierta y los posibles puntos calientes en los que se alcancen mayores temperaturas.

En el canal de aire entre los paneles y la cubierta, bien de plástico o de aislante, se ubican cuatro sondas de temperatura, dos en la entrada (S3 y S4) y dos a la salida (S1 y S2) a una distancia de $80 \mathrm{~cm}$ de la entrada y salida tal y como se muestra en la Figura 3.52a. Estos 
sensores nos informan de la temperatura del aire en el canal. El caudal de aire se obtiene a partir de la velocidad registrada por los 4 anemómetros, colocados dos en la entrada (AN3 y AN4) y dos en la salida (AN1 y AN2), cercanos a las sondas de temperatura, alejados de la sección de entrada y de los laterales del canal evitando perturbaciones en la distribución de velocidades.

La temperatura de la cubierta de plástico es medida por Pt100 adhesivas, similares a las utilizadas para medir la temperatura del panel. Se han utilizado un total de 12 sondas, colocadas simétricamente a las de los paneles fotovoltaicos (Figura 3.52b). Estos sensores se han denominado de forma similar a las de los paneles de modo que las tres sondas adheridas al plástico bajo el panel 1 son PL1.1, PL1.2 y PL1.3, las simétricas al panel 2 PL2.1, PL2.2, PL2.3 y así sucesivamente.

Por último, nos queda mencionar los sensores utilizados en el interior del invernadero para medir la temperatura alcanzada en él. Se han colocado cuatro sondas de temperatura, similares a las ubicadas en el canal de aire, sobre unos soportes que las elevan del suelo y las posiciona a media altura, permitiendo así medir la temperatura del interior de forma más precisa, sin interferir la temperatura del suelo o cubierta. Estos sensores de han denominado como SI1, SI2, SI3 y SI4 (Figura 3.52c).

a)

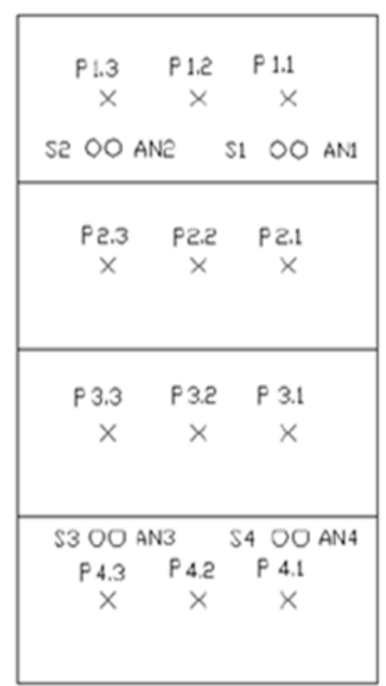

b) PLáSTICD

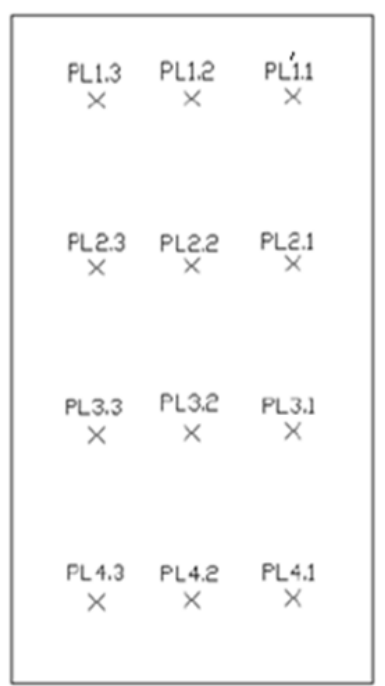

C) INTERIOR
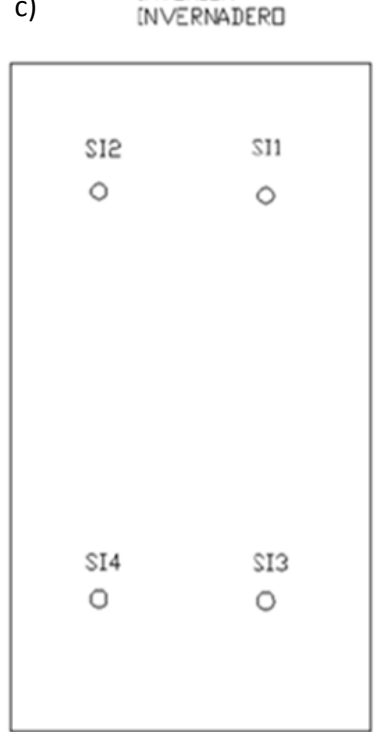

Figura 3.52 Ubicación de los sensores utilizados en la instalación experimental. a) Sensores emplazados en el canal de aire y adheridos a los paneles. b) Sensores adheridos a la cubierta de plástico. c) Sondas de temperatura en el interior del invernadero.

En el interior del invernadero se dispone también de un aerotermo controlado con un PID y Din-a-mite que utilizaremos para simular distintas temperaturas en el interior del invernadero, para evaluar la trasferencia de calor a los paneles y por ende la influencia en su respuesta eléctrica. 
Las condiciones ambientales, radiación solar, temperatura ambiente, velocidad y dirección del viento son medidas con la misma estación meteorológica utilizada en la otra instalación experimental. Para el registro de datos de esta instalación, se ha modificado la inclinación del piranómetro, haciéndola coincidir con la que disponen los paneles fotovoltaicos $\left(22^{\circ}\right.$ respecto la horizontal).

Las variables eléctricas de los paneles fotovoltaicos son medidas de la misma forma que se midieron en la instalación experimental anteriormente descrita, utilizando las mismas cargas electrónicas. En esta instalación, cada carga nos mostrará la curva característica de dos paneles fotovoltaicos conectados en serie. De ella podremos obtener los valores de tensión de circuito abierto $\left(V_{o c}\right)$, intensidad de cortocircuito $\left(I_{s c}\right)$ y el punto de máxima potencia $\left(P_{m}\right)$.

Todas las variables medidas son registradas por el mismo sistema de adquisición de datos conectado al ordenador, para poder tratarlos y analizarlos posteriormente. El procedimiento llevado a cabo en el registro de las variables ha sido similar a la metodología utilizada en la anterior instalación experimental. De este modo, recogemos las variables termodinámicas en un fichero independiente al de las variables eléctricas de los paneles, al presentar una frecuencia de muestreo distinta.

\subsubsection{DESCRIPCIÓN DE LA INSTRUMENTACIÓN UTILIZADA}

A continuación se va a detallar la instrumentación empleada en la instalación experimental descrita, para ello se va a hacer una diferenciación entre:

A) Condiciones ambientales: aquellos instrumentos que nos permiten obtener los valores de radiación solar y el resto de variables meteorológicas representativas.

B) Variables de operación: medición de los parámetros propios específicos que posibilitan la caracterización de la instalación experimental de estudio.

El emplazamiento de la instalación experimental así como de los dispositivos para la medición de las condiciones ambientales es el mismo, en la azotea del Aulario General del Campus universitario Alfonso XIII de la Universidad Politécnica de Cartagena.

\subsubsection{INSTRUMENTACIÓN PARA LA MEDIDA DE LAS CONDICIONES AMBIENTALES}

Los aparatos de medida utilizados son los mismos que los presentados en la estación meteorológica descrita en el 3.2.1.1 Las condiciones ambientales medidas en esta instalación experimental son:

- Humedad relativa

- Temperatura ambiente

- Velocidad del viento 
- Dirección del viento

- Radiación global y dufusa

Estos sensores presentan las mismas características que los descritos en la instalación anterior, incluidas en las tablas; Tabla 3.3, Tabla 3.4 y Tabla 3.5. La única diferencia es su emplazamiento. Los sensores de humedad y temperatura ambiente y el anemómetro se han colocado en las inmediaciones de la instalación, para recoger los valores de las medidas de una manera más exacta y precisa.

En esta sección no incluiremos de nuevo el principio de funcionamiento de cada uno, así como sus especificaciones técnicas, tan sólo describiremos su ubicación y utilización. El sensor de temperatura y humedad relativa se ha colocado en un lateral del frontal de la instalación, junto al panel 1, tal y como se muestra en la Figura 3.53. Se ha utilizado el mismo modelo que se disponía en la estación meteorológica (EE21) por ser recomendado para la utilización al aire libre, al poseer un elemento de protección y por su sencillo diseño permitiendo la ventilación natural y facilitando el acceso al sensor para su montaje y desmontaje.

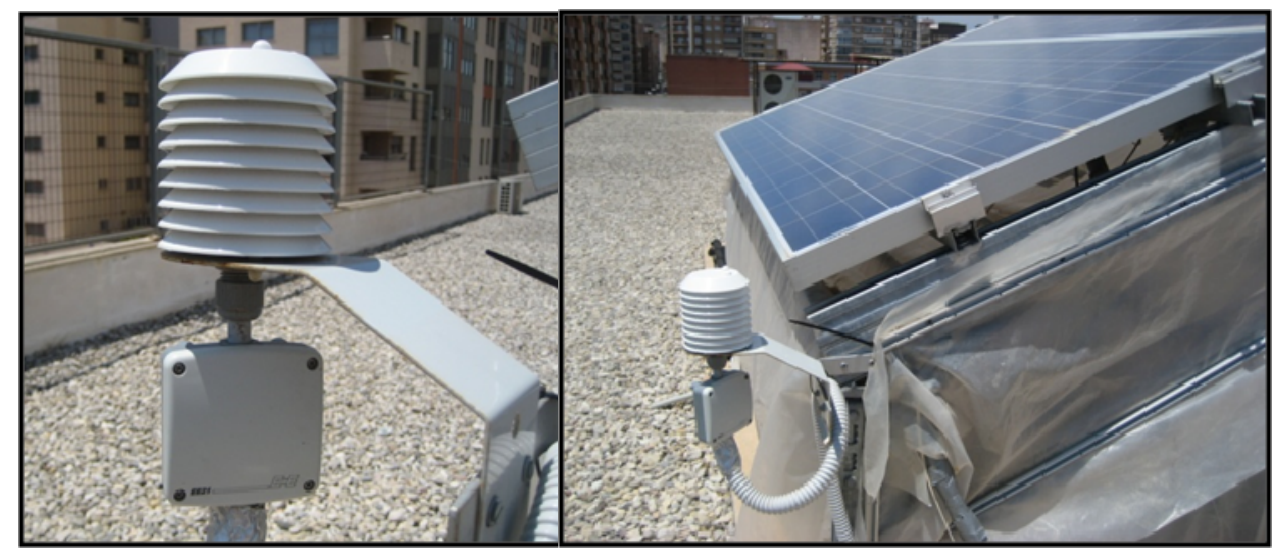

Figura 3.53 Transmisor de la temperatura ambiente y su ubicación en la instalación experimental.

La velocidad y dirección del viento se mide utilizando un anemómetro ultrasónico, cuya principal ventaja es que emplea un sensor único sin partes móviles para la obtención de ambas medidas, abarcando los $360^{\circ}$ y presenta una puesta en funcionamiento en condiciones de poco tiempo. Además es un sensor ligero y compacto con un montaje estándar. El anemómetro se ha colocado en el centro de la parte superior de la cubierta, junto al panel 4, elevándolo unos $40 \mathrm{~cm}$ del plano en el que están los paneles, con el fin de evitar cualquier perturbación y tener unos valores correctos (Figura 3.54). 


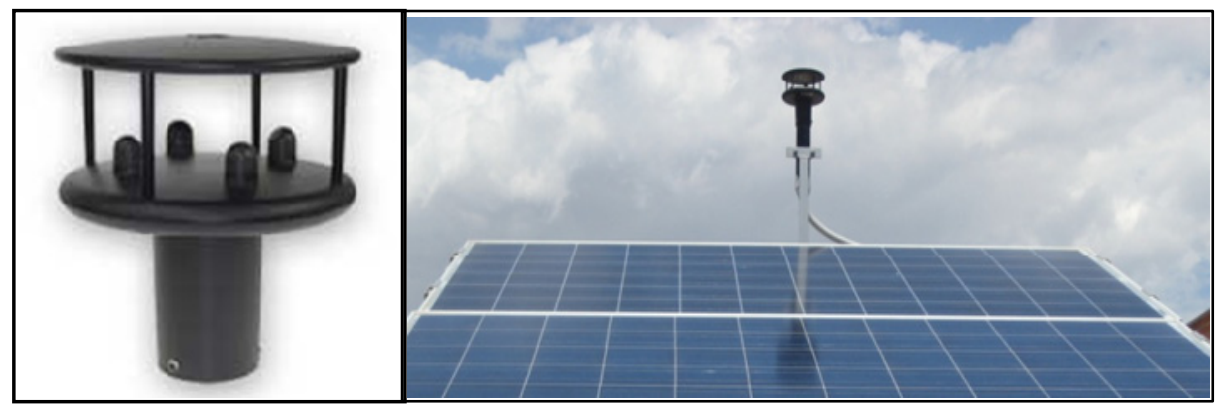

Figura 3.54 Anemómetro Windsonic y su ubicación en la instalación experimental.

El piranómetro fijado en la instalación anterior, no se ha cambiado de ubicación puesto que ambas se encuentran muy próximas y con la misma orientación. Lo que si se ha modificado ha sido su inclinación, adoptándole la que tienen los paneles sobre el invernadero $\left(22^{\circ}\right)$.

\subsection{INSTRUMENTACIÓN DE LAS VARIABLES DE OPERACIÓN DE LA INSTALACIÓN}

Los sensores utilizados para medir las variables de operación de la instalación se presentaron previamente, indicando su finalidad y ubicación, siendo:

- Transmisor de temperatura de contacto (paneles fotovoltaicos y cubierta de plástico)

- Transmisor de temperatura del aire en el canal y del interior del invernadero

- Anemómetros

- Aerotermo

- Controlador PID yDin-a-mite

- Carga electrónica

- Adquisición de datos

En esta sección se pretende detallar el funcionamiento de cada uno, así como sus especificaciones técnicas. Dado que algunos de estos sensores se corresponden al mismo modelo, fabricante y por ende mismas características técnicas que los utilizados en la instalación experimental anterior, nos limitaremos a definir y especificar tan sólo los que no se hayan incluido hasta ahora.

Los transmisores de temperatura de contacto (paneles y plástico), anemómetros, carga electrónica y sistema de adquisición de datos son los sensores definidos en la instalación anterior. Sus especificaciones técnicas se mostraron en las tablas; Tabla 3.8,Tabla 3.10, Tabla 3.11 y Tabla 3.12. A continuación, se describen el resto de sensores: transmisor de temperatura de aire en el canal y en el interior del invernadero, aerotermo, y el sistema de control PID-Din-a-mite. 


\section{TRANSMISOR DE TEMPERATURA DEL AIRE EN EL CANAL Y EN EL INTERIOR DEL} INVERNADERO

Este transmisor nos proporciona las medidas de temperatura en el ambiente que le rodea (Figura 3.55). Se ha utilizado el mismo modelo para obtener la temperatura en el interior del invernadero y la del aire que circula entre los paneles y la cubierta, tanto a la entrada como a la salida. La medida de la temperatura se realiza mediante un sensor de temperatura Pt1000, que se basa en la variación de la resistencia del platino con la temperatura.

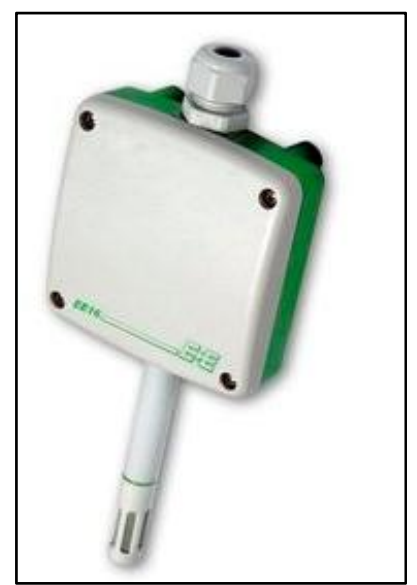

Figura 3.55 Transmisor de la temperatura del aire tanto en el canal como en el interior del invernadero.

\section{- Principio de Operación}

Para obtener el dato de la temperatura los transmisores llevan incorporados un detector de temperatura por resistencia (RTD) de platino (PRTD), la Pt 1000 clase A, DDIN-EN 60571.

EI RTD es un sensor de temperatura basado en el cambio de resistividad que sufren las estructuras cristalinas de los metales con la temperatura, su comportamiento es aproximadamente lineal para ciertos metales.

Un RTD se fabrica para tener un valor nominal ' $R_{0}$ ' a una temperatura dada (por ejemplo $1000 \mathrm{ohms} \mathrm{a} 0^{\circ} \mathrm{C}$ ). Al medir su resistencia a una temperatura desconocida y al compararla con $R_{0}$ (valor que se debe ajustar el resistor de referencia), puede conocerse la variación ' $d R$ '. Como la característica $R=f(T)$ también es conocida, la variación de resistencia ' $d T$ ' desde el punto inicial será conocida. 


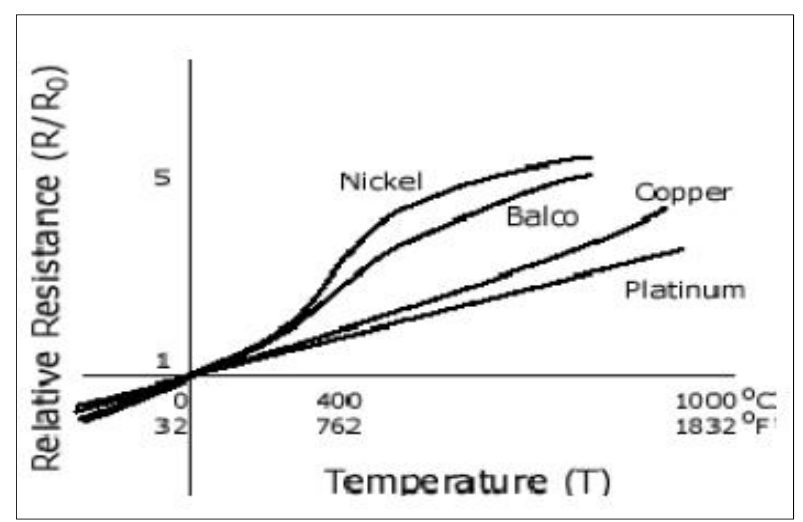

Figura 3.56 Curvas características de algunos metales.

El platino es el más popular de éstos, debido a su característica muy cercana a la linealidad en un rango amplio de temperaturas, estable a largo plazo. El coste de las PRTD's se vieron reducidos al implementarse en película delgada.

Las principales características encontradas en el platino son:

- Estabilidad química; resistencia a la oxidación y corrosión.

- Facilidad de manofactura.

- Disponibilidad de alambre de alta pureza.

- Buena reproducibilidad de características eléctricas (permite el poder reemplazar el elemento sensor sin tener que recalibrar el instrumento).

- Valores típicos: 100, 500, 1000 ohms.

- Identificación: Se identifican por el metal del que se componen (según la tabla periódica) y la resistencia que presentan a $0^{\circ} \mathrm{C}$. Ejemplo; Pt100, Ni120, Cu200, etc.

- Precision de los RTD (dada alrededor de los $0^{\circ} \mathrm{C}$, donde es mayor): Clase A es $\pm 0.15^{\circ} \mathrm{C}$ y Clase $\mathrm{B}$ es $\pm 0.30^{\circ} \mathrm{C}$.

Las principales características del sensor de temperatura, vienen recogidas en la siguiente tabla.

\begin{tabular}{|l|c|}
\cline { 2 - 2 } \multicolumn{1}{c|}{} & $\begin{array}{c}\text { Temperatura interior } \\
\text { invernadero y del aire }\end{array}$ \\
\hline Modelo & EE16 \\
\hline Fabricante & $\mathrm{E}+\mathrm{E}$ Elektronik \\
\hline Rango & $-25^{\circ} \mathrm{C}$ a $60^{\circ} \mathrm{C}$ \\
\hline Tipo de sensor & $\mathrm{Pt} 1000 \mathrm{Clase} \mathrm{A}$ \\
\hline Exactitud & $\pm 0,3^{\circ} \mathrm{C}$ a $20^{\circ} \mathrm{C}$ \\
\hline Temperatura de operación & $-5^{\circ} \mathrm{C}$ a $50^{\circ} \mathrm{C}$ \\
\hline
\end{tabular}




\begin{tabular}{|l|c|}
\hline Salida & $0-10 \mathrm{Vcc}$ \\
\hline Alimentación & $10-35 \mathrm{Vcc}$ \\
\hline Temperatura de operación & $-35 \mathrm{a}+70^{\circ} \mathrm{C}$ \\
\hline
\end{tabular}

Tabla 3.14 Características del sensor de temperatura del aire en el canal y en el interior del invernadero.

\section{AEROTERMO}

El aerotermo utilizado nos permite aumentar la temperatura del interior del invernadero, a través de un sistema de control PID para poder simular diferentes condiciones de trabajo.

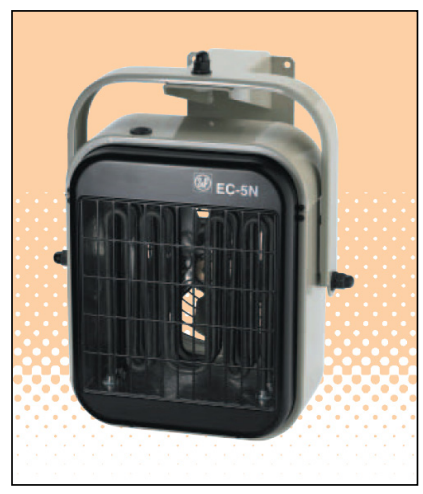

Figura 3.57 Aerotermo para calentar el interior del invernadero.

El aerotermo eléctrico está dotado de un ventilador axial, que permite unificar la temperatura del aire. El ventilador estará siempre en funcionamiento y la resistencia eléctrica funcionará cuando el PID- Din-a-mite detecten una temperatura inferior a la fijada, de manera continua hasta que se alcance.

\begin{tabular}{|l|c|}
\cline { 2 - 2 } \multicolumn{1}{c|}{} & Aerotermo \\
\hline Modelo & EC-3N \\
\hline Fabricante & Soler \& Palau \\
\hline Potencia total & $3033 \mathrm{~W}$ \\
\hline Potencia calefacción & $3000 \mathrm{~W}$ \\
\hline Caudal ventilador & $350 \mathrm{~m}^{3} / \mathrm{h}$ \\
\hline Velocidad ventilador & $1300 \mathrm{r} . \mathrm{p} . \mathrm{m}$. \\
\hline Proteccion salpicaduras & $\mathrm{IP24}$ \\
\hline
\end{tabular}

Tabla 3.15 Características técnicas del aerotermo.

\section{SISTEMA DE CONTROL: PID Y DIN-A-MITE}

Como se ha mencionado, se dispone de un P.I.D. y de un regulador de intensidad con el fin de fijar una temperatura en el interior del invernadero, superior a la existente. La temperatura deseada se introduce en el PID, el cual está conectado a una sonda que mide la temperatura en el interior. EI PID comparará ambos valores y si la existente en el interior del invernadero es inferior a la fijada, mandará una señal al DIN-A-MITE para 
que actúe sobre la corriente de alimentación del calefactor, de la red, para que por aproximaciones sucesivas se consiga la temperatura deseada. El diagrama de conexión se muestra a continuación.

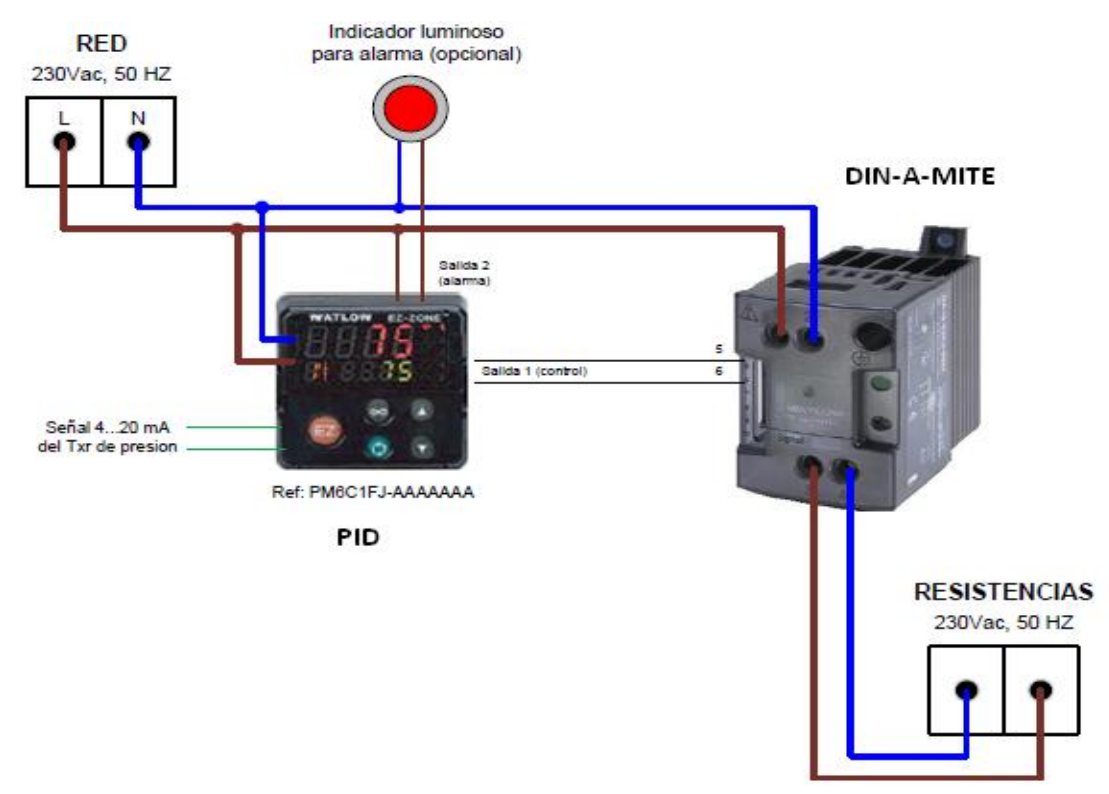

Figura 3.58 Diagrama de conexión entre DIN-A-MITE y PID.

Sus principales características se incluyen a continuación.

\begin{tabular}{|l|c|c|}
\cline { 2 - 3 } \multicolumn{1}{c|}{} & PID & Din-a-mite \\
\hline Modelo & Serie 96 & Style $\mathrm{A}$ \\
\hline Fabricante & \multicolumn{2}{c|}{ Watlow } \\
\hline Alimentación & $\begin{array}{c}\text { Monofásico, máximo } \\
18 \mathrm{~A} \text { a } 50^{\circ} \mathrm{C} \text { carga } \\
\text { resistiva }\end{array}$ & $100-240 \mathrm{~V}(\mathrm{CA})$ \\
\hline Rango de & $-10^{\circ} \mathrm{C}-50^{\circ} \mathrm{C}$ & $-18^{\circ} \mathrm{C}-65^{\circ} \mathrm{C}$ \\
funcionamiento & $0-90 \% \mathrm{HR}$ & $0-90 \% \mathrm{HR}$ \\
\hline
\end{tabular}

Tabla 3.16 Características técnicas del PID y Din-a-mite.

\subsubsection{CONCLUSIONES (CONCLUSIONS)}

Se han descrito las instalaciones experimentales diseñadas y construidas en la Universidad Politécnica de Cartagena, objeto de estudio. Se describe su diseño constructivo tanto para la configuración prototipo fiel a la instalación comercial de referencia, como para otras configuraciones propuestas, con el propósito de estudiar una posible mejora en el comportamiento eléctrico de los módulos fotovoltaicos, mediante la refrigeración con aire 
por su cara posterior aprovechando el efecto chimenea creado. Además se incluye la descripción y características de la instrumentación utilizada en la medición y registro de datos.

La primera instalación experimental consta de dos módulos fijados a una estructura soporte, con igual inclinación y orientación. Uno de los paneles presenta una superficie metálica bajo su cara posterior, existiendo un espacio entre ellas que constituye el canal de aire de refrigeración. El otro panel, sin ninguna superficie inferior se considera de referencia, para comparar el comportamiento de ambos. Se ha descrito las diferentes configuraciones estudiadas, la ubicación de todos los sensores de medida y las características de la instrumentación utilizada en la medida y registro de datos.

La segunda instalación experimental, ha sido diseñada y construida fiel a la instalación agroenergética, Coronil IV, de la que se ha elegido una unidad estructural, constituida por una estructura metálica destinada a soportar cuatro módulos fotovoltaicos sobre la cubierta de plástico del invernadero. Esta instalación, replica de la comercial de referencia, dispone de un espacio libre entre la cubierta y los módulos, permitiendo la circulación de aire a través de un canal divergente, por el efecto chimenea creado por convección natural. El diseño de esta instalación ha permitido modificar la sección de entrada de aire, lo cual nos permite comparar el funcionamiento de los paneles, al igual que se ha modificado la cubierta de plástico por un material aislante, para cada sección de estudio. Las diferentes configuraciones de estudio, el emplazamiento de los sensores utilizados y sus características se han detallado.

\section{CONCLUSIONS}

The experimental facilities which were designed and built for the study have been described. The description includes the structural design for the prototype configuration which is similar to the reference configuration of a commercial facility, as well as other proposed configurations. This was in order to study a possible improvement in the electrical performance of photovoltaic modules, by air cooling through their back face taking advantage of the chimney effect created. Furthermore, the descriptions and characteristics of the sensors and instrumentations used to measure and register the data have been included.

The first experimental facility consisted of two photovoltaic modules which are mounted on a fixed structure, with the same slope or pitch angle and orientation. A panel was placed above a steel plate, with an air channel underneath the panel. The other module, without any surface underneath it, was considered as the reference panel working under the same environmental conditions to compare both electrical functions. This study describes the different analysed configurations, the collocation of all sensors and the characteristic of the instrumentations used. 
The second experimental facility has been designed and built true to the commercial agroenergetic facility (Coronil IV) from which the structural unit was chosen: consisted of a metal structure to support four photovoltaic modules on the plastic greenhouse roof. The designed prototype and the original facility contained a space between the roof and the photovoltaic modules which allowed the air circulation through a divergent channel by the chimney effect created by natural convection. The design of the experimental facility allowed variation in the inlet air section, whose purpose was to compare the panels functioning in each case, as well as the plastic roof was changed by an insulation material for each studied section. The different configurations, the sensors collocation and characteristic have been described in detail. 


\section{CAPITULO 4. DESCRIPCIÓN DE LA METODOLOGÍA LLEVADA A CABO EN EL REGISTRO DE DATOS E INCERTIDUMBRE DE LAS VARIABLES}

Una vez presentadas las instalaciones experimentales y las diferentes configuraciones que serán objeto de análisis, se va a describir el proceso llevado a cabo en la toma de datos en ambas instalaciones, incluyendo además las incertidumbres obtenidas de todas las variables que intervienen en el análisis.

El procedimiento llevado a cabo en el registro y tratamiento de datos de cada instalación experimental es muy similar, diferenciándose en el número de variables medidas y la frecuencia de muestreo en los ensayos, según el estudio a realizar. El proceso se ha automatizado mediante el uso del software de Lab-view ${ }^{\circledR}$ junto a la implementación de un código encargado de registrar los valores de las variables a medir, cada 15 minutos. Las variables eléctricas del panel son medidas por la carga electrónica que se activará mediante la señal de disparo generada por una tarjeta de National Instrument ${ }^{\circledR}$.

Las medidas de las variables se han procurado registrar en días soleados y con buenas condiciones ambientales, escogiendo los meses de mayor radiación solar y temperatura ambiente, a fin de poder evaluar la influencia de la temperatura en el comportamiento eléctrico de los paneles. No obstante, los datos de todas las variables recogidas son previamente estudiados para verificar si las medidas diarias son válidas para el análisis o en caso contrario rechazarlos.

Con el fin de asegurar de forma cuantitativa la calidad de los valores de las variables obtenidas, se ha realizado su correspondiente análisis de incertidumbre. En este capítulo además se presentan los procedimientos llevados a cabo para calcular tanto las incertidumbres típicas de las variables primarias, medidas directamente, como la incertidumbre típica combinada de las variables que dependen de las anteriores, y así obtener sus correspondientes estimaciones. 


\subsection{METODOLOGIA EN EL REGISTRO DE DATOS}

El conjunto de todas las variables de estudio medidas en cada instalación se describieron en el capítulo anterior, secciones 3.2.1.1 y 3.2.2.1. El tratamiento de los datos se ha realizado de forma automática, utilizando el software de Lab-view $^{\circledR}$ y un código implementado que se encarga de recoger pares de valores medidos cada 15 minutos, obtener su media y registrarlos cronológicamente en una hoja de cálculo diariamente. Para medir las variables eléctricas del panel, se requiere dar una señal de disparo a la carga electrónica para trazar la curva característica en ese instante y de ella obtener los parámetros de funcionamiento. Su funcionamiento se activa a través de una tarjeta de National Instrument ${ }^{\circledR}$.

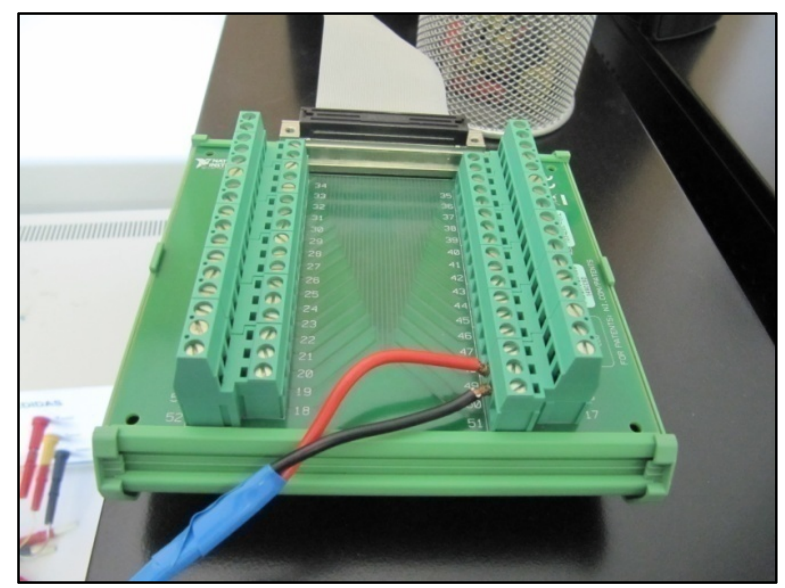

Figura 4.1 Fotografía de la tarjeta utilizada para el disparo de la carga electrónica.

El proceso de adquisición y tratamiento de datos, para cada instalación, se han dividido en dos grupos. Un primer grupo engloba todas las variables termodinámicas, tales como temperaturas de panel, del aire en el canal, velocidades, radiación solar, etc. y el segundo grupo contiene las variables eléctricas características de los paneles fotovoltaicos. El hecho de separarlas en su medición y registro se debe a que todas las variables del primer grupo medidas requieren menor frecuencia de muestreo que las del segundo grupo, para finalmente obtener las variables de estudio necesarias en el análisis. Como se ha mencionado, cada 15 minutos, en el intervalo de un segundo se recogen pares de valores de cada variable, de los que se obtiene su media que se considera el valor registrado en ese instante. Para proceder igualmente con las variables eléctricas se deben trazar dos curvas características en el mismo instante, lo cual resulta imposible hacerlo en la misma configuración del sistema de adquisición, dado que para obtener una curva precisa, se necesita registrar entre 25 y 40 pares de puntos (intensidad, tensión), lo cual requiere una alta frecuencia de muestreo, para el mismo intervalo de tiempo en la medida, Figura 4.2. Por esta razón, se han dividido en dos grupos las variables en el proceso de adquisición de los datos, implementando por separado el procedimiento descrito. 


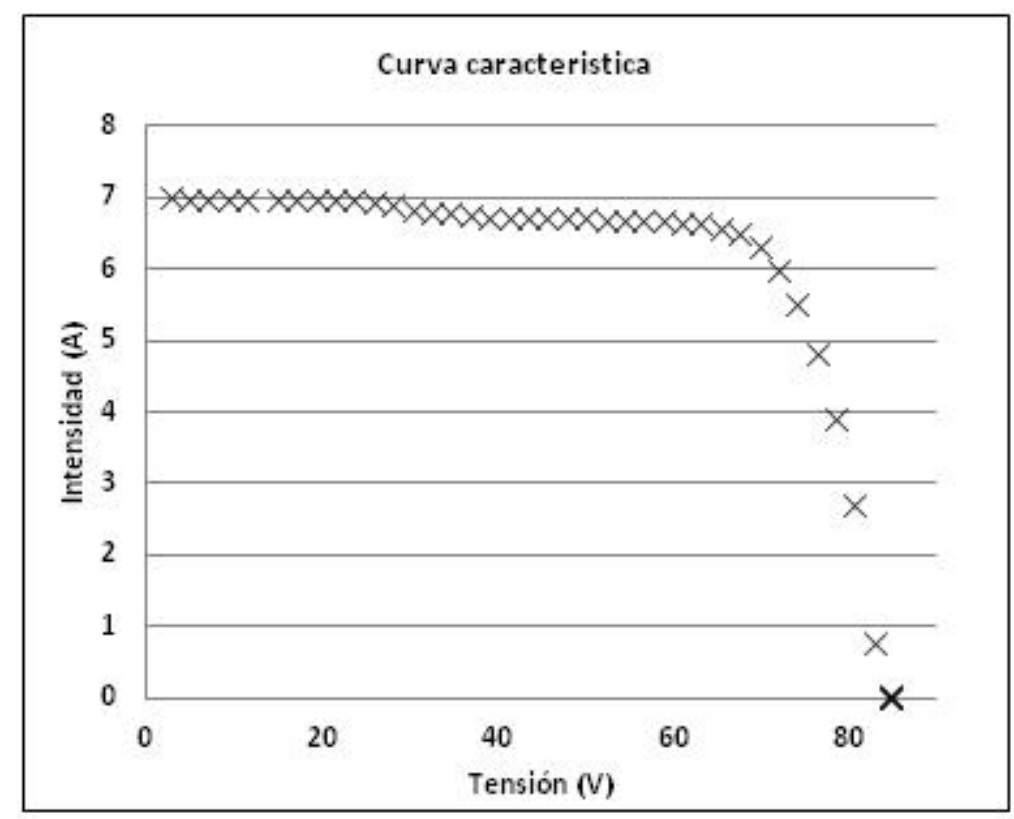

Figura 4.2 Ejemplo de curva característica I-V obtenida de los paneles 1 y 2 conectados en serie en la instalación experimental del invernadero

Labview $^{\circledR}$ es un entorno de desarrollo de National Instruments ${ }^{\circledR}$ basado en programación gráfica. Entre los campos de utilización destacan la adquisición de datos y el procesado de señales, el control de instrumentos, la automatización de sistemas de pruebas y validación, los sistemas embebidos para monitoreo y control y la enseñanza.

En nuestro caso lo utilizamos para llevar a cabo la adquisición de datos durante un intervalo de tiempo fijado por el usuario junto con el correspondiente registro de dichos datos. Posteriormente con un software propio estos datos son procesados, tratados estadísticamente y utilizados a conveniencia en los distintos análisis y estudios que se han llevado a cabo.

La aplicación construida consta de un Panel Frontal sencillo (Figura 4.3) en el que el usuario indica unos pocos parámetros necesarios para llevar a cabo la adquisición de datos.

En una primera columna se define el número de ensayos que se van a realizar, el tiempo que va a haber entre medidas.

En la segunda columna se fija el tiempo durante el cual los paneles van a estar cortocircuitados (t pulsado) y el tiempo durante el cual se van a estar tomando puntos de la curva V-I de los paneles ( $t$ final $(s)$ ).

A título informativo y para comprobación del usuario, en la tercera columna se incluye el tamaño de las medidas realizadas en cada caso. 


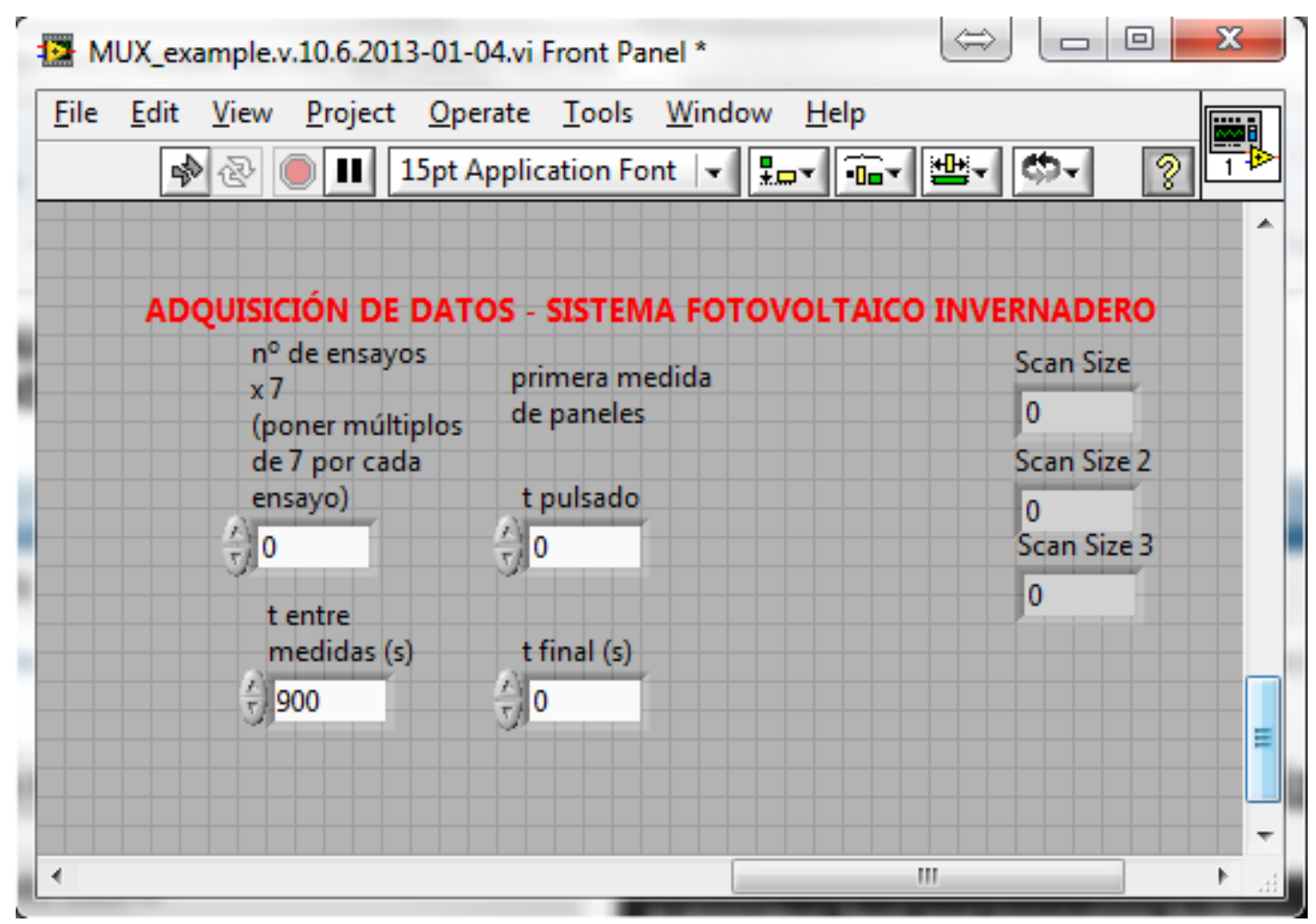

Figura 4.3 Panel frontal de aplicación desarrollada en Labview ${ }^{\circledR}$.

Para su construcción se ha realizado un diagrama de bloques basado en lo que se denomina una estructura de casos (Case structure). Esta estructura consta de tres "casos" que se ejecutan cada vez que pasa el "tiempo entre medidas" mencionado anteriormente y que el usuario introdujo en el panel central.

Cada caso corresponde a cada una de las medidas realizadas y tras su realización finaliza con la escritura de los datos en un fichero que luego será procesado. En los dos primeros casos se realizan las medidas de las variables termodinámicas y en el tercero las medidas asociadas a la caracterización de la curva I-V de los paneles. Cada uno de estos casos se construye utilizando los diagramas de bloques sobre los que se desarrolla la programación en Labview $^{\circledR}$.

A modo de ejemplo se incluye uno de estos casos en la Figura 4.4. En la zona superior se observan los sensores cuyos valores van a ser medidos con el Data Logger y que van a ser registrados. Tal y como se comentó arriba, en nuestro caso los sensores monitorizados tienen salida en tensión, intensidad y en el caso de los sensores de temperatura, son resistencias. En el cuadro central dentro del caso incluido en la figura aparecen diferentes componentes enlazados y que directamente tienen que ver con el propio sistema de adquisición. Los datos son registrados dos veces cada cierto tiempo (que es fijado a través de un temporizador). Finalmente cuando este cuadro central ha realizado las dos tomas de datos, éstos son almacenados en un fichero con un nombre dado por el programa. Para la definición de los datos, su formato y el modo en el que se realiza su registro se utiliza el componente azul de la derecha de la Figura 4.4 llamado "Write to file". 


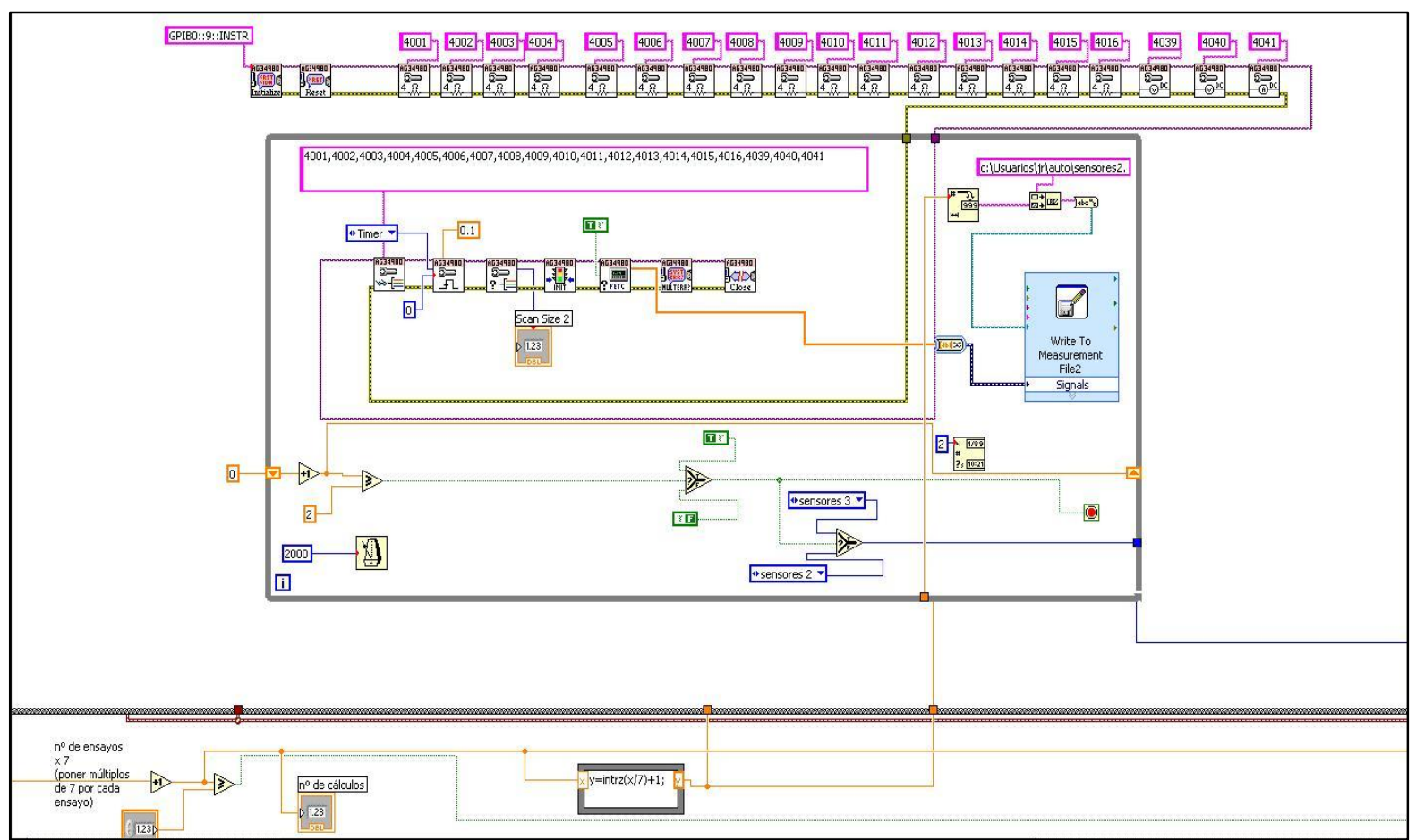

Figura 4.4 Diagrama de bloques de uno de los casos implementados en LabView ${ }^{\circledR}$.

Una vez registrados los datos diariamente, se procederá a su tratamiento en hojas de cálculos que nos permita tener el conjunto de todas las variables objeto de estudio, tanto las medidas como las que se obtienen a partir de éstas. Se han creado varias hojas de cálculo modelo para cada configuración, obteniendo los cálculos necesarios para obtener las variables deseadas o valores medios al introducir los nuevos datos medidos, con el fin de agilizar el tratamiento de datos diario. Además, las hojas de cálculo proporcionan gráficas de control, que nos permite detectar algún error en la medida, valores anómalos, conocer la evolución de la radiación solar etc., sirviendo como instrumento imprescindible para el posterior análisis. 


\subsection{ANALISIS DE INCERTIDUMBRE}

El objetivo de una medición es conocer el valor de una magnitud. Sin embargo, debido a las imperfecciones existentes siempre, tanto en el procedimiento de medida como en el instrumento utilizado, nunca es posible conocer el valor exacto de la magnitud, sino sólo una estimación del mismo. Por ello, toda medida lleva asociada una estimación de su resultado y una incertidumbre, la cual establece un intervalo de confianza alrededor de la estimación de la magnitud.

Se denomina incertidumbre típica a la desviación típica de la estimación del resultado de un medida, representándose por $u(y)$. Normalmente la magnitud buscada en una medida no se obtiene de forma directa, sino que se deriva a partir de una ecuación o procedimiento de medida en el que se miden diversas magnitudes primarias o de entrada. Dicho procedimiento establece una relación funcional entre el resultado de la medida ' $Y$ ' y las magnitudes primarias ' $X$ ' de la siguiente forma:

$$
Y=f\left(X_{1}, X_{2}, \ldots, X_{m}\right)
$$

Cada una de las magnitudes primarias requerirá una estimación y una incertidumbre típica ' $u\left(x_{i}\right)$ '. Estas incertidumbres típicas se combinarán entre sí para formar la incertidumbre típica combinada de la magnitud $Y$. Finalmente, a partir de ésta se obtendrá la incertidumbre expandida ' $U$ ' que representa el intervalo de confianza dentro del que se encuentra el valor verdadero de la magnitud con una cierta probabilidad.

A continuación se mostrará de forma resumida los procedimientos llevados a cabo para calcular cada una de estas incertidumbres, así como para determinar las estimaciones de las magnitudes primarias y del resultado de la medida, siguiendo la metodología propuesta por la Guía BIPM/ISO [74].

\subsubsection{EVALUACIÓN DE LA INCERTIDUMBRE TÍPICA, COMBINADA Y EXPANDIDA}

La determinación del valor de una magnitud se reduce a un problema estadístico, el que dicho valor representa una variable aleatoria con una cierta distribución. Cuando se realiza una medida lo único que se puede conocer es una estimación de la variable con una cierta incertidumbre.

Las denominadas magnitudes primarias pueden ser magnitudes que se obtienen experimentalmente a través de una serie de medidas, coeficientes o valores dados por fabricantes, catálogos, tablas... o correcciones debidas a la precisión de los equipos de medida, incertidumbre en el conocimiento de coeficientes. Todas ellas requieren determinar tanto su estimación ' $x_{i}$ ' como su incertidumbre típica ' $u\left(x_{i}\right)$ '. En el estudio que 
nos concierne, las magnitudes primarias son magnitudes determinadas experimentalmente y su mejor estimación es la media muestal, $x_{i}=\bar{X}_{i}$.

Como se ha mencionado, la incertidumbre no es sino la desviación típica de la estimación. Existen dos procedimientos para evaluarla, el tipo A y tipo B. La evaluación tipo A se basa en procedimientos estadísticos, siendo precisa la obtención de una muestra de la magnitud. Por el contrario, la evaluación tipo B se basa en el conocimiento adquirido por la experiencia, información de referencias, catálogos, certificados, etc., en resumen, procedimientos no estadístico, aunque lo que determinarán si es un valor estadístico.

La evaluación tipo A, considera incertidumbre típica como el valor de la desviación típica experimental de la media, como variable cuantificadora de la bondad de la estimación. De este modo, para una magnitud de entrada $X_{i}$ determinada a partir de $N$ observaciones independientes, $X_{i k}$, la incertidumbre típica de su estimación $x_{i}=\bar{X}_{i}$ es

$$
u\left(x_{i}\right)=s\left(\bar{X}_{i}\right)=\sqrt{\frac{S^{2}\left(X_{i}\right)}{N}}
$$

, siendo $s^{2}$ la varianza experimental que viene dada por:

$$
s^{2}\left(X_{i}\right)=\frac{\sum_{k=1}^{N}\left(X_{i, k}-\bar{X}_{i}\right)^{2}}{N-1}
$$

La evaluación tipo B engloba diversas formas de presentar la incertidumbre típica de una magnitud, según los datos que se conozcan de ella en catalogo, manual u otra fuente. En nuestro análisis se ha obtenido mediante una distribución rectangular de la estimación de la medida., dado que se conocen los límites superior e inferior para situar el valor de la magnitud, $\left(a_{2}, a_{1}\right)$ dados por la precisión de los equipos de medida. De esta forma, la probabilidad de que el valor de la magnitud esté situado en dicho intervalo es, a efectos prácticos, de 1 , y de que esté fuera de él de 0 . Además, puede suponerse que la magnitud se distribuye de forma equiprobable dentro del citado intervalo. Así que la estimación de Xi

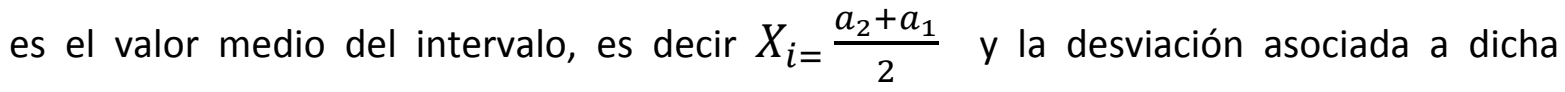
estimación es:

$$
u\left(x_{i}\right)=\sqrt{\frac{\left(a_{2}-a_{1}\right)^{2}}{12}}=\frac{\left(a_{2}-a_{1}\right)}{2 \sqrt{3}}
$$

La obtención de la incertidumbre típica combinada de una variable que es función de variables primarias, $Y=f\left(X_{1}, X_{2}, \ldots, X_{m}\right)$, medidas experimentalmente depende de si la variables de entrada son independientes o están correlacionadas entre sí. El grado de correlación viene caracterizado por el coeficiente de correlación estimado, $-1 \leq r\left(x_{i}, x_{j}\right) \leq 1$. 
Si las variables son independientes entre sí, el coeficiente de correlación tiene valor nulo, lo que significa que una variación de una de ellas, no entraña ninguna variación previsible en cualquier otra. En tal caso, la incertidumbre típica combinada de $Y$, denotada como $u_{c}(y)$, es una desviación típica estimada y caracteriza la dispersión de los valores que podrían ser razonadamente atribuidos al mensurado $Y$. Su valor se obtiene combinando apropiadamente las incertidumbres típicas de las estimaciones de las variables de entrada mediante la siguiente expresión:

$$
u_{c}^{2}(y)=\sum_{i=1}^{M}\left[\frac{\partial f}{\partial x_{i}}\right]^{2} u^{2}\left(x_{i}\right)
$$

Cada $u\left(x_{i}\right)$ es la incertidumbre típica evaluada como se ha descrito previamente.

Cuando alguna de las variables de entrada están significativamente correlacionadas, es necesario tener en cuenta dicha correlación para evaluar la incertidumbre típica combinada, mediante el coeficiente de correlación $r\left(x_{i}, x_{j}\right)$. La expresión conveniente para obtener la varianza combinada es:

$$
\begin{gathered}
u_{c}^{2}(y)=\sum_{i=1}^{M} \sum_{j=i+1}^{M}\left[\frac{\partial f}{\partial x_{i}}\right]\left[\frac{\partial f}{\partial x_{j}}\right] u\left(x_{i}, x_{j}\right)= \\
=\sum_{i=1}^{M}\left[\frac{\partial f}{\partial x_{i}}\right]^{2} u^{2}\left(x_{i}\right)+2 \sum_{i=1}^{M-1} \sum_{j=i+1}^{M} \frac{\partial f}{\partial x_{i}} \frac{\partial f}{\partial x_{j}} u\left(x_{i}\right) u\left(x_{j}\right) r\left(x_{i}, x_{j}\right)
\end{gathered}
$$

Ambas expresiones están basadas en un desarrollo en serie de Taylor de primer orden, expresando lo que se conoce como 'Ley de propagación de la incertidumbre'[75].

Aunque la incertidumbre típica combinada puede ser utilizada universalmente para expresar la incertidumbre de un resultado de medida, es conveniente dar una medida de la incertidumbre que defina, alrededor del resultado de medida, un intervalo en el interior del cual pueda esperarse encontrar gran parte de la distribución de valores que podría ser razonadamente atribuidos al mensurado.

La nueva medida de la incertidumbre, que satisface la exigencia de aportar un intervalo se denomina incertidumbre expandida, representada por $U$, y se obtiene multiplicando la incertidumbre típica combinada $u_{c}(y)$ por un factor de cobertura $k_{c}$ :

$$
U=k_{c} u_{c}(y)
$$

Resulta una interpretación más clara en la representación del resultado de una medida en la forma $Y=y \pm U$, lo que se interpreta como una mejor estimación del valor atribuible al 
mensurado, y que puede esperarse que en el intervalo $(y-U, y+U)$ esté comprendida una fracción importante de la distribución de valores atribuidos a la variable $Y$.

La idea de la incertidumbre expandida radica en los intervalos de confianza, aunque estadísticamente no es correcto hablar así, pues en el caso de la incertidumbre pueden intervenir varias variables con diferentes distribuciones cada una de ellas (básicamente normales y rectangulares). Si no existiese este problema, se podría identificar unívocamente el factor de cobertura con un cierto nivel de confianza. Para simplificar el problema, el factor de cobertura se suele tomar entre 2 y 3 , asumiendo que el 2 se identifica aproximadamente con un nivel de confianza del $95 \%$ y el de 3 con uno del $99 \%$.

\subsubsection{CÁLCULO DE LA INCERTIDUMBRE EN LAS VARIABLES DE ESTUDIO}

El procedimiento, llevado a cabo en Mazón-Hernández et al. [76] y A.S. Kaiser et al. [77], para evaluar la incertidumbre de todas las variables que intervienen en el análisis objeto de estudio, puede resumirse en seis etapas, siendo el mismo para ambas instalaciones experimentales.

1 - Identificar las variables primarias o de entrada que se miden y registran experimentalmente y las variables que se obtienen mediante una función matemática, dependiente de las primarias. Una vez identificadas, expresar matemáticamente la relación existente entre ellas.

En ambas instalaciones, las variables de entrada son temperaturas de panel, temperatura y velocidad del aire en el canal, radiación por unidad de superficie, tensión e intensidad en el punto de máxima potencia, tal y como se mencionó en los apartados 3.2.1.1 y 3.2.2.1. Sin embargo, las variables radiación solar, temperatura media del panel, constante de Ross $(k)$, potencia y rendimiento eléctrico del panel se obtienen a partir de las siguientes relaciones:

$$
\begin{gathered}
G_{T}=G_{\text {pira }} * S \\
T_{\text {panel }}=\frac{1}{n} \sum_{i=1}^{n} T_{\text {panel }, i} \\
k=\frac{\Delta \mathrm{T}}{\mathrm{G}_{\text {pira }}}=\frac{T_{\text {panel }}-T_{\text {amb }}}{G_{\text {pira }}} \\
P_{m}=V_{m p} * I_{m p}
\end{gathered}
$$




$$
\eta=\frac{P_{m}}{G_{T}}=\frac{V_{m p} * I_{m p}}{G_{p i r a} * S}
$$

Siendo $S$ la superficie de captación de radiación solar.

2 - Determinar el valor estimado de las magnitudes de entrada a partir del análisis estadístico. Con tal fin, sucesivas veces, se midieron 25 valores consecutivos de cada variable en un rango de 2 segundos, con el fin de estar bajo las mismas condiciones ambientales. A partir de esos 25 valores se calculó el valor estimado de cada una de ellas, siguiendo el procedimiento descrito en 4.2.1.

3 - Evaluación de la incertidumbre típica de cada una de las estimaciones obtenidas de las variables de entrada, que se han obtenido experimentalmente y registradas. En este cálculo, se ha considerado la precisión de los aparatos de medida, así como los errores de lectura y rango que se muestra en la siguiente tabla.

\begin{tabular}{|c|c|c|c|}
\hline Sensor & Characteristics & $\begin{array}{c}\text { Sensor } \\
\text { Accuracy }\end{array}$ & $\begin{array}{c}\text { *Accuracy } \\
\text { (\%reading+\%range) }\end{array}$ \\
\hline $\begin{array}{l}\text { Flexible and } \\
\text { robust Pt100 } \\
\text { Probe }\end{array}$ & $\begin{array}{l}\text { RTD 4-wires. Measure the } \\
\text { temperature of panel. } \\
\text { Range: }-50^{\circ} \mathrm{C}-150^{\circ} \mathrm{C}\end{array}$ & $\begin{array}{l}\text { Quality B } \\
\pm 0.5100^{\circ} \mathrm{C}\end{array}$ & $\pm 0.0600^{\circ} \mathrm{C}$ \\
\hline $\begin{array}{l}\text { Precision Pt } \\
100 \text { Probe }\end{array}$ & $\begin{array}{l}\text { RTD 4-wire. Measure the } \\
\text { temperature of air flow. } \\
\text { Range: }-50^{\circ} \mathrm{C}-250^{\circ} \mathrm{C}\end{array}$ & $\begin{array}{l}\text { Quality A } \\
\pm 0.3600^{\circ} \mathrm{C}\end{array}$ & $\pm 0.0600^{\circ} \mathrm{C}$ \\
\hline $\begin{array}{c}\text { Hot film } \\
\text { anemometer } \\
\mathrm{s}\end{array}$ & $\begin{array}{c}\text { Measure the air velocity, } \\
\text { natural convection. Range: } \\
4-20 \mathrm{~mA}, 0-2 \mathrm{~m} / \mathrm{s}\end{array}$ & $\pm 0.0610 \mathrm{~m} / \mathrm{s}$ & $0.0050 \%+0.0005 \%$ \\
\hline $\begin{array}{c}\text { Hot film } \\
\text { anemometer } \\
\mathrm{s}\end{array}$ & $\begin{array}{l}\text { Measure the air velocity, } \\
\text { forced convection. Range: } 4 \text { - } \\
20 \mathrm{~mA}, 0-20 \mathrm{~m} / \mathrm{s}\end{array}$ & $\pm 0.2100 \mathrm{~m} / \mathrm{s}$ & $0.0050 \%+0.0005 \%$ \\
\hline $\begin{array}{l}\text { Precision } \\
\text { pyranometer }\end{array}$ & $\begin{array}{l}\text { Measure the global } \\
\text { radiation. Range: } 4-20 \mathrm{~mA}, 0- \\
1200 \mathrm{~W} / \mathrm{m}^{2}\end{array}$ & $\pm 1.0900 \mathrm{~W} / \mathrm{m}^{2}$ & $0.0050 \%+0.0005 \%$ \\
\hline Variable load & $\begin{array}{c}\text { Electronic governor. Obtain } \\
\text { the curve I-V. Range: 0-100V, } \\
0-10 \mathrm{~A}\end{array}$ & $\begin{array}{l} \pm 5.000 \mathrm{mV} \\
\pm 5.400 \mathrm{~mA}\end{array}$ & $\begin{array}{l}\text { V: } 0.0035 \%+0.0005 \% \\
\text { A: } 0.0050 \%+0.0005 \%\end{array}$ \\
\hline
\end{tabular}

Tabla 4.1 Precisión y errores de lectura y rango de los sensore de medida de las variables de entrada.

4 - Evaluar las covarianzas o coeficientes de correlación asociadas a las estimaciones de entrada que están correlacionadas con las variables dependientes, con el fin de obtener la estimación de la radiación global, temperatura media, coeficiente de Ross, potencia y rendimiento, a partir de las magnitudes de entrada de las que dependen.

5 - Determinar la incertidumbre típica combinada de las variables dependientes, a partir de las incertidumbres típicas y coeficientes de correlación de las estimaciones de entrada aplicando la ley de la propagación de la varianza. 
Los resultados obtenidos se muestran en la Tabla 4.2, denotando con subíndices numerales el número de los sensores y con las letras ' $i$, $o$ ' referidas a la entrada y salida del canal de aire respectivamente.

\begin{tabular}{|c|c|c|}
\hline Variable & Media & Incertidumbre \\
\hline$T_{\text {panel, } 1}$ & $40.0389^{\circ} \mathrm{C}$ & $0.6522^{\circ} \mathrm{C}$ \\
\hline$T_{\text {panel, } 2}$ & $37.2556^{\circ} \mathrm{C}$ & $0.8083^{\circ} \mathrm{C}$ \\
\hline$T_{\text {panel, } 3}$ & $35.3573^{\circ} \mathrm{C}$ & $0.8431^{\circ} \mathrm{C}$ \\
\hline$T_{\text {panel, } 4}$ & $33.8190^{\circ} \mathrm{C}$ & $0.5784^{\circ} \mathrm{C}$ \\
\hline$T_{\text {panel, } 5}$ & $33.8397^{\circ} \mathrm{C}$ & $0.6541^{\circ} \mathrm{C}$ \\
\hline$T_{\text {air }, i, 1}$ & $29.8217^{\circ} \mathrm{C}$ & $0.8504^{\circ} \mathrm{C}$ \\
\hline$T_{\text {air }, i, 2}$ & $29.2886^{\circ} \mathrm{C}$ & $0.9243^{\circ} \mathrm{C}$ \\
\hline$T_{\text {air }, 0,1}$ & $30.1329^{\circ} \mathrm{C}$ & $1.0847^{\circ} \mathrm{C}$ \\
\hline$T_{\text {air }, 0,2}$ & $31.1338^{\circ} \mathrm{C}$ & $1.1246^{\circ} \mathrm{C}$ \\
\hline$T_{a m b}$ & 18.2977 & $0.9801^{\circ} \mathrm{C}$ \\
\hline$v_{a i r, 1}$ & $3.6492 \mathrm{~m} / \mathrm{s}$ & $0.5280 \mathrm{~m} / \mathrm{s}$ \\
\hline$v_{a i r, 2}$ & $3.4423 \mathrm{~m} / \mathrm{s}$ & $0.5420 \mathrm{~m} / \mathrm{s}$ \\
\hline$G_{\text {pira }}$ & $457.8771 \mathrm{~W} / \mathrm{m}^{2}$ & $6.7962 \mathrm{~W} / \mathrm{m}^{2}$ \\
\hline$S_{\text {panel }}$ & $1.7521 \mathrm{~m}^{2}$ & $0.0004 \mathrm{~m}^{2}$ \\
\hline$V_{o c}$ & $26.9491 \mathrm{~V}$ & $0.3202 \mathrm{~V}$ \\
\hline$I_{s c}$ & $7.7788 \mathrm{~A}$ & $0.1534 \mathrm{~A}$ \\
\hline$V_{m p}$ & $20.8423 \mathrm{~V}$ & $0.4253 \mathrm{~V}$ \\
\hline$I_{m p}$ & $5.4683 \mathrm{~A}$ & $0.1798 \mathrm{~A}$ \\
\hline$G_{T}^{*}$ & $802.2 \mathrm{~W}$ & $11.9870 \mathrm{~W}$ \\
\hline$T_{\text {panel }}{ }^{*}$ & 36.06 & $0.3195^{\circ} \mathrm{C}$ \\
\hline$\Delta T^{*}$ & $17.76^{\circ} \mathrm{C}$ & $1.0309^{\circ} \mathrm{C}$ \\
\hline$k^{*}$ & $0.02214^{\circ} \mathrm{Cm}^{2} / \mathrm{W}$ & $0.0013^{\circ} \mathrm{Cm}^{2} / \mathrm{W}$ \\
\hline$P_{m} *$ & $114.2479 \mathrm{~W}$ & $4.4091 \mathrm{~W}$ \\
\hline$\eta^{*}$ & 0.1421 & 0.0058 \\
\hline
\end{tabular}

Tabla 4.2 Resultado de la evaluación de la Incertidumbre de las variables. ${ }^{*}$ Resultados calculados mediante la ley de propagación de incertidumbre. 


\subsection{CONCLUSIONES (CONCLUSIONS)}

Con el fin de realizar un correcto método en el registro y tratamiento de las medidas, reduciendo los posibles errores accidentales o aleatorios, se ha diseñado un determinado procedimiento válido en la medición de ambas instalaciones experimentales. Se ha utilizado el software Labview $^{\circledR}$, basado en programación gráfica, junto a la implementación de un código, para llevar a cabo la adquisición de las variables medidas además de su correspondiente registro. De esta forma, el proceso queda totalmente automatizado.

La carga electrónica proporciona la curva característica del panel fotovoltaico, para así obtener sus variables eléctricas en un instante, mediante una señal de disparo enviada por una tarjeta de National Instrument ${ }^{\circledast}$. El resto de variables son medidas a través del sistema de adquisición descrito. La medición de todas las variables se realizará cada 15 minutos, obteniendo un par de valores de cada una, de los que se obtendrá su valor medio y se registraran de forma consecutiva. Se ha utilizado una mayor frecuencia de muestreo para las variables eléctricas, con el fin de obtener el mayor número de puntos que definan el par de curvas características de forma precisa y obtener sus variables eléctricas en el tiempo de medida. En ese mismo instante, la aplicación desarrollada y programada registra el resto de variables.

El análisis de incertidumbre llevado a cabo en el conjunto de variables objeto de análisis, muestra la estimación del resultado de medida junto al intervalo de confianza alrededor de su estimación. Para ello, se tomaron muestras de 25 valores consecutivos de cada variable en intervalos cortos de tiempo (2s), para que las condiciones ambientales fuesen las mismas.

Para obtener la incertidumbre típica de las variables medidas experimentalmente se ha considerado la precisión y errores de los sensores utilizados. Sin embargo, la estimación de las variables obtenidas a partir de éstas requiere el cálculo de la incertidumbre típica combinada. Las incertidumbres obtenidas muestran la exactitud y precisión de las variables objeto de estudio. Los valores obtenidos muestran que los datos medidos y calculados son fiables.

\section{CONCLUSIONS}

The methodology which was carried out for the process of data recording and measurement has been described. In order to develop a correct method for data recording and data processing, and to reduce the possible accidental errors, a determinate valid process which could be used in both experimental facilities was created. The software used was Labview ${ }^{\circledR}$, which is based on graphic programming with a code implementation; with which it was possible to adquire and record the measured data. In this way, the process was fully automated. 
The electronic load provides the characteristic curve of the photovoltaic panel and the electrical variables can be obtained from it instantly, thanks to a shoot signal which was sent by an electronic card of National Instrument ${ }^{\circledR}$. The other variables were measured using the acquisition system described previously (the data logger of Agilent). The measurement process of all variables was made every 15 minutes, recording a pair of values of each variable to calculate their mean and then saving them chronologically. The sampling frequency of the electrical variables was higher than what was used for other variables, with the purpose of getting a higher number of points which define the characteristic curve in each measurement moment. For the same instant, the programmed application recorded the other variables.

The data uncertainty analysis was carried out for all measured variables aimed to be studied, and shown is the estimation of the measurement and the confidence interval of the estimation. In order to calculate the uncertainty of the variables measured, 25 samples of measurable variables were collected the same day, in short intervals (2s), to be under the same environmental conditions.

To calculate the standard uncertainty of the experimental measured variables, it was necessary to consider the precision and errors of the sensors and measuring equipments used. However, the estimation of the variables which were calculated from the measured ones required a calculation process to obtain the combined standard uncertainty. The results of the uncertainties show the accuracy and precision of the variables studied. The uncertainties obtained are very low, which means that the data collected are sufficiently reliable. 


\section{CAPITULO 5. DISCUSIÓN DE LOS RESULTADOS}

En este capítulo se presenta el análisis de los resultados obtenidos de las diferentes variables medidas en ambas instalaciones fotovoltaicas experimentales, descritas en el apartado 3.2. Todas las variables de estudio que se muestran, se han obtenido mediante el procedimiento de registro y tratamiento descrito en el capítulo anterior. El capítulo se ha estructurado en tres apartados acordes a los estudios realizados con cada instalación, que se resumen a continuación.

I. ESTUDIO COMPARATIVO EN EL COMPORTAMIENTO DE PANELES FOTOVOLTAICOS TRABAJANDO EN UNA PLANTA SOLAR FRENTE A LOS VALORES MEDIDOS EN LA INSTALACIÓN EXPERIMENTAL

a) Estudio de los parámetros del panel en la planta solar

- Comparación con los valores de proporcionados por fabricante

- Relación de dependencia con la temperatura de funcionamiento

b) Comparativa de los valores de la planta solar e instalación experimental

II. COMPORTAMIENTO DEL PANEL FOTOVOLTAICO COLOCADO SOBRE UNA CUBIERTA METÁLICA

a) Estudio en convección natural

- Comparación entre el panel de referencia y sobre cubierta metálica

- Comportamiento del panel al variar la sección de paso de aire

b) Estudio en convección forzada

- Comparación entre el panel de referencia y sobre cubierta metálica

- Comportamiento del panel al variar la sección de paso de aire

- Comportamiento del panel al variar la velocidad inducida para cada sección

c) Comparación entre convección natural y forzada

- Variables influyentes en temperatura de funcionamiento y Potencia pico

- Relación del rendimiento según la temperatura

d) Generalización de resultados

- Análisis de variables influyentes: sección y velocidad del canal de aire

- Estudio coeficiente de Ross

- Correlaciones propuestas generalizadoras de resultados

III. COMPORTAMIENTO DEL PANEL FOTOVOLTAICO COLOCADO SOBRE UNA CUBIERTA DE INVERNADERO

a) Influencia de la temperatura del panel en las variables eléctricas

- Estudio del comportamiento del panel según la sección del canal de aire

- Estudio del comportamiento del panel según el material utilizado en la cubierta para cada sección de aire

b) Influencia de la velocidad del viento

- Estudio del comportamiento del panel según la sección del canal de aire

- Estudio del comportamiento del panel según el material utilizado en la cubierta para cada sección de aire 
c) Transferencia de calor en el canal de aire de refrigeración

- Estudio del comportamiento del panel según la sección del canal de aire

- Estudio del comportamiento del panel según el material utilizado en la cubierta para cada sección de aire

El primer apartado consiste en un estudio comparativo del comportamiento de los paneles fotovoltaicos trabajando en una planta solar fotovoltaica, Coronil II, frente a los valores medidos en la instalación experimental. Se han estudiado los parámetros característicos del panel, tensión de circuito abierto, intensidad de cortocircuito, factor de llenado y eficiencia. Los valores experimentales de estas variables se han comparado con los valores proporcionados por el fabricante bajo las mismas condiciones. Además se obtienen las relaciones de dependencia con la temperatura de cada parámetro, obteniendo un buen ajuste en las correlaciones. Por último se comparan los resultados experimentales con los de la planta fotovoltaica, concretamente la correlación de la eficiencia eléctrica, lo cual muestra un comportamiento similar en ambos casos. De este modo, la respuesta de los paneles en una planta solar fotovoltaica, se puede predecir a partir de un prototipo experimental, para diferentes condiciones o configuraciones.

El segundo apartado engloba los estudios realizados correspondientes a los resultados medidos de la primera instalación experimental descrita, y así caracterizar el comportamiento eléctrico del módulo fotovoltaico sobre una cubierta metálica, el cual es refrigerado con aire, mediante convección natural y forzada, a través del canal creado entre su cara posterior y la superficie metálica, considerando tres secciones de paso de aire. En primer lugar se analizan los resultados obtenidos en convección natural, comparando el comportamiento de un módulo considerado de referencia (al estar fijo a la estructura sin ninguna superficie inferior) y del que se encuentra sobre la cubierta metálica, para los diferentes espesores en el canal. Se analizan las temperaturas de funcionamiento alcanzadas de cada panel en las tres configuraciones planteadas, así como su influencia sobre el rendimiento. Tras el estudio en convección natural, se propone estudiar la respuesta térmica y eléctrica del panel refrigerándolo por convección forzada, mediante un ventilador de impulsión desde la parte inferior. Posteriormente se muestran los resultados obtenidos en estas condiciones de refrigeración, para las mismas secciones de aire estudiadas anteriormente y cada una de ellas a diferentes velocidades forzadas. A continuación, se realiza un estudio comparativo de los resultados medidos en las diferentes configuraciones, tanto en convección natural como en forzada, para las mismas condiciones ambientales en las que existe mayor influencia térmica. Se analiza y compara la influencia sobre la temperatura y potencia eléctrica del panel, de la secciones de aire en convección natural y forzada junto a la velocidad inducida para cada una de ellas. Por último, se analiza las variables influyentes en la refrigeración del panel para diferentes condiciones ambientales (temperatura ambiente y radiación solar) sobre el coeficiente de Ross, con la finalidad de obtener una correlación empírica que nos permita determinar la temperatura del módulo para las diferentes configuraciones estudiadas. 
En el último apartado se estudia el comportamiento de los módulos fotovoltaicos que se encuentran ubicados sobre la cubierta de un invernadero, existiendo un espacio entre ambas superficies, diseño constructivo basado en la instalación agroenergética Coronil IV. En esta instalación también se ha modificado la sección de aire en la entrada y se ha incorporado un material aislante sobre la cubierta de plástico, para las dos secciones estudiadas, lo que nos ha permitido comparar cuatro configuraciones de refrigeración con aire por convección natural. El análisis comparativo de las configuraciones engloba el efecto de la temperatura del módulo sobre los principales parámetros eléctricos, tales como tensión de circuito abierto, intensidad de cortocircuito y eficiencia. Se observa la misma dependencia en cada una, pero una mejora para la mayor sección de paso de aire y siendo la cubierta de aislante. En el análisis se observó una considerable influencia de la velocidad del viento sobre la temperatura y eficiencia eléctrica, lo cual se presenta para cada una de las configuraciones. Por último se expone el análisis de transferencia de calor en el canal de aire, proveniente de los paneles fotovoltaicos y la cubierta del invernadero. Se ha obtenido la potencia calorífica absorbida en cada configuración, lo que nos muestra la configuración que permite que el panel alcance menores temperaturas y con lo cual, mejore su producción eléctrica. 


\subsection{ESTUDIO COMPARATIVO EN EL COMPORTAMIENTO DE PANELES FOTOVOLTAICOS TRABAJANDO EN UNA PLANTA SOLAR FRENTE A LOS VALORES MEDIDOS EN LA INSTALACIÓN EXPERIMENTAL}

Como primer apartado de este capítulo, se presenta la comparación en el funcionamiento del módulo fotovoltaico, referido a los parámetros proporcionados por el fabricante, entre los resultados experimentales y los proporcionados por la planta fotovoltaica Coronil II, descrita en la sección 3.1.1. El estudio llevado a cabo muestra la influencia de la temperatura de funcionamiento del panel sobre sus parámetros eléctricos, tales como la intensidad de cortocircuito, la tensión de circuito abierto, el factor de llenado y la eficiencia eléctrica. A partir de los datos proporcionados de la instalación solar compuesta por más de 1700 módulos y tras realizar un filtrado justificado de los datos recogidos en los meses de Mayo, Junio, Julio y Agosto, se obtiene la influencia que tiene la temperatura en el rendimiento de la instalación completa, comparado con la obtenida en la instalación experimental [78].

La planta solar fotovoltaica consta de seis modelos diferentes de módulos fotovoltaicos, tal y como se expuso en el capítulo 3. Los paneles que se han analizado son los del modelo ET270, el mismo que los utilizados en la instalación experimental. Estos paneles se han conectado a un mismo inversor en agrupaciones que forman $466.56 \mathrm{kWp}$ que suponen 1728 paneles. Las características y parámetros proporcionados por el fabricante son las mostradas en la Figura 3.12 y Figura 5.1.
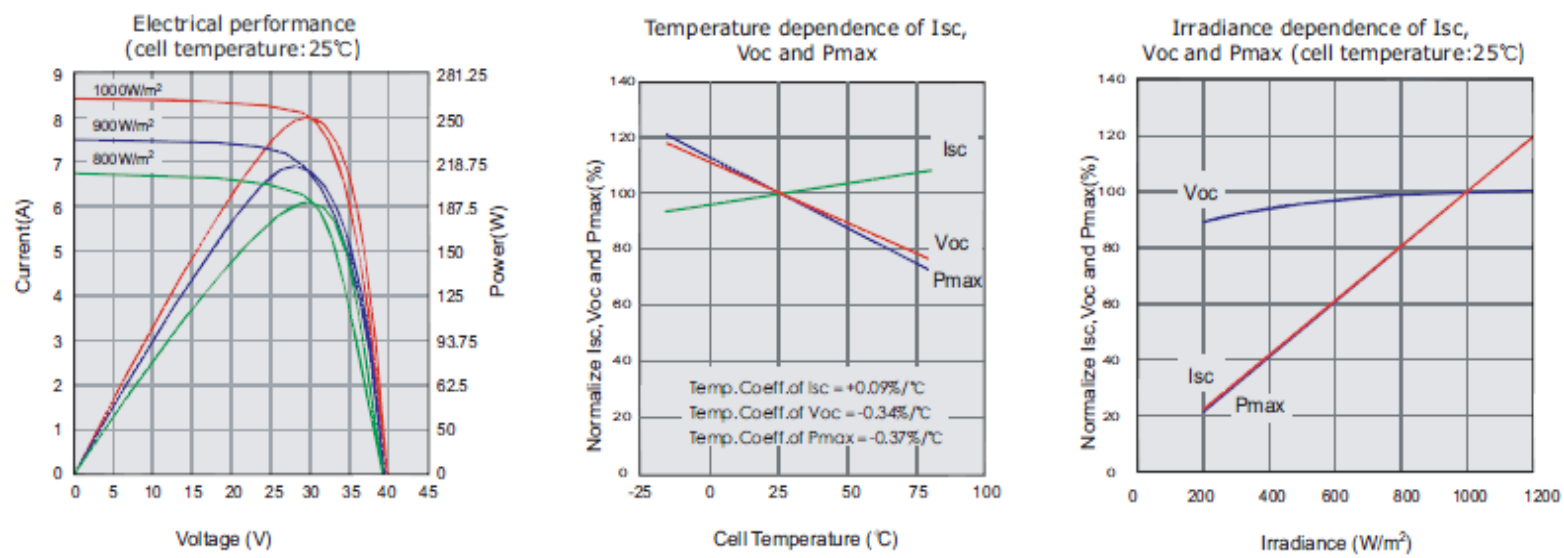

Figura 5.1 Parámetros eléctricos característicos de los paneles fotovoltaicos ET270.

En la instalación se ha medido la potencia que da cada inversor, la radiación solar en cada una de las agrupaciones, temperatura ambiente y la temperatura de cinco paneles diferentes colocados en diferentes partes de la agrupación correspondiente. Estas medidas se toman simultáneamente en intervalos de 5 minutos a lo largo de todos los días.

Para comparar los parámetros eléctricos obtenidos en la instalación con los que se deberían obtener según las curvas del fabricante, tan sólo es posible teniéndolos todos en las mismas 


\subsection{ESTUDIO COMPARATIVO EN EL COMPORTAMIENTO DE PANELES FOTOVOLTAICOS TRABAJANDO EN UNA PLANTA SOLAR FRENTE A LOS VALORES MEDIDOS EN LA INSTALACIÓN EXPERIMENTAL}

condiciones ambientales, para ello se han utilizado los parámetros ofrecidos por el fabricante, expuestos en la Figura 5.1, siguiendo el método descrito por Eduardo Lorenzo et al. [79] para el cálculo de la $R_{s}$, obteniéndose un valor de $4.635 \mathrm{~m} \Omega$ con un factor $m=1$ para el panel.

$$
\begin{gathered}
\frac{P_{m}(G)}{P_{m, o}}(\%)=\frac{25}{300} \cdot G_{p i r a}\left(\frac{W}{m^{2}}\right) ; \frac{I_{s c m a x}(G)}{I_{s c, o}}(\%)=\frac{25}{300} \cdot G_{p i r a}\left(\frac{W}{m^{2}}\right) ; \\
\frac{I_{s c}(T)-I_{s c, o}}{I_{s c, o}}(\%)=0.065 \cdot\left(T\left({ }^{\circ} \mathrm{C}\right)-25\right) ; \\
\frac{V_{o c}(T)-V_{o c, o}}{V_{o c, o}}(\%)=-0.346 \cdot\left(T\left({ }^{\circ} \mathrm{C}\right)-25\right) ; \\
\frac{P_{m}(T)-P_{m, o}}{P_{m, o}}(\%)=-0.488 \cdot\left(T\left({ }^{\circ} \mathrm{C}\right)-25\right) ;
\end{gathered}
$$

A continuación se muestran la comparativa entre los resultados experimentales obtenidos en el banco de ensayos en condiciones reales de operación con los resultados que se derivan de los parámetros proporcionados por el fabricante en esas condiciones. En la Figura 5.2 se ha representado las variables $I_{s c}$ (Figura 5.2 a) y $P_{m}$ (Figura $5.2 \mathrm{~b}$ ) obtenidas a partir de la curva característica I-V medida en la instalación y las deducidas según los parámetros del fabricante en las mismas condiciones. Es relevante la diferencia positiva en los datos experimentales en ambas variables, achacable a que la temperatura de funcionamiento real es mayor que la de ensayo y lo que conlleva una intensidad de trabajo mayor.

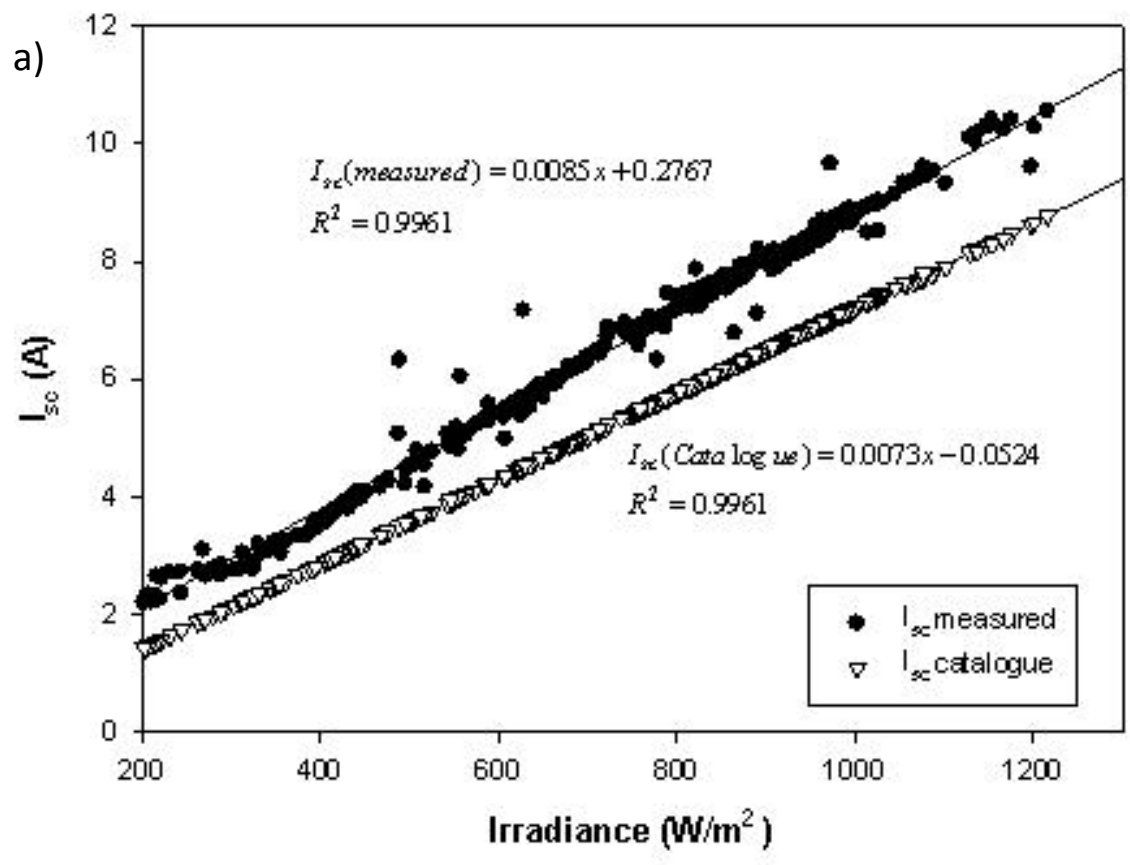




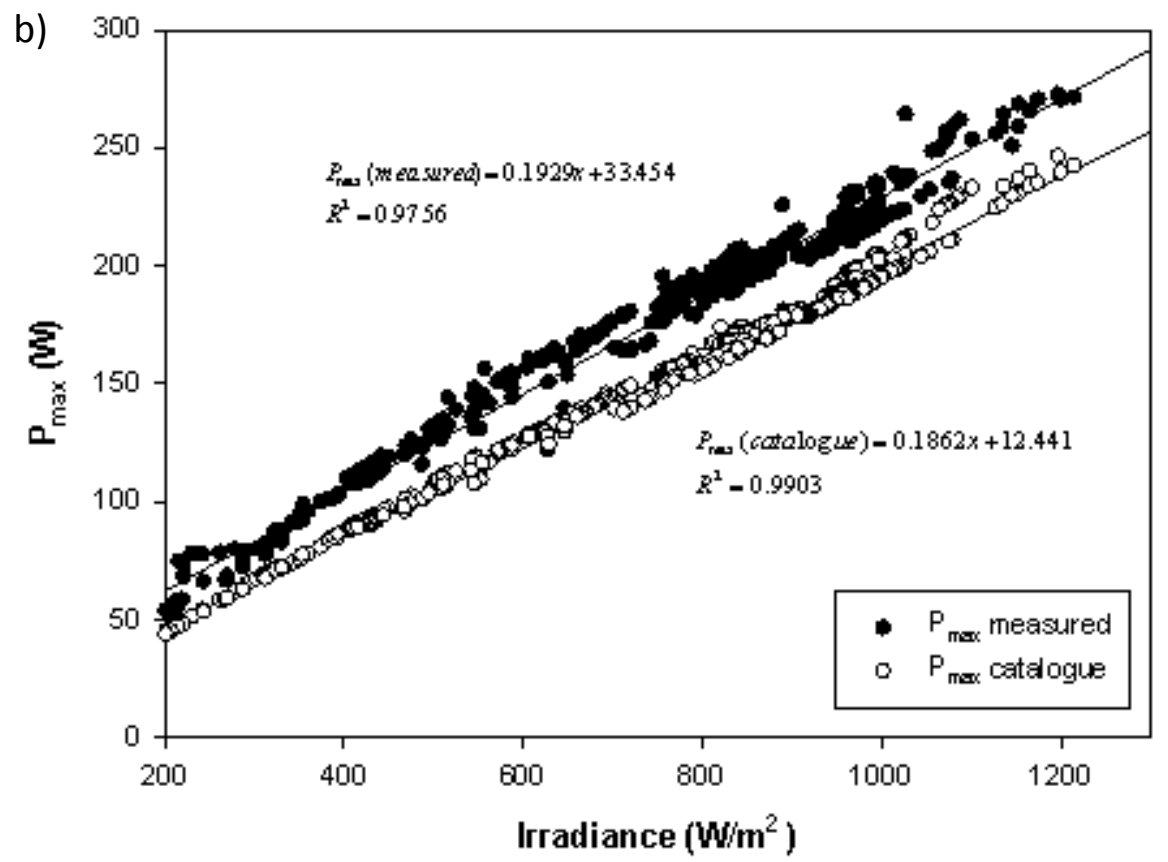

Figura 5.2 Comparativa de los resultados experimentales medidos en la instalación, con los proporcionados por el fabricante, en función de la radiación solar. a) Intensidad de cortocircuito b) Potencia máxima.

En función de los valores experimentales de temperatura del panel se ha obtenido la comparación entre los datos medidos y proporcionados por el fabricante, de la tensión de circuito abierto y el Factor de Llenado (Figura 5.3). Se observa que los valores en ambos casos son diferentes, existiendo una reducción en la tensión de circuito abierto de los valores medidos de casi $8 \mathrm{~V}$, respecto los obtenidos del catálogo, pero la pendiente o tasa de variación respecto la temperatura se mantiene similar. En cuanto al Factor de Llenado se obtiene un valor medio similar para ambos casos, pero teniendo mayor pendiente los valores experimentales medidos, lo cual indica la influencia de la temperatura. 
a)
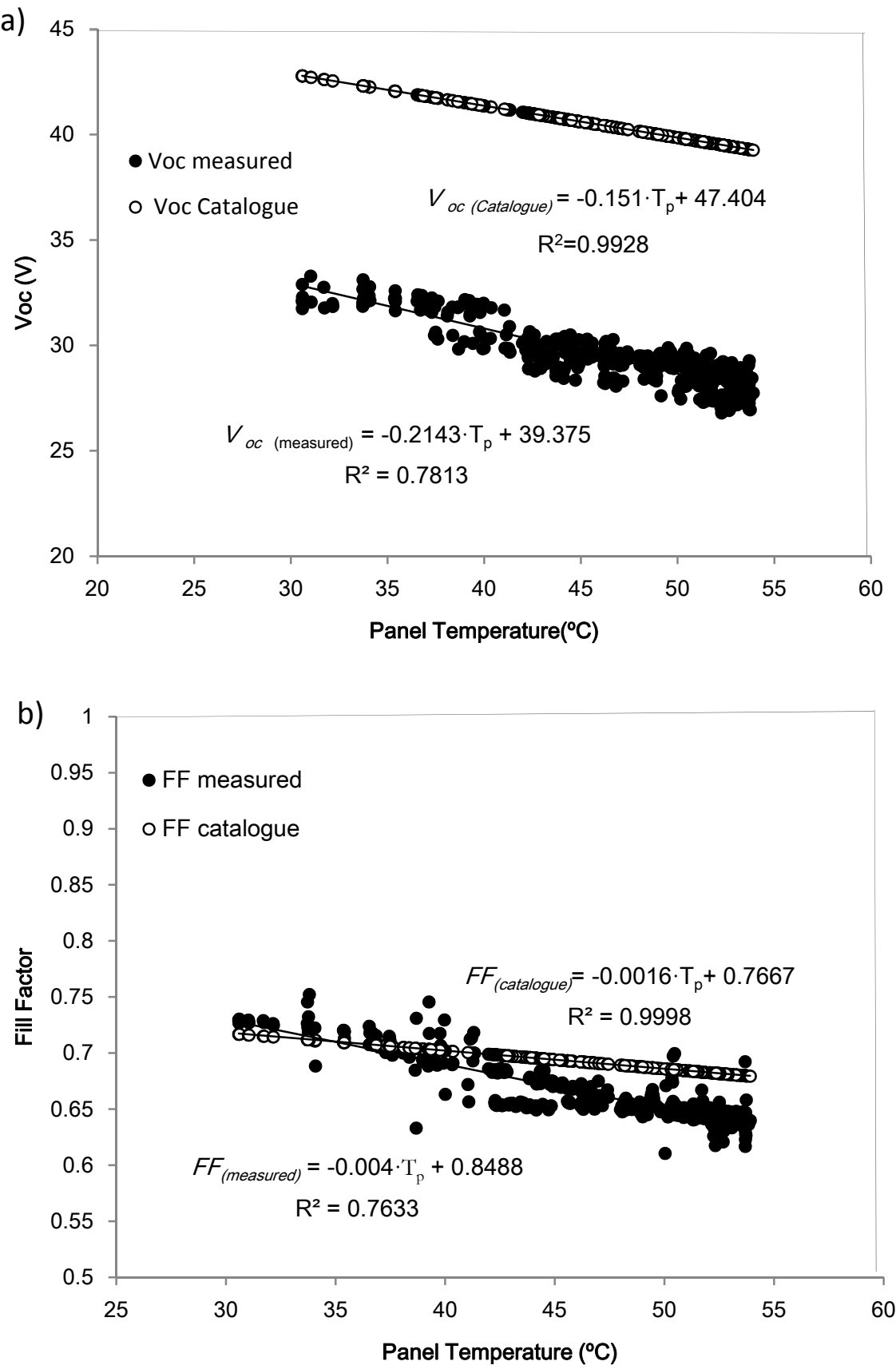

Figura 5.3 Comparativa de los resultados experimentales medidos en la instalación, con los proporcionados por el fabricante, en función de la temperatura del panel. a) Tensión de circuito abierto b) Factor de llenado.

Finalmente, comparando el rendimiento eléctrico del panel en función de su temperatura de funcionamiento medida (Figura 5.4), se observa una buena correlación. Estos valores fueron obtenidos del ensayo de diferentes días despejados pero con diferente temperatura ambiente y velocidad de viento, por ello existe una pequeña dispersión, pero la correlación obtenida presenta un buen ajuste. Además, podemos destacar que los valores de rendimiento medidos experimentalmente son mayores a los obtenidos por el fabricante, para las mismas condiciones. 


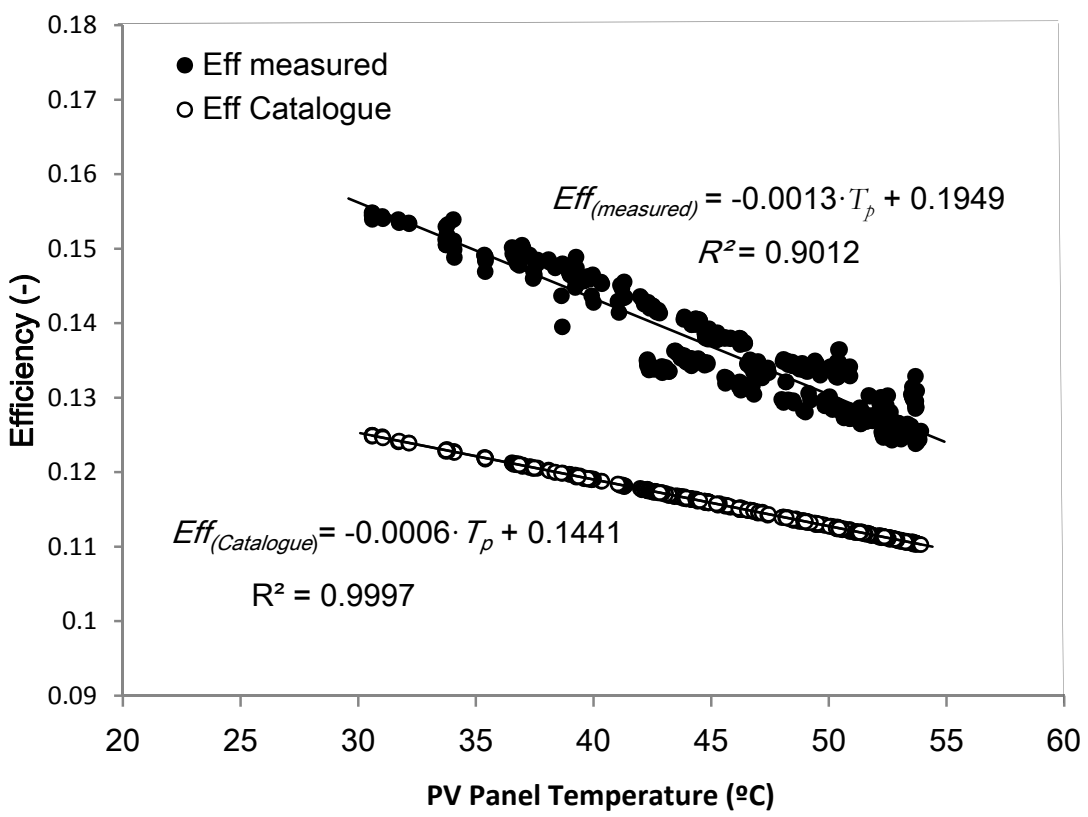

Figura 5.4 Comparativa en la eficiencia eléctrica de los resultados experimentales medidos en la instalación, con los proporcionados por el fabricante, en función de la temperatura del panel.

Con los datos del mes de agosto de la planta fotovoltaica Coronil II se ha realizado un filtrado en función de la evolución de la potencia y temperatura a lo largo de un día para poder evitar los fenómenos de inercia térmica y las sombras debidas a nubes. Este proceso evita la obtención de valores erróneos y no útiles en el cálculo del rendimiento del generador fotovoltaico. La siguiente figura muestra en la izquierda, la radiación solar de cuatro días, dos nublados y dos despejados y en la derecha la potencia en las horas centrales del día para cada uno de los días. Se aprecia que la radiación en los días 2 y 10 de agosto presenta fluctuaciones en las horas centrales del día, debido a la presencia de nubes, por lo que la potencia eléctrica obtenida en esos instantes se ve reducida respecto al resto. Con ello, se pone de manifiesto la importancia de este filtrado para un correcto cálculo del rendimiento.
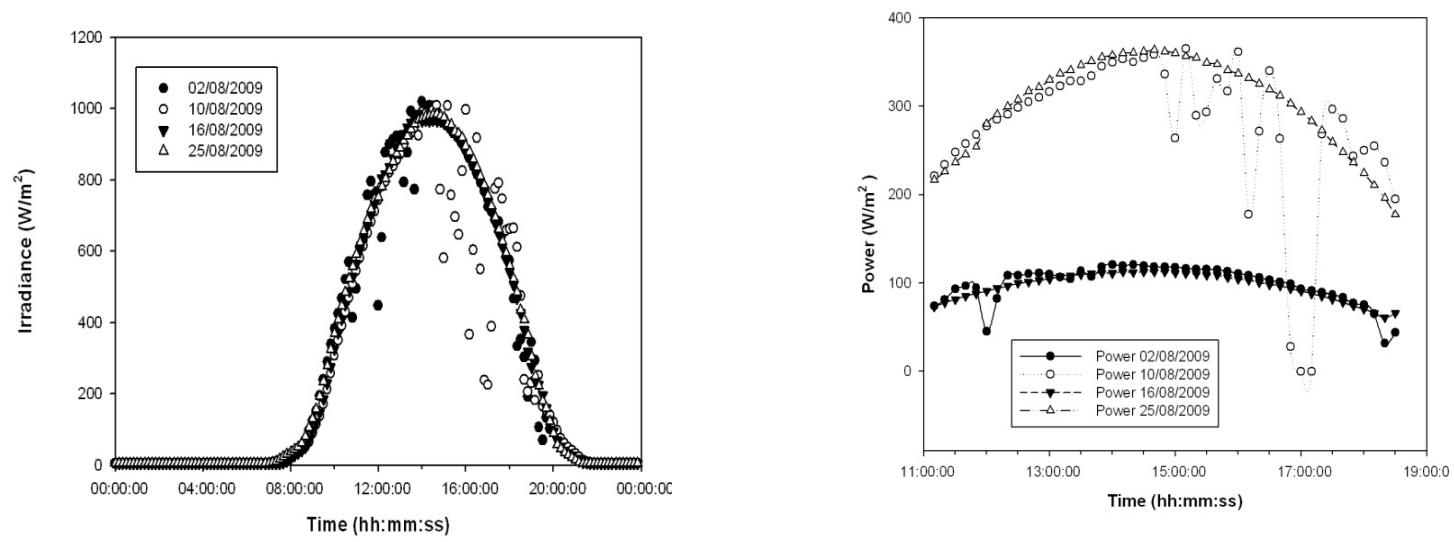

Figura 5.5 Radiación solar y potencia obtenida en la planta solar fotovoltaica Coronil II, a lo largo de cuatro días de agosto. 


\subsection{ESTUDIO COMPARATIVO EN EL COMPORTAMIENTO DE PANELES FOTOVOLTAICOS TRABAJANDO EN UNA PLANTA SOLAR FRENTE A LOS VALORES MEDIDOS EN LA INSTALACIÓN EXPERIMENTAL}

Una vez filtrados los datos del mes de Agosto de la planta solar fotovoltaica Coronil II, se ha representado el rendimiento en función de la temperatura media de los paneles medidos con el fin de obtener la correlación entre ambas variables y poder compararlas con la obtenida en la instalación experimental (Figura 5.6). Cabe destacar que la correlación obtenida con los datos de la planta presenta la misma pendiente que la correlación obtenida con los datos experimentales, lo que nos indica que la tasa de variación o influencia de la temperatura del módulo sobre su rendimiento es similar. Por consiguiente, si se desea conocer el comportamiento eléctrico de una planta fotovoltaica, para diferentes condiciones o configuraciones, se puede predecir a partir de un prototipo experimental. El grado de ajuste de ambas es elevado, obteniéndose una mejor correlación de los datos provenientes de la planta de Coronil II debido a que se dispone de un número de días medidos mayor.

$$
\begin{aligned}
& \eta_{\text {experimental }}=-0.0013 \cdot T_{p}+0.1949 \text { con } R^{2}=0.9012 \\
& \eta_{P V \text { plant }}=-0.0013 \cdot T_{p}+0.1893 \text { con } R^{2}=0.9262
\end{aligned}
$$

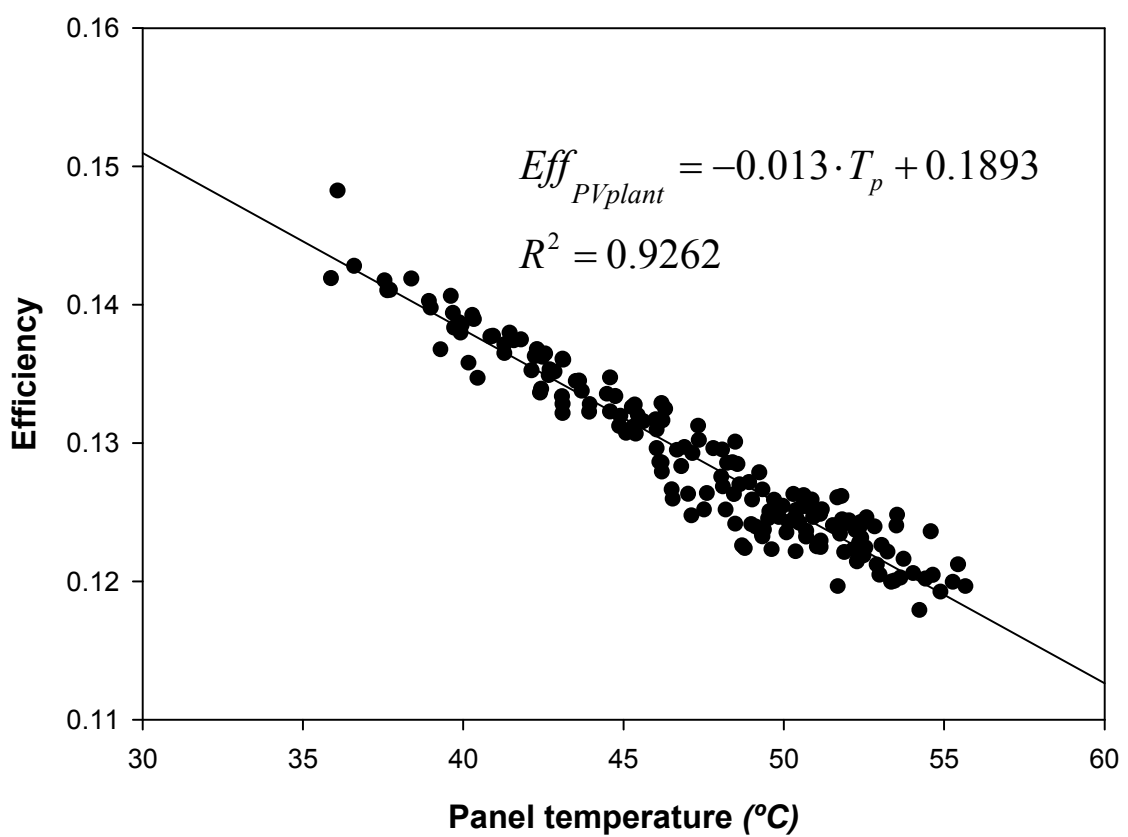

Figura 5.6 Correlación del rendimiento de los paneles en la planta fotovoltaica Coronil II con la temperatura alcanzada por el panel.

\subsubsection{CONCLUSIONES (CONCLUSIONS)}

Se han calculado los parámetros de funcionamiento de un panel fotovoltaico en una instalación experimental y se ha comparado con los proporcionados por el fabricante bajo 
las mismas condiciones,obteniendose tendencias similares. Además la curva de rendimiento obtenida coincide con la obtenida en un campo solar en explotación con más de 1700 paneles.

Se ha establecido un método para filtrar los datos provenientes de una instalación real completa para poder obtener la influencia de la temperatura de los paneles sobre el rendimiento de estos. La correlación obtenida para el rendimiento de un panel fotovoltaico y su temperatura en una instalación experimental es similar a la de un generador fotovoltaico complejo, funcionando en una planta solar bajo condiciones reales.

Los resultados concluyen que se puede conocer y predecir el comportamiento eléctrico de una planta fotovoltaica, para diferentes condiciones o configuraciones, a partir de un prototipo experimental.

\section{CONCLUSIONS}

This section presents the results of a photovoltaic panel measurement in the instrumented experimental facility and the extrapolation of these results to a photovoltaic generator in a solar plant. The functioning parameters of the photovoltaic panel were calculated in the experimental facility and compared with the parameters provided by the manufacturer. The influence of the operating temperature of the panel on the electrical parameters of the module was obtained as: short-circuit current, open circuit voltage, the fill factor and efficiency. Using available data from a real installation with more than 1700 modules installed, and with a justified filtering process of collected data, the influence of temperature on the system performance is compared with the results from experimental facility.

A method to filter the data of the solar plant was made to study the temperature influence on the performance of the corresponding panels with the same model and characteristics. The correlation of the module performance and its temperature calculated with the experimental data is very similar to the corresponding correlation of the commercial solar system which works with more than 1700 modules and under the same environmental conditions.

The results concluded that the electrical behaviour of a solar plant could be predicted and known, by the measuring an experimental prototype for different configurations or conditions. 


\subsection{COMPORTAMIENTO DEL PANEL FOTOVOLTAICO COLOCADO SOBRE UNA CUBIERTA METÁLICA}

Con el fin de estudiar el comportamiento eléctrico de los paneles fotovoltaicos sobre una cubierta metálica, se han ensayado diferentes configuraciones de refrigeración con aire por su cara posterior, por convección natural y forzada $[77,80]$.

El estudio de esta instalación en convección natural consiste en analizar el comportamiento de las variables eléctricas en ambos módulos fotovoltaicos, el de referencia (panel A) y el panel sobre la cubierta metálica (panel B) y la mayor o menor influencia de la temperatura de funcionamiento del panel en cada caso. Además, se analizarán las variables eléctricas y temperaturas para diferentes secciones de paso de aire, con el fin de conocer la configuración que permita una mayor refrigeración y por ende una mejora en el rendimiento.

Una vez estudiada en convección natural, la repercusión de la temperatura del panel en la producción eléctrica al estar emplazado sobre una cubierta, dependiendo de la sección de paso, es estudiada y comparada con los mismos casos en convección forzada. Un ventilador se encargará de impulsar el aire por el canal desde la parte inferior mediante el acoplamiento de una tobera metálica, para cada una de las secciones ensayadas en convección natural. Con esta configuración se pretende comparar la evolución de las temperaturas y las variables eléctricas entre el panel de referencia (aislado y bajo las condiciones ambientales) y el panel sobre la cubierta metálica refrigerado por convección forzada para diferentes secciones de paso de aire. Cada sección se ha ensayado a tres regímenes de funcionamiento del ventilador, fijando tres velocidades forzadas del aire en el canal para poder estudiar su influencia en la respuesta eléctrica del panel fotovoltaico.

Posteriormente, se realiza un estudio comparativo de todos los resultados obtenidos tanto en convección natural como forzada, analizando la influencia de variables tales como el espesor del canal de aire, la velocidad inducida en el canal sobre la temperatura y eficiencia eléctrica del panel, comparándolo con el panel de referencia para así poder elegir la configuración más idónea.

Como último punto, se pretende generalizar el comportamiento de un módulo fotovoltaico integrado sobre la cubierta con un canal de aire por su cara posterior que permita su refrigeración, bien por convección natural o forzada, para diferentes secciones del canal y bajo diferentes condiciones ambientales. Con tal fin, tras identificar las variables realmente influyentes, se establecen correlaciones explicitas que nos permita determinar la temperatura del panel, su potencia y rendimiento. Finalmente, comprobaremos la bondad del ajuste y compararemos con correlaciones dadas por otros autores. 


\subsubsection{CONVECCIÓN NATURAL}

Siguiendo la metodología descrita en la toma de los datos y su tratamiento posterior, se han registrado las variables medidas durante varios días en el periodo comprendido entre el 2005-2010 y 30-08-2010. Cada día se han medido simultáneamente las variables de ambos paneles, para poder compararlas bajo las mismas condiciones ambientales. Para el análisis, se han filtrado los datos de días poco soleados y nubosos, recopilando así los valores de días similares en radiación y temperatura ambiente.

La configuración del panel B, refrigerado por su cara posterior se detalla en la Figura 5.7, en la que la separación entre el panel y la superficie metálica. ' $b$ ', se ha variado con el fin de cuantificar su influencia en el comportamiento eléctrico del panel. En adelante, se hará referencia a la variable adimensional que caracteriza la separación del canal de aire, relación de aspecto, con forme a la bibliografía. La relación de aspecto $(b / L)$ se define como la relación entre el espesor del canal $(b)$ y su longitud $(L)$.

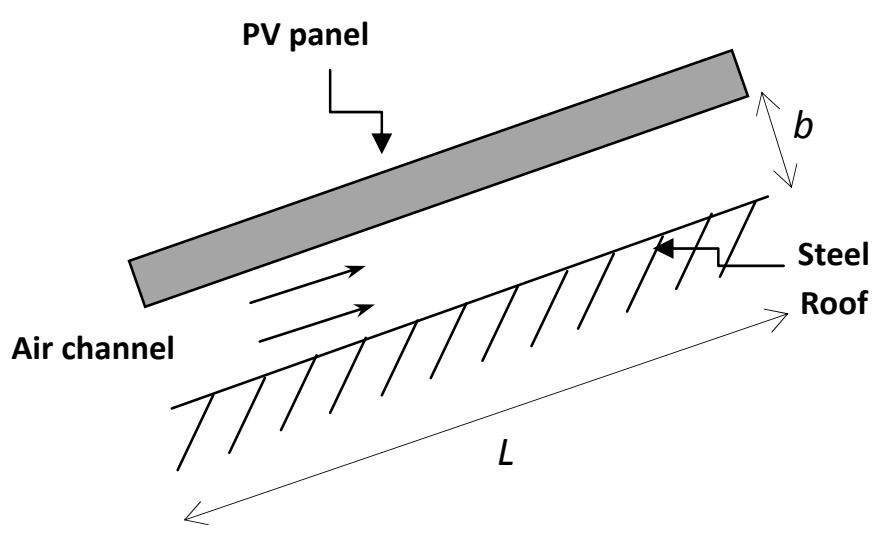

Figura 5.7 Configuración del panel B, representando el canal de aire entre el panel fotovoltaico y la superficie metálica.

Esta configuración del panel $\mathrm{B}$ se ha medido para tres relaciones de aspecto diferentes, siendo $0.0525,0.0675$ and 0.0825 . Los datos obtenidos muestran que el Panel B, sobre la cubierta metálica, alcanza mayores temperaturas que el panel $A$, panel de refencia sin ninguna superficie inferior, para los tres casos experimentales, estando ambos paneles bajo las mismas condiciones ambientales. 


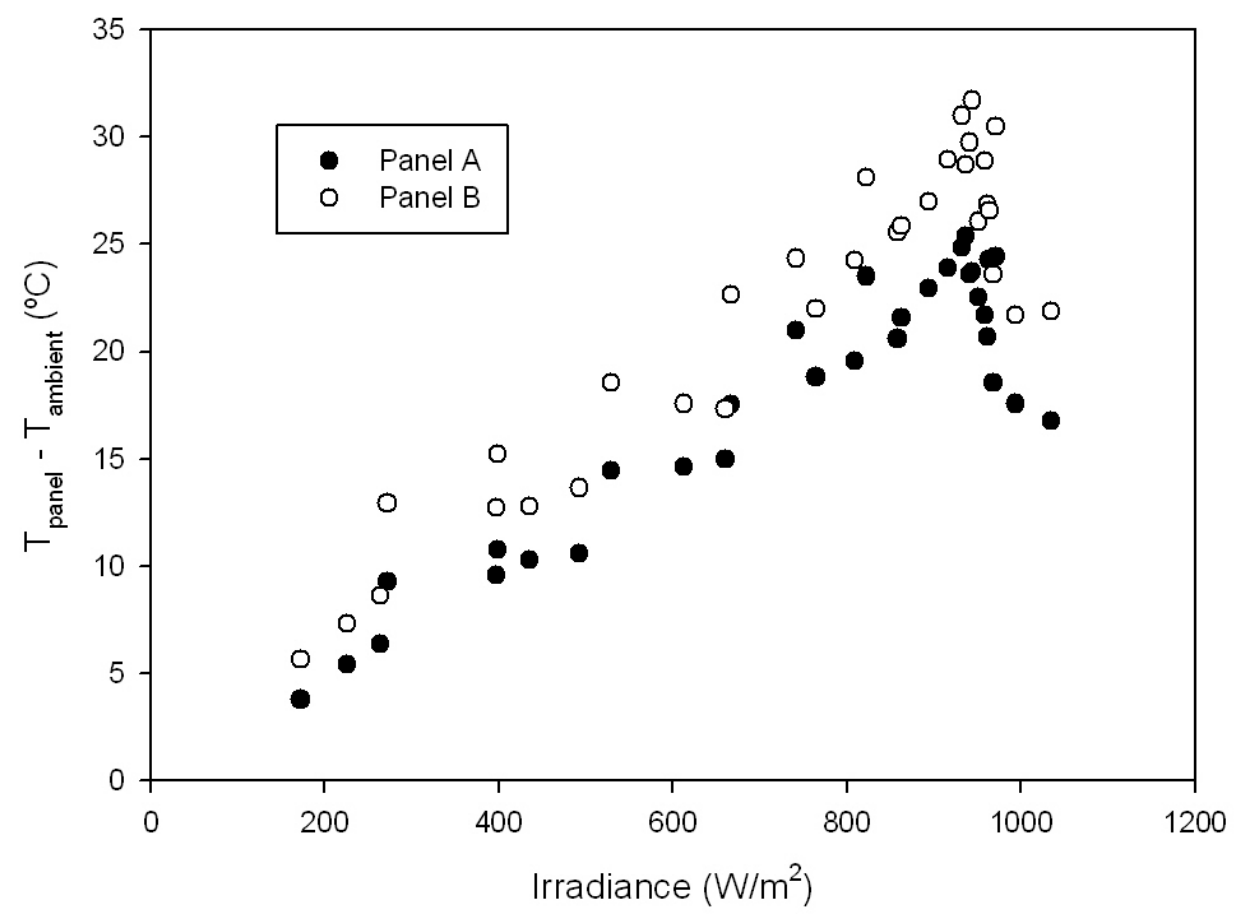

Figura 5.8 Diferencia de temperatura de cada panel fotovoltaico y la ambiente respecto la radiación solar, en convección natural para diferentes relaciones de aspecto del canal de aire.

El hecho de estar el módulo fotovoltaico sobre una cubierta metálica, dejando una separación entre ambas superficies, reduce su refrigeración por la cara posterior, alcanzando mayores temperaturas que un panel sin ninguna superficie en su cara posterior, siendo de las mismas características y funcionando bajo las mismas condiciones ambientales y constructivas. La Figura 5.8 representa el salto de temperatura de cada panel con la ambiente, respecto la radiación solar, medidos para diferentes relaciones de aspecto, a lo largo de diferentes días. Podemos apreciar, que para cada valor de radiación, se tiene un par de puntos, correspondientes al salto de temperatura de cada panel con la ambiente, siendo siempre mayor la del panel sobre la cubierta metálica.

Por lo tanto, la producción eléctrica del panel B y por ende su rendimiento, es inferior a la del Panel A, para cada una de las relaciones de aspecto, de acuerdo a la proporcionalidad inversa entre el rendimiento y la temperatura, que se explicó en el apartado 2.4. Esto se muestra en la siguiente gráfica, que representa los valores del rendimiento de cada panel correspondientes a las temperaturas mostradas en la figura anterior, en función de la radiación solar. Se aprecia como el rendimiento del panel A cuya temperatura era inferior, alcanza valores superiores que el panel $B$, en mayor o menor rango para los tres casos experimentales ensayados. 


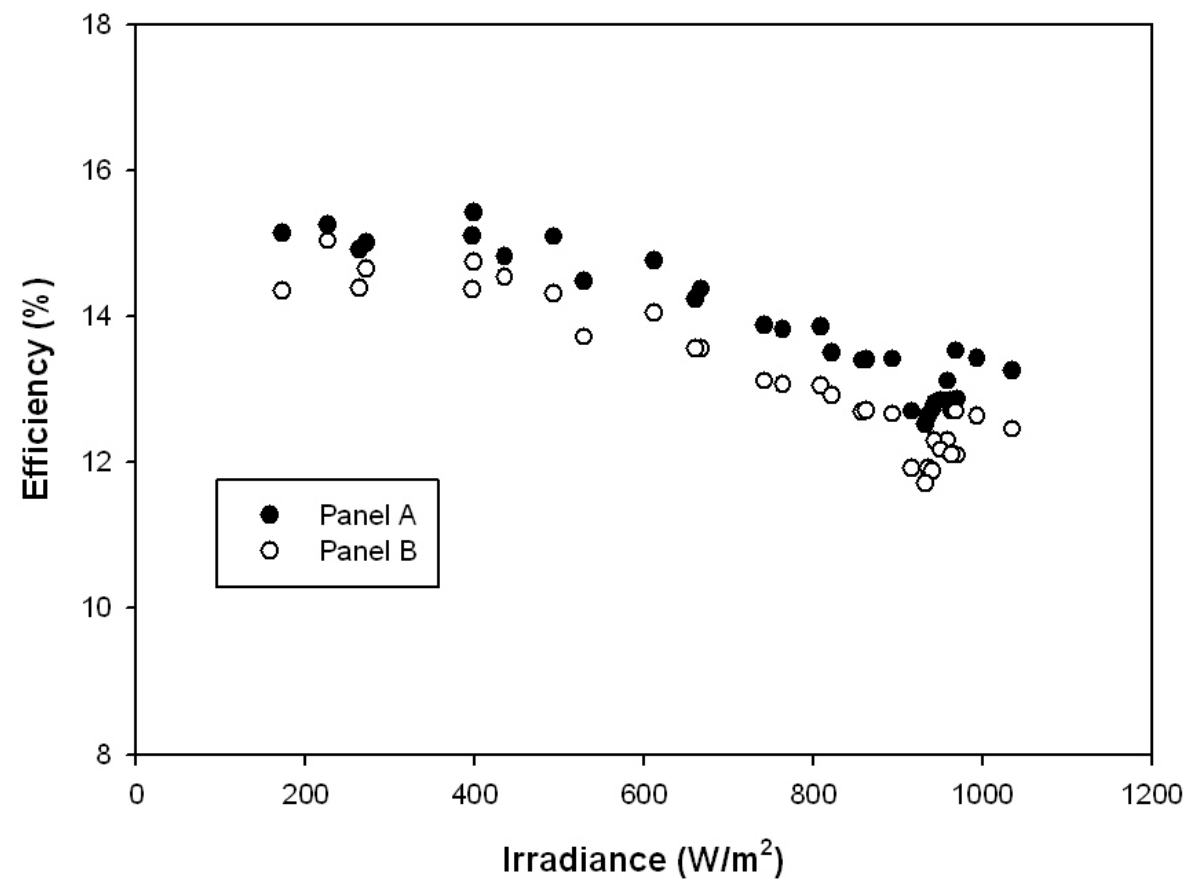

Figura 5.9 Rendimiento eléctrico del Panel A y Panel B respecto la radiación solar, en convección natural, para diferentes relaciones de aspecto del canal de aire.

Por lo tanto, el comportamiento de un panel fotovoltaico sobre una cubierta metálica, como presentan las naves industriales, es afectado por la alta temperatura alcanzada debido a la transferencia de calor de la superficie metálica al panel y un menor efecto de refrigeración por convección natural, cuando el espacio entre ambas superficies es reducido.

Como era de esperar, cuando la separación del canal de aire debajo del panel $\mathrm{B}$ es menor, la temperatura que alcanza el panel $B$ respecto el panel $A$, de referencia, es mucho mayor, siendo hasta $8-10^{\circ} \mathrm{C}$ superior para altos valores de radiación solar. Esto se debe a que el panel $\mathrm{B}$ está menos refrigerado por convección natural y además la plancheta metálica trasfiere calor al aire en el canal de paso, lo que impide una buena refrigeración y por consiguiente el rendimiento del panel B obtenido en este caso es mucho peor. Sin embargo, para la mayor relación de aspecto medida, los resultados experimentales muestran que la máxima diferencia de temperatura entre ambos paneles llega a ser de $5-6^{\circ} \mathrm{C}$ a medio día, cuando la radiación solar es mayor, y el rendimiento del panel $\mathrm{B}$ es alrededor de un $0.9 \%$ menor que el panel A, como se muestra en la Figura 5.10. 
a)

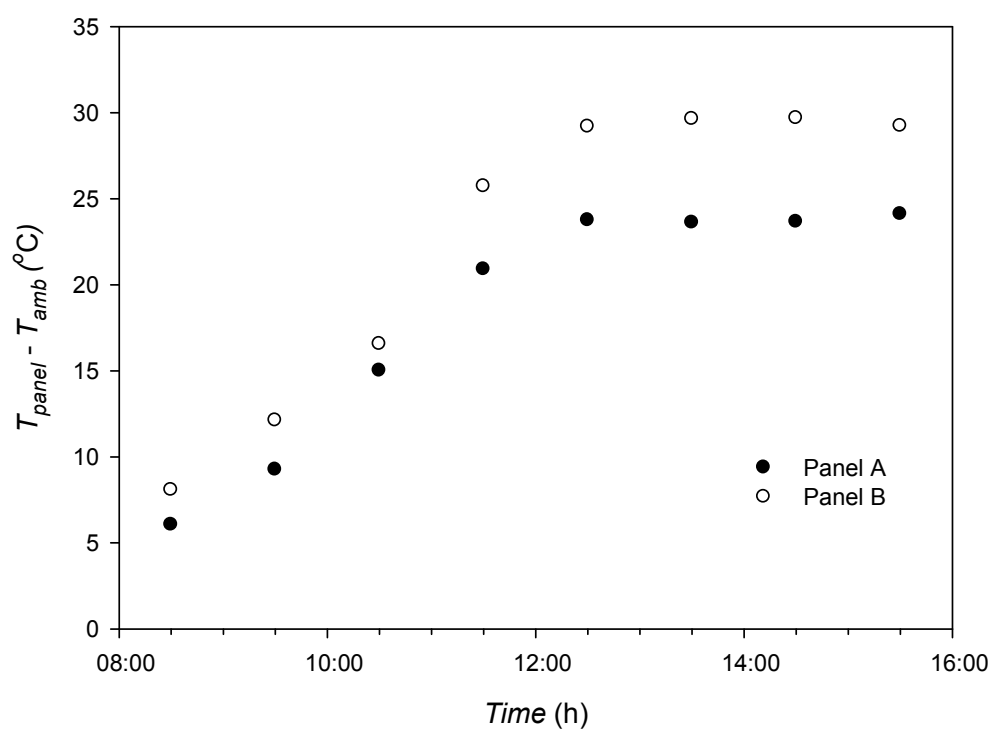

b)

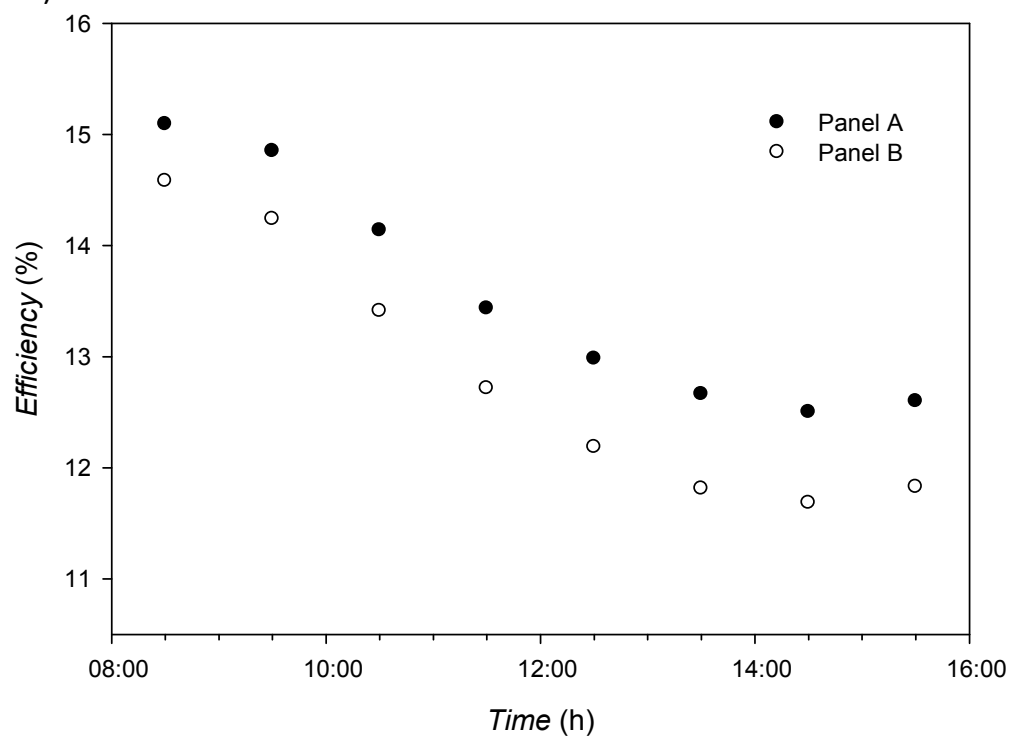

Figura 5.10 Comparación del comportamiento entre ambos paneles, panel $A$ y panel $B$ con $b / L=0.0825$. a) Diferencia de temperatura de panel y la ambiente b) Rendimiento eléctrico a lo largo del día.

Tras los resultados obtenidos, la colocación de un panel sobre una cubierta metálica trae consigo un aumento de la temperatura del panel y una reducción de su rendimiento. No obstante, se pretende comparar el comportamiento eléctrico del panel para las diferentes relaciones de aspecto y determinar su influencia en esta aplicación, con el fin de seleccionar la más idónea desde el punto de vista eléctrico.

La Figura 5.11 representa la diferencia de temperatura del panel y la ambiente respecto la radiación solar medida para las tres relaciones de aspecto ensayadas experimentalmente del módulo fotovoltaico colocado sobre la plancheta metálica. En ella se aprecia que hay pequeñas diferencias de los valores de temperatura, siendo mayores a altos valores de radiación, a partir de $600 \mathrm{~W} / \mathrm{m}^{2}$, para los cuales la temperatura del panel con relación de 
aspecto 0.0525 , es de $5-7^{\circ} \mathrm{C}$ superior a la del panel con la mayor relación de aspecto, $b / L=0.0825$. Para los diferentes días medidos, se observa que a mediodía, cuando la radiación solar es máxima, se aprecian diferencias considerables en la temperatura alcanzada por el panel para las tres configuraciones.

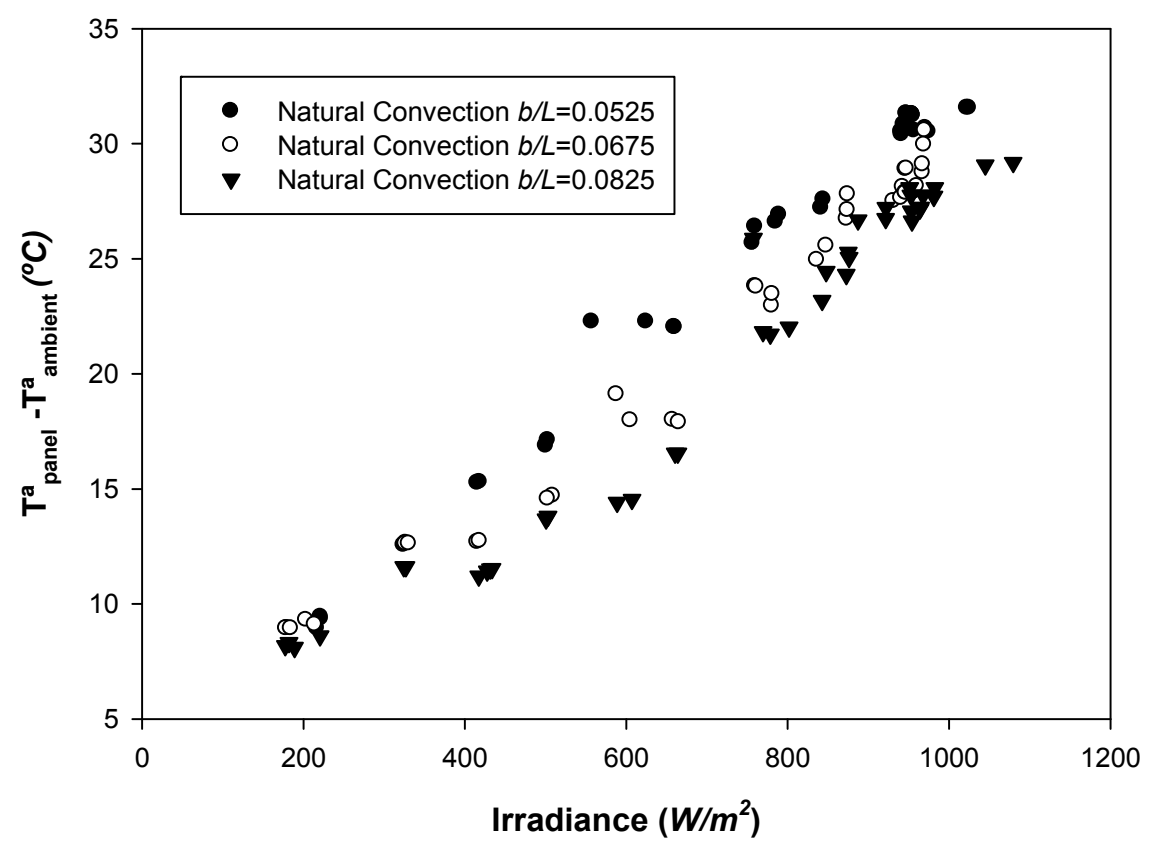

Figura 5.11 Influencia de la relación de aspecto en convección natural sobre la temperatura del panel.

Por consiguiente, aumentando la relación de aspecto se consigue una mejor refrigeración del panel por su cara posterior, lo que se traduce en una reducción de su temperatura entre $5-7^{\circ} \mathrm{C}$ la temperatura del panel, para las mismas condiciones de radiación solar, obteniéndose una mejora del rendimiento del $0.5 \%$ tal y como se muestra en la siguiente figura. Para la mayor relación de aspecto, el rendimiento eléctrico obtenido es mayor que para el resto de las relaciones de aspecto debido a que la temperatura alcanzada es menor, cuando la radiación solar es superior a los $600 \mathrm{~W} / \mathrm{m}^{2}$. 


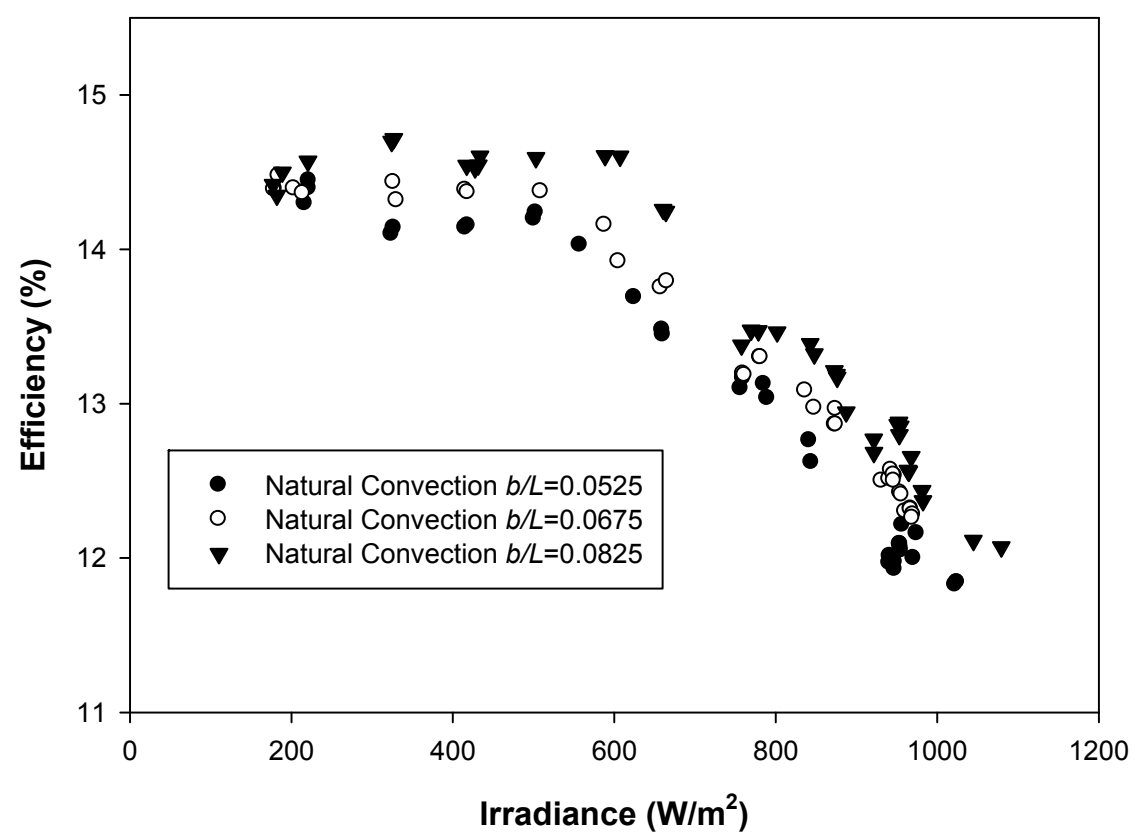

Figura 5.12 Influencia de la relación de aspecto en convección natural sobre el rendimiento eléctrico del panel.

En las figuras anteriores se observa que para valores bajos de radiación solar (a primeras y últimas horas del día), los valores medidos de temperatura y rendimiento del panel fotovoltaico son muy similares, sin diferencias algunas. Esto se debe a que la relación de aspecto no afecta en el comportamiento eléctrico del módulo, cuando los valores de radiación solar son bajos.

Este hecho se explica también en la Figura 5.13, mostrando la influencia de la relación de aspecto en las variables eléctricas del panel, tales como la tensión de circuito abierto $\left(V_{o c}\right)$, intensidad de cortocircuito $\left(I_{s c}\right)$ y la potencia máxima $\left(P_{m}\right)$ en dos situaciones diferentes, para bajos y altos valores de radiación solar.

En el primer caso en el que se muestran los valores medidos para una radiación de 970 $\mathrm{W} / \mathrm{m}^{2}$ la tensión de circuito abierto cuando la relación de aspecto es mayor, mientras que la intensidad de cortocircuito disminuye considerablemente y la potencia aumenta alrededor de un $7.5 \%$ para la mayor separación del canal de aire, debido a que el panel está mejor refrigerado por convección natural, alcanzando menor temperatura. Por lo tanto, la producción eléctrica mejora cuando la separación entre el panel y la cubierta metálica es mayor (Figura 5.13a). En el otro caso, para una radiación baja de $325 \mathrm{~W} / \mathrm{m}^{2}$ las variables eléctricas apenas sufren variación alguna con la relación de aspecto, lo que explica porque el rendimiento del panel toma valores similares para las tres relaciones de aspecto para bajos valores de radiación (Figura 5.13b). 

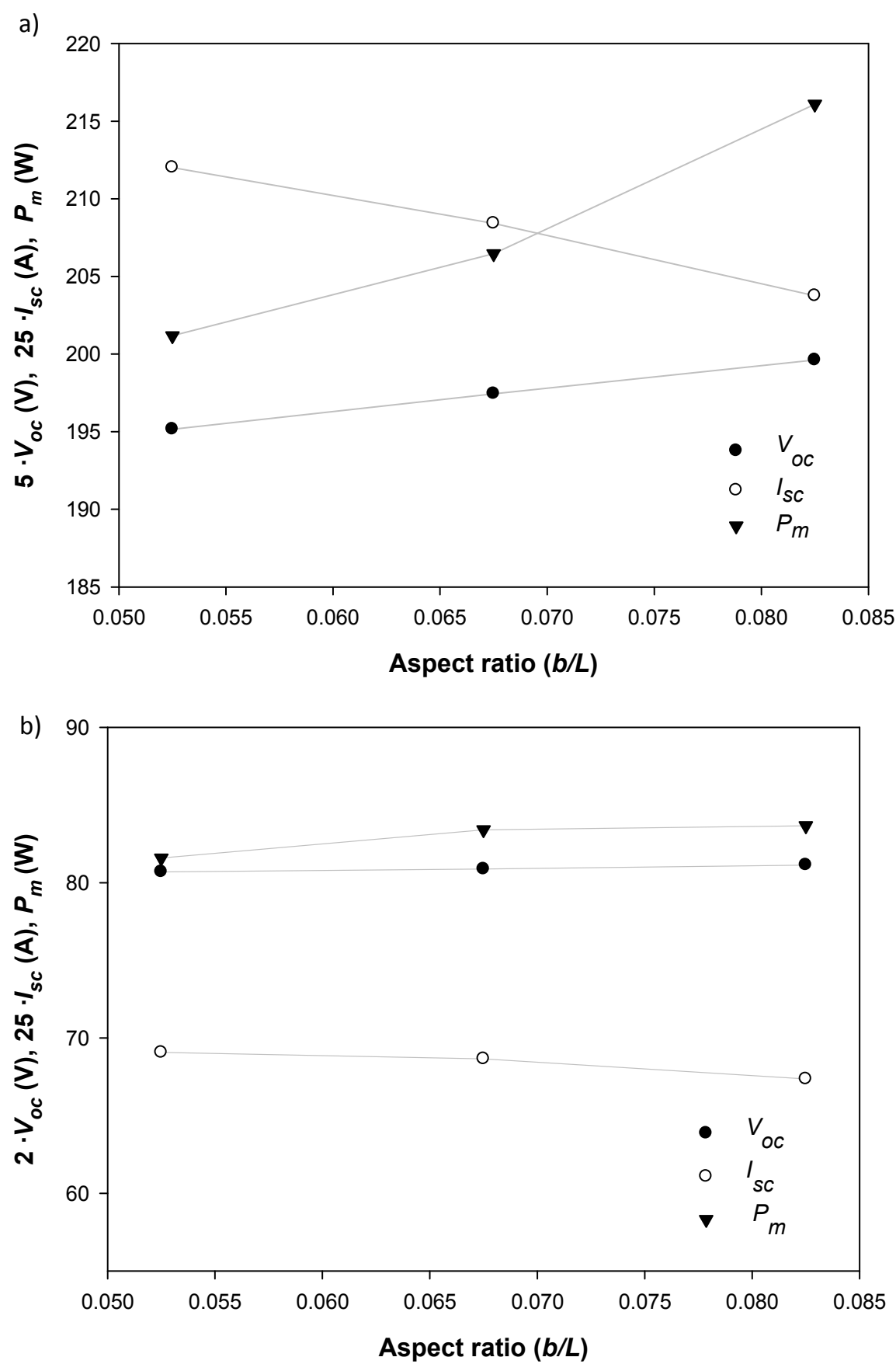

Figura 5.13 Influencia de la relación de aspecto sobre las variables eléctricas a diferentes condiciones ambientales. a) Alta radiación solar, con $\mathrm{G}_{\text {pira }}=970 \mathrm{~W} / \mathrm{m}^{2}$ y Táamb $=29^{\circ} \mathrm{C}$. b) Media-baja radiación solar, con $\mathrm{G}_{\text {pira }}=225 \mathrm{~W} / \mathrm{m}^{2}$ y $\mathrm{T}^{\mathrm{a}} \mathrm{amb}=23^{\circ} \mathrm{C}$.

Por consiguiente, para analizar y estudiar la influencia de la temperatura de funcionamiento del panel en las diferentes configuraciones, se deben comparar los valores medidos para valores de radiación solar altos.

\subsubsection{CONVECCIÓN FORZADA}

Una vez analizada la influencia negativa en la producción eléctrica del panel fotovoltaico, debida a una insuficiente separación entre éste y la superficie metálica lo cual permite su 
refrigeración por convección natural, se ha analizado el comportamiento del panel en convección forzada mediante el uso de un ventilador, para las mismas relaciones de aspecto previamente estudiadas. Las configuraciones en convección forzada se han medido y estudiado además, para tres regímenes de funcionamiento del ventilador, fijando tres valores de velocidad forzada a través del canal de aire siendo de 2,3 y $4 \mathrm{~m} / \mathrm{s}$ (valores medios medidos en el canal) y cada una ha sido medida y estudiada para cada sección de paso de aire bajo el módulo fotovoltaico. En los resultados mostrados a continuación, sólo se han incluido los correspondientes a dos velocidades testeadas, la de menor y mayor valor, al mostrar diferencias más significantes entre ellas en los resultados obtenidos.

Las medidas experimentales muestran que el panel B refrigerado por su cara posterior mediante convección forzada alcanza temperaturas menores que el panel $A$ de referencia para todos los casos estudiados, como era de esperar, y consecuentemente su producción eléctrica es mayor incluso para la menor relación de aspecto y la menor velocidad forzada, por el hecho de que el aire forzado por el ventilador permite una mayor refrigeración del módulo fotovoltaico, tal y como se muestran en las Figura 5.14 y 5.15 .

a)

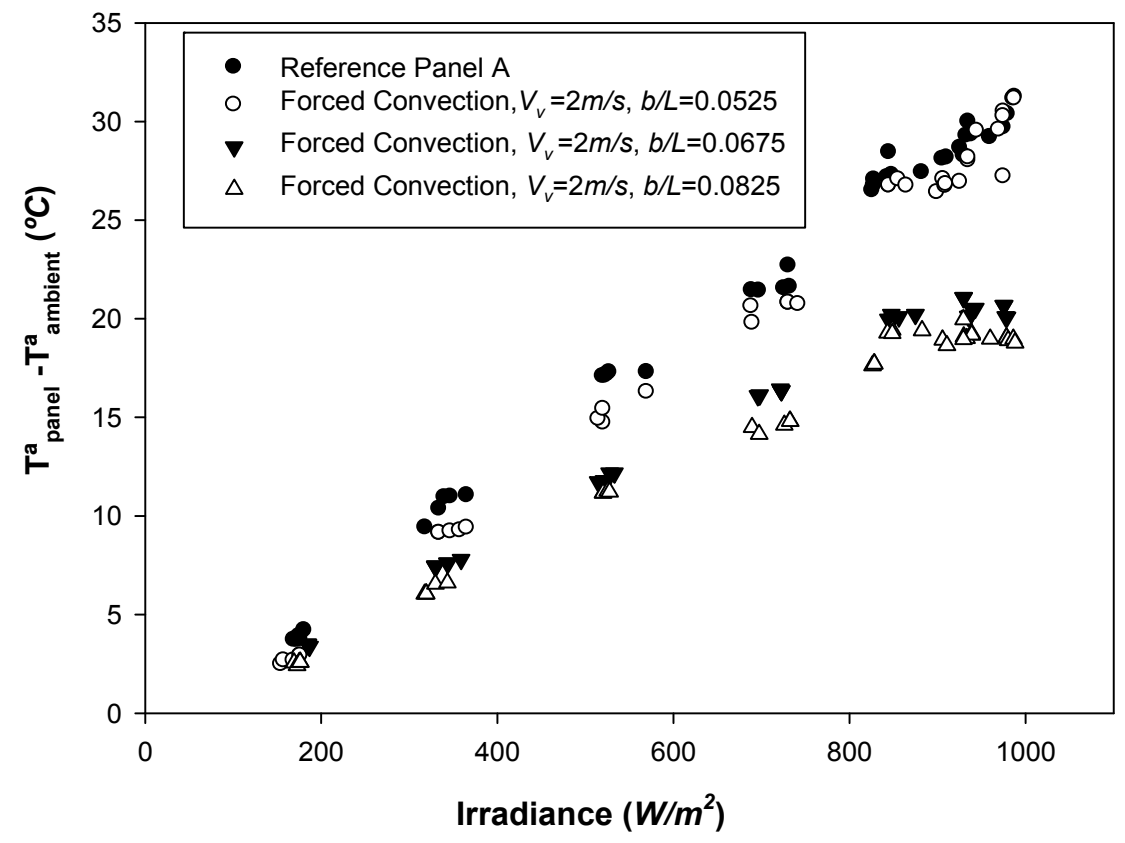


b)

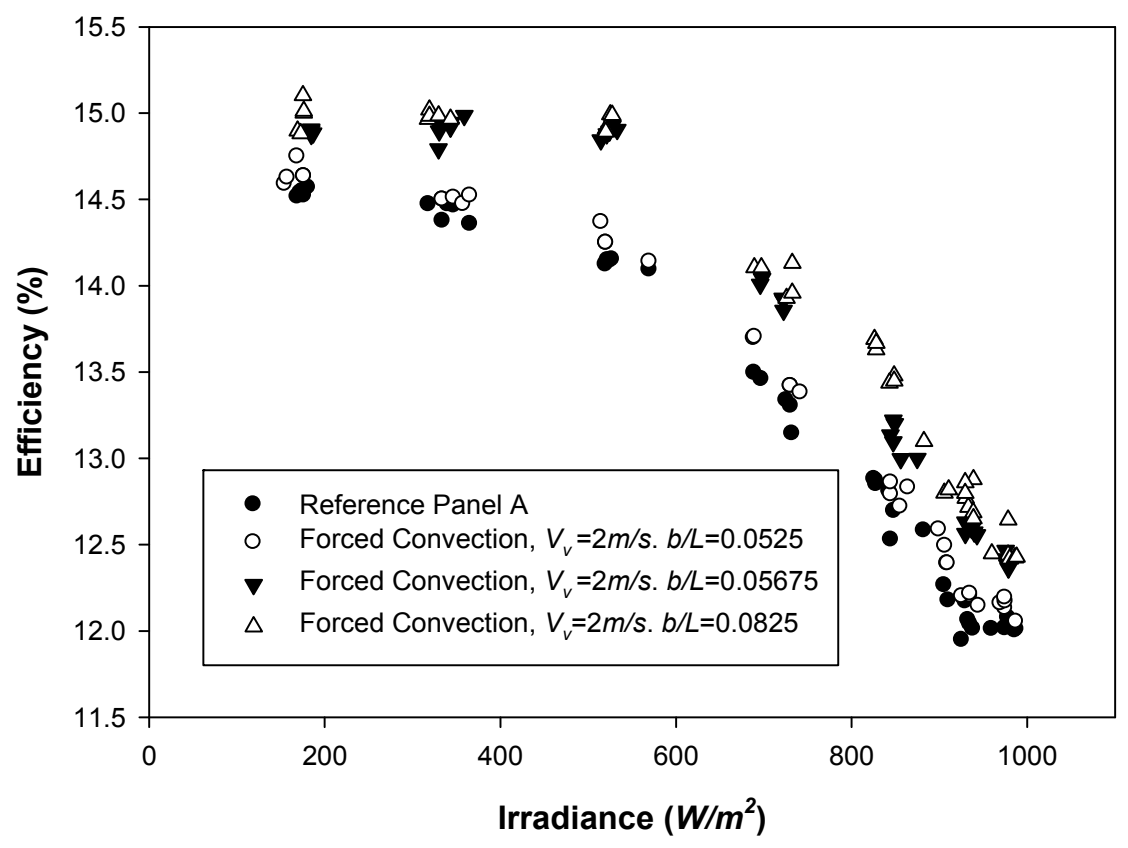

Figura 5.14 Influencia de la relación de aspecto en la temperatura y rendimiento del panel en función de la radiación solar para $\mathrm{V}_{\mathrm{v}}=2 \mathrm{~m} / \mathrm{s}$. a) Diferencia de temperatura del panel con el ambiente. b) Rendimiento del panel, para las diferentes relaciones de aspecto

Los resultados experimentales muestran que el módulo fotovoltaico se encuentra a menor temperatura cuando la separación del canal de aire es mayor, permitiéndole una mayor refrigeración, para las relaciones de aspecto comprendidas entre 0.0525 y 0.0825 . Además, se representa el comportamiento del panel de referencia sin canal de aire, Panel $A$, cuya temperatura es superior a la del Panel B para cualquiera de las relaciones de aspecto y su rendimiento inferior, lo que nos indica que la refrigeración del panel por su cara posterior a una velocidad forzada de 2 y $4 \mathrm{~m} / \mathrm{s}$ consigue una mayor eficiencia eléctrica, al no alcanzar tan elevadas temperaturas como las del panel de referencia.

Para una velocidad forzada de $2 \mathrm{~m} / \mathrm{s}$, no existen apenas diferencias en el comportamiento del panel para la menor relación de aspecto (0.0525) y el panel de referencia, siendo los valores de temperatura que alcanzan como el rendimiento en ambos casos muy similares, de modo que la mejora en producción eléctrica por refrigeración para la mínima separación del canal es muy pequeña (Figura 5.14). Sin embargo, para la velocidad forzada de $4 \mathrm{~m} / \mathrm{s}$, si existen diferencias significativas en su comportamiento, consiguiendo reducir entre $3-5^{\circ} \mathrm{C} \mathrm{la}$ temperatura del módulo con la mínima separación respecto al panel de referencia, lo que supone un rendimiento $0.5 \%$ superior (Figura 5.15 ).

Los resultados obtenidos para los casos correspondientes con $b / L=0.0675$ y $b / L=0.0825$ presentan una mejora considerable para ambas velocidades forzadas, respecto al panel de referencia, teniendo el panel una temperatura considerablemente inferior y consiguiendo un rendimiento en torno $0.5-0.9 \%$ mayor para valores de radiación superior a los $600 \mathrm{~W} / \mathrm{m}^{2}$. 
Además, entre ambas separaciones no hay apenas diferencias significativas para ambas velocidades forzadas, lo cual indica que el pequeño incremento en la separación del canal, no supone una gran mejora.

a)

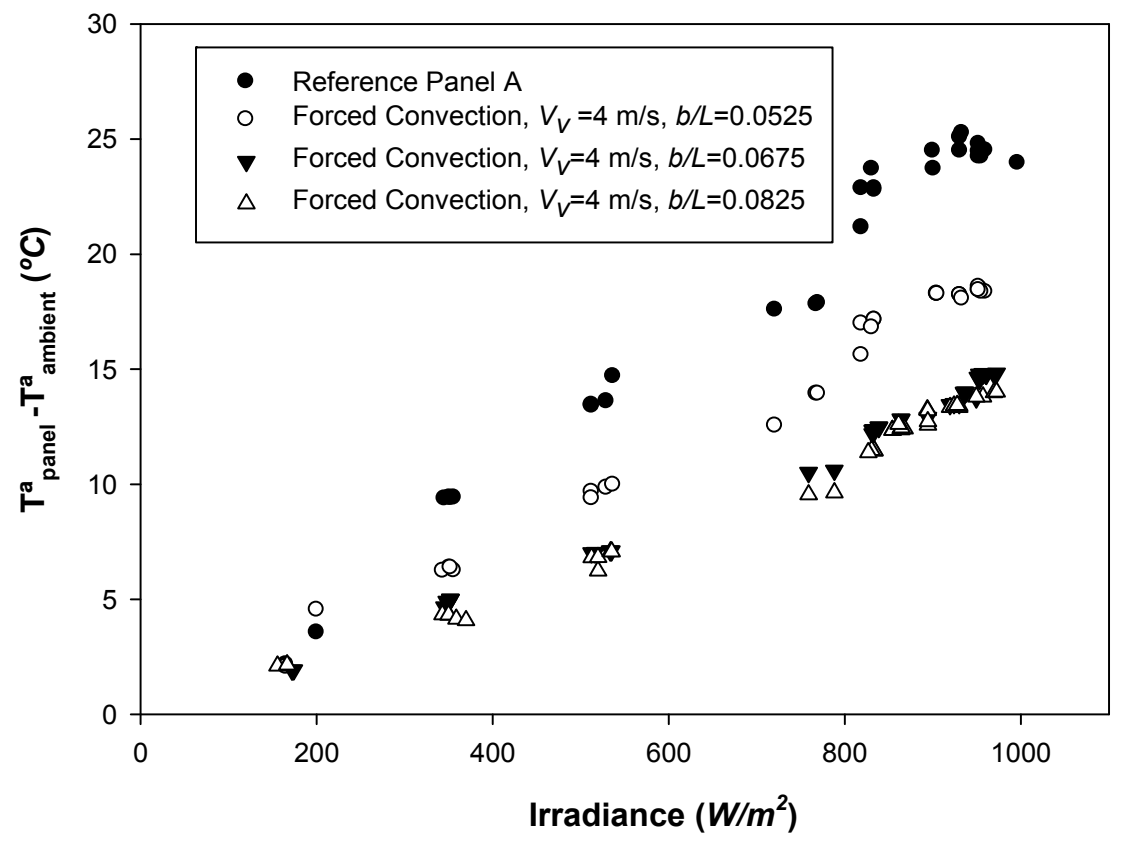

b)

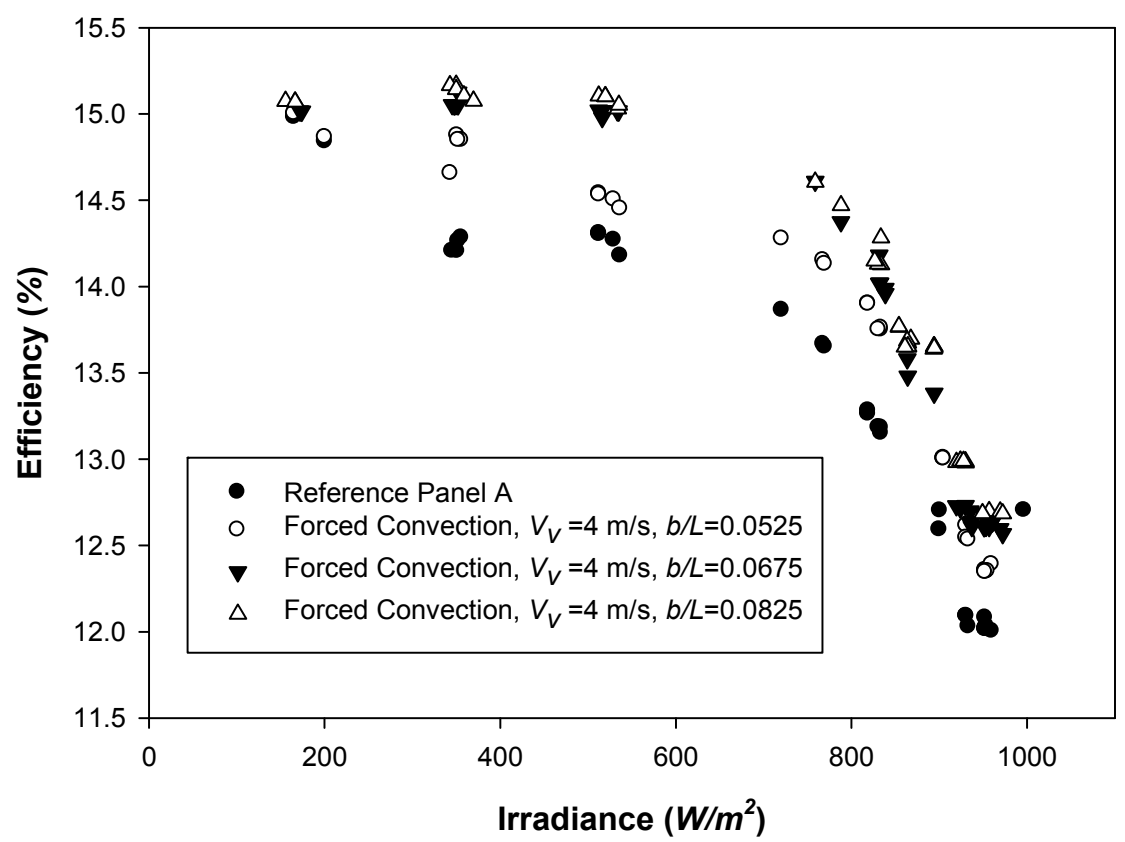

Figura 5.15 Influencia de la relación de aspecto en la temperatura y rendimiento del panel en función de la radiación solar para $\mathrm{V}_{\mathrm{v}}=4 \mathrm{~m} / \mathrm{s}$. a) Diferencia de temperatura del panel con el ambiente. b) Rendimiento del panel, para las diferentes relaciones de aspectos 
Comparando los resultados obtenidos para ambas velocidades forzadas, cabe destacar que a mayor velocidad inducida en el canal, el salto de temperatura del panel y la ambiente llega a ser $5-7^{\circ} \mathrm{C}$ inferior, para cada una de las relaciones de aspecto, debido a que el flujo de aire inducido a través del canal es mayor, permitiendo una mayor refrigeración del canal. Además, la mejora de la transferencia de calor entre el módulo y el aire, con el aumento del caudal de aire, se llega a conseguir tanto, aumentando la velocidad forzada para la misma relación de aspecto, como si incrementamos la sección de paso de aire para la misma velocidad forzada.

Los resultados muestran que el panel alcanza la mayores temperaturas en los casos de menor velocidad inducida y la mínima relación de aspecto, de hecho en esos casos el rendimiento obtenido por el panel es menor. No obstante, cuando el panel está bien refrigerado, para $V_{v}=4 \mathrm{~m} / \mathrm{s}$, el peor rendimiento alcanzado es de $12.5-13 \%$, dependiendo de la relación de aspecto, mientras que para una menor refrigeración $\left(V_{v}=2 \mathrm{~m} / \mathrm{s}\right)$, el peor rendimiento alcanzado es de $12-12.5 \%$ lo que indica que existe un aumento de la eficiencia eléctrica a mayor velocidad forzada.

Por consiguiente, la refrigeración del panel por su cara posterior mediante convección forzada, supone una mejora del rendimiento eléctrico, comparado con los resultados obtenidos en convección natural, por el hecho de que la inducción de aire mantiene al módulo a menores temperaturas de funcionamiento.

\subsubsection{COMPARACIÓN ENTRE CONVECCIÓN NATURAL Y FORZADA}

Resumiendo el análisis de resultados visto hasta el momento, la temperatura de funcionamiento del panel aumenta cuando éste se encuentra sobre una superficie o cubierta metálica, lo que conlleva una disminución considerable de la producción eléctrica, especialmente a elevados valores de radiación solar. Este efecto negativo podría ser mejorado proporcionando un canal de aire entre ambas superficies, el cual permita al panel no llegar a altas temperaturas gracias a un mayor efecto de refrigeración sobre el panel por el efecto chimenea creado mediante convección natural. Además, los resultados obtenidos muestran que un aumento en la separación del canal de $0.06 \mathrm{~m}$, llega a reducir la temperatura del módulo hasta $5-6^{\circ} \mathrm{C}$ y mejora ligeramente su rendimiento eléctrico (Figura 5.11 y Figura 5.12). Sin embargo, se alcanza una mayor reducción en la temperatura del panel fotovoltaico, aumentando el caudal de aire a través del canal mediante convección forzada, con lo que, a mayor velocidad inducida y separación del canal, la temperatura del panel es menor y su eficiencia eléctrica mejora considerablemente, comparado con el comportamiento de un panel sin canal de aire (Figura 5.14 y Figura 5.15).

En las figuras 5.14 y 5.15 se mostraba la relación del salto de temperatura del panel y la temperatura ambiente con la radiación solar para diferentes relaciones de aspecto, fijando 
la velocidad inducida en el canal de aire. Del mismo modo, se ha representado la misma relación para diferentes valores de velocidad inducida fijando la relación de aspecto, con el objeto de poder compararla con las propuestas por Nordmann y Clavadetscher [71], tanto para convección natural como forzada, observándose un buen ajuste de los datos (Figura 5.16).

a)

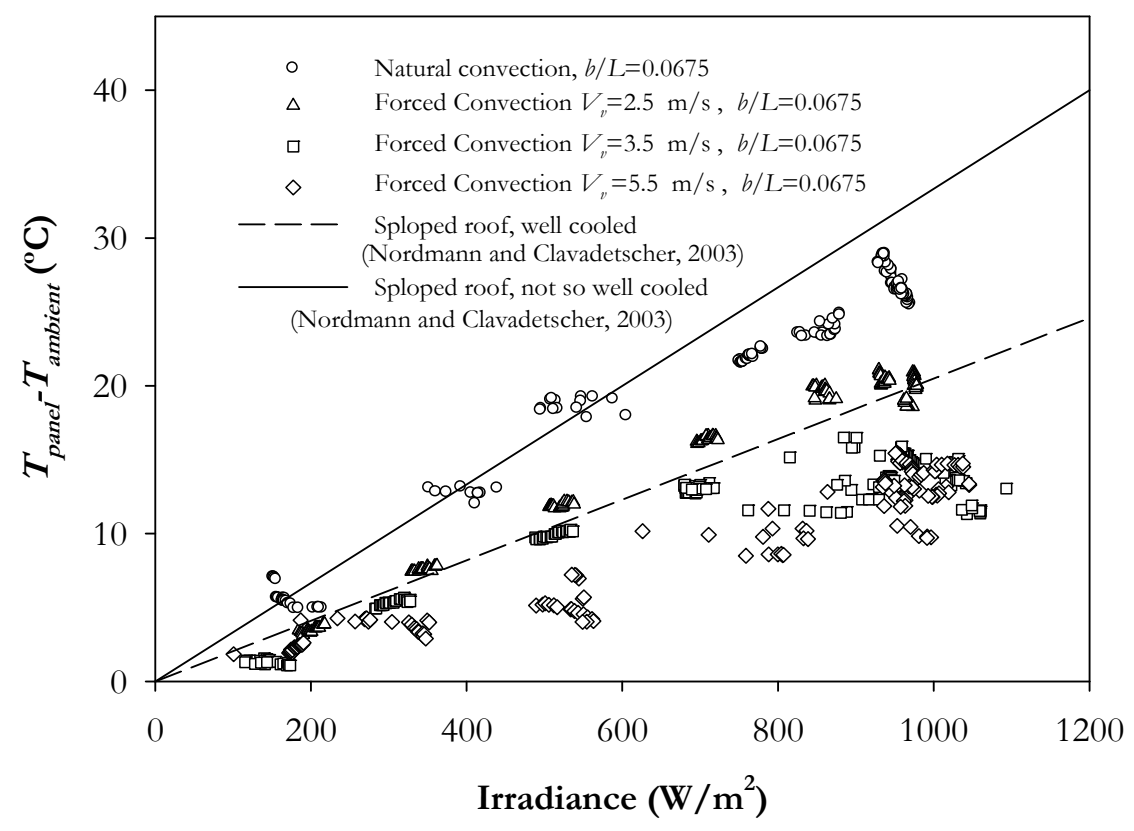

b)

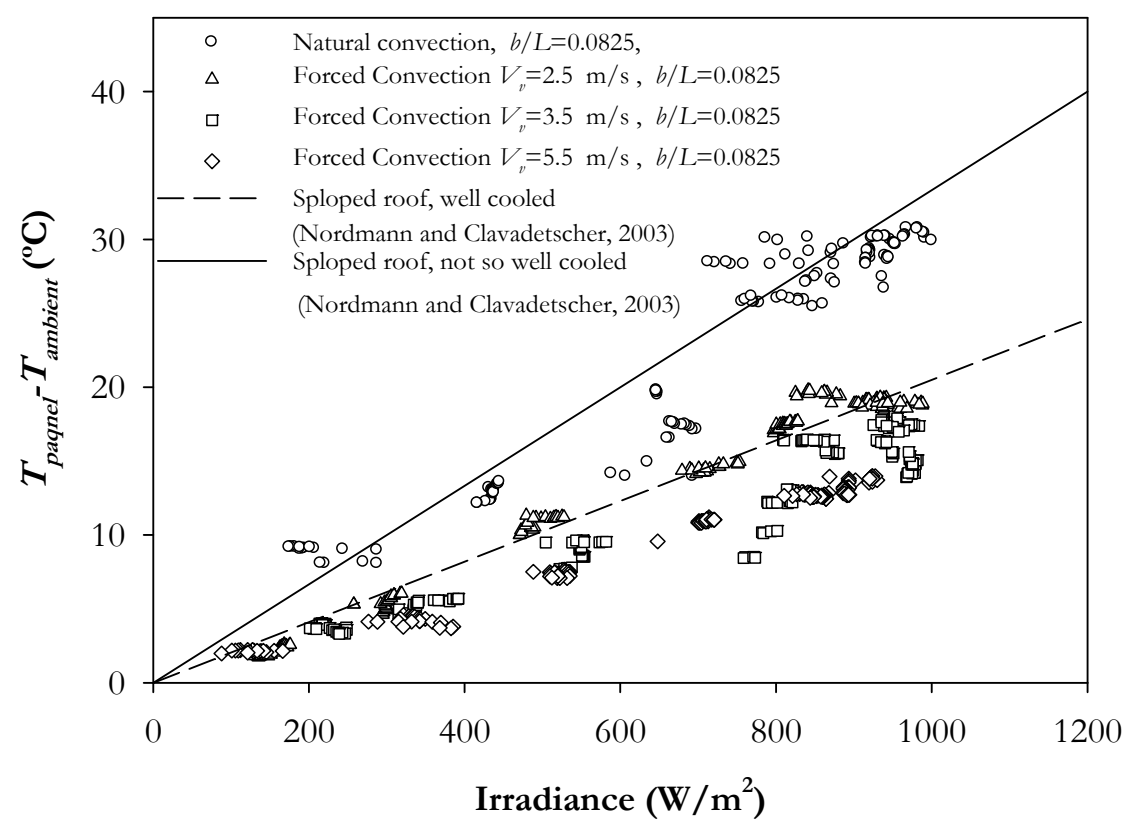

Figura 5.16. Diferencia entre temperatura de panel y ambiente en función de la radiación solar para diferentes niveles de velocidad inducida. a) $b / L=0.0675$. b) $b / L=0.0825$ 
Un aspecto que se debe señalar es el hecho de que para irradiancias bajas, los datos experimentales aparecen en varios grupos, debido a que los valores que se han medidos toman valores muy cercanos con lo que se aprecian los efectos transitorios en la temperatura o incluso que el módulo no tenga tiempo suficiente para ajustar su temperatura cuando hay un cambio en el nivel de radiación solar.

A pesar de ello, los resultados experimentales presentados en la Figura 5.16 para los casos de convección naturales muestran una pendiente muy similares a los propuestos en Nordmann y Clavadetscher (2003), con una desviación máxima de $5^{\circ} \mathrm{C}$ en la mayoría de los casos. Esta variación puede ser debido al hecho de que la diferencia de la temperatura no sólo está fuertemente influenciada por la irradiación sino también por la velocidad del viento. En convección forzada se obtienen conclusiones similares al comparar los resultados experimentales para un nivel bajo de velocidad inducida $\left(V_{f} \approx 2.5 \mathrm{~m} / \mathrm{s}\right)$ con los propuestos en Nordmann (2003) para un sistema fotovoltaico de techo inclinado bien refrigerado. Sin embargo, es de destacar que para mayores valores de velocidad inducida, $\left(V_{f} \approx 3.5 \mathrm{~m} / \mathrm{s}\right.$ y $V_{f} \approx 5.5 \mathrm{~m} / \mathrm{s}$ ) la refrigeración obtenida en este estudio es superior al propuesto en [71]. Este hecho pone de manifiesto la necesidad de llevar a cabo un estudio exhaustivo de la influencia de la convección forzada inducida en la temperatura del módulo operativo como se verá en la sección 6.2.4 [77]. Las diferencias entre los resultados obtenidos para ambas relaciones de aspecto presentados no son muy significativas. Algunos autores [65,81]) estudiaron la influencia de la relación de aspecto de los módulos fotovoltaicos en los canales inclinados y señalaron la importante influencia de este parámetro de la temperatura del módulo. Se determinó un valor óptimo para la relación de aspecto alrededor de 0,1.

A continuación se pretende comparar las diferentes configuraciones estudiadas, tanto en convección natural como en forzada. En los resultados mostrados previamente, se ha observado que el comportamiento eléctrico del panel empeora a elevados valores de radiación solar, cuando el panel se calienta y la temperatura tiene una influencia significante. Por lo tanto, la comparación de resultados llevada a cabo, se ha hecho con los datos correspondientes a dichas condiciones, radiación solar aproximada a $950 \mathrm{~W} / \mathrm{m}^{2}$ y temperatura ambiente de $28^{\circ} \mathrm{C}$. En la Figura 5.17, se muestra la temperatura del panel respecto a la ambiente y la potencia eléctrica en función de la velocidad del aire en el canal, para las diferentes secciones de paso de aire experimentadas.

Los resultados obtenidos revelan que para una relación de aspecto dada, la potencia eléctrica obtenida por un módulo refrigerado por aire inducido es 3-5\% mayor que por convección natural, y como era de esperar, aumenta cuando la velocidad inducida en el canal es mayor. Esta mejoría en el comportamiento eléctrico se debe a que las temperaturas alcanzadas por el panel, respecto del ambiente, disminuye alrededor de $10-16^{\circ} \mathrm{C}$ por refrigeración inducida. Comparando ambos casos de convección forzada, para la mayor 
velocidad inducida, el aumento en la potencia es de $2.4 \%$, siendo su temperatura $7^{\circ} \mathrm{C}$ inferior.
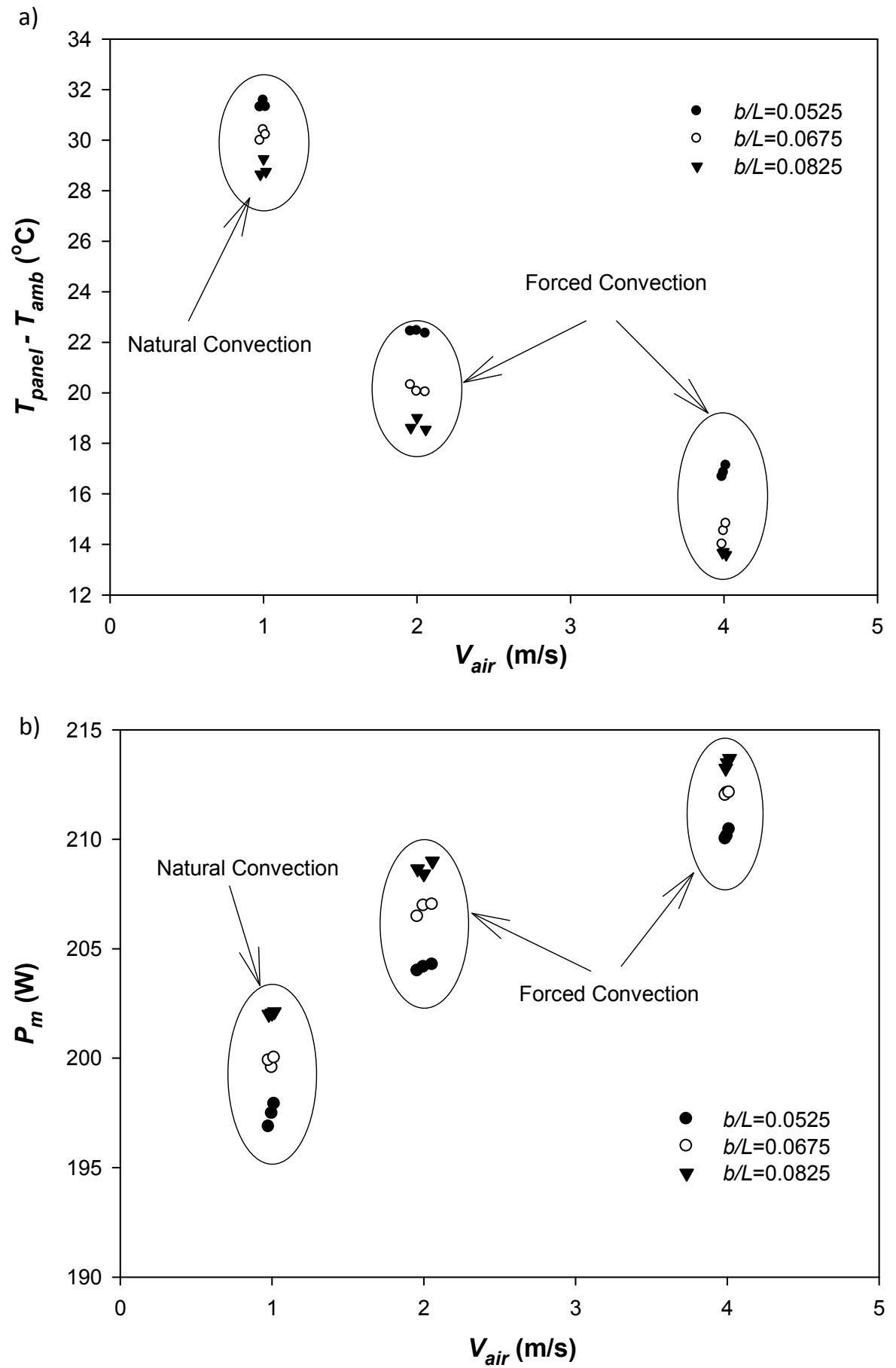

Figura 5.17 Comparación entre convección natural y forzada para las diferentes relaciones de aspecto, para una radiación de $950 \mathrm{~W} / \mathrm{m} 2$ y Táambiente de $28^{\circ} \mathrm{C}$. a) Potencia pico. b) Diferencia de temperatura del panel y ambiente.

Desde otro punto de vista, tanto en convección natural y forzada, la producción eléctrica obtenida aumenta un 2-2.5\% para una mayor separación en el canal de aire, refrigerando al panel más eficientemente, por lo que la temperatura panel alcanzada es de $5-7^{\circ} \mathrm{C}$ menor. 
Además, se puede apreciar que el panel presenta un comportamiento muy similar para las relaciones de aspecto de 0.0675 y 0.0825 , para las que no hay apenas diferencias significativas en la potencia y temperatura de funcionamiento, por consiguiente las mayores disimilitudes en los resultados se han obtenido entre la menor y mayor relación de aspecto. Por este motivo, se han analizado la relación negativa de la temperatura sobre el rendimiento eléctrico para estos dos casos, ambos en convección natural y forzada (Figura 5.18).
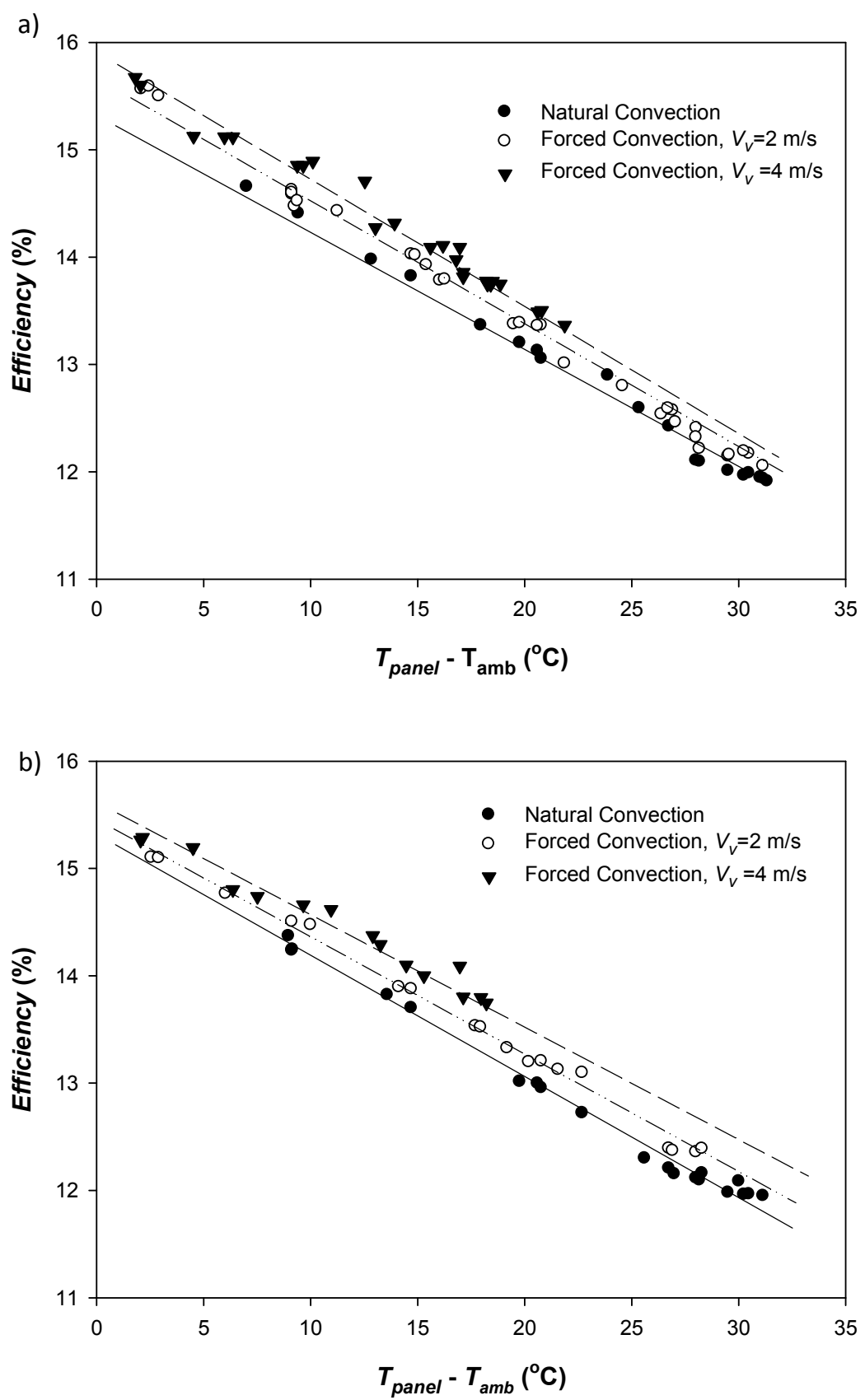
Figura 5.18 Relación entre el rendimiento del panel con la temperatura. a) Para la menor relación de aspecto medida (0.0525). b) Pala la mayor relación de aspecto medida (0.0825).

Los resultados experimentales reflejan la dependencia negativa entre la temperatura y el rendimiento eléctrico de un panel fotovoltaico para las diferentes configuraciones. Mientras que la diferencia de temperatura entre el panel y el ambiente no es muy alta, se aprecia muy pequeñas diferencias en los valores del rendimiento entre las diferentes configuraciones, pero cuando el panel alcanza elevadas temperaturas el rendimiento disminuye bruscamente y se pueden apreciar diferencias en los valores dependiendo de la configuración y de la relación de aspecto.

Los menores valores de eficiencia eléctrica medidos corresponden para el mayor salto de temperatura, si los comparamos entre ambas relaciones de aspecto se observa que para la mayor relación de aspecto el rendimiento mínimo obtenido es mayor, tanto en convección natural e inducida, y en este caso se percibe una mejora considerable en el rendimiento del panel entre las diferentes configuraciones (convección natural y forzada).

\subsubsection{GENERALIZACIÓN DE RESULTADOS}

A la vista de los resultados presentados, la temperatura de funcionamiento de los módulos fotovoltaicos integrados en cubiertas está influenciada por la capacidad de ventilación del canal de aire, creado bajo el módulo. La ventilación a su vez, depende de diversos factores tales como la velocidad del viento, la separación entre el panel y la cubierta, y la velocidad del aire en el canal. Por ello, cabe la necesidad de desarrollar un modelo experimental, en el que se estudie la influencia de dichas variables en la temperatura del módulo, estableciendo correlaciones semiempíricas que nos permita determinar la temperatura del módulo para diferentes configuraciones y condiciones ambientales.

Previamente se debe asegurar que tanto la relación de aspecto como la velocidad inducida en el canal de aire son variables influyentes al coeficiente de Ross, mediante un análisis estadístico que nos permita determinar si existen diferencias significativas en la distribución de $k$ para diferentes valores de $b / L$ y $V_{v}$. En A.S. Kaiser et al. [77] se detalla el estudio estadístico llevado a cabo con los datos experimentales, en el que se afirma una influencia significativa de la relación de aspecto y la velocidad inducida en la distribución del coeficiente de Ross.

De acuerdo a los estudios bibliográficos presentados en el apartado 2.5, a partir de los resultados experimentales medidos se obtendrá una correlación para el parámetro de Ross en función de las variables influyentes. Una vez obtenida dicha correlación, utilizando la ecuación 2.18 se tiene la expresión que nos permitirá obtener la temperatura de funcionamiento del panel, bajo diferentes condiciones ambientales y constructivas. 
Del análisis de las distribuciones de puntos de datos (Figura 5.19), se puede deducir que hay una relación no lineal entre las variables dependientes e independientes. Se ha detectado que un modelo que se ajuste a esta distribución de datos toma la forma:

$$
k=A \cdot\left(1+V_{v}\right)^{\left(B \frac{b}{L}+C\right)}
$$

donde $A, B$ y $C$ son las constantes de ajuste del modelo.

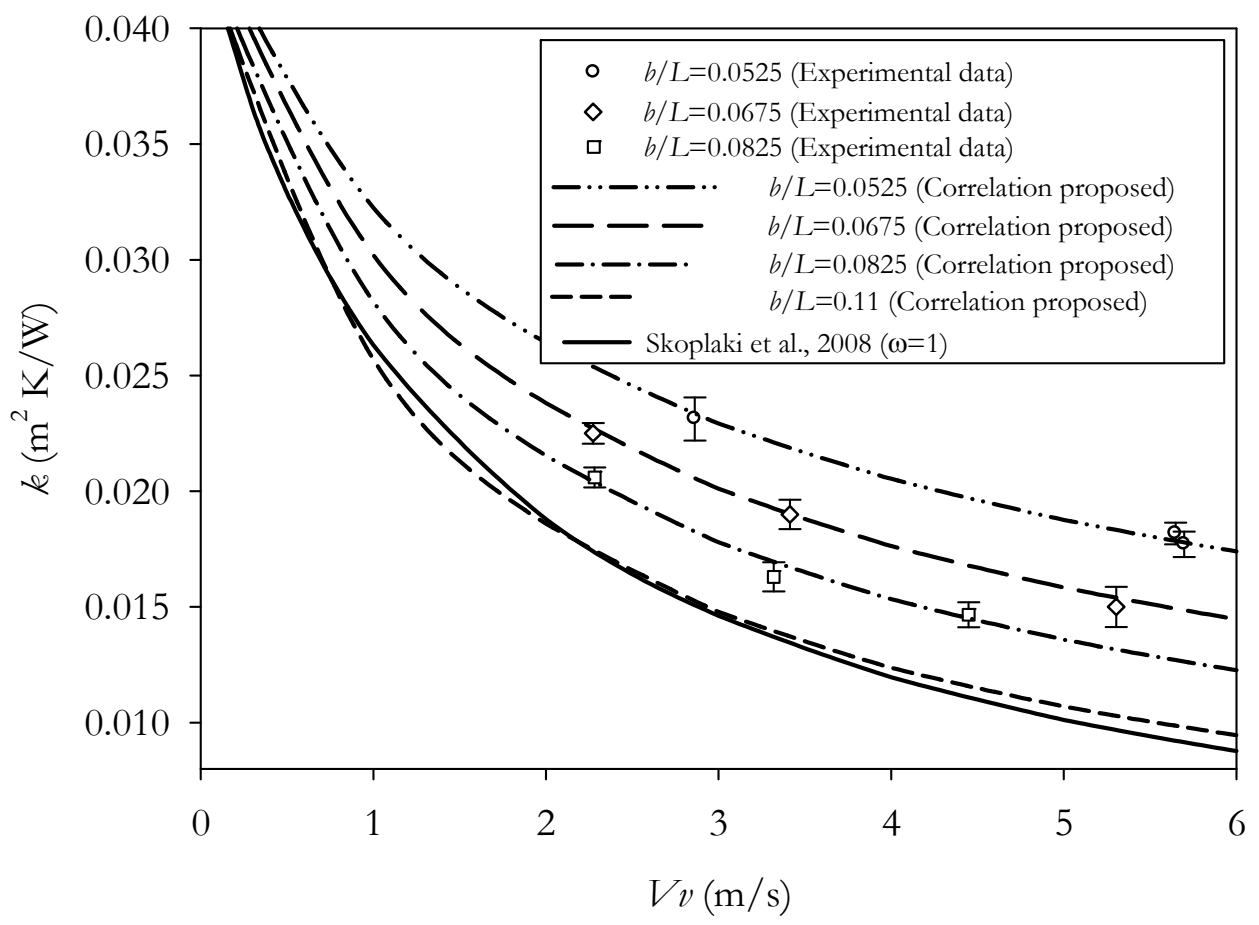

Figura 5.19 Resultados experimentales y correlaciones propuestas del coeficiente de Ross (k) medido para diferentes relaciones de aspecto y velocidades inducidas en el canal. Correlaciones experimentales propuestas por Skoplaki et al. [72] para sistemas PV no integrados en cubierta $(w=1)$.

Con el fin de aplicar la teoría de regresión lineal a la ecuación. 5.7, se han llevado a cabo las siguientes trasformaciones para convertir esta expresión en lineal:

$$
Y=A_{1} X_{1}+B X_{2}+C
$$

siendo $Y=\ln k / \ln \left(1+V_{v}\right), \quad X_{1}=1 / \ln \left(1+V_{v}\right), \quad X_{2}=b / L$ y $A_{1}=\ln A$. El modelo de regresión obtenido mediante el uso del software SPSS, se resume en la Tabla 5.1, donde $\mathrm{R}$ representa el valor del coeficiente de correlación múltiple y $\mathrm{R}^{2}$ mide la proporción de variabilidad total de la variable independiente que es explicada por el modelo, tomando un valor de 0,995 , lo que significa que $X_{1}$ y $X_{2}$ representan el 99,5\% de la variación en $Y$.

\begin{tabular}{|l|l|l|l|l|}
\hline$R$ & $R^{2}$ & Adjusted $R^{2}$ & F-Change & Sig. F Change \\
\hline 0.997 & 0.995 & 0.995 & 55.678 & 0.000 \\
\hline
\end{tabular}

Tabla 5.1 Resumen del modelo de regresión 


\begin{tabular}{|c|c|c|c|c|c|}
\hline \multirow{2}{*}{ Model } & \multicolumn{2}{|c|}{$\begin{array}{c}\text { Unstandardized } \\
\text { coefficients }\end{array}$} & $\begin{array}{c}\text { Standardized } \\
\text { Coefficient }\end{array}$ & \multirow{2}{*}{ t } & \multirow{2}{*}{ Sig. } \\
\cline { 2 - 4 } & $\mathbf{b}$ & Std. error & Beta & & \\
\hline Constant & -0.162 & 0.008 & & -20.291 & 0.000 \\
\hline$X_{1}$ & -3.092 & 0.120 & -0.886 & -250.52 & 0.000 \\
\hline$X_{2}$ & -6.311 & 0.121 & 0.184 & -52.142 & 0.000 \\
\hline
\end{tabular}

Tabla 5.2 Coeficientes del modelo de regresión.

Los parámetros del modelo realizado se presentan en la Tabla 5.2, en la que se incluyen la estimación de los b-values y su contribución individual de cada valor predicho del modelo. Sustituyéndolos en la Ecuación 5.8 se obtiene:

$$
Y=-3.092 X_{1} \pm 6.311 X_{2}-0.162
$$

Cada uno de estos valores (b-values) tiene un error estándar asociado el cual indica hasta qué punto estos valores variarían en diferentes muestras, y estos errores se utilizan para determinar si el dicho valor difiere significativamente de cero. Esto viene probado con el valor de significancia t-test asociado a cada b-value (la columna denominada Sig.), al ser inferior a 0,05 entonces cada valor predicho está haciendo una contribución significativa al modelo. Por consiguiente, la función experimental calculada mediante la correlación de las mediciones experimentales obtenidas en este trabajo se escribe como

$$
k=0.045\left(1+V_{v}\right)^{\left(-6.311 \frac{b}{L}-0.162\right)}
$$

Los valores predichos de la ecuación. 5.10 se comparan en la Figura 5.19 con los datos experimentales de este estudio para diferentes configuraciones, y con la correlación propuesta por Skoplaki et al. [72] (Ec. 2.20). Los símbolos presentados con forma circular, de rombo y cuadrada muestran los datos experimentales medidos para relaciones de aspecto de $b / L=0.0525 ; b / L=0.675$ y $b / L=0825$ respectivamente, para un rango de velocidad inducida en el canal desde $2 \mathrm{~m} / \mathrm{s}$ hasta $6 \mathrm{~m} / \mathrm{s}$. Las curvas trazadas representan las líneas de tendencia de la correlación propuesto en este trabajo como una función de la relación de aspecto y la velocidad inducida en el canal.

Como se muestra en la Figura 5.19, la correlación propuesta pone en manifiesto que el módulo fotovoltaico integrado en el canal se comporta de la misma manera como un módulo independiente (sin integración), para valores de $b / L$ mayores que 0.11 . Los resultados obtenidos por Skoplaki et al. [72] (representados en la figura por la línea continua) son muy similares. Esta misma tendencia también se propone por Gan [65] para una configuración de integración fotovoltaica refrigerada por convección natural, en la que se propone una separación crítica en el canal de aire bajo el panel crítico de 0,11 m como el espacio de aire mínimo que se requiere para minimizar el sobrecalentamiento de los dispositivos fotovoltaicos, para una longitud del módulo de 1.209 m (esto corresponde a una relación de aspecto de 0.09). 
Cabe señalar que para una relación de aspecto constante, el valor de la velocidad inducida dentro del canal afecta fuertemente en la refrigeración del módulo. Además, para cada velocidad inducida, los valores del coeficiente de Ross aumentan con la disminución del espacio de aire en el canal (Figura 5.19). A la vista de los resultados, se deduce que esta correlación es válida para velocidades inducidas en el rango de 2-6 m / s, y relaciones de aspecto en el rango de 0,0525-0,0825.

A partir de la ecuación 5.10, se propone la siguiente expresión para determinar la temperatura de funcionamiento de un panel fotovoltaico integrado en una cubierta, en función de la temperatura ambiente, radiación, velocidad inducida y la relación de aspecto.

$$
T_{\text {panel }}=T_{a m b}+0.045\left(1+V_{v}\right)^{\left(-6.311 \frac{b}{L}-0.162\right)} G_{\text {pira }}
$$

A partir de la correlación obtenida, podemos obtener los valores predichos de la temperatura del módulo para las diferentes condiciones ambientales y geométricas medidas en la instalación y así establecer la bondad del ajuste comparándolos con la temperatura medida bajos dichas condiciones, tal y como se incluye en [77].

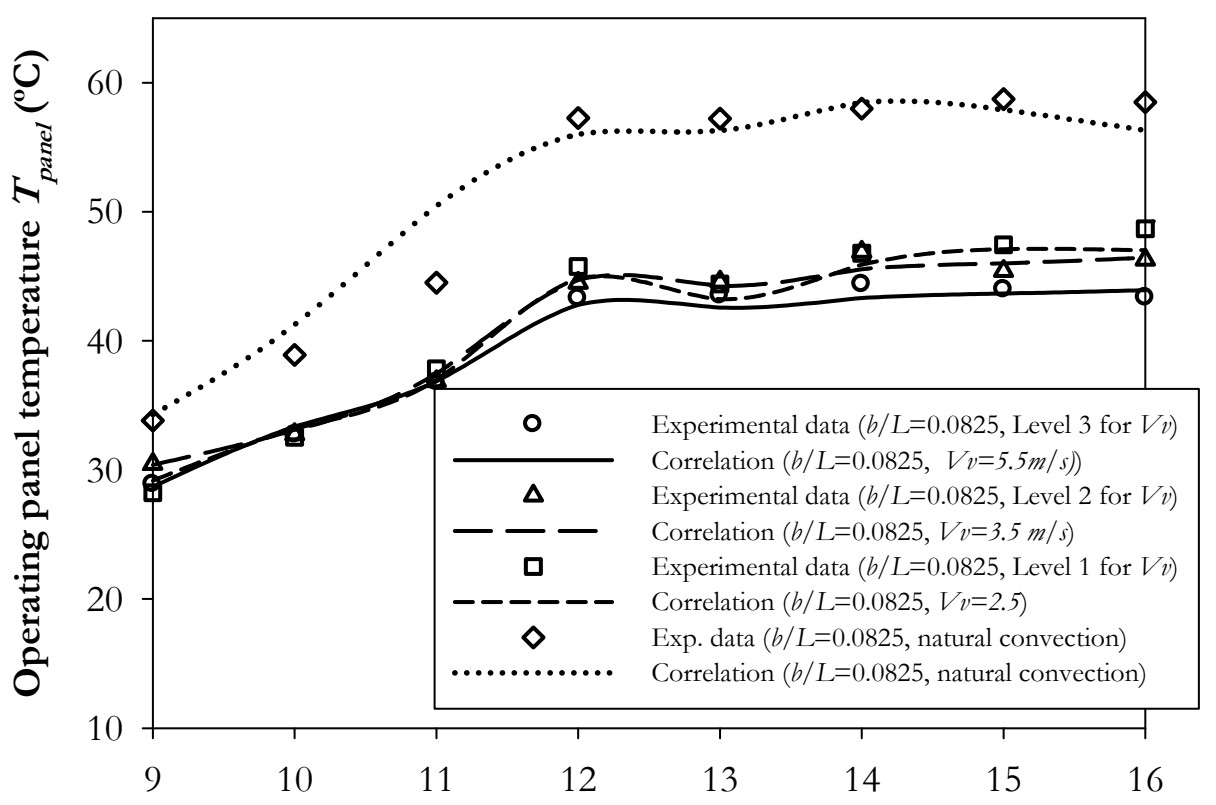

Time (h)

Figura 5.20 Comparación de los valores experimentales medidos y los predichos por el modelo experimental para la temperatura del panel fotovoltaico integrado sobre cubierta, a lo largo de un día y para diferentes valores de velocidad inducida en el canal ( $b / L=0.0825)$.

La Figura 5.20 muestra una comparación entre la evolución de los datos experimentales medidos para diferentes niveles de velocidad inducida, con los valores predichos obtenidos a través de la ecuación 5.11, a lo largo de un día típico. En ella se aprecia que la correlación 
propuesta sigue la misma tendencia que los datos experimentales, obteniéndose en la mayoría de los casos unas diferencias (en promedio) inferiores al 5\%.

A partir de la correlación de la temperatura del panel, se puede estimar la eficiencia eléctrica, asumiendo la expresión lineal con la temperatura propuesta por Evans et al. [82] que junto las medidas experimentales se deduce la siguiente expresión:

$$
\eta_{\text {panel }}=0.15\left[1-0.006\left(T_{\text {panel }}-25\right)\right]
$$

Sustituyendo la ecuación. 5.11, nos permite obtener una expresión empírica que predice el rendimiento eléctrico de un módulo fotovoltaico en función de las condiciones ambientales (temperatura ambiente y radiación solar), y configuraciones de estudio; la relación de aspecto como variable geométrica y velocidad inducida en el canal como parámetro de ventilación.

$$
\eta_{\text {panel }}=0.15\left[1-0.006\left(T_{a m b}+0.045\left(1+V_{v}\right)^{\left(-6.311 \frac{b}{L}-0.162\right)} G_{\text {pira }}-25\right)\right]
$$

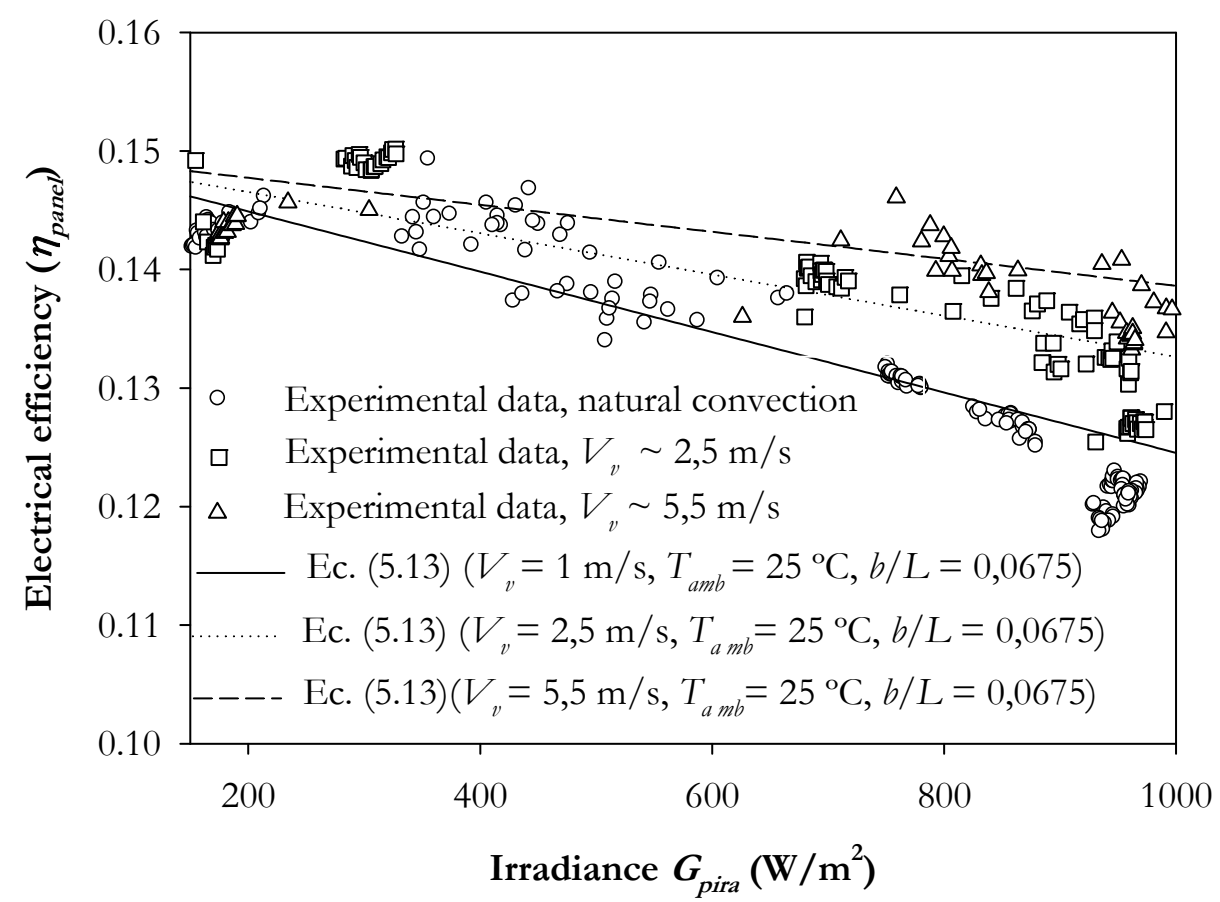

Figura 5.21 Comparación entre los datos experimentales de la eficiencia eléctrica con la correlación propuesta para diferentes valores de velocidad inducida, $b / L=0.0675$ y $T_{a m b}=25^{\circ} \mathrm{C}$ [77]. 


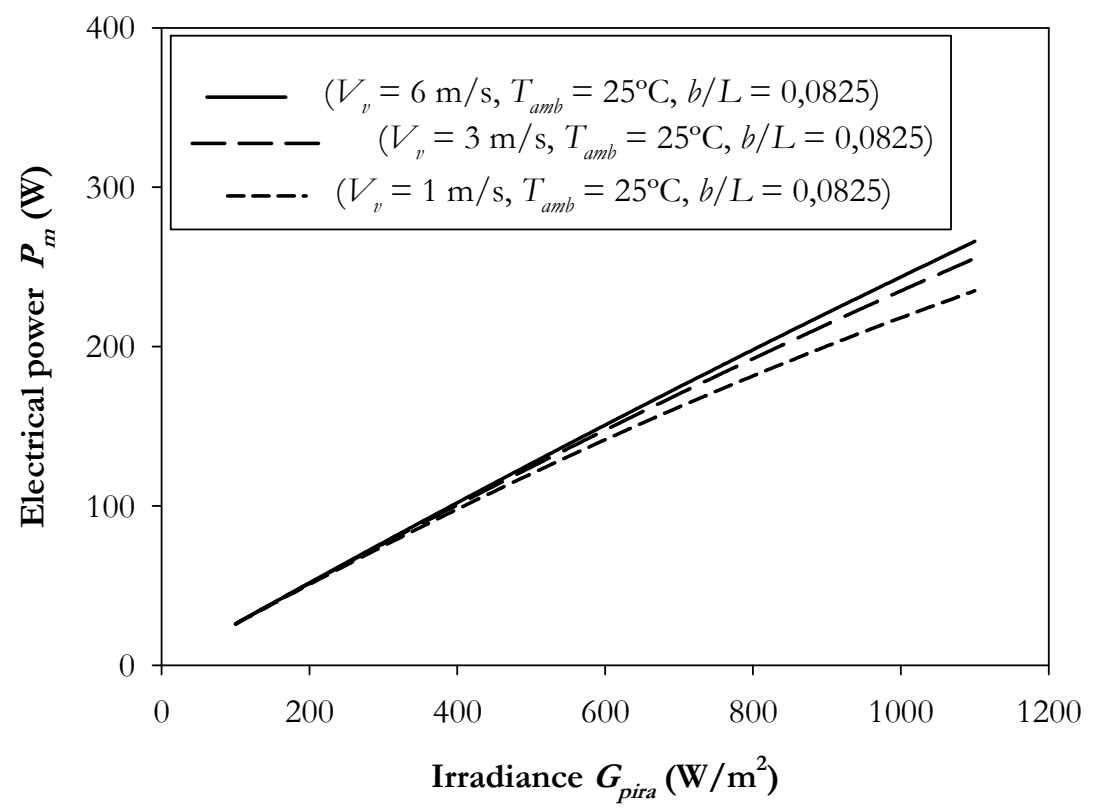

Figura 5.22 Influencia de la velocidad inducida del aire en el canal sobre la potencia pico del panel fotovoltaico en función de la radiación solar, a partir de la correlación propuesta para $b / L=0.0825$ y $T_{a m b}=25^{\circ} \mathrm{C}$.

Se puede apreciar en la Figura 5.21, que las tendencias entre los valores experimentales y los propuestos por la correlación son muy similares. Del mismo modo, la potencia pico del módulo puede ser estimada a partir de la ecuación 5.12 , ya que $P_{m}=\eta_{\text {panel }} \cdot S \cdot G_{\text {pira }}$, obteniéndose un buen ajuste de los valores predichos, tal y como se estudió en [77]. Además se analizó la influencia de la de la velocidad inducida en la potencia (Figura 5.22), obteniéndose un aumento del $19.13 \%$ comparando convección natural $\left(V_{v}=0.5 \mathrm{~m} / \mathrm{s}\right)$ y convección forzada $\left(V_{v}=6 \mathrm{~m} / \mathrm{s}\right)$.

$$
P_{m}=0.15 \cdot S \cdot G_{\text {pira }}\left[1-0.006\left(T_{a m b}+0.045\left(1+V_{v}\right)^{\left(-6.311 \frac{b}{L}-0.162\right)} G_{p i r a}-25\right)\right]
$$

\subsubsection{CONCLUSIONES (CONCLUSIONS)}

Se ha analizado la influencia en la temperatura de funcionamiento de las variables eléctricas de dos paneles fotovoltaicos del mismo modelo y especificaciones técnicas y funcionando en las mismas características constructivas y condiciones ambientales. La diferencia entre ambos reside en que uno de ellos está colocado sobre una cubierta metálica (panel B), existiendo un espacio entre ambas superficies que permite la circulación de aire a su través. Dicha separación, caracterizada por la variable relación de aspecto $(b / L)$, se ha modificado con el fin de estudiar su influencia. El otro panel carece de ninguna superficie inferior, ni canal de aire y se ha considerado como panel de referencia (panel A). El estudio realizado 
compara ambos paneles para tres secciones de circulación de aire, tanto para refrigeración natural como forzada.

Mediante convección natural, el comportamiento del panel fotovoltaico colocado sobre una cubierta metálica difiere al del panel sin ella. Independientemente de la sección del canal de aire, el panel $\mathrm{B}$ alcanza temperaturas hasta $5-10^{\circ} \mathrm{C}$ mayores que las del panel de referencia, $\mathrm{y}$ su rendimiento es $1-1.5 \%$ inferior, en mayor o menor medida dependiendo de la radiación solar y la relación de aspecto testeada. Por consiguiente, la colocación de un panel sobre una cubierta metálica modifica tanto la temperatura de funcionamiento como su producción eléctrica, debido a la transferencia de calor de la superficie metálica al canal y al reducir la refrigeración mediante convección natural por su cara posterior.

Cuando la cubierta metálica está más próxima al módulo, la refrigeración del panel es más limitada y la diferencia de su temperatura con la del panel A es mayor que cuando el panel fotovoltaico se encuentra más separado. Esto indica que la separación existente influye en la temperatura y consecuentemente en las variables eléctricas. Comparando la diferencia de temperatura del panel con el ambiente, para las tres relaciones de aspecto, existen diferencias significativas a partir de radiaciones altas. Para la mayor sección del canal ensayada $(b / L=0.0825)$, el salto de temperaturas es de $5-7^{\circ} \mathrm{C}$ inferior a la medida para la menor sección de aire $(b / L=0.0525)$, observándose mayor diferencia térmica a partir de valores de radiación solar de $600 \mathrm{~W} / \mathrm{m}^{2}$. Esto implica una mayor producción eléctrica, obteniendo un rendimiento alrededor del 0.5-0.8\% superior al aumentar la relación de aspecto, ya que permite una mayor refrigeración del panel. Además se obtienen considerables diferencias en las variables eléctricas, intensidad de cortocircuito, tensión de circuito abierto, consiguiendo un aumento de la potencia de un $7.5 \%$. Sin embargo, para bajos valores de radiación solar y temperatura ambiente, no existen apenas variaciones.

En conclusión, la refrigeración por la cara posterior de un módulo fotovoltaico a través del un canal de aire creado entre éste y una superficie metálica es reducida, comparado con un panel libre de ninguna superficie inferior, implicando mayores temperaturas de funcionamiento y menor eficiencia eléctrica. Además, la separación existente en el canal de aire es una variable influyente en la temperatura de funcionamiento del módulo y sus variables eléctricas, mayormente para altos valores de temperatura ambiente y radiación solar. Un aumento de $6 \mathrm{~cm}$ reduce la temperatura del panel $5-6^{\circ} \mathrm{C}$ y aumenta su rendimiento 0.6-1.3\%.

En segundo lugar, se ha estudiado como afecta la refrigeración forzada, a través del mismo canal de aire en la cara posterior del panel B, en su temperatura de operación y rendimiento, comparándolo con el panel de referencia y para las mismas relaciones de aspecto propuestas en convección natural y en cada una se han fijado tres valores de velocidad forzada $(2,3,4 \mathrm{~m} / \mathrm{s})$. 
Los resultados medidos muestran que el módulo fotovoltaico sobre la cubierta metálica, alcanza menores temperaturas que el panel de referencia y un mayor rendimiento, al impulsar aire por el canal, para las tres secciones de paso de aire y regímenes de funcionamiento del ventilador. Por consiguiente, existe una mejora en el comportamiento del panel en estas condiciones respecto a otro sin refrigeración inducida. Cabe resaltar que para la menor relación de aspecto y velocidad inducida, la temperatura y rendimiento del panel es similar a los valores del panel de referencia, así que esta configuración no supone gran mejoría. Sin embargo, para la menor sección de aire a mayor velocidad, existen diferencias con el panel de referencia. Las menores temperaturas de panel obtenidas corresponden para la mayor relación de aspecto del canal y mayor velocidad forzada, ya que se aumenta el caudal de aire de refrigeración, lo que conlleva un aumento de la trasferencia de calor existente en el canal.

La velocidad forzada del aire en el canal influye en las variables de operación del módulo. Los diferentes ensayos realizados concluyen que para la mayor velocidad inducida se consigue reducir $5-7^{\circ} \mathrm{C}$ la temperatura del panel y aumentar el rendimiento (0.5-1\%) en cada sección de aire, respecto el menor valor de velocidad forzada. Sin embargo, apenas existen diferencias significativas en los resultados obtenidos para la velocidad inducida de $3 \mathrm{~m} / \mathrm{s}$.

Como se concluyó en convección natural, la relación de aspecto influye en la temperatura del panel, así como en sus variables eléctricas. Esto también sucede al inducir aire en el canal, pero se han obtenido bastante similitud en los valores correspondientes a las dos relaciones de aspecto de mayor valor (0.0675 y 0.0825), en ambas velocidades forzadas, por consiguiente el pequeño incremento de la separación del canal no supone un gran avance.

La refrigeración del panel B mediante convección forzada, supone una mejora del rendimiento eléctrico, comparado con los resultados en convección natural, al aumentar la transferencia de calor en el canal de aire. La configuración correspondiente a la relación de aspecto $b / L=0.0675$ es la más idónea, obteniéndose un mejor comportamiento en el panel. No obstante, la refrigeración inducida con el uso de un ventilador, sería una opción adecuada si la mejora en la producción eléctrica fuese mayor al consumo eléctrico que supone. En este trabajo no se ha medido la potencia consumida por el ventilador para cada régimen de funcionamiento, sería un aspecto a tener en cuenta y valorar en trabajos futuros.

Con los resultados obtenidos para las diferentes configuraciones, tanto en convección natural y forzada, se ha realizado un análisis comparativo, considerando las variables influyentes en las variables eléctricas del módulo fotovoltaico tales como la relación de aspecto y velocidad en el canal de aire. Además las medidas experimentales se han comparando con modelos propuestos por otros autores, obteniéndose tendencias muy similares en convección natural y forzada. 
Comparando los resultados según la velocidad en el canal, los resultados muestran que para una relación de aspecto dada, la temperatura que alcanza el panel, respecto al ambiente, disminuye en torno un $10-16^{\circ} \mathrm{C}$ mediante refrigeración inducida frente a la convección natural, siendo la diferencia mayor al aumentar la velocidad inducida. Esta diferencia en el comportamiento se traduce a obtener un aumento del 3-5\% de la potencia eléctrica del panel cuando el aire es inducido en contra de la convección natural, aumentando su valor cuando la velocidad forzada es mayor. Las diferencias entre los dos casos de convección forzada son menores, aumentando la potencia un $2.4 \%$ y reduciendo $7^{\circ} \mathrm{C}$ la temperatura de funcionamiento para el mayor valor de la velocidad inducida ensayada.

La sección del canal de aire de refrigeración es otra variable que interviene en la ventilación, el análisis comparativo revela que para una misma velocidad (bien sea convección natural o forzada), la producción eléctrica aumenta un 2-2.5\% para la mayor separación en el canal de aire que permite una mayor refrigeración de éste, siendo su temperatura de $5-7^{\circ} \mathrm{C}$ menor. Sin embargo, entre las relaciones de aspecto 0.0675 y 0.0825 existen menores diferencias significativas a las obtenidas entre la mayor y menor sección de aire. Se ha obtenido la relación negativa de la temperatura del módulo en su rendimiento, para las relaciones de aspecto más dispares, tanto en convección natural como forzada. Para ambas secciones, el panel alcanza menores temperaturas máximas para la mayor velocidad inducida, resultando obtener mejor rendimiento que el resto de casos, los cuales llegan a alcanzar mayores temperaturas máximas de panel, obteniendo menores rendimientos. Las mayores diferencias entre las configuraciones se obtienen cuando su temperatura de funcionamiento aumenta, y su rendimiento disminuye bruscamente. Podemos concluir que, la mayor sección de aire en el canal presenta valores mínimos del rendimiento mayores que para una sección menor, tanto en convección natural e inducida, obteniéndose una mejoría de la eficiencia del módulo en ambos casos. Habría que analizar el gasto eléctrico en convección inducida y compararlo con la mejora en la producción del panel para confirmar su idoneidad.

Finalmente, para globalizar los resultados para las diferentes configuraciones, se ha desarrollado un modelo experimental para determinar la influencia de la relación de aspecto y de la ventilación inducida bajo el panel en su temperatura de funcionamiento (y por consiguiente en la eficiencia eléctrica del módulo PV) al estar integrado sobre una cubierta, para varios valores de la radiación solar incidente, temperatura ambiente, relaciones de aspecto, y condiciones de velocidad inducida. Se utiliza el coeficiente de Ross, $k$, para caracterizar el comportamiento de cada configuración estudiada.

Con respecto a la influencia de la relación de aspecto, cuanto mayor es, más bajos son los valores de $k$ por lo tanto menor es la temperatura del módulo. Se considera un valor crítico de 0.11 para la relación de aspecto la cual permite minimizar el sobrecalentamiento de los módulos fotovoltaicos, para los casos en los que la ventilación dentro del canal se produce por convección natural. 
En cuanto a la influencia de la velocidad inducida, se aprecia que podemos obtener una misma refrigeración del módulo fotovoltaico (mismo valor de $k$ ); tanto para los casos de mayores velocidades inducidas y menor relación de aspecto, como para convección natural y mayor relación de aspecto (Figura 5.19). Considerando una relación de aspecto constante, el valor de la velocidad inducida dentro del canal afecta fuertemente la refrigeración del módulo.

Tras un análisis estadístico caracterizando las variables influyentes, se han propuesto correlaciones semiempíricas para el coeficiente de Ross y así obtener las correspondientes a la temperatura del módulo, eficiencia eléctrica y potencia, obteniéndose un buen ajuste con las medidas experimentales. Estas correlaciones nos permiten predecir el comportamiento térmico del módulo PV para diferentes configuraciones de integración fotovoltaica sobre cubiertas y para diversas condiciones ambientales. Además se obtuvo un aumento del $19.13 \%$ en la potencia al variar la velocidad inducida del canal desde $V_{v}=0.5$ (ventilación natural) a $V_{v}=6 \mathrm{~m} / \mathrm{s}$ (ventilación forzada).

\section{CONCLUSIONS}

This section is focused on the influence of the operation temperature of two similar photovoltaic panels from the same model and technical characteristics, as well as operating under the same structural characteristics and environmental conditions. The main difference between both modules lies in that one of them was placed on a steel plate (panel B), existing a space between both surfaces what allowed the air circulation through it. This air spacing, characterised by the variable aspect ratio $(b / L)$, had been modified in order to study its influence. The other module lacked any surface or plate underneath it and it was considered as a reference panel (panel A). The study carried out compares both panels, for three sections of the air cooling channel by natural and forced convection.

Firstly, the comparison by natural convection showed that the behaviour of the panel placed on a steel surface differed to the reference panel. Independently of the air spacing of the channel, panel $\mathrm{B}$ reached temperatures $5-10^{\circ} \mathrm{C}$ higher than panel $\mathrm{A}$ and its performance was 1-1.5\% lower, with the exent of the variation depending on the solar radiation and the aspect ratio tested. Consequently, the positioning of a photovoltaic panel on a steel roof modified the operating temperature and its electrical production, due to the heat transfer from the steel plate toward the air channel, and reducing the air cooling by natural convection of the module at its back face.

In addition, when the air spacing was reduced, the air cooling was more restricted and its temperature difference with panel $A$ is quite higher than the cases in which panel $B$ and steel plate were more separated. This fact indicates that the air spacing has influence on the 
temperature, and as a consequence, on the electrical variables. Comparing the temperature gap between the panel and ambient, for the three aspect ratios, there were significant differences at high solar radiations. The case of higher aspect ratio $(b / L=0.0825)$, the temperature gap is $5-7^{\circ} \mathrm{C}$ lower than the smallest air section $(b / L=0.0525)$, showing a higher thermal difference from radiation values of $600 \mathrm{~W} / \mathrm{m}^{2}$. Therefore, the electrical production was better, obtaining an efficiency of $0.5-0.8 \%$ higher with the increase of the aspect ratio which allowed for a better panel air cooling. Hence, under these conditions the electrical variables such as the de open circuit voltage, short-circuit current had many differences when the air channel section increased, experiencing an electrical power increase of $7.5 \%$. However, there were minimal differences at lower values of solar radiation and ambient temperature.

In conclusion, the air cooling of a photovoltaic panel through a channel created underneath it with a steel plate is reduced in comparison to a module without any surface underneath, implying higher operating temperatures and lower electrical efficiency. Therefore, the air spacing is an influential variable on the panel temperature and its electrical variables at high values of ambient temperature and solar radiation. An increase of $6 \mathrm{~cm}$ (in the air spacing of the channel) reduces the module temperature $5-6^{\circ} \mathrm{C}$ and improves the performance 0.6 $1.3 \%$.

Secondly, the effect of air cooling by forced convection was studied through the same air channel in its back face, on the operating temperature and performance, comparing it with the reference panel, for the same aspect ratios proposed in natural convection, and at three different induced velocities $(2,3,4 \mathrm{~m} / \mathrm{s})$ for each one.

The experimental results showed that the photovoltaic module placed on a steel plate reached fewer temperatures than the reference panel and a better efficiency, when the air is induced in the channel by a fan, for the different air spacing sections and fan operation regimes. As a result, an improvement of the panel functioning existed, respect to other panel which was not cooling by induced air. It should be noted that the case with smallest aspect ratio and induced velocity presented a similar panel temperature and performance to the values of the reference panel, so this configuration did not mean a great improvement. However, there were differences for the smallest air section and higher induced velocity with panel $A$. The lowest operating temperatures matched the configuration with the highest aspect ratio and induced velocity due to the air flow increased and it entailed an increase of the heat transfer in the air channel.

The induced velocity in the channel has influence on electrical operating variables of the photovoltaic panels. The different experimental tests concluded that a higher induced velocity reduces $5-7^{\circ} \mathrm{C}$ the module temperature and increases the efficiency $(0.5-1 \%)$ for each air channel section compared to the lower value of induced velocity. 
As it was concluded in natural convection, the aspect ratio influenced the operating temperature, as well as its electrical variables. This fact also happened to induce air through the channel, but similarity was obtained in the values for the two higher aspect ratios (0.0675 and 0.0825), thus the small increase of the channel separation is not a breakthrough.

The air cooling by forced convection of panel B, improves the electrical performance compared to the results in natural convection, because of an increase of heat transfer in the air channel. The corresponding case with aspect ratio $b / L=0.0675$ is the ideal configuration, obtaining better electrical functioning. Nevertheless, the induced air cooling using a fan would be a suitable option if the improvement of electricity production by modules was higher than the electricity consumption in which fan usage was supposed. The consumed power by the fan has not been measured in this study and this would be an aspect to consider in future studies.

A comparative analysis with all results for the different configurations tested in natural and forced convection were made, considering the influential variables in the electrical functioning of the photovoltaic panels. These included: the aspect ratio and the velocity of the air in the channel. Furthermore, experimental measurements were compared with models proposed by other authors, resulting very similar trends at natural and forced convection.

Comparing the experimental data for a given aspect ratio, the results showed that the temperature gap between the panel and the ambience decreases by around $10-16^{\circ} \mathrm{C}$ when the panel experiences air cooling by forced convection in the face of natural convection, this being the greatest difference with an increase of the air velocity. This difference in the operation of the module means an increase of 3-5\% of the electrical power panel when air is induced contrary to natural convection, increasing its value at higher forced velocity. The differences between the two cases of forced convection are less, increasing the power around $2.4 \%$ and reducing the operating temperature $7^{\circ} \mathrm{C}$ for the highest value of induced velocity tested.

The air channel section is other variable studied, and thus, for a given air velocity (either natural or forced convection) the comparative analysis shows that the electrical production increases $2-2.5 \%$ for the highest air spacing, allowing better cooling effect, and an operating temperature of $5-7^{\circ} \mathrm{C}$ lower. However, there were hardly any differences between the two higher aspect ratios, the major dissimilarities were obtained between the highest and smallest air section. The comparative analysis also includes the negative correlation of the efficiency versus the panel temperature for the most different aspect ratios. This is both in natural and forced convection. For both sections, the module reaches lower maximum temperatures at the highest induced velocity which results in a better efficiency than the 
other cases. These other cases reach higher maximum temperatures and lower efficiencies. The significant differences between the configurations were obtained when the operating temperature increased and performance decreased sharply. In conclusion, the widest section of air in the channel had higher minimum values of performance than the configuration with lower section at natural and induced convection, yielding an improvement of module efficiency in both cases. It would be necessary to analyze the electrical spending in induced convection and compare it with the improvement of panel production to confirm its suitability.

Finally, in order to globalise the results at different configurations, an experimental model to determine the influence of the channel aspect ratio and the forced ventilation on the panel temperature (and consequently on the electric efficiency of the PV module) in a roof integrated configuration, for various values of the incident solar radiation, ambient temperatures, aspect ratios, and forced ventilation conditions is developed. The Ross coefficient, $k$, is employed to characterize the behavior of each configuration studied.

With respect to the influence of the aspect ratio, the higher it is, the lower the values of $k$ and the lower the temperature of the module. A critical channel aspect ratio of 0.11 can be considered to minimize overheating of PV devices, for the cases in which ventilation within the channel is produced by natural convection. Regarding the influence of the induced velocity, if values higher than those corresponding to the natural convection ventilation case are considered, lower values of the aspect ratio may be used for obtaining the same cooling in the PV module (Figura 5.19). For a constant aspect ratio, the value of the induced velocity within the channel affects strongly the cooling of the module.

Semi empirical correlations for the Ross coefficient, module temperature, electrical efficiency and power output are proposed with a good agreement with respect to the experimental measurements. These correlations may predict the thermal behavior of the PV module in BIPV configurations, for various ambient conditions. Similar evolutions with the time were obtained between the measurements and the experimental correlation proposed. An increase in the power output over $19 \%$ from the natural ventilation case $\left(V_{v}=0.5 \mathrm{~m} / \mathrm{s}\right)$ to the case of $V_{v}=6 \mathrm{~m} / \mathrm{s}$ was also observed. 


\subsection{COMPORTAMIENTO DEL PANEL FOTOVOLTAICO COLOCADO SOBRE UNA CUBIERTA DE UN INVERNADERO}

En este apartado se analiza el comportamiento eléctrico de los módulos fotovoltaicos emplazados en la cubierta de un invernadero. Los resultados que se presentan se han obtenido de la instalación experimental construida, cuyo diseño está basado en la instalación agroenérgetica Coronil IV. Con tal fin, el invernadero experimental se ha diseñado de forma que pueda modificarse el espacio existente entre la parte posterior de los paneles y la cubierta del invernadero, lo que nos ha permitido ensayar cuatro configuraciones de refrigeración con aire mediante convección natural, tal y como se describió en la 3.2.2.

Las configuraciones estudiadas se diferencian entre sí en uno de los siguientes aspectos, o bien en la separación existente entre los módulos y la cubierta del invernadero en la entrada del aire o en el tipo de material utilizado en la cubierta del invernadero. De este modo dos configuraciones presentan una pequeña sección de entrada de aire similar, diferenciándose en el material constituyente de la cubierta del invernadero, plástico o material aislante. Las otras dos configuraciones estudiadas se diferencian entre sí en el material de la cubierta y presentan una mayor sección de entrada de aire. En el estudio realizado, se han designado de la siguiente manera;

- Configuración 1: Para la menor separación entre los paneles y la cubierta del invernadero, siendo de $15 \mathrm{~cm}$, con la cubierta del invernadero de plástico.

- Configuración 2: Con una separación similar a la anterior $(18 \mathrm{~cm})$, colocando un material aislante de $10 \mathrm{~cm}$ de espesor, en la cubierta del invernadero.

- Configuración 3: La sección de entrada de aire se ha aumentado, siendo la separación entre módulo y cubierta de plástico de $50 \mathrm{~cm}$.

- Configuración 4: La cubierta del invernadero es de material aislante y la separación entre ésta y los paneles es de $45 \mathrm{~cm}$.

Los resultados experimentales que se presentan a continuación, han sido recogidos durante los días correspondientes al periodo comprendido entre 10-05-2011 y 20-08-2013, siguiendo la metodología descrita. Una vez tratadas el conjunto de las variables medidas en cada configuración, para realizar un análisis más adecuado, se ha procedido a un filtrado de datos, eliminando los correspondientes a días nublados, poco soleados y con menor temperatura ambiente, con el fin de tener valores de días en similares condiciones ambientales de temperatura y radiación solar.

El estudio y análisis llevado a cabo ha sido como el presentado por Lorenz Fonfria S. et. Al [83]. En primer lugar se muestra los efectos del aumento de la temperatura del panel en los principales parámetros eléctricos del panel, para cada configuración y unas condiciones ambientales similares, comparándolos con los valores teóricos. A continuación, se analiza la 
influencia de la velocidad del viento tanto en la temperatura del panel como en su rendimiento eléctrico. Por último se incluye el análisis de la transferencia de calor entre los paneles fotovoltaicos y la cubierta con el fluido caloportador (aire), comparando la potencia calorífica absorbida por el aire para cada configuración.

El estudio comparativo del comportamiento del panel fotovoltaico sobre la cubierta del invernadero para las diferentes configuraciones ensayadas se ha llevado a cabo con las variables eléctricas recogidas de los dos paneles inferiores (entrada del canal de aire), conectados en serie entre sí. Por consiguiente, los valores de temperatura de panel a los que se hacen referencia en los resultados expuestos, corresponde al valor medio entre ambos paneles.

\subsubsection{INFLUENCIA DE LA TEMPERATURA DEL PANEL EN LAS VARIABLES ELÉCTRICAS}

Con el fin de estudiar el comportamiento eléctrico del panel fotovoltaico cuando está emplazado sobre la cubierta de un invernadero, se han analizado los coeficientes de temperatura de las principales variables eléctricas de los paneles (tensión de circuito abierto, intensidad de cortocircuito y rendimiento), mostrando su dependencia con la temperatura.

Como se mencionó en el apartado anterior, la temperatura que alcanza el panel depende fuertemente de las variables ambientales, temperatura y radiación solar, pero también se ve afectada de la velocidad del aire como se verá más adelante. Por consiguiente, para comparar los coeficientes de temperatura para las diferentes configuraciones, se han filtrado los datos para unas condiciones similares, siendo: radiación solar $850-900 \mathrm{~W} / \mathrm{m}^{2}$, temperatura ambiente $20-30 \circ \mathrm{C}$ y velocidad del viento $0-3 \mathrm{~m} / \mathrm{s}$. En todos los casos, los datos presentan un buen ajuste. 
a)

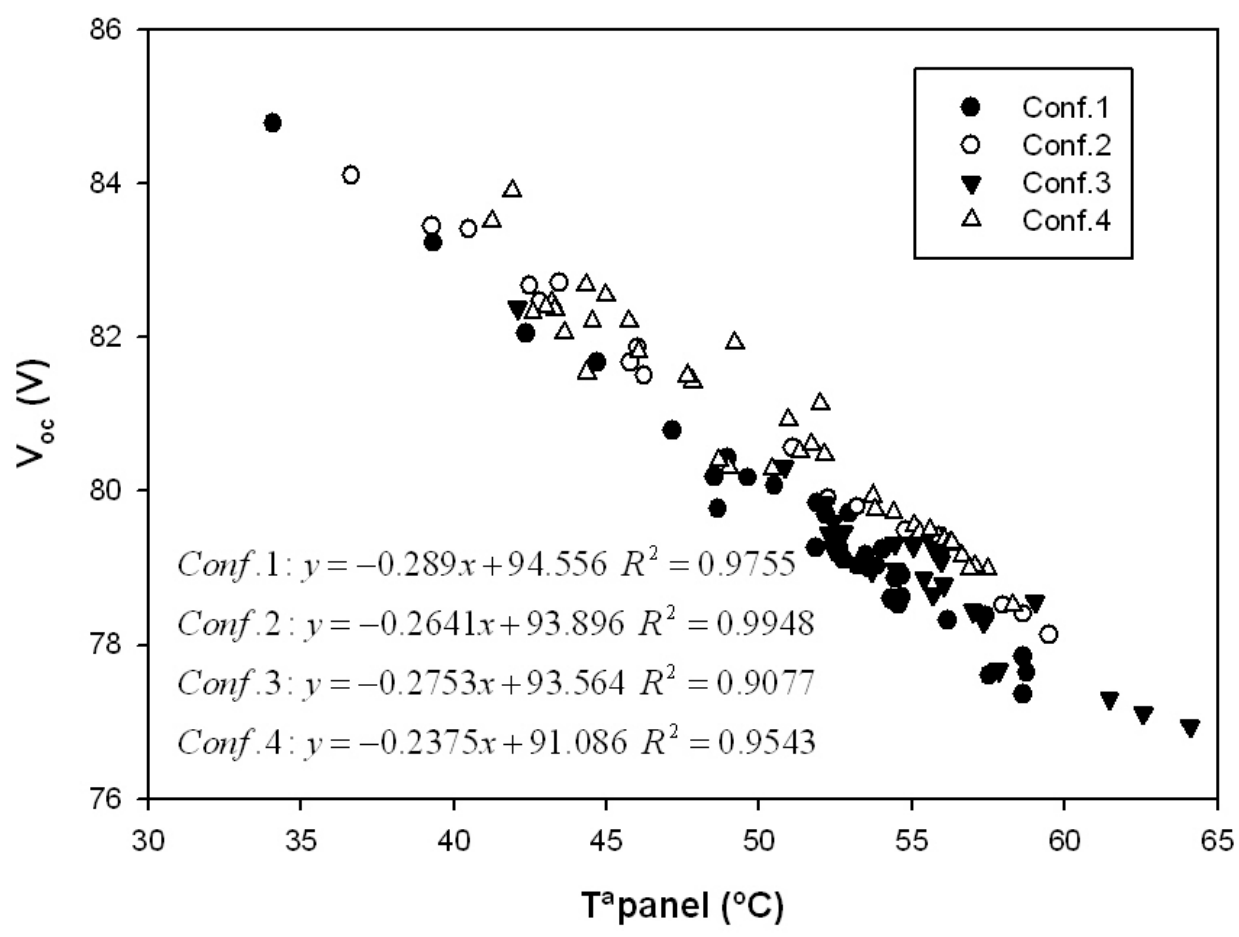

b)

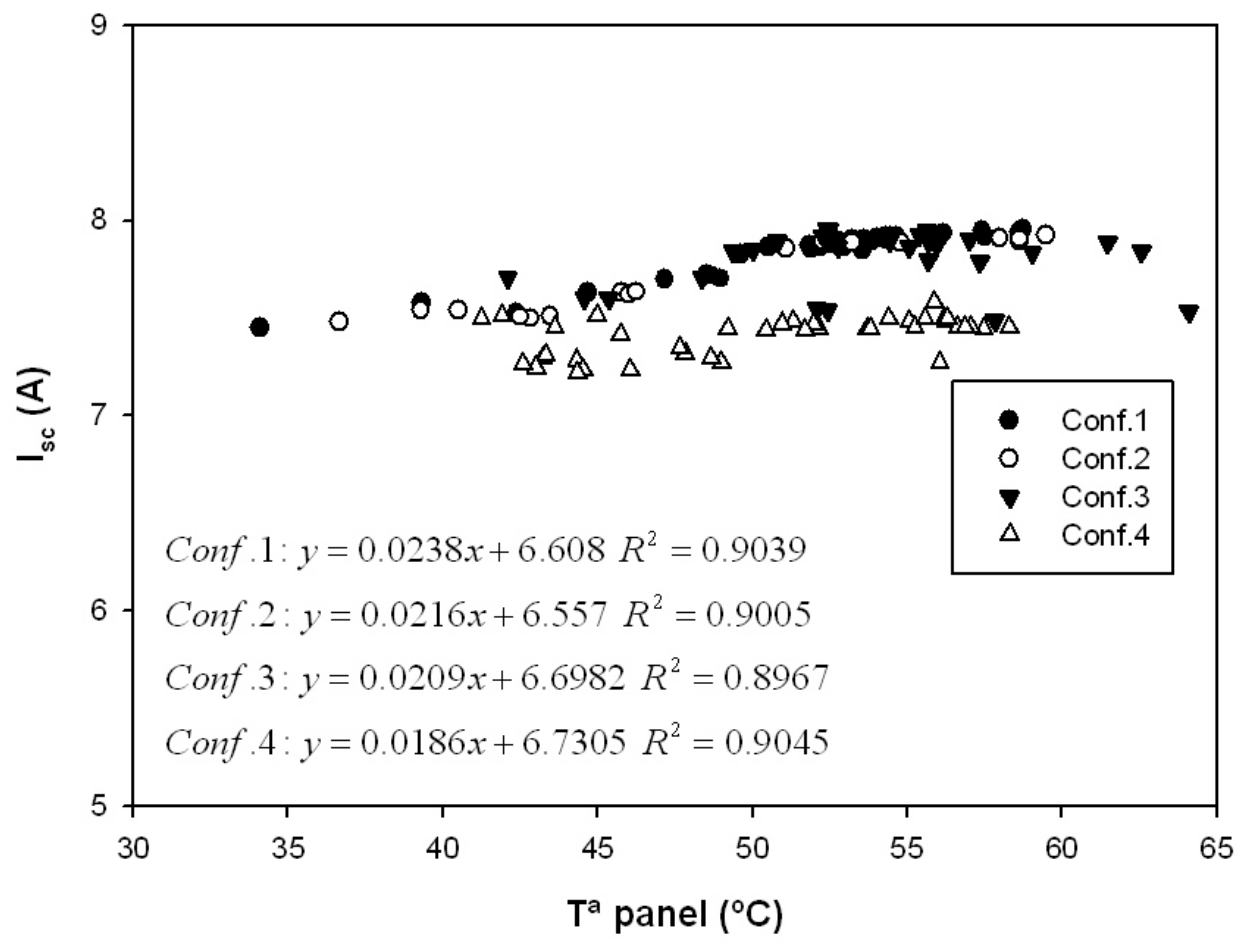


c)

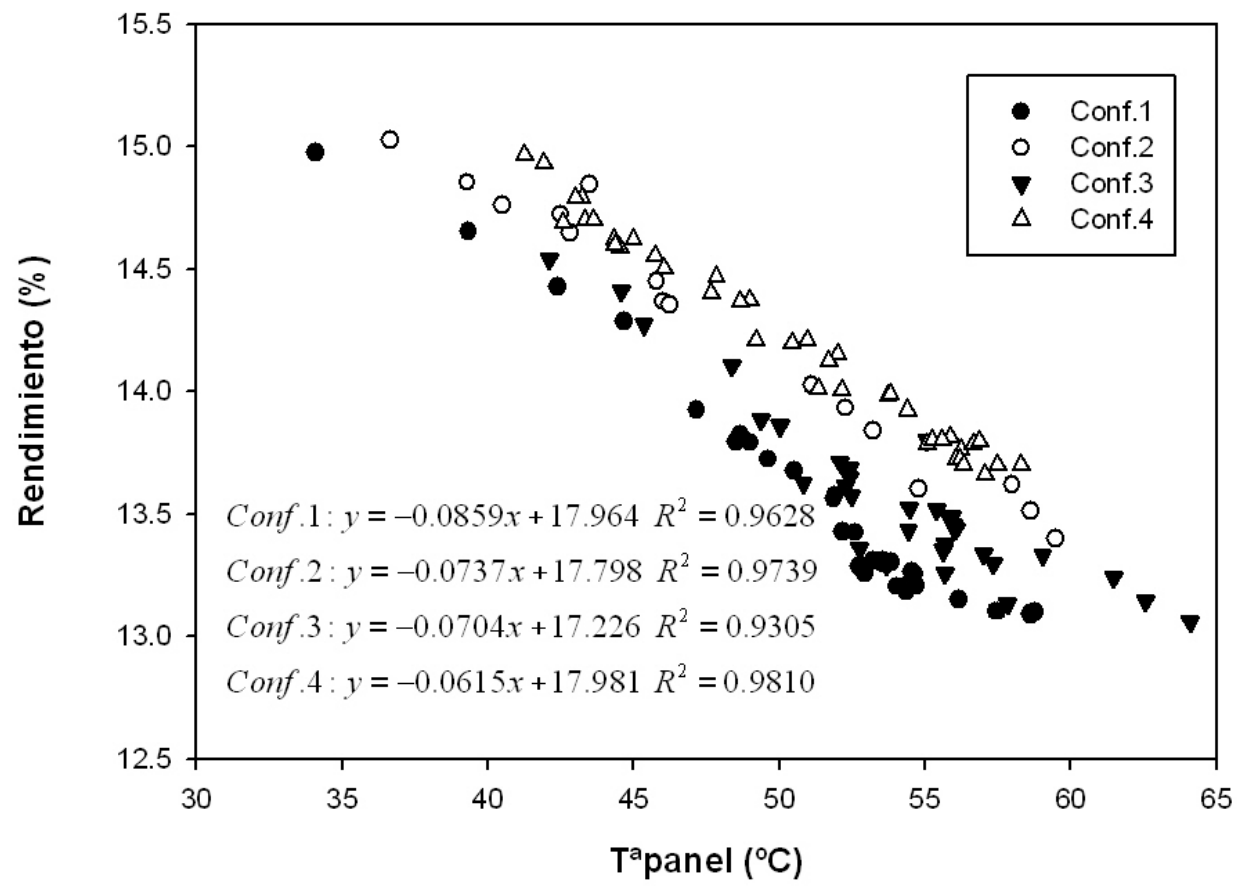

Figura 5.23 Dependencia con la temperatura de: a) la tensión de circuito abierto (Voc), b) la intensidad de cortocircuito (Isc) y c) el rendimiento.

Se observa que la tensión de circuito abierto disminuye con la temperatura del panel de forma lineal y que su evolución es similar para las diferentes configuraciones, existiendo pequeña diferencia en el valor del coeficiente de temperatura. La tensión de circuito abierto alcanzada en la configuración 4, para las diferentes temperaturas del panel, es mayor que los valores medidos en las otras, siendo la Voc de la configuración 1 la de menor valor.

La intensidad de cortocircuito aumenta ligeramente con la temperatura, en las cuatro configuraciones presenta un coeficiente de temperatura (pendiente) muy pequeño, ya que en esas condiciones apenas hay variación. Al igual que la tensión, existen diferencias en los valores medidos entre las configuraciones. Cuando la sección de entrada de aire es menor y la cubierta es de plástico (Conf.1), la intensidad de cortocircuito es mayor, mientras que para una mayor sección y usando aislante (Conf.4) la intensidad alcanzada es menor.

Por último, el rendimiento de la instalación aumenta a medida que la temperatura media de los paneles es menor y los mayores valores obtenidos corresponden a la configuración 4, en la que los paneles alcanzan una temperatura menor ya que no existe transferencia de calor entre el interior del invernadero y los paneles y además existe un mayor caudal de aire de refrigeración.

Siguiendo la misma metodología explicada en el apartado 5.1, descrita por Eduardo Lorenzo et al. [64], se ha comparado los parámetros eléctricos de las variables medidas en la instalación con los que se deberían de obtener según la curva del fabricante, bajo las mismas condiciones. Las correlaciones resultantes son: 


$$
\begin{gathered}
V_{\text {oc }}(\text { Catalogue })=-0.30191 T_{\text {panel }}+95.808 \\
I_{s c}(\text { Catalogue })=0.003135 T_{\text {panel }}+6.92618 \\
\eta_{(\text {Catalogue })}=-0.0072 T_{\text {panel }}+16.9352
\end{gathered}
$$

Se observa que los coeficientes de temperatura, que indican la tasa de variación respecto la temperatura, se mantienen similares a los obtenidos experimentalmente, diferenciándose en el término independiente.

\subsubsection{INFLUENCIA DE LA VELOCIDAD DEL VIENTO}

Se ha estudiado como afecta la velocidad del viento en la temperatura de trabajo del panel (Figura 5.24) y en el rendimiento (Figura 5.25), acotando los valores de la temperatura ambiente entre $20-30^{\circ} \mathrm{C}$ y para irradiancias mayores a $300 \mathrm{~W} / \mathrm{m}^{2}$. Para ello se han representado las medidas para dos rangos de velocidades de viento, bajas velocidades de viento $(0-2 \mathrm{~m} / \mathrm{s})$ y velocidades mayores $(8-11 \mathrm{~m} / \mathrm{s})$. Se han considerado velocidades de viento extremas para poder visualizar mejor la influencia de este parámetro.

En los resultados obtenidos, se aprecia dispersión en las medidas, debido a que todos los datos no se encuentran exactamente en las mismas condiciones ambientales, lo cual existe influencia de diversas variables. Acotando más el rango de los valores ambientales medidos, un filtrado más preciso, no se obtenían suficientes valores para observar una clara influencia en la velocidad del viento, por ello finalmente se cogieron los rangos mencionados.

Independientemente de la configuración, se observa que para mayores velocidades de viento, el salto de temperaturas es menor $\left(2-7^{\circ} \mathrm{C}\right)$, para un valor de radiación solar dado. Dado que la temperatura ambiente está acotada $\left(20-30^{\circ} \mathrm{C}\right)$, esto significa que la temperatura media del panel disminuye, es decir, los paneles se refrigeran en mayor medida cuando la velocidad del viento es mayor. 

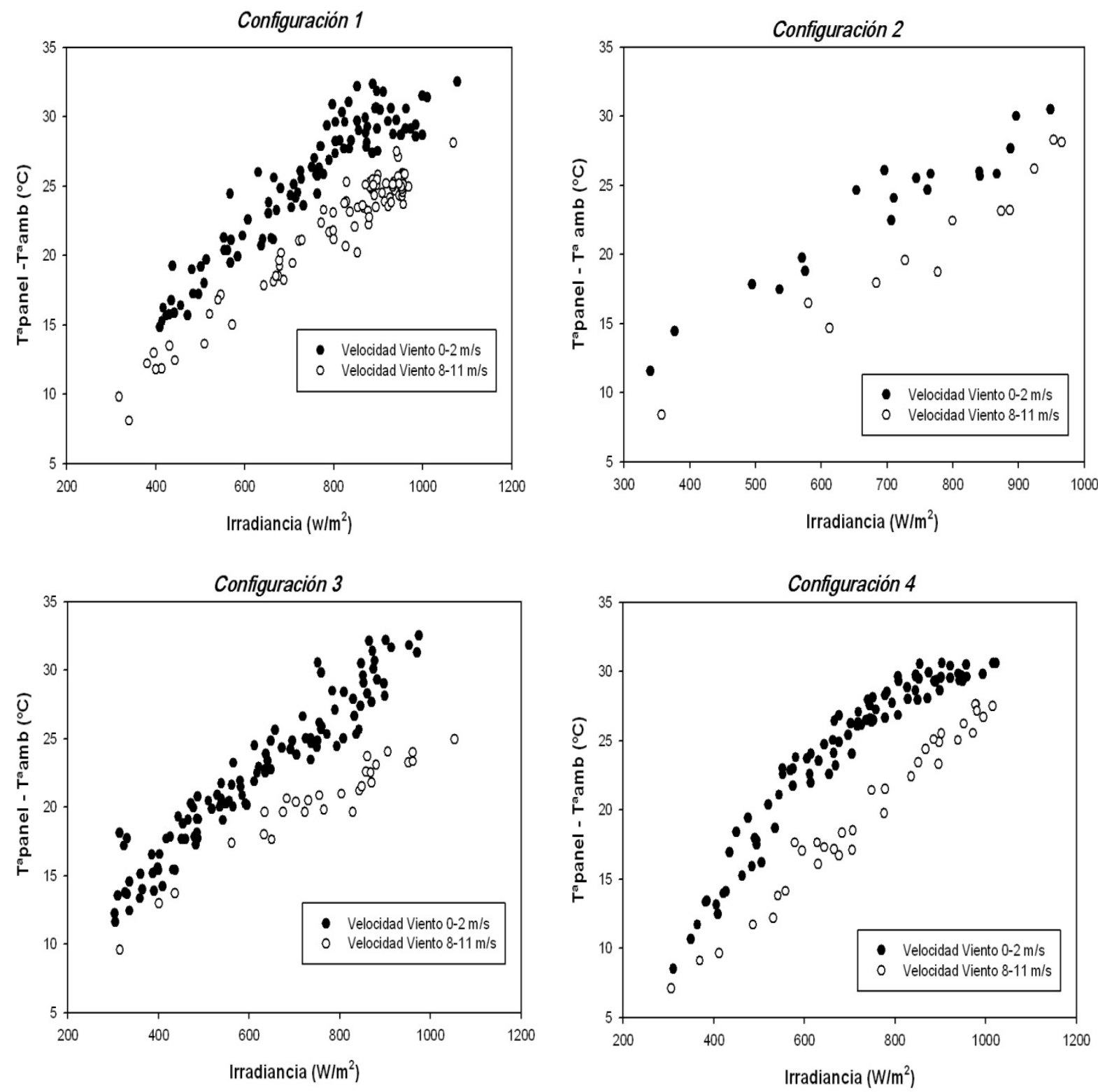

Figura 5.24 Influencia de la velocidad del viento en el salto de temperatura del panel respecto la ambiente en función de la radiación solar, para las diferentes configuraciones de estudio.

Comparando las configuraciones con similar sección de entrada de aire, no se aprecian grandes diferencias en cuanto a las temperaturas. Sin embargo, se observa que los valores máximos de temperatura alcanzados se obtienen para las configuraciones 1 y 3 , es decir, cuando la cubierta del invernadero es de plástico, mientras que al estar el aislante (configuración 2 y 4), el mayor valor del salto de temperatura del panel respecto la temperatura ambiente, es menor. Esto se debe a la influencia térmica del interior del invernadero, que al estar el plástico permite una mayor transferencia de calor al aire en el canal.

Consecuentemente, el rendimiento de los paneles también está influenciado por la velocidad del viento como se muestra a continuación. Para un valor de radiación solar dado, 
cuando los valores de velocidades de viento son bajos, el rendimiento del panel es menor comparado con los de mayor velocidad de viento, dado que el panel se encuentra a mayor temperatura como hemos visto anteriormente, sea cual sea la configuración ensayada.
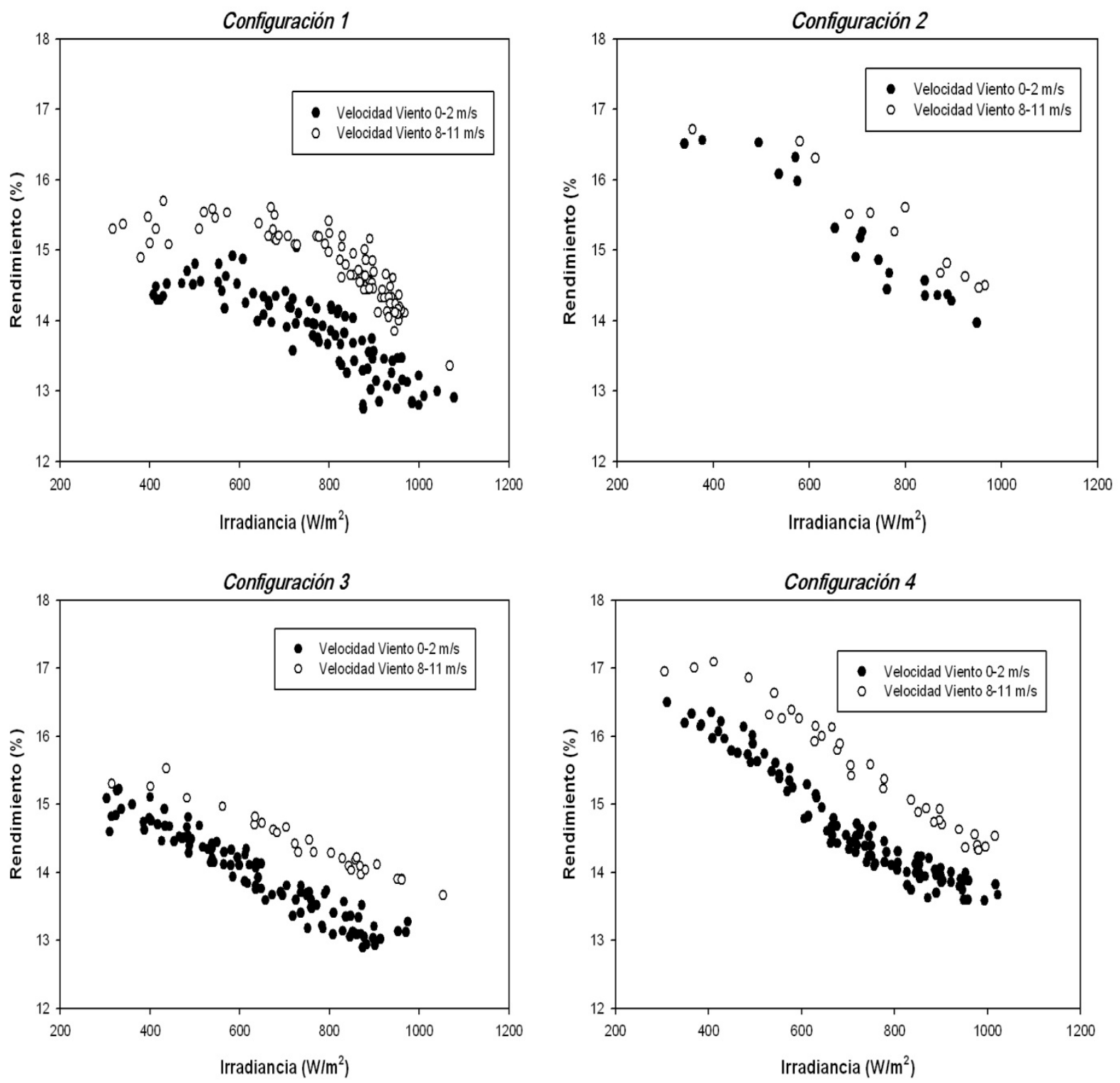

Figura 5.25 Influencia de la velocidad del viento en el rendimiento del panel en función de la radiación solar, para las diferentes configuraciones de estudio.

Comparando el comportamiento eléctrico del panel según su configuración, los resultados muestran que los mayores valores de eficiencia se obtienen para las configuraciones en las que se utiliza el material aislante (configuraciones 2 y 4), siendo la configuración 4, con mayor sección de entrada, la que registra los valores máximos. Los paneles en las configuraciones 1 y 3 , que se encuentran a mayor temperatura, presentan menores valores de su eficiencia eléctrica, inexistiendo apenas diferencia entre ellas. 
Por consiguiente la velocidad del viento es una variable que influye considerablemente en el comportamiento del panel, por esta razón en la sección anterior se analizó la dependencia de las variables eléctricas con la temperatura, para valores bajos de velocidad del viento.

\subsubsection{TRANSFERENCIA DE CALOR EN EL CANAL DE AIRE DE REFRIGERACIÓN}

Los resultado de la Figura 5.24 muestran que la colocación de un material aislante en la cubierta del invernadero, implica una mejora en el rendimiento, dado que la temperatura que alcanza el módulo es menor que cuando el material de la cubierta es plástico. Esto induce a que el material aislante impide parcialmente la transferencia de calor del interior del invernadero al aire que circula por el canal, mientras que su ausencia la permite en mayor medida, lo cual influye en la temperatura y rendimiento del panel.

Fijando las mismas condiciones te temperatura, radiación solar y velocidad de viento que en la sección 5.3.1, se ha representado el salto de temperatura del panel respecto a la superficie inferior (plástico o aislante), para las cuatro configuraciones de estudio (Figura 5.26). Comparando las configuraciones con el mismo material, se aprecia una mayor diferencia de temperatura para la mayor sección de temperatura, como consecuencia de una mayor refrigeración del panel al aumentar el caudal de aire.

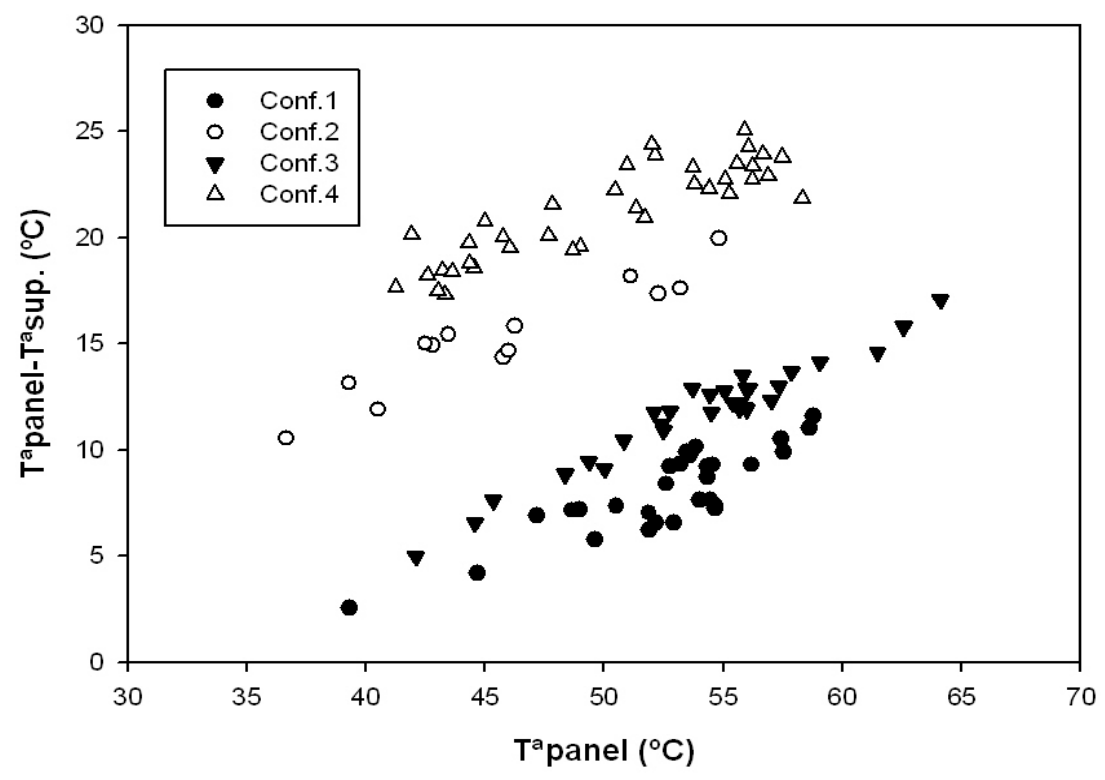

Figura 5.26 Diferencia de temperatura del panel respecto a la de la superficie de la cubierta del invernadero para las cuatro configuraciones estudiadas.

Los resultados obtenidos también muestran que para una misma temperatura alcanzada por el panel, su diferencia respecto a la de la superficie inferior es mayor cuando el material de la cubierta es el aislante y bastante inferior cuando es plástico. El plástico permite transferir 
el calor a través del aire, el cual también se transfiere al módulo y por ello su temperatura es similar a la de la superficie inferior. Sin embargo, la temperatura del panel difiere bastante a la de la superficie aislante, debido a que la transferencia de calor es menor, como se estudiará a continuación.

El propósito de esta sección es caracterizar el comportamiento del aire en el canal, estudiando la transferencia de calor existente, para las diferentes configuraciones. El problema de transmisión de calor que tiene lugar en el canal de aire, existente entre la cara posterior de los módulos fotovoltaicos y la cubierta del invernadero, bien sea de plástico o aislante, será principalmente convectivo. Si se aplica un volumen de control a la zona de estudio en el canal, la potencia calorífica absorbida por el aire circulante tendrá la expresión:

$$
\dot{Q} \text { panel }+\dot{Q} i n v=\Delta \dot{H} \text { aire }=\dot{m}_{a} \cdot C p \cdot\left(T_{\text {aire salida }}-T_{\text {aire entrada }}\right)
$$

Siendo:

$$
\begin{array}{r}
\dot{m}_{a}=V_{v} \cdot S_{\text {canal }} \cdot \rho_{\text {aire }} \\
\rho_{\text {aire }}=\frac{P_{\text {atm }}}{R_{g(\text { aire })} \cdot T_{\text {media aire }}}
\end{array}
$$

Donde: $C_{\text {paire }}=1.012 \mathrm{~kJ} / \mathrm{kg}^{\circ} \mathrm{C}, \quad R_{\text {g(aire) }}=287 \mathrm{~m}^{2} / \mathrm{s}^{2} \mathrm{~K}, \quad P_{\text {atm }}=101325 \mathrm{~Pa}$. Se tienen los valores experimentales de la velocidad del aire en el canal $\left(V_{v}\right)$ y el salto de temperaturas ente la entrada y la salida del mismo. La superficie de la sección transversal del canal $\left(S_{\text {canal }}\right)$ es diferente para cada configuración propuesta, tomado los valores: $0.3 \mathrm{~m}^{2}$ para la configuración 1 , 1.103. $\mathrm{m}^{2}$ para la configuración 2 , 1.103. $\mathrm{m}^{2}$ para la configuración 3 y 0.762 . $\mathrm{m}^{2}$ para la configuración 4 . Los valores obtenidos de la potencia calorífica absorbida por el canal se han representado en la Figura 5.27. 

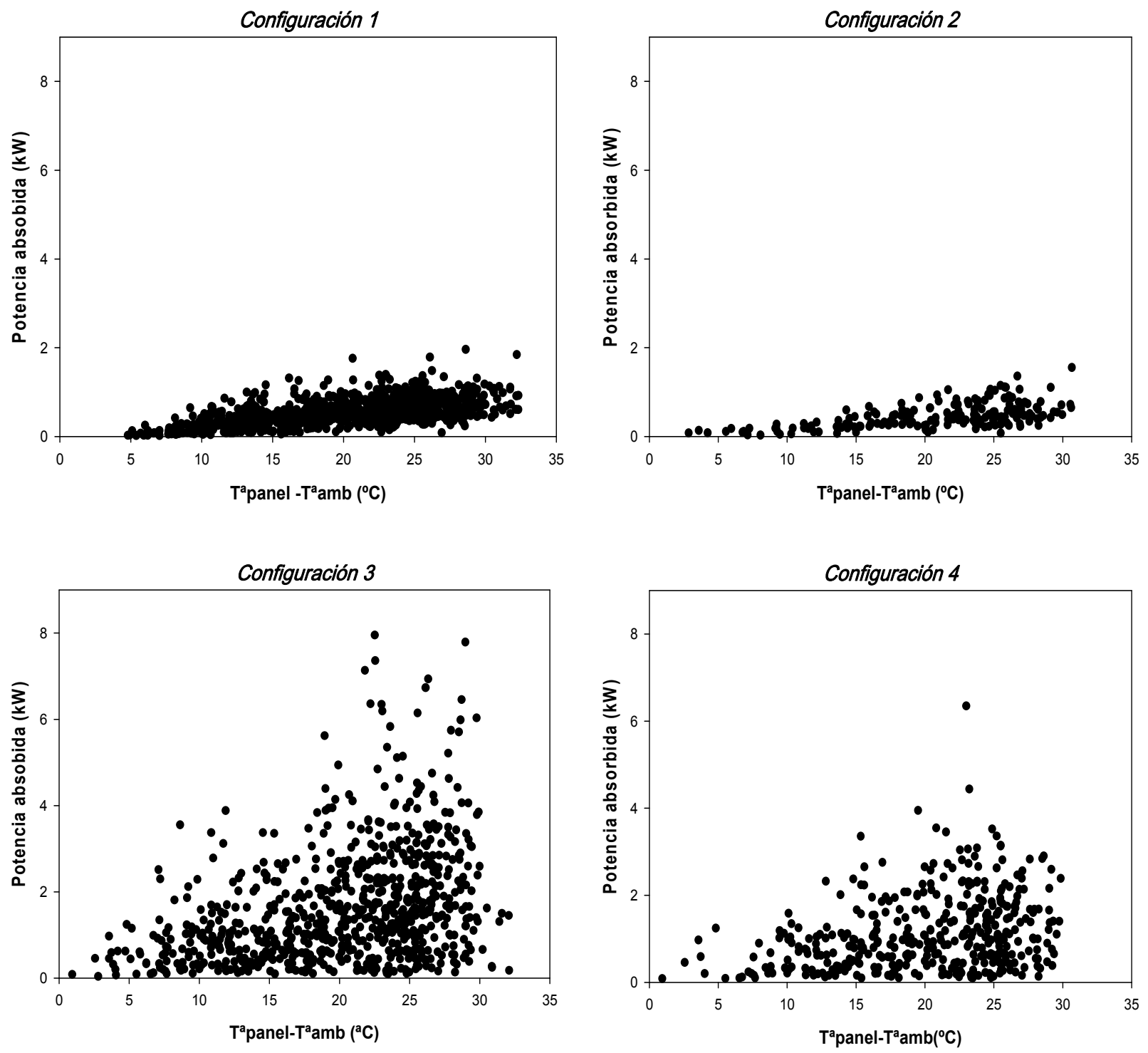

Figura 5.27 Potencia calorífica absorbida por el canal de aire circulante por el canal entre los módulos fotovoltaicos y la cubierta del invernadero, para las configuraciones propuestas.

Cada configuración presenta un límite máximo de potencia referida al calor que es capaz de absorber el aire que circula por el canal. Como es de esperar, a mayor diferencia de temperatura del panel, respecto el ambiente, la transferencia de calor al aire aumenta. Los resultados obtenidos afirman que al colocar un aislante en la cubierta del invernadero, la transferencia de calor es menor si se compara con la configuración que dispone del plástico con una sección similar. Sin embargo, las máximas temperaturas alcanzadas por el panel son similares, lo que indica que el calor se trasfiere al canal de aire sin afectar a la de funcionamiento del panel. Las configuraciones de mayor sección, por las que circula mayor caudal de aire, registran valores superiores de potencia absorbida, siendo el máximo del orden de $8 \mathrm{~kW}$ para la configuración 3. Este calor absorbido corresponde al transmitido desde los módulos fotovoltaicos y en mayor medida por la cubierta, del interior del invernadero. Sin embargo, en la configuración 4, la máxima potencia absorbida es del orden de 4-6 kW, algo 
menor que la configuración 3 debido a que se reduce la transmisión de calor a través del aislante, por consiguiente la potencia absorbida por el aire es menor. El aumento de la sección de aire consigue que se trasfiera mayor calor al aire y la refrigeración del panel será considerablemente mayor, obteniendo un mejor comportamiento eléctrico.

\subsubsection{CONCLUSIONES (CONCLUSION)}

Se ha estudiado el comportamiento de paneles fotovoltaicos sobre la cubierta de un invernadero, fiel al diseño de una planta agroenergética, con el propósito de modificarlo y comparar diferentes configuraciones. Se han medido cuatro configuraciones, para dos secciones de entrada de aire en el canal entre módulos y la cubierta, y para cada sección se ha utilizado diferente material constituyente de la cubierta, tanto plástico como aislante o panel sándwich.

Se han obtenido las correlaciones correspondientes de los parámetros característicos del panel fotovoltaico con la temperatura, para cada configuración y en unas condiciones similares de elevada radiación y temperatura ambiente y baja velocidad del viento. Se han obtenido un buen ajuste en los diferentes casos experimentales. Se han comparado con las correlaciones obtenidas a partir de los valores del fabricante, siguiendo la metodología propuesta por Eduardo Lorenzo et al.[64]. Los coeficientes de temperaturas de las variables medidas experimentalmente en cada configuración, comparados con los obtenidos con los datos del fabricante, presentan la misma influencia o tasa de variación con la temperatura, y se han obtenido valores similares.

En todos ellos se observa la disminución de la tensión de circuito abierto y rendimiento con el aumento de la temperatura del panel y un ligero aumento de la intensidad de cortocircuito. Para una temperatura de funcionamiento del panel determinada, el rendimiento del panel en la configuración 4 (mayor separación en el canal y con cubierta de aislante), es mayor al resto.

En el análisis de los resultados experimentales se ha percibido una gran influencia de la velocidad del viento, en el comportamiento de los paneles fotovoltaicos. Se ha estudiado dicha influencia en la temperatura de funcionamiento del panel y en el rendimiento para cada configuración, considerando dos rangos de valores extremos de velocidad de viento. Para mayores velocidades de viento, la temperatura del módulo se reduce $2-7^{\circ} \mathrm{C}$ lo que indica una mayor refrigeración del panel. En las configuraciones con cubierta de plástico, se obtienen mayores temperaturas de panel, lo que muestra una influencia térmica del interior del invernadero. Del mismo modo, el rendimiento presenta diferencias significativas en función de la velocidad viento, en cada configuración, obteniéndose menores valores para bajas velocidades de viento, en las que se alcanzaba mayores temperaturas. Además los 
resultados muestran que los mayores valores de rendimiento se obtienen para la configuración que presenta mayor sección de entrada y con material aislante en la cubierta.

Por último se ha cuantificado la transferencia de calor en el canal de aire, en cada configuración de ensayo, obteniendo la potencia absorbida desde el panel y el interior del invernadero. Cada configuración alcanza un límite máximo de calor absorbido por el aire en el canal, que se corresponde a mayores saltos de temperatura de panel respecto el ambiente. Los resultados concluyen que la colocación de un aislante en la cubierta del invernadero, para una sección similar, la trasferencia de calor es menor comparándola con la obtenida cuando está el plástico. Además, las máximas temperaturas alcanzadas por el panel son menores. Esto se debe a que la mayor transmisión de calor se produce desde el módulo fotovoltaico, ya que el aislante impide el paso de calor en el interior del invernadero. Además, considerando el mismo material en la cubierta, cuando la sección del canal de aire es mayor se aumenta el caudal de aire, por consiguiente el calor absorbido es mayor.

La colocación de un material aislante y el aumento de la sección de paso permiten una mayor refrigeración del panel, consiguiendo un mejor comportamiento eléctrico.

\section{CONCLUSIONS}

The electrical functionality of the photovoltaic panels placed on roof of a greenhouse is similar to the design of a photovoltaic greenhouse system that was studied, with the purpose of modifying and comparing different configurations. Four different configurations were measured for two inlet sections of the air channel between the panel and the roof, and using two materials in the roof surface for each section, plastic and insulating material (the sandwich panel).

The analysis includes the correlations of the characteristic parameters of the photovoltaic panel with the temperature for each configuration and under similar conditions of high solar radiation and ambient temperature, as well as low wind velocity. A good agreement was obtained in the different experimental cases. These experimental correlations have been compared with the calculated correlations with the data provided by the manufacturer, according to the methodology proposed by Eduardo Lorenzo [64]. The temperature coefficients of the experimental measured variables, in each configuration, present the same association or rate variation with the temperature compared them with result obtained from the manufacturer data.

The correlations show the decrease of the open circuit voltage and efficiency and a slightly increase of the short-circuit current when the temperature increases. The performance of the modules at configuration 4 (higher section and with a panel sandwich in the roof) is better than the other cases, for a panel temperature given. 
A great influence of the wind velocity has been perceived in the experimental results analysis on the behaviour of the photovoltaic panels. Thus, this influence was studied comparing the temperature and efficiency of the panel for each configuration, at two extreme range of value of wind velocity. At the higher wind velocity, the module temperature decreased $2-7^{\circ} \mathrm{C}$, what indicated a better air cooling of the panel. The higher panel temperatures reached were recorded in the configuration which had plastic roof, and indicated a thermal influence of the heat inside of the greenhouse. Similarly, there were differences in the results of the panel efficiency depending on the value of the wind velocity. The worst results were at lower velocity when the temperature was higher, for each configuration. The best results of the efficiency were obtained in the configuration which had a higher section of the air channel and panel sandwich on the roof.

Finally, the heat transfer in the air channel was quantified for each configuration under the same environmental condition, obtaining the absorbed power from the photovoltaic panel and the greenhouse interior toward the air channel. The results showed that each configuration reached a maximum limit of absorbed heat by the air, which corresponded at higher temperature difference between panel and ambient. The study concludes that the insulating material on the roof reduces the heat transfer compared with the plastic material, at the same section of the channel. Moreover, the highest panel temperatures reached were lower than for the cases with plastic on the roof. This is due to the insulating material not allowing the heat transfer through the roof, from the interior of the greenhouse. Comparing the configuration with the same material on the roof, the absorbed heat is higher when the air channel section increases, because of the air flow is higher.

The positioning of an insulating material on the roof and an increase of the air channel section allows the panel to be better at cooling and consequently obtaining a better electrical production level. 


\section{CAPITULO 6. CONCLUSIONES Y TRABAJOS FUTUROS (CONCLUSIONS)}

The two commercial photovoltaic systems which have been used as prototype for the design and build of the experimental facility were studied and were described. The first solar photovoltaic system, referred to as Coronil II, is made up of 51412 photovoltaic panels ground-mounted on a fixed structure. Using data from the solar plant from the different panel models, one of them was selected due to it providing better electrical behavior at high temperature. This is the one that was used in our experimental facilities. The collected measured data in the photovoltaic plant, in the months of May, June, July and August 2010, were screened to study and analyze the electrical variables of PV modules. These had the same model and features to those used in experimental facilities, under similar environmental conditions of operation. The other commercial photovoltaic system (Coronil IV) is an agroenergetic or photovolatic greenhouse and is made up of 4464 photovoltaic modules which are integrated on the roof of the greenhouse. The modules are the same model as what was chosen from the other plant. This photovoltaic application implies the modules were near the plastic roof of the greenhouse, so the high temperatures reached inside it could affect the panel behavior due to the heat transfer between inside and the air channel. For this reason, an experimental facility had been designed and built in order to study this influence.

The experimental facilities which were designed and built for the study have been described. The description includes the structural design for the prototype configuration which is similar to the reference configuration of a commercial facility, as well as other proposed configurations. This was in order to study a possible improvement in the electrical performance of photovoltaic modules, by air cooling through their back face taking advantage of the chimney effect created. Furthermore, the descriptions and characteristics of the sensors and instrumentations used to measure and register the data have been included. The first experimental facility consisted of two photovoltaic modules which are mounted on a fixed structure, with the same slope or pitch angle and orientation. A panel was placed above a steel plate, with an air channel underneath the panel. The other module, without any surface underneath it, was considered as the reference panel working under the same ambient conditions to compare both electrical functions. The second experimental facility has been designed and built true to the commercial agroenergetic facility (Coronil IV) from which the structural unit was chosen; consisted of a metal structure to support four photovoltaic modules on the plastic greenhouse roof. The designed prototype and the original facility contained a space between the roof and the photovoltaic modules which allowed the air circulation through a divergent channel by the chimney effect created by natural convection. The design of the experimental facility allowed variation in the inlet air section, whose purpose was to compare the panels functioning in each case, as well as the plastic roof insulation material was changed for each studied section. 
The methodology which was carried out for the process of data recording and measurement has been described. In order to develop a correct method for data recording and data processing and to reduce the possible accidental errors, a determinate valid process which could be used in both experimental facilities was created. The data uncertainty analysis was carried out for all measured variables aimed to be studied, and shown is the estimation of the measurement, and the confidence interval of the estimation. The uncertainties obtained are very low, which means that the data collected are sufficiently reliable.

The results of a photovoltaic panel measurement in the instrumented experimental facility and the extrapolation of these results to a photovoltaic generator in a solar plant were presented. The results concluded that the electrical functionality of a solar plant could be predicted and known by the measuring an experimental prototype for different configurations or conditions.

It was shown the study carried out compares two photovoltaic panels, one of them was placed on a steel plate (panel B), existing a space between both surfaces, for three sections of the air cooling channel by natural and forced convection and other module lacked any surface or plate underneath it and it was considered as a reference panel (panel A). The experimental results concluded that the air cooling of a photovoltaic panel through a channel created underneath it with a steel plate is reduced by natural convection, in comparison to a module without any surface underneath, implying higher operating temperatures and lower electrical efficiency. Therefore, the air spacing is an influential variable on the panel temperature and its electrical variables at high values of ambient temperature and solar radiation. An increase of 6 $\mathrm{cm}$ (in the air spacing of the channel) reduces the module temperature $5-6^{\circ} \mathrm{C}$ and improves the performance $0.6-1.3 \%$.

On the other hand, the air cooling by forced convection of panel B, improves the electrical performance $(\approx 1 \%)$ compared to the results in natural convection, because of a decrease of panel temperature $\left(5-7^{\circ} \mathrm{C}\right)$ due to an increase of heat transfer in the air channel. The corresponding case with aspect ratio $b / L=0.0675$ is the ideal configuration, obtaining better electrical functioning. Nevertheless, the induced air cooling using a fan would be a suitable option if the improvement of electricity production by modules was higher than the electricity consumption in which fan usage was supposed. The consumed power by the fan has not been measured in this study and this would be an aspect to consider in future studies.

The comparative analysis with all results for the different configurations tested in natural and forced convection were made, considering the influential variables in the electrical functioning of the photovoltaic panels; the aspect ratio and velocity of the air in the channel. The analysis conclude that the temperature gap (panel - ambience) decreases by around 10$16^{\circ} \mathrm{C}$ and electrical power panel increases 3-5\% when the panel experiences air cooling by forced convection in the face of natural convection, for a given aspect ratio. The differences 
between the two cases of forced convection are less, increasing the power around $2.4 \%$ and reducing the operating temperature $7^{\circ} \mathrm{C}$ for the highest value of induced velocity tested. Moreover, a higher aspect ratio allowed better cooling effect with an operating temperature of $5-7^{\circ} \mathrm{C}$ lower and an efficiency $2-2.5 \%$ higher, for a given air velocity in the channel. As it was mentioned there were hardly any differences between the two higher aspect ratios. The widest section of air in the channel had higher minimum values of performance than the configuration with lower section at natural and induced convection, yielding an improvement of module efficiency in both cases. It would be necessary to analyze the electrical spending in induced convection and compare it with the improvement of panel production to confirm its suitability.

In order to globalise the results at different configurations, an experimental model to determine the influence of the channel aspect ratio and the forced ventilation on the panel temperature (and consequently on the electric efficiency of the PV module) in a roof integrated configuration, for various values of the incident solar radiation, ambient temperatures, aspect ratios, and forced ventilation conditions is developed (employing the Ross coefficient, $k$, to characterize the behavior of each configuration studied). With respect to the influence of the aspect ratio, the higher it is, the lower the values of $k$ and the lower the temperature of the module. A critical channel aspect ratio of 0.11 can be considered to minimize overheating of PV devices, for the cases in which ventilation within the channel is produced by natural convection. Regarding the influence of the induced velocity, if values higher than those corresponding to the natural convection ventilation case are considered, lower values of the aspect ratio may be used for obtaining the same cooling in the PV module. For a constant aspect ratio, the value of the induced velocity within the channel affects strongly the cooling of the module. Semi empirical correlations for the Ross coefficient, module temperature, electrical efficiency and power output are proposed with a good agreement with respect to the experimental measurements. These correlations may predict the thermal behavior of the PV module in BIPV configurations, for various ambient conditions. Similar evolutions with the time were obtained between the measurements and the experimental correlation proposed. An increase in the power output over $19 \%$ from the natural ventilation case $\left(V_{v}=0.5 \mathrm{~m} / \mathrm{s}\right)$ to the case of $V_{v}=6 \mathrm{~m} / \mathrm{s}$ was also observed.

The electrical functionality of the photovoltaic panels placed on roof of a greenhouse was studied with the aim of comparing four configurations: two inlet sections of the air channel between the panel and the roof, and using two materials in the roof surface for each section, plastic and insulating material (the sandwich panel). A good agreement as obtained in the correlations of the characteristic parameters of the photovoltaic panel with the temperature for each configuration and under similar conditions of high solar radiation and ambient temperature, as well as low wind velocity. The result shown that the performance of the modules at configuration 4 (higher section and with a panel sandwich in the roof) is better than the other cases. A great influence of the wind velocity has been perceived in the 
experimental results analysis on the functionality of the photovoltaic panels. The worst results were at lower wind velocity when the temperature was higher, for each configuration. The higher panel temperatures reached were recorded in the configuration which had plastic roof, and indicated a thermal influence of the heat inside of the greenhouse. The analysis of the heat transfer concluded that the insulating material on the roof reduces the heat transfer compared with the plastic material, at the same section of the channel. Moreover, the maximum panel temperatures reached were lower than for the cases with plastic on the roof. This is due to the insulating material not allowing the heat transfer through the roof, from the interior of the greenhouse. The positioning of an insulating material on the roof and an increase of the air channel section allows the panel to be better at cooling and consequently obtaining a better electrical production level.

\section{TRABAJOS FUTUROS}

Como desarrollos futuros del presente trabajo, pueden plantarse los siguientes:

Análisis del factor de Ross de paneles integrados sobre la cubierta de invernaderos considerando las variables influyentes en su refrigeración para establecer un modelo experimental.

> Estudiar la posibilidad de globalizar los resultados experimentales en una correlación que nos permita determinar la temperatura de funcionamiento de un panel integrado sobre cualquier cubierta.

Extrapolar los resultados obtenidos a otras configuraciones de integración fotovoltaica sobre otras cubiertas. 


\section{BIBLIOGRAFÍA}

[1] International Energy Agency, Medium-Term Renewable Energy Market Report 2013, OECD/IEA, Paris.

[2] Krauter S., Increased electrical yield via water flow over the front of photovoltaic panels, Solar Energy Materials \& Solar Cells, vol. 82, pp.131-137, 2004.

[3] M. Abdolzadeh, M. Ameri, Improving the effectiveness of a photovoltaic water pumping system by spraying water over the front of photovoltaic cells, Renewable Energy, vol.37, pp. 91-96, 2008.

[4] Short T, Oldach R., Solar powered water pumps: the past the present and the future, Journal of Solar Energy Engineering, vol.125, pp. 76-82, 2003.

[5] Argaw N., Optimal load matching in photovoltaic water pumps coupled with DC/AC inverter, International Journal of Solar Energy, vol.18, pp. 41-52, 1995.

[6] Oldach R., Argaw N., Evolution of the solar powered water pumps, International Journal of Solar Energy, vol.11, pp.26-37, 1999.

[7] Krauter, Hanitsch R., The influence of the capsulation on the efficiency of PV-modules, In Proceedings of the 1st word renewable energy congress, vol. 1, pp.141-144, Reading: UK; 1990 September 23-28.

[8] Krauter S, Hanitsch R, Strauss PH., Simulation-program for selecting efficiency improving strategies of PV-module encapsulations under operating conditions, In Proceedings of renewable energy sources '91, international conference, vol. 3,pp. 48-53, Prague: CFSR, 1990 July $1-4$.

[9] Ronnelid M, Perers B, Karisson B, Krohn P., Cooling of PV modules equipped with lowconcentrating CPC reflectors, In Procedding of ISES Solar World Congress; 1999.

[10] Krauter S., Thermal and optical enhanced PV-modules, In proceeding of the $13^{\text {th }}$ European Photovoltaic Solar Energy Conference, pp.2306-2309, Nice France, October 23-27.

[11] Karauter S., Hanitsch R., Moreira L., New optical and thermal enhanced PV modules performing $12 \%$ better under true module rating conditions, In Proceeding of the $25^{\text {th }}$ IEEEPV-Specialists Conference, pp. 1323-1326, Washington DC, USA, 1996 May 13-19.

[12] Earle Wilson, Theoretical and operational thermal performance of a 'wet' crystalline silicon PV module under Jamaican conditions, Renewable Energy, vol.34, pp. 1655-1660, 2007. 
[13] Cordero N., Ginige R., Corbett B., Kennedy K., Thermal modelling of TPV systems, In Proceedings of the eighth intersociety conference on Thermomechanical phenomena in electronic systems, pp. 605-609, 2002.

[14] Radziemska E., The effect of temperature on the power drop in crystalline silicon solar cell, Renewable Energy, vol. 28, pp. 1-12, 2003.

[15] T.T. Chow, Performance analysis of photovoltaic-thermal collector by explicit dynamic model, Solar Energy, vol. 75, pp. 143-152, 2003.

[16] Huang B.J, Lin T.H., Hung, F.S. Sun W.C., Performance evaluation of Solar photovoltaic/thermal systems, Solar Energy, vol. 70 (5), pp. 443-448, 2001.

[17] Brogren M, Karlisson B., Low-concentrating water-cooled PV-thermal hybrid systems for high latitudes, In Proceeding of Conference record of the twenty-ninth IEEE photovoltaic specialists conference, pp. 1733-1736, 2002.

[18] Guohui Gan., Numerical determination of adequate air gaps for building-integrated photovoltaics, Solar Energy, vol. 83 (8), pp. 1253-1273, 2009.

[19] Arvind Tiwari, M.S. Sodha, Avinash Chandra, J.C. Joshi, Performance evaluation of photovoltaic thermal solar air collector for composite climate of India, Solar Energy Materials \& Solar Cells, vol. 90, pp. 175-189, 2006.

[20] Swapnil Dubey, G.S. Sandhu, G.N. Tiwari, Analytical expression for electrical efficiency of PV/T hybrid air collector, Applied Energy, vol.86, pp. 697-705, 2009.

[21] Nynne Friling, Maía José Jimenez, Hans Bloem, Henrik Madsen, Modelling the heat dynamics of building integrated and ventilated photovoltaic modules, Energy and Buildings vol. 41 (10), pp. 1051-1057, 2009.

[22] Sweelem E., Fahmy F., Abd-El Aziz M., Increased efficiency in the conversion of solar energy to electric power, Energy Sources, vol. 21, pp. 367-377, 1999.

[23] Kern Jr., EC, Russell MC., Combined photovoltaic and thermal hybrid collector systems, In Proceedings of the 13th IEEE photovoltaic specialists, pp. 1153-1157, Washington USA, 1978.

[24] Hendrie SD., Evaluation of combined photovoltaic/thermal collectors, In Proceedings of international conference ISES, vol. 3, pp. 1865-1869, Atlanta, USA, 1979 May 28- June 1.

[25] Florschuetz LW., Extention of the Hottel-Whillier model to the analysis of combined photovoltaic/thermal flat plate collectors, Sol Energy, vol.22, pp.361-366, 1979.

[26] S.A. Kalogirou, Use of TRYNSYS for modeling and simulation of a hybrid PV-thermal solar system for Cyprus, Renewable Energy, vol. 23, pp. 247-260, 2001. 
[27] Lee WM, Infield DG, Gottschalg R. Thermal modelling of building integrated PV systems In: Proceedings of 17th PV solar energy conference. Munich, 22-26 October, 2001. p. 2754-7.

[28] Chow TT, Hand JW, Strachan PA., Building-integrated photovoltaic and thermal applications in a subtropical hotel building, Applied Thermal Engineering, vol. 23, pp. 20352049, 2003.

[29] Araki K, Uozumi H, Yamaguchi M., A simple passive cooling structure and its heat analysis forconcentrator PV module, In Proceeding of conference record of the twenty-ninth IEEE photovoltaic specialists conference, pp.1568-1571, 2002.

[30] Farahat MA., Improvement the thermal electric performance of a photovoltaic cells by cooling and concentration techniques, In Proceeding of 39th International universities power engineering conference UPEC-conference proceedings, vol. 2, pp. 623-628, 2004.

[31] D. Infield, L. Mei, U. Eicker, Thermal Performance estimation of ventilated PV facades, Sol. Energy, vol. 76 (1-3), pp. 93-98, 2004.

[32] Meier C, Hasler CA., Proceeding of the 11th EU Photovoltaic Solar Energy Conference and Exhibition, Montreaux, Switzerland, 12-16th October, 1992.

[33] Joachim Benemann, Oussama Chehab, Eric Schaar-Gabriel, Solar Energy Materials \& Solar Cells, vol. 67, pp. 345-350, 2001.

[34] AbuBakr S. Bahaj, Photovoltaic roofing: issues of design and integration into buildings, Renewable energy, vol. 28, pp. 2195-2204, 2003.

[35] http://www.bpsolar.com

[36] Guoguang Yu, Huiquing Xu, Jicai Ding, Hongshan Xu, Xianbi Xiang, Xianbo Liao, Building integrated solar power generation on roof, In Proceeding of IEEE 2010.

[37] Sujata Nayak, G.N. Tiwari, Energy and exergy analysis of photovoltaic/thermal integrated with a solar greenhouse, Energy and Buildings vol. 40 (11), pp. 2015-2021, 2008.

[38] A. Yano, Electrical energy generated by photovoltaic modules mounted inside the roof or a north-south oriented greenhouse, Biosystems Engineering, vol. 103 (2), pp.228-238, 2009.

[39] E.Skoplaki, J.A. Palyvos, Operating temperature of photovoltaic modules: A survey of pertinent correlations, Renewable Energy, vol. 34, pp. 23-29, 2009.

[40] Binkworth, B.J., Cross, B.M., Marsahall, R.H.,Yang, H., Thermal regulation of photovoltaic cladding, Solar Energy vol.61, pp. 169-178, 1997.

[41] J.K. Tonui, Y. Tripanagnostopoulos, Performance improvement of PV/T solar collectors with natural air flow operation, Solar Energy, vol. 82, pp. 1-12, 2008. 
[42] Krauter S., Arauja, R.G., Schroer, S., Hanitsh, R., Salhi, M.J., Triebel, C., Lemoine, R., Combined photovoltaic and solar thermal systems for façade integration and building insulation, Solar Energy, vol. 67, pp. 239-248, 1999.

[43] Maycock P, Stirewalt E., A guide to the photovoltaic revolution. Pennsylvania: Rodale Press; 1985.

[44] Angrist S., Direct energy conversion. Boston: Allyn and Bacon; 1982.

[45] Hu C, White R., Solar cells: from basic to advance systems. New York: McGraw-Hill; 1983.

[46] Graff K, Fischer H., Carrier lifetime in silicon and its impact on solar cell characteristics, In Proceeding of Seraphin BO, editor, Topics in applied physics - solar energy.

[47] Skoplaki, E., Palyvos, J.A., On the temperature dependence of photovoltaic module electrical performance; a review of efficiency, power correlation, Solar Energy vol. 83, pp.614624, 2009.

[48] Amy de la Breteque E., Thermal aspects of c-Si photovoltaic module energy rating, Solar Energy, vol. 83, pp. 1425-1433, 2009.

[49]Green M.A., Solar Cells, Prentice-Hall, Inc., Englewood cliffs, 1982.

[50] Akira Usami, Shiro Seki, Yuichi Mita, Hiromu Kobayashi, Hajime Miyashiro, Nobuyuki Terada, Temperature dependence of open-circuit voltage in solar cells, Solar Energy Materials \& Solar Cells, vol. 93, pp. 840-842 2009.

[51] Priyanka Singh, S.N. Singh, M. Lal, M. Husain, Temperature dependence of I-V characteristics and performance parameters of silicon solar cell, Solar Energy Materials \& Solar Cells, vol. 92, pp. 1611-1616, 2008.

[52] Würfek, P., Phisics of Solar Cells:From principles to new concepts, Wiley,VCH,2005.

[53] Van Dyk EE, Scott BJ, Meyer EL, Leitch AWR, Temperature dependence of performance of crystalline silicon modules, S. Afr. J. Sci. vol. 96, pp. 198-200, 2000.

[54]Gxasheka A.R., van -dyk E.E., Meyer E.L., Evaluation of performance parameters of PV modules deployed outdoors, Renewable Energy, vol. 30, pp. 611-620, 2005.

[55] Mazer JA., Solar cells: An introduction to crystalline photovoltaic technology, Kluwer Academic Publications, 1997, p. 108.

[56] Meyer EL, On the reliability, degradation, and failure of photovoltaic modules, PhD Thesis, University of Port Elizabeth, 2002, p- 73-74. 
[57] King D.L., Dudley J.K., Kratochvil J.A., Boyson W.E., Temperature coefficient for PV modules arrays: measurements methods, difficulties and results, In Proceedings $25^{\text {th }}$ IEEE photovoltaic specialists conference, pp. 1183-1186, 1997.

[58] Tomasz Kozak, Witold Maranda, Andrzej Napieralski, Gilbert De Mey, Alexis De Vos, Influence of Ambient Temperature on the Amount of Electric Energy Producted by Solar Modules, In proceeding of MIXDES $16^{\text {th }}$ International Conference 'Mixed Design of integrated Circuits and Systems, pp. 351-354, 2009.

[59] Palyvos J.A., A survey of wind convection coefficient correlations for building envelope energy systems modeling, Applied Thermal Engineering, vol. 28, pp. 801-808, 2008.

[60] Khedari J., Hirunlabh J., Bunnag T., Experimental study of a roof solar collector towards the natural ventilation of new houses, Energy and Buildings, vol. 26, pp. 159-164, 1997.

[61] Khedari J., Mansirisub W., Chaima S., Pratinthong, N., Hirunlabh, J., Field measurements of performance of roof solar collector, Energy and Buildings, vol. 31, pp. 171-178, 2000.

[62]Hirunlabh J., Wachirapuwadon S., Pratinthong N., Khedari J., New configurations of a roof solar collector maximizing natural ventilation, Building and Environment, vol. 36, pp. 383-391, 2001.

[63] Sandberg M., Moshfegh B., Buoyancy-induced air flow in photovoltaic facades: Effect of geometry of the air gap and location of solar cell modules, Building and Environment vol. 37, pp. 211-218, 2002.

[64] Ryan D., Burek S.A.M., Experimental study of the influence of collector height on the steady state performance of a passive solar air heater, Solar Energy vol. 84, pp. 1676-1684, 2010.

[65] Gan G., Numerical determination of adequate air gaps for building-integrated photovoltaics, Solar Energy vol. 83, pp. 1253-1273, 2009.

[66] Brinkworth B.J., Marshall R.H., Ibarahim Z., A validated model of naturally ventilated PV cladding, Solar Energy vol. 69, pp. 67-81, 2000.

[67] Jie J., Hua Y., Wei H., Gang P., Jianping L., Bin J., Modeling of a novel Trombe wall with PV cells, Building and Environment vol. 42, pp. 1544-1552, 2007.

[68] Pantic S., Candanedo L., Athienitis A.K., Modeling of energy performance of a house with three configurations of building-integrated photovoltaic/thermal systems, Energy and Buildings vol. 42, pp. 1779-1789, 2010.

[69] Khedari J., Ingkawanich S., Waewsak J., Hirunlabh J., A PV system enhanced the performance of roof solar collector, Building and Environment, vol. 37, pp. 1317-1320, 2002. 
[70] Ross R.G., Interface design considerations for terrestrial solar cell modules, In Proceedings of the 12th IEEE Photovoltaic Specialists Conference, pp. 801-806, Baton Rouge, LA, USA, Nov. 15-18, 1976.

[71] Nordmann T., Clavadetscher L., Understanding temperature effects on PV system performance, In Proceedings of the Third World Conference on Photovoltaic Energy Conversion, pp. 2243-2246, Osaka, Japan, May 11-18, 2003.

[72] Skoplaki E., Boudouvis A.G., Palyvos J.A., A simple correlation for the operating temperature of photovoltaic modules of arbitrary mounting, Solar Energy Materials and Solar Cells vol. 92, pp. 1393-1402, 2008.

[73] Gerardo Ruiz Chavarría, Determinación experimental de las características de vórtices anulares, Latin-American Journal of Physics Education, Volumen 4, pp. 903-908, Suppl. 1, 2010,.

[74] Evaluación de datos de medición. Guía para la expresión de la incertidumbre de medida.

(C) JCGM 2008. NIPO Edicion digital 1, Septiembre 2008.

[75] Taylor B.N., Kuyatt C.E., Guidelines for evaluating and expressing the uncertainty of NIST measurement results, NTIS Technical note1297, $1994 .$.

[76] R. Mazón-Hernández, JR García-Cascales, F Vera-García, A Sánchez-Kaiser, B ZamoraParra, Development of an installation to reduce the temperature of photovoltaic modules and improve their efficiency, In Proceedings of the International Conference on Renewable Energies and Power Quality (ICREPQ'10), 23-25 March 2010, Granada, Spain, 2010.

[77] A.S. Kaiser, B. Zamora, R. Mazón, J.R. García, F. Vera, Experimental study of the cooling by forced convection on building integrated photovoltaic modules, Applied Energy, vol. 135, pp. 88-97, 2014.

[78] Vera García F., Mazón Hernández R., García-Cascales J.R., Sánchez Kaiser A., Zamora Parra B., Estudio comparativo de la influencia de la temperatura de paneles fotovoltaicos trabajando en un huerto solar frente a valores obtenidos en banco de ensayos, XV Congreso Ibérico y X Ibericoamericano de Energía Solar (CIES), 20-22 Junio, Vigo, España, 2012.

[79] Lorenzo E., Electricidad solar, Ingeniería de los sistemas fotovoltaicos, PROGENSA. ISBN: 84-86505-45-3, 1994.

[80] R. Mazón-Hernández, J. R. García-Cascales, F. Vera-García, A. S. Káiser, and B. Zamora, Improving the Electrical Parameters of a Photovoltaic Panel by Means of an Induced or Forced Air Stream, International Journal of Photoenergy, Volume 2013 (2013), Article ID 830968, 10 pages. 
[81] Brinkworth B.J., Optimum depth for PV cooling ducts, Solar Energy vol. 80, pp. 1131-1134, 2006.

[82] Evans D.L., Florschuetz L.W., Cost studies on terrestrial photovoltaic power systems with sunlight concentration, Solar Energy, vol.19, pp. 255-262, 1977.

[83] Lorenz Fonfria S., Mazón Hernández R., Vera García F., García-Cascales J.R., Sánchez Kaiser A., Zamora Parra B., Estudio de la influencia de la refrigeración con aire de forma natural en el comportamiento de instalaciones fotovoltaicas agroenergéticas en cubiertas, XV Congreso Ibérico y X Ibericoamericano de Energía Solar (CIES), 20-22 Junio, Vigo, España, 2012. 


\section{ANEXO A: PRINCIPIOS DE FUNCIONAMIENTO EN EL APROVECHAMIENTO SOLAR FOTOVOLTAICO}

La energía solar fotovoltaica se basa en la captación de la energía radiante del Sol y en su transformación en energía eléctrica mediante células solares y gracias al efecto fotovoltaico. La luz solar está compuesta por fotones de distinta energía, correspondientes a las distintas longitudes de onda del espectro solar. Por consiguiente, cuando un fotón incide sobre las células fotovoltaicas puede ser absorbido, reflejado o pasar a su través. Para que un fotón genere electricidad debe ser absorbido por la célula, si esto ocurre, la energía de dicho fotón es transmitida a un electrón de un átomo de la célula, el cual la usara para escapar de su posición normal y formar parte de una corriente en un circuito eléctrico.

Las células solares están constituidas por materiales semiconductores especialmente tratados para formar dos capas dopadas distintas, tipo $\mathrm{p}$ y tipo $\mathrm{n}$, formando así un campo eléctrico, positivo y negativo.

Para poder entender el funcionamiento de los dispositivos fotovoltaicos, se debe comprender el comportamiento de los materiales que los constituyen, los semiconductores. Por ello, a continuación se exponen algunos conceptos físicos y eléctricos básicos, necesarios para poder conocer e interpretar el principio de funcionamiento de la célula solar. 


\section{A.1 PRINCIPIOS FÍSICOS DE FUNCIONAMIENTO DE MÓDULOS FOTOVOLTAICOS}

La física clásica considera que la materia está constituida por átomos. Cada átomo consiste en un núcleo que contiene un determinado número de protones y neutrones. Además, el átomo está compuesto por un determinado número de electrones que rodean el núcleo en órbitas específicas las cuales se encuentran agrupadas en lo que llamamos capas. Dichas capas se presentan en niveles de energía: $K, L, M, N, O, P, Q$, tal como se ilustra en la siguiente figura:

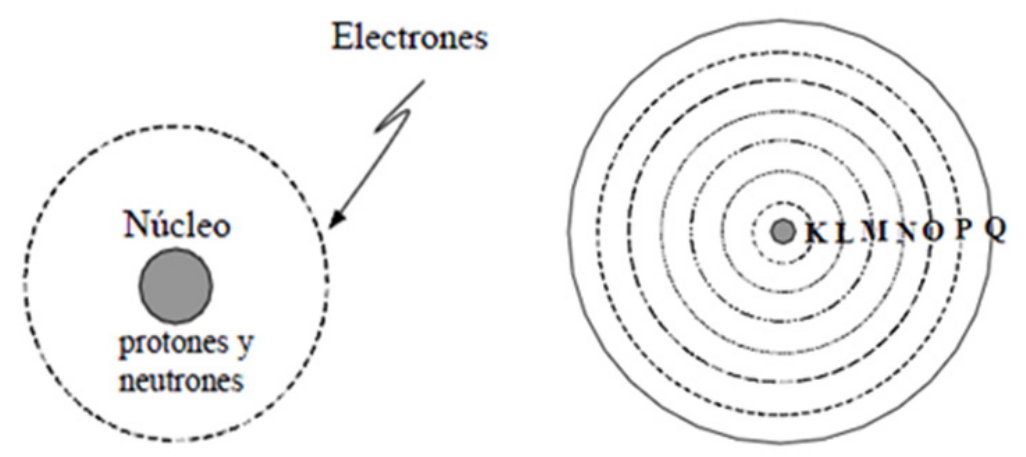

Figura A.1 Estructura del átomo y sus niveles de energía

La capa más interna es la de menor energía y contiene dos orbitales. La siguiente capa, de mayor energía, contiene 8 orbitales. La última capa (también denominada capa de valencia), cuando se presenta completa, puede llegar a tener un total de 8 electrones, que reciben la denominación de electrones de valencia. Los electrones de valencia son los únicos en condiciones de participar en fenómenos químicos y eléctricos.

Según la fuerza en que los electrones de valencia estén ligados al núcleo y, por tanto, según la facilidad con que se pueden desplazar de un átomo al contiguo, los materiales se pueden clasificar en 3 clases: conductores, semiconductores y aislantes.

Conductores: Los conductores como son los metales (cobre y aluminio), están formados por átomos en los que los electrones no están muy ligados al núcleo y fácilmente se desplazan al otro con tal que exista una pequeña diferencia de potencial, por tanto, apenas necesitan energía para conducir.

Semiconductores: A muy bajas temperaturas, los semiconductores tienen la propiedad de un aislante; sin embargo, a temperaturas más altas algunos electrones tienen libertad de movimiento y los materiales adoptan las propiedades de un conductor, si bien de un conductor pobre. No obstante, los semiconductores tienen algunas características útiles que lo hacen distintos tanto de los aislantes como de los conductores.

Aislantes: En los materiales aislantes, como el polietileno y el vidrio, los electrones de valencia están ligados con firmeza a los núcleos de los átomos y muy pocos pueden liberarse para conducir electricidad. La aplicación de un campo eléctrico no causa un flujo de corriente 
pues no hay portadores móviles de carga. Por tanto, la energía necesaria para conducir es muy elevada.

\section{A.1.1 COMPORTAMIENTO ELÉCTRICO DE LOS SEMICONDUCTORES}

Para tratar de explicar cómo se comportan los materiales, se utiliza el denominado modelo de bandas de energía. Los electrones dentro de un material se pueden desplazar únicamente a niveles de energía permitidos. En la figura siguiente se muestra dicho modelo de bandas de energía.

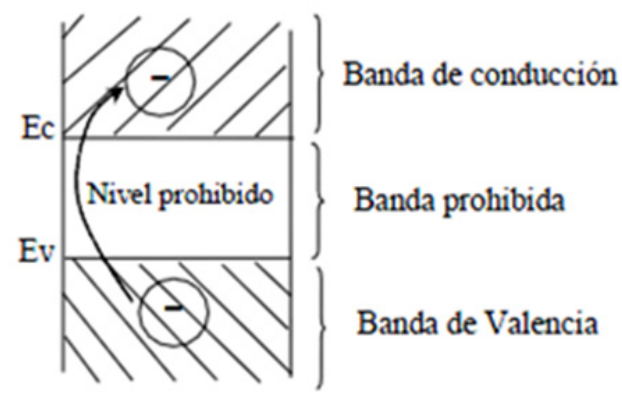

Figura A.2 Modelo de bandas de energía

El ancho de la banda prohibida o 'gap' de energía $\left(E_{g}\right)$ es la diferencia entre la energía de conducción $\left(E_{c}\right)$ y la energía de valencia $\left(E_{v}\right)$, como se indica en la siguiente ecuación:

$$
E_{g}=E_{c}-E_{v}
$$

La energía $E_{g}$ se puede definir como la energía necesaria para que un electrón pase de una banda a otra. Ésta energía depende del material y se suele expresar en electrón-voltios (1 $\mathrm{eV}=1,602.1019 \mathrm{~J})$. Por ejemplo, los semiconductores para conducir, necesitan una energía entre $0,8 \mathrm{eV}$ y $3 \mathrm{eV}$, mientras que los aislantes para conducir necesitan una energía mayor que $5 \mathrm{eV}$.

La siguiente figura muestra el modelo de bandas de energía para los 3 tipos de materiales mostrando la región donde se aplica a cada uno de ellos. 


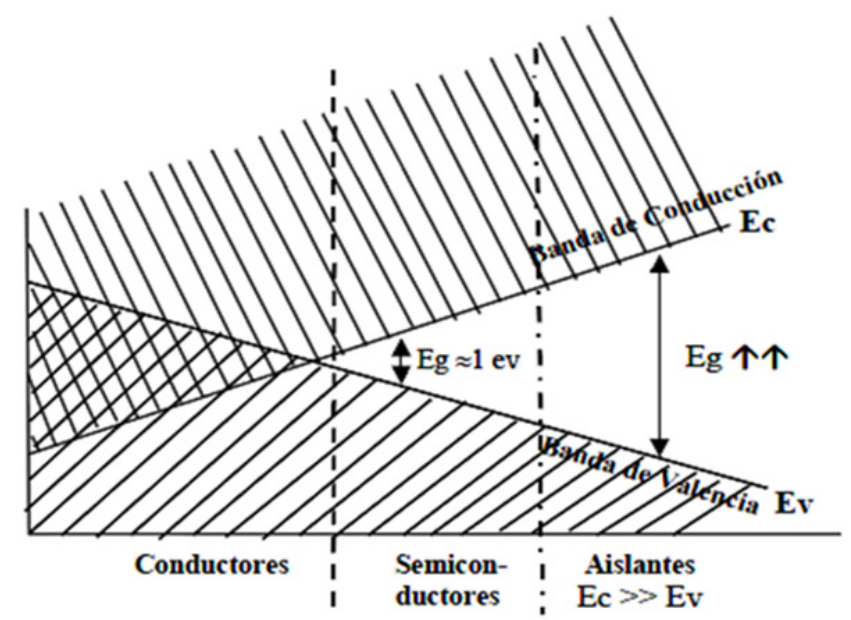

Figura A.3 Modelo de bandas de energía para conductores, semiconductores y aislantes

Como se puede observar en la figura, los materiales conductores (metales) tienen solapadas las bandas de conducción y de valencia, lo que demuestra que prácticamente no necesitan energía para conducir, mientras que los semiconductores si la requieren.

Los semiconductores se pueden presentar de dos maneras, como elementos simples, es el caso de los elementos de la columna $4 \mathrm{~A}$ de la tabla periódica, como pueden ser el Silicio (Si) y el Germanio ( $\mathrm{Ge}$ ) y también se presentan como compuestos químicos complejos, tal como el Arseniuro de Galio, Fosfuro de Indio, Teluro de Cadmio, Sulfuro de Cadmio.

Un semiconductor intrínseco es un cristal puro que no está dopado o lo que es lo mismo no contiene impurezas. En un cristal intrínseco (puro), cada átomo se posiciona formando una especie de retícula, con cuatro átomos cercanos. Cada par de átomos cercanos forma lo que se denomina enlaces covalente. Estos enlaces están formados por los 4 electrones de la capa de valencia.

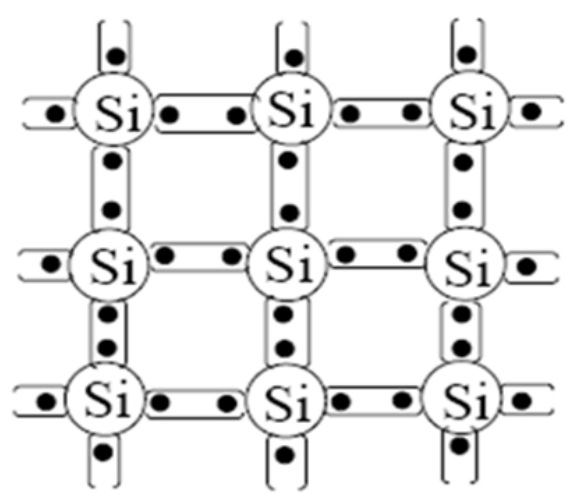

Figura A.4 Cristal de silicio intrínseco

A la temperatura de $0 \mathrm{~K}$, los electrones están en los menores estados de energía disponibles, con lo cual los enlaces no se rompen. En estas condiciones el material se comporta como un aislante eléctrico. 
Si al semiconductor intrínseco se le aplica una fuente de energía como puede ser luz, calor, campo eléctrico, campo magnético, etc., algunos enlaces covalentes se rompen por ionización térmica, con lo cual se generan electrones libres y huecos en igual número. El hueco es la ausencia de electrón y puede entenderse como un portador de carga positiva que se mueve libremente por el cristal (el valor de la carga de un hueco es igual que la del electrón pero con signo positivo).

Para la generación de electrones libres, el Silicio necesita una energía de 1,1 eV y el Germanio 0,8 eV. Cuando el cristal puro se somete a una fuente de energía, se puede romper un enlace, creando un hueco y un electrón libre que pueden moverse con libertad por todo el cristal. Incluso a "temperatura ambiente" (aproximadamente $300 \mathrm{~K}$ ), algunos electrones alcanzan la suficiente energía térmica como para liberarse de sus enlaces. La siguiente figura muestra un cristal de silicio donde se libera un electrón y se crea un hueco.

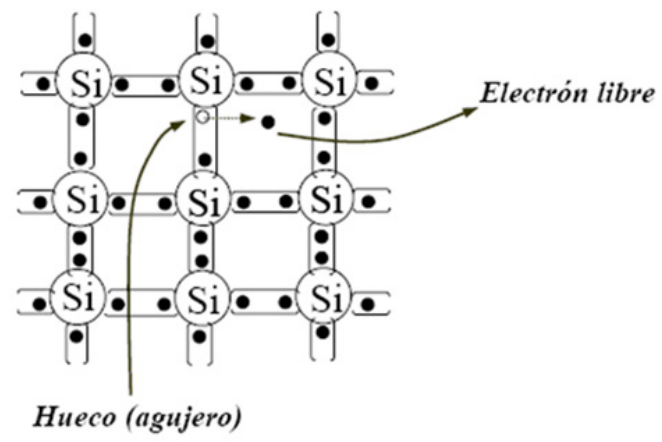

Figura A.5 Creación de un electrón-hueco en un cristal de silicio

En los semiconductores la conducción de electricidad es debida tanto los electrones como a los huecos que se mueven en sentido contrario. La Figura A.6 muestra como cuando los electrones se desplazan a la derecha para llenar un hueco el hueco se desplaza en sentido contrario, es decir, a la izquierda.

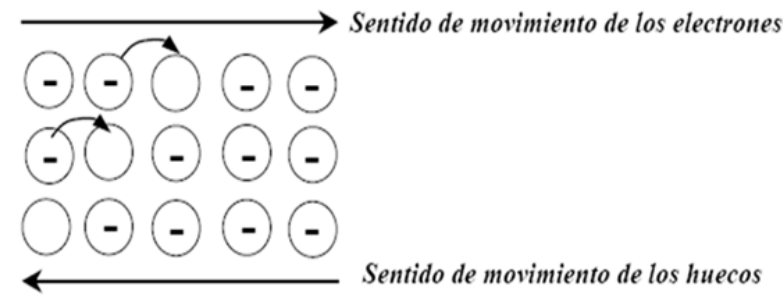

Figura A.6 Movimiento de los electrones y los huecos en semiconductores

En un semiconductor intrínseco, existe un número igual de huecos y electrones libres que pueden moverse con facilidad por el cristal. Así, podemos decir que en un material puro:

$$
n_{e}=p=n_{i}
$$


Donde $n_{\mathrm{e}}$ es la concentración de electrones libre, $p$ se refiere a la concentración de huecos y $n_{i}$ es la concentración intrínseca de electrones o huecos que es constante para cada material a una determinada temperatura: Ej. $n_{i}=1,45.1010 \mathrm{~cm}^{3}$ a $300 \mathrm{~K}$ para el Silicio.

El semiconductor extrínseco, consiste en un semiconductor al cual se le añaden impurezas para aumentar el número de portadores libres. También se suele hablar de semiconductores dopados. Los semiconductores con impurezas son materiales en los que predominan portadores de una clase (huecos ó electrones).

Por lo tanto, existen dos tipos de impurezas, donadoras en semiconductores tipo $n$ e impurezas aceptadoras en semiconductores tipo $p$.

Para formar un semiconductor tipo $n$ se añaden impurezas donadoras, $N_{D}$, con lo cual, se aumenta el número de electrones, de modo que los electrones son los portadores mayoritarios y los huecos son los portadores minoritarios. Las impurezas donadoras son átomos pertenecientes a la columna $5 \mathrm{~A}$ de la tabla periódica de los elementos (átomos pentavalentes), como pueden ser el Arsenio, Antimonio y Fósforo.

Para formar un semiconductor tipo $p$ se añaden impurezas aceptadoras, $N_{A}$, con lo cual, se aumenta el número de huecos, en este caso los huecos son los portadores mayoritarios y los electrones son los portadores minoritarios. Las impurezas aceptadoras son átomos pertenecientes a la columna $3 \mathrm{~A}$ de la tabla periódica de los elementos (átomos trivalentes), como pueden ser el Boro, Indio o Galio.

Al añadir impurezas donadoras a un semiconductor provoca una disminución de huecos. Por otro lado, al añadir impurezas aceptadoras a un semiconductor provoca una disminución de electrones por debajo del nivel del intrínseco. Se puede demostrar que en un semiconductor extrínseco o dopado, el producto de la concentración de huecos y electrones es una constante independiente de la cantidad de impurezas aceptadoras o donadoras que se añaden: $\quad n \cdot p=n_{i}{ }^{2}$

Como ya se ha mencionado, $n_{i}$ es la concentración de electrones o huecos en el semiconductor intrínseco.

\section{A.1.2 LA UNIÓN PN}

La unión PN consta de un único cristal de material semiconductor, que está dopado de forma que resulta ser un material de tipo $n$ en un lado y de tipo $p$ en el otro. Se pueden añadir impurezas al cristal a medida que va creciendo, o añadirlas más tarde, ya sea por difusión de átomos de impurezas en el cristal, o por implantación de iones. En la retícula cristalina, es importante que en la unión de la parte ' $N$ ' con la parte ' $P$ ' no haya ninguna interrupción. Esto solo será posible si la unión se constituye como un solo cristal. Sin embargo, resulta 
instructivo imaginar la formación de una unión PN juntando un cristal de tipo $p$ y un cristal de tipo $n$.

Antes de unir las dos mitades de la unión, el lado ' $N$ ' tiene una alta concentración de electrones libres y una baja concentración de huecos. En la mitad de tipo $p$ tenemos la condición inversa.

Debido al alto gradiente de concentración de portadores de un mismo tipo a cada lado de la unión (en un lado son mayoritarios y en el otro minoritarios), tienden a pasar por difusión desde el lado donde son mayoría al lado donde son minoría.

Al ocurrir esto, dejan en las proximidades de la unión una zona de cargas fijas (negativas en la zona ' $\mathrm{P}$ ' y positivas en la ' $\mathrm{N}$ ') produciéndose a ambos lados de la unión un dipolo eléctrico que crea un campo eléctrico dirigido de la zona ' $N$ ' a la zona ' $P$ ' que tiende a compensar esta difusión de portadores, llegándose así a una situación de equilibrio.

Así cuando tenemos un semiconductor tipo $p$ en contacto con un semiconductor tipo $n$, podemos resumir lo que se ha expuesto anteriormente con los pasos que se describen a seguir:

19. Se produce una difusión de huecos de la región ' $P$ ' a la región ' $N$ ' y una difusión de electrones de la región ' $N$ ' a la región ' $P$ '.

2‥ Al haber difusión algunos huecos que pasan de la región ' $P$ ' a la región ' $N$ ' y algunos electrones que pasan de la zona ' $\mathrm{N}$ ' a la zona ' $\mathrm{P}$ ', se recombinan hasta alcanzar el equilibrio.

3o. Tal como se muestra en la Figura A.7, después del proceso de difusión y recombinación, se produce en la unión una zona de deplexión (también llamada zona de carga espacial ó zona de vaciamiento) formada por las cargas estáticas (iones) de la estructura cristalina.

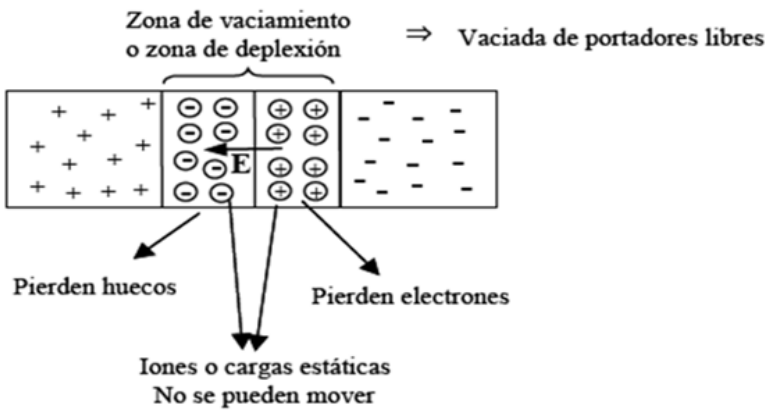

Figura A.7 Zona de deplexión en la unión p-n

4ㅇ. En esa zona de deplexión que se ha formado se crea un campo eléctrico $\vec{E}$ (de la región ' $\mathrm{N}$ ' a la región ' $\mathrm{P}$ ' (o de los iones + a los iones -) con lo cual se produce una caída de 
potencial sobre dicha región (de signo contrario) denominado potencial de contacto o potencial de unión $\left(\mathrm{V}_{\mathrm{o}}\right)$. Su magnitud es del orden de 0,3 a 0,7 V, dependiendo del tipo de semiconductor, Germanio o Silicio, respectivamente.

5‥ El campo eléctrico impide que más portadores atraviesen la unión.

6‥ Existen dos tipos de corriente:

Corriente de difusión $\left(I_{D}\right) \Rightarrow$ debida a los portadores mayoritarios. Electrones de la región ' $N$ ' pasan a la región ' $P$ ' y los huecos de la región ' $P$ ' a la región ' $N$ '. Cuanto mayor es el potencial de unión, menor es la corriente de difusión $I_{D}$.

Corriente de arrastre, deriva o saturación inversa $\left(I_{S}\right) \Rightarrow$ debida a los portadores minoritarios. Algunos huecos (generados térmicamente) en la región ' $N$ ' se mueven por difusión hacia la unión. Allí experimentan el campo eléctrico que los arrastra hacia la región ' $P$ '. Análogamente, algunos electrones (generados térmicamente) en la región ' $\mathrm{P}$ ' se mueven por difusión hacia la unión. Allí experimentan el campo eléctrico $(\vec{E})$ que los arrastra hacia la región ' $N$ '. Ambos procesos (los huecos de la región ' $N$ ' a la región ' $P$ ' y los electrones de la región ' $P$ ' a la región ' $N$ ') forman la corriente de saturación inversa $\mathrm{I}_{\mathrm{s}}$, la cual depende básicamente de la temperatura y del potencial de la unión.

En condiciones de circuito abierto, no existe corriente externa y por tanto $I_{D}=I_{S}$ (equilibrio). En esta situación, circuito abierto, la tensión es nula, con lo cual la tensión o potencial de unión se compensa con la tensión de las uniones metal-semiconductor (ver Figura A.8). Por lo tanto, se cumple, como es de esperar, el principio de conservación de energía.

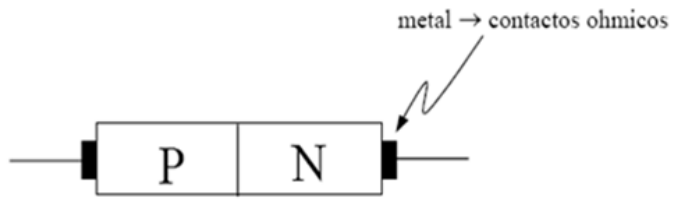

Figura A.8 Circuito abierto en la unión p-n

\section{A.1.3 PRINCIPIO DE FUNCIONAMIENTO DE LA CÉLULA SOLAR}

Como se mencionó previamente, las células solares están constituidas por materiales semiconductores, principalmente silicio, y son elementos que transforman directamente parte de la energía solar que reciben en energía eléctrica. Los electrones de valencia del material semiconductor de la célula, que están ligados débilmente al núcleo de sus átomos, son arrancados por la energía de los fotones de la radiación solar que inciden sobre ella. A este fenómeno se denomina efecto fotovoltaico. 
Como ya se ha comentado anteriormente, la rotura de enlaces y por tanto, la aparición de un par electrón-hueco puede producirse por la absorción de un fotón de energía suficiente (efecto fotovoltaico) o por agitación térmica. El proceso contrario, es decir, la recombinación o desaparición de un par electrón-hueco puede producirse al encontrarse un electrón libre y un hueco (esto es difícil, ya que se necesita condiciones muy específicas) o por la existencia de un defecto de la estructura del material semiconductor.

Tanto la energía necesaria para que ocurra el proceso de generación como la cedida en el de recombinación, tienen un valor determinado, $E_{g}$, denominado ancho de banda prohibida. Así, estos dos fenómenos pueden escribirse con la ecuación reversible siguiente:

$$
e^{-}+h^{+} \leftrightarrow E_{g}
$$

Los electrones libres y los huecos creados por la ruptura del par electrón-hueco tienden a difundirse desde las zonas iluminadas, donde se crean, a las zonas oscuras. Para evitar la recombinación es necesario crear en el interior del semiconductor un campo eléctrico, mediante una unión ' $\mathrm{P}-\mathrm{N}$ ', que separe físicamente éstos dos tipos de portadores o cargas libres móviles, apareciendo así una intensidad de corriente neta que atraviesa la célula solar en sentido de ese campo.

De los dos posibles motivos de recombinación (antes mencionados), el más importante es la existencia de defectos en el cristal que se denominan trampas. Supóngase un semiconductor tipo ' $n$ ', en el que los huecos son minoritarios, y supóngase un defecto en el cristal en estado neutro, como los electrones son muy numerosos, la "trampa o defecto" rápidamente "captura" uno, quedando ionizada negativamente (que es, por ello, el estado de equilibrio de la "trampa" en un semiconductor de este tipo) a la espera de poder capturar un hueco, que es más difícil por ser éstos últimos minoritarios. Cuando lo consigue, de nuevo su estado es neutro y se ha producido una recombinación. Rápidamente captura un electrón y queda cargada negativamente otra vez, a la espera de otro hueco para completar otra recombinación.

Para garantizar que el número de recombinaciones sea el menor posible, es decir, para que se pueda aprovechar la mayoría de las cargas libres producidas por la ruptura de los pares electrón-hueco gracias a los fotones de la radiación solar incidente, el número de "trampas" o defectos del cristal ha de ser la menor posible. Esto se consigue utilizando cristales de silicio puro o silicio monocristalino.

Con estos conceptos ya se puede comprender el principio físico del funcionamiento de una célula solar. Cuando la radiación solar incide sobre la célula, los fotones con energía suficiente rompen el par electrón-hueco dejando éstos portadores libres (efecto fotovoltaico). El campo eléctrico de la unión ' $\mathrm{P}-\mathrm{N}$ ' separa éstos portadores para evitar que se recombinen, llevando los electrones a la zona ' $N$ ' y los huecos a la zona ' $P$ ', apareciendo de 
ese modo una intensidad de corriente neta que atraviesa la célula solar en el sentido de ese campo, de la zona ' $N$ ' a la zona ' $P$ '.

El proceso del principio físico de la celda solar se puede resumir en los siguientes pasos:

- Los fotones incidentes son absorbidos y se generan pares electrón-hueco, tanto en la región $\mathrm{P}$ de la unión como en la región $\mathrm{N}$. Supondremos que se genera una pareja por fotón.

- Los electrones y huecos generados a una distancia inferior a $L_{p} \circ L_{n}$ (longitud de difusión del hueco y electrón) de la zona de vaciamiento, llegan a ella por difusión. En la zona de vaciamiento también se generan pares electrón-hueco debido a la radiación que incide.

- En la zona de vaciamiento, cada miembro de la pareja es separado por el campo eléctrico presente: los huecos se dirigen a la región $\mathrm{P}$ y los electrones a la región $\mathrm{N}$. Éste proceso se puede observar a continuación.

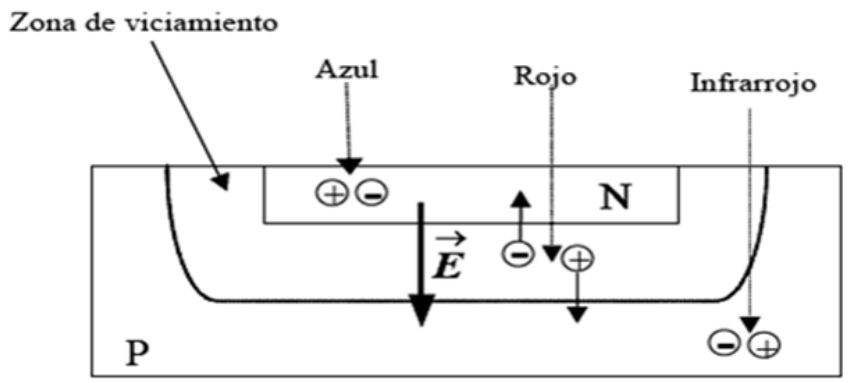

Figura A.9 Separación de los portadores por el campo de la unión p-n

- Si la celda está en circuito abierto, la acumulación de cargas de signos diferentes en los huecos se dirigen a la región $\mathrm{P}$ y los electrones a la región $\mathrm{N}$. Éste proceso se puede observar a continuación.

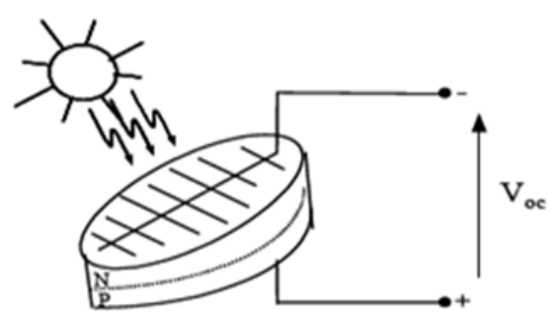

Figura A.10 Célula solar en circuito abierto

- Si la celda está cortocircuitada se genera una corriente de corto circuito $I_{s c}$. Observar que el sentido de la corriente es el mismo que el de la corriente inversa de saturación de la unión PN (diodo). La Figura A.11 ilustra ésta situación: 


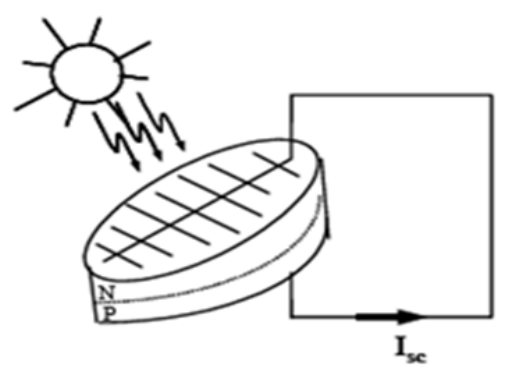

Figura A.11 Célula solar cortocircuitada

Por tanto, si mediante una carga exterior $(R)$ se cierra el circuito, la corriente fotovoltaica generada (I) sale de la célula hacia el circuito exterior por la región ' $P$ ', atraviesa la carga y entra de nuevo a la célula por la región ' $N$ '. Esto que se acaba de mencionar se puede observar en la figura siguiente:

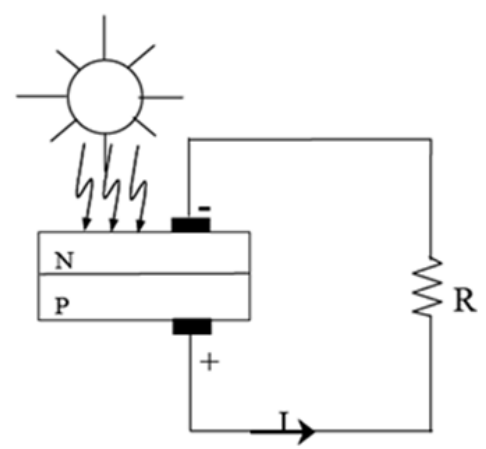

Figura A.12 Corriente fotovoltaica generada

Podemos concluir que la diferencia entre una celda solar y un diodo está en la circulación de la corriente. En un diodo, debido a que funciona con una fuente de tensión que se le aplica en el circuito que esté conectado, cuando está polarizado directamente (se le aplica un potencial más positivo a la región $\mathrm{P}$ y un potencial más negativo a la zona $\mathrm{N}$ ), entonces la corriente que participa en el proceso es la corriente de difusión, con lo cual internamente la corriente circula de la región $\mathrm{P}$ a la región $\mathrm{N}$.

Por otro lado, en la celda solar, debido a la radiación térmica, actúa como un generador, siendo la corriente de saturación inversa $\left(I_{s}\right)$ la corriente que interviene en el proceso y, por tanto, circula de la región $\mathrm{N}$ a la región $\mathrm{P}$. 


\section{A.2 PRINCIPIOS ELÉCTRICOS DE FUNCIONAMIENTO DE MÓDULOS FOTOVOLTAICOS}

Antes de expresar las variables eléctricas que caracterizan a la célula fotovoltaica, así como sus ecuaciones, se van a explicar unos conceptos eléctricos de partida que nos permitirá comprender el funcionamiento eléctrico de una célula fotovoltaica, su curva característica, las variables que la caracterizan, su circuito equivalente...

En el apartado anterior se ha visto la unión P-N en circuito abierto (equilibrio) y sin ninguna fuente de energía exterior aplicada. Si se aplica una tensión directa a la unión P-N, el campo eléctrico se reduce y no se puede parar el flujo de electrones y huecos. Es entonces cuando se produce una corriente. El flujo de corriente aumenta con la tensión externa aplicada, este fenómeno es conocido como la ley del diodo ideal, que se puede expresar por:

$$
I=I_{S}\left[e^{\frac{q V}{K T}}-1\right]
$$

Donde:

$I_{s}$ : corriente de saturación de oscuridad.

$V$ : tensión aplicada.

$q$ : carga de electrón $\left(1,6 \times 10^{-19} \mathrm{C}\right)$

$K:$ constante de Boltzmam: $\mathrm{K}=1,38 \times 10^{-23} \mathrm{~J} / \mathrm{K}$

$T$ : temperatura absoluta.

$\frac{k T}{q}=V_{T}$ : potencial térmico (para el silicio a $25^{\circ} \mathrm{C}$ es igual a $25,7 \mathrm{mV}$ )

La expresión del diodo para los diodos reales es la que sigue:

$$
I=I_{S}\left[e^{\frac{V}{m V_{T}}}-1\right]
$$

Donde $m$ es el factor de idealidad que varía entre 1 y 2 , dependiendo del material y la estructura física del diodo. Si graficamos la expresión del diodo se obtiene la curva característica I-V que sigue: 


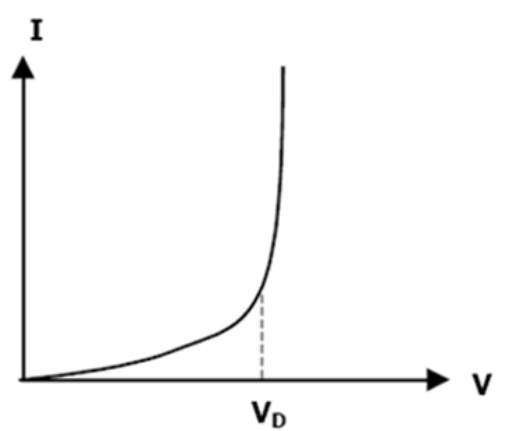

Figura A.13 Curva característica de un diodo

El comportamiento de una célula fotovoltaica se puede ver como el de un diodo, en general de silicio, diseñada para maximizar la absorción de fotones y minimizar la reflexión.

Cuando se conecta una célula fotovoltaica a una resistencia de carga y se ilumina, circula una corriente $I$. En este caso, se puede observar que en la célula la corriente circula de cátodo a ánodo, es decir, internamente circula del semiconductor tipo $\mathrm{N}$ al tipo $\mathrm{P}$ (contrario al sentido de un diodo).

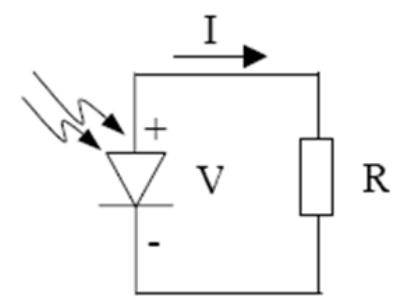

Figura A.14 Circulación de corriente en la célula

El símbolo de una célula o un panel solar fotovoltaico se puede encontrar representado de la siguiente manera:

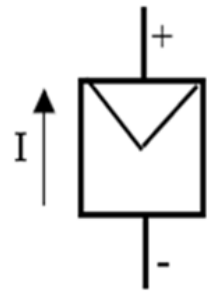

Figura A.15 Símbolo eléctrico de un panel solar

La iluminación de una célula fotovoltaica añade una corriente 'fotogenerada' a la curva característica $I \cdot V$ de modo que su ecuación característica se puede expresar por:

$$
I=I_{S}\left[e^{\frac{V}{m V_{T}}}-1\right]-I_{L}
$$

Dónde $I_{L}$ es la corriente fotogenerada (generada por el efecto fotovoltaico). 
La incidencia de la luz tiene el efecto de mover la curva $I-V$ hacia abajo, en el 4 음 cuadrante, tal como se muestra en la siguiente figura:

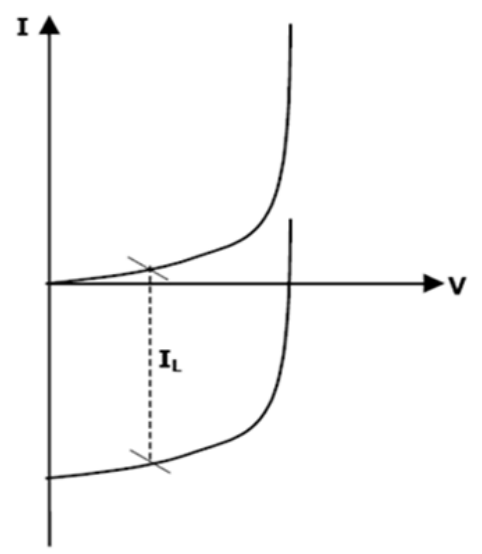

Figura A.16 Curva I-V de una célula fotovoltaica

El modelo o circuito equivalente ideal de una célula fotovoltaica se representa por una fuente de corriente en paralelo con un diodo. La siguiente figura muestra el modelo ideal de una célula fotovoltaica cuando se conecta a una resistencia de carga:

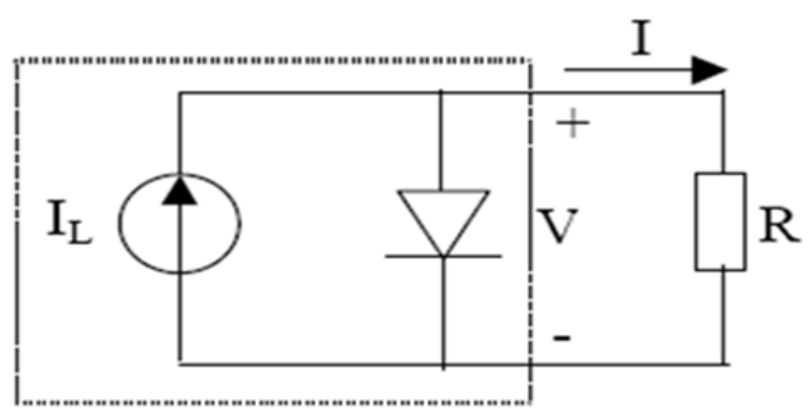

Figura A.17 Circuito ideal de una célula fotovoltaica

No obstante, por acuerdo, la curva característica $I-V$ suele representarse en el primer cuadrante mediante la siguiente ecuación característica:

$$
I=I_{L}-I_{S}\left[e^{\frac{V}{m V_{T}}}-1\right]
$$

Por tanto, la curva I-V característica quedaría: 


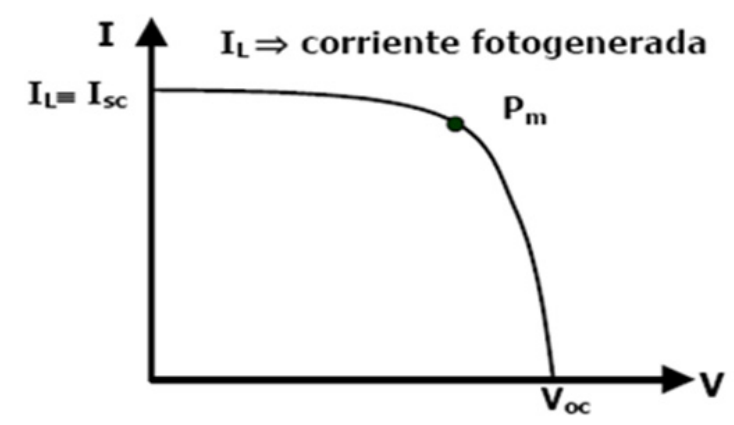

Figura A.18 Curva característica de una célula fotovoltaica

\section{A.2.1 VARIABLES CARACTERÍSTICAS}

Atendiendo a la ecuación característica de una célula fotovoltaica, para diversas situaciones podemos definir una serie de variables que caracterizan su comportamiento.

a) Corriente de cortocircuito (I $\underline{s c}$ : Si cortocircuitamos la célula $(R=0)$, entonces la tensión es nula, $V=0$, y por consiguiente la corriente es: $I_{S C}=I_{L}$. Basta con sustituir $V=0$ en la ecuación característica. Con lo que $I_{s c}$ es indirectamente proporcional a la luz incidente.

b) Tensión de circuito abierto ( $V_{o c}$ : Si abrimos el circuito $(R=\infty)$, entonces $I=0$ y la tensión de la célula es:

$$
V_{o c}=m \cdot V_{T} \ln \left(1+\frac{I_{L}}{I_{S}}\right)
$$

Se puede observar que $V_{O C}$ aumenta logarítmicamente con la irradiación incidente.

Para tener una idea del orden de magnitud, se puede decir que una célula fotovoltaica de silicio monocristalino genera un voltaje de circuito abierto $\left(V_{O C}\right)$ entorno a los $0,7 \mathrm{~V}$ y una corriente de cortocircuito $\left(\mathrm{I}_{\mathrm{Sc}}\right)$ que depende del área de la célula, aproximadamente $3 \mathrm{~A}$ para un área de $100 \mathrm{~cm}^{2}$.

Ambos parámetros se obtienen en unas condiciones estándar de medida de uso universal según la norma EN61215. Establecidas como sigue y que el fabricante debe especificar:

Irradiancia: $1000 \mathrm{~W} / \mathrm{m} 2(1 \mathrm{~kW} / \mathrm{m} 2)$

Distribución espectral de la radiación incidente: AM1.5 (masa de aire)

Incidencia normal

Temperatura de la célula: $25 \% \mathrm{C}$

c) Temperatura de Operación Nominal de la Célula: Otro parámetro que debería ser suministrado es la TONC o Temperatura de Operación Nominal de la Célula. 
Dicho parámetro se define como la temperatura que alcanzan las células solares cuando se somete al módulo a las siguientes condiciones de operación:

Irradiancia: $800 \mathrm{~W} / \mathrm{m}^{2}$

Distribución espectral de la radiación incidente: AM1.5 (masa de aire)

Incidencia normal

Temperatura ambiente: 20 으

Velocidad del viento: $1 \mathrm{~m} / \mathrm{s}$

d) Potencia: La expresión de la potencia entregada por la célula se puede encontrar de la expresión:

$$
P=V \cdot I=V \cdot I_{L}-V \cdot I_{S}\left[e^{\frac{V}{m V_{T}}}-1\right]
$$

Para un valor de la corriente fotovoltaica, $I_{m p}$ y un valor de la tensión, $V_{m p}$, la potencia entregada a la carga será máxima $\left(P_{m}\right)$, a ese punto se le denomina 'Punto de Máxima Potencia'(PMP).

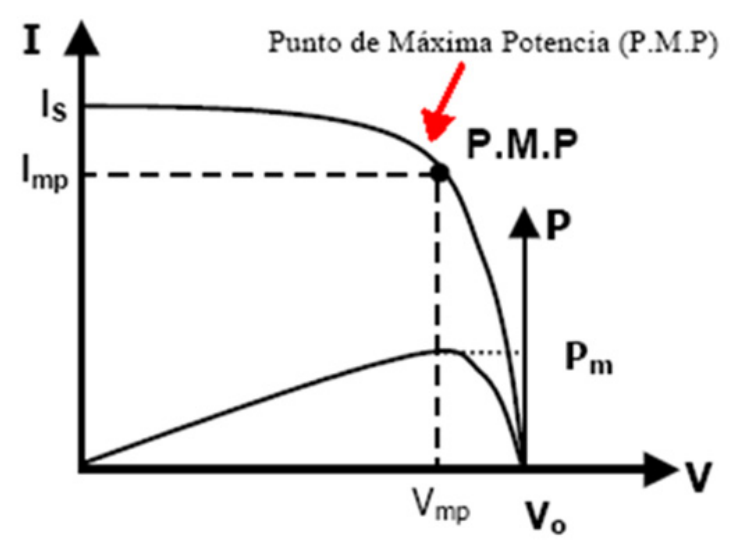

$$
\begin{aligned}
& \mathrm{P}_{\mathrm{m}} \text { : máximo valor de potencia que } \\
& \text { puede entregar el dispositivo. }
\end{aligned}
$$

$I_{m p}:$ corriente a máxima potencia.

$\mathrm{V}_{\mathrm{mp}}$ : tensión a máxima potencia.

Figura A.19 Representación del PMP en la curva característica

Con tal de obtener el mayor rendimiento, lo mejor es hacer trabajar a la célula solar siempre en este valor de potencia máxima mediante un regulador electrónico.

El valor de la tensión de la célula para la potencia máxima, $V_{m p}$ se encuentra haciendo $\frac{d P}{d V}=0$. Por tanto derivando la ecuación de la potencia respecto a la tensión se obtiene:

$$
\left(1+\frac{V_{m p}}{V_{T}}\right) \cdot e^{\frac{V}{m V_{T}}}=1+\frac{I_{L}}{I_{S}}
$$


Y esta ecuación implícita permite encontrar la tensión en el punto de máxima potencia $V_{m p}$. Sustituyendo luego éste valor de tensión en la ecuación de la corriente obtenemos la corriente en el punto de máxima potencia $I_{\mathrm{mp}}$.

e) Eficiencia: Se define el rendimiento o eficiencia ( $\eta$ ) de una célula solar fotovoltaica como el cociente entre la potencia máxima que puede dar a la carga y la potencia luminosa recibida por la célula.

$$
\eta=\frac{V_{m p} \cdot I_{m p}}{P_{L}}
$$

Siendo $P_{L}$ la potencia luminosa (radiación solar) recibida por la célula fotovoltaica.

f) Factor de forma o de relleno: Otra relación importante es el factor de forma o de relleno, $(F F)$. Este factor se define como el cociente entre la potencia máxima que la célula solar fotovoltaica puede dar a la carga y la potencia teórica máxima definida por el punto de cortocircuito y circuito abierto $\left(\mathrm{I}_{\mathrm{sc}}, \mathrm{V}_{\mathrm{oc}}\right)$ :

$$
F F=\frac{V_{m p} \cdot I_{m p}}{V_{o c} \cdot I_{S C}}
$$

Es una medida de la calidad de la unión y de la resistencia serie de la célula. Cuanto mayor es este factor, cuanto más próximo a 1 , la curva característica I- $V$ con iluminación se aproxima más al rectángulo de máxima potencia teórica y, por tanto, la célula es de mayor calidad.

\section{A.2.2 CIRCUITO REAL EQUIVALENTE}

Vistas todas las características anteriores, desde el punto de vista eléctrico una célula fotovoltaica puede representarse por un circuito equivalente (ver figura 3.20).

La célula fotovoltaica al recibir la radiación solar se comporta como un generador de corriente, corriente fotovoltaica, con un diodo en paralelo para detraer la corriente de la oscuridad. Sin embargo, en una célula solar real existen otros efectos, no considerados hasta ahora, que afectan al comportamiento externo de la misma y se representan mediante dos resistencias que representan las pérdidas intrínsecas al diseño y al comportamiento de los materiales de la célula

La resistencia serie, $R_{s}$, es debida principalmente a la resistencia del volumen del material ofrecida por las propias capas semiconductoras, a las interconexiones y a la resistencia entre los contactos metálicos y el semiconductor.

La resistencia paralelo, $R_{p}$, es debida a la no idealidad de la unión PN y a las impurezas cerca de la unión así como a las fugas de corriente por la superficie de los bordes de la célula y 
posibles caminos de difusión a lo largo de dislocaciones, impurezas, pequeños cortocircuitos metálicos, etc. En muchos casos de interés práctico el efecto de resistencia paralelo no tiene apenas importancia en funcionamiento normal.

Con la presencia de ambas resistencias, serie y paralelo, desde el punto de eléctrico una célula fotovoltaica puede representarse por un circuito equivalente como el que se muestra en la figura siguiente:

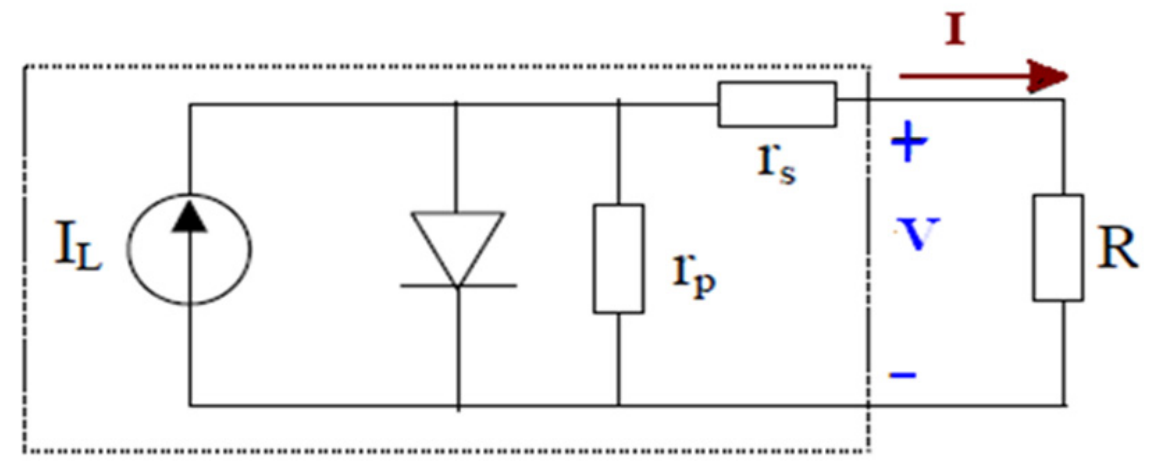

Figura A.20 Circuito equivalente de una célula fotovoltaica

Teniendo en cuenta $R_{S}$ y $R_{P}$, según sigue del análisis de nudos del circuito equivalente de la figura anterior, la ecuación de la célula será:

$$
I(V)=I_{S C}-I_{S}\left(e^{\left(\frac{V+I \cdot R_{S}}{m \cdot V_{T}}\right)}-1\right)-\frac{V+I \cdot R_{S}}{R_{P}}
$$




\section{A.3 PRINCIPIOS DESCRIPTIVOS DE LOS DISPOSITIVOS FOTOVOLTAICOS}

Un sistema fotovoltaico, como se ha comentado anteriormente, se basa en la propiedad que tienen ciertos materiales de convertir la energía luminosa que reciben en energía eléctrica. A la energía luminosa incidente total por unidad de área se le denomina Irradiancia global $G$ y se mide en vatios por metro cuadrado $\left(\mathrm{W} / \mathrm{m}^{2}\right)$. Normalmente, la irradiación se refiere a un cierto periodo de tiempo, y así se habla, por ejemplo, de irradiación horaria, diaria o mensual, como la energía luminosa incidente por unidad de superficie en una hora, un día o un mes, respectivamente.

Debido a la naturaleza aleatoria de la energía solar, no se puede determinar con exactitud la radiación que llegará a la superficie terrestre en el lugar de la instalación. Hay que conformarse con trabajar con datos estadísticos basados en la "historia solar" del lugar, datos normalmente recogidos en las estaciones meteorológicas, y también en tablas y bases de datos. En la mayoría de los casos no encontraremos información detallada y tendremos que asumir valores aproximados para tener cierta idea de la radiación en un lugar determinado a priori.

\section{A.3.1 DESCRIPCIÓN GENERAL DEL SISTEMA}

Un sistema fotovoltaico consta de tres elementos principales, el panel o campo de paneles, el regulador de carga y la batería o acumulador. Los paneles son responsables de generar energía eléctrica, la batería de almacenarla y el regulador de que la batería funcione de manera óptima. Es importante tener en cuenta que los paneles y las baterías de un sistema fotovoltaico trabajan en corriente continua, de modo que si el rango de tensión de operación de tus equipos no incluye la tensión de operación de la batería será necesario utilizar algún tipo de conversor. Si los equipos que quieres alimentar utilizan otra tensión de continua diferente a la de la batería será necesario el uso de un conversor y si alguna de los equipos trabajan en corriente alterna se precisará de un inversor. 


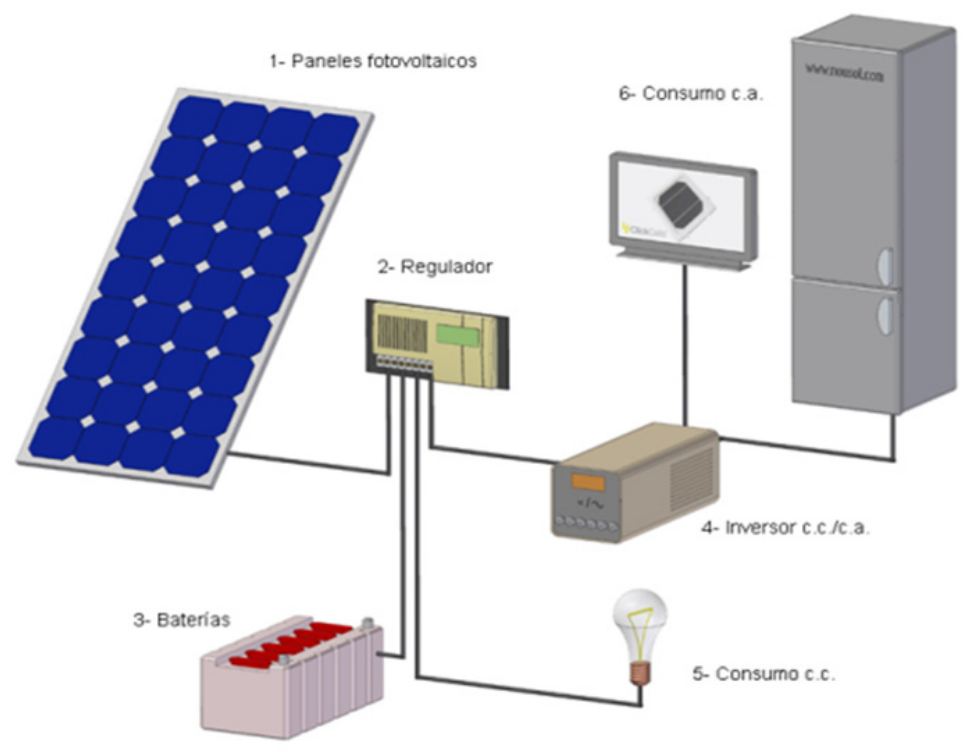

Figura A.21 Elementos del sistema fotovoltaico

\section{A.3.1.1 El generador fotovoltaico o campo de paneles}

Es el elemento captador de energía, que recoge la radiación solar y la transforma en energía eléctrica. Está formado por un conjunto de paneles o módulos fotovoltaicos conectados en serie y/o paralelo, que deben proporcionar la energía necesaria para el consumo. La corriente que da un campo de paneles varía proporcionalmente a la irradiación solar y la potencia de éstos. Como la irradiación solar varía en el tiempo debido a las condiciones climatológicas, la hora del día, etcétera, debemos contar con un acumulador de energía para disponer de energía durante cualquier instante.

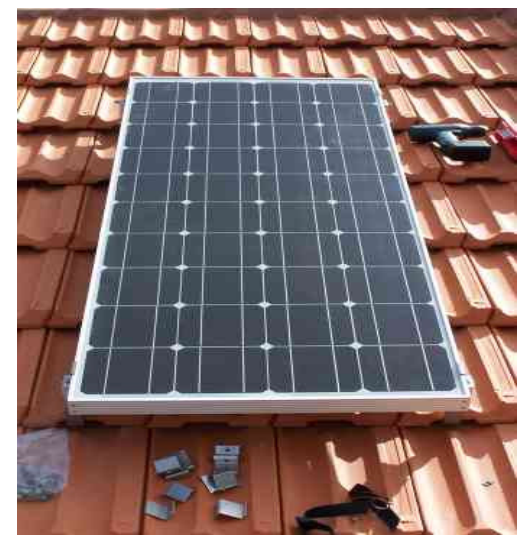

Figura A.22 Panel solar fotovoltaico

\section{A.3.1.2 La batería o acumulador}

La batería se encarga de almacenar la energía producida por los paneles que no se consume inmediatamente, para disponer de ella en periodos de baja o nula irradiación solar. Otra importante función de las baterías es la de proveer una intensidad de corriente superior a la que el dispositivo fotovoltaico puede entregar. Tal es el caso de un motor, que 
en el momento del arranque puede demandar una corriente de 4 a 6 veces su corriente nominal durante unos pocos segundos.

Normalmente el banco de baterías y los módulos fotovoltaicos trabajan conjuntamente para alimentar las cargas. Durante la noche toda la energía demandada por la carga la provee el banco de baterías. En horas tempranas de la mañana los módulos comienzan a generar, pero si la corriente que entregan es menor que la que la carga exige, la batería deberá contribuir en el aporte. A partir de una determinada hora de la mañana la energía generada por los módulos fotovoltaicos superada la energía promedio demandada. Los módulos no solo atenderán la demanda sino que además, todo exceso se almacenara en la batería que empezara a cargarse y a recuperarse de su descarga de la noche anterior. Finalmente durante la tarde, la corriente generada decrece y cualquier diferencia con la demanda la entrega a la batería. En la noche, la generación es nula y todo el consumo lo afronta la batería.

Las baterías que usualmente se utilizan en esta aplicación son de plomo-ácido de electrolito líquido. Dentro de ésta categoría (plomo-ácido), las de plomo - antimonio, plomo - selenio y plomo - calcio son las más comunes. Los acumuladores electroquímicos como las baterías de plomo-ácido también cumplen dos importantes misiones:

- Suministrar una potencia instantánea superior a la que el campo de paneles puede generar, necesaria para la puesta en marcha de algunos elementos (por ejemplo, el motor del frigorífico).

- Determinar el margen de tensiones de trabajo de la instalación.

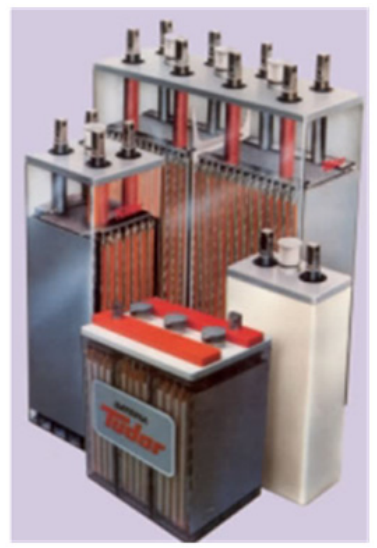

Figura A.23 Diferentes baterías para fotovoltaica

Se puede hacer una clasificación de las baterías en base a su capacidad de almacenamiento de energía (medido en Ah a la tensión nominal) y a su ciclo de vida (número de veces en que la batería puede ser descargada y cargada a fondo antes de que se agote su vida útil).

La capacidad de almacenaje de energía de una batería depende de la velocidad de descarga y se corresponde a un tiempo de descarga de 10 horas. Cuanto mayor es el tiempo de 
descarga, mayor es la cantidad de energía que la batería entrega. Un tiempo de descarga típico en sistemas fotovoltaicos es 100 horas. Por ejemplo, una batería que posee una capacidad de 80 Ah en 10 hs (capacidad nominal) tendrá 100 Ah de capacidad en 100 horas.

Dentro de las baterías de plomo - ácido, las denominadas estacionarias de bajo contenido de antimonio son una buena opción en sistemas fotovoltaicos. Ellas poseen unos 2500 ciclos de vida cuando la profundidad de descarga es de un $20 \%$ (es decir que la batería estará con un $80 \%$ de su carga) y unos 1200 ciclos cuando la profundidad de descarga es del $50 \%$ (batería con $50 \%$ de su carga). Las baterías estacionarias poseen además, una baja auto-descarga (3\% mensual aproximadamente contra un $20 \%$ de una batería de plomo - ácido convencional) y un reducido mantenimiento.

\section{A.3.1.3 El regulador de carga}

El regulador asegura que la batería funcione en condiciones apropiadas, evitando la sobrecarga y sobredescarga de la misma, ambos fenómenos muy perjudiciales para la vida de la batería. El procedimiento que utiliza para ello es determinar el estado de carga de la batería a partir de la tensión a la que ésta se encuentra.

A partir de este parámetro y el conocimiento del tipo de tecnología que se usa en la batería se controla la entrada y salida de corriente en la misma. Los reguladores actuales introducen microcontroladores para la correcta gestión de un sistema fotovoltaico. Su programación elaborada permite un control capaz de adaptarse a las distintas situaciones de forma automática, permitiendo la modificación manual de sus parámetros de funcionamiento para instalaciones especiales. Incluso los hay que memorizan datos que permiten conocer cuál ha sido la evolución de la instalación durante un tiempo determinado. Para ello, consideran los valores de tensión, temperatura, intensidad de carga y descarga, y capacidad del acumulador incluyendo elementos que, aunque no sean imprescindibles, realizan útiles tareas de control o seguridad: amperímetros, voltímetros, contadores de amperios-hora, temporizadores, alarmas, etcétera.

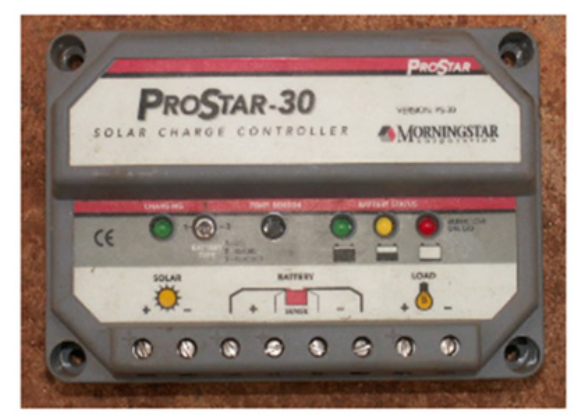

Figura A.24 Controlador de carga solar de 30A para un campo de paneles de corriente máxima 25A. 


\section{A.3.1.4 El convertidor o inversor}

La electricidad que proporciona el sistema paneles-acumulador es continua, y se extrae a una tensión determinada, lo cual no siempre coincide con las exigencias de los equipos de consumo. Un convertidor continua-alterna (las siglas en inglés DC/AC), permite alimentar equipos que funcionen con corriente alterna. Si fuese necesario también se pueden usar convertidores continua-continua (en inglés, DC/DC) que transformen la tensión continua de las baterías en tensión de alimentación también continua pero de distinto valor. A la hora de diseñar un sistema de comunicaciones que usa energía fotovoltaica es recomendable que todas las cargas trabajen a la tensión que suministran las baterías evitando el uso de convertidores.
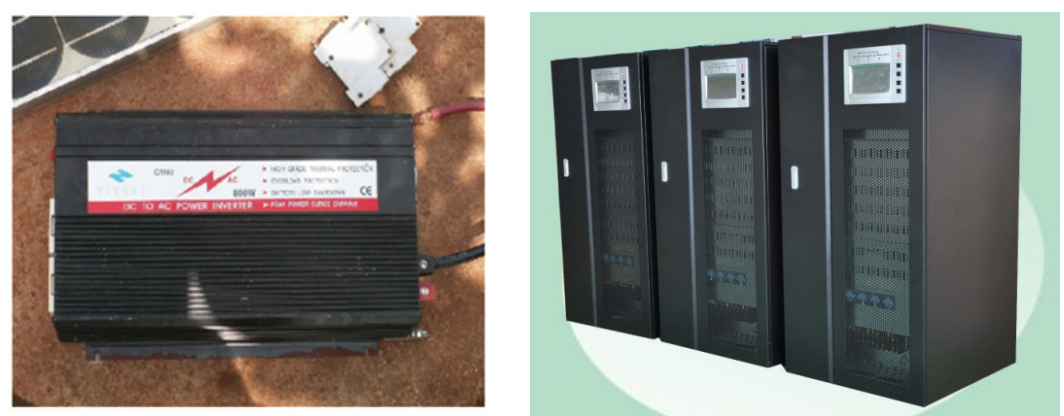

Figura A.25 Inversores DC/AC de baja potencia para un módulo fotovoltaico y grupos de inversores para grandes centrales fotovoltaicas

\section{A.3.1.5 Los equipos de consumo o cargas}

Son los equipos que se conectan al sistema y que consumen la energía generada por el mismo (equipos de comunicaciones inalámbricas, enrutadores, estaciones de trabajo, iluminación, TVs, etcétera.). Aunque no es posible saber con certeza absoluta cuál va a ser el consumo total de dichos equipos en operación es vital, para un cálculo correcto del sistema, hacer una buena estimación del mismo. Asimismo, hay que tener cuidado en elegir equipos eficientes, para no derrochar energía. Por ejemplo, en escenarios donde sea necesario dimensionar equipos de comunicaciones por energía solar debemos considerar equipos basados en arquitecturas de bajo consumo.

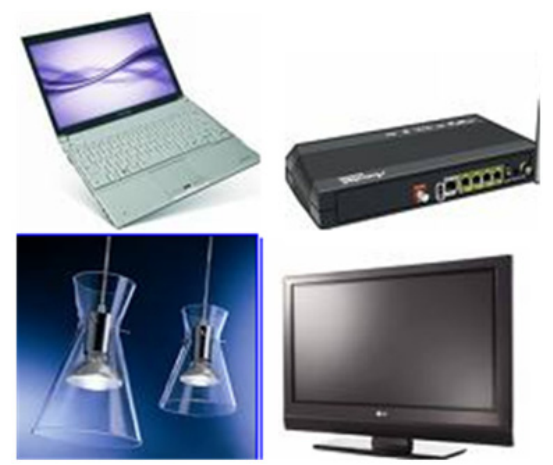

Figura A.26 Diferentes equipos de consumo 


\section{A.3.2 DESCRIPCIÓN GENERAL DE LAS INSTALACIONES FOTOVOLTAICAS}

En la actualidad, se distinguen dos grandes grupos en los que las instalaciones fotovoltaicas se dividen según nuestras necesidades y aplicaciones, las instalaciones aisladas y las que están conectadas a la red eléctrica. En el primer caso, las posibilidades de aplicación son enormes, desde viviendas o equipamientos aislados $y / 0$ independientes hasta centrales eléctricas rurales, telecomunicaciones, bombeo de agua, protección catódica, señalizaciones, equipos de sonido, sistemas de iluminación etc.

Una instalación solar fotovoltaica puede situarse casi en cualquier lugar con buena radiación solar, requiriendo diferentes tamaños. Se trata de una tecnología renovable de generación de electricidad fácilmente instalable y cuya producción puede distribuirse directamente en los puntos de consumo de nuestros pueblos y ciudades, donde y cuando se consume la mayoría de la electricidad del país. De esta forma, cualquier edificio puede convertirse en una pequeña central generadora de electricidad.

Sin embargo, y valorando positivamente las posibilidades que ofrecen los sistemas aislados, sobre todo en zonas rurales apartadas de centros urbanos y por su contribución a la solidaridad, se considera que donde la energía solar fotovoltaica puede ofrecer un diferencial significativo en Europa es en los sistemas conectados a la red, dado que los niveles de electrificación son próximos al nivel de saturación.

A continuación se presentan de manera descriptiva cada una de ellas.

\section{A.3.2.1 Instalaciones fotovoltaicas aisladas de la red}

Las instalaciones aisladas de la red tienen como objetivo proporcionar energía a zonas rurales, señalizaciones, bombeo de agua o alumbrado público, en general. Por esta razón se suele necesitar baterías o acumuladores para poder seguir haciendo uso de la energía en las horas de menor producción, como pueden ser las nubes o las noches. Estas instalaciones solares suelen estar fijas pero su posición debe ser estudiada previamente.

En la siguiente figura se representa un esquema genérico de la instalación. Podemos ver que el módulo fotovoltaico está directamente conectado al regulador de la carga, el cual desvía la electricidad a donde es preciso, o al consumo que funciona con corriente continua, o a la batería si está descargada. De la batería saldrá la electricidad demandada por el consumo de corriente alterna, pero antes pasará por el inversor para convertir la corriente continua en corriente alterna. 


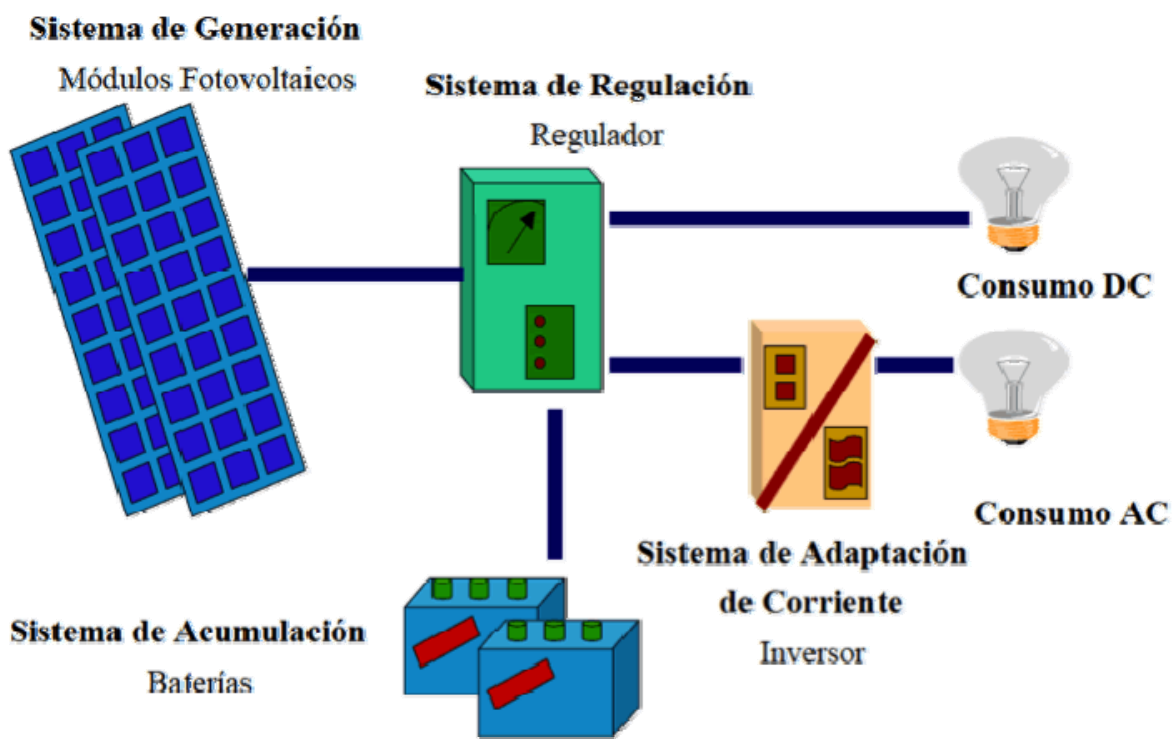

Figura A.27 Esquema de una instalación aislada de la red

Los paneles deben de estar orientados al sur pero la inclinación es lo que varía según el hemisferio, la posición exacta donde nos encontremos y la utilidad que le vayamos a dar a la energía producida. Por ejemplo, si nos encontramos en Cartagena cuya latitud es de $37^{\circ}$ y la instalación es para un funcionamiento anual, la inclinación deberá de ser de $37^{\circ}$, si su uso fuera en invierno o verano, la inclinación variaría sumándole o restándole a la latitud 15 grados respectivamente.

\section{A.3.2.2 Instalaciones fotovoltaicas conectadas a la red}

Estas instalaciones se usan para generar electricidad y abastecer a la población, suele tratarse de campos o centrales fotovoltaicas. Generalmente se ubican varios módulos sobre una estructura que puede ser fija o móvil que permita un mayor aprovechamiento de la radiación solar a lo largo del día.

En estas instalaciones no es necesario el uso de baterías porque la electricidad generada se inyecta directamente a la red eléctrica. El campo de módulos fotovoltaicos se conectan al inversor/es que convierten la corriente continua generada en alterna al igual que se incorporan aparatos de control para una correcta inyección de la electricidad (Figura A.28). 


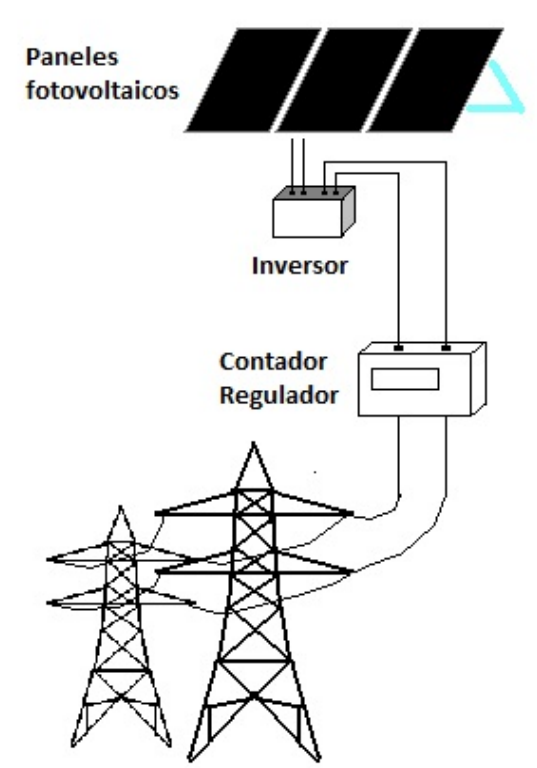

Figura A.28 Esquema de una instalación conectada a la red

En las instalaciones fotovoltaicas conectadas a la red, los paneles fotovoltaicos suelen emplazarse sobre estructuras móviles, seguidores solares, con el fin de obtener una mayor generación de energía eléctrica gracias a su sistema de seguimiento con el que se aprovecha al máximo la luz solar a lo largo del día.

Un seguidor solar es un dispositivo mecánico capaz de orientar los paneles solares de forma que éstos permanezcan aproximadamente perpendiculares a los rayos solares, siguiendo al sol desde el este en la alborada hasta el oeste en la puesta. Podemos encontrar seguidores solares a uno o dos ejes.

El seguidor solar a un eje goza de un grado de libertad, de modo que puede girar en torno a un eje. Generalmente realiza un seguimiento del Sol de este a oeste, desde que amanece hasta que anochece a lo largo de un día en un plano paralelo al suelo. Con este sistema de seguimiento se aumenta un $27 \%$ la producción anual respecto la generada por una instalación solar fotovoltaica fija, sin seguimiento alguno. Este tipo de seguidores son más sencillos lo que conlleva menores costes, ero ofrecen un seguimiento poco preciso captando menor energía que los de dos ejes.

Los seguidores a dos ejes gozan de dos grados de libertad los que permiten llevar a cabo un doble seguimiento del Sol, de este a oeste y además de norte a sur simultáneamente, por lo que la producción eléctrica es un $5 \%$ mayor que el seguimiento a un eje y alrededor de un $35 \%$ mayor respecto a una instalación fotovoltaicas sin seguimiento.

En la siguiente figura se muestra una comparación de la energía capaz de recibir los paneles fotovoltaicos en instalaciones de seguimiento a dos ejes e instalaciones fijas. 


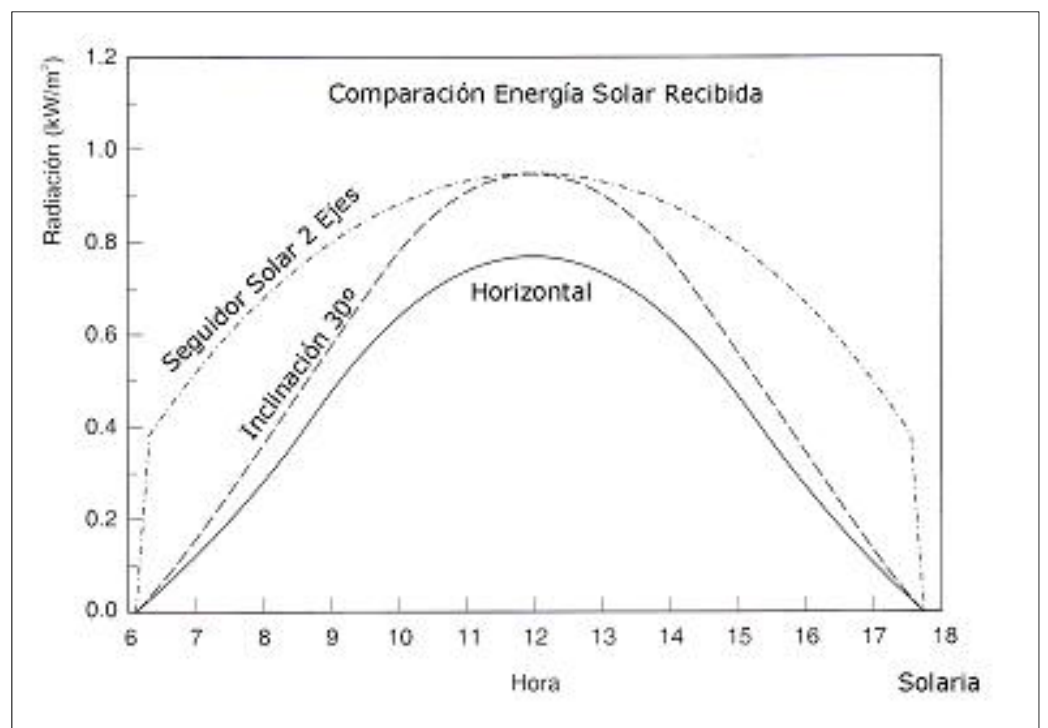

Figura A.29 Comparación de la radiación captada por instalaciones fijas e instalaciones con seguimiento a dos ejes a lo largo de un día

Mediante un seguimiento a dos ejes se aprovecha totalmente la radiación solar a lo largo del día, dado que las instalaciones fijas (con inclinación de panel de $30^{\circ}$ ) desaprovechan entre 100 y $400 \mathrm{~W} / \mathrm{m}^{2}$ de radiación a primeras y últimas horas de luz solar mientras que al mediodía (de 11 a 13h) se observa como ambas instalaciones reciben la misma radiación, generando la misma energía ya que es cuando ambos reciben los rayos perpendicularmente a sus superficies.

\section{A.3.2.3 Instalaciones fotovoltaicas según la potencia instalada}

En un contexto de continuo crecimiento del sector de la energía solar, se han multiplicado las instalaciones fotovoltaicas en nuestro país. Es por ello que existe otra clasificación de éstas atendiendo la potencia instalada conforme establece la Asociación de la Industria Fotovoltaica (ASIF).

La potencia de las instalaciones fotovoltaica se da en Wp (vatios pico), que corresponde a la potencia que dan los módulos a condiciones estándar de medida $\left(25^{\circ} \mathrm{C}\right.$ a $\left.1000 \mathrm{~W} / \mathrm{m}^{2}\right)$. La potencia en $\mathrm{Wp}$ del módulo corresponde, aproximadamente, a la potencia máxima que puede generar.

Existen tres rangos de potencia representativos de los distintos tipos de instalaciones de generación fotovoltaica, además d una cuarta tipología, correspondiente a las centrales.

- Instalaciones pequeñas (hasta $5 \mathrm{~kW}$ ): Son orientadas a aplicaciones rurales aisladas por ser una solución limpia y muchas veces económica, o aplicaciones conectadas a red sobre tejados, azoteas de casas, hechas por particulares en zonas de su propiedad o influencia. Con la generación de $3 \mathrm{kWp}$ se cubriría el consumo propio de una casa tipo medio en el que vivan entre 2 y 3 personas, excluyendo el consumo de calefacción y aire acondicionado. 
- Instalaciones medianas (entre 5 y $100 \mathrm{kWp}$ ): Estas instalaciones se utilizan en electrificaciones rurales centralizadas, o conectadas a red en edificios, normalmente integrados en la arquitectura de los mismos, instalaciones diseñadas por arquitectos innovadores y realizadas por comunidades de vecinos, empresas constructoras o corporaciones públicas y privadas que desean incorporar energía fotovoltaica en sus edificios o construcciones emblemáticas como valor añadido. Una instalación de $30 \mathrm{kWp}$ en un edificio supondría cubrir las necesidades eléctricas de diez viviendas medias.

- Instalaciones grandes (entre $100 \mathrm{kWp}$ y $1 \mathrm{MWp}$ ): Son generalmente instalaciones conectadas a la red, de superficies extensas, promovidas generalmente por empresas que, además de contribuir a una generación limpia, desean un refuerzo de la imagen de la empresa o entidad promotora. Una planta de $300 \mathrm{kWp}$ cubre el consumo de un edificio tipo medio.

- Centrales fotovoltaicas (entre 1 y $50 \mathrm{MWp}$ ): Son centrales de generación, promovidas generalmente por empresas o consocios de empresas, siendo generalmente una de ellas la empresa local de distribución. Estas empresas desean conseguir cierto rendimiento económico y una componente de generación verde. Una planta de $3 \mathrm{MWp}$ cubre el consumo de una población o urbanización de aproximadamente 500 vecinos. 


\section{ANEXO B: CONFIGURACIÓN DEL CAMPO FOTOVOLTAICO DE LA INSTALACIÓN SOLAR CORONIL II}

La configuración del campo fotovoltaico con los distintos modelos de paneles instalados y la potencia pico por inversor se presentan a continuación.

\begin{tabular}{|c|c|c|c|c|c|c|c|c|c|c|c|c|c|c|c|c|c|c|c|c|c|}
\hline \multirow{4}{*}{ DISTRIBUCIÓN } & \multicolumn{3}{|c|}{$\mathrm{c} 7$} & \multirow{2}{*}{\multicolumn{4}{|c|}{\begin{tabular}{|c|}
\multicolumn{1}{c}{${ }^{c}$} \\
\end{tabular}}} & \multicolumn{4}{|c|}{ C6 } & \multicolumn{3}{|c|}{$c_{4}$} & \multicolumn{3}{|c|}{$\mathrm{Cs}$} & \multicolumn{3}{|c|}{$\mathrm{C2}$} & \multirow{2}{*}{$\frac{\mid c 1}{125}$} \\
\hline & \begin{tabular}{|l|l|}
17 & 12 \\
\end{tabular} & 13 & 14 & \begin{tabular}{|l|}
16 \\
6
\end{tabular}$-10$ & & & 18 & 18 & $\begin{array}{ll}\mathrm{nO} \\
\mathrm{nO}\end{array}$ & & & \begin{tabular}{l|l}
113 & 11 \\
11
\end{tabular} & \begin{tabular}{l|l|}
14 & 116 \\
\end{tabular} & & \begin{tabular}{|l|l|l|}
17 & $\mathrm{HI}$ \\
\end{tabular} & 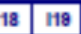 & 120 & \begin{tabular}{|l|l|l|}
121 & 122 \\
\end{tabular} & 123 & \begin{tabular}{|l|l|}
124 & -1 \\
\end{tabular} & \\
\hline & \begin{tabular}{l|l|l}
7.1 & 7.2 \\
\end{tabular} & 73 & 7.4 & 8.1 & 8.2 & \begin{tabular}{l|l|l|l|}
8.3 & \\
\end{tabular} & 8.4 & 6.1 & \begin{tabular}{l|l|l|l|l|}
62 & \\
\end{tabular} & \begin{tabular}{l|l}
5.3 & 6 \\
\end{tabular} & 5.4 & \begin{tabular}{l|l}
4.1 & 4. \\
\end{tabular} & \begin{tabular}{l|l|}
1.2 & 4.3 \\
\end{tabular} & 4.4 & \begin{tabular}{l|l|l}
3.1 & 3.2 \\
\end{tabular} & \begin{tabular}{l|l|}
12 & 2.3 \\
\end{tabular} & 3.4 & \begin{tabular}{l|l}
2.1 & 2.2 \\
\end{tabular} & 23 & 24 & 1.1 \\
\hline & Trato 1 & Trat & too 2 & Trat & & Trate & & \begin{tabular}{|l|l|l|} 
Trato \\
\end{tabular} & & Trato & & $T r=07$ & & atos 8 & Tratos & & tho 10 & Traso 11 & Trato & & $\overline{T 13}$ \\
\hline Sharp 173 & & & & & & & & & & & & & & & & 342 & & \begin{tabular}{|l|l|l|}
2654 & 2654 \\
\end{tabular} & & 666 & 2564 \\
\hline Sharp 180 & & & & & & & & & & & & & & & $25922_{259}$ & 168 & & 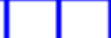 & 2592 & 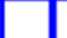 & 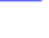 \\
\hline Solar World 210 & & & & & & & & & & & & $\left.2178\right|_{211}$ & & & & 352 & & & & & \\
\hline Surtech 250 & & & & & 1332 & & 1900 & & & & & & & & & & & & & - & \\
\hline Surtech 270 & & & & 1728 [ & 432 & & & 1772 & & 17728 & & & & & & & & & & 180 & \\
\hline Surtech 280 & & 1656 & & & & & & & & & & & & & & & & & & 216 & \\
\hline ET 220 & $\left.1728\right|_{172}$ & & 1729 & & & 1728 & & & & & & & & & & & & & & 432 & 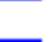 \\
\hline YINGLIZZ & & & & & & & & & 2112 & & 112 & & 2112 & 2112 & & 528 & 2112 & & & 528 & \\
\hline TOTAL & $\left.1728\right|_{172}$ & $\left.\right|_{1656}$ & 1728 & $\mid 1728$ & & $|1728|_{1}$ & & 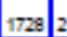 & & $1728]_{21}$ & & & $178 \mid 2112$ & & & 1390 & & $\left.2654\right|_{2654}$ & & 2022 & 2564 \\
\hline
\end{tabular}

\begin{tabular}{|c|c|c|c|c|c|c|c|c|c|c|c|c|c|c|c|c|c|c|c|c|c|c|c|c|c|}
\hline \multirow[b]{2}{*}{ DISTRIBUCIÓN } & \multicolumn{4}{|c|}{$\mathrm{c7}$} & \multicolumn{4}{|c|}{ C8 } & \multicolumn{4}{|c|}{$\mathrm{c} 6$} & \multicolumn{4}{|c|}{$\mathrm{c}_{4}$} & \multicolumn{4}{|c|}{$\mathrm{Cs}$} & \multicolumn{3}{|c|}{$\mathrm{C}_{2}$} & & \multirow{2}{*}{$\frac{91}{126}$} \\
\hline & 11 & 12 & 13 & 14 & 16 & 18 & 17 & 18 & 18 & 110 & 111 & 112 & \begin{tabular}{|l|l|}
173 \\
\end{tabular} & 114 & & ne & \begin{tabular}{|l|l|}
117 \\
\end{tabular} & \begin{tabular}{l|l|l|l|}
18 & -1 \\
\end{tabular} & 119 & 120 & \begin{tabular}{|l|l|l|}
121 & $\mathrm{~B}$ \\
\end{tabular} & 122 & 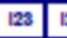 & 124 & \\
\hline & & 72 & 7.3 & 7.4 & 8.1 & 82 & 8.3 & 8.4 & 6.1 & 6.2 & \begin{tabular}{l|l}
6.3 & \\
\end{tabular} & 6.4 & 4.1 & \begin{tabular}{l|l}
4.2 & \\
\end{tabular} & $\begin{array}{ll}43 \\
\end{array}$ & 4.4 & 3.1 & 3.2 & & 2.4 & & 2.2 & & 2.4 & 1.1 \\
\hline & Trate & & Trats & & $T \pi T_{1}$ & & Trat & & Trat & & Trato & & \begin{tabular}{|l|l|}
$T R^{2}$ \\
\end{tabular} & & Trato & & Trato & & Trato & 10 & \begin{tabular}{|l|l|} 
Trato 1 \\
\end{tabular} & & Treto & & $\overline{\tau_{19}}$ \\
\hline Shap 173 & & & & & & & & & & & & & 1 & & & & 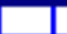 & 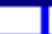 & 592 & & & 451 & & & 461 \\
\hline Shapp 180 & & & & & & & & & & & & & & & & & 467 & 457 & 302 & & & & 457 & & 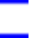 \\
\hline Soler World 210 & & & & & & & & & & & & & 457 & 457 & & & & & 73,9 & & & & & & \\
\hline Suntech 260 & & & & & & 346 & & & & & & & & & & & & & & & & & & & 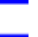 \\
\hline Suntech 220 & & & & & 467 & 117 & & & 457 & & 457 & & & & & & & 1 & 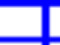 & 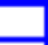 & & & & 48,5 & 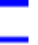 \\
\hline Suntech 280 & & & 464 & & & & & & & & & & & & & & & & 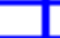 & & & & & 50,5 & \\
\hline ET 270 & 457. & 467 & & 467 & & & 457 & & & & & & & & & & & & 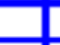 & 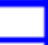 & & & & 1117 & \\
\hline YINCLI Z20 & & & & & & & & & & 465 & & 455 & & & 465 & 465 & & & 116 L. & 455 & & & & 115 & \\
\hline TTOTAL & |457| & 467 & 54 & 467 & 167. & 463 & 467 & & 457 & 455 & 457 & $-6=$ & & & & & & & 279 & & & & 45 & $45:$ & 451 \\
\hline
\end{tabular}

Figura B.1 Distribución de los diferentes paneles fotovoltaicos y potencia pico por inversor en el campo fotovoltaico Coronil II. 


\section{ANEXO C: CARGA ELECTRÓNICA PARA PANELES FOTOVOLTAICOS}

\section{1.- INTRODUCCIÓN.}

Para obtener la característica V-I de un panel solar, este deberá estar conectado a una carga variable que permita absorber la energía que genere en sus diferentes puntos de funcionamiento. Se ha diseñado una carga electrónica que podrá ser controlada desde un ordenador personal. La carga diseñada tendrá dos posibles modos de funcionamiento: a corriente constante y a tensión constante.

Las características de esta carga son:

- Tensiones de funcionamiento: 0-50V.

- Corriente de pico: 25A.

- Potencia máxima: 300W.

Para obtener la característica completa de un panel deberá funcionar no solo como carga sino también como "generador", ya que para obtener con seguridad el valor nulo de tensión (corriente de cortocircuito) se hará funcionar al panel como carga, es decir, con tensión negativa en sus extremos.

\section{2.- Característica V-I.}

Debido a que la característica de un generador fotovoltaico es una función decreciente la tensión en el panel disminuirá siempre que se aumente la corriente o viceversa. Gracias a esta propiedad puede asegurarse que mediante una fuente de corriente se puede obtener cualquier tensión en bornes de un sistema fotovoltaico.

Se puede simplificar el modelo para un panel fotovoltaico y linealizarlo, como se ve en la Fig. C.1, aproximando la curva característica a una recta de pendiente negativa " $\mathrm{k}$ "

$$
I(s)=-k V(s)
$$




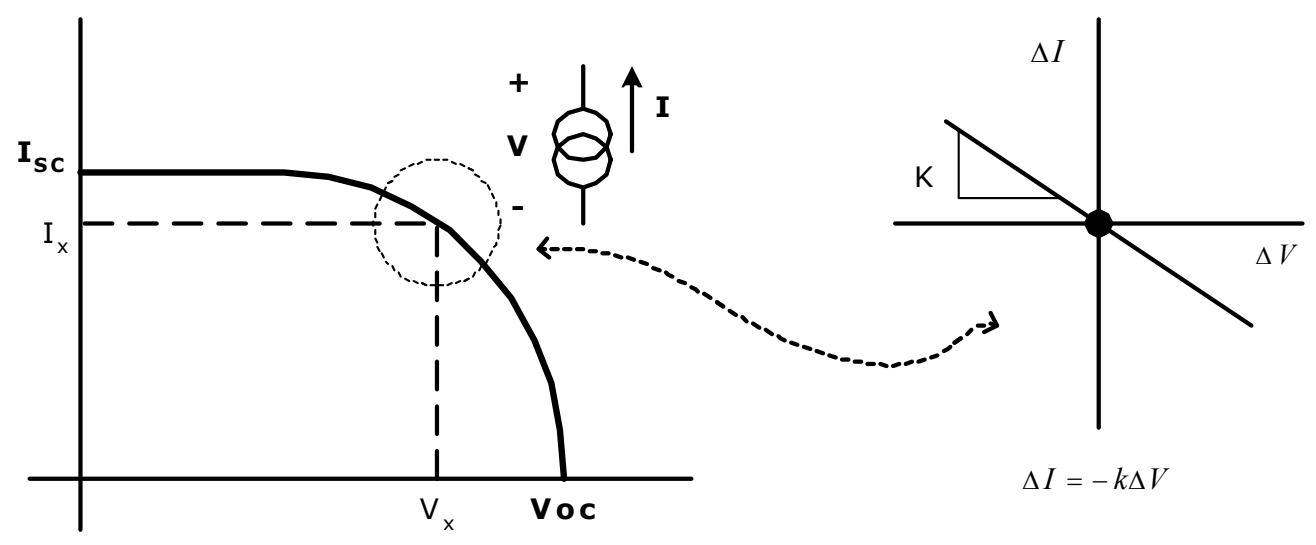

Figura C.3 Curva característica y linealización.

\section{C.3 Carga electrónica.}

En el circuito de la Fig. C.2, donde $\mathrm{I}_{\mathrm{FV}}$ es la corriente que proporciona el panel, la tensión en bornes del condensador puede controlarse mediante la corriente $\mathrm{I}_{\mathrm{T}}$. Si esta corriente es superior a la aportada por la célula $\left(I_{\mathrm{FV}}\right)$ la tensión en el condensador decrecerá y en caso contrario aumentará, con lo que se hace el sistema más sensible a las variaciones de tensión.
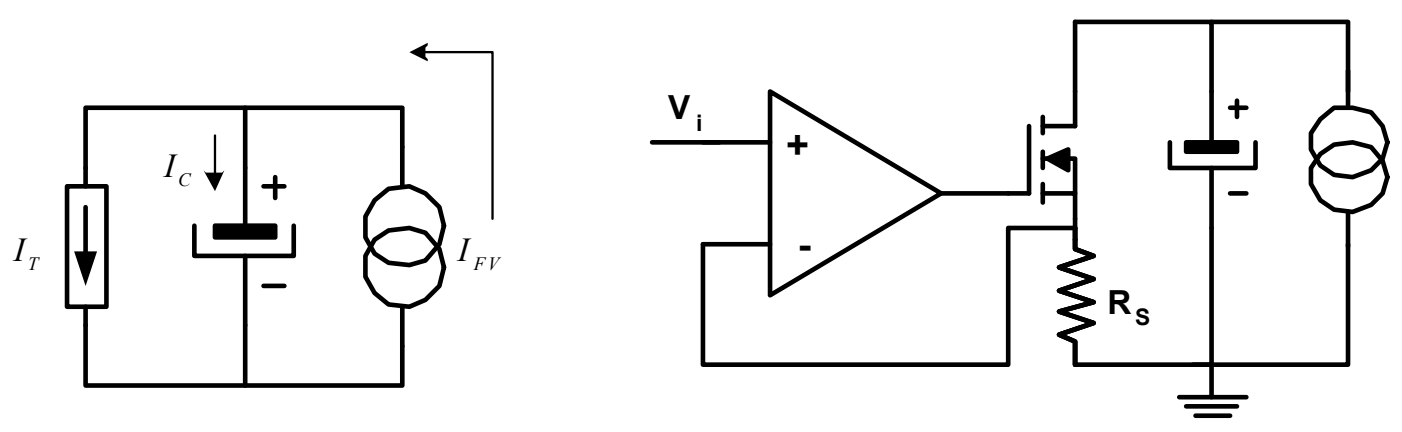

Figura C.4 Circuito simplificado. Fuente de corriente.

$$
\begin{gathered}
i_{c}=C \frac{d v}{d t} \\
V(s)=\frac{I_{c}(s)}{C s} \mathrm{ec} \\
I_{T}+I_{C}=I_{F V}
\end{gathered}
$$

Teniendo en cuenta la ecuación linealizada de la característica de la célula o de un panel, Ec. C.1, la función de transferencia del sistema panel-fuente-condensador es la Ec.C.5, 


$$
V(s)=\frac{-I_{T}}{C s+k}
$$

Con la fuente de corriente $I_{T}$ se puede variar la tensión y la corriente en la célula. Aumentando o disminuyendo $\mathrm{I}_{\mathrm{T}}$ (Fig.C.2 (izq.)) variará la tensión en la célula solar (como ya se ha mencionado).

La fuente de corriente ha sido implementada, como muestra la Fig. C.2 (dcha.), con un operacional y transistores MOS, dada la facilidad de estos para su conexión en paralelo, para así poder trabajar con potencias elevadas.

Uno de los problemas que presenta el sistema es que la dinámica del panel es desconocida, desconocemos el valor de $k$ pero si los límites entre los que variará, pero se puede considerar que el conjunto Operacional-Transistor MOS es muy rápido pudiéndose expresar la corriente a través del mismo como:

$$
I_{T} \approx \frac{V_{\text {control }}}{R}
$$

La Fig. C.3 muestra el diagrama de bloques del sistema. La tensión en bornes de la célula no está referida a masa por lo que deberá utilizarse un amplificador diferencial. En el circuito ha sido implementado mediante un amplificador operacional, con una ganancia $\beta$.

La tensión, $\mathrm{V}$, es comparada con la tensión de referencia, $\mathrm{V}_{\text {ref, }}$ que es la que se pretende que siga el sistema total. Para poder comparar el valor de " $\mathrm{V}$ " con la tensión de referencia, esta deberá ser multiplicada por la ganancia del amplificador diferencial. La diferencia entre estos dos valores es el error cometido.

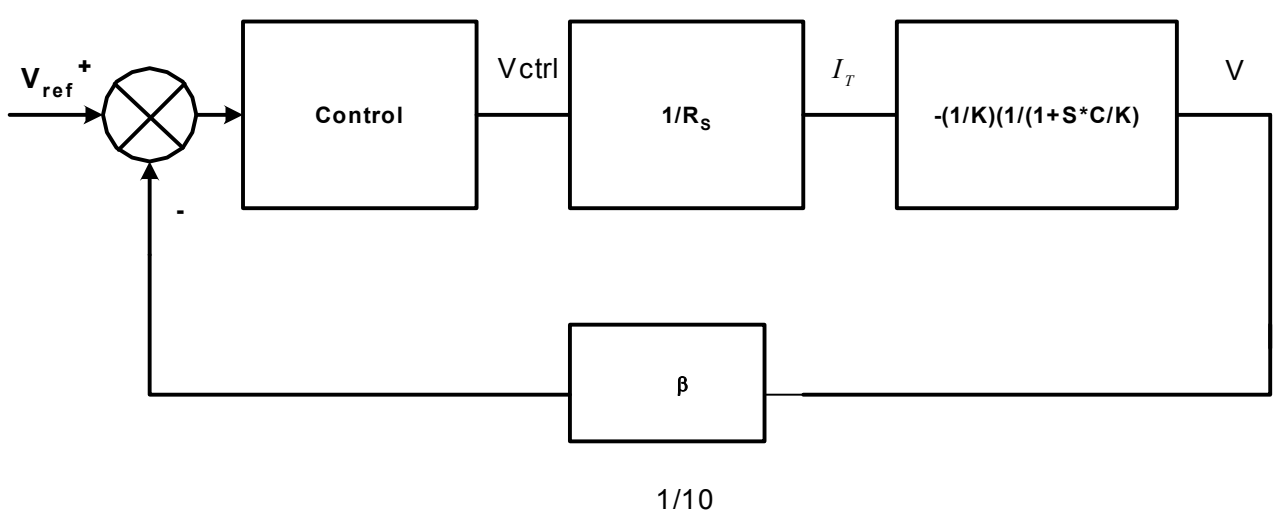

Figura C.3. Diagrama de bloques del sistema completo. 


\section{C.4.- CONTROL Y ESTABILIDAD.}

El sistema es sencillo de controlar ya que es un sistema de primer orden, pero tiene un problema: "k" es variable en función del punto de trabajo.

A continuación se va a estudiar el uso de dos tipos de control: proporcional (P) y proporcionalintegral (PI).

\section{C.4.1.- Control proporcional.}

En el caso de este control en el diagrama de bloques de la Fig. C.3, el bloque de control es una constante "-G". En este caso la función de transferencia viene dada por la Ec. C.7.

$$
\frac{V(S)}{V_{r e f}(S)}=\frac{\frac{G}{R K} \frac{1}{1+S \frac{C}{K}}}{1+\beta \cdot \frac{G}{R K} \frac{1}{1+S \frac{C}{K}}}
$$

Este sistema será estable si todos los polos están situados en el semiplano negativo. Las raíces del sistema, Ec. C.8, deberán cumplir

$$
-\left(\frac{\beta \cdot G}{R \cdot K}+1\right) \frac{K}{C}<0
$$

Por lo que el sistema será estable para cualquier valor de k, al ser positivas todas las variables.

Esta es una buena solución para la estabilidad pero al estar ante un sistema de primer orden de tipo 0 (ningún polo en el origen) siempre habrá error a la salida.

El error ante entrada escalón puede obtenerse con el teorema del valor final, Ec. C.9

$$
e_{r p}=\frac{R \cdot k}{R \cdot k+\beta \cdot G}
$$

El error varía con $\mathrm{k} y$, como podemos recordar, puede tomar valores dentro de un amplio rango, con lo que será difícil cuantificar el error. En la Fig. C.4 se puede ver la variación de la respuesta ante entrada escalón unitario dependiendo de la pendiente $\mathrm{k}$ del punto de trabajo, si recordamos que la ganancia del lazo es 10 para $k=0$ el error es nulo. Este problema se puede solucionar con un control PI. 


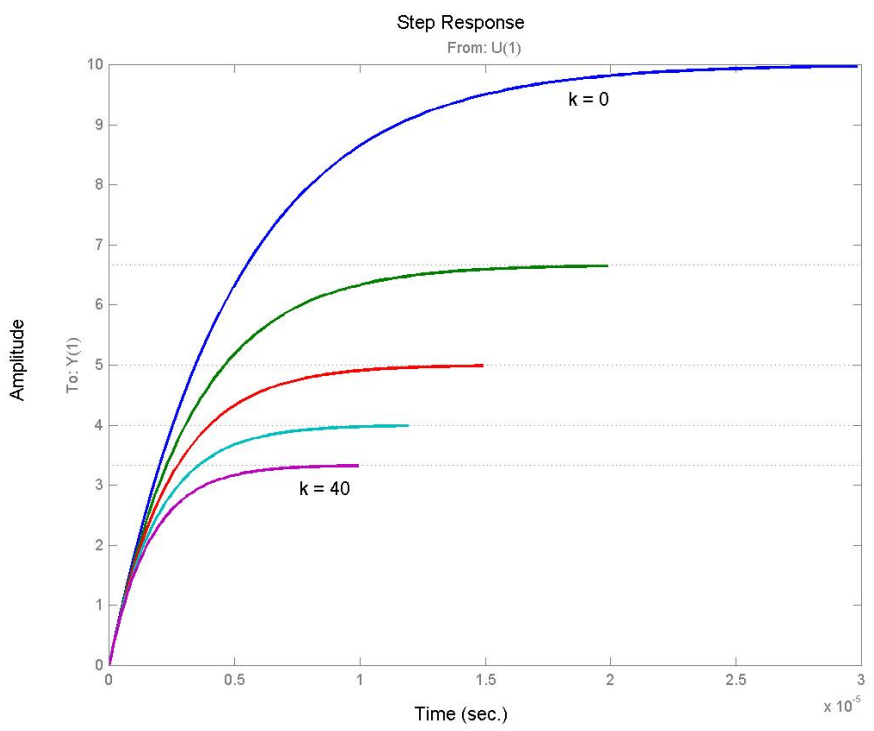

Figura C.4. Respuesta ante escalón unitario.

\section{C.4.2.- Control proporcional-integral.}

Este control tiene varias ventajas frente al control proporcional: el error de posición será nulo y el sistema será más rápido al introducir un cero en el sistema.

El bloque de control de la Fig. C.3 es ahora un control PI, Ec. C.10, y la función de transferencia del sistema total viene dada por la Ec. C.11.

$$
\begin{gathered}
P I(S)=-\frac{\alpha\left(\frac{S}{\omega_{z}}+1\right)}{S} \\
\frac{V(S)}{V_{r e f}(S)}=\frac{1}{\beta} \frac{\frac{S}{\omega_{z}}+1}{S^{2} \frac{R \cdot C}{\beta \cdot \alpha}+S\left(\frac{R \cdot K}{\beta \cdot \alpha}+\frac{1}{\omega_{z}}\right)+1}
\end{gathered}
$$

La condición de estabilidad, polos en el semiplano negativo, Ec. C.12, se cumple para todos los valores de $\mathrm{k}$.

$$
-\left(\frac{R \cdot k}{\alpha \cdot \beta}+\frac{1}{w_{z}}\right)<0
$$

\section{C.4.3 Implementación del control PI.}


La Fig. C.5 representa el circuito del controlador proporcional-integral y un sustractor, siendo la Ec. C.13 su función de transferencia.

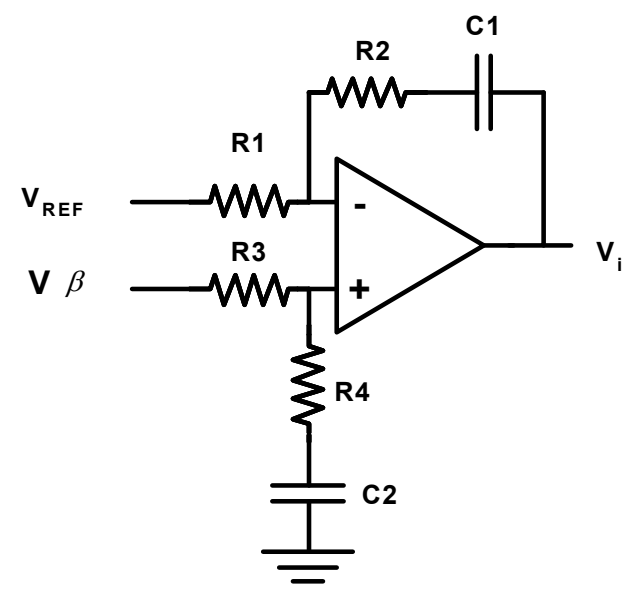

Figura C.5. Control Proporcional-Integral.

$$
V_{\text {control }}=V^{\prime}{ }_{c} \frac{1}{R_{1}}\left(\frac{R_{4}+\frac{1}{s C_{2}}}{R_{3}+R_{4}+\frac{1}{s C_{2}}}\right)\left(R_{1}+R_{2}+\frac{1}{s C_{1}}\right)-V_{r e f} \frac{1}{R_{1}}\left(R_{2}+\frac{1}{s C_{1}}\right)
$$

Si tomamos $R_{1}=R_{3}, R_{2}=R_{4}, C_{1}=C_{2}$ nos queda,

$$
V_{\text {control }}=\frac{1}{R_{1}}\left(R_{2}+\frac{1}{s C_{1}}\right)\left(V_{c}^{\prime}-V_{\text {ref }}\right)
$$

función de transferencia de un PI.

Si se comparan la Ec. C.14 y la ecuación general de un PI, Ec. C.10, 


$$
\begin{gathered}
\alpha=\frac{1}{R_{1} C_{1}} \\
w_{z}=\frac{1}{R_{2} C_{1}}
\end{gathered}
$$

Tomando $R_{1}=4.7 \mathrm{k}, R_{2}=100 \mathrm{k}$ y $C_{1}=0.1 \mathrm{nF}$ se tendrá en este caso $\alpha=2 \cdot 10^{6}$ y $\omega_{z}=10^{5} \mathrm{rad} / \mathrm{seg}$ y el sistema será estable.

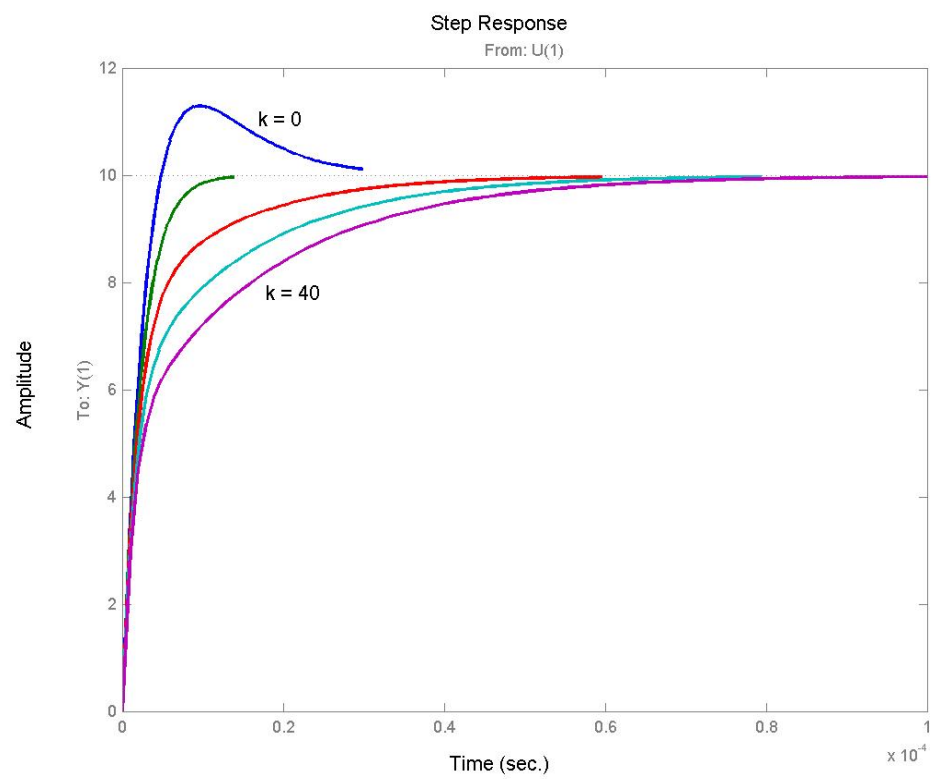

Figura C.6. Respuesta a escalón unitario con control PI

En la Fig. C.6 se ha representado la respuesta del sistema para una entrada escalón unidad y se puede ver que ahora el error en régimen permanente es nulo para cualquier punto de trabajo del panel.

\section{C.5. ELECCIÓN DEL TRANSISTOR.}

Los MOSFETs son ideales para trabajar en paralelo en conmutación aunque también tienen muy buenas características para trabajar en sistemas lineales. Pero para que los transistores puestos en paralelo trabajen adecuadamente se debe establecer el punto de trabajo.

El reparto de corriente entre los transistores conectados en paralelo es desigual. Otra variable importante a tener en cuenta es la temperatura de la unión, ya que si no hay un reparto equitativo de corrientes, por las diferencias entre curvas características, uno de los transistores disipará más potencia y se calentará más que el resto, aumentando su ganancia y la corriente hasta producirse la rotura. 
Una solución es la selección de los componentes con las características más parecidas o el uso de resistencias de ecualización que establecerán un punto de trabajo en el que la diferencia en el reparto de corrientes será menor.

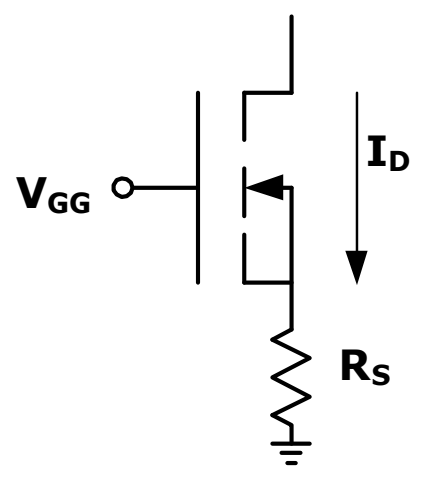

Figura C.7. Resistencia de ecualización.

$\mathrm{Si}$, por ejemplo, trazamos la curva $\mathrm{V}_{\mathrm{GG}}-\mathrm{I}_{\mathrm{D}}$ del transistor IRFP140N podemos ver que para una tensión de $4.5 \mathrm{~V}$ y suponemos un transistor trabajando a $25 \circ \mathrm{C}$ y otro a 175 으 $\mathrm{C}$ uno tendrá una corriente de 7 amperios y el segundo transistor una corriente de 8.5 amperios, una diferencia considerable. Pero si nos fijamos en valores de tensiones más bajas el reparto de corrientes es peor, incluso puede llegar a dejar de conducir alguno de los transistores, Fig. C.8.

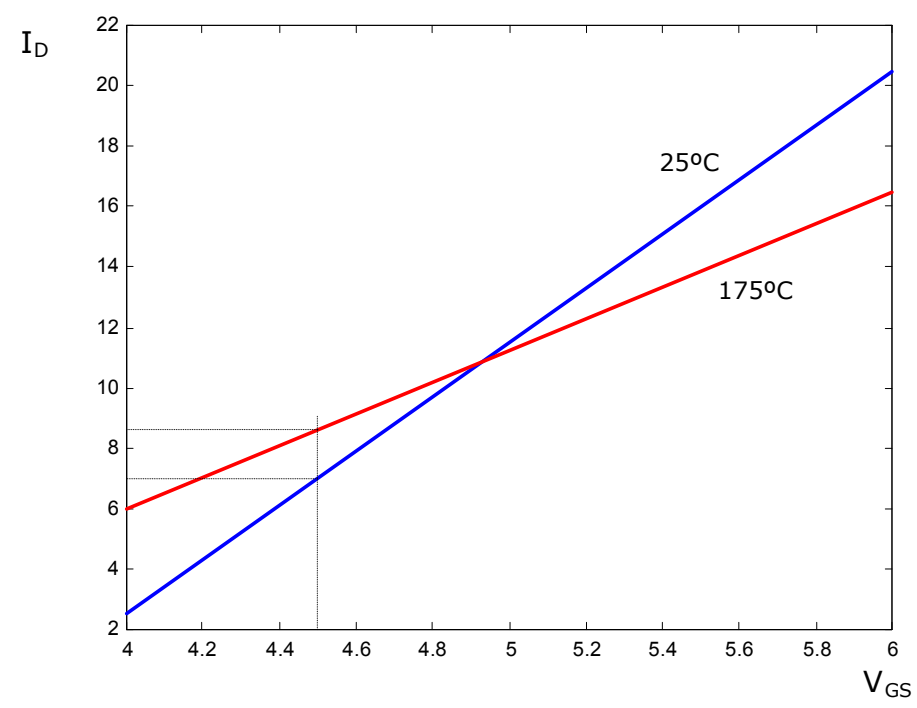

Figura C.8. Curva de transconductancia.

Si se emplea una resistencia de ecualización variará el punto de trabajo de manera que la tensión será $\mathrm{V}_{\mathrm{GS}}=\mathrm{V}_{\mathrm{GG}}-\mathrm{I}_{\mathrm{D}} \mathrm{R}_{\mathrm{S}}$, con lo que se desplazará el punto de trabajo y se consigue disminuir la diferencia entre corrientes. 


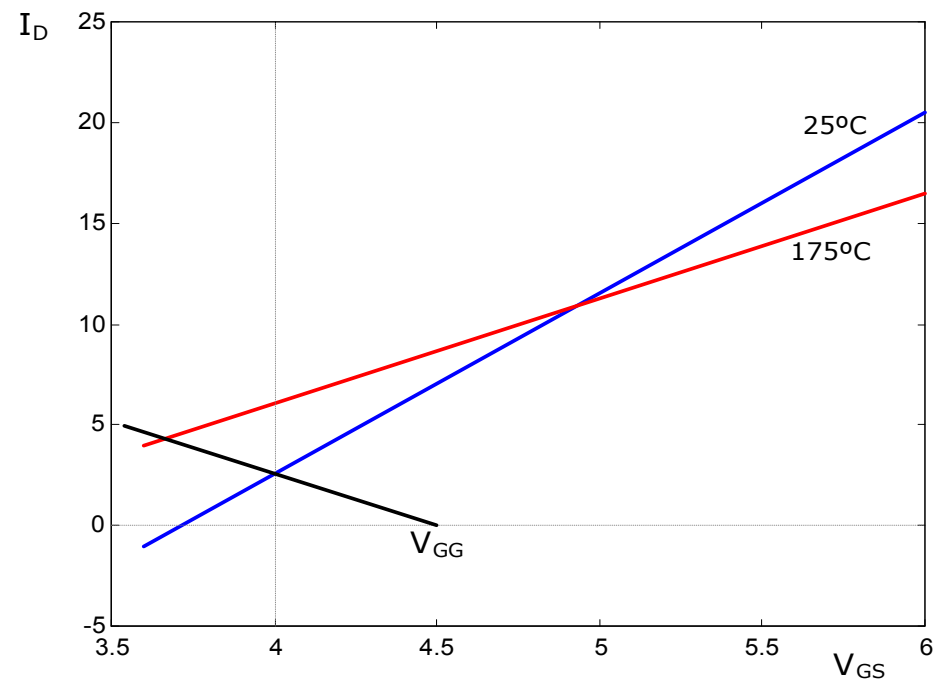

Figura C.9. Punto de trabajo.

Si tenemos $\mathrm{V}_{\mathrm{GG}}=4.5 \mathrm{~V}$ y la pendiente de la curva es $-\frac{1}{R_{S}}$, con $\mathrm{R}_{\mathrm{S}}=0.2 \Omega$, ahora la corriente del transistor que disipa menos potencia, el que está a $25 \circ \mathrm{O}$, es de 2.5 amperios. Para una mayor resistencia habrá un mejor reparto de corrientes pero también habrá mayores pérdidas. La primera característica a buscar en el transistor será la tensión, ya que por corriente no hay límite si se ponen varios transistores en paralelo.

Se eligió el transistor IRFP140N con las siguientes características:

- $\operatorname{ID}(25 \circ \mathrm{C})=42 \mathrm{~A}$.

- $\mathrm{VDSS}=100 \mathrm{~V}$.

- $\mathrm{PD}=160 \mathrm{~W}$.

De las características que tiene la carga se puede ver que cumple con la corriente máxima (25A) y la tensión máxima (50V) pero para poder disipar la potencia requerida serán necesarios 2 transistores. El problema que presenta es que trabajando como carga será difícil encontrar un disipador usando solo 2 transistores.

\section{C.6. DISIPADOR.}

De las tablas de características del transistor:

- Temperatura máxima de la unión, $\mathrm{T}_{\mathrm{jc}}=175$ 으

- Temperatura ambiente máxima, $\mathrm{T}_{\mathrm{a}}=60 \mathrm{\circ} \mathrm{C}$ 
- Resistencia unión-carcasa, $\mathrm{R}_{\mathrm{jc}}=0.95$ 으 $\mathrm{C}$

- Resistencia carcasa-disipador, $\mathrm{R}_{\mathrm{cs}}=0.24$ 으 $/ \mathrm{W}$

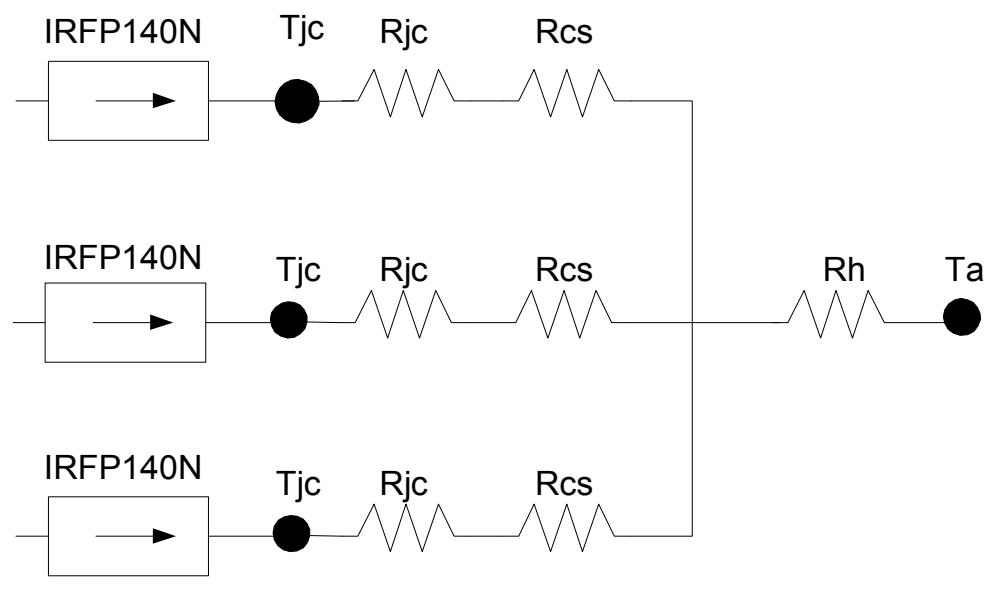

Figura C.10. Resistencia térmica

Se han tomado valores extremos de la temperatura ambiente ya que el equipo estará instalado a la intemperie. Para la temperatura de la unión se tomará un valor de trabajo de 150 ㄷ $\mathrm{C}$ para tener un margen de seguridad (donde la potencia será la máxima a la que trabaja la carga, 300W).

$$
T_{j c}=\left(R_{j c}+R_{c s}\right) \frac{P}{n}+P \cdot R_{h}+T_{a}
$$

Con estos valores la resistencia térmica del disipador debe ser $R_{h}=-0.295$, valor imposible.

En la siguiente gráfica se ha representado la resistencia térmica que deberá tener el disipador en función del número de transistores empleados para poder elegir el número adecuado.

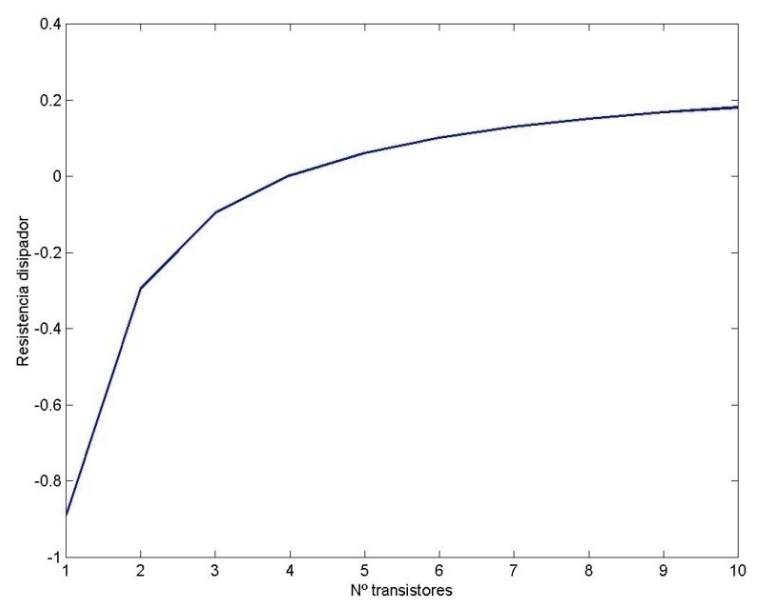


Figura C.11. Elección no transistores IRFP140N.

Si se usan 7 transistores la resistencia térmica es aproximadamente de 0.15 por lo que se eligió el disipador $\mathrm{P} 3 / 180$ con $\mathrm{R}_{\mathrm{h}}=0.145$ para un solo elemento y ventilación forzada. En tablas del disipador será necesario un flujo de aire de $60 \mathrm{~m}^{3} / \mathrm{h}$.

Dado el precio del transistor usado y el número que hay que emplear se comparó con otro transistor de características similares y de menor precio, el IRL540N, con las siguientes características:

- $\mathrm{I}_{\mathrm{D}}(25 \circ \mathrm{C})=36 \mathrm{~A}$.

- $\mathrm{V}_{\mathrm{DSS}}=100 \mathrm{~V}$.

- $\mathrm{P}_{\mathrm{D}}=140 \mathrm{~W}$.

- $\mathrm{R}_{\mathrm{jc}}=1.1$

- $\mathrm{R}_{\mathrm{cS}}=0.5$

En principio habrá que usar 3 transistores en paralelo para obtener la potencia máxima que se pedía.

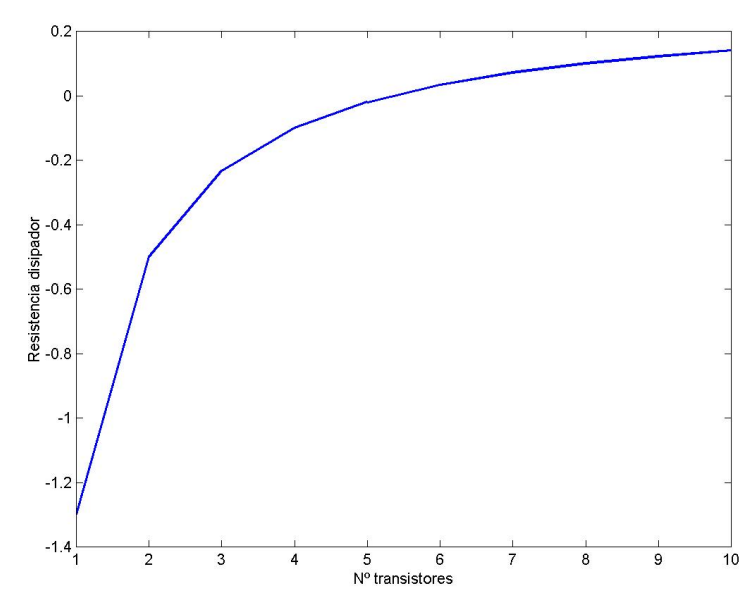

Figura C.12. Elección no transistores IRL540N

Si ahora se comprueba con el mismo disipador el número de transistores que hay que emplear es 10. Al ser mayor aún el número de transistores que se usan la diferencia de precio no es razonable si se compara con el otro transistor y menos para un prototipo, aunque si se debería tener en cuenta para la fabricación en serie.

\section{C.7. FUENTE}

Hay que considerar que en el transistor hay una caída de tensión y en las resistencias habrá otra caída de tensión, por lo que la tensión en el condensador no puede llegar a "0" voltios. 
Esto se ha solucionado con una fuente que reste dicha caída de tensión como se ve en la Fig. C.13:

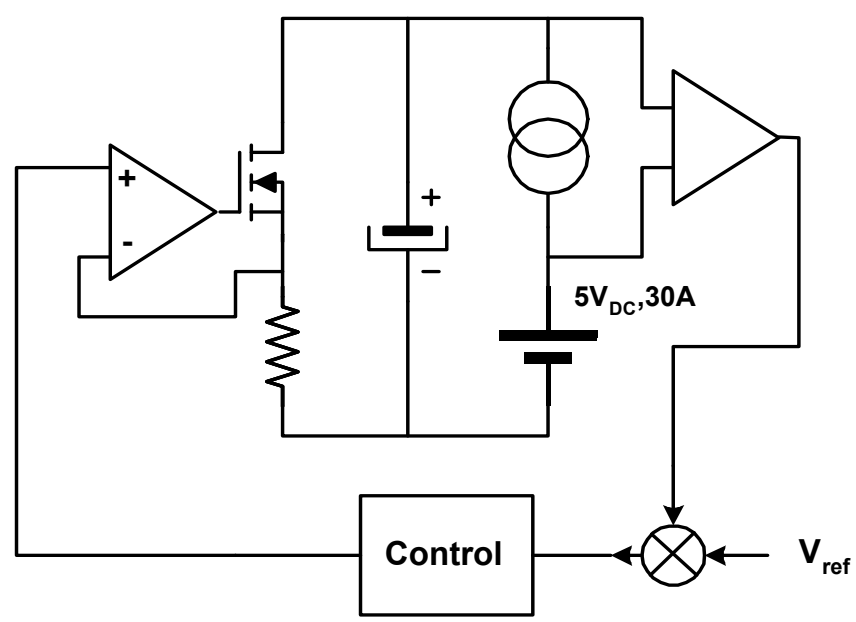

Figura C.13. Fuente de tensión para obtener tensiones negativas.

Si se considera que el valor de la resistencia es de $0.05 \Omega$ y que la corriente máxima en la carga serán $25 \mathrm{~A}$ la caída máxima en la resistencia será de $1.25 \mathrm{~V}$.

De las características del transistor se puede comprobar en la característica de salida que para una tensión $\mathrm{V}_{\mathrm{GS}}=4.5 \mathrm{~V}$ la caída de tensión $\mathrm{V}_{\mathrm{DS}}$ máxima que tendremos será de $1.5 \mathrm{~V}$, considerando una temperatura de la unión de 175으. Con estos valores la máxima caída de tensión que tendrá será de $2.75 \mathrm{~V}$. Se puede usar una fuente de PC que tiene diferentes salidas $(5 \mathrm{~V} / 30 \mathrm{~A}, \pm 12 \mathrm{~V}, 3.3 \mathrm{~V})$. Esta es una solución barata y con ella se podrán obtener las diferentes tensiones necesarias para el circuito.

En el circuito se añadió además, a modo de protección contra errores de conexión, un diodo entre la fuente de tensión y el panel, Fig. C.14. Se eligió el 43CTQ100, con una caída de tensión de $1 \mathrm{~V}$. Teniendo en cuenta todas las caídas de tensión del diodo, del transistor y de la resistencia la mínima tensión que se podrá obtener es $\mathrm{V}_{\mathrm{min}}=-1.25 \mathrm{~V}$. 


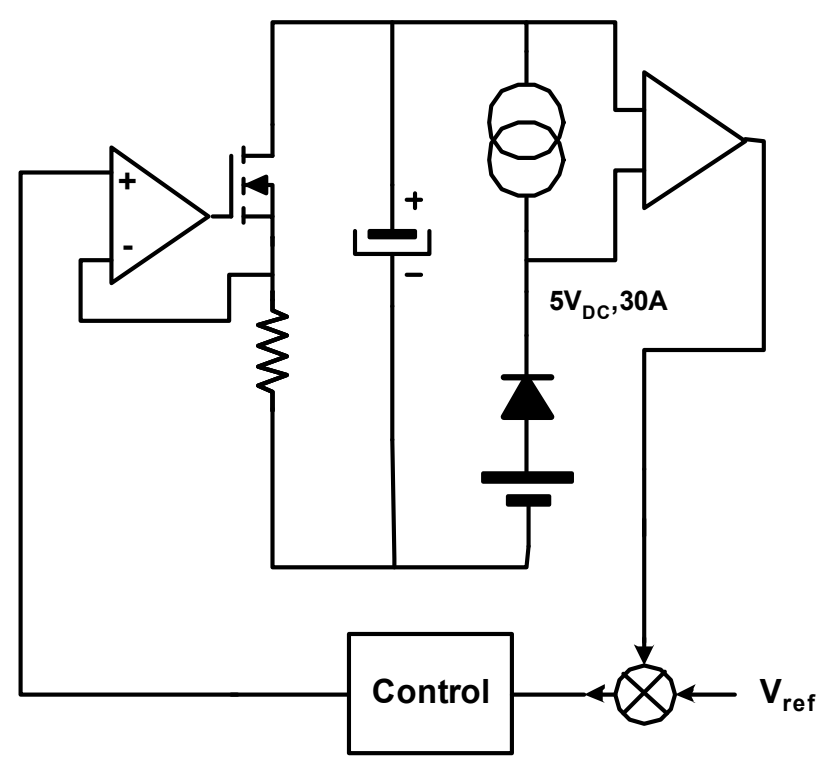

Figura C.14. Diodo de protección.

\section{C.8. SIMULACIÓN.}

El circuito que se muestra en la Fig. C.15 está conectado a un panel solar de característica V-I la mostrada en la Fig. C.16. Esta curva ha sido obtenida mediante simulación con la carga electrónica.

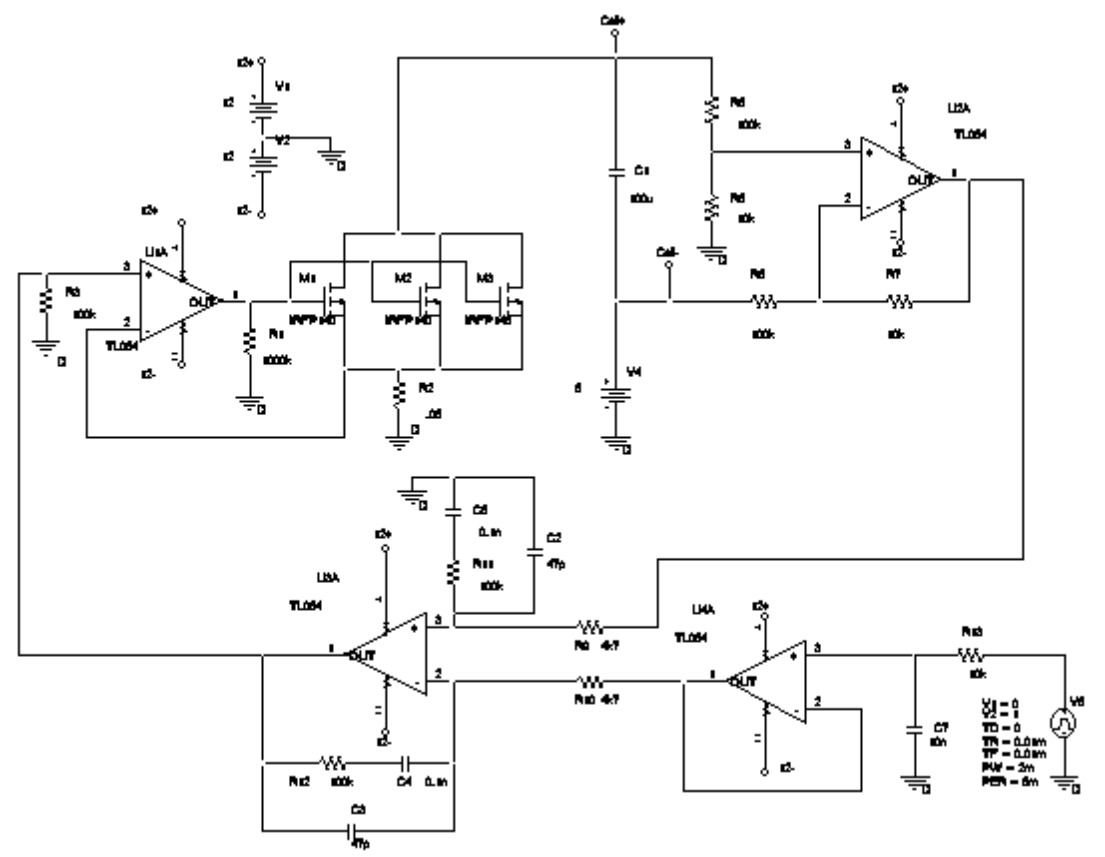

Figura C.15. Circuito para la simulación.

La curva característica que se obtiene con este esquema es bastante aproximada a la curva real de un panel fotovoltaico. 


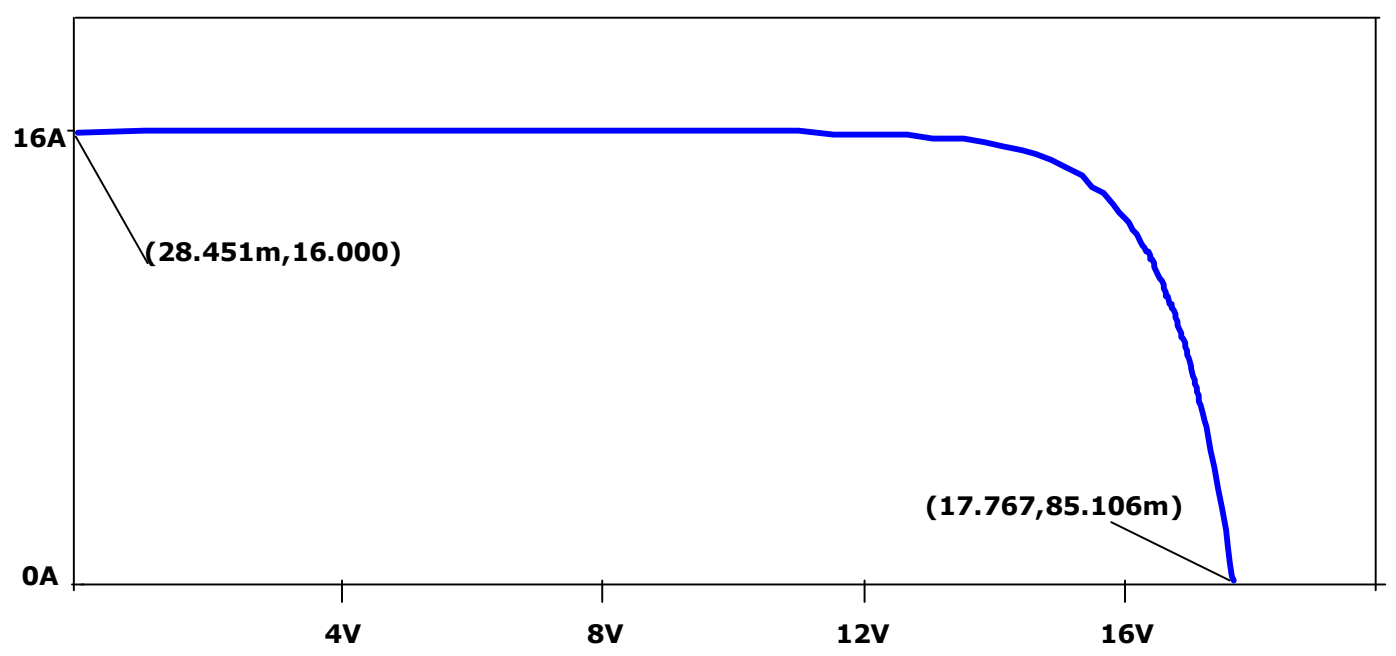

Figura C.16. Característica V-I.

En la Fig. C.17 se han representado la tensión de referencia con línea continua y la tensión en la célula multiplicado por la ganancia del operacional, $\beta$, con línea discontinua.

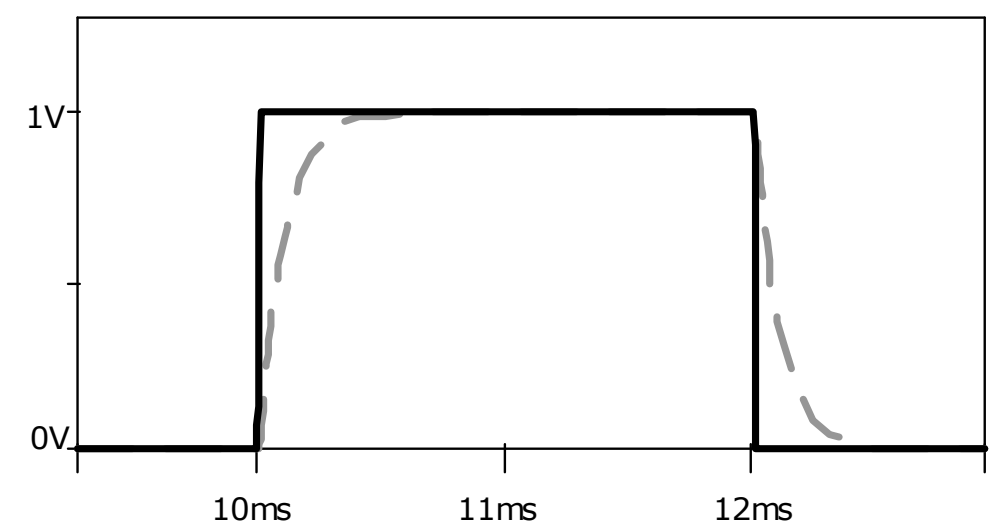

Figura C.17. Respuesta dinámica.

\section{C.9. RESULTADOS.}

Las siguientes imágenes fueron obtenidas en laboratorio. En la Fig. C.18 se puede ver la tensión y corriente que se obtuvieron usando como panel fotovoltaico una fuente de corriente. 


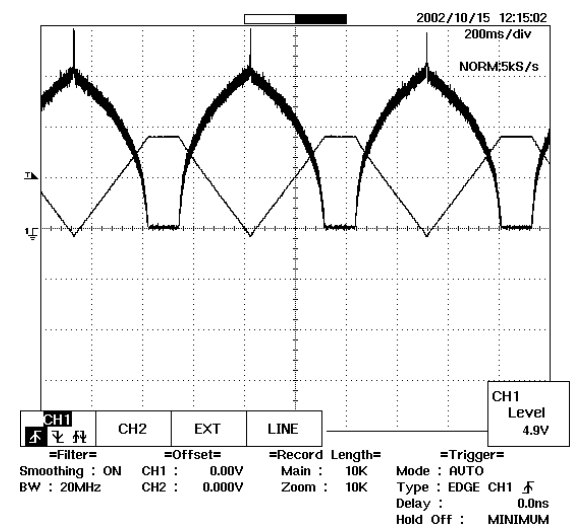

Figura C.18. Medidas de osciloscopio

En la Fig. C.19 se puede ver la curva característica obtenida

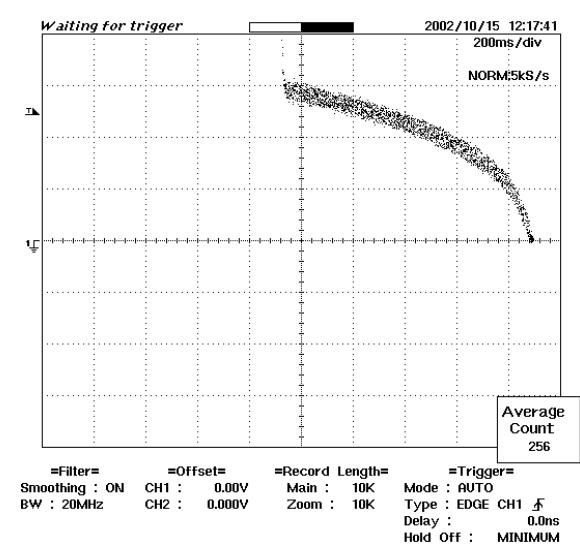

Figura C.19. Curva característica. 
